Portland State University

PDXScholar

$7-27-2020$

\title{
Determinants of Student Information Technology Adoption
}

Hans P. VanDerSchaaf

Portland State University

Follow this and additional works at: https://pdxscholar.library.pdx.edu/open_access_etds

Part of the Engineering Commons, and the Higher Education Commons Let us know how access to this document benefits you.

\section{Recommended Citation}

VanDerSchaaf, Hans P., "Determinants of Student Information Technology Adoption" (2020). Dissertations and Theses. Paper 5503.

https://doi.org/10.15760/etd.7377

This Dissertation is brought to you for free and open access. It has been accepted for inclusion in Dissertations and Theses by an authorized administrator of PDXScholar. Please contact us if we can make this document more accessible: pdxscholar@pdx.edu. 
Determinants of Student Information Technology Adoption

by

Hans P. VanDerSchaaf

A dissertation submitted in partial fulfillment of the requirements for the degree of

Doctor of Philosophy

in

Technology Management

Dissertation Committee:

Tuğrul Daim, Chair

Mark Ahn

Nuri Başoğlu

Robert Fountain

Portland State University

2020 
(C) 2020 Hans P. VanDerSchaaf

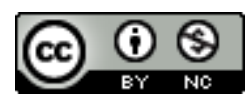

This work is licensed under a Creative Commons

Attribution-NonCommercial 4.o International License 


\begin{abstract}
Innovating service delivery in higher education is central to supporting institutional and societal goals of increasing the numbers of college graduates and for transforming higher education institutions to center on the needs of today's students. Within this context, technology plays a critical role. This research seeks to contribute to institutional, academic and educational technology sector efforts to dramatically enhance service quality, in support of improving undergraduate student outcomes (student success), by identifying the determinants of student information technology adoption and removing barriers to accessing higher education.

Using a mixed-methods and empirical approach based on the Unified Theory of Acceptance and Use of Technology (UTAUT), after an extensive literature review, individual interviews and focus groups, a web-based survey was administered to undergraduate students at Portland State University in Portland, Oregon to learn about their experiences with myPSU. myPSU is a web-based digital services platform (available as a native mobile application and website) that aids students in accessing services and resources critical to maintaining their enrollment. Structural Equation Modeling (SEM), including Principal Components Analysis (PCA), was used to analyze 1,841 valid survey responses and derive statistical results.
\end{abstract}

The findings suggest that effort expectancy and social influence stand out as critical influences on behavioral intention to adopt myPSU, and new to 
UTAUT, that social influence and a students' basic technology skills are significant determinants of effort expectancy. The model accounts for $42 \%$ of the variance for effort expectancy, $56 \%$ of the variance for behavioral intention to use and $83 \%$ of the variance for use behavior.

Theoretically, this study contributes to the development of the UTAUT technology adoption model by suggesting the need, at least in a higher education context, of including skills as an important factor, as well as supporting the idea that more complex relationships exist between latent variables than a strict application of the UTAUT model affords. Also, PCA was leveraged to simplify the research model and its use raised questions about what role performance expectancy (perceived usefulness) might play in student information technology adoption. In sum, this research uniquely contributes to the research literature. It applies UTAUT to a higher education context to study the delivery of technology-enabled services and in doing so it makes contributions towards explaining the critical determinants of the adoption of software for accessing university services (one type of student information technology), related to how UTAUT could be applied in the university setting and how the model could be enhanced. 


\section{Acknowledgments}

As I've learned in the past several years, pursuing a $\mathrm{PhD}$ requires focus, diligence, late nights, openness to learning new ideas and most importantly, a strong support network. I could not have achieved this learning and finished this study without help from many others. My committee has provided tremendous encouragement and support and without a doubt, I am a better scholar because of your feedback and questions. Dr. Tuğrul Daim has guided me as a mentor and friend; his passion for students and learning kept me going when I hit bumps on the path. Dr. Mark Ahn posed insightful questions that challenged me to connect this research more to practice. Dr. Nuri Başoğlu was instrumental in aiding me with connecting this work to the technology adoption field and developing a robust mixed-methods approach. And, Dr. Robert Fountain's coaching and expertise in applied statistics was a tremendous help as we navigated through new terrain for me.

My former colleagues at Portland State University were a tremendous help. Not only did key institutional leaders - the Provost, Chief Information Officer and Director of Institutional Research and Planning - support this research, their questions and feedback along the journey undoubtedly enhanced this study. Many of my former colleagues contributed their expertise to this study. I am also deeply grateful for the efforts of the following, plus many others, on standing up and enhancing myPSU: the Redesign myPSU project leads and project team; the Vice President for Academic Innovation, Planning, and 
Partnerships; two Provosts; the CIO's office and its leadership team; the Web and Mobile Team; and the Office of Student Success, including its student employees and senior project manager. I am indebted to the PSU students who took time out of their busy schedules to help another student by offering their perspectives, opinions and experiences for this research. I hope that this study honors everyone's engagement, and is helpful to Portland State University as it continues to be a national model for student success.

Finally, undertaking a PhD while working full-time and with two young children, especially during the COVD-19 pandemic, would not have been possible without a partner who took on some of my parenting and household responsibilities, and more importantly, provided unwavering support during the tough times when I was exhausted and when we could not have as much time together as we would have liked. It's your turn next and I owe you - big time. To our children, thanks for your understanding of the times when I had to study. To my father and sister, your interest and support buoyed me through many of the challenging times - thank you! To my mom, I think I inherited just a little bit of your love of learning and your curiosity. 


\section{Table of Contents}

Abstract

Acknowledgments

List of Tables

List of Figures

1. Chapter One: Introduction and Research Objective 1

1.1. Introduction and Purpose of Research Study 1

1.2 Research Objective and Research Questions 2

1.3 Research Approach Summary 4

1.4 Importance of Research Topic 5

2. Chapter Two: Research Approach 10

3. Chapter Three: Literature Review - Student Success and Student $\begin{array}{ll}\text { Information Technology } & 16\end{array}$

3.1 Defining Student Success 16

3.2 Student Success Metrics Frameworks 19

3.3 Student Success Metrics Related to Studied Population 26

3.4 Benchmarking 28

3.5 Student Information Technology in Support of Student Success 36

3.6 Higher Education Students and Technology 51

4. Chapter Four: Literature Review - Technology Adoption Models and Taxonomy $\quad 55$

4.1 Technology Adoption Models $\quad 55$

4.2 Technology Adoption, E-Services and Student Success 64

4.3 Research Related to Student Information Technology Adoption 66

4.4 Taxonomy of Factors Related Student Information Tech. Adoption $\quad 71$

4.5 Research Gaps and Questions $\quad 72$

5. Chapter Five: Unit of Analysis - myPSU 74

6. Chapter Six: Preliminary Research Model 79

6.1 Unified Theory of Acceptance and Use of Technology 79

6.2 Extending and Modifying UTAUT 80

6.3 Preliminary Research Model and Hypotheses $\quad 81$

7. Chapter Seven: Qualitative Methods and Research Model 88

$\begin{array}{ll}7.1 \text { Experts } & 88\end{array}$

$\begin{array}{ll}7.2 \text { Individual Interviews } & 91\end{array}$

$\begin{array}{ll}7.3 \text { Focus Groups } & 100\end{array}$

7.4 Qualitative Results $\quad 110$

7.5 Research Model and Hypotheses 114

8. Chapter Eight: Quantitative Methods - Structural Equation

Modeling and Data Collection $\quad 126$

8.1 Structural Equation Modeling $\quad 126$

8.2 SEM Popularity and Limitations $\quad 133$

8.3 SEM Process Summary $\quad 135$

8.4 SEM Process - Measurement Model 136 
$\begin{array}{ll}\text { 8.5 Data Collection } & 138\end{array}$

8.6 Principal Components Analysis $\quad 178$

8.7 Confirmatory Factor Analysis $\quad 182$

8.8 SEM Process - Structural Model 189

9. Chapter Nine: Structural Equation Modeling Analysis and Results 194

9.1 Descriptive Statistics for Each Indicator 196

9.2 SEM Approach \#1 197

9.3 SEM Approach \#2 206

9.4 SEM - Approach \#3 217

10. Chapter Ten: Discussion, Conclusion and Research

$\begin{array}{ll}\text { Contributions } & 241\end{array}$

10.1 Findings and Discussion 241

10.2 Conclusion 250

10.3 Research Contributions $\quad 252$

10.4 Limitations and Future Research 253

10.5 Closing 254

References $\quad \mathbf{2 5 7}$

Appendices $\quad \mathbf{2 8 7}$

Appendix A: Taxonomy of Factors Related to University Student Adoption of

Technology

287

Appendix B: Preliminary Research Model Detailed Taxonomy 304

Appendix C: Individual Interviews Appendices 310

Appendix D: Focus Group Appendices $\quad 328$

Appendix E: Research Model Detailed Taxonomy 350

Appendix F: Expert Panel Materials $\quad 356$

Appendix G: Pilot Tester Materials $\quad 363$

Appendix H: Data Collection Materials 367

Appendix I: Frequencies and Means for Indicator Variables 377

Appendix J: Revised Research Model Detailed Taxonomy 393 


\section{List of Tables}

Table 1: Summary of Research Approach 12

Table 2: Postsecondary Metrics Framework 24

Table 3: Student Success Metrics and Definitions $\quad 26$

Table 4: Peer Institutions Summary 29

Table 5: Benchmarks and Outcomes Associated with Student Success Metrics for Studied Population

Table 6: Institutional and Student Characteristics Related to Student Success IPEDS and HECC Data

Table 7: Comparison Features of E-Learning, W-Learning and M-Learning 44

Table 8: Literature Review Summary: Higher Education E-Services Concepts 48

Table 9: Summary of Technology Adoption Models 63

Table 10: Summary of Descriptive Statistics 68

Table 11: Preliminary Research Model Taxonomy (Summary) 86

Table 12: Summary of Content Experts (Professionals) who Participated in Interviews 98

Table 13: Summary of Content Experts (Professionals) who Participated in a Focus Group 108

Table 14: Examples of Synthesis Comments from the Qualitative Methods 111

Table 15: Evaluation Data from Interviews and Focus Groups 112

Table 16: Summary of Decisions with Respect to the Preliminary Research Model as a Result of Qualitative Methods $\quad 115$

Table 17: Research Model Taxonomy (Summary) 121

Table 18: Survey Instrument Validation Actions 146

Table 19: Summary of Expert Panelists $\quad 150$

Table 20: Survey Instrument Pilot Testing Tool 154

Table 21: Summary of Pilot Testing Results 155

Table 22: Sample Size Requirements 160

Table 23: Target Population $\quad 162$

Table 24: Results for Developing the Analytic Sample 168

Table 25: Survey Response Rates 169

Table 26: Target Population and Demographics of Respondents (Analytic Sample) 171

Table 27: One Sample Test of a Proportion Results 173

Table 28: ANOVA Results for Performance Expectancy (Item PE1) 176

Table 29: ANOVA Results for Effort Expectancy (Item EE1) 176

Table 30: ANOVA Results for Social Influence (Item SI1) 177 
Table 31: ANOVA Results for Facilitating Conditions (Item FC1) 177

Table 32: ANOVA Results for Perceived Quality (Item PQ1) 177

Table 33: ANOVA Results for Self-Efficacy and Skills (Item SS1) 177

Table 34: ANOVA Results for Behavior Intention (Item BI1) 178

Table 35: Goodness of Fit Measures and Recommended Values 186

Table 36: Approach \#1 Reliability Analysis 198

Table 37: Approach \#1 - Measurement Model - Goodness of Fit Measure Comparisons 202

Table 38: Approach \#1 - Structural Model - Goodness of Fit Measure Comparisons 205

Table 39: Approach \#2 - Principal Components Analysis - Factor Analysis Results $\quad 207$

Table 40: Approach \#2 - Revised Model/Taxonomy with Reliability Analysis Results 209

Table 41: Approach \#2 - Measurement Model - Goodness of Fit Measure Comparisons 213

Table 42: Approach \#2 - Structural Model - Goodness of Fit Measure Comparisons $\quad 216$

Table 43: Approach \#3 - Principal Components Analysis - Factor Analysis Results 218

Table 44: Approach \# 3 - Revised Research Model/Taxonomy with Reliability Analysis Results

Table 45: Revised Research Model Taxonomy (Summary) 222

Table 46: Approach \#3 - Measurement Model - Goodness of Fit Measure Comparisons 226

Table 47: Discriminant Validity of the Measurement Model (Final Fit) 227

Table 48: Approach \#3 - Structural Model - Goodness of Fit Measure Comparisons 230

Table 49: Approach \# 3 - Results of the Structural Model Analysis of the Revised Research Model 233

Table 50: Comparison of SEM Approaches using Final Structural Models for each Approach 


\section{List of Figures}

Figure 1: Theory of Reasoned Action 57

Figure 2: Theory of Planned Behavior $\quad 58$

Figure 3: Technology Acceptance Model $\quad 59$

Figure 4: Technology Acceptance Model 2

Figure 5: Task-Technology Fit Model $\quad 61$

Figure 6: Unified Theory of Acceptance and Use of Technology (UTAUT) Model 63

Figure 7: Research Gaps, Research Objective and Research Questions $\quad 73$

Figure 8: myPSU Homepage $\quad 76$

Figure 9: Visual Depiction of PSU's Efforts to Improve the Student Experience 77 Figure 10: Unified Theory of Acceptance and Use of Technology (UTAUT) Model 80 Figure 11: Visual Diagram of Preliminary Research Model 85

Figure 12: Latent Constructs/Factors and Indicators for Preliminary Research Model Organized as a Taxonomy $\quad 85$

Figure 13: Visual Diagram of Research Model with Hypotheses 120

Figure 14: Research Model Factors and Indicators, Organized as a Taxonomy 121 Figure 15: Example Measurement Model 129

Figure 16: Example Structural Model from 130

Figure 17: SEM Data Analysis Process 136

Figure 18: Example of the Expert Panel Evaluation Tool 152

Figure 19: Visualization of the Overall Response Rate with Reminders $\quad 170$

Figure 20: Visual Diagram of Research Model with Hypotheses 195

Figure 21: Research Model Factors and Indicators, Organized as a Taxonomy 196

Figure 22: Approach \#1 - Measurement Model with Standardized Loadings (Final Model) 201

Figure 23: Approach \#1 - Structural Model with Standardized Loadings (Final Model) 204

Figure 24: Approach \#2 - Measurement Model with Standardized Loadings (Final Model) 212

Figure 25: Approach \#2 - Structural Model with Standardized Loadings (Final Model) 215

Figure 26: Approach \#3 - Measurement Model with Standardized 225

Figure 27: Approach \#3 - Revised Research Model with Hypotheses 228

Figure 28: Approach \#3 - Structural Model (Revised Research Model) with

Standardized Loadings 232

Figure 29: Approach \# 3 - Visual Diagram of Structural Model (Revised Research Model) with Standardized Loadings 


\section{Chapter One: Introduction and Research Objective}

\subsection{Introduction and Purpose of Research Study}

Technology is central to the delivery of services across the world, from making online payments for household utilities, to the processing of loan applications, to automated email, push and/or text messages, to the crowd-sourcing of parking availability and traffic conditions. It is nearly impossible to find a service that does not hinge on technology. Given technology's ubiquity, consumers have increasingly high expectations for robust and personalized digital experiences and in parallel, organizations often use technology to create operating leverage, generate more business opportunities, personalize services, reduce costs and solve mission-critical problems [1].

This rings true in the higher education sector, where there is an immense need to effectively leverage technology, particularly for public universities in the United States. They face tremendous budget and performance pressure in part due to demographic changes (e.g. fewer high school students are projected to enroll in college) [2] and also due to increasing expectations from the public and state legislators to increase graduation rates to deliver on the promises of a populace with college degrees. College graduates experience increased social mobility, lifetime earnings and civic engagement, and provide the country with a more educated and future-prepared workforce [3]. 
Technology innovations can be critical for higher education institutions in improving organizational effectiveness, particularly when used to support efforts to improve the retention and graduation rates of undergraduate students, often dubbed "student success." Student success efforts are critical to many higher education institutions' long-term viability, as attainment rates across the country are well below what would be ideal [4], with one in three students who enroll in college never earning a degree [5].

At the center of student success efforts at campuses across the United States are the information technologies that support staff and faculty with improving undergraduate retention and graduation and student-facing technology related to academic success and accessing university services (e.g. paying bills) - i.e. student success technology. Student success technology is an important component of student information technology [6], [7], [8], [9], [10], [11], [12], [13], [14], [15].

\subsection{Research Objective and Research Questions}

This study seeks to contribute to knowledge at the intersection of undergraduate students' adoption of technology-enabled services and higher education sector strategies focused on leveraging technology to improve student services and undergraduate degree attainment. Thus, the research objective is to contribute to institutional, academic and educational technology sector efforts to dramatically enhance service quality, in support of improving undergraduate 
student outcomes, by identifying the determinants of student information technology adoption. This research focuses on two research questions:

- 1. What are the critical factors that influence undergraduate students themselves in adopting software for accessing university services (one type of student information technology)?

- 2. To what degree does the Unified Theory of Acceptance and Use of Technology (UTAUT) technology adoption model predict adoption of software for accessing university services (one type of student information technology)?

The unit of analysis, i.e. the platform that is the focus of this research, is a web-based digital services platform, called myPSU, that aids Portland State University students in accessing services and resources critical to maintaining their enrollment. myPSU is available as both a native mobile application and as a website, with content between the two being very similar. As a self-service platform intended to help students more easily access services and thus reduce barriers, myPSU is a critical type of student information technology in support of student success. Undergraduate students at Portland State University were surveyed for this research, which resulted in an analytic sample of 1,841 respondents. The web survey was based on the Unified Theory of Acceptance and Use of Technology (UTAUT) and was developed through the use of a research model that was evaluated via semi-structured interviews and focus groups. The 
web survey responses were statistically analyzed using Structural Equation Modeling (SEM).

\subsection{Research Approach Summary}

The research in this study used a mixed methods approach, drawing on qualitative and quantitative research methods, which is often common [16]. An extensive literature review was conducted, which is appropriate for exploratory research when a researcher has little information about a topic [16]. The literature review: describes the importance of the dissertation topic; defines and discusses key concepts (student success, student information technology in support of student success, e-services technologies, etc.); describes relevant technology adoption models; identifies factors related to university student adoption of technology to create a taxonomy; and identifies gaps in the literature. Exploratory research continued through semi-structured interviews and focus groups to arrive at a research model that builds on UTAUT, a technology adoption model that has demonstrated high predictive capabilities and is widely used across sectors. Next, causal research was conducted using quantitative methods. The quantitative methods involved surveying end users undergraduate students at Portland State University and the target population to provide data that was used to empirically evaluate the research model using Structural Equation Modeling (SEM). The SEM results provide information about the determinants of adoption for myPSU. 


\subsection{Importance of Research Topic}

This research topic relates to dialogue about how universities can best sustain themselves, societal goals to increase degree attainment, and most relevant, the acceleration and utility of technology-enabled services. From an economic perspective, the above research questions are relevant in relation to institutions' strategies to enhance their services experiences as a way to differentiate their "product" and create a sustained competitive advantage, both of which are critical to survival [17], [18], [19], [20].

From a social perspective, these research questions are relevant to nationwide goals and massive efforts to improve undergraduate degree attainment and meet societal goals of an informed and educated citizenry, to workforce needs for more workers with college degrees and to goals of increasing social mobility through college degree attainment [21].

At the same time that demand is increasing for workers with a post-secondary credential - recovery from the Great Recession was marked by more employment opportunities for those with education beyond high school [22] and the majority of the fastest-growing occupations now require a postsecondary education [23] - large numbers of Americans do not possess a college degree. The Lumina Foundation reports that "The share of Americans with degrees and post-high school credentials is now at just under 47 percent, up one percentage point from a year earlier. At the same time, disparities in attainment across racial/ethnic groups remain, threatening prospects for 
continued improvement of overall attainment levels" [24]. Additionally, undergraduate departure and graduation rates are still incredibly low in relation to goals set by national organizations to increase the number of adults who have postsecondary credentials (undergraduate degrees as well as associate's degrees) [4]. For example, the College Board is working to increase the percentage of adults with a college education from the current $39 \%$ to $55 \%$ by 2025 , and the Bill and Melinda Gates Foundation has a goal to double the number of low-income students who earn post-secondary credentials by the age of 26 [4]. Also consider that between 1983 and 2010 "approximately 28 percent of first-year students enrolled in four-year colleges and universities depart[ed] at the end of their first year" [25] and only a little more than half of undergraduate college students complete their postsecondary degrees within six years [4]. In the U.S., the percentage of the population with at least a high school diploma is $92 \%$, with an associate's or higher degree is $46 \%$, and a bachelor's degree or higher is $36 \%$ [26]. Internationally, three countries that are members of the Organization for Economic Cooperation and Development (OECD) have post-secondary attainment rates that were higher than the U.S.: Republic of Korea (47\%); Japan (50\%); and Canada (56\%) [27].

From a technological perspective, the research questions relate to the delivery of services, many of which now depend heavily on technology and are an area of ongoing innovation, fueled in large part by mass customization and the experience economy. Technology-enabled services range from mobile banking 
apps, to enhanced point-of-sale experiences (e.g. tap and pay), to moving paper processes to online digital environments, to more self-service options for busy customers, to smart city/Internet of Things-driven sensors that improve urban transportation systems. Services now account for an incredibly large part of economies around the world, including in the United States. As of 2016, services in the United States accounted for nearly $80 \%$ of Gross Domestic Product, whereas agriculture was $1 \%$ and industry $20 \%$ [28]. Technology is ubiquitous in service delivery, such as online purchases including through smartphones [29] and consumers expect that organizations are focused on improving the entirety of the customer experience.

In this era of services, technology has become prominent and is fundamentally altering the relationship between customer and firm [30]. Bittner and Brown call for a "service imperative" for organizations to improve their competitiveness and thrive in this "new world," and for academic institutions to foster graduates who can build services knowledge and their careers in this domain [31]. The imperative is clear - organizations, including higher education institutions, "must actively manage and measure service delivery across all site types and access methods to ensure the quality of the entire customer experience" [32].

When considering services in higher education, student services play a critical role in a university. They can affect the financial and learning bottom lines by enhancing enrollment, affecting students' academic success and their 
personal growth [33], [34]. For online students, the quality of services can have a profound influence on their experience and learning [35], and online services can provide them with convenience and foster student engagement [34]. For "nontraditional" students (e.g. those who are enrolled part-time, working while enrolled, and/or have families; they are increasingly become the "traditional" student), access to online services can be particularly important so they can study while on breaks from work or find help outside of traditional business hours [36]. Institutions, like Lone Star College, are expanding service offerings by taking actions such as increasing service hours [37]. They are finding that face-to-face students also want to access services remotely, due to the flexibility and efficiency they offer.

Central to the development and enhancements of services generally, and in higher education specifically, is service innovation, which includes services delivery, innovation adoption, service strategy and service process improvements [38]. Service innovations in higher education range from moving processes online, to developing and deploying mobile apps and their accompanying push technologies to help students navigate these unreasonably complex bureaucracies, to developing self-service applications that enable students to make degree plans tied to their career objectives, to facilitating up-to-date communications between students and academic advisors (e.g. text messaging, social media, etc.). While from an outsider perspective, the above might not appear to be innovations, given the technology developments in our broader 
economy and how this has shaped students' expectations for e-services [34], including a strong dissatisfaction with student-facing technology [36], they are indeed novel in many higher education institutions [39] and as such constitute “innovations" [40].

The opportunity in front of higher education institutions and society at large to improve service delivery and student attainment is quite substantial, given the size of the higher education sector - in 2015-16, the number of students enrolled in postsecondary institutions was $26,963,399$ in 6,602 institutions [41] and the large and fast-growing educational technology (edtech) sector. The edtech sector, according to recent research, is growing significantly faster than GDP, with the global market projected to grow at $17 \%$ per year to $\$ 252$ billion by 2020. Further, the global education market, at $\$ 5$ trillion, is eight times larger than the software market, yet is only $2 \%$ digitized [42]. Consumers are increasingly conducting transactions online [29], organizations are expected to actively manage service delivery [32] and in higher education, there is a strong dissatisfaction with student-facing technology and legacy systems [36]. Higher education faces a clear and challenging mandate to change to this new paradigm of service [43], and technology plays an absolutely central role. 


\section{Chapter Two: Research Approach}

The research approach for this study reflects the emerging nature of technology-enabled service enhancements research in higher education, as it uses mixed methods to conduct both exploratory and evaluative research.

A research approach is the plan and the procedures for research that "span the steps from broad assumption to detailed methods of data collection, analysis and interpretation" [44]. It is synonymous with research design, which "provides the basic directions or 'recipe' for carrying out the project" [16]. Creswell (2014) suggests that there are three research approaches - 1. Qualitative; 2. Quantitative; and 3. Mixed methods - and that the research approach involves both philosophical assumptions and distinct methods or procedures [44]. Critically, the research approach is intimately intertwined with the research questions and the purpose of the research [45], [46]. Dominant philosophical worldviews include the postpositivist worldview, which is the worldview adopted for this study. Postpositivists "hold a deterministic philosophy in which causes (probably) determine effects or outcomes," are reductionist in that they seek to reduce research ideas "out there" in the world into ideas that are small enough to test, and deploy the scientific method - "a researcher begins with a theory, collects data that either supports or refutes the theory, and then makes necessary revisions and conducts additional tests" [44].

This study started with exploratory research - performed when a researcher has little information [16] - and used a literature review followed by 
qualitative methods (semi-structured interviews and focus groups, with students and experts) to develop a research model. Next, causal research - which "tests whether one event causes another" [16] - was conducted, using quantitative methods. The quantitative methods included surveying end users (undergraduate students at Portland State University) to provide data that was used to empirically evaluate the research model through Structural Equation Modeling (SEM). Using more than one research approach is often common in a research endeavor [16] and it is common that a qualitative study precedes a quantitative study [47].

Combining or integrating data from qualitative and quantitative methods, as happened for this postpositivist study, is often considered a mixed methods approach [44] and assumes that these methods are complementary [48]. Mixed methods provide a more "complete understanding of a research question than either approach alone" [44]. Qualitative methods use qualitative data "descriptions of things made without assigning numbers directly" [16] - collected through observation or interviews, including focus groups, where the focus is to take an in depth dive into a question or issue. Qualitative methods are often utilized in the exploratory stage of the research process to help refine research problems, generate ideas and develop theories [16]. Quantitative methods, on the other hand, use quantitative data - "measurements in which numbers are used directly to represent the characteristics of something" [16] - such as identified through surveys, performance data, or census data [44], where the focus is to 
describe, predict, and/or build and test theory [47]. Quantitative methods can be used in later stages of a research process when the researcher has identified a well-defined research problem or theoretical model [16]. In the business research domain, which this study draws from, quantitative data collection often refers to survey research [16].

Following is a summary of the research approach. Importantly, the Principal Components Analysis (PCA), Confirmatory Factor Analysis and second phase of SEM are iterative processes.

Table 1: Summary of Research Approach

\begin{tabular}{|l|l|l|}
\hline Research step & Description & Actual participants \\
\hline $\begin{array}{l}\text { 1. Conduct } \\
\text { literature review }\end{array}$ & $\begin{array}{l}\text { Describes the importance of the } \\
\text { research topic; defines and describes } \\
\text { key concepts (student success, } \\
\text { student success metrics and } \\
\text { benchmarks, student information } \\
\text { technology in support of student } \\
\text { success, e-services technologies, } \\
\text { etc.); describes relevant technology } \\
\text { adoption models; identifies factors } \\
\text { related to university student } \\
\text { adoption of technology to create a } \\
\text { taxonomy; and identify gaps in the } \\
\text { literature. }\end{array}$ & n/a \\
\hline $\begin{array}{l}\text { 2. Articulate unit } \\
\text { of analysis }\end{array}$ & $\begin{array}{l}\text { Describes the myPSU platform, i.e. } \\
\text { the unit of analysis, as an example of } \\
\text { a student information technology in } \\
\text { support of student success - that is } \\
\text { focused on accessing university } \\
\text { services and resources. }\end{array}$ & $\mathrm{n} / \mathrm{a}$ \\
\hline $\begin{array}{l}\text { 3. Develop } \\
\text { research model }\end{array}$ & $\begin{array}{l}\text { The research model is based on the } \\
\text { literature review, UTAUT, the unique } \\
\text { technology that will be evaluated, } \\
\text { and is developed using qualitative } \\
\text { methods. It includes latent } \\
\text { constructs and their related } \\
\text { indicators/observed variables and is } \\
\text { organized as a taxonomy of factors }\end{array}$ & $\mathrm{n} / \mathrm{a}$ \\
\hline
\end{tabular}




\begin{tabular}{|c|c|c|}
\hline & $\begin{array}{l}\text { related to the adoption and use of } \\
\text { student information technology in } \\
\text { support of student success. }\end{array}$ & \\
\hline $\begin{array}{l}\text { 3a. Develop a } \\
\text { preliminary research } \\
\text { model }\end{array}$ & $\begin{array}{l}\text { Involves evaluating the taxonomy of } \\
\text { factors derived from the literature } \\
\text { review in light of UTAUT and } \\
\text { myPSU to create a taxonomy of } \\
\text { adoption factors, i.e. a preliminary } \\
\text { research model. }\end{array}$ & $\mathrm{n} / \mathrm{a}$ \\
\hline $\begin{array}{l}\text { 3b. Conduct } \\
\text { semi-structured } \\
\text { interviews }\end{array}$ & $\begin{array}{l}\text { Evaluate the preliminary research } \\
\text { model through semi-structured } 1: 1 \\
\text { interviews, including brainstorming } \\
\text { of factors that might be missing from } \\
\text { the model. }\end{array}$ & $\begin{array}{l}17 \text { interviews of } 60 \text { minutes } \\
\text { each: } 11 \text { lay experts } \\
\text { (undergraduate students); and } \\
6 \text { content experts (professionals } \\
\text { in the higher education or } \\
\text { educational technology sectors) }\end{array}$ \\
\hline $\begin{array}{l}\text { 3c. Conduct focus } \\
\text { groups }\end{array}$ & $\begin{array}{l}\text { Evaluate the preliminary research } \\
\text { model through focus groups, } \\
\text { including brainstorming of factors } \\
\text { that might be missing from the } \\
\text { model. }\end{array}$ & $\begin{array}{l}\text { Two focus groups of } 90 \text { minutes } \\
\text { each, totaling } 16 \text { participants: } \\
\text { One focus group of nine lay } \\
\text { experts (students); and one } \\
\text { focus group of seven content } \\
\text { experts (professionals from } \\
\text { Portland State University) }\end{array}$ \\
\hline $\begin{array}{l}3 \text { d. Develop } \\
\text { research model }\end{array}$ & $\begin{array}{l}\text { Analyze and synthesize results from } \\
\text { the semi-structured interviews and } \\
\text { focus groups, and in light of UTAUT, } \\
\text { to develop the research model. }\end{array}$ & $\mathrm{n} / \mathrm{a}$ \\
\hline $\begin{array}{l}\text { 3e. Identify research } \\
\text { hypotheses }\end{array}$ & $\begin{array}{l}\text { Identify research hypotheses to be } \\
\text { evaluated with Structural Equation } \\
\text { Modeling. }\end{array}$ & $\mathrm{n} / \mathrm{a}$ \\
\hline $\begin{array}{l}\text { 4. Structural } \\
\text { Equation } \\
\text { Modeling } \\
\text { (iterative } \\
\text { process), first } \\
\text { phase }\end{array}$ & $\begin{array}{l}\text { Specify and evaluate the } \\
\text { measurement model, which is a } \\
\text { manifestation of the research model } \\
\text { in a form that can be statistically } \\
\text { analyzed. }\end{array}$ & $\mathrm{n} / \mathrm{a}$ \\
\hline $\begin{array}{l}\text { 4a. Specify the } \\
\text { measurement model }\end{array}$ & $\begin{array}{l}\text { Specify the measurement model, } \\
\text { which is a manifestation of the } \\
\text { research model in a form that can be } \\
\text { statistically analyzed to evaluate the } \\
\text { degree to which the latent constructs } \\
\text { define the indicators/observed } \\
\text { variables. }\end{array}$ & $\mathrm{n} / \mathrm{a}$ \\
\hline 4b. Survey end users & $\begin{array}{l}\text { Survey end users to provide data to } \\
\text { empirically evaluate and improve the }\end{array}$ & $\begin{array}{l}\text { Read aloud: Three graduate } \\
\text { students }\end{array}$ \\
\hline
\end{tabular}




\begin{tabular}{|c|c|c|}
\hline & $\begin{array}{l}\text { research model, including: survey } \\
\text { design (developing and validating } \\
\text { the survey instrument using experts } \\
\text { and a pilot test) and data collection } \\
\text { (administering the survey). }\end{array}$ & $\begin{array}{l}\text { Expert panel: } \\
\text { Eight participants: Seven } \\
\text { content experts (professionals } \\
\text { in the higher education sector); } \\
\text { and one lay expert } \\
\text { (undergraduate student) } \\
\text { Pilot test: } 21 \text { undergraduate } \\
\text { students } \\
\text { Survey: } \\
\text { 1,841 respondents (analytic } \\
\text { sample) who were } \\
\text { undergraduate students at } \\
\text { Portland State University; } 23 \% \\
\text { response rate }\end{array}$ \\
\hline $\begin{array}{l}\text { 4c. Evaluate survey } \\
\text { results }\end{array}$ & $\begin{array}{l}\text { Evaluate survey results to edit the } \\
\text { data and conduct an evaluation of } \\
\text { the response rate and nonresponses, } \\
\text { resulting in the analytic sample for } \\
\text { evaluation. }\end{array}$ & $\mathrm{n} / \mathrm{a}$ \\
\hline \multicolumn{3}{|c|}{$\begin{array}{l}\text { Note: steps } 4 d-5 b \text { below are an iterative process, often involving the evaluation of several } \\
\text { model iterations. In this research, three approaches were used (one that did not use PCA and } \\
\text { two that used PCA) }\end{array}$} \\
\hline $\begin{array}{l}\text { 4d. Principal } \\
\text { Components } \\
\text { Analysis }\end{array}$ & $\begin{array}{l}\text { Use Principal Components Analysis } \\
\text { (PCA), a technique of Exploratory } \\
\text { Factor Analysis (EFA), to evaluate } \\
\text { whether the latent constructs and } \\
\text { their corresponding indicators are } \\
\text { measuring what the theory suggests } \\
\text { they should be measuring. A } \\
\text { reliability analysis can also be } \\
\text { conducted at this step. Based on the } \\
\text { results of the principal components } \\
\text { analysis and the reliability analysis, } \\
\text { adjust the measurement model. }\end{array}$ & $\mathrm{n} / \mathrm{a}$ \\
\hline $\begin{array}{l}\text { 4e. Confirmatory } \\
\text { Factor Analysis }\end{array}$ & $\begin{array}{l}\text { Conduct Confirmatory Factor } \\
\text { Analysis (CFA), another approach to } \\
\text { examining the relationships between } \\
\text { the observed variables/indicators } \\
\text { and latent constructs (i.e. factors), } \\
\text { using goodness of fit measures, the } \\
\text { significance of the indicator paths, } \\
\text { discriminant validity and } \\
\text { modification indices to evaluate and } \\
\text { improve the measurement model. } \\
\text { The goals are that the measurement }\end{array}$ & $\mathrm{n} / \mathrm{a}$ \\
\hline
\end{tabular}




\begin{tabular}{|l|l|l|}
\hline & $\begin{array}{l}\text { model appropriately captures the } \\
\text { nature of the relationships between } \\
\text { observed variables and latent } \\
\text { constructs and can be used to } \\
\text { develop the structural model. }\end{array}$ & \\
\hline $\begin{array}{l}\text { 5. Structural } \\
\text { Equation } \\
\text { Modeling, second } \\
\text { phase }\end{array}$ & $\begin{array}{l}\text { Specify and evaluate the structural } \\
\text { model in order to evaluate the } \\
\text { hypotheses/paths between latent } \\
\text { constructs. }\end{array}$ & $\mathrm{n} / \mathrm{a}$ \\
\hline $\begin{array}{l}\text { 5a. Specify } \\
\text { structural model }\end{array}$ & $\begin{array}{l}\text { Specify the structural model by } \\
\text { adding paths that connect the latent } \\
\text { constructs/variables. The paths } \\
\text { represent the hypothesized } \\
\text { dependent relationships between the } \\
\text { variables and are based on the theory } \\
\text { the researcher has hypothesized. }\end{array}$ & $\mathrm{n} / \mathrm{a}$ \\
\hline $\begin{array}{l}\text { 5b. Evaluate } \\
\text { structural model }\end{array}$ & $\begin{array}{l}\text { Use goodness-of-fit measures and } \\
\text { tests for the significance of paths to } \\
\text { assess the model, and make } \\
\text { adjustments to the model to achieve } \\
\text { an adequate fit. }\end{array}$ & $\mathrm{n} / \mathrm{a}$ \\
\hline $\begin{array}{l}\text { 5c. Identify final } \\
\text { structural model }\end{array}$ & $\begin{array}{l}\text { Identify the final structural model } \\
\text { and analyze hypotheses. }\end{array}$ & $\mathrm{n} / \mathrm{a}$ \\
\hline
\end{tabular}




\section{Chapter Three: Literature Review - Student Success and Student Information Technology}

\subsection{Defining Student Success}

Student success is, in its most basic form, and when considered from an institutional view, when an undergraduate student remains enrolled in college until degree completion - that is, getting students through college [49], [50]. A critical part of student success is college student retention, which is the continuous enrollment of students from one fall semester to the following fall semester. Retention is a multifaceted concept, including "campus culture, institutional type and characteristics, student profile and admission criteria" [51]. Student success efforts often involve initiatives across and between postsecondary institutions and involve departments, people (e.g. academic advisors), programs, services, tools and software to aid students in achieving their educational goals [52].

Beyond graduation and retention, student success for some institutions includes the ability to "deliver an outstanding education that enables students to learn, thrive, complete their degrees at high rates, and find meaningful work" [53]. Even more broadly, it can also include academic competence (e.g. writing and speaking in a clear manner), cognitive skill development, and preparation for adulthood and citizenship [25]. At the individual student level, studies have shown that a student's integration into the academic and social environments of a university can influence their desire to stay and persist [51]. Student success can 
also be thought of as students' success within courses [49] and in academic programs [54]. To add further depth, student retention often depends on institutional type. For example, in non-residential campuses, some argue that success is largely dependent on what happens in the classroom, as often this might be the only place where students meet each other and faculty [55]. When institutions first started focusing on retention, it was viewed in terms of the deficiencies of the individual, i.e. blaming the victim. Today, with a more informed understanding of how individuals, institutions and society interact, retention has shifted "to take account of the role of the environment, in particular the institution, in student decisions to stay or leave" [55].

There are also more nuanced definitions of student success. Students often think about success in terms of earning a degree, but perhaps even more potently, they consider success in light of the skills and competencies they desire for next steps and careers post-graduation [52]. Students' own goals of success shift at different times in their academic careers. They may start out thinking of success as completing courses with good grades and obtaining a degree, but as they progress in their education, their definition of success may become broader and consider goals of achieving financial security and career advancement [50]. For others, success might be defined as the ability to make it to class every day, given the barriers they might encounter in accessing higher education [52].

From another perspective, student success can be defined in terms of educational system and national goals. Retention may be defined as graduation 
within a "system" of higher education, i.e. starting at one institution and graduating from another [54], such as between institutions that are in close geographical proximity (e.g. a community college and a university). Or, student success may be defined to encompass starting at one institution and graduating from another, which might not be in the same system of higher education. This is now measurable as a result of more expansive data sharing [56]. Several national foundations, notably the Bill \& Melinda Gates Foundation and the Lumina Foundation, conceive of student success as efforts to increase low-income students' completion rates across the country [22], [57].

Based on the above, student success for this study is defined as supporting undergraduate students with remaining enrolled in college until degree completion and, drawing on the definition of student success at the University of South Florida [58], it encompasses:

- Higher persistence and graduation rates

- Lower student costs and debt

- Higher satisfaction with the university

- Higher progression to careers or post-graduate programs

- Acquisition of the skills, knowledge and dispositions to succeed

In relation to the topic of information technology adoption of software for accessing university services, the most relevant parts of the student success definition are: Higher persistence and graduation rates; lower student costs; and higher satisfaction with the university. 


\subsection{Student Success Metrics Frameworks}

With a clear definition of student success in mind, this section discusses key student success metrics and metrics frameworks, to assist with drawing a conceptual connection between this study and student outcomes and institutional performance measures. While the topic of how best to measure performance in higher education has been an area of interest for quite some time, there is not yet a consensus on the one best way to do so [59]. Additionally, while there is general agreement that measuring performance is critical and important to translate organizational strategy into results [59], there are mixed reviews of the actual effectiveness of adopting performance-based measures to improve institutional performance [6o]. Nonetheless, it is becoming more common for states across the country to tie funding allocations to institutional performance [61], driven by accountability considerations including return on public dollar investments in higher education [62], [63], [61]. The 2010-2011 National Governors Association Chair's initiative, Complete to Compete, recommends that all states collect data from all public, postsecondary institutions [64]. States like Tennessee and Minnesota have in place robust higher education performance measures [65], [66].

The most common performance metrics related to student success are retention and graduation metrics [59], with graduation rate being the most widely adopted indicator [63]. However, many argue that as the student population is shifting from primarily traditional, full-time students to those 
whose enrollment patterns fluctuate more, have reduced course loads, and are transferring more between institutions, the value of these traditional measures is declining [67], [68]. Some argue that there ought to be more of an emphasis on measures focused on student experiences [6o] and there are increasing calls for metrics that focus on equity and seek to "include all students and accurately represent the higher education experience of populations that are underserved and may be 'invisible' in other data collections" [69].

For these reasons and others, measuring student success and developing appropriate measures is complicated [49], [70]. "Retention is a complex personal, social and academic enterprise" [71], and while the metrics can be defined in straightforward ways, students' paths can be anything but straight [49]. Considering the idea of retention illustrates this complexity. Retention can be thought of as a student being retained within a major, or measured at the individual course level, or measured in terms of continued enrollment at the institution [54]. Due in large part to these complexities, retention and graduation efforts require a set of measures [49]. Some posit that an institution's retention rate can be misleading, as retention rates can vary significantly depending on which kinds of students enroll [72] - academic ability is an important predictor of a student's ability to persist [56]. Measurement efforts are catching up to accommodate the new kinds of data that are needed as a result of demographic shifts in student populations. For example, the widely referenced Student Achievement Measure (SAM) tracks student movement across institutions [50]. 


\section{Metrics Frameworks}

Several student success metrics frameworks have been introduced in recent years that are useful for considering student success metrics in light of this study. The Complete to Compete framework, sponsored by the National Governors Association, was informed by a focus on supporting states and their governors to improve their higher education accountability systems [62]. The first part of this framework, articulated in "Complete to Complete: Common Completion Metrics" describes college completion metrics and was adopted by 30 states [62], [73]. It responded to gaps in federal data. For example, the federal

graduation rate data by the U. S. Department of Education's Integrated Postsecondary Education Data System (IPEDS) accounted for only $48 \%$ of all undergraduates enrolled in four-year public institutions and $32 \%$ of those enrolled in two-year public institutions - and it did not account for part-time and transfer students [73].

The Complete to Compete framework recommends tracking outcome metrics, which "quantify the end-product of the educational process - mainly the completion of an academic program" and progress metrics, which "measure student movement from semester-to-semester and year-to-year toward the completion of an academic program" [73]. The suggested outcome metrics are degrees awarded, graduation rates, transfer rates, time and credits to degree. The framework's suggested progress metrics are enrollment in remedial education, success beyond remedial education, success in first-year college courses, credit 
accumulation, retention rates and course completion. A second component of the Complete to Compete framework focuses on efficiency and effectiveness metrics [62], which provide a broader perspective on student success. These metrics are related to meeting workforce needs, student output relative to input, return on investment, and quality/student learning [62].

A second metrics framework is the Advancing by Degrees framework, which draws on an analysis of data from two large postsecondary systems California Community Colleges and the State University System of California [74]. The authors posit that institutions and university systems should focus on milestones - the "intermediate and final outcome measures" - and indicators which help to articulate why students are not making progress [75]. Example milestones are that students return for subsequent terms, begin college-level coursework in math and English, and complete a certificate or a degree [74]. Example indicators are that students begin remedial coursework in the first term (if needed), complete college-level math and/or English in the first or second year, complete a high percentage of the courses attempted (low rate of course dropping and/or failure), register on time for courses, and enroll continuously, without dropping out [74].

A third metrics framework is the Postsecondary Metrics Framework developed by the Bill \& Melinda Gates Foundation in partnership with the The Institute for Higher Education Policy [76], [69]. A hallmark of this framework is that it is designed to use outcomes best suited for “"post-traditional' students - 
the low-income, first-generation, adult, transfer, and part-time students who make up the new majority on today's campuses" [76], as these students have been ignored in many metrics.

The Postsecondary Metrics Framework is driven by several core design principles. The first principle is that it is important to count all students and institutions, for example by counting students who do not enter college during the traditional fall term, to "disaggregating data to ensure equitable access and success for diverse populations" [76]. This principle is related to the awareness that students "whose college experiences were most often excluded from or obscured by current data - low-income students, students of color, adult students, transfer students, and part-time students - were the very populations...leaders needed to target to close gaps and raise completion rates" [76].

A second core design principle is that it is important to count all outcomes, i.e. those that have not been traditionally captured, such as credit accumulation and measuring transfer students' completion at a students' initial and subsequent institutions. The third core design principle is that costs - to the students, the institutions and the public - are important to consider [76]. There are three major categories of metrics: performance metrics, which measure institutional performance related to "access, progress, completion, cost, and post-college outcomes"; efficiency measures that consider how resources relate to college completion; and equity metrics, which work to include all and "accurately 
represent the higher education experience of populations that are underserved and may be 'invisible' in other data collections" [69].

Table 2: Postsecondary Metrics Framework [76], [69]

\begin{tabular}{|c|c|c|c|c|c|}
\hline & Access & Progression & Completion & Cost & $\begin{array}{l}\text { Post-Coll } \\
\text { ege } \\
\text { Outcome } \\
\text { s }\end{array}$ \\
\hline Performance & Enrollment & $\begin{array}{l}\text { Credit } \\
\text { Accumulation } \\
\text { Credit } \\
\text { Completion } \\
\text { Ratio } \\
\text { Gateway } \\
\text { Course } \\
\text { Completion } \\
\text { Program of } \\
\text { Study Selection } \\
\text { Retention Rate } \\
\text { Persistence } \\
\text { Rate }\end{array}$ & $\begin{array}{l}\text { Transfer Rate } \\
\text { Graduation } \\
\text { Rate } \\
\text { Success Rate } \\
\text { Completers }\end{array}$ & $\begin{array}{l}\text { Net Price } \\
\text { Unmet } \\
\text { Need } \\
\text { Cumulativ } \\
\text { e Debt }\end{array}$ & $\begin{array}{l}\text { Employme } \\
\text { nt Rate } \\
\text { Median } \\
\text { Earnings } \\
\text { Loan } \\
\text { Repaymen } \\
\text { t and } \\
\text { Default } \\
\text { Rates } \\
\text { Graduate } \\
\text { Education } \\
\text { Rate } \\
\text { Learning } \\
\text { Outcomes }\end{array}$ \\
\hline Efficiency & $\begin{array}{l}\text { Expenditures } \\
\text { per Student }\end{array}$ & $\begin{array}{l}\text { Cost for Credits } \\
\text { not Completed } \\
\text { Cost for } \\
\text { Completing } \\
\text { Gateway } \\
\text { Courses } \\
\text { Change in } \\
\text { Revenue from } \\
\text { Change in } \\
\text { Retention }\end{array}$ & $\begin{array}{l}\text { Time/Credits } \\
\text { to Credential } \\
\text { Cost of Excess } \\
\text { Credits to } \\
\text { Credential } \\
\text { Completions } \\
\text { per Student }\end{array}$ & $\begin{array}{l}\text { Student } \\
\text { Share of } \\
\text { Cost } \\
\text { Expenditu } \\
\text { res per } \\
\text { Completio } \\
\mathrm{n}\end{array}$ & $\begin{array}{l}\text { Earnings } \\
\text { Threshold }\end{array}$ \\
\hline Equity & $\begin{array}{l}\text { Enrollment by } \\
\text { [at least] } \\
\text { Preparation, } \\
\text { Economic } \\
\text { Status, Age, } \\
\text { Race/Ethnicit } \\
\text { y }\end{array}$ & $\begin{array}{l}\text { Progression } \\
\text { Performance } \\
\text { by [at least] } \\
\text { Preparation, } \\
\text { Economic } \\
\text { Status, Age, } \\
\text { Race/Ethnicity }\end{array}$ & $\begin{array}{l}\text { Completion } \\
\text { Performance } \\
\text { by [at least] } \\
\text { Preparation, } \\
\text { Economic } \\
\text { Status, Age, } \\
\text { Race/Ethnicit } \\
\text { y }\end{array}$ & $\begin{array}{l}\text { Net Price } \\
\text { and } \\
\text { Unmet } \\
\text { Need by } \\
\text { [at least] } \\
\text { Preparatio } \\
\text { n, } \\
\text { Economic } \\
\text { Status, }\end{array}$ & $\begin{array}{l}\text { Debt by } \\
\text { [at least] } \\
\text { Preparatio } \\
\text { n, } \\
\text { Economic } \\
\text { Status, }\end{array}$ \\
\hline
\end{tabular}




\begin{tabular}{|c|c|c|c|c|}
\hline & & & $\begin{array}{l}\text { Age, } \\
\text { Race/Ethn } \\
\text { icity } \\
\\
\text { Debt by } \\
\text { [at least] } \\
\text { Preparatio } \\
\text { n, } \\
\text { Economic } \\
\text { Status, } \\
\text { Age, } \\
\text { Race/Ethn } \\
\text { icity, } \\
\text { Completio } \\
\text { n Status }\end{array}$ & $\begin{array}{l}\text { Age, } \\
\text { Race/Ethn } \\
\text { icity, } \\
\text { Completio } \\
\text { n Status }\end{array}$ \\
\hline $\begin{array}{l}\text { Key Student Char } \\
\text { Enrollment Status } \\
\text { Credential-seekin } \\
\text { Academic Prepars } \\
\text { Race/Ethnicity, A } \\
\text { Status }\end{array}$ & $\begin{array}{l}\text { acteristics } \\
\text { s, Attendance Intensity, } \\
\text { g Status, Program of Study, } \\
\text { ation, Economic Status, } \\
\text { ge, Gender, First-generation }\end{array}$ & \multicolumn{3}{|c|}{$\begin{array}{l}\text { Key Institutional Characteristics } \\
\text { Sector, Level, Credential/Program Mix, } \\
\text { Size, Resources, Selectivity, Diversity, } \\
\text { Minority-serving Institution (MSI) Status, } \\
\text { Post-traditional Populations, Modality }\end{array}$} \\
\hline
\end{tabular}

In addition to the above frameworks, some institutions such as Portland State University are using Net Promoter Score (NPS) to gauge the overall experiences and satisfaction of students. While not without criticism [77], NPS, developed by Bain and Company, has obtained notoriety as a simple and effective way to gauge customer satisfaction, experience and loyalty [78]. NPS is calculated by subtracting the percentage of customers who are detractors (rating of $0-6$, Not Likely at All) from the percentage who are promoters (rating of 9 or 10, Extremely Likely) in response to the question: "How likely is it you would recommend us to a friend?" [79]. 


\subsection{Student Success Metrics Related to Studied Population}

Based on an analysis of the three metrics frameworks from above, plus other sources and an examination of the critical factors that would enable an organization to drive and measure success [80], and in light of Portland State University undergraduate students as the target population of this study, the table below describes student success metrics related to the research topic and the studied population.

Table 3: Student Success Metrics and Definitions Related to Studied Population

\begin{tabular}{|c|c|c|}
\hline Metric & Definition & References \\
\hline \multicolumn{3}{|l|}{ Progression Metrics } \\
\hline Full-Time Retention Rate & $\begin{array}{l}\text { The full-time retention rate is the percent of the } \\
\text { (fall full-time cohort from the prior year minus } \\
\text { exclusions from the fall full-time cohort) that } \\
\text { re-enrolled at the institution as either full- or } \\
\text { part-time in the current year. }\end{array}$ & {$[81],[82]$} \\
\hline Part-Time Retention Rate & $\begin{array}{l}\text { The part-time retention rate is the percent of the } \\
\text { (fall part-time cohort from the prior year minus } \\
\text { exclusions from the fall part-time cohort) that } \\
\text { re-enrolled at the institution as either full- or } \\
\text { part-time in the current year. }\end{array}$ & {$[81],[82]$} \\
\hline Credit Accumulation & $\begin{array}{l}\text { The percentage of students earning sufficient } \\
\text { credits toward on-time completion in their first } \\
\text { year. }\end{array}$ & {$[69]$} \\
\hline Credit Completion Ratio & $\begin{array}{l}\text { The number of credits completed, divided by the } \\
\text { number of credits attempted by first-year } \\
\text { students. }\end{array}$ & {$[69]$} \\
\hline $\begin{array}{l}\text { Complete } 30-45 \text { credits in } \\
\text { the first year* }\end{array}$ & Complete $30-45$ credits in the first year. & {$[74]$} \\
\hline \multicolumn{3}{|l|}{ Completion Metrics } \\
\hline $\begin{array}{l}\text { Graduation Rate - } \\
\text { Bachelor Degree Within } 4 \\
\text { Years }\end{array}$ & $\begin{array}{l}\text { 4-year graduation rate of the subcohort of } \\
\text { full-time, first-time students seeking a bachelor's } \\
\text { or equivalent degree. }\end{array}$ & {$[81],[82]$} \\
\hline $\begin{array}{l}\text { Graduation Rate - } \\
\text { Bachelor Degree within } 6 \\
\text { Years }\end{array}$ & $\begin{array}{l}\text { 6-year graduation rate of the subcohort of } \\
\text { full-time, first-time students seeking a bachelor's } \\
\text { or equivalent degree. }\end{array}$ & {$[81],[82]$} \\
\hline
\end{tabular}




\begin{tabular}{|c|c|c|}
\hline $\begin{array}{l}\text { Pell Grant Recipients - } \\
\text { Bachelor's Degree Rate } \\
\text { within } 6 \text { Years }\end{array}$ & $\begin{array}{l}\text { Bachelor degree graduation rate within } 150 \% \text { of } \\
\text { normal time (6-years) of the full-time, first-time, } \\
\text { bachelor's degree seeking Pell grant recipient } \\
\text { cohort. }\end{array}$ & {$[81],[82]$} \\
\hline $\begin{array}{l}\text { Bachelor's completion rate } \\
\text { if continued to junior year: } \\
\text { 1st-time/Freshman }\end{array}$ & $\begin{array}{l}\text { At the university, a completion is the awarding of } \\
\text { a bachelor's or advanced degree or professional } \\
\text { certificate. }\end{array}$ & {$[83]$} \\
\hline $\begin{array}{l}\text { Bachelor's completion rate } \\
\text { if continued to junior year: } \\
\text { Transfer students }\end{array}$ & $\begin{array}{l}\text { At the university, a completion is the awarding of } \\
\text { a bachelor's or advanced degree or professional } \\
\text { certificate. }\end{array}$ & {$[83]$} \\
\hline $\begin{array}{l}\text { Completion rate for } 1 \text { st } \\
\text { generation students }\end{array}$ & $\begin{array}{l}\text { At the university, a completion is the awarding of } \\
\text { a bachelor's or advanced degree or professional } \\
\text { certificate. }\end{array}$ & {$[83]$} \\
\hline $\begin{array}{l}\text { First-time, full-time - } \\
\text { Percent graduated from } \\
\text { institution, graduated } \\
\text { from another institution, } \\
\text { or still enrolled - within six } \\
\text { years }\end{array}$ & $\begin{array}{l}\text { First-time, full-time - Percent graduated from } \\
\text { institution, graduated from another institution, or } \\
\text { still enrolled - within six years, Fall 2009, Fall } \\
\text { 2010, Fall } 2011 \text { or Fall } 2012 \text { cohort. }\end{array}$ & {$[84]$} \\
\hline $\begin{array}{l}\text { Full-time transfer - } \\
\text { Percent graduated from } \\
\text { institution, graduated } \\
\text { from another institution, } \\
\text { or still enrolled - within six } \\
\text { years }\end{array}$ & $\begin{array}{l}\text { Full-time transfer - Percent graduated from } \\
\text { institution, graduated from another institution, or } \\
\text { still enrolled - within six years, Fall 2009, Fall } \\
\text { 2010, Fall } 2011 \text { or Fall } 2012 \text { cohort. }\end{array}$ & {$[84]$} \\
\hline Credits to Credential & $\begin{array}{l}\text { The average credits accumulated from the first } \\
\text { date of entry to the institution to date of } \\
\text { completion for all completers in a given year. }\end{array}$ & [69] \\
\hline $\begin{array}{l}\text { Cost of Excess Credits to } \\
\text { Credential }\end{array}$ & $\begin{array}{l}\text { The per-student expenditures for excess credits to } \\
\text { credential for all completers with excess credits in } \\
\text { a given year. }\end{array}$ & {$[69]$} \\
\hline Time to Credential & $\begin{array}{l}\text { The average time accumulated from first date of } \\
\text { entry to the institution to date of completion for } \\
\text { all completers in a given year. }\end{array}$ & {$[83]$} \\
\hline Net Promoter Score & $\begin{array}{l}\text { The overall experiences and satisfaction of a } \\
\text { customer. Measured by subtracting the } \\
\text { percentage of detractors from the percentage of } \\
\text { promoters. }\end{array}$ & [78], [79] \\
\hline
\end{tabular}

* Original metric reads "Complete 20-30 credits in the first year", which is for a semester-system calendar. Portland State University is on the quarter-system calendar, which means that 1 credit in a semester-system is equivalent to 1.5 credits in a quarter-system. Thus, for this metric to be applicable to Portland State University, it has been converted to "Complete 30-45 credits in the first year." 


\subsection{Benchmarking}

In order to better understand student success metrics for Portland State University undergraduate students, and to add additional context for this study, it is helpful to understand Portland State data when compared to other institutions and benchmarks. There are no readily available student success benchmarks that Portland State University is using, based on a thorough search of the University's website and publicly available information from its Office of Institutional Research and Planning [85].

Benchmarking is a strategic process by which organizations compare their processes and/or outcomes to other organizations in an effort to improve performance [86], [87]. "Benchmarks are outcomes such as numbers, measures, and standards, identifying the gap between where you are and where others are" [87]. Full-scale benchmarking is quite rare in higher education [86], [87], and it is almost all performance-based, which "compares selected indicators or metrics among similar institutions to evaluate relative performances" [86]. Performance-based benchmarks based on external organizations are used in this study to help inform what constitutes "good" performance [88].

The steps to develop the benchmarks for this study follow the first steps of an overall benchmarking process and were to: decide what to benchmark (i.e. which student success metrics), and select the comparators and collect data to establish benchmarks [89], [90]. 


\subsubsection{Peer Institutions for Benchmarking}

Four types of peers, or comparators, can be considered for benchmarking: competitors, aspirational, peer and predetermined (natural, traditional, jurisdictional and classification-based) [91]. This study used peers, aspirational peers and jurisdictional peers (the most relevant public institutions in Oregon). It is important to note that in a true benchmarking process, identifying the peer institutions would involve a "variety of institutional stakeholders" [92] and would involve in-depth discussion of the factors that influence peer selection, such as an institution's mission, its Carnegie Classification of Institutions of Higher Education, its demographic characteristics, or the types of students who are admitted [91], [92].

Table 4: Peer Institutions Summary [81]

\begin{tabular}{|l|l|r|}
\hline Institution & Location & 2017 enrollment \\
\hline Portland State University & Portland, Oregon & 26,693 \\
\hline Peer institutions & Fairfax, Virginia & 35,984 \\
\hline George Mason University & Indianapolis, Indiana & 29,791 \\
\hline $\begin{array}{l}\text { Indiana University-Purdue } \\
\text { University-Indianapolis }\end{array}$ & San Diego, California & 35,158 \\
\hline San Diego State University & Arlington, Texas & 46,497 \\
\hline The University of Texas at Arlington & Chicago, Illinois & 30,539 \\
\hline University of Illinois at Chicago & Memphis, Tennessee & 21,521 \\
\hline University of Memphis & Toledo, Ohio & 20,579 \\
\hline University of Toledo & Milwaukee, Wisconsin & 24,988 \\
\hline University of Wisconsin-Milwaukee & \multicolumn{2}{|l}{} \\
\hline Western Michigan University & \multicolumn{2}{|l}{} \\
\hline Aspirational peer institutions & Atlanta, Georgia & 32,816 \\
\hline Georgia State University & Orlando, Florida & 66,059 \\
\hline University of Central Florida & Tampa, Florida & 43,540 \\
\hline University of South Florida-Main Campus & 30,896 \\
\hline Jurisdictional peer institutions & Corvallis, Oregon & \\
\hline Oregon State University &
\end{tabular}




\subsubsection{Benchmarks and Outcomes for the Studied Population}

In order to develop benchmarks and outcomes associated with student success metrics for the studied population, a detailed research process and review was conducted of:

- Jurisdictional peers data in comparison to Portland State University data using State of Oregon Higher Education Coordinating Commission data, which annually highlights key public higher education data for Oregonians [93];

- National data in comparison to Portland State University using averages of all public, private nonprofit and private for-profit institutions in the United States using IPEDS (Integrated Postsecondary Education Data System maintained by the U.S. Department of Education's National Center for Education Statistics), [94], which only accounts for progress at a student's original institution [95] and largely considers only "traditional" students [68];

- Peer and aspirational peer data in comparison to Portland State University using Integrated Postsecondary Education Data System (IPEDS) and Student Achievement Measure (SAM) data, which tracks student movement across postsecondary institutions [96]; and

- Additional critical metrics from the metrics frameworks described above that are directly related to the surveyed population and degree planning 
software, plus Net Promoter Score, using a combination of State of Oregon Higher Education Coordinating Commission and Portland State University data, as available.

These results from the above research are summarized below, and grouped into progression and completion metrics.

Table 5: Benchmarks and Outcomes Associated with Student Success Metrics for Studied Population

\begin{tabular}{|c|c|c|c|c|}
\hline Metric & $\begin{array}{l}\text { Outcome for } \\
\text { Portland State } \\
\text { University } \\
\text { Undergraduat } \\
\text { es, i.e. Studied } \\
\text { Population }\end{array}$ & Benchmark & $\begin{array}{l}\text { About } \\
\text { Benchmark }\end{array}$ & $\begin{array}{l}\text { Refere } \\
\text { nces }\end{array}$ \\
\hline \multicolumn{5}{|l|}{ Progression Metrics } \\
\hline Full-Time Retention Rate & 72.6 & 86.5 & $\begin{array}{l}\text { Aspirational } \\
\text { peers average; } \\
\text { IPEDS }\end{array}$ & {$[81]$} \\
\hline Part-Time Retention Rate & 45.2 & 67.1 & $\begin{array}{l}\text { Aspirational } \\
\text { peers average; } \\
\text { IPEDS }\end{array}$ & {$[81]$} \\
\hline Credit Accumulation & $\begin{array}{r}\text { not currently } \\
\text { feasible - in } \\
\text { progress }\end{array}$ & not available & $\mathrm{n} / \mathrm{a}$ & $\mathrm{n} / \mathrm{a}$ \\
\hline Credit Completion Ratio & $\begin{array}{r}\text { not currently } \\
\text { feasible - in } \\
\text { progress }\end{array}$ & not available & $\mathrm{n} / \mathrm{a}$ & $\mathrm{n} / \mathrm{a}$ \\
\hline $\begin{array}{l}\text { Complete } 30-45 \text { credits in the first } \\
\text { year* }\end{array}$ & 39.6 credits & $\begin{array}{r}\text { Complete } \\
30-45 \text { credits } \\
\text { in the first } \\
\text { year }\end{array}$ & $\begin{array}{l}\text { Advancing by } \\
\text { Degrees } \\
\text { Framework }\end{array}$ & {$[74]$} \\
\hline $\begin{array}{l}\text { Student Experience Improvements - } \\
\text { More Useful Degree Planning } \\
\text { Experience }\end{array}$ & not available & not available & $\mathrm{n} / \mathrm{a}$ & $\mathrm{n} / \mathrm{a}$ \\
\hline \multicolumn{5}{|l|}{ Completion Metrics } \\
\hline $\begin{array}{l}\text { Graduation Rate - Bachelor Degree } \\
\text { Within } 4 \text { Years }\end{array}$ & 19.2 & 34.9 & $\begin{array}{l}\text { Aspirational } \\
\text { peers average; } \\
\text { IPEDS }\end{array}$ & {$[81]$} \\
\hline $\begin{array}{l}\text { Graduation Rate - Bachelor Degree } \\
\text { within } 6 \text { Years }\end{array}$ & 44.6 & 63.2 & $\begin{array}{l}\text { Aspirational } \\
\text { peers average; } \\
\text { IPEDS }\end{array}$ & {$[81]$} \\
\hline
\end{tabular}




\begin{tabular}{|c|c|c|c|c|}
\hline $\begin{array}{l}\text { Pell Grant Recipients - Bachelor's } \\
\text { Degree Rate within } 6 \text { Years }\end{array}$ & 47.0 & 62.7 & $\begin{array}{l}\text { Aspirational } \\
\text { peers average; } \\
\text { IPEDS }\end{array}$ & {$[81]$} \\
\hline $\begin{array}{l}\text { Bachelor's completion rate if } \\
\text { continued to junior year: } \\
\text { 1st-time/Freshman }\end{array}$ & 74.0 & 82.0 & $\begin{array}{l}\text { Jurisdictional } \\
\text { peers average; } \\
\text { HECC }\end{array}$ & $\begin{array}{l}{[97]} \\
{[98]} \\
{[99]}\end{array}$ \\
\hline $\begin{array}{l}\text { Bachelor's completion rate if } \\
\text { continued to junior year: Transfer } \\
\text { students }\end{array}$ & 61.0 & 63.0 & $\begin{array}{l}\text { Jurisdictional } \\
\text { peers average; } \\
\text { HECC }\end{array}$ & $\begin{array}{l}{[97]} \\
{[98]} \\
{[99]}\end{array}$ \\
\hline $\begin{array}{l}\text { Completion rate for 1st generation } \\
\text { students }\end{array}$ & 52.0 & 56.0 & $\begin{array}{l}\text { Jurisdictional } \\
\text { peers average; } \\
\text { HECC }\end{array}$ & $\begin{array}{l}{[97]} \\
{[98]} \\
{[99]}\end{array}$ \\
\hline $\begin{array}{l}\text { First-time, full-time - Percent } \\
\text { graduated from institution, } \\
\text { graduated from another institution, } \\
\text { or still enrolled - within six years, Fall } \\
\text { 2009, Fall 2010, Fall } 2011 \text { or Fall } \\
2012 \text { cohort }\end{array}$ & 74.0 & 86.0 & $\begin{array}{l}\text { Jurisdictional } \\
\text { peers average; } \\
\text { SAM }\end{array}$ & {$[84]$} \\
\hline $\begin{array}{l}\text { Full-time transfer - Percent } \\
\text { graduated from institution, } \\
\text { graduated from another institution, } \\
\text { or still enrolled - within six years, Fall } \\
\text { 2009, Fall 2010, Fall } 2011 \text { or Fall } \\
2012 \text { cohort } \\
\end{array}$ & 78.0 & 83.0 & $\begin{array}{l}\text { Jurisdictional } \\
\text { peers average; } \\
\text { SAM }\end{array}$ & {$[84]$} \\
\hline Credits to Credential & $\begin{array}{r}\text { not available; } \\
\text { however, in } \\
2017-18, \text { of the } \\
\text { PSU graduates } \\
\text { who graduated } \\
\text { with more than } \\
240 \text { credits (i.e. } \\
\text { excessive } \\
\text { credits), } 54.3 \% \\
\text { of those credits } \\
\text { were } \\
\text { accumulated at } \\
\text { PSU }\end{array}$ & not available & $\mathrm{n} / \mathrm{a}$ & [100] \\
\hline $\begin{array}{l}\text { Cost of Excess Credits to } \\
\text { Credential }\end{array}$ & $\begin{array}{r}\text { not currently } \\
\text { feasible - in } \\
\text { progress }\end{array}$ & $\begin{array}{r}\text { not available; } \\
\text { however, at } \\
\text { least } 180 \\
\text { credits are } \\
\text { required to } \\
\text { graduate from } \\
\text { Portland State } \\
\text { University }\end{array}$ & $\mathrm{n} / \mathrm{a}$ & [101] \\
\hline
\end{tabular}




\begin{tabular}{|l|r|r|l|l|}
\hline Time to Credential & 4.8 years & 4.4 years & $\begin{array}{l}\text { Jurisdictional } \\
\text { peers average; } \\
\text { HECC }\end{array}$ & $\begin{array}{l}{[97],} \\
{[98],} \\
\text { [99] }\end{array}$ \\
\hline Net Promoter Score & -1.0 & not available & n/a & [102] \\
& & & & \\
\hline
\end{tabular}

IPEDS = Integrated Postsecondary Education Data System ; HECC $=$ State of Oregon Higher Education Coordinating Commission; SAM= Student Achievement Measure

* Original metric reads "Complete 20-30 credits in the first year", which is for a semester-system calendar. Portland State University is on the quarter-system calendar, which means that 1 credit in a semester-system is equivalent to 1.5 credits in quarter-system. Thus, for this metric to be applicable to Portland State University, it has been converted to "Complete 30-45 credits in the first year."

\subsubsection{Contextualizing Portland State University Outcomes}

While it is beyond the scope of this study to provide a detailed analysis for Portland State University outcomes in relation to the above benchmarks, for every student success performance metric listed above, Portland State University is underperforming. The reasons for this are likely complex and could be due to many factors. Institutional and student characteristics are likely contributors, as these contextual factors create opportunities or challenges for an institution in meeting performance benchmarks.

Portland State University and its students, as compared to peers, tend to have more challenges that could negatively impact reaching performance benchmarks. In relation to national data (IPEDS), Portland State University tends to be less selective in admissions (which could indicate it is more of an access university); its students tend to have about the same financial need (with the exception of jurisdictional peers - PSU students have far greater need); PSU 
receives significantly less state funding per student; and PSU serves proportionally more transfer students (particularly when compared to jurisdictional peers).

In relation to comparisons with jurisdictional peers (State of Oregon Higher Education Coordinating Commission data), Portland State University tends to serve a population with backgrounds and circumstances that challenge their persistence in higher education. Portland State University serves proportionally more first-generation students, proportionally more students who are receiving public grant aid, and proportionally more part-time students, who often balance completing responsibilities between work, family and school, which can negatively impact persistence [103], [25], [104], [105], [106], [107], [108]. Critically, a more detailed analysis that is beyond the scope of this study (and not easily available via publicly accessible information) would be to disaggregate data by preparation, economic status, age and/or race/ethnicity as suggested by the Postsecondary Metrics Framework [76].

Additionally, it is quite possible there are internal opportunities at Portland State University for improvements, too. However, not all is bleak - in Fall 2018, Portland State University had its highest first-year retention rate ever, of $74.0 \%$ [100], showing the university is on the right track to making critical student success improvements. The table below summarizes Portland State University's profile and student characteristics in relation to its peers. 
Table 6: Institutional and Student Characteristics Related to Student Success IPEDS and HECC Data

\begin{tabular}{|c|c|c|c|c|c|}
\hline Variable & $\begin{array}{l}\text { Portl } \\
\text { and } \\
\text { State } \\
\text { Univ } \\
\text { ersit } \\
\text { y }\end{array}$ & $\begin{array}{l}\text { Peer } \\
\text { averag } \\
\text { e }\end{array}$ & $\begin{array}{l}\text { Aspiratio } \\
\text { nal peer } \\
\text { average }\end{array}$ & $\begin{array}{l}\text { Jurisdi } \\
\text { ctional } \\
\text { peer } \\
\text { averag } \\
\text { e }\end{array}$ & $\begin{array}{l}\text { Summary of impact } \\
\text { on student success }\end{array}$ \\
\hline \multicolumn{6}{|l|}{ IPEDS Data } \\
\hline $\begin{array}{l}\text { Total enrollment, average, } \\
\text { 2013-2017 }\end{array}$ & $\begin{array}{r}27,35 \\
3\end{array}$ & 28,965 & 45,808 & 26,665 & $\begin{array}{l}\text { It is possible that an } \\
\text { institution's size enables } \\
\text { it to develop economies } \\
\text { of scale, which could } \\
\text { positively enhance the } \\
\text { resources and } \\
\text { infrastructure available } \\
\text { for student success } \\
\text { efforts. PSU is } \\
\text { considerably smaller } \\
\text { than the aspirational } \\
\text { peers. }\end{array}$ \\
\hline $\begin{array}{l}\text { Undergraduate enrollment, } \\
\text { average, 2013-2017 }\end{array}$ & $\begin{array}{r}21,85 \\
6\end{array}$ & 21,772 & 36,939 & 22,412 & $\mathrm{n} / \mathrm{a}$ \\
\hline $\begin{array}{l}\text { Percent admitted, average, } \\
2013-2017\end{array}$ & 79.4 & 70.9 & 52.2 & 77.5 & $\begin{array}{l}\text { PSU has a higher } \\
\text { admittance rate, which } \\
\text { could indicate it is more } \\
\text { of an access institution. }\end{array}$ \\
\hline $\begin{array}{l}\text { Percent of full-time } \\
\text { first-time undergraduates } \\
\text { awarded any financial aid, } \\
\text { average, 2012-2013 - } \\
2016-2017\end{array}$ & 79.0 & 82.5 & 91.7 & 79.6 & $\begin{array}{l}\text { A lower proportion of } \\
\text { PSU's students were } \\
\text { awarded financial aid. }\end{array}$ \\
\hline $\begin{array}{l}\text { Percent of full-time } \\
\text { first-time undergraduates } \\
\text { awarded Pell grants, average, } \\
\text { 2012-2013 - 2016-2017 }\end{array}$ & 41.6 & 40.6 & 44 & 26.5 & $\begin{array}{l}\text { PSU students have about } \\
\text { the same financial need } \\
\text { as peers and aspirational } \\
\text { peers, but significantly } \\
\text { more need compared to } \\
\text { jurisdictional peers }\end{array}$ \\
\hline $\begin{array}{l}\text { State appropriations per } \\
\text { enrollment, average, } \\
2012-2013-2016-2017\end{array}$ & 2,586 & 4,804 & 5,269 & 3,866 & $\begin{array}{l}\text { PSU receives } \\
\text { significantly less state } \\
\text { funding than peers. }\end{array}$ \\
\hline
\end{tabular}




\begin{tabular}{|l|r|r|r|r|l|}
\hline $\begin{array}{l}\text { Percent of transfer-in degree } \\
\text { or certificate-seeking } \\
\text { undergraduate enrollment, } \\
\text { average, 2013-2017 }\end{array}$ & 14.8 & 9.8 & 11.7 & 7.5 & $\begin{array}{l}\text { PSU serves } \\
\text { proportionally more } \\
\text { transfer students }\end{array}$ \\
\hline State of Oregon Higher Education Coordinating Commission Data
\end{tabular}

[81], [81], [82], [83], [97], [98], [99]

\subsection{Student Information Technology in Support of Student Success}

\subsubsection{Student Success Technology Definition}

Institutions across the country are leveraging information technology to improve student success. They are improving the service experiences of students by creating more seamless and intuitive ways to access and utilize services through technology that helps them stay enrolled and conduct university-related business. Access to such tools can be particularly important for non-traditional students, many of whom are first-generation [6]. Institutions are also providing administrators, staff and advisors with the data and technology tools they need to 
effectively and proactively identify students who could benefit from assistance, and then deliver services according to unique student needs.

The use of information technology to support undergraduate degree attainment, or "student success technology", can be thought of in a few different ways. Student success technologies can include degree audit tools; degree planning or mapping tools; online self-service tools for student business; early-alert systems to catch academic troubles; and "digital tools that keep a record of services used, advice given, or decisions made" [6]. These tools enable real-time and proactive support for students, such as communication campaigns delivered via email, SMS for coaching and advising, and mobile app notifications to support students in completing critical administrative tasks (e.g. resolving account holds that prevent registration). Galanek et al. (2018) describe the student-facing technology related to student success as "technology tools that aid in academic success" and "technology tools that aid in the work of being a student" [7]. Tools that aid in academic success include guidance about what courses a student might take in the future; early-alert systems designed to catch potential academic trouble as soon as possible; tools that suggest how to improve performance in a course; and tools that suggest new or different academic resources. Tools that aid in the work of being a student include degree planning or mapping tools that identify courses needed to complete a degree; degree audit tools that show the degree requirements completed; self-service tools for conducting student-related business; self-service systems for tracking credits, 
credit transfers, and dual enrollment; and self-service referral systems to social or community resources [7].

Additionally, others have conceived of student success technology through a concept called Integrated Planning and Advising for Student Success [iPASS] systems, which focuses on faculty and staff use of technology to reimagine advising to provide more robust supports for students [8], [9], [10], [11]. There is general agreement that "iPASS technology tools are most commonly used for three functions: (1) course or degree planning, to help students make suitable and accurate course selection decisions; (2) coaching and career advising, to better connect students to services and support; and (3) early alerts and predictive analytics, which provide timely information to advisors, students, and others when students are at risk of falling off track to graduation" [9], [10], [11].

Clearly, a focus of student success technology is to support advising [12], which is helpful for all students, but particularly for distant learners, as it minimizes their feelings of isolation [13]. The use of predictive analytics is noticeably more present in advising services, yet still relatively new [15]. Predictive analytics enable more timely and customized service delivery, such as helping students better plan their courses, enhancing recruiting and retention efforts [14], as well as enabling targeted outreach and interventions by advisors [15].

Building off of the research described above, this study suggests that a comprehensive definition of student success technology is: staff/faculty-facing 
technology that supports staff and faculty with improving undergraduate degree persistence and attainment and student-facing technology that facilitates student agency and provides supports related to academic success and the non-academic work of being a student. Specific technologies within the student success technology domain include: advising analytics and reporting; case management and constituent relationship management; predictive analytics and diagnostics; early alerts; academic tutoring platforms; coaching/non-academic advising platforms; online self-service tools for student business/resources; degree audit and degree (or course) planning/mapping; transfer articulation; tools that suggest how to improve performance in a course; and tools that suggest new or different academic resources. myPSU, described in detail below, is an example of an online self-service tool for students to conduct business and access resources.

Student success technology is positioned to substantially enhance efforts to improve student success, as "the role of the environment [including technology], in particular the institution, [is critical] in student decisions to stay or leave" [55].

\subsubsection{Student Success Technology and E-Services}

In an effort to anchor this study and situate student success technology within the broad ecosystem of services and technologies that universities use, it is helpful to consider the relationship between e-services and student success technology, since so little relative research exists on student success technology [9]. 
Per Bittner and Brown, services are "deeds, processes and performances...provided to customers in exchange relationships among organizations and individuals" [31]. Defined in a higher education context - and drawing from definitions of e-services in the public sector literature [109], e-commerce literature [110], and higher education [111], [34] - e-services are information and communication technologies to enable web-based service delivery that seamlessly bring together distributed resources to enable complex transactions. E-services provide higher education institutions with the ability to improve the efficiency and effectiveness with which services are provided to students, employees, the public, community partners and other stakeholders.

Building on this definition, e-services in higher education can be categorized into two broad camps - e-learning and administrative services. While very little research exists on administrative e-services, fairly extensive research exists on student and faculty adoption of e-learning [112], learning management systems [113] and m-learning (mobile learning) [114]. E-learning services consist of a continuum of enhanced, blended and online learning [115] that uses electronic technologies to deliver educational curriculum outside of a physical (i.e. traditional) classroom [116]. In contrast, administrative e-services are e-services that students use when accomplishing tasks related to maintaining their enrollment. These services include items such as scheduling advising appointments, paying bills, applying for financial aid, signing up for campus clubs, finding on-campus parking, applying for scholarships, applying for 
admission and accessing academic supports [33], [117]. They are often accessed via web applications [34] as is the case with myPSU, however as described below they can encompass other technologies, too.

Administrative e-services and student success technology are closely related. While the technologies that underpin administrative e-services and student success technology are very similar, the end goals that the technologies enable, i.e. how the technology is utilized, are different. Administrative e-services focus on maintaining enrollment, and student success technology's goals, while including maintaining enrollment, are more specific, with explicit end goals of helping students persist and graduate, and student success technology includes creating ecosystems of tools that are intentionally leveraged together [10].

Importantly, e-services play a critical role for students who are enrolled exclusively online. While campus-based students are able to visit offices in person for help with a registration problem, for example, this is not true for online students, who must access services from a distance, particularly calling on faculty for assistance [118]. This shift also influences administrators and student affairs professionals [119] - who are increasingly being called on to improve e-services and is redefining the role and nature of their work [120] by calling on them to intentionally support online students [121]. There is very little information and research about which departments are leading the provision of support services for online student services, leaving gaps that position student affairs professionals quite well [34]. However, these professionals have large gaps in 
technical knowledge and expertise to bridge in order thrive in this digital age [122], [119], [123] and have the requisite skills to facilitate the high levels of coordination across campus units to support technologies [123]. Further, many campuses have failed to provide the same level of services to off-campus students [124].

\subsubsection{E-Services Technologies in Higher Education}

A wide range of technologies support e-services in higher education. Enterprise Resource Planning systems (ERPs) are critical components of e-service delivery in higher education [125]. They integrate information from departments across organizations into a single computer system [126] and in universities are often referred to as student information systems [127], for services such as student records, financial aid, admissions procedures, finance and human resources [128]. Many universities have legacy ERP systems (often more than a decade old) that challenge the service needs in today's mobile-focused world [36].

University ERP implementations have required significant investments to digitize this information [128] [125], but these efforts have consolidated disparate information and systems to enable institutions to adopt modern technology and more efficient business processes [129]. Additional benefits include improving self-service for students and staff, and support of more multifaceted and data-based decision-making [130]. Despite these significant benefits, universities have legacy ERP systems (often more than a decade old) that challenge the 
service needs in today's mobile-focused world [36] that, for example, display clunky and antiquated user interfaces that can confuse and confound students and faculty alike, creating a "digital downgrade" in campus life [36].

Student portals can create a "one stop shop" for students to access e-services. Despite their prevalence, there are many definitions. The Gartner Group, as described in Pickett and Hamre 2002 [131] defines portals as those that provide "connection, content, commerce and community." They excel and provide real benefit by centralizing disparate information into one source [131]. Benefits of portals include improved navigation for students, reducing time they spend accessing services online and reducing confusion [132], [133].

Mobile services, often delivered through smartphones, are quite prominent and are understandably central to the student experience [134]. They are defined as interactions between mobile customers and technology systems or employees when supported by a mobile telecommunications network [135]. Mobile services are critical components of e-services, particularly with the growing adoption of smartphone technology.

There are many categories of mobile services, including Short Message Service (SMS), Multimedia Messaging Service (MMS), email, information services (such as news, entertainment, music, and location-based services), and transaction-based services, such as mobile banking [135]. Mobile Instant Messaging is also becoming more prevalent in higher education [136], as is interest in augmented reality, which seeks to promote learning that is both 
autonomous and collaborative [137]. Libraries, by adapting services to mobile environments, have played a prominent role in catalyzing mobile services development in the broader campus environment [138]. Importantly, compared with traditional means of electronic commerce or services, mobile services provide more freedom, as customers/clients can access services independent of physical location [139].

By far the majority of research related to mobile services in higher education is about mobile learning (m-learning), which includes communication between students and faculty/instructors; learning materials; and sharing assignments [117]. Some argue m-learning consists of two main branches learning material services and learning administrative services [140]. M-learning has been researched broadly, as well as in specific geographical or institutional contexts (see for example Nassuora (2012) [141], which studied mobile learning in Saudi Arabia).

A variety of features and technology have been used for electronic learning approaches as articulated by Alzaza and Yaakub (2011), highlighting that m-learning is somewhat distinct from e-learning and w-learning in that it is accessed from mobile devices anywhere at any time [117].

Table 7: Comparison Features of E-Learning, W-Learning and M-Learning

\begin{tabular}{|l|l|l|l|}
\hline Feature & E-learning & W-learning & M-Learning \\
\hline Protocol & Web-based & Web-Based & $\begin{array}{l}\text { Wireless Application } \\
\text { Protocol-based }\end{array}$ \\
\hline Accessibility & Anywhere & Campus & Anywhere and anytime \\
\hline Network & Wired & Wireless & Wireless \\
\hline
\end{tabular}




\begin{tabular}{|l|l|l|l|}
\hline Device size & PC or laptop & Laptop or tablet PC & $\begin{array}{l}\text { Mobile phone, smartphone or } \\
\text { PDA phone }\end{array}$ \\
\hline Screen size & $\begin{array}{l}\text { "Normal" screen } \\
\text { size, }\end{array}$ & "Medium" screen size, & $\begin{array}{l}\text { Very small (mobile phone) to } \\
\text { a maximum of 480 } \times 640\end{array}$ \\
\hline
\end{tabular}

Adapted from Alzaza and Yaakub (2011) [117]

Social media are defined as user-generated content activities expressed in interactive social environments, such as communicating with friends and sharing content (photos, videos, etc.) [142] and are more comfortable for students to use as compared to faculty [143]. Text messaging is prevalent throughout the world and the adoption of SMS as an educational resource is becoming increasingly popular [144]. SMS in higher education can be helpful for time-sensitive communications, such as reminding students of deadlines (e.g. a library book is due soon) [145], or to help answer prospective students' questions through automated "chatbots" [146]. Students report that text messaging (e.g. using WhatsApp) and chatting through their mobile devices are the most important functions when using these devices [147].

Text messaging is prevalent throughout the world and the adoption of SMS as an educational resource is becoming increasingly popular [144]. SMS in higher education can be helpful for time-sensitive communications, such as reminding students of deadlines (e.g. a library book is due soon) [145], or to help answer prospective students' questions through automated "chatbots" [146]. Students report that text messaging (e.g. using WhatsApp) and chatting through their mobile devices are the most important functions when using these devices 
[147]. The predominant research focuses on text messaging/SMS in higher education are in four areas: administrative support (communicating about room changes, submission deadlines, library notices etc.), tutor support, subject learning (such as language learning) and in-class use to facilitate student-student interactions [148], [149], [150], [151], [144].

Instant messaging (IM) is finding increasing reception in higher education, indicating a shift in perception for students to see the platforms are relevant in non-social circumstances [145]. Many students are daily IM users and they are incredibly comfortable with this technology [152], [145]. Libraries are increasingly using IM to support service delivery [136].

Mobile applications - applications, or "apps" - that are used on mobile devices (smartphones or handheld devices such as tablets) - are increasingly being used in higher education to facilitate educational activities and support education processes [153]. There are three generally accepted forms of mobile apps - web applications, native applications, and hybrid applications [154]-[156]. Web applications, or mobile websites, are not truly apps. Rather, they are websites that live on a server, are developed such that they have the look and feel of native applications on a mobile device, and can be bookmarked, for example, to provide easy access [157], [154]. Native apps, in contrast, live on a mobile device and because they are developed specifically for certain platforms, can seamlessly use all of a device's features [157]. Hybrid apps work across multiple platforms and devices [158]. 
Recent research seeks to identify the basic features that enterprise mobile apps in higher education provide, including: campus communications, providing an electronic single point of contact, checking grades, support for surveys, tests and exams, and accessing their class schedules [153], [159], [160]. For academic purposes, students use apps for education (e.g. Khan Academy), books, references and productivity (e.g. Evernote, Dropbox, etc.) [161].

Notable features at specific universities include: predicted stop times for shuttle service at the Massachusetts Institute of Technology; near real-time athletic score updates at the University of Alabama; and a mobile orientation guide for students new to Columbia University [159]. In a study on mobile learning services for higher education students in Malaysia, top features for students were accessing exam results and registering for courses [117].

Smartphones are the most prolific mobile device for students when accessing mobile services and the number of students who own them continues to climb. From 2015 to 2016, the percent of students owning a smartphone has increased from an estimated $92 \%$ to $96 \%$ [162] and are increasingly taking the place of tablets [163]. Students use their phones for a variety of purposes, including sending and receiving emails, specific apps (such as the American Chemical Society's app for accessing research articles), text messaging and instant messaging [163], [164]. However, for academic purposes, students prefer tablets compared to smartphones [161]. Also, students view themselves as skilled smartphone users [165]. Given the prevalence and popularity of smartphones, 
universities have no choice but to, at a minimum, provide mobile-responsive information, but also leverage the touch technology that is a defining feature of smartphones [36].

Table 8: Literature Review Summary: Higher Education E-Services Concepts

\begin{tabular}{|c|c|c|}
\hline Research area & Concepts & Related references \\
\hline $\begin{array}{l}\text { E-services in the } \\
\text { public and private } \\
\text { sectors }\end{array}$ & $\begin{array}{l}\text { E-services in the public and private sectors } \\
\text { are loosely defined as the use of information } \\
\text { technology to fulfill citizens' and customers' } \\
\text { service needs and largely focus on online } \\
\text { services delivered through internet-based } \\
\text { applications [166], [167], [168], [169]. }\end{array}$ & $\begin{array}{l}{[166],[167],[168]} \\
{[169]}\end{array}$ \\
\hline $\begin{array}{l}\text { E-services in } \\
\text { higher education }\end{array}$ & $\begin{array}{l}\text { - Are largely undefined [111]. } \\
\text { - Stem from institutional goals to support } \\
\text { students more effectively and efficiently } \\
\text { [111]. } \\
\text { - Cover a large swath of how services in } \\
\text { higher education are delivered [34], [170]. } \\
\text { - Are important for all students, but } \\
\text { particularly distance learners [118]. } \\
\text { - Administrators and student affairs } \\
\text { professionals are increasingly being called on } \\
\text { to improve e-services and the shift in } \\
\text { technological needs by students is redefining } \\
\text { the role and nature of their work to more } \\
\text { intentionally support online students [120], } \\
\text { [121]. } \\
\text { - Large gaps in technological knowledge exist } \\
\text { for student affairs professionals [122], [119], } \\
\text { [123]. } \\
\text { - Very little research exists on which } \\
\text { departments lead the provisions of services } \\
\text { for online students [34]. }\end{array}$ & $\begin{array}{l}{[111],[34],[170],} \\
{[118],[120],[121],} \\
{[122],[119],[123]}\end{array}$ \\
\hline $\begin{array}{l}\text { E-learning services } \\
\text { in higher education }\end{array}$ & $\begin{array}{l}\text { - Fairly extensive research exists on this } \\
\text { topic, especially in relation to e-learning, } \\
\text { learning management systems and mobile } \\
\text { learning [112], [113], [114], [141]. } \\
\text { - Largely delivered through Internet and } \\
\text { Communication Technologies that are } \\
\text { dominant in other (i.e. outside of higher } \\
\text { education) parts of students' lives [116], } \\
\text { [145]. }\end{array}$ & $\begin{array}{l}{[112],[113],[114],} \\
{[141],[116],[145] .}\end{array}$ \\
\hline $\begin{array}{l}\text { Administrative } \\
\text { services in higher }\end{array}$ & $\begin{array}{l}\text { - Are largely undefined [124]. } \\
\text { - Are often accessed via web applications }\end{array}$ & $\begin{array}{l}{[124],[34],[124]} \\
{[171],[172],[15],}\end{array}$ \\
\hline
\end{tabular}




\begin{tabular}{|c|c|c|}
\hline education & $\begin{array}{l}\text { [34]. } \\
\text { - Include services such as scheduling } \\
\text { appointments, finding on-campus parking, } \\
\text { and accessing academic supports [124]. } \\
\text { - Are generally replacing high-touch human } \\
\text { service delivery [171]. } \\
\text { - Are adopting technologies first deployed in } \\
\text { the private sector, such as Customer } \\
\text { Relationship Management software [172]. } \\
\text { - Universities are increasing their } \\
\text { investments in administrative service } \\
\text { technologies [15]. } \\
\text { - Are often delivered through critical } \\
\text { Enterprise Resource Planning systems [125], } \\
\text { [126], which are often legacy systems that } \\
\text { are challenged in our mobile-first world [36]. }\end{array}$ & {$[125],[126],[36]$} \\
\hline $\begin{array}{l}\text { Mobile Services } \\
\text { and applications in } \\
\text { Higher Education }\end{array}$ & $\begin{array}{l}\text { - Mobile services and applications are critical } \\
\text { parts of the student experience [134], [153], } \\
\text { [159], [160], as they provide tremendous } \\
\text { freedom and flexibility [139], and are } \\
\text { becoming more prevalent in higher } \\
\text { education [153], mirroring trends in broader } \\
\text { society [136]. } \\
\text { - Yet, despite the increasing use of mobile } \\
\text { services, such as text messages and social } \\
\text { media, they seemed to be untapped avenues } \\
\text { for e-service delivery [143], [144]. } \\
\text { - Most of the research on mobile services in } \\
\text { higher education has focused on mobile } \\
\text { learning. } \\
\text { - Mobile services are used for many of the } \\
\text { same e-services that can also be delivered } \\
\text { over the internet [153], [159], [160]. }\end{array}$ & $\begin{array}{l}{[134],[153],[159],} \\
{[160],[139],[136],} \\
{[143],[144]}\end{array}$ \\
\hline $\begin{array}{l}\text { Relative } \\
\text { importance of } \\
\text { e-services }\end{array}$ & $\begin{array}{l}\text { - Students appear to spend more time online } \\
\text { studying (1-4 hours per day) than using } \\
\text { social media, watching TV, or playing video } \\
\text { games [7]. } \\
\text { - Learning management systems (LMS) are } \\
\text { one of the most widely used e-services by } \\
\text { students, as they are used for most or all of } \\
\text { students' courses [7]. } \\
\text { - Tools that aid in the work of being a } \\
\text { student (e.g. registration tools, self-service } \\
\text { tools for conducting student business, } \\
\text { self-service systems for tracking credits) tend } \\
\text { to be more used by students than tools that } \\
\text { aid in academic access (such as guidance } \\
\text { about courses to take in the future) [7]. } \\
\text { - Of the tools that aid in the work of being a }\end{array}$ & [7] \\
\hline
\end{tabular}


student, the following tools are of a similar

value to students: Degree planning or

mapping tools that identify courses needed

to complete your degree; degree audit tools

that show the degree requirements

completed; self-service tools for conducting

student-related business; and self-service

systems for tracking credits, credit transfers, and dual enrollment. Self-service referral systems to social or community resources are less useful [7].

The conclusions from this discussion include that overall, very little, if any, research has looked at e-services in their totality for all students. While e-services have been particularly relevant for online students, all students have increasing expectations of e-services on their campuses. Further, most studies on e-services in higher education focus on particular categories of e-services, such as mobile learning, while there is a dearth of research about administrative services and about student success technology. In terms of the value that students place on e-services, while learning management systems are highly used, students tend to place more value on tools that aid in the work of being a student, as compared to tools that aid in academic success. Highly used e-services that aid in the transactional parts of being a student are: Degree planning or mapping tools that identify courses needed to complete your degree; degree audit tools that show the degree requirements completed; self-service tools for conducting student-related business and accessing services; and self-service systems for tracking credits, credit transfers, and dual enrollment. 


\subsection{Higher Education Students and Technology}

To further contextualize this inquiry into student information technology that supports student success, it is important to understand who today's higher education students are and how they relate to technology. The higher education student body in the United States is shaped by the demographics of its students and is quite different from what it has been in recent decades. For example, $61 \%$ of students receive Pell grants (Federal grants for students with financial need), $26 \%$ are employed full-time, $28 \%$ have children, $42 \%$ are students of color, and $47 \%$ are 22 years of age or older [173].

The majority of twenty-first century students are facile with technology and are markedly more adept at accessing the internet and its services than older adults [174]. Correspondingly, students are more and more comfortable learning at a distance - growth rates in online student enrollment have been significantly higher than the overall growth in higher education [37]. Thus, students expect that institutions keep their technologies and service delivery up-to-date.

Despite the prevalence of technology and students' expectations that universities offer, at a minimum, service that is comparable to what they experience in their personal lives [124], universities have large gaps to address. For example, a 2016 survey found that nearly one-third of respondents in the U.S. "think less of their institutions because of their digital strategies" and that overall (results were largely consistent country to country), approximately one-third of students feel that "administrative systems do not meet their 
expectations" [175]. This level of satisfaction appears to be in striking contrast with customer satisfaction in the private sector. In a 2014 Fiserv survey on digital banking, $92 \%$ of respondents said they were satisfied or very satisfied with digital banking and $92 \%$ said they were satisfied or very satisfied with mobile banking [176]. Additionally, when considering customer satisfaction in the internet retail industry, a recent survey indicates an average satisfaction score of 81 on a 100 point scale with Costco and Nordstrom on top and Amazon with a score of 86 [177]. E-services are critical in higher education particularly for students engaged in online learning, seamless administrative processes can be as "much a factor in learner satisfaction and success as the design of learning resources" [178].

In relation to the use of technology in advising, Kalamkarian and Karp found that "students' attitudes toward technology-mediated advising varied depending on the advising context. In particular, students preferred in-person interaction with an advisor for cognitive support, but expressed more willingness to receive administrative and affective support through technology" [179].

At the heart of universities' goals to improve student success are efforts to support undergraduate first-generation college students (FGCS). Although there are several definitions of first-generation college students [180], for this study they are defined as "undergraduate students whose parents had not participated in postsecondary education" [181]. First-generation students are a sizable number, although their proportions have decreased over time, from 1999-2000 when the proportion was $37 \%$ to 2011-2012 when the proportion was $33 \%$ [181]. 
Researchers consistently find that FGCS are more likely to leave a four-year institution at the end of their first year, compared to their traditional counterparts, and are less likely to graduate [106], [181], [182].

FGCS face unique challenges in enrolling in and completing college as compared to their peers who have family members who attended college or earned a bachelor's degree - including low socio-economic backgrounds [183]; the need for employment, yet employment creates less time for studying [182]; a lack of cultural capital that prepares them to navigate college life [106]; and cultural deficits in the classroom [104].

The most relevant research about FGCS and student success technology finds that "student success technologies are seen as useful [for FGCS] because they mitigate or moderate some of the things that make being a student difficult" [6]. A counterpoint is that a survey of 226 Hispanic college freshmen about educational uses of internet sites found that there were no differences between first-generation college students and non-first-generation college students [184].

Turning to broader data on college students to inform this study, the majority of twenty-first century students are comfortable with technology and are markedly more adept at accessing the internet and its services than older adults [174]. Correspondingly, students are more and more comfortable learning at a distance - growth rates in online student enrollment have been significantly higher than the overall growth in higher education [37]. Today's U.S. undergraduate students' ownership of technology continues to grow. From 2015 
to 2017, smartphone ownership increased from $92 \%$ to $97 \%$ and laptop ownership rose from $91 \%$ to $95 \%$. In addition, "Practically all college and university students have access to the most important technologies for their academic success. US students reported near-universal access to a desktop, laptop, tablet, or smartphone, with no systematic differences in access based on ethnicity, gender, age, and socioeconomic status" [7]. Smartphones are increasingly taking the place of tablets [163]. Further, students own more devices, proportionally, than the general public - more than half of students own a laptop, a tablet, and a smartphone, compared with only a third of the American public [162].

Additional research adds texture to these trends, showing for example that university students demonstrate positive attitudes about using the Internet and that they view it as a functional tool to support their learning [185]. Based on a review of the technology adoption literature related to gender, it is possible that males and females might derive differing levels of satisfaction from student-success-technology, suggesting that gender might moderate the relationship between first-generation status and satisfaction [186], [187], [188], [189]. 


\section{Chapter Four: Literature Review - Technology Adoption Models and Taxonomy}

\subsection{Technology Adoption Models}

Central to this study is examining the determinants that inform and help predict why end users adopt technology. One body of research - technology acceptance or adoption models - has focused for decades on understanding the dimensions and factors that inform end user adoption of technology [139]. These models, summarized below, have been applied in a variety of settings, including mobile services [190], government e-services [191] and health information services [192] as well as to study the adoption of devices such as smartphones [193]. They inform the research focus of this study, as they provide the theoretical underpinning for many empirical research studies about technology adoption.

Technology adoption models and technology acceptance models are derivatives of diffusion theory, which "provides a context in which one may examine the uptake and impact of information technology over time" [194]. Notably, Rogers' Diffusion of Innovation Model (DIM) examines factors that influence how information technology spreads and adopts through a community [195]. It focuses on groups and not individuals [196] and consists of five attributes related to adoption: relative advantage, compatibility, complexity, trialability and observability [195], [197]. Additionally, the model states that longer-term adoption of an innovation, or its institutionalization, is different from initial adoption, and that institutionalization might even be more important 
[198]. Complementary, yet distinct from DIM, technology adoption models, developed over the past few decades, include both factors directly related to end user acceptance, such as perceived usefulness, but also attitudes toward technology as well as social influences, motivation and environmental factors [199], [194].

\subsubsection{Theory of Reasoned Action}

One of the earliest technology adoption models, if not the earliest, the Theory of Reasoned Action (TRA), was introduced by Fishbein and Ajzen in 1979 and stems from the social psychology literature [194]. TRA supposes that an individual's behavior, such as whether to use a particular technology, is influenced by an intention to perform the behavior and "this intention is influenced jointly by the individual's attitude and subjective norm" [194]. Fishbein and Ajzen articulate subjective norm as the degree to which an individual perceives that most people who are important to this person think that the person should or should not conduct the behavior [200]. It has been used in a host of technology-related adoption research, ranging from the acceptance of green information technology by information technology professionals [201], to why college students share their locations on Facebook [202], to informing a model to understand the decision-making process related to software piracy [203]. TRA has been found to have had a high degree of predictive capabilities, including in situations where researchers have overstepped the boundary conditions of the model [204]. 


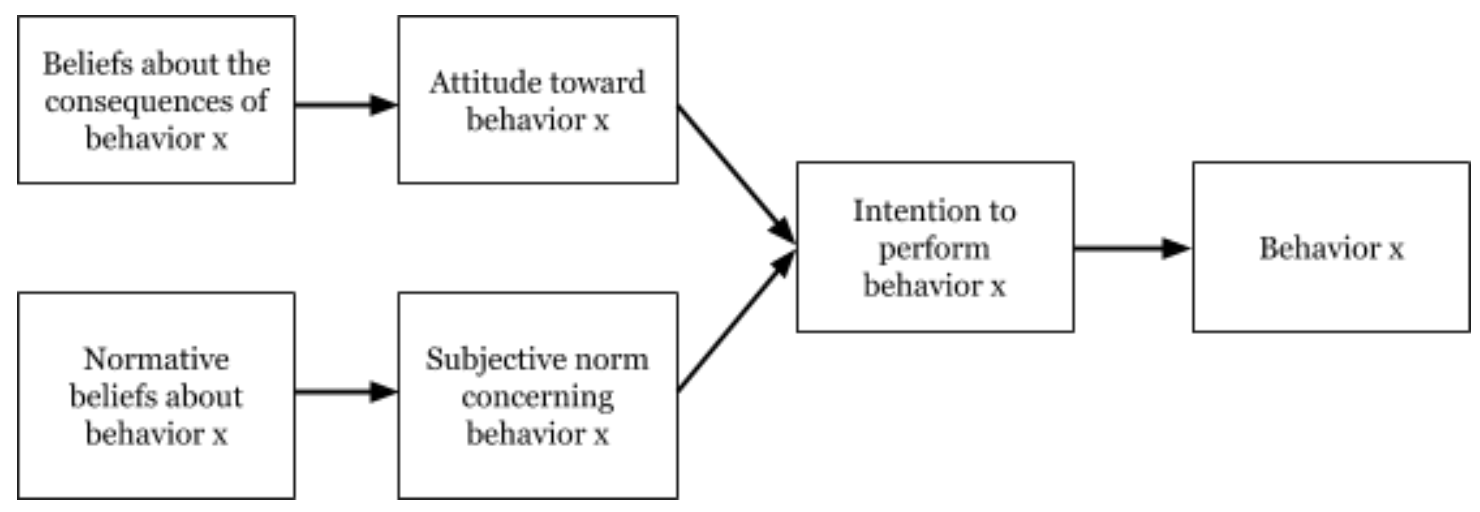

Figure 1: Theory of Reasoned Action (adapted from Fishbein and Ajzen (1975)) [200]

\subsubsection{Theory of Planned Behavior}

An extension of TRA is the theory of planned behavior (TPB), which was also developed by Ajzen [205]. As with TRA, TPB focuses on an individual's intention to perform a behavior (indication of how much effort an individual is willing to expend to perform a behavior [205]) and perceived social pressure, but is extended by taking into account perceived behavioral control [206] - that "people's behavior is strongly influenced by their confidence in their ability to perform it" [205]. In essence, increased confidence leads to increased chances of perseverance of executing a behavior. An important concept in technology adoption models, such as TPB, is that intentions predict behavior. This emphasis has been informed by the work of Ajzen (2005) as well as recent analysis by Sauro (2019), which shows that intentions may predict behavior better than feelings and beliefs [207], [208]. 


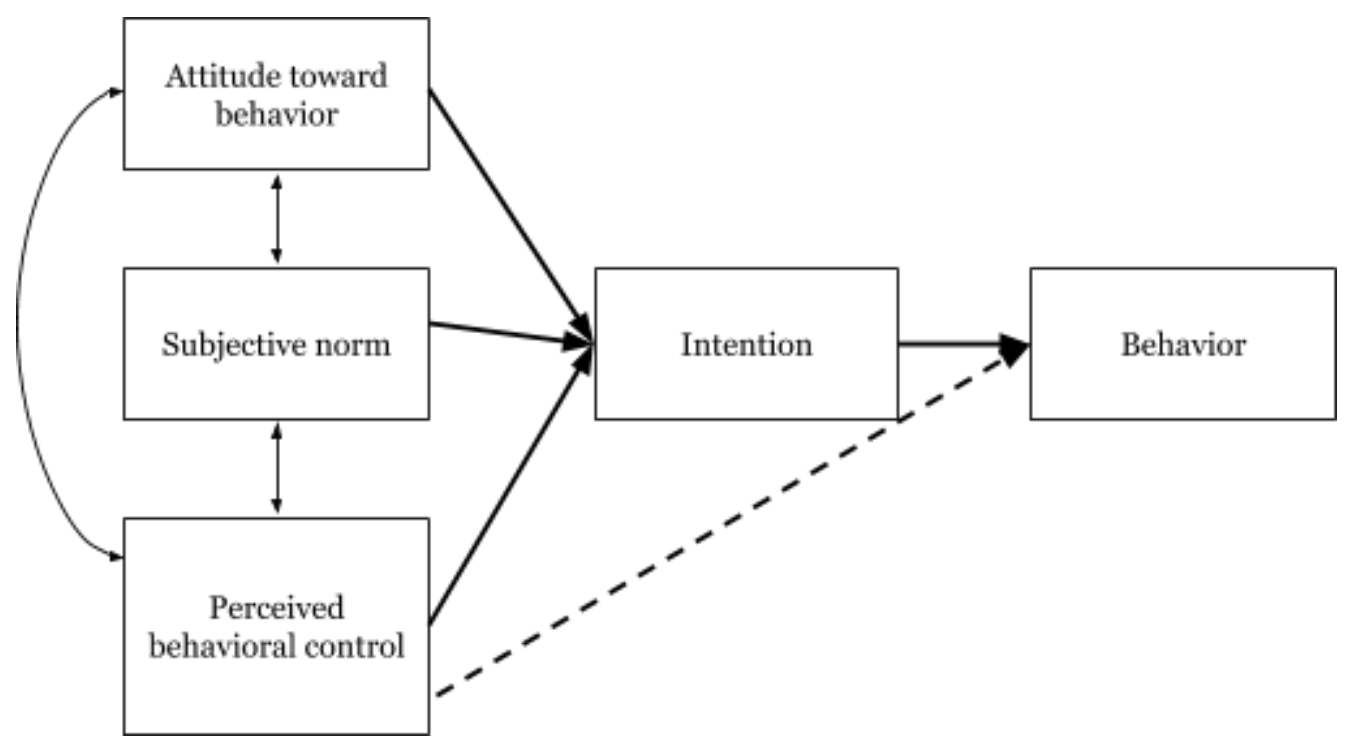

Figure 2: Theory of Planned Behavior (adapted from (Ajzen 1991)) [205]

\subsubsection{Technology Acceptance Model}

Another derivative of the Theory of Reasoned Action is the Technology Acceptance Model (TAM), developed by Davis (1989) [209], [194], which was specifically tailored for modeling user acceptance of information systems [210]. TAM argues that perceived usefulness ("prospective user's subjective probability that using a specific application system will increase his or her job performance within an organizational context") and ease of use ("the degree to which the prospective user expects the target system to be free of effort”) [210] have a large influence over a user's attitude toward using the system, which in turn can predict actual system use [211]. External variables (such as touch screens that enhance usability) also influence perceived usefulness and perceived ease of use [210]. TAM has been extended in a variety of ways, notably in research on mobile-commerce adoption [189]. Despite its "relative simplicity" analyses of 
TAM applications find that it accounts for $30-40 \%$ of IT acceptance [212], [213] and some scholars have called for its integration into a broader model that would "include variables related to both human and social change processes, and to the adoption of the innovation model" [214].

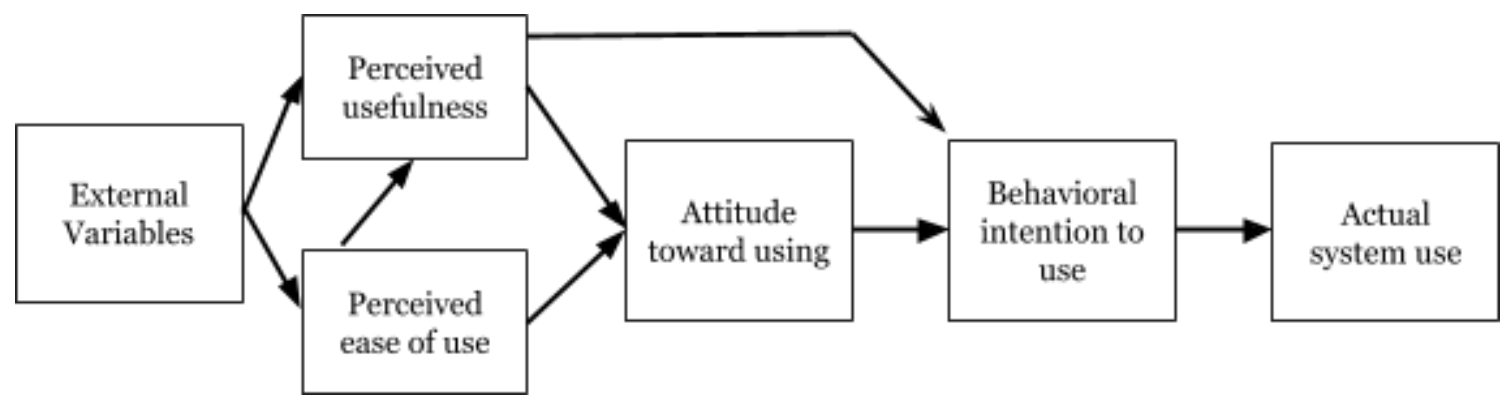

Figure 3: Technology Acceptance Model (first modified version of the model) [210], [211]

\subsubsection{Technology Acceptance Model 2}

The Technology Acceptance Model was extended, called Technology Acceptance Model 2 (TAM2), through a study conducted by Venkatesh and Davis (2000) where they incorporated two additional theoretical constructs: social influence processes and cognitive instrumental processes [215], [213]. Social influence processes include subjective norm, voluntariness (the degree to which potential adopters perceive the decision about an adoption to be "non-mandatory"), and image ("the degree to which use of an innovation is perceived to enhance one's image or status in one's social system" [197], [215], [212]. The cognitive instrumental processes include job relevance, output quality, result demonstrability, and perceived ease of use [215]. TAM2 was developed through a longitudinal study with respect to four information systems at four 
organizations - two involved voluntary usage and two involved mandatory usage and found that it accounted for $40-60 \%$ of the variance in perceptions of usefulness [215].

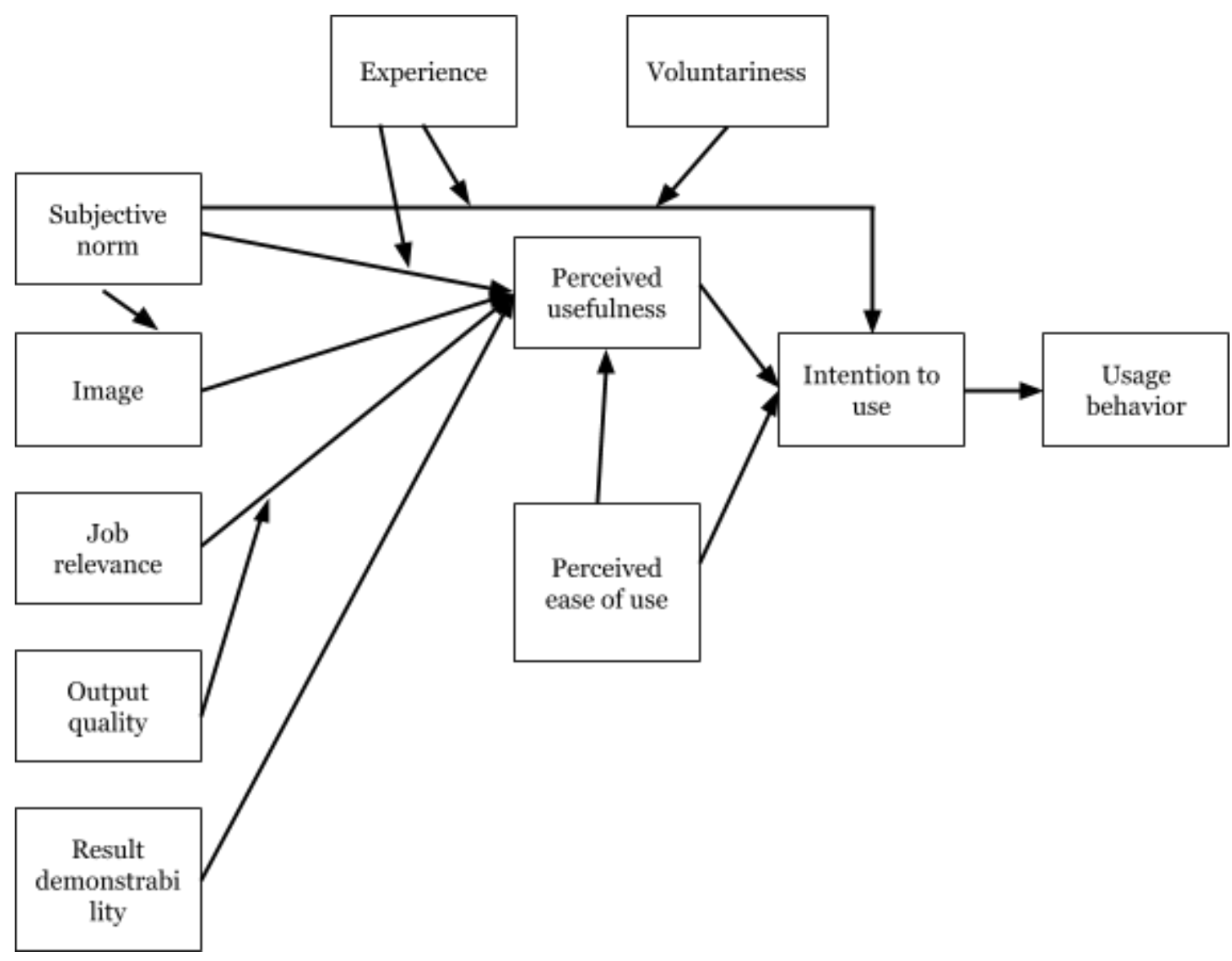

Figure 4: Technology Acceptance Model 2 (adapted from Venkatesh and Morris (2000)) [215]

\subsubsection{Task-Technology Fit}

The Task-Technology Fit (TTF) model was articulated by Goodhue (1995) [216] and Goodhue and Thompson (1995) [217]. It asserts that individual performance improves only when "there is correspondence between [information system] functionality and the task requirements of users" [217]. It stems from 
two primary streams of research about technology and performance: utilization focus research (notably TAM) and fit-focus research (links performance with the degree that technology fits the requirements of a task) [217]. Dishaw and Strong (1999) posit that while TAM focuses on attitudes toward using a particular technology, TTF focuses on the "match between user tasks and needs and the available functionality of the IT" and addresses a gap in TAM on an explicit task focus [218]. In some cases, TTF and TAM have been combined into an integrated model that outperforms either alone [218], [219] and this combined model has been extended to include computer self-efficacy (the "judgement of one's ability to use a computer") [220].

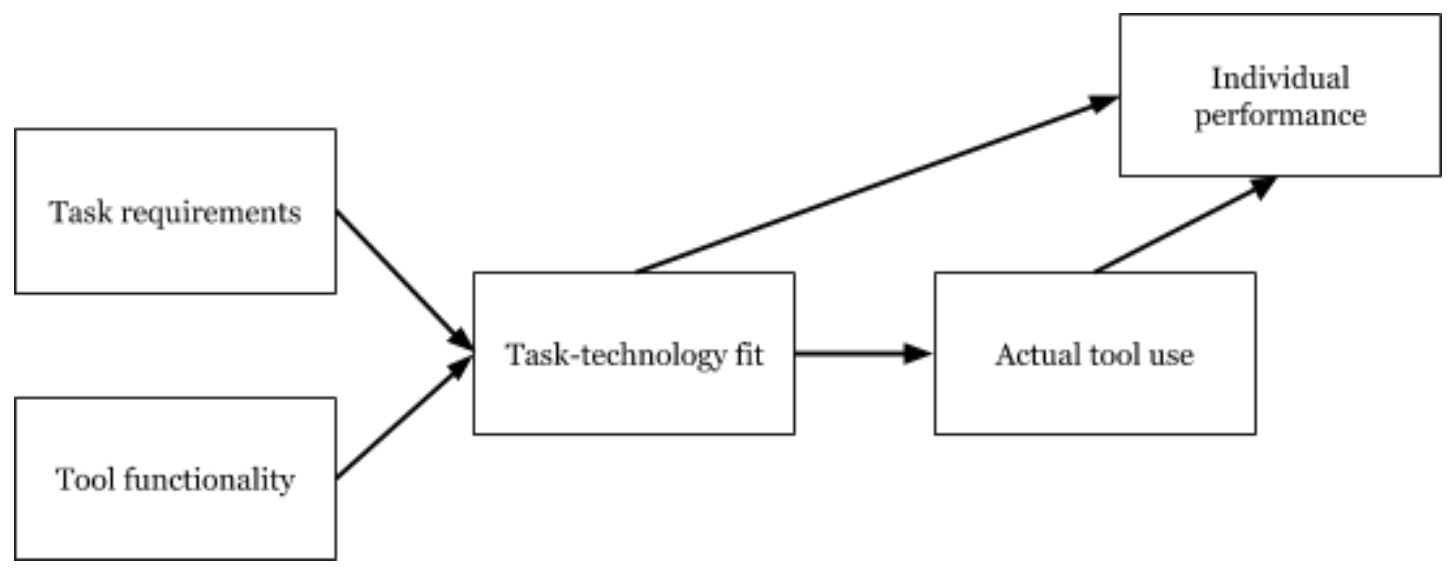

Figure 5: Task-Technology Fit Model (adapted from Dishaw and Strong (1999)) [218] 4.1.6 Unified Theory of Acceptance and Use of Technology

The Unified Theory of Acceptance and Use of Technology (UTAUT), developed by Venkatesh et al. (2003) is a synthesis of eight various acceptance models: Theory of Reasoned Action (TRA), Technology Acceptance Model (TAM), Motivational Model (MM), Theory of Planned Behavior (TPB), a model 
combining the technology acceptance model and the theory of planned behavior, the model of PC utilization, Innovation Diffusion Theory (IDT) and Social Cognitive Theory (SCT) [199]. UTAUT posits that performance expectancy, effort expectancy, and social influence are direct determinants of intention to use and that intention and facilitating conditions are direct determinants of usage behavior [199]. Further, it posits that age, gender, experience and voluntariness moderate these relationships [221]. It has been applied in fields as diverse as communication, banking, education and health [222], user acceptance of mobile technologies [223], and use of smartphones as smart pedagogical tools [224]. UTAUT has been deployed primarily in organizational contexts [225].

UTAUT has been successful in explaining the variance in behavioral intention to use a technology and technology use, particularly in organizational contexts [225]. "In longitudinal field studies of employees' acceptance of technology, UTAUT explained 77 percent of the variance in behavioral intention to use a technology and 52 percent of the variance in technology use" [221]. While UTAUT has been integrated and extended in a wide variety of settings and user types, some argue that its success has "bound research that extends UTAUT" and call for a shift to new extensions and explorations based on the model [221]. One such extension is UTAUT2 which focuses on adoption in the consumer context by adding three new concepts: hedonic motivation (enjoyment), price value, and habit [225]. 


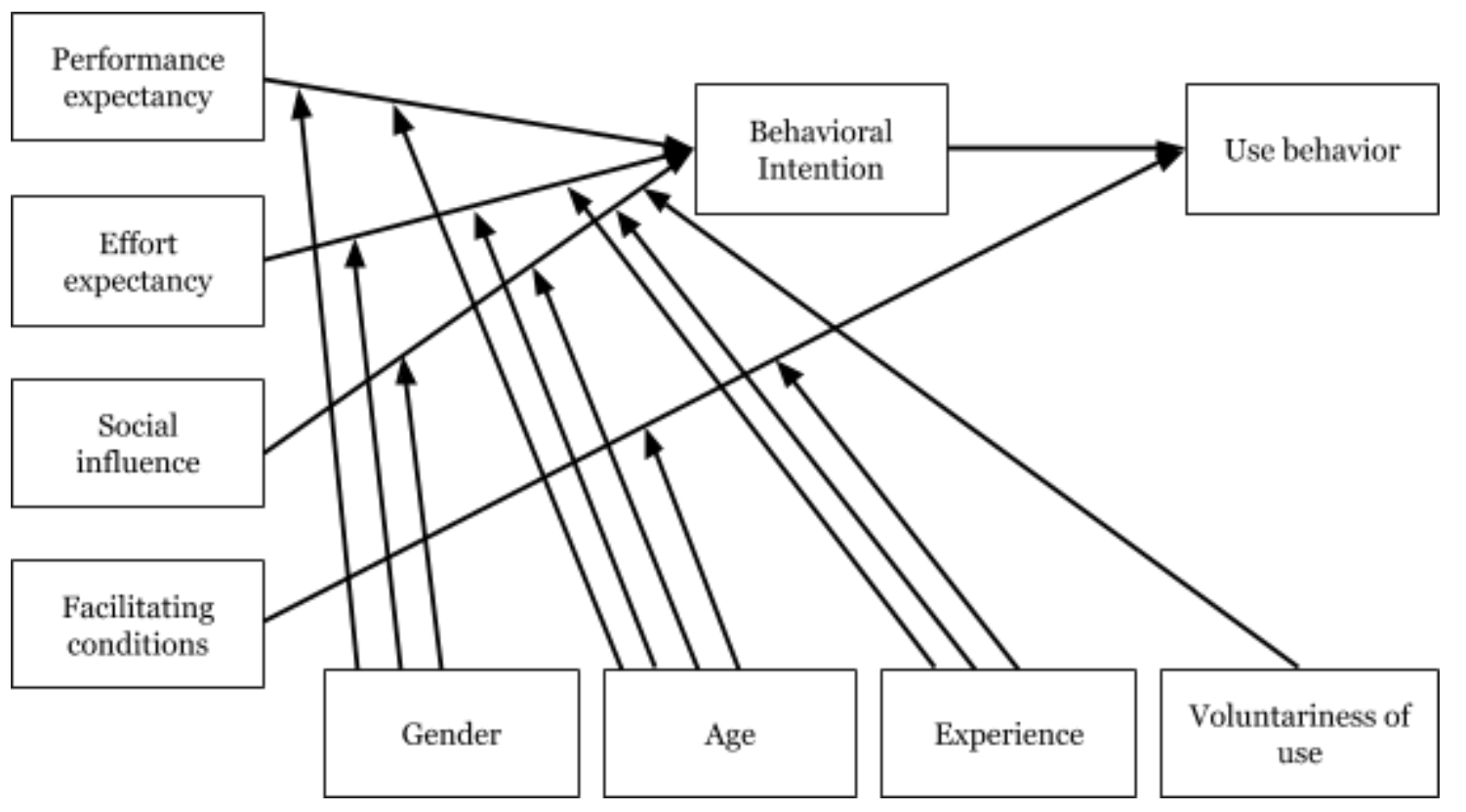

Figure 6: Unified Theory of Acceptance and Use of Technology (UTAUT) Model [199], [221]

Table 9: Summary of Technology Adoption Models

\begin{tabular}{|l|l|l|l|l|l|}
\hline Theory & $\begin{array}{l}\text { Main } \\
\text { Independent } \\
\text { Factors }\end{array}$ & $\begin{array}{l}\text { Main } \\
\text { Dependent } \\
\text { Factors }\end{array}$ & Origin & $\begin{array}{l}\text { Originatin } \\
\text { g } \\
\text { Discipline }\end{array}$ & $\begin{array}{l}\text { Key } \\
\text { Litera } \\
\text { ture }\end{array}$ \\
\hline $\begin{array}{l}\text { Theory of } \\
\text { Reasoned } \\
\text { Action } \\
\text { (TRA) }\end{array}$ & $\begin{array}{l}\text { Attitude toward } \\
\text { behavior; } \\
\text { subjective norm }\end{array}$ & $\begin{array}{l}\text { Behavioral } \\
\text { intention; } \\
\text { behavior }\end{array}$ & $\begin{array}{l}\text { (original } \\
\text { technology } \\
\text { adoption } \\
\text { model) }\end{array}$ & $\begin{array}{l}\text { Social } \\
\text { psychology }\end{array}$ & $\begin{array}{l}{[200],} \\
{[204]}\end{array}$ \\
\hline $\begin{array}{l}\text { Theory of } \\
\text { Planned } \\
\text { Behavior } \\
\text { (TPB) }\end{array}$ & $\begin{array}{l}\text { Attitude toward } \\
\text { behavior; } \\
\text { subjective norm; } \\
\text { perceived behavior } \\
\text { control }\end{array}$ & $\begin{array}{l}\text { Behavioral } \\
\text { intention; } \\
\text { behavior }\end{array}$ & $\begin{array}{l}\text { Derived from } \\
\text { TRA }\end{array}$ & $\begin{array}{l}\text { Social } \\
\text { psychology }\end{array}$ & $\begin{array}{l}{[205],} \\
{[206]}\end{array}$ \\
\hline $\begin{array}{l}\text { Technology } \\
\text { Acceptance } \\
\text { Model } \\
\text { (TAM }\end{array}$ & $\begin{array}{l}\text { External variables; } \\
\text { perceived } \\
\text { usefulness; } \\
\text { perceived ease of } \\
\text { use }\end{array}$ & $\begin{array}{l}\text { Attitude } \\
\text { toward using; } \\
\text { behavioral } \\
\text { intention; } \\
\text { actual system } \\
\text { use }\end{array}$ & $\begin{array}{l}\text { Derived from } \\
\text { TRA }\end{array}$ & $\begin{array}{l}\text { Information } \\
\text { systems }\end{array}$ & $\begin{array}{l}{[209],} \\
{[210]}\end{array}$ \\
\hline $\begin{array}{l}\text { Technology } \\
\text { Acceptance } \\
\text { Model 2 } \\
\text { (TAM2) }\end{array}$ & $\begin{array}{l}\text { Social influence } \\
\text { processes; } \\
\text { cognitive } \\
\text { instrumental }\end{array}$ & $\begin{array}{l}\text { Attitude } \\
\text { toward using; } \\
\text { behavioral } \\
\text { intention; }\end{array}$ & $\begin{array}{l}\text { Derived from } \\
\text { TAM }\end{array}$ & $\begin{array}{l}\text { Information } \\
\text { systems }\end{array}$ & $\begin{array}{l}{[213],} \\
{[215]}\end{array}$ \\
\hline
\end{tabular}




\begin{tabular}{|c|c|c|c|c|c|}
\hline & $\begin{array}{l}\text { processes; } \\
\text { perceived } \\
\text { usefulness; } \\
\text { perceived ease of } \\
\text { use }\end{array}$ & $\begin{array}{l}\text { actual system } \\
\text { use }\end{array}$ & & & \\
\hline $\begin{array}{l}\text { Task-techn } \\
\text { ology Fit } \\
\text { (TTF) }\end{array}$ & $\begin{array}{l}\text { Task } \\
\text { characteristics, } \\
\text { technology } \\
\text { characteristics; } \\
\text { task-technology fit }\end{array}$ & Actual tool use & $\begin{array}{l}\text { Utilization } \\
\text { focus models } \\
\text { (e.g. TAM) and } \\
\text { fit focus } \\
\text { models }\end{array}$ & $\begin{array}{l}\text { Information } \\
\text { systems }\end{array}$ & $\begin{array}{l}{[216],} \\
{[217]}\end{array}$ \\
\hline $\begin{array}{l}\text { Unified } \\
\text { Theory of } \\
\text { Acceptance } \\
\text { and Use of } \\
\text { Technology } \\
\text { (UTAUT) }\end{array}$ & $\begin{array}{l}\text { Performance } \\
\text { expectancy; effort } \\
\text { expectancy; social } \\
\text { influence; } \\
\text { facilitating } \\
\text { conditions }\end{array}$ & $\begin{array}{l}\text { Behavioral } \\
\text { intention; } \\
\text { usage behavior }\end{array}$ & $\begin{array}{l}\text { TRA; TAM; } \\
\text { TPB; } \\
\text { Motivation } \\
\text { Model; a model } \\
\text { combining } \\
\text { TAM and TPB; } \\
\text { the model of } \\
\text { PC utilization; } \\
\text { Innovation } \\
\text { Diffusion } \\
\text { Theory (IDT); } \\
\text { and Social } \\
\text { Cognitive } \\
\text { Theory (SCT) }\end{array}$ & $\begin{array}{l}\text { Information } \\
\text { systems }\end{array}$ & $\begin{array}{l}\text { [199], } \\
\text { [221] }\end{array}$ \\
\hline
\end{tabular}

Influenced by Aldhaban (2016) [226]

\subsection{Technology Adoption, E-Services and Student Success}

Technology adoption, such as articulated in the above technology adoption models, can be crucial to the realization of organizational strategies to improve e-service delivery and customer experience. This study examines student information technology adoption in support of student success through the case of student adoption of the myPSU software, which is used for accessing university services. Through this case a critical question emerges - how are student information technology adoption and student success related conceptually? 
Building off of the work from the Portland State project team tasked with redesigning how students could access university services and resources, and in support of improving student success goals [227], [228], this study suggests there could be a positive relationship between student information technology adoption and student success - that by making critical technology and technology-enabled services easier to use, it makes it easier for students to be retained - for several reasons. First, it is possible the myPSU software enhancements reduce "bureaucratic hassles" by creating easier ways to complete business-related tasks. Limited research shows that reducing bureaucratic hassles in online services can promote student belonging, which in turn influences persistence [229], [230]. Additional research shows that college students who have higher financial need might disproportionately benefit from and rely on technology, suggesting that by improving service delivery through technology, high-risk students might benefit more than other students [7], [231].

Second, improving students' experiences could indirectly contribute to improving retention based on Braxton et al.'s theory of student persistence in commuter colleges and universities [25]. Braxton et al.'s theory posits that organizational characteristics, such as institutional integrity and institutional commitment to student welfare, positively influence persistence. It is possible that using a software platform like myPSU to improve access to university services is a component of institutional commitment to student welfare and that by improving technology-enabled services, students will experience a higher 
degree of institutional commitment. Additionally, it is possible that the myPSU platform will contribute to student satisfaction with the university, as it is cutting-edge software that could make their experiences more enjoyable.

\subsection{Research Related to Student Information Technology Adoption}

If one accepts the premise that technology can improve access to university services and as such, contribute to student success albeit indirectly, it is worthwhile to explore the factors that influence student adoption of technology, such as myPSU. A first step in building a research model to evaluate student adoption of myPSU is to conduct a literature review to identify the technologies that have been studied and the factors that influence said adoption, and to present these factors in a taxonomy, or a means to classify or organize findings. This section describes these findings.

\subsubsection{Methodology}

This study used an in-depth literature review and the author conducted a keyword search for "technology adoption factors higher education students" in the ACM, IEEE Xplore and EBSCO host databases, and Google Scholar, using all available publication dates. This search returned the following: ACM - 28 papers; IEEE Xplore - 22 papers; EBSCOhost - 29 papers; Google Scholar - 200 papers; total of 279 papers. The author found 4 duplicates, which then resulted in 275 papers. The first review of the 275 papers involved using titles and abstracts to filter out papers that were not relevant based on these attributes: unit of analysis included higher education students, the research used a formal technology 
adoption model and the research topic was related to higher education. Out of an abundance of caution, if it was not clear from the title or abstract whether a paper included the attributes, it was kept in the sample. This resulted in 127 papers. The second review examined these 127 papers in more detail by reading the papers to confirm or disconfirm their validity based on the aforementioned attributes, and also whether the study was an empirical study that developed and tested hypotheses based on and to improve a technology adoption model. This resulted in 53 papers, which became the sample for this review.

\subsubsection{Results}

Many of the technology adoption models discussed above were utilized in the 53 papers that form the sample for this review. Of the 53 papers that studied university student adoption of technology: 48 papers focused on technology adoption in a learning context/environment; none examined the adoption of student information technology in support of student success; 37 used TAM, TAM2 or TAM3 as the adoption model; 11 used UTAUT, UTAUT2, or an adaptation of UTAUT as the adoption model; and 49 studied student adoption exclusively while the rest had a combination of other populations along with students. In terms of adoption factors, the papers researched 129 unique adoption factors, had 156 unique findings about adoption factors (i.e. whether the factor positively or negatively influenced adoption, or had no significant effect), which the author of this paper divided into 36 categories. 
Table 10: Summary of Descriptive Statistics

\begin{tabular}{|l|l|}
\hline Criteria & Statistic \\
\hline $\begin{array}{l}\text { \# of empirical research papers that studied university student adoption } \\
\text { of technology }\end{array}$ & 53 \\
\hline $\begin{array}{l}\text { \# of papers focused on technology adoption in a learning } \\
\text { context/environment }\end{array}$ & 48 \\
\hline $\begin{array}{l}\text { \# of papers that examined the adoption of student } \\
\text { information technology in support of student success }\end{array}$ & o \\
\hline \# of papers that used TAM, TAM2 or TAM3 as the adoption model & 37 \\
\hline $\begin{array}{l}\text { \# of papers that used UTAUT, UTAUT2, or an adaptation of UTAUT as } \\
\text { the adoption model }\end{array}$ & 11 \\
\hline \# of papers that exclusively studied the student population & 49 \\
\hline \# of unique adoption factors & 129 \\
\hline $\begin{array}{l}\text { \# of unique findings about adoption factors (i.e. whether positive } \\
\text { influence, negative influence, or no effect) }\end{array}$ & 156 \\
\hline \# of adoption factor categories (determined by the author of this paper) & 36 \\
\hline
\end{tabular}

\subsubsection{Technologies}

A wide variety of e-services and systems were studied across the 53 papers that were reviewed. To aid with synthesizing the findings from these papers, this author categorized the studies into the following broad categories of technology: e-learning systems, podcasts, smartphones, internet banking services, Web 2.o, cloud computing, mobile learning (m-learning), social networking sites, Information and Communication Technologies (ICT), Massive Online Open Courses (MOOCs), tablet personal computers, e-portfolios and ubiquitous learning (u-learning). This section briefly describes the technologies that might not be commonly understood. 
Not surprisingly, a large body of research focuses on the adoption of online systems used to aid classroom instruction and information exchanges, including chat areas, syllabi, assessments and lecture slides that are available from any internet-connected device [232]. This group of technologies can be described as e-learning, which are "methods of learning which use electronic instructional content delivered via the internet and is a term which is synonymous with Web-based or online learning" [233]. Podcasting, which takes the form of podcasts, is when a digital sound object is posted to a website or blog in a form that a user can then download directly to a personal computer or a portable audio device [234]. Smartphones are popular with college students, as they are with the general populace, and are symbolic devices that signal "affiliation and timely technology adoption" [235]. The Kim et al. (2014) study included using Innovation Diffusion Theory, developed by Rogers 1995, and posits that the speed by which individuals and groups adopt technology is influenced by personal, social and technological factors [236]. Internet banking services are consumer-facing online services where customers can access financial account information and conduct transactions [237].

Web 2.o technology involves the use of social tools through the Web where users actively create content, including generating knowledge and information to share with others online [238]. In higher education it includes technologies such as blogs, wikis (collaboratively created web pages where users add content [239]), content distributed through RSS feeds ("a standardised format that allows users 
to subscribe to a website's content using tools such as newsreaders or aggregators" [240]), media-sharing, and social networking sites [238]. A strand of research also looked at cloud computing adoption. Cloud computing allows on-demand access to centralized computing resources, including networks, servers, storage and services that require minimal management effort and overhead [241].

M-learning, a branch of e-learning, is the focus of another strand of research. It is defined as a part of e-learning in which in educational interactions, the "sole or dominant technologies are handheld or palmtop devices" [242]. In comparison to traditional course management systems, social network sites provide socially-relevant features such as media sharing, tagging, real-time activity streaming, group affiliations and profile pages [243]. Information and Community Technologies (ICT) includes tools for communications and the dissemination, storing and managing of information [244].

Massive Online Open Courses (MOOCs) are an extension of the network teaching system or e-learning where thousands of students are enrolled in an online courses that are offered for free and without credit [245]. [246]. Tablet computers were studied by Moran, Hawkes and El Gayar (2010) in terms of the adoption of tablet computers in a learning environment by undergraduate students [247]. One paper researched the adoption of e-portfolios, defined as systems that "allow information to be stored, accessed, updated, and presented in various electronic formats as a record or evidence of student learning and 
achievement" [248]. Finally, "U-learning is an advanced form of simple mobile learning in which learning environments can be accessed in various contexts and situations" [224].

\subsection{Taxonomy of Factors Related Student Information Technology Adoption}

Through the analysis of the 53 papers, and the adoption research they conducted, 129 unique adoption factors were identified, and there were 156 unique findings about adoption factors (i.e. whether they had a positive influence, negative influence, or had no effect on adoption; e.g. in some cases, one study found a factor to have a positive influence on adoption, while another paper found the same factor had no influence on adoption). In order to develop a taxonomy of these factors, they were organized into 36 categories: Accessibility; Age; Anxiety; Attitude; Behavioral intention; Communicativeness; Compatibility; Control; Cost and value; Ease of travel; Effort expectancy; Enjoyment; Ethnicity; Facilitating conditions; Features; Feedback; Gender; Habits; Individual characteristics; Miscellaneous; Mobility; Perceived complexity; Perceived ease of use; Perceived quality; Perceived usefulness; Performance expectancy; Personal innovativeness; Reliability; Resources; Security; Self-efficacy; Skills and experience; Social influence; Support and training; Trust; and Voluntariness of use. The details of this taxonomy are in Appendix A, including definitions of each factor. 
Given the prevalence of papers that used TAM or a TAM-derivative, the ten factors with the most references (i.e. findings), all of which had a positive influence on adoption, are the following (in order from most to least number of references): Perceived usefulness, Perceived ease of use, Self-efficacy, Social influence, Attitude toward the system, Performance expectancy, Behavioral intention to use, Subjective norm, Facilitating conditions, and Effort expectancy. Interestingly, the 11th most referenced factor is that Perceived ease of use had no statistically significant influence on adoption.

\subsection{Research Gaps and Questions}

In light of the above, the primary research objective for this research is to contribute to institutional, academic and educational technology sector efforts to dramatically enhance service quality, in support of improving undergraduate student outcomes, by identifying the determinants of student information technology adoption. This research focuses on two research questions: 1. What are the critical factors that influence undergraduate students themselves in adopting software for accessing university services (one type of student information technology)? 2. To what degree does the Unified Theory of Acceptance and Use of Technology (UTAUT) technology adoption model predict adoption of software for accessing university services (one type of student information technology)? These research questions stem from the literature review and respond to the following gaps: 
- RG1 - There is limited research about the factors that influence undergraduate students themselves in adopting software for accessing university services (one type of student information technology)

- RG2 - There is limited research about a technology adoption model that seeks to predict student adoption of software for accessing university services (one type of student information technology)

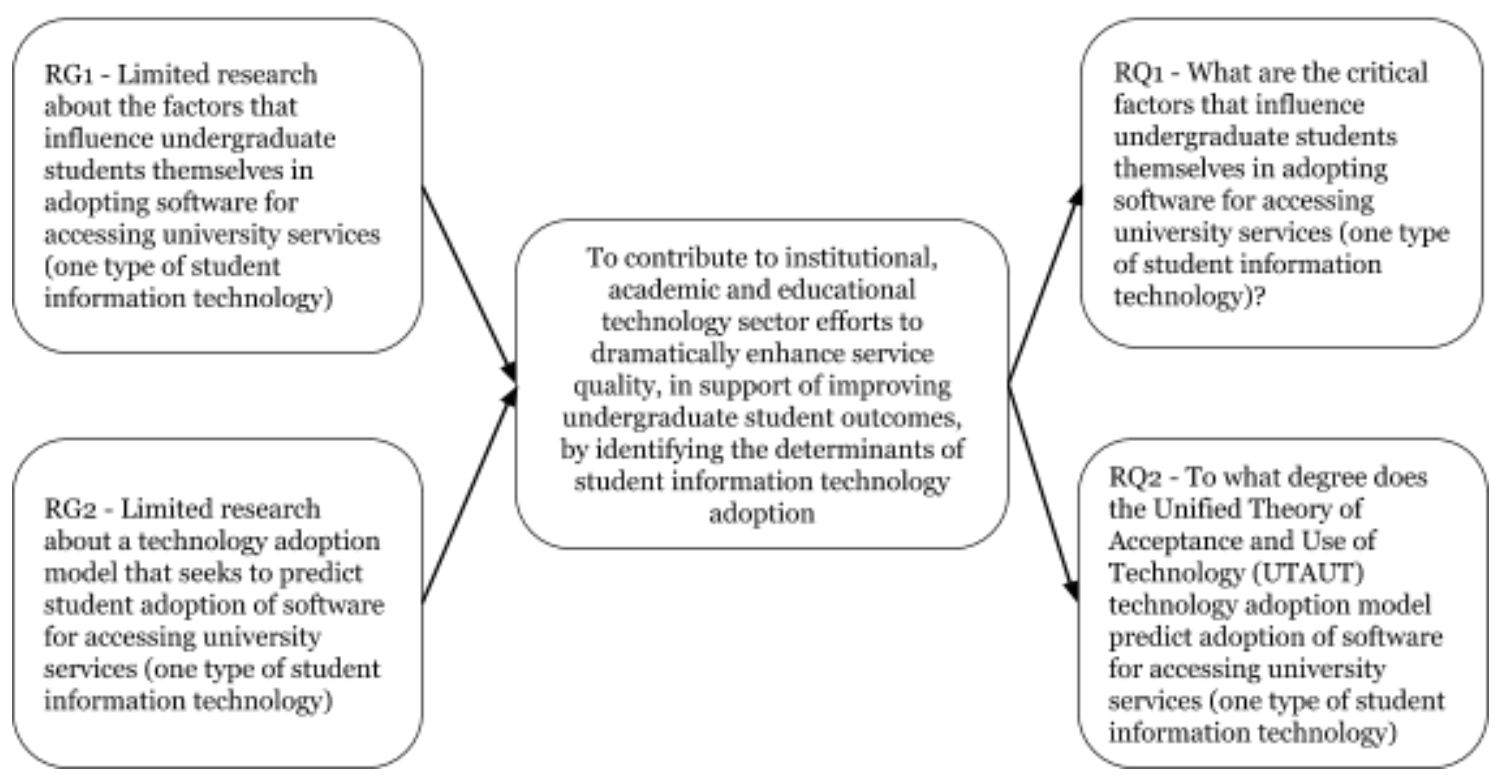

Figure 7: Research Gaps, Research Objective and Research Questions 


\section{Chapter Five: Unit of Analysis - myPSU}

As a unit of analysis, this research studied the adoption of a web-based digital services platform, branded myPSU, that aids undergraduate and graduate students in accessing services and resources critical to maintaining their enrollment. myPSU is available to Portland State University students as both a native mobile application and as a website, with content between the two being very similar. The underlying software platform that powers myPSU is developed and maintained by Modo Labs, with design, content, configurations and data integrations managed by staff at Portland State University [228].

myPSU is intended to be "a single point of entry for students to access online resources and services, and a place for connecting with the PSU community" [249], [250] and strives to "be personalized and flexible, mobile-friendly, provide access to improved services, and leverages the functionality of existing web platforms" [228].

myPSU's design prioritizes features and content germane to accessing services and student success. myPSU provides critical access to university resources (calendars, campus map, library, university-related software, etc.) and services (academic advising, career services, financial wellness center, resource centers, tutoring, etc.), and the means to conduct the business of being a student (viewing account balance, accessing the platform to pay bills, accessing information about financial aid, accessing the platform for registering for courses, viewing course schedule, etc.). In addition, key features include: 
- Access to information about classes (how to register, location, time/day, maps to classes, instructor name and contact information, etc.)

- Access to financial information (financial aid information, account balance, easy access to paying bills, etc.)

- Access to academic planning resources (academic advising, degree audit, the Schedule Planner software, etc.)

- Access to student account information

- Access to critical university-related software platforms (personalized checklist of business-related items, learning management system, student information system, university email, etc.)

- Notifications of critical university information (emergency alerts, campus closures, etc.)

- An interactive campus map

- Easy access to university calendars

In sum, as a self-service software platform intended to help students access services, myPSU is a critical type of student information technology in support of student success. 


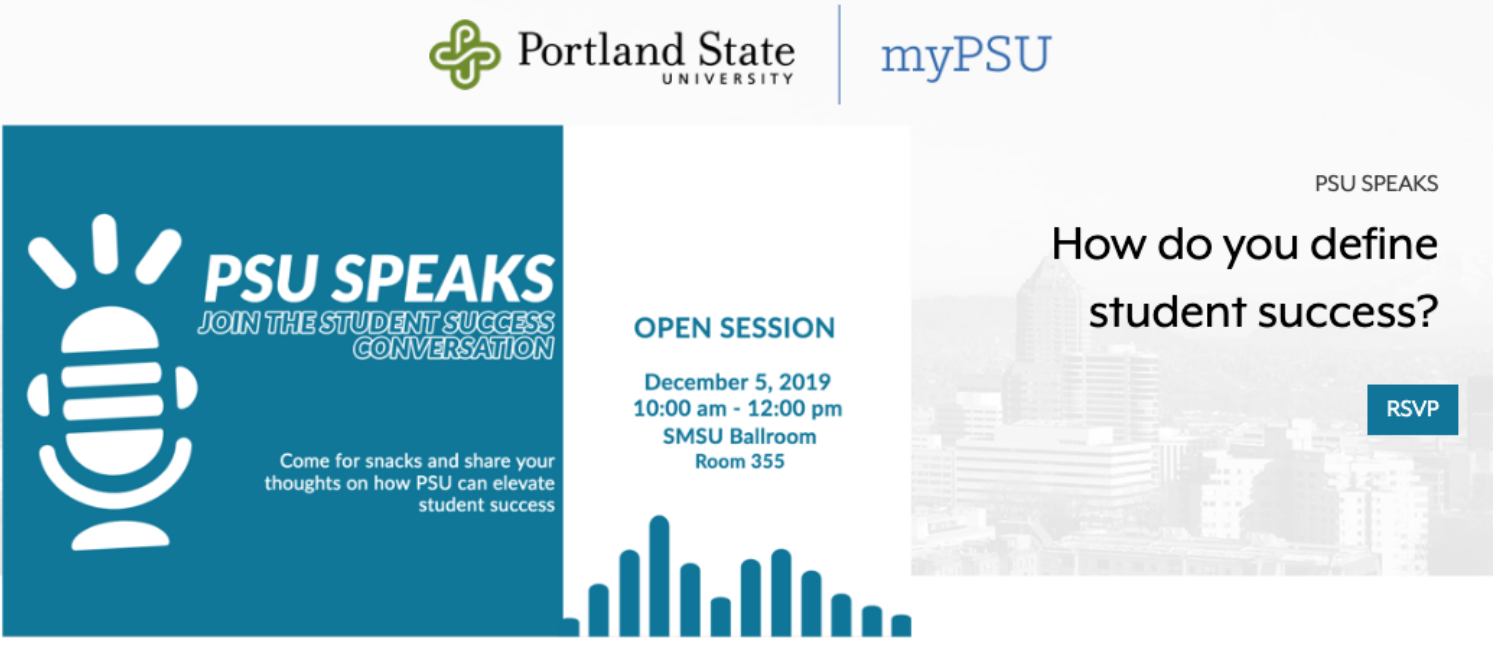

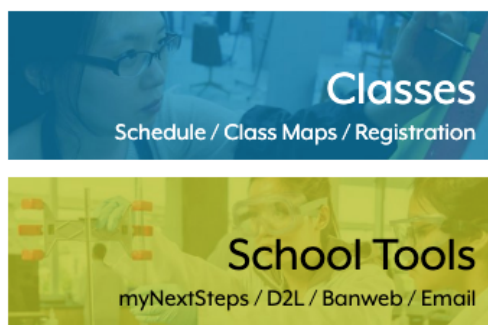

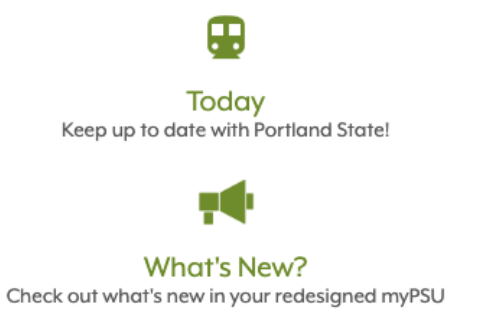

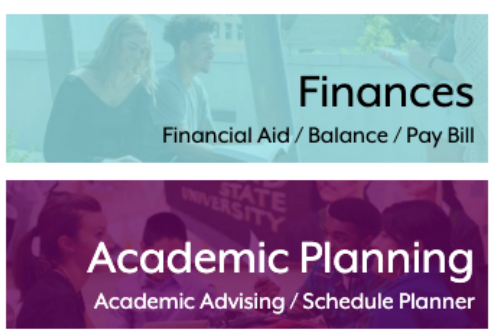
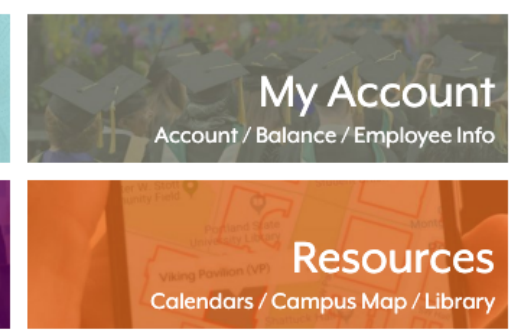

Figure 8: myPSU Homepage

myPSU was launched by the Redesign myPSU project [227], [249] as part of Portland State University's efforts to reimagine the student experience. Starting in Spring 2015, PSU embarked on an effort to improve undergraduate student retention and graduation rates (i.e., student success) by dramatically improving students' experiences. Based on student feedback, a core component of this work was an effort to improve undergraduate and graduate students' 
abilities to access services through the Redesign myPSU initiative. Student feedback was central to the Redesign myPSU effort as well, including a survey that was administered in Spring 2016 to understand student satisfaction with digital services and students' overall experiences with the university, including use of Net Promoter Score [249]. The Redesign myPSU efforts culminated in September 2017 in a successful implementation of a reimagined myPSU website (my.pdx.edu) and a myPSU mobile app, as foundational elements to improve students' experiences, and thus their success [228].

\section{BUILDING THE BEST STUDENT EXPERIENCE}

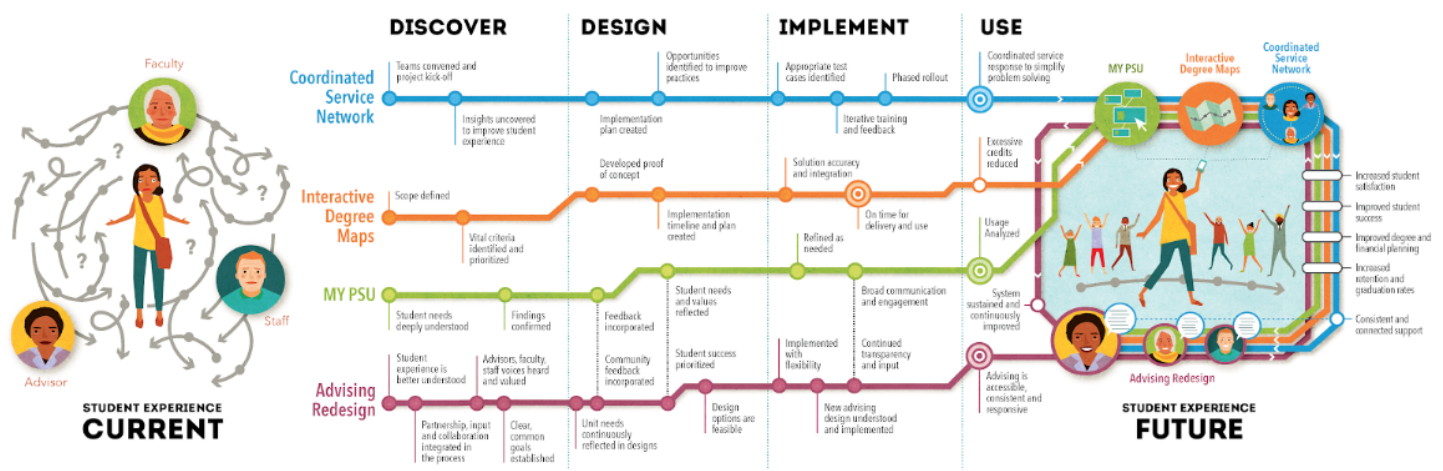

Figure 9: Visual Depiction of PSU's Efforts to Improve the Student Experience [250]

As the work to improve the student experience developed after September 2017, the university and its leadership began to consider more concretely how efforts to improve student experiences related to improving retention and graduation rates. To this end, the team adopted Braxton et al.'s theory of student persistence in commuter colleges and universities [25], [251]. Braxton et al.'s theory posits that organizational characteristics, such as institutional integrity 
and institutional commitment to student welfare, positively influence persistence. The team suggests that myPSU is a component of institutional commitment to student welfare. By improving myPSU, the team considered that students could experience a higher degree of institutional commitment, and thus an increased likelihood of persistence [251].

This study focuses on the adoption of software for accessing university services for several reasons. Self-service software related to navigating through an institution and completing business-related tasks is central to student information technology in support of student success [7]. Second, as stated earlier, it is possible the myPSU software enhancements reduce "bureaucratic hassles" by creating easier ways to complete business-related tasks and impact persistence [229], [230]. Thus, by more fully understanding the critical factors that influence student adoption of software for accessing university services, it is possible that universities and others could use this information to make critical technology and technology-enabled services easier to use. These changes in turn, could contribute to efforts to improve student retention and graduation rates on university campuses. 


\section{Chapter Six: Preliminary Research Model}

\subsection{Unified Theory of Acceptance and Use of Technology}

The preliminary research model for this study was developed through two primary steps: identification of factors, derived from the literature review, that relate to the focus of this study (on the critical determinants of student information technology that could influence undergraduate students themselves in adopting technology for accessing university services); and identification of an existing adoption model that is aligned with the research topic and has an adequate theoretical basis (UTAUT) [226].

An existing technology adoption model that is a strong fit with the research topic of student information technology in support of student success is the Unified Theory of Acceptance and Use of Technology (UTAUT). UTAUT is a strong fit for several reasons. UTAUT has been widely applied across industries and user types [221], including in educational institutions and to examine digital learning adoption [221]. UTAUT also emphasizes facilitating conditions - "the degree to which an individual believes that an organizational and technical infrastructure exists to support use of the system" [199] - which are relevant to this study because of the role that universities themselves play in supporting self-service software for accessing university services. UTAUT, which was designed for primary use in organizational contexts [225], is a stronger fit for this study as compared to UTAUT2. The constructs added in UTAUT2 are related to consumer contexts (hedonic motivation, price value and habit) [225] and not 
directly relevant to students in terms of the factors that influence their adoption of myPSU. While students might be considered "consumers" of education (i.e. they pay tuition and fees), in terms of myPSU adoption, they are more akin to participants in the Portland State University organization, as opposed to consumers.

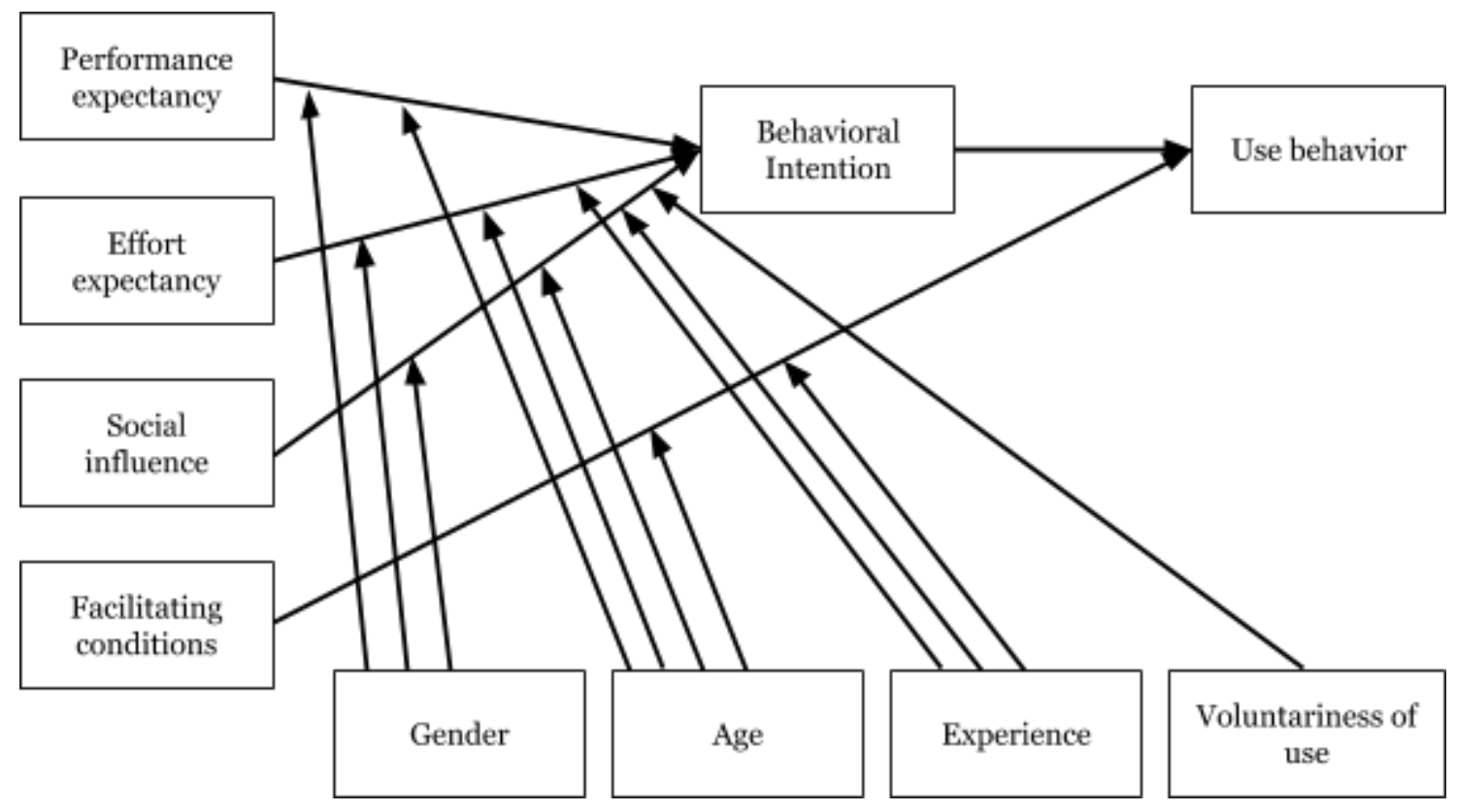

Figure 10: Unified Theory of Acceptance and Use of Technology (UTAUT) Model [199], [221]

\subsection{Extending and Modifying UTAUT}

UTAUT has been extended, modified and integrated with other technology adoption models extensively [221]. As the literature review conducted for this study did not identify any adoption studies related to student information technology in support of student success, nor any applications of UTAUT in this domain, it is appropriate to look at studies in corollary fields to demonstrate that 
modifying, extending and integrating UTAUT with other technology adoption models is appropriate. Wang et al. (2009) adapted UTAUT to investigate the determinants of mobile learning adoption, including examining if age and gender differences influence adoption [252]; Mosunmola et al. (2018) adapted UTAUT to study the adoption of mobile learning in a Nigerian educational institution [253]; and Marchewka and Kostiwa (2007) adapted UTAUT to study the adoption of a web-based course management tool by students at a large midwestern university in the United States [254]. Additionally, Moran et al. (2010) modified UTAUT when they studied the adoption of tablet computers in a learning environment by undergraduate students at a small upper Midwestern University in the United States [247]. Therefore, it is appropriate to use UTAUT as a base model and modify it in relation to the specific context of the adoption of the myPSU website and mobile app by undergraduate students at Portland State University.

\subsection{Preliminary Research Model and Hypotheses}

The preliminary research model was developed in a multi-step process. First, a taxonomy of factors was developed through a literature review. Second, an appropriate technology adoption model was identified (UTAUT) that is a strong fit with the unit of analysis for this study (self-service software for accessing university services). Third, the factors/constructs in UTAUT (i.e. performance expectancy, effort expectancy, social influence, facilitating conditions, behavioral intention and use behavior) were defined in light of the 
literature and the unit of analysis. This was based on information identified in the literature review as well as through a review of the seminal paper on UTAUT, Venkatesh et al. (2003) [199], and by studying Moran et al.'s (2010) application of UTAUT in a higher education context [247].

Fourth, the taxonomy of factors that was developed in the literature review (129 unique adoption factors with 156 unique findings about adoption) was evaluated and filtered to identify those factors that might be most relevant to the unit of analysis. This review included removing factors that were found to have not been statistically significant, removing those that were not relevant to self-service software for non-academic work (such as ease of travel, cost, etc.), and combining factors that were very similar. When a factor was identified as being related to self-service software adoption, it was placed as a latent construct or added as an indicator for a latent construct that was already in the UTAUT model (either as a stand-alone indicator or in support of a related indicator). During the filtering, guidelines for specifying a measurement model used in SEM were followed:

- In terms of gauging how many new constructs ought to be added to the UTAUT model, the researcher considered model complexity. In contexts such as this study, where the literature is limited in terms of empirical research on constructs and indicators, decisions about what to include in the model hinges on a researcher's expertise and also benefits from input from experts in the field [255]. 
- Additionally, researchers using SEM should strive to use a model that is as "simple as possible while respecting theory and prior empirical results" [255]. Thus, adding new constructs to UTAUT was kept to a minimum, as researchers want constructs and models that are overidentified and yet parsimonious, so that there is enough information to identify a solution for a set of structural equations [256], [257]. Parsimony refers to the goal of using as few factors as possible in a model [258].

- Finally, when specifying a measurement model, it is recommended that researchers identify at least 3-4 indicators for each latent construct so that the construct is adequately defined and the overall model is identified [257], [259], [255], [256], with 3-5 indicators being acceptable as well [255].

- However, when it was not clear about whether an indicator should be included, the researcher erred toward including more indicators than the recommended amount for several reasons: 1 . The expert feedback via the focus groups and semi-structured interviews would be used to help filter the taxonomy; 2. The statistical analysis of the measurement model (principal components analysis and Cronbach's alpha) could help reduce the number of indicators per construct; and 3. There are other SEM technology adoption studies that use more than 4 indicators, e.g. Wang and Wang (2009) (used TAM and DeLone and McLean's information system success model) [260]; Pituch and Lee (2006) (used TAM and 
Theory of Reasoned Action) [261]; and Saadé and Bahli (2005) (used TAM) [262].

Fifth, the preliminary research model was identified. The model, described below, consists of nine total factors/constructs (six from UTAUT and three added to UTATU) with 37 indicators and an average of four indicators per construct. All constructs include three or more indicators. Many of the indicators and factors in this preliminary research model were drawn from research that used other technology adoption models, such as Personal Cloud Adoption Model (PCAM), UTAUT2, TAM, TRA, TPB and the Diffusion of Innovation (DoI). 


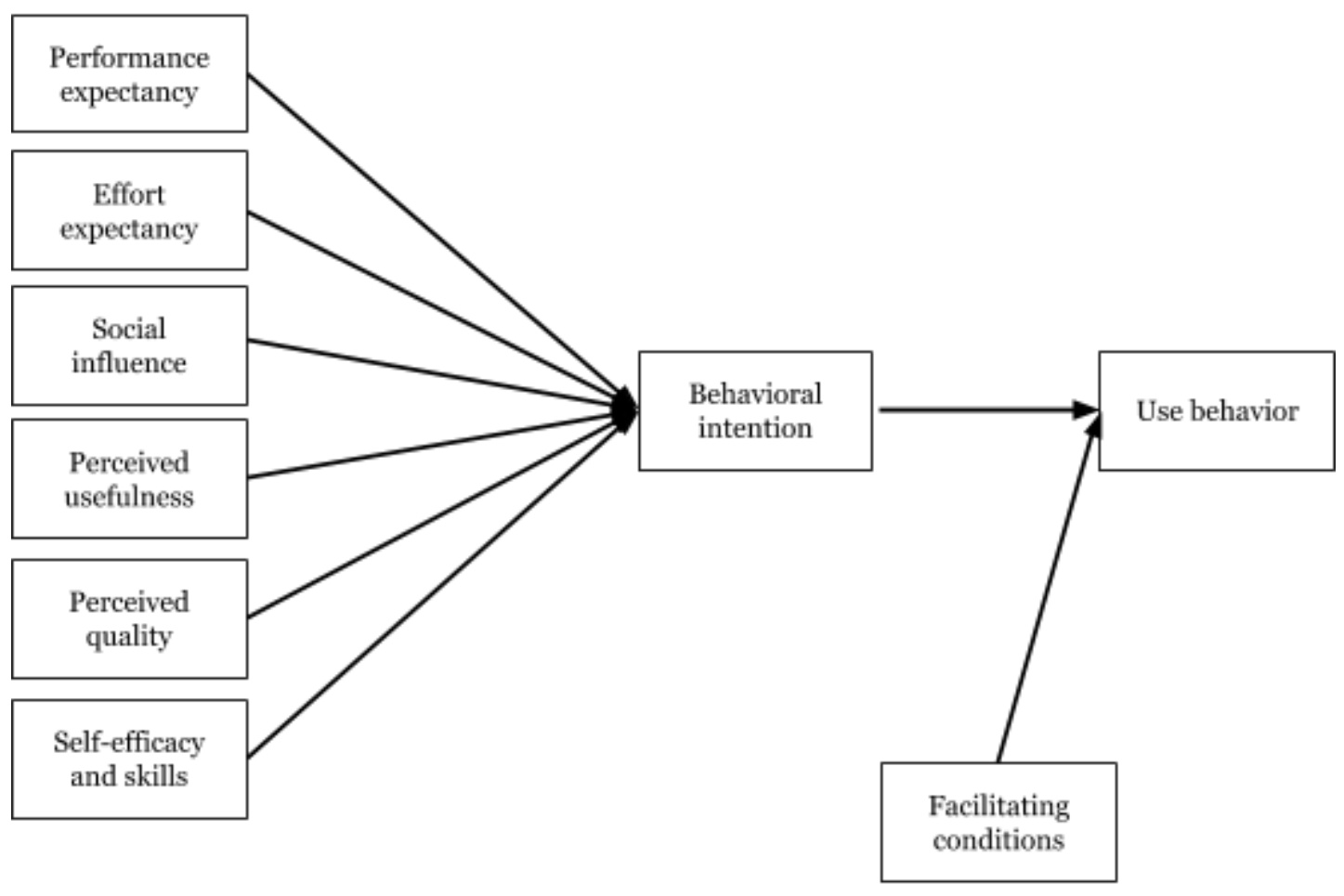

Figure 11: Visual Diagram of Preliminary Research Model

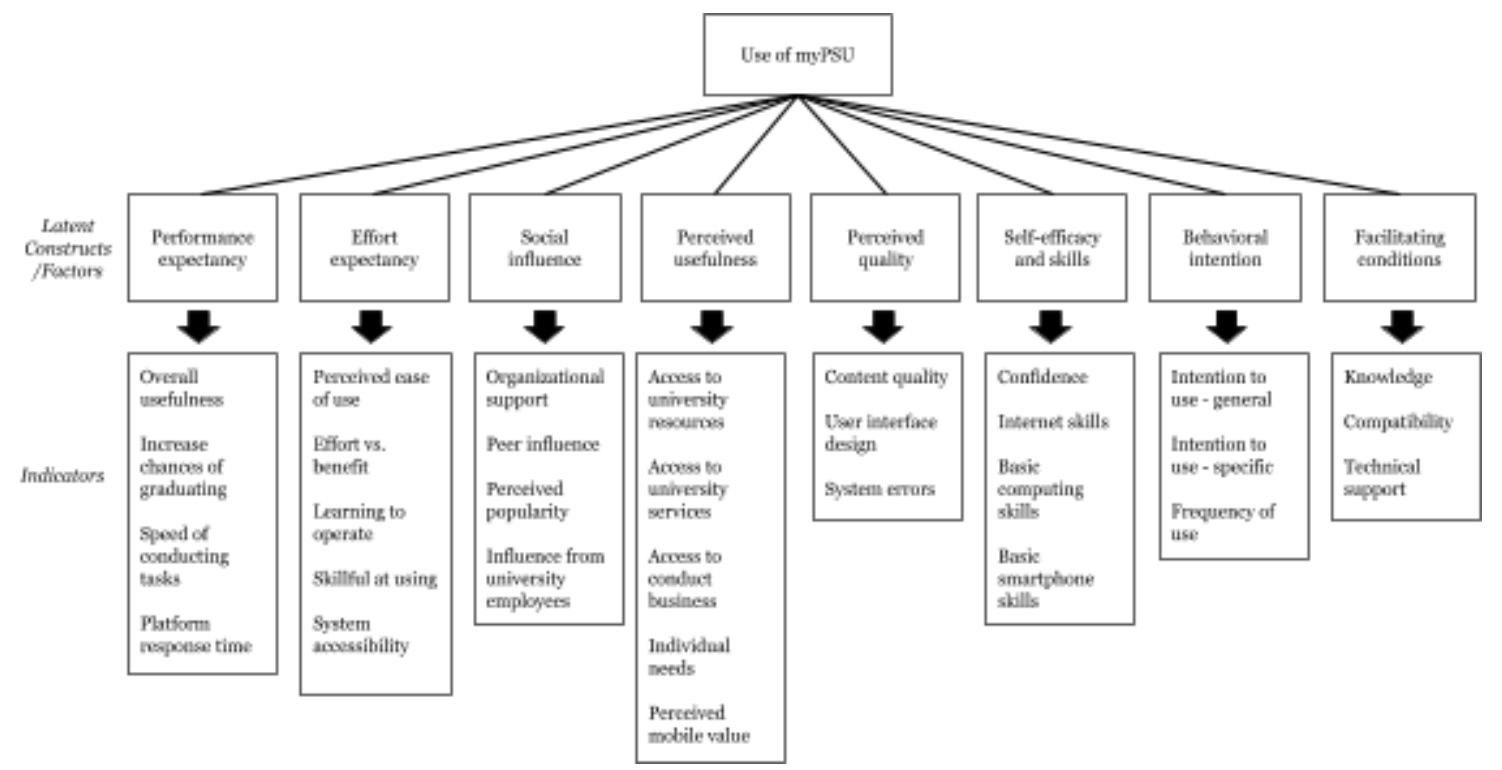

Figure 12: Latent Constructs/Factors and Indicators for Preliminary Research Model Organized as a Taxonomy 
The following table defines each construct. Appendix B contains a more

detailed taxonomy of the preliminary research model with the definitions for

each latent construct and each indicator.

Table 11: Preliminary Research Model Taxonomy (Summary)

\begin{tabular}{|c|c|c|c|}
\hline $\begin{array}{l}\text { Factors and } \\
\text { indicators }\end{array}$ & Definition & $\begin{array}{l}\text { Reference(s) for } \\
\text { definition(s) }\end{array}$ & $\begin{array}{l}\text { Reference(s) for } \\
\text { studies indicating } \\
\text { an influence on } \\
\text { other factors }\end{array}$ \\
\hline \multicolumn{4}{|c|}{ UTAUT Factors } \\
\hline $\begin{array}{l}\text { Performance } \\
\text { expectancy }\end{array}$ & $\begin{array}{l}\text { The degree to which an } \\
\text { individual believes that } \\
\text { using a technology will } \\
\text { help them overall. }\end{array}$ & $\begin{array}{l}\text { [263], } \\
{[199]}\end{array}$ & $\begin{array}{l}\text { [263], [264], [253], } \\
{[265],[266],[267],} \\
{[247],[252],[268]}\end{array}$ \\
\hline $\begin{array}{l}\text { Effort } \\
\text { expectancy }\end{array}$ & $\begin{array}{l}\text { "Degree of ease } \\
\text { associated with the use } \\
\text { of the system" [199]; } \\
\text { construct includes } \\
\text { perceived ease of use }\end{array}$ & [199] & $\begin{array}{l}\text { [253], [265], [266], } \\
{[247],[254],[252],} \\
{[268]}\end{array}$ \\
\hline Social influence & $\begin{array}{l}\text { "Extent to which users } \\
\text { perceive that those } \\
\text { important to them } \\
\text { believe they should be } \\
\text { using a technology" } \\
\text { [263] }\end{array}$ & {$[263]$} & $\begin{array}{l}\text { Social influence - } \\
{[264],[253],[265],} \\
{[266],[267],[247],} \\
{[254],[252],[224],} \\
{[268],[269] ;} \\
\text { Subjective norm - } \\
{[270],[233],[271],} \\
{[242],[112],[272],} \\
{[273],[274]}\end{array}$ \\
\hline $\begin{array}{l}\text { Facilitating } \\
\text { conditions }\end{array}$ & $\begin{array}{l}\text { "The degree to which an } \\
\text { individual believes that } \\
\text { an organizational and } \\
\text { technical infrastructure } \\
\text { exists to support the use } \\
\text { of the system" [199] }\end{array}$ & [199] & $\begin{array}{l}{[263],[275],[266],} \\
{[267],[247],[268],} \\
{[276],[269]}\end{array}$ \\
\hline $\begin{array}{l}\text { Behavioral } \\
\text { intention to use }\end{array}$ & $\begin{array}{l}\text { "The decision maker's } \\
\text { disposition toward using } \\
\text { a system" [271] }\end{array}$ & {$[271]$} & $\begin{array}{l}{[277],[270],[241]_{2}} \\
{[271],[244],[264],} \\
{[278],[247],[279]}\end{array}$ \\
\hline Use behavior & $\begin{array}{l}\text { Actual usage of the } \\
\text { system. }\end{array}$ & [199] & - \\
\hline \multicolumn{4}{|c|}{ Factors added to UTAUT } \\
\hline $\begin{array}{l}\text { Perceived } \\
\text { usefulness }\end{array}$ & $\begin{array}{l}\text { The degree to which a } \\
\text { person believes that } \\
\text { using the features of a } \\
\text { particular technology are } \\
\text { useful in accomplishing } \\
\text { a desired task. }\end{array}$ & $\begin{array}{l}{[271]_{2}[209]_{2}[261],} \\
{[279]}\end{array}$ & $\begin{array}{l}\text { Perceived usefulness } \\
\text { as defined related to } \\
\text { Davis 1989- [277], } \\
{[270],[262],[280],} \\
{[281],[282],[232],} \\
{[233],[243],[271],}\end{array}$ \\
\hline
\end{tabular}




\begin{tabular}{|c|c|c|c|}
\hline & & & $\begin{array}{l}{[244],[237],[283],} \\
{[242],[245],[284],} \\
{[285],[286],[112],} \\
{[234],[287],[288],} \\
{[289],[272],[290],} \\
{[278],[224],[261],} \\
{[273],[291],[292],} \\
{[276],[269],[274],} \\
{[279],[293],[294],} \\
{[295] ; \text { System }} \\
\text { functionality/user } \\
\text { tools - }[261] ;[279]\end{array}$ \\
\hline $\begin{array}{l}\text { Perceived } \\
\text { quality }\end{array}$ & $\begin{array}{l}\text { The user's opinion of the } \\
\text { quality of a software } \\
\text { platform. }\end{array}$ & $\begin{array}{l}\text { [271], [260], [296], } \\
\text { [271] }\end{array}$ & $\begin{array}{l}\text { System quality - } \\
{[277],[271],[291] ;} \\
\text { Information quality - } \\
{[271],[260],[291]}\end{array}$ \\
\hline $\begin{array}{l}\text { Self-efficacy and } \\
\text { skills }\end{array}$ & $\begin{array}{l}\text { The judgement of one's } \\
\text { own ability to perform } \\
\text { specific } \\
\text { technology-related tasks } \\
\text { and the skills to do so. }\end{array}$ & $\begin{array}{l}\text { [233], } \\
\text { [292] }\end{array}$ & $\begin{array}{l}\text { Self-efficacy - [277], } \\
{[233],[271],[270],} \\
{[286],[112],[234],} \\
{[278],[265],[247],} \\
{[297],[276],[295] ;} \\
\text { Skills - [295], [290], } \\
{[292],[292],[263],} \\
{[286],[274],[112]}\end{array}$ \\
\hline
\end{tabular}

The research methodology in this study draws on Aldhaban (2016), who studied the adoption of smartphones in emerging regions and used experts to provide feedback on the preliminary research model through focus groups and interviews, and used expert panels to evaluate and validate the survey instrument [226]. 


\section{Chapter Seven: Qualitative Methods and Research Model}

The preliminary research model was evaluated through two main qualitative approaches - semi-structured interviews and focus groups - and resulted in the research model that was evaluated using Structural Equation Modeling.

\subsection{Experts}

As described below, experts were used in both the semi-structured interviews and focus groups and played a critical role in this study. Experts are called upon to provide information, knowledge and insights to aid both qualitative and quantitative research. As a social science research method, which this study draws on for the qualitative methods, expert interviews are becoming increasingly popular, and much more so in recent times [298]. An expert is someone who "has a background in the subject matter at the desired level of detail and who is recognized by his or her peers or those conducting the study as being qualified to solve the questions" [299]. Expert judgement can be viewed as a representation of their knowledge at the time of answering a technical question [299]. In many cases, their expertise stems from their professional activities [298]. Experts can be called on to sanction a study or research question and are called on to provide objective and informed opinions [30o]. Critically, their participation in a research methodology is determined deliberately [301].

Expert interviews, both individual and group, are often utilized when exploratory research questions are at hand and there is little or no knowledge in 
the literature [298], [302], [299]. Additionally, experts can help sift through information [303], as they have deep insights into their fields of knowledge. Experts can be used in semi-structured interviews, such as to help identify the questions that should be asked in a survey, or to explain themes that have emerged from a questionnaire [304]. Additionally, they can be used in semi-structured focus groups to provide feedback on factors for technology adoption [226].

As with any method, there are advantages and disadvantages of using experts. The advantages include that they can provide information when other sources (e.g. measurements, observations or experimentation) are not available, they have capabilities with respect to knowledge in their field that surpasses novices, and their interactions can result in ideas, insights and results that would not have been otherwise achieved [299]. Disadvantages include that the data that experts provide can be conditional (e.g. they might understand the problem differently than another expert) [299], and might have bias (e.g. response bias, such as when an expert may not want to reveal sensitive information, resulting in an incomplete view of the situation; or participation bias, which reflects that interviews, or focus groups, take significant time and not all possible participants might be able to participate, resulting in a skewed view of a situation or research question) [304]. At times experts disagree, perhaps because they interpreted a question differently [299]. 
Experts are used in the technology management field quite often as sources of data for quantitative, qualitative and mixed methods research. Dickinger et al. (2006), in their research on mobile technology adoption, used experts in 1:1 interviews in the exploratory phase of their research, which was followed by focus groups, and then eventually by a questionnaire that was statistically evaluated [305]. Bhatiasevi (2016), in a study that extended UTAUT to the adoption of mobile banking, used experts to verify the research framework prior to conducting a survey [306]. Alateyah et al. (2013) also used experts when they researched the adoption of e-government services in Kuwait using a combination of the Technology Adoption Model, the Diffusion of Innovations Model and UTAUT [307]. Mahdizadeh et al. (2008) studied the factors that influence the use of e-learning environments by university faculty, and used experts to provide feedback on the survey instrument [308].

In this study, experts were engaged in the semi-structured interviews and focus groups to evaluate the preliminary research model as well as in evaluating the validity of the survey instrument. A mix of content experts and lay experts were used. Content experts are professionals or those who have substantive academic experience in the field of student success technology, and lay experts are those "for whom the topic is most salient" - in this case, undergraduate students [309], [310]. 


\subsection{Individual Interviews}

\subsubsection{Defining Individual Interviews}

Individual interviews, like focus groups, provide a helpful way to elicit detailed information. In the case of this study, they were used to elicit information from individuals and hinge on one-to-one interactions between an interviewer and an interviewee [311]. The interviews were used to evaluate the preliminary research model. Both types of interviews - individual interviews and focus groups - are often used in qualitative research [312] and in the process of designing a survey instrument [313], [311] as was the case with this study.

Interviews provide the opportunity to ask concise and unambiguous questions, and also provide the opportunity to probe and elicit clarifying information [304], including discussions that are reflective, organic and which create space for mutual discovery [314]. Additionally, interviews can be conceived of as guided question-answer conversations, but unlike conversations, interviews have "a specific structure and purpose" [314].

Interviews are used in a variety of settings, including in information technology research, such as with empirical software engineering research [312] and in social science investigations where approximately $90 \%$ of such investigations use interviews [314].

Interviews, unlike surveys, for example, are dynamic engagements. Participants have the opportunity to provide full accounts of their perspectives, expertise and opinions, while researchers have the opportunity to understand 
nuances about particular issues or topics that are communicated through both verbal language and nonverbal cues [314]. Interviews can also be helpful for topics that are not easily observed or accessed in an efficient manner [314].

\subsubsection{Advantages and Disadvantages of Individual Interviews}

There are both advantages and disadvantages of individual interviews. The advantages include that they provide space for the interviewer and interviewee to explore new terrain, and to do so somewhat organically, as they engage in a conversational dialogue about the topics at hand [314]. Interviews can also provide the opportunity for people to share more of their experiences and stories, as compared to surveys [313]. With interviews, exploring new terrain and sharing experiences in such a format creates opportunities to dig deeper into a topic and gather richer data [302].

Disadvantages of interviews include that a lack of standardization in the questions can create questions about the reliability of the data, bias (such as interviewer or interviewee bias) can unduly influence data, and due to the relatively small number of interviews that can be accomplished in a research endeavor (given the amount of effort each interview requires), it is important to consider how generalizable the data might be [304]. Finally, given the amount of influence that the interviewer can have on how comfortable the interviewees feel, significant care is required to how interviews are conducted in order to create the right context [312], [315]. 


\subsubsection{Designing Individual Interviews}

Designing individual interviews - while perhaps not as complicated as focus groups because of the fewer number of interviewees that are involved, and not having to facilitate group dynamics - still requires significant planning, preparation and facilitation. Attention to individual interviews is critical to not only "ensure useful data, but also because interviews are intrusive and overtly directed by the researcher" [314]. In interviews in software engineering research, for example, four areas that have been found to be challenging are "estimating the necessary effort, ensuring that the interviewer had the needed skills, ensuring good interaction between interviewer and interviewees, and using the appropriate tools and project artifacts" [312]. Drawing on Hove and Anda (2005) [312] interviews involve several critical steps including: scheduling the interview; collecting any background information that might be helpful; preparing the interview guide/interview process and questions; holding the interview; and documenting results (such as synthesizing the interview and transcription).

\section{Recruiting}

Sampling is an important consideration for interviews, whereby the researcher intentionally chooses respondents who are reflective of the research objectives and questions [314]. One technique that is helpful for difficult-to-access populations is called snowball sampling, whereby "researchers begin by identifying several participants who fit the study's criteria and then ask these people to suggest a colleague, a friend, or a family member [314]. Caution 
must be taken when snowballing is used, as there is a risk of the “overrepresentation of a single, networked group" [313].

When recruiting participants, it is important to frame the interview as something that might be appealing and to tap into someone's expertise [314] and to be flexible with time, location and schedules, as to make it as easy as possible for participation. One modality for individual interviews is technology mediated approaches that enable interviews at a distance, such as telephone interviews, synchronous video conferencing or asynchronous email interviews [314]. Mediated interviews can reach participants who are in wide geographical areas in cost-effective ways, as well as encourage more openness as compared to in person interviews [314]. However, there are some downsides, such as it can be difficult to see or pick up on nonverbal data such as facial expressions and tone of voice, and potential participants might be limited by those who have prerequisite technical expertise [314]. Incentives can also be helpful when recruiting participants, in that they can help increase response rates and are common practice for qualitative research [316].

\section{Interview Structure}

As moderators play critical roles in focus groups, so do interviewers in one-to-one interviews. Tracy (2013) suggests good interviewing traits include knowledge about the topic, being sensitive, open-minded, probing, and attentive, and having the skills to interpret (able to clarify the interviewee's responses) [314]. However, while the interviewer and interviewee are partners in dialogue, 
there is a difference in power, with the interviewer often holding more power, requiring more sensitivity and ethical care, including of the data that stems from an interview [314]. Interviewers, as with focus group moderators, must be able to think quickly and respond to stimuli in a way that moves the conversation forward, and simultaneously, providing space for the interviewee to reflect and clarify [314], [312]. Critical verbal communications from the interviewer include ensuring confidentiality, phrasing questions in a non-threatening manner and not disagreeing with an interviewee [312]. For Saunders, Lewis and Thornhill (2016), critical aspects of semi-structured and in-depth interviews include the nature of comments when opening an interview, the approach to questioning, active listening and summarizing, and testing understanding [304].

The structure of interviews is an important consideration [314], as it is with focus groups. Unstructured interviews are an open-ended approach, where the interviewer provides very little guidance [311]. On the other end of the spectrum, structured interviews are a close-ended approach where the observation instrument consists of "items accompanied by different predesigned or precoded responses" [311] and where numeric data is the result [311]. In between these two poles are semi-structured interviews, where "the researcher has a list of themes and possibly some key questions to be covered, although their use may vary from interview to interview" [304] and where there are a "series of predetermined but open-ended questions" [315]. Participants also have the freedom to introduce new ideas during semi-structured interviews, which is 
perhaps why they are considered one of the most effective approaches for qualitative data collection [317].

Creating an interview guide - a formal list of questions, which can be flexibly used in the course of an interview - is a critical part of preparing for semi-structured interviews [314], which were used in this study. The kinds of questions and the ways in which they are asked can help shape the tenor, tone and information that is shared during an interview. Tracy (2013) provides several helpful tips for the questions themselves, including that they should be simple, facilitate answers that are open and complex and non-leading [314]. Elicitation, whereby materials or objects are used, can be helpful in enabling a rich dialogue [314]. Additionally, directive questions, while they can at times provide too much structure, can also provide a mechanism for interviewees to react to data and research [314] which in this case was the preliminary research model. Asking the interviewees to respond to a research model is an opinions/value question type, which is commonly accepted in semi-structured interviews [312]. Given that interviews can at times veer off course and gather too much information, it is important that care is dedicated to collecting only information that is necessary for the research at hand [302]. Finally, the interview will begin with a short synopsis of the topics to be discussed and also the review and signing of the informed consent (also shared in advance) [318].

Interview logistics are also very important, such as considering an appropriate physical space (not too many distractions and adequate privacy) 
[314], a locale where the interviewee will be comfortable and sharing relevant information ahead of time (e.g. preliminary research model was shared in this case) to help enhance credibility [304].

7.2.4 Semi-Structured Interviews in this Study

Following the best practices and guidelines above, semi-structured individual interviews were used in this study. The main objective of the individual interviews was to elicit opinions and impressions of the preliminary research model [312] in two areas: 1. Introducing new latent constructs/factors and/or indicators; and 2. Identifying the most important latent constructs and indicators.

17 interviews of 60 minutes each were conducted. 11 lay experts (undergraduate students) participated and six content experts (professionals in the higher education or educational technology sectors) participated. The interviews were conducted in-person and over video conference, were recorded, were conducted by the researcher and occurred in February 2020, prior to the State of Oregon's COVID-19 stay-at-home order (which was issued on March 23, 2020) and prior to Portland State University's move to all-remote learning (which started with the Spring 2020 term, beginning on March 30, 2020). The students were recruited through a variety of means at Portland State University: direct email; outreach to Portland State employees who were asked to share the interview opportunity with students; and the interview opportunity was posted on Portland State's jobs/internship board. Each participant was provided with a 
\$25 Amazon.com gift card as an incentive for participation. The students who participated in interviews were diverse, and included: a mix of class levels and majors; students who received financial aid and those who did not; first-generation college students and those who were not; students who lived with a disability and those who did not; and students who identified as White or Hispanic or Latino.

The six content experts, i.e. professionals in the higher education or educational technology sectors, were recruited via email using contacts this researcher developed during his recent career in higher education and student success. No financial incentives were provided to the content experts. The experts included those in leadership positions in higher education institutions and educational technology companies.

Table 12: Summary of Content Experts (Professionals) who Participated in Interviews

\begin{tabular}{|l|l|c|}
\hline $\begin{array}{l}\text { Partici } \\
\text { pant }\end{array}$ & Role Description & $\begin{array}{l}\text { Years of professional } \\
\text { experience in higher } \\
\text { education, educational } \\
\text { technology and/or the } \\
\text { technology innovation } \\
\text { sector(s) }\end{array}$ \\
\hline 1 & $\begin{array}{l}\text { Higher education institution information technology } \\
\text { leader }\end{array}$ & 33 \\
\hline 2 & $\begin{array}{l}\text { Higher education institution information technology } \\
\text { leader }\end{array}$ & 17 \\
\hline 3 & $\begin{array}{l}\text { Higher education institution innovation/academic } \\
\text { affairs leader }\end{array}$ & 20 \\
\hline 4 & Educational technology sector leader & 20 \\
\hline 5 & Product manager in the educational technology sector & 14 \\
\hline 6 & Higher education institution student services leader & 14 \\
\hline
\end{tabular}


The semi-structured interviews focused on two primary questions: Q1 What are your initial impressions of the model [preliminary research model]? and Q2 - To what degree do the factors and/or indicators relate to adoption of myPSU by undergraduate students?. A latent construct, or a factor, is a concept that cannot be directly measured and must be approximately measured by multiple indicators [256], or observed variables, that could be items in a survey [257], as was the case with this research.

The interviewer first welcomed the participants and introduced the interview by summarizing the preliminary research model, discussed the overall research design and the role of the interviews, and reviewed a summary of myPSU (if the participants were not familiar with it). The in-depth discussion part of the interviews first walked the participants through the model in summary and asked participants for their overall impressions of the model. Next, the in-depth discussion turned to a review of the model in detail, which focused on which factors and/or indicators related to myPSU, and if they were important. New indicators were also solicited and notes and comments about factors and indicators were captured. The interviewer used an evaluation sheet to capture participant feedback and any notes. Last, the interview closed by asking if there were any closing reactions or thoughts on the preliminary research model.

The results of the interviews are summarized in section 7.4. Overall, they were incredibly helpful, and affirmed many parts of the preliminary research model, while adding new indicators and an in-depth understanding of whether 
some indicators or factors should be included in the model. As compared to focus groups, given the one-to-one dynamic of individual interviews, the interviews provided the opportunity to dig deeper into particular issues and opinions.

The recruitment and consent materials and the facilitation guide for the individual interviews are provided in Appendix C.

\subsection{Focus Groups}

\subsubsection{Defining Focus Groups}

Focus groups, the second qualitative step in the research approach, are group discussions that focus on a specific topic or situation [319], [320], are sometimes called "group depth interviews" [320] and are a type of semi-structured interview [16]. Focus groups were used in this study to evaluate the preliminary research model. Group interviews were first used in the 1920 s and were originally called "focused interviews" [319]. An important distinction between focus groups and individual interviews is that in focus groups the group is the main focus of the data, rather than individuals [319].

Focus groups tend to be used for exploratory research, as was the case with this study, when little is known about a topic, when one wants to have an in-depth understanding of a topic, when one wants to understand quantitative findings in more depth, for brainstorming or developing new ideas or solutions, for aiding in designing additional research [319], or for developing data to enable the development of theory [321]. Focus groups can be used as a stand-alone research technique, but they are often used as part of mixed method approaches 
in more quantitatively oriented studies, such as in studies that involve surveys [319]. As focus groups tend to be quite helpful for exploratory research, they are often used earlier in research projects to develop research hypotheses that can be tested using quantitative data analysis with larger samples [320], [322], [323]. Focus groups can also be used to help develop and refine quantitative survey research instruments or questionnaires [324], [325]. In postpositivist research, focus groups are used to facilitate interactions between individuals to "articulate pre-held views about a particular issue or topic" [304].

Focus groups are quite versatile and materialize differently across fields [320]. As such, the "underlying conceptual domain of any field influences how its researchers select samples and construct questions" [320]. Focus groups are most commonly thought of in relation to marketing, advertising or consumer research, but they have been used in many other settings [319], [326]. For example, employee focus groups are common, as are political focus groups [319] and in academic research, they are used in the fields of communication studies, education, political science, public health, business, sociology, aging and criminology [326]. Focus groups have been used in technology adoption research, for example to study consumer adoption of mobile multimedia services [327], website adoption to identify the key adoption factors for tourism websites [328], for consumer adoption of mobile payments [329], for adoption of government e-services [191], and for the adoption of smartphones in emerging regions [226]. 
Relatedly, focus groups have been used to understand higher education students' impressions of service quality as part of a mixed methods research design [323].

\subsubsection{Advantages and Disadvantages of Focus Groups}

As with any research method, including focus groups, there are both advantages and disadvantages. The advantages of focus groups include that they create opportunities for a group to interactively exchange ideas, with less influence from the researcher [319] and where participants both query each other and explain themselves to each other [326]. The group dynamics can also spark new ideas, yielding more fruitful information based on their collective nature, as compared to individual interviews [326], [320]. Focus groups are less costly than individual interviews - the direct interaction with participants allows for clarification of responses. Another advantage is that the flexibility of focus groups, in terms of the research questions that can be explored, enables them to be used in a variety of settings [320].

Disadvantages of focus groups include that the opinions of participants are likely influenced by others in the group [319]. Power dynamics can create focus groups where participants' ideas are not equally shared and where some participants might fabricate stories [319]. At times, there can be miscommunication between participants and the moderator [319], the results are not generalizable to a larger population, results can be biased by very opinionated participants, and moderator bias can cue participants about which answers are 'desirable' [320]. However, "the issue of interviewer effects is hardly limited to 
focus groups" [326]. Despite these and other disadvantages, focus groups are highly regarded as a robust research method, in part due to the situation that "all research tools in the social sciences have significant limitations" [320].

\subsubsection{Designing Focus Groups}

There are eight steps in the process of designing a focus group. Drawing on Davis (2017) these steps are to: 1 . Determine research questions and objectives for the study; 2. Define the population; 3. Determine the sample; 4 . Decide on the sample size, i.e. number of focus groups and number of participants in each group; 5 . Decide how to recruit participants; 6 . Consider any ethical factors, such as related to human subjects protections; 7. Decide on the focus group logistics (venue, time of day, etc.); and 8. Create the facilitation guide, which embodies what the focus group will discuss [319]. In business research, which has similar goals to that of the technology management field, focus groups can include collecting data based on experts' and managers' perspectives [330].

\section{Group Size}

Group size is a key consideration for designing focus groups. Typically, focus groups involve approximately six to eight participants [331], [314], [322], although the sizes can vary between 6 to 12 participants [320]. The decision on the optimal size hinges on whether breadth or depth is required. Larger groups are better for breadth, and smaller groups are best suited for depth [331]. There are particular risks with larger groups: they can be difficult to moderate; outgoing members of the group might dominate the discussion; and participants might be 
frustrated if they do not have the opportunity to share their views [322]. Because of the tendency for not all invitees to attend focus groups, a common practice is to over recruit for participants, while balancing goals to not have groups that are too large [322]. In order to honor the contributions of focus group members, incentives are often used, which also is a "symbol of the researchers' respect for the participation of these people" [332].

\section{Group Composition}

Group composition is also an important consideration when designing focus groups. A case can be made for groups that consist of strangers, as well as a case for pre-existing groups. Pre-existing groups can consist of individuals who are acquaintances (such as in work settings), family groups, social groups, support groups or friendship groups [322]. Advantages of pre-existing groups include that recruiting can involve much less effort, as often a researcher can coordinate with just one person from the group, and it is possible that pre-existing groups have lower attrition rates [322]. Groups of strangers, which are often favored by market research, can benefit from participants feeling more comfortable with speaking openly and freely without fear of repercussions, and also create the context where group members feel comfortable with challenging each other [322].

Venue

An additional consideration for focus group design includes the choice of venue. A more accessible venue could make it easier for participants to attend, 
and if a focus group is held in a location where it is more comfortable for one person in the group, such as in someone's home, the host might display more of these traits in the dialogue, perhaps tainting the results [322].

\section{Ethics}

Another consideration is ethics, which refers to the "prevention of harm or distress to the study participants, ensuring that the study's benefits outweigh any risks to the research, ensuring that no participants are coerced or unduly influenced, and obtaining appropriate consent from the participants" [319]. Informed consent disclosures can support participants in understanding these topics [319].

\section{Structure of Focus Groups}

A critical component of focus group design is considering how structured or unstructured the focus group will be. The decision about degree of structure stems from the study objectives or research questions [319], [322], the specificity of the information required and how the information will be used [320]. Some posit that as a general rule, if the objective of the focus group is to generate raw materials for a quantitative study (e.g. accumulating vocabulary for designing a survey instrument), then more open-ended questions might be the most appropriate. However, if the need for the focus group is to provide context and perspective on a particular part of a topic, the nature of the questions will be more structured [319], [322]. "More structured approaches to focus groups are 
especially useful when there is a strong, preexisting agenda for the research" [333].

The degree of structure influences the critical role of the moderator, as the quality of the focus group relies heavily on the skills of the moderator [319], [320], [326], [322]. The moderator stimulates discussion and balances how directive/non-directive the conversation will be based on the needs for structure [331]. The moderator must avoid controlling the group too much, while at the same creating space for all attendees to equally contribute [322]. Too much control can stymie the group, while too little control creates a risk that the session will not be focused [319]. Skills like listening, clarifying and interpreting are important for interviewers and moderators [314], and the moderator works to create a comfort zone so that participants are comfortable with sharing their ideas and opinions [320].

A facilitation or moderator guide - which provides an outline of the questions to be explored - is a crucial tool for guiding a focus group [319]. Focus groups have four general stages, which can be reflected in the guide: introduction; rapport building; in-depth discussion; and closure [319]. The ordering and design of questions and exercises is important [324], and there are a variety of exercises moderators can use to guide focus groups and elicit data that matches the research questions, such as card sorts, where participants sort cards (such as a list of product characteristics) into categories and then discuss 
the categorizations [319], or in commercial research, where flipcharts are used to visually convey participant ideas and/or themes from the group as a whole [322].

Capturing data from the focus groups is also crucial. Researchers are advised to take notes during the session when feasible and critically to take notes immediately following a focus group to capture salient observations [324]. While some argue that transcription is also important, as it minimizes the risk of selective and superficial analysis and aids with indexing the results [322], some argue that there are occasions when transcripts are not necessary, such as when the conclusions of the research are rather straightforward [334].

\subsubsection{Focus Groups in this Study}

Following the best practices and guidelines above, focus groups were used in this study. Two focus groups of 90 minutes each were conducted, totaling 16 participants: One focus group consisted of nine lay experts (students); and one focus group consisted of seven content experts (professionals from Portland State University). The focus groups were conducted in person on the Portland State University campus, were recorded, were moderated by the researcher and occurred in February and early March 2020, prior to the State of Oregon's COVID-19 stay-at-home order (which was issued on March 23, 2020) and prior to Portland State University's move to all-remote learning (which started with the Spring 2020 term, beginning on March 30, 2020).

The nine student participants were recruited through a variety of means at Portland State University: direct email; outreach to Portland State employees 
who were asked to share the opportunity with students; and the focus group opportunity was posted on Portland State's jobs/internship board. The diverse recruitment methods and the method of selecting students helped insure diverse perspectives and helped minimize the chances that the focus group participants were familiar with each other. Each student participant was provided with a $\$ 40$ Amazon.com gift card as an incentive for participation. The students who participated in interviews were diverse, and included: a mix of class levels and majors; students who received financial aid and those who did not; first-generation college students and those who were not; students who lived with a disability and those who did not; and students who identified as White, Asian, Middle Eastern or North African, and multi-racial.

The seven content experts were Portland State University staff members whom the researcher recruited via email using contacts this researcher developed during his recent career in higher education and student success. No financial incentives were provided to the content experts. The experts included those in staff and leadership positions at Portland State University across information technology, student services and academic advising.

Table 13: Summary of Content Experts (Professionals) who Participated in a Focus Group

\begin{tabular}{|l|l|l|}
\hline Participant & Role Description & $\begin{array}{l}\text { Years of professional } \\
\text { experience in higher } \\
\text { education, educational } \\
\text { technology and/or the } \\
\text { technology innovation } \\
\text { sector(s) }\end{array}$ \\
\hline 1 & $\begin{array}{l}\text { Portland State University information } \\
\text { technology leader }\end{array}$ & 20 \\
\hline
\end{tabular}




\begin{tabular}{|c|c|c|}
\hline 2 & $\begin{array}{l}\text { Portland State University information } \\
\text { technology leader }\end{array}$ & 24 \\
\hline 3 & $\begin{array}{l}\text { Portland State University student services } \\
\text { staff member }\end{array}$ & 19 \\
\hline 4 & $\begin{array}{l}\text { Portland State University student services } \\
\text { staff member }\end{array}$ & 22 \\
\hline 5 & $\begin{array}{l}\text { Portland State University academic advising } \\
\text { leader }\end{array}$ & 23 \\
\hline 6 & $\begin{array}{l}\text { Portland State University academic advising } \\
\text { leader }\end{array}$ & 25 \\
\hline 7 & $\begin{array}{l}\text { Portland State University student services } \\
\text { staff member }\end{array}$ & 18 \\
\hline
\end{tabular}

The focus groups utilized two primary questions: Q1. In reference to the preliminary research model information: What are your impressions of the model? What factors and/or indicators do you believe should be removed? What factors and/or indicators do you believe should be added? and Q2. What factors and/or indicators are most important to undergraduate students' adoption of myPSU? The moderator first welcomed the participants, facilitated introductions and introduced the focus group by summarizing the preliminary research model, discussing the overall research design and how the focus groups fit in.

The in-depth discussion section of the focus groups entailed two parts. First, the participants worked individually, using the evaluation sheet, to evaluate the preliminary research model on whether each indicator was related to myPSU adoption and whether it was one of the more important indicators for myPSU adoption. Additionally, the participants provided any notes or comments, and ideas for new indicators. Each person then added the information from their 
evaluation sheet to a physical representation of the preliminary research model posted on the wall by adding red stickers if indicator or factor did not relate to myPSU adoption and by adding green stickers if indicator or factor was the most important to myPSU adoption. This visual display enabled participants and the moderator to have a visual heat map of perspectives on the preliminary research model. During the second part of the in-depth discussion, the moderator reviewed the visual of the taxonomy and solicited feedback from the focus group participants, which created a group discussion about the factors and indicators. Last, the focus group closed by asking if there were any closing reactions or thoughts on the preliminary research model.

The results of the focus groups are summarized in section 7.4, and no new indicators or factors were identified in the focus groups. The focus groups built on the interviews by helping the researcher develop a more nuanced understanding of where there was consensus and where there were differences with respect to the factors and indicators in the preliminary research model. The recruitment and consent materials and the facilitation guide for the focus groups are provided in Appendix D.

\subsection{Qualitative Results}

As a result of the interviews (17 participants) and focus groups (16 participants), the preliminary research model was evaluated. The interview participants also provided five new indicators: personalize, awareness, tutorial or training, simplified version of the university (one-stop shop) and mobile app. The 
evaluation sheet results from the qualitative methods were added to a detailed synthesis sheet (summary below) and the comments from the interviews and focus groups were reviewed and synthesized into themes and critical ideas that were used to inform the development of the research model. Comments included:

- "It's [myPSU] a great support system for students"

- "If it's [myPSU] fast, I'll rely on it more, makes it useful to me."

- "People expect things to work quickly"

- "If it's [myPSU] is easy to use, I'll use it more"

- "Having an app on the phone makes myPSU easy to access"

Examples of the researcher's synthesis of the comments are included below.

Table 14: Examples of Synthesis Comments from the Qualitative Methods

\begin{tabular}{|l|l|}
\hline Indicator & Example Synthesis Comment \\
\hline $\begin{array}{l}\text { Increase chances of } \\
\text { graduating }\end{array}$ & $\begin{array}{l}\text { Nearly all comments questioned why this is in the model - } \\
\text { graduation does not seem to apply to software generally, } \\
\text { particularly one like myPSU. }\end{array}$ \\
\hline Speed of conducting tasks & Speed is important, especially for busy students. \\
\hline Effort vs. benefit & $\begin{array}{l}\text { Mixed views - some said that they will not take the effort to work } \\
\text { with a difficult system, even if it provides benefits, while others } \\
\text { said that they are willing to work with a difficult system if the } \\
\text { benefits are great enough. }\end{array}$ \\
\hline Learning to operate & $\begin{array}{l}\text { Learning to operate and skillful at using seem very similar - } \\
\text { learning to operate seems to have more resonance, as learning } \\
\text { how to use myPSU at the beginning seems more important than } \\
\text { becoming skillful, since the technology is not that complicated to } \\
\text { use. }\end{array}$ \\
\hline Perceived popularity & $\begin{array}{l}\text { Seems to be that for most students, perceived popularity does not } \\
\text { apply to a platform like this in a university setting and experts } \\
\text { seem to be uncertain about the value of this indicator. }\end{array}$ \\
\hline Individual needs & $\begin{array}{l}\text { Some confusion about what “individual needs" means but once } \\
\text { explained, it makes sense - need to define better, such as } ~ \\
\text { software has the key functionality that a user needs" - this } \\
\text { definition made sense to students. }\end{array}$ \\
\hline
\end{tabular}


The evaluation data from the interviews and focus groups generally shows widespread agreement on which indicators are related to myPSU adoption. All but one indicator (Increase chances of graduating) had $50 \%$ or more of the participants in agreement that the indicator was related to myPSU adoption and only four of the 37 indicators, or $11 \%$, had $75 \%$ or less agreement about whether the indicator was related to myPSU. There was generally less agreement in terms of whether an indicator was considered the most important for myPSU adoption. Only 11 of the 37 indicators, or $30 \%$, were indicated as the most important by $50 \%$ or more of the participants. The evaluation data from the interviews and focus groups is provided below.

Table 15: Evaluation Data from Interviews and Focus Groups

\begin{tabular}{|c|c|c|c|c|}
\hline Factors and Indicators & \begin{tabular}{|l} 
Total \\
Who \\
Indicated \\
Related to \\
myPSU \\
Adoption
\end{tabular} & $\begin{array}{l}\text { \% Who } \\
\text { Indicated } \\
\text { Related to } \\
\text { myPSU } \\
\text { Adoption }\end{array}$ & $\begin{array}{l}\text { Total Who } \\
\text { Indicated } \\
\text { Most } \\
\text { Important } \\
\text { for myPSU } \\
\text { Adoption }\end{array}$ & $\begin{array}{l}\text { \% Who } \\
\text { Indicated } \\
\text { Most } \\
\text { Important } \\
\text { for myPSU } \\
\text { Adoption }\end{array}$ \\
\hline \multicolumn{5}{|c|}{ Performance expectancy factor } \\
\hline Overall usefulness & 33 & $100 \%$ & 31 & $94 \%$ \\
\hline Increase chances of graduating & 11 & $33 \%$ & 1 & $3 \%$ \\
\hline Speed of conducting tasks & 30 & $91 \%$ & 17 & $52 \%$ \\
\hline Platform response time & 30 & $91 \%$ & 18 & $55 \%$ \\
\hline \multicolumn{5}{|l|}{ Effort expectancy factor } \\
\hline Perceived ease of use & 32 & $97 \%$ & 27 & $82 \%$ \\
\hline Effort vs. benefit & 32 & $97 \%$ & 20 & $61 \%$ \\
\hline Learning to operate & 25 & $78 \%$ & 9 & $28 \%$ \\
\hline Skillful at using & 22 & $67 \%$ & 6 & $18 \%$ \\
\hline System accessibility & 30 & $91 \%$ & 20 & $61 \%$ \\
\hline \multicolumn{5}{|l|}{ Social influence factor } \\
\hline Organizational support & 33 & $100 \%$ & 27 & $82 \%$ \\
\hline
\end{tabular}




\begin{tabular}{|l|c|c|c|c|}
\hline Peer influence & 21 & $64 \%$ & 10 & $30 \%$ \\
\hline Perceived popularity & 19 & $58 \%$ & 6 & $18 \%$ \\
\hline Influence from university employees & 26 & $79 \%$ & 12 & $36 \%$ \\
\hline
\end{tabular}

\section{Perceived usefulness factor}

\begin{tabular}{|l|c|c|c|c|}
\hline Access to university resources & 32 & $97 \%$ & 20 & $61 \%$ \\
\hline Access to university services & 32 & $97 \%$ & 15 & $45 \%$ \\
\hline Access to conduct business & 33 & $100 \%$ & 25 & $76 \%$ \\
\hline Individual needs & 25 & $76 \%$ & 12 & $36 \%$ \\
\hline Perceived mobile value & 28 & $85 \%$ & 17 & $52 \%$ \\
\hline
\end{tabular}

\section{Perceived quality factor}

\begin{tabular}{|l|l|l|l|l|}
\hline Content quality & 31 & $94 \%$ & 22 & $67 \%$ \\
\hline User interface design & 30 & $94 \%$ & 26 & $81 \%$ \\
\hline System errors & 32 & $97 \%$ & 22 & $67 \%$ \\
\hline
\end{tabular}

\section{Self-efficacy and skills factor}

\begin{tabular}{|l|c|c|c|c|}
\hline Confidence & 26 & $79 \%$ & 16 & $48 \%$ \\
\hline Internet skills & 25 & $76 \%$ & 10 & $30 \%$ \\
\hline Basic computing skills & 26 & $79 \%$ & 15 & $45 \%$ \\
\hline Basic smartphone skills & 30 & $91 \%$ & 12 & $36 \%$ \\
\hline
\end{tabular}

\section{Behavioral intention factor}

\begin{tabular}{|l|l|l|l|l|}
\hline Intention to use - general & 30 & $91 \%$ & 15 & $45 \%$ \\
\hline Intention to use - specific & 29 & $88 \%$ & 12 & $36 \%$ \\
\hline Frequency of use & 31 & $94 \%$ & 20 & $61 \%$ \\
\hline
\end{tabular}

\section{Facilitating conditions factor}

\begin{tabular}{|l|l|l|l|l|}
\hline Knowledge & 24 & $75 \%$ & 15 & $47 \%$ \\
\hline Compatibility & 30 & $91 \%$ & 23 & $70 \%$ \\
\hline Technical support & 25 & $76 \%$ & 14 & $42 \%$ \\
\hline
\end{tabular}

\section{Use behavior factor}

\begin{tabular}{|l|c|c|c|c|}
\hline $\begin{array}{l}\text { Usage of the software platform - } \\
\text { general. }\end{array}$ & 29 & $88 \%$ & 9 & $27 \%$ \\
\hline $\begin{array}{l}\text { Usage of the software platform - } \\
\text { specific }\end{array}$ & 28 & $85 \%$ & 5 & $15 \%$ \\
\hline Frequency of use & 27 & $82 \%$ & 12 & $36 \%$ \\
\hline $\begin{array}{l}\text { Usage of the software platform to } \\
\text { access university resources }\end{array}$ & 30 & $91 \%$ & 18 & $55 \%$ \\
\hline
\end{tabular}




\begin{tabular}{|l|c|c|c|c|}
\hline $\begin{array}{l}\text { Usage of the software platform to } \\
\text { access university services }\end{array}$ & 29 & $88 \%$ & 16 & $48 \%$ \\
\hline $\begin{array}{l}\text { Usage of the software platform to } \\
\text { conduct the business of being a } \\
\text { student }\end{array}$ & 31 & $94 \%$ & 22 & $67 \%$ \\
\hline New indicators & - & - & - & - \\
\hline Personalize & - & - & - & - \\
\hline Awareness & - & - & - & - \\
\hline Tutorial or Training & - & - & - & - \\
\hline $\begin{array}{l}\text { Simplified version of the university - } \\
\text { one-stop shop }\end{array}$ & - & - & - & - \\
\hline Mobile app &
\end{tabular}

\subsection{Research Model and Hypotheses}

\subsubsection{Research Model Development}

After the semi-structured interviews and focus groups, the data from these methods was synthesized and evaluated, resulting in a research model with hypotheses, to be used for data collection (i.e. the survey). The overall goal in developing the research model was to balance these considerations:

- Incorporating the feedback from the qualitative participants.

- Maintaining a research model that extended UTAUT, while keeping enough of the UTAUT model intact so that key UTAUT constructs remained in the model (i.e. a model that was grounded in theory).

- Using guidelines for building a model that could be evaluated using SEM (same guidelines as were used for developing the preliminary research model). 
- Relying on the researcher's expert judgement to resolve any competing interests or ideas that emerged.

The development of the research model included the following steps to analyze and filter the interview and focus group feedback. First, the results were aggregated from across the focus groups and interviews. Second, given there was generally widespread agreement on whether the indicators were related to myPSU adoption, indicators were dropped where fewer than two-thirds of the participants thought that an indicator was related to myPSU adoption. The following indicators were dropped: Increase chances of graduating, Skillful at using and Perceived popularity. Third, of the remaining indicators, indicators where less than $50 \%$ of the participants indicated the indicator was one of the most important for adoption were considered for deletion. The fourth step in the filtering process was to determine which factors/latent constructs were still necessary for the model, and then reorganize the indicator variables accordingly. In doing so, the guidelines for SEM model building discussed above in reference to the development of the preliminary research model were utilized. A table describing the decisions with respect to each indicator in the preliminary research model is below.

Table 16: Summary of Decisions with Respect to the Preliminary Research Model as a Result of Qualitative Methods

\begin{tabular}{|l|l|}
\hline Factors and indicators & Final decisions and justifications \\
\hline Performance expectancy factor & $\begin{array}{l}\text { Kept - moved to Perceived usefulness construct, as } \\
\text { this was more closely aligned with UTAUT. }\end{array}$ \\
\hline Overall usefulness
\end{tabular}




\begin{tabular}{|l|l|}
\hline Increase chances of graduating & $\begin{array}{l}\text { Dropped - did not meet the threshold of more than } \\
50 \% \text { who thought it was among the most important } \\
\text { indicators that influence adoption of myPSU. }\end{array}$ \\
\hline Speed of conducting tasks & Kept \\
\hline Platform response time & Kept - moved to Perceived quality construct. \\
\hline
\end{tabular}

\section{Effort expectancy factor}

\begin{tabular}{|l|l|}
\hline Perceived ease of use & Kept \\
\hline Effort vs. benefit & Kept \\
\hline Learning to operate & $\begin{array}{l}\text { Kept - while it was below the two-thirds threshold } \\
\text { for whether participants thought it was related to } \\
\text { myPSU adoption, as many commented about the } \\
\text { similarities between Skillful at using and Learning } \\
\text { to operate. If they would have been evaluated as } \\
\text { one idea, it might have had a higher importance. }\end{array}$ \\
\hline Skillful at using & $\begin{array}{l}\text { Dopped - did not meet the threshold of more than } \\
50 \% \text { who thought it was among the most important } \\
\text { indicators that influence adoption of myPSU. }\end{array}$ \\
\hline System accessibility & $\begin{array}{l}\text { Kept - but based on feedback, modified definition } \\
\text { to relate to being able to easily navigate to and find } \\
\text { the myPSU website. }\end{array}$ \\
\hline
\end{tabular}

Social influence factor

\begin{tabular}{|l|l|}
\hline Organizational support & $\begin{array}{l}\text { Dropped - Organizational support and Influence } \\
\text { from university employees are related; retained } \\
\text { Influence from university employees. }\end{array}$ \\
\hline Peer influence & $\begin{array}{l}\text { Kept - while only 64\% of participants thought that } \\
\text { Peer influence was related to the adoption of } \\
\text { myPSU, it was kept in the model as many in the } \\
\text { interviews and the focus groups articulated that it } \\
\text { was important. }\end{array}$ \\
\hline Perceived popularity & $\begin{array}{l}\text { Dropped - did not meet the threshold of more than } \\
\text { 5o\% who thought it was among the most important } \\
\text { indicators that influence adoption of myPSU. }\end{array}$ \\
\hline Influence from university employees & Kept \\
\hline Perceived usefulness factor & $\begin{array}{l}\text { Dropped as a construct - not enough indicators } \\
\text { remained; moved indicators that had been in this } \\
\text { construct to Performance expectancy, which } \\
\text { provided stronger alignment with UTAUT. }\end{array}$ \\
\hline Access to university resources & $\begin{array}{l}\text { Kept - many thought that both Access to university } \\
\text { resources and Access to university services were } \\
\text { very similar, so combined them into one indicator- }\end{array}$ \\
\hline
\end{tabular}




\begin{tabular}{|c|c|}
\hline & $\begin{array}{l}\text { Access to university services and resources - and } \\
\text { moved this to the Performance expectancy } \\
\text { construct. }\end{array}$ \\
\hline Access to university services & $\begin{array}{l}\text { Dropped as its own indicator - combined Access to } \\
\text { university resources and Access to university } \\
\text { services, as many thought they were very similar. }\end{array}$ \\
\hline Access to conduct business & $\begin{array}{l}\text { Kept - moved to the Performance expectancy } \\
\text { construct. }\end{array}$ \\
\hline Individual needs & $\begin{array}{l}\text { Dropped - when considering the confusion about } \\
\text { the term "individual needs" and its derivative } \\
\text { definition related to Interactivity and control - the } \\
\text { degree of control a user has when interacting with a } \\
\text { system in order to customize how it is used [279] - } \\
\text { it did not seem to fit, as myPSU cannot be } \\
\text { customized. }\end{array}$ \\
\hline Perceived mobile value & Kept - moved to Performance expectancy construct. \\
\hline \multicolumn{2}{|l|}{ Perceived quality factor } \\
\hline Content quality & Kept \\
\hline User interface design & Kept \\
\hline System errors & Kept \\
\hline \multicolumn{2}{|c|}{ Self-efficacy and skills factor } \\
\hline Confidence & $\begin{array}{l}\text { Kept - while less than } 50 \% \text { thought it was among } \\
\text { the most important indicators that influence } \\
\text { adoption of myPSU, it could be important for } \\
\text { subpopulations of students, which was particularly } \\
\text { germane for this context. }\end{array}$ \\
\hline Internet skills & $\begin{array}{l}\text { Dropped - and combined into Basic computer } \\
\text { skills. }\end{array}$ \\
\hline Basic computing skills & $\begin{array}{l}\text { Kept - while less than } 50 \% \text { thought it was among } \\
\text { the most important indicators that influence } \\
\text { adoption of myPSU, it could be important for } \\
\text { subpopulations of students, which was particularly } \\
\text { germane for this context. }\end{array}$ \\
\hline Basic smartphone skills & $\begin{array}{l}\text { Kept - while less than } 50 \% \text { thought it was among } \\
\text { the most important indicators that influence } \\
\text { adoption of myPSU, it could be important for } \\
\text { subpopulations of students, which was particularly } \\
\text { germane for this context. }\end{array}$ \\
\hline \multicolumn{2}{|l|}{ Behavioral intention factor } \\
\hline Intention to use - general & Kept \\
\hline
\end{tabular}




\begin{tabular}{|c|c|}
\hline Intention to use - specific & $\begin{array}{l}\text { Dropped - the idea of gauging more specifically } \\
\text { how users intend to use the platform is reflected in } \\
\text { the addition of more gradations of intention to use } \\
\text { in the Behavioral intention construct, as a } \\
\text { reflection of user personas and their corresponding } \\
\text { usage patterns. }\end{array}$ \\
\hline Frequency of use & $\begin{array}{l}\text { Kept - but used the following to generate individual } \\
\text { indicators to gauge different kinds of behavioral } \\
\text { intention, based on student personas and usage } \\
\text { patterns: Several times a day; Several times a week; } \\
\text { Several times a term; and In the next term. }\end{array}$ \\
\hline \multicolumn{2}{|l|}{ Facilitating conditions factor } \\
\hline Knowledge & $\begin{array}{l}\text { Dropped - did not meet the threshold of more than } \\
50 \% \text { who thought it was among the most important } \\
\text { indicators that influence adoption of myPSU; and } \\
\text { was very similar to items in the self-efficacy bucket. }\end{array}$ \\
\hline Compatibility & $\begin{array}{l}\text { Kept - changed to Seamless experience, as this } \\
\text { language was likely to be more understandable by } \\
\text { students. }\end{array}$ \\
\hline Technical support & $\begin{array}{l}\text { Kept - while only } 42 \% \text { thought it was among the } \\
\text { most important indicators that influence adoption } \\
\text { of myPSU, it is theoretically important for UTAUT. }\end{array}$ \\
\hline \multicolumn{2}{|l|}{ Use behavior factor } \\
\hline Usage of the software platform - general. & Kept \\
\hline Usage of the software platform - specific & $\begin{array}{l}\text { Dropped - idea of gauging more specifically how } \\
\text { users actually use the platform is reflected in the } \\
\text { addition of more gradations of intention to use, as a } \\
\text { reflection of user personas and their corresponding } \\
\text { usage patterns. }\end{array}$ \\
\hline Frequency of use & Kept \\
\hline $\begin{array}{l}\text { Usage of the software platform to access } \\
\text { university resources }\end{array}$ & $\begin{array}{l}\text { Dropped - combined with Usage of the platform to } \\
\text { access university services to create Usage of the } \\
\text { platform to access university services and } \\
\text { resources. }\end{array}$ \\
\hline $\begin{array}{l}\text { Usage of the software platform to access } \\
\text { university services }\end{array}$ & $\begin{array}{l}\text { Dropped - combined with Usage of the platform to } \\
\text { access university resources to create Usage of the } \\
\text { platform to access university services and } \\
\text { resources. }\end{array}$ \\
\hline $\begin{array}{l}\text { Usage of the software platform to conduct } \\
\text { the business of being a student }\end{array}$ & Kept \\
\hline \multicolumn{2}{|l|}{ Possible new factors and indicators } \\
\hline
\end{tabular}




\begin{tabular}{|l|l|}
\hline Personalize & Dropped - myPSU cannot be personalized. \\
\hline Awareness & $\begin{array}{l}\text { Added - added this as a new indicator under the } \\
\text { Social influence factor. }\end{array}$ \\
\hline Tutorial or Training & $\begin{array}{l}\text { Added - added training as an indicator under the } \\
\text { Facilitating conditions construct. }\end{array}$ \\
\hline $\begin{array}{l}\text { Simplified version of the university - } \\
\text { one-stop platform }\end{array}$ & $\begin{array}{l}\text { Added - added as an indicator under the } \\
\text { Performance expectancy construct, as well as in the } \\
\text { Use behavior construct, about myPSU being a } \\
\text { one-stop shop, representing a simplified version of } \\
\text { the university. }\end{array}$ \\
\hline Mobile app & $\begin{array}{l}\text { Added - added under Effort expectancy construct - } \\
\text { having myPSU as a mobile app influences } \\
\text { adoption. }\end{array}$ \\
\hline
\end{tabular}

\subsubsection{Research Model and Hypotheses}

The research model was developed by synthesizing the qualitative feedback as described above. The results of the qualitative analysis are that following SEM guidelines, of the eight latent constructs, all have at least three indicators, and seven have five or fewer indicators (one has six indicators). Additionally: six UTAUT latent constructs were maintained, to help ground the model in theory - Performance expectancy, Effort expectancy, Social influence, Facilitating conditions, Behavioral intention to use, and Use behavior - and all of which are shaped by the specific indicators to this unique context; and two new latent constructs were added - Perceived quality and Self-efficacy and skills. The research model, representing these constructs and the changes from the qualitative methods, is presented below, along with a detailed taxonomy of the research model in Appendix E. 


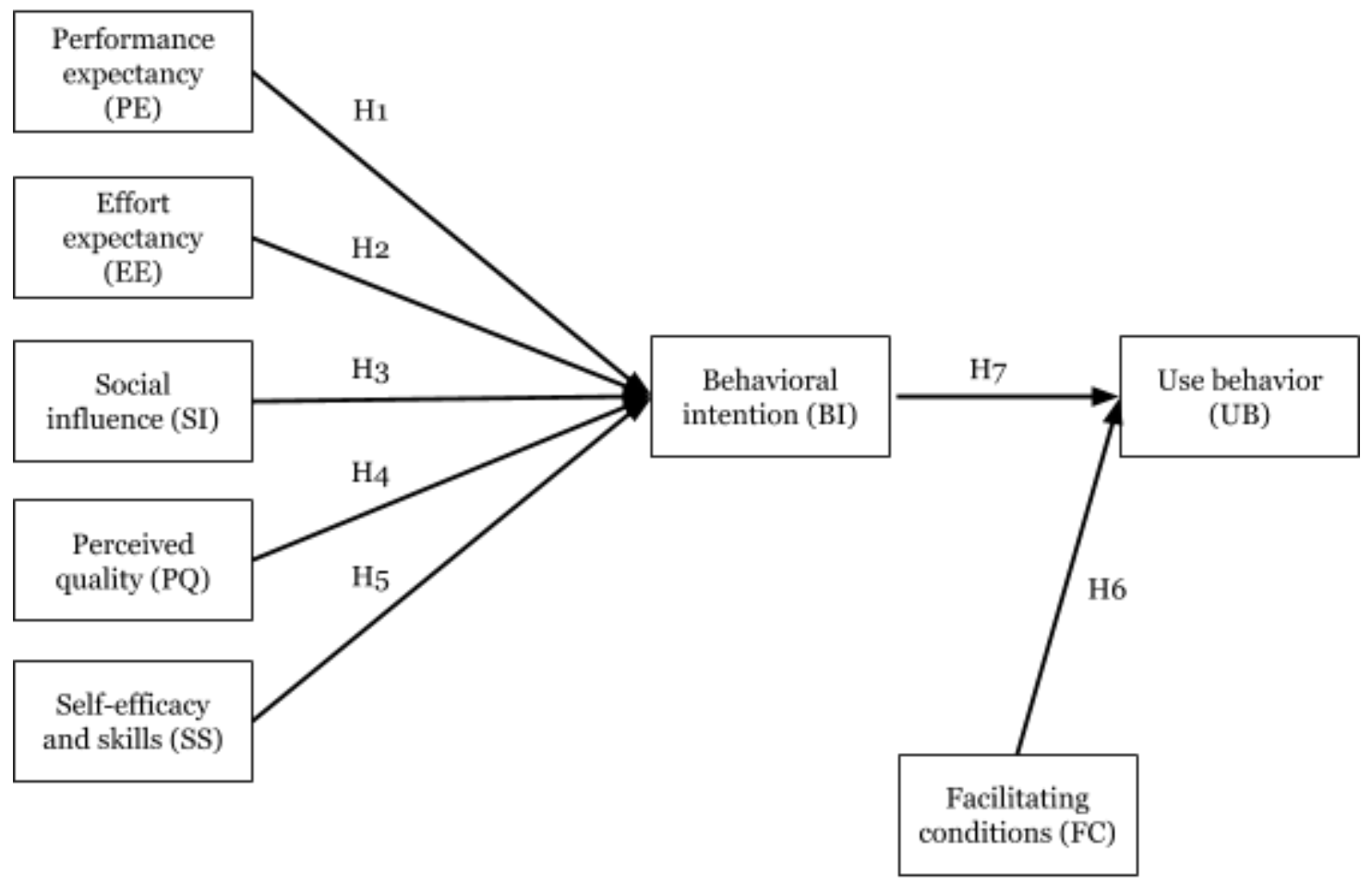

Figure 13: Visual Diagram of Research Model with Hypotheses 


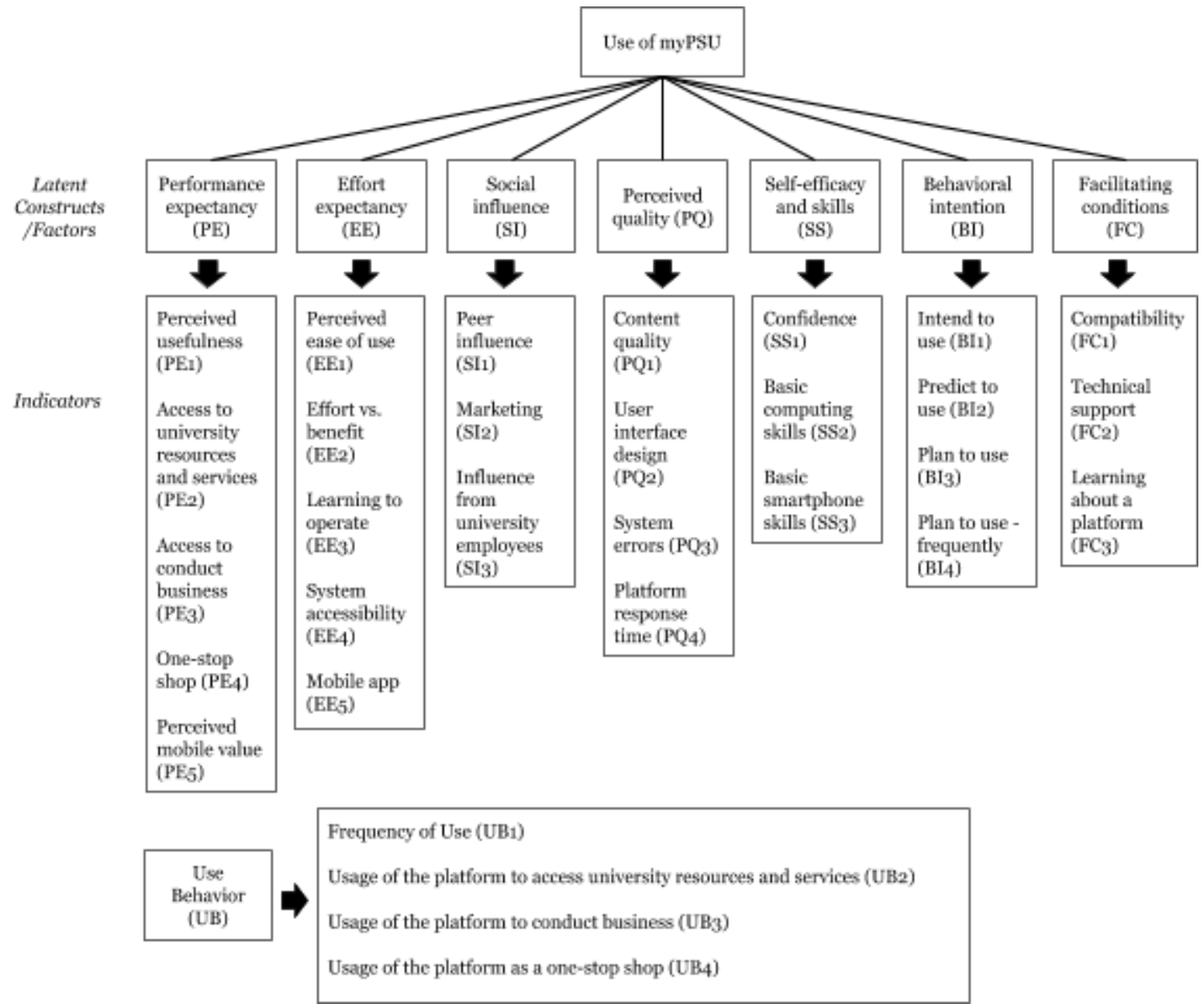

Figure 14: Research Model Factors and Indicators, Organized as a Taxonomy

Table 17: Research Model Taxonomy (Summary)

\begin{tabular}{|l|l|l|l|}
\hline $\begin{array}{l}\text { Factors and } \\
\text { indicators }\end{array}$ & Definition & $\begin{array}{l}\text { Reference } \\
\text { (s) for } \\
\text { definition( } \\
\text { s) }\end{array}$ & $\begin{array}{l}\text { Reference(s) } \\
\text { for studies } \\
\text { indicating an } \\
\text { influence on } \\
\text { other factors }\end{array}$ \\
\hline UTAUT Factors & \multicolumn{2}{|l|}{} \\
\hline $\begin{array}{l}\text { Performance } \\
\text { expectancy }\end{array}$ & $\begin{array}{l}\text { The degree to which an individual } \\
\text { believes that using a technology will } \\
\text { help them overall. }\end{array}$ & $\begin{array}{l}{[263],} \\
{[199]}\end{array}$ & $\begin{array}{l}{[263],[264],} \\
{[253],[265],} \\
{[266],[267],} \\
{[247],[252],} \\
{[268]}\end{array}$ \\
\hline $\begin{array}{l}\text { Effort } \\
\text { expectancy }\end{array}$ & $\begin{array}{l}{[253],[265],} \\
{[266],[247],} \\
{[254],[252],} \\
{[268]}\end{array}$ \\
\hline
\end{tabular}




\begin{tabular}{|c|c|c|c|}
\hline Social influence & $\begin{array}{l}\text { "Extent to which users perceive that } \\
\text { those important to them believe they } \\
\text { should be using a technology" [263] }\end{array}$ & [263] & $\begin{array}{l}\text { Social influence - } \\
\text { [264], [253], } \\
{[265],[266],} \\
{[267],[247],} \\
{[254],[252],} \\
{[224],[268],} \\
{[269] ; \text { Subjective }} \\
\text { norm - [270], } \\
\text { [233], [271], } \\
{[242],[112],} \\
{[272],[273],} \\
{[274]}\end{array}$ \\
\hline $\begin{array}{l}\text { Facilitating } \\
\text { conditions }\end{array}$ & $\begin{array}{l}\text { "The degree to which an individual } \\
\text { believes that an organizational and } \\
\text { technical infrastructure exists to } \\
\text { support the use of the system" [199] }\end{array}$ & [199] & $\begin{array}{l}263],[275], \\
{[266],[267],} \\
{[247],[268],} \\
{[276],[269]}\end{array}$ \\
\hline $\begin{array}{l}\text { Behavioral } \\
\text { intention to use }\end{array}$ & $\begin{array}{l}\text { "The decision maker's disposition } \\
\text { toward using a system" [271] }\end{array}$ & [271] & $\begin{array}{l}{[277],[270],} \\
{[241],[271],} \\
{[244],[264],} \\
{[278],[247],} \\
{[279]}\end{array}$ \\
\hline Use behavior & Actual usage of the system. & [199] & - \\
\hline \multicolumn{4}{|c|}{ Factors added to UTAUT } \\
\hline $\begin{array}{l}\text { Perceived } \\
\text { quality }\end{array}$ & $\begin{array}{l}\text { The user's opinion of the quality of a } \\
\text { software platform. }\end{array}$ & $\begin{array}{l}\text { [271], [260], } \\
{[296],[271]}\end{array}$ & $\begin{array}{l}\text { System quality - } \\
\text { [277], [271], } \\
\text { [291]; } \\
\text { Information } \\
\text { quality - [271], } \\
\text { [26o], [291] }\end{array}$ \\
\hline $\begin{array}{l}\text { Self-efficacy and } \\
\text { skills }\end{array}$ & $\begin{array}{l}\text { The judgement of one's own ability to } \\
\text { perform specific technology-related } \\
\text { tasks and the skills to do so. }\end{array}$ & $\begin{array}{l}{[233],} \\
{[292]}\end{array}$ & $\begin{array}{l}\text { Self-efficacy - } \\
\text { [277], [233], } \\
{[271],[270],} \\
{[286],[112],} \\
{[234],[278],} \\
{[265],[247],} \\
{[297],[276],} \\
{[295] ; \text { Skills - }} \\
{[295],[290],} \\
{[292],[292],} \\
{[263],[286]_{,}} \\
{[274]_{2}[112]}\end{array}$ \\
\hline
\end{tabular}

Deriving from the research model, the following hypotheses were developed. 
H1: Performance expectancy - the degree to which an individual believes that using a technology will help them overall - is hypothesized to positively influence Behavioral intention to use. Performance expectancy is conceptualized to focus on whether a technology is helpful, or useful, overall. This definition is based on Adam et al. (2015) [263] and Venkatesh et al. (2003) [199].

While in UTAUT, perceived usefulness from TAM is incorporated into the performance expectancy construct [199], in this study's preliminary research model, perceived usefulness was pulled out as a unique construct, with a focus on perceived usefulness at the feature level. However, qualitative feedback led to a reduction in the number of indicators for Perceived usefulness. The remaining indicators were so few that they were incorporated into Perceived usefulness, following SEM guidelines. This change brought the definition of the Performance expectancy construct for this research to be in line with the UTAUT conceptualization of the construct. Performance expectancy has been found in a variety of studies to have a positive influence on the adoption of technology [263], [264], [253], [265], [266], [267], [247], [252], [268].

H2: Effort expectancy - "degree of ease associated with the use of the system" [199] - is hypothesized to positively influence Behavioral intention to use. Effort expectancy has been found in a variety of studies to have a positive influence on the adoption of technology [253], [265], [266], [247], [254], [252], [268]. 
H3: Social influence - "extent to which users perceive that those important to them believe they should be using a technology" [263] - is hypothesized to positively influence Behavioral intention to use. Social influence has been found in a variety of studies to have a positive influence on adoption of technology [264], [253], [265], [266], [267], [247], [254], [252], [224], [268], [269]). Subjective norm, which is highly related to social influence, has also been found in a variety of studies to have a positive influence on adoption of technology [270], [233], [271], [242], [112], [272], [273], [274].

H4: Perceived quality - the user's opinion of the quality of a software platform - is hypothesized to positively influence Behavioral intention to use. System quality and information quality have been combined to create this construct, as research indicates that perhaps "distinctions between system quality and information quality may no longer be pivotal for mobile applications" [291]. System quality has been found in a variety of studies to have a positive influence on adoption of technology [277], [271], [291]. Information quality has been found in a variety of studies to have a positive influence on the adoption of technology [271], [260], [291].

H5: Self-efficacy and skills - the judgement of one's own ability to perform specific technology-related tasks and the skills to do so - is hypothesized to positively influence Behavioral intention to use. The use of this construct follows other UTAUT-based studies where self-efficacy was included as an exogenous construct [221]. Self-efficacy has been found in a variety of studies to have a 
positive influence on adoption of technology [277], [233], [271], [270], [286], [112], [234], [278], [265], [247], [297], [276], [295]. Skills has also been found in a variety of studies to have a positive influence on adoption of technology [295], [290], [292], [292], [263], [286], [274], [112].

H6: Facilitating conditions - "the degree to which an individual believes that an organizational and technical infrastructure exists to support the use of the system" [199] - is hypothesized to positively influence Use behavior (actual use). Facilitating conditions has been found to have a positive influence on adoption of technology [263], [275], [266], [267], [247], [268], [276], [269].

H7: Behavioral intention to use - "The decision maker's disposition toward using a system" [271] - is hypothesized to positively influence Use behavior (actual use). Behavioral intention to use has been found in a variety of studies to have a positive influence on the adoption of technology [277], [270], [241] $\_$[271], [244], [264], [278], [247], [279]. Behavioral intention is widely accepted as an antecedent of actual usage [335]. 


\section{Chapter Eight: Quantitative Methods - Structural Equation Modeling and Data Collection}

With the research model and hypotheses completed, the next step was to evaluate the model and hypotheses by using Structural Equation Modeling (SEM). This chapter discusses the SEM methodology, including data collection via a web survey. The data collection process is integrated into this chapter, and the SEM analysis results are provided in Chapter 9.

\subsection{Structural Equation Modeling}

Structural Equation Modeling is a comprehensive statistical technique in which a series of dependent relationships can be examined simultaneously, including the examination of the relationships between independent variables [256], [336], [337]. SEM is an important technique of multivariate analysis, which refers to statistical techniques that examine more than two variables simultaneously [256]. SEM "incorporates and integrates path analysis and factor analysis" [257]. Path analysis analyzes path models, which contain only observed variables and also where independent variables can be both "causes and effects of other variables" [257], and factor analysis, which reveals "the latent structure (dimensions) of a set of variables" [258]. For example, if one hypothesizes that a variable can be both a dependent and independent variable in the same theory, SEM can be used to evaluate such a hypothesis [256]. A dependent variable, often denoted by ' $y$ ', is the "variable that is explained by the set of independent 
variables" and the independent variable, ' $\mathrm{x}$ ', is the "variable(s) selected as predictors and potential explanatory variables of the dependent variable" [256].

According to Hair et al. (2013), SEM models have three distinguishing characteristics: 1 . They estimate multiple and interrelated relationships; 2 . They can represent unobserved concepts in these relationships, including accounting for measurement error; and 3. SEM models seek to illuminate the entire set of relationships [256]. SEM can be conducted for single groups or sub-groups to make comparisons [338].

Critical components of SEM are the specification of the measurement model and the structural model. The measurement model is identified at the beginning of SEM, and reflects the researcher's understanding of theory. It reflects variables that are "conceptualized as a latent construct measured by multiple indicators" [257] and that come together to represent constructs [256]. A latent construct (or latent variable or factor) is a concept that cannot be directly measured and must be approximately measured by multiple indicators [256], which could be items in a survey [257]. For example, job satisfaction is a latent construct that might be measured by indicators such as compensation, autonomy with completing tasks and the degree of meaning one derives from work. However, combining variables (such as gender, race and other demographic variables) without any "single underlying continuum of meaning" would not be appropriate [257]. Use of a measurement model allows the removal 
of measurement error from the latent variables, which creates stronger predictive power [339].

The structural model builds on the measurement model by adding the dependence relationships, or causal paths, between constructs, or latent variables [340], [257], [341] and provides the magnitude or significance of the dependence relationships [226], [256]. Thus, SEM models include multiple indicators for each latent construct and paths that connect the latent constructs [257]. SEM models also include exogenous and endogenous constructs, or variables. Exogenous constructs are latent, multi-item equivalents of an independent variable and are determined by factors outside of the model. Endogenous constructs, on the other hand, are latent, multi-item equivalents to dependent variables, and in path diagrams endogenous constructs have one or more arrows that lead to them [256], which implies a causal relationship [257]. Measurement and SEM models are often displayed visually using path diagrams, and in SEM models, most straight arrows connecting variables indicate a regression relationship, and the absence of path and covariance arrows connecting variables indicates there is no direct relationship [257]. Curved arrows represent correlations between variables (but not causality) [256]. 


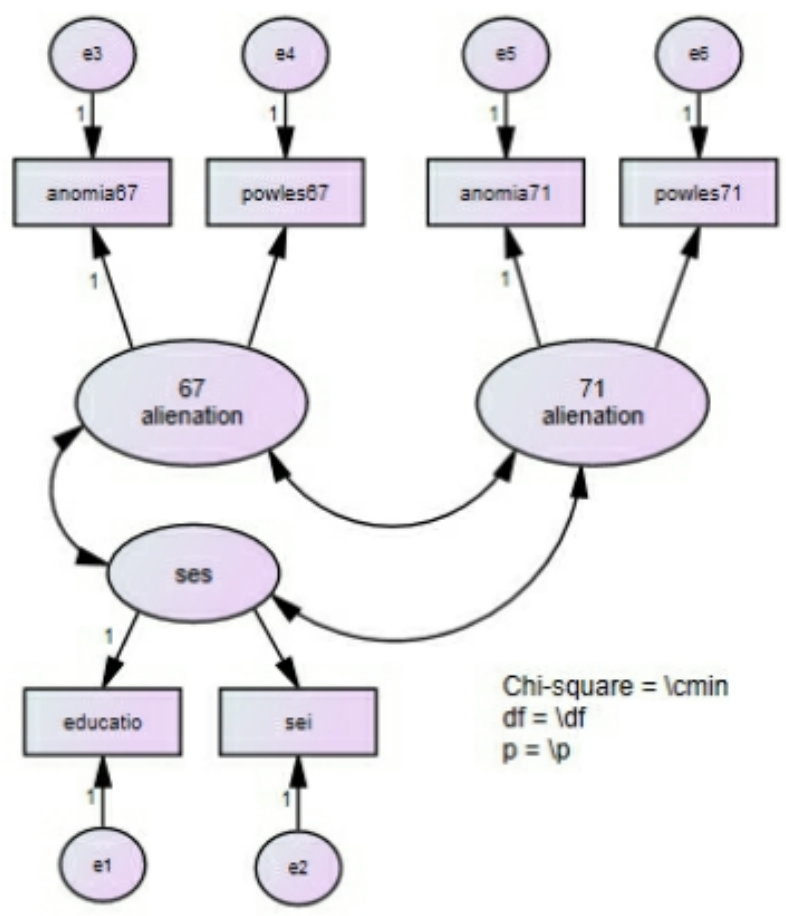

Figure 15: Example Measurement Model from [257] (using Wheaton data, 1977) 


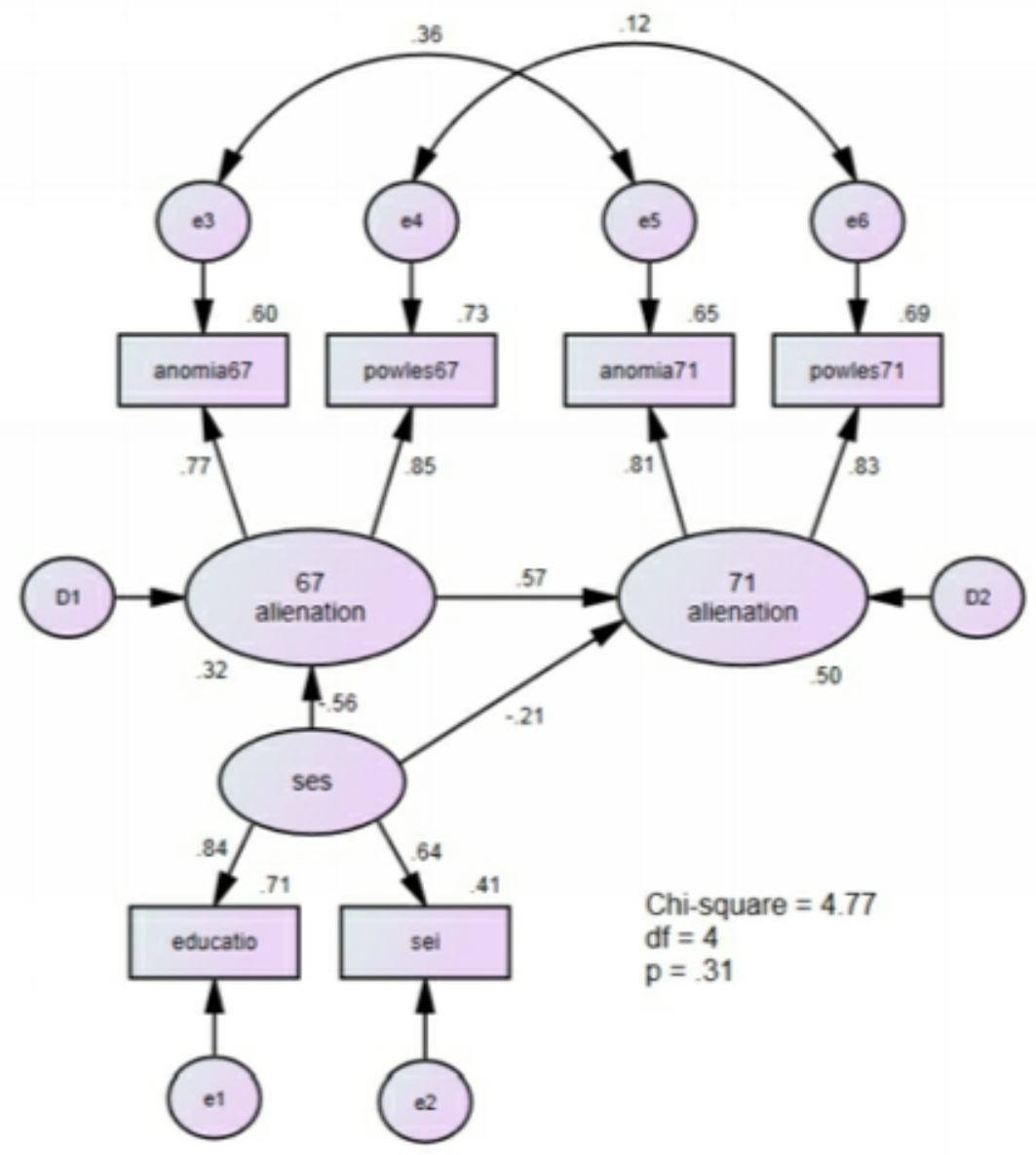

Figure 16: Example Structural Model from [257] (using Wheaton data, 1977)

SEM builds on multiple regression and is considered a second-generation multivariate technique [342]. SEM has several advantages in that, for example, SEM: accommodates multiple independent variables, where they can be both "causes and effects of other variables;" accommodates multiple latent independent variables (in regression models only observed variables are modeled), where each latent variable can be defined by multiple indicators; models correlated independent variables and correlated error; allows interpretation when multicollinearity exists; and improves statistical estimation 
by reducing measurement error by using Confirmatory Factor Analysis (only the dependent variable in regression has an error term) [257]. In relating SEM to path models, which "are structural models for observed variables" [255], path models only contain observed variables, but like SEM models, in path models independent variables can "be both causes and effects of other variables" [257]. Unlike in SEM models, in path models exogenous variables are "assumed to be measured without error" and "partial coefficients are calculated using only the independent variables in a direct path to the endogenous variable" [257]. Other multivariate techniques can bypass measurement error [256]. Variables in SEM can be either observed or latent. Observed variables are those which are present in the data set, whereas latent variables are those that are "constructed as a linear combination of observed variables through a process of confirmatory factor analysis" [338]. In other words, the latent variables are mathematically inferred from variables that have been observed, such as through measurement, observing behavior or responding to survey questions.

There are two types of SEM: covariance-based SEM, which is primarily used to confirm or reject theories "(i.e., a set of systematic relationships between multiple variables that can be tested empirically)" and partial least squares structural equation modeling (PLS-SEM), which is used primarily to develop theories in exploratory research [343]. Covariance-based SEM analyzes how well a theorized model estimates the covariance matrix for a sample data set [343]. A covariance represents the "strength of the linear association between $X$ and $Y$ and 
their availabilities" [255]. A SEM model must only be developed based "first and foremost by a strong theoretical base" [256] - and is more popular than PLS-SEM [344]. The theory helps to specify the relationships in both measurement and structural models and provides assistance with making modifications to proposed relationships [256]. Understandably, the insights and judgement of the researcher are central to covariance-based SEM [257], and covariance-based SEM is the technique used in this study. Thus, in this study "SEM" will refer to covariance-based SEM.

In SEM, models can either be formative or reflective. Formative models have arrows that are drawn from the indicators to the latent variables and "each indicator represents a dimension of meaning" and collectively define the latent variable [257]. Reflective models are those where the arrows are drawn from the latent variables to the indicators and where "the indicators are thought to be representative reflections of the latent variable" [257]. "Reflective models are customary because factors...are assumed to be the 'reality' which determines variance in the measured indicator variables" [257]. This study uses reflective models.

A key part of SEM is determining model fit, both when specifying the measurement model and when specifying the structural model. Statistically speaking, "model fit is determined by the correspondence between the observed covariance matrix and an estimated covariance matrix that results from the proposed model" [256] and there are a large number of goodness of fit 
coefficients to assess both measurement models and structural models [257]. The purpose of the fit measures is to verify whether or not a model provides an acceptable fit to the data, i.e. upholding or disconfirming that the measurement and structural models proposed by the researcher are adequate [257]. Although a model might be determined to be a good fit, this is not proof of causation, and also means that other models also may be a good fit and may even be a better fit [257]. In terms of causality, "meeting goodness of fit criteria does not assure that the causal model is true, but failing to meet fit criteria is reason to strongly suspect the model is false" [257]. There is some debate about the utility of fit measures, with some rejecting their use while others embrace it [257]. In practice though, "the great majority of SEM studies finding their way to publication report goodness of fit measures" [257].

\subsection{SEM Popularity and Limitations}

SEM is quite popular, particularly with applied researchers, having been utilized in a variety of disciplines [345]. Its success stems from its ability to measure latent constructs while testing the relationships between latent constructs [344]. It has been applied in marketing and consumer research and is widely established, as it takes into account the errors prone to behavioral science data and can correct for unreliability when multiple indicators for each latent construct are present [259]. It has also been applied to investigate predictors of emotional well-being with multiple groups [346], the "perceived enjoyment on pre-service teachers' intention to use technology" [347], the adoption of 
enterprise resource planning (ERP) systems [348], in higher education to analyze student e-learning portal use [349] and in health care information technology adoption [350]. It has also been applied in the biological sciences [340], psychology [340], social sciences [340], political science [345] and economics [345].

While the ability to specify latent constructs, describe the relationships between latent constructs and conduct global assessments of fit of complex models are large draws for using SEM [340], it does have limitations. Critiques of using SEM for empirical research include concerns about how it has been applied in practice, in that it has many pitfalls that can lead inexperienced researchers astray [259]. Some argue that it is important that SEM authors are transparent about the high likelihood of omitted variables and that they can have unexpected and harmful effects on parameter estimates and broader inferences about structure, among other items [351]. Judging the fit of a model can also be difficult, as some argue there is a lack of clear guidelines for choosing which fit indices to use and the rationales for fit indices can be unclear [352]. SEM works best with large samples, which can be difficult to obtain at times. "A SEM model with only a few variables can have complex path coefficients that add up to a surprisingly large number of estimated parameters and hence require large data sets" [338]. Finally, Kline (2005) lists 44 ways that SEM can be misapplied, including not having sufficient numbers of indicators for latent constructs (he suggests a rule of thumb of 2-4 indicators per construct, with 4 being ideal), 
collecting data prior to specifying the model, not checking the accuracy of the data input and using a small sample to estimate a complex model [255].

\subsection{SEM Process Summary}

SEM involves two main phases: specifying and evaluating the measurement model; and specifying and evaluating the structural model [257], [256]. Relatedly, Hair et al. (2013) describe an all-encompassing SEM process that can be conceptualized in 6 main stages: Stage 1: Defining individual constructs; Stage 2: Developing the overall measurement model; Stage 3: Designing a study to produce empirical results; Stage 4: Assessing the measurement model validity; Stage 5: Specifying the structural model; and Stage 6: Assessing structural model validity [256]. For this study, these stages have been incorporated in the research approach. 
Specify and evaluate the measurement model (first phase of SEM)

Specify and evaluate the structural model (second phase of SEM)

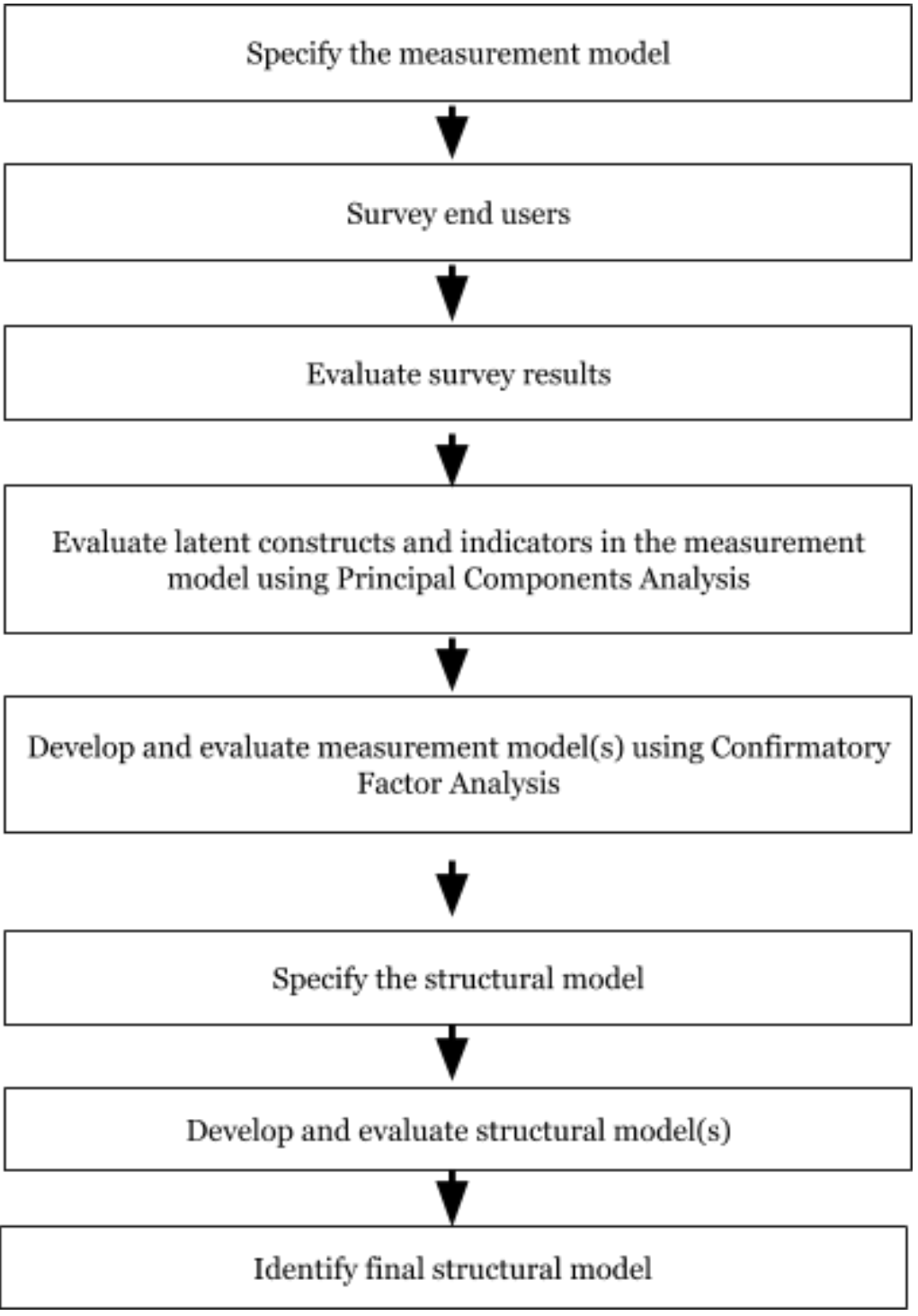

Figure 17: SEM Data Analysis Process

\subsection{SEM Process - Measurement Model}

A measurement model is a representation of the hypothesized research theory about how latent constructs are represented by indicators [257]. The measurement model enables the isolation of measurement error, and the removal of measurement error from the latent constructs. This, in turn, facilitates 
"stronger predictive power because measurement error is assumed to be a random error and as such has no explanatory power" [339]. Additionally, this generally results in larger estimates of the path coefficients when assessing the structural model, as compared to traditional regression models, where one assumes no error in predictors [339]. The goal of the measurement model stage of SEM is to specify a measurement model that adequately, as determined by goodness of fit measures, defines the latent constructs in terms of the indicators that define them, thus resulting in a valid model.

In this study, a multi-step process was used to develop the measurement model: (1) Specify a possible theoretical research/measurement model; (2) Survey end users to generate data to empirically evaluate and improve the model; (3) Evaluate survey results to gauge response rate, reliability and validity (4) Use principal components analysis, a technique of Exploratory Factor Analysis (EFA), to evaluate whether the factors and their corresponding indicators are measuring what the theory suggests they should be measuring and based on this analysis, specify the measurement model; and (5) Conduct Confirmatory Factor Analysis (CFA), another approach to examining the relationships between the observed variables/indicators and latent constructs (i.e. factors), to develop estimations, goodness of fit measures, the significance of path weights, discriminant validity statistics and modification indices to be used in evaluating and improving the measurement model [257]. The goals are that the measurement model appropriately captures the nature of the relationships between observed variables 
and latent constructs and that the measurement model can be used to develop the structural model.

The first step in the measurement model phase is to identify which indicator variables are thought to be "representative reflections of the latent variables" constructs based on theory [257]. In the case of this study, the hypothesized latent constructs and their indicators were identified by considering: UTAUT; the taxonomy of adoption factors identified in the literature; how the unit of analysis (software for accessing university services, i.e. myPSU) is used in context (by undergraduate students and considering student success); and feedback elicited through the qualitative methods. When specifying a measurement model, it is recommended that researchers identify at least 3-4 indicators for each latent construct so that the construct is adequately defined [257], [259], [255]. Additionally, "models using only two indicators per latent variable are more likely to be under - identified and/or fail to converge and error estimates may be unreliable" [257].

\subsection{Data Collection}

\subsubsection{Survey Design}

The second step in the measurement model phase of SEM is to design and implement a survey of end users, using a representative sample, to provide data for empirically evaluating and improving the measurement model [256]. A survey is a means of gathering information about a studied population, such as their characteristics, actions and opinions, and in relation to a predetermined topic 
using predefined and structured questionnaires [353], [304], [354]. A questionnaire, for the purposes of this study, is defined as "a general term to include all methods of data collection in which each person is asked to respond to the same set of questions in a predetermined order" [304] and is synonymous with "instrument," which is the primary term used in this study. Surveys have been used as an important data gathering method across many disciplines, including in the social sciences [355] and management information systems [354].

In this study, the survey was used as an explanatory research method, as it enables the examination and analysis of relationships between variables, such as use of the survey data to test theory [304], [353], which was to evaluate the research model using SEM. Exploratory research, in contrast, is not the best suited method for questionnaires, as it benefits from open ended questions while descriptive research is for probing attitude and opinions for understanding "variability in different phenomena" [304]. Additionally, the survey was cross-sectional, in that it was a snapshot of students' experiences at a particular point of time, as opposed to a longitudinal study, which is a "series of snapshots [that is a] representation of events over a given [time] period" [304].

There are three broad classifications of the means of collecting quantitative survey data - self-completion, interviewer completed and observation [16]. Self-completion methods include mail surveys, Internet surveys or other electronic surveys [16], such as web-based surveys. A web survey is a 
"data collection technique in which the questionnaire is delivered electronically to each respondent's email address. She or he then reads and answers the same set of questions in a predetermined order without an interviewer being present before returning it electronically" [304].

Web surveys are a widely accepted technique for assessing university-related issues [356]. They are popular for many reasons, including they allow a large amount of data to be collected [355], [356], they are relatively low cost [304], [356] and data input is automated [304]. Challenges of web surveys include possible nonresponse bias and data quality [356]. Some have concluded that for studying students in higher education, web surveys are likely an ideal instrument [357] as they have few coverage and sampling problems [356].

This study utilized a self-completion data collection approach through a web survey that was distributed via email to a sample of the target population. Respondents clicked/tapped on a link in the email that took them to the web survey.

Survey Design

The major steps in the survey process germane to this step of SEM are the survey design (developing and validating the survey instrument), data collection (administering the survey), and data editing and nonresponse evaluation [358]. Critically, before developing a survey, it is important that researchers are clear 
about what is being studied (i.e. clear research questions) and what is expected from the survey [16].

Developing a Survey Instrument

Developing a survey instrument generally entails several main steps:

- Generating the survey items, or questions, and corresponding scales based on literature

- Evaluating and validating the survey items based on expert feedback and adjusting the instrument to account for this feedback

- Testing the instrument and modifying it as needed to create the final survey instrument

Survey items, or questions, must be directly related to the research questions at hand and the method of administering questionnaires, such as web-based surveys or face-to-face, must also be taken into account when developing the survey questions [16]. In the case of using SEM for technology adoption, and as was the case in this study, each survey question represents an indicator variable in the research model and whenever possible it is best if the survey items are based on items validated in other technology adoption studies [199]. The indicators are each a component of a multi-item scale that maps to a related latent construct. Scales are widely used as they produce very superior measurement properties [355]. In the event that new indicators are needed in a SEM study, care should be taken to ensure that the corresponding survey questions are developed with the following considerations in mind: 
- Clarity of the question text, given the complexity inherent in asking questions about behaviors [358]

- Familiar wording [358], [16]

- Short question text [358] with a goal of survey completion of less than 13 minutes if at all possible [356]

- Question text modeled after questions used in published technology adoption studies

- Avoidance of leading questions [358]

- Ordering the questions in a logical order [358]

Another critical component of survey design is considering how the survey questions will be answered [358]. Two broad types of questions - closed-ended and open-ended - lead to different types of response. Closed-ended questions, which were used in the survey for this study and following other technology adoption studies, are those where respondents select from predetermined answers [16], [358]. Open-ended questions allow respondents to answer in their own words [16], [358]. Relatedly, measurement is important, as it refers to ensuring the accuracy of findings. "Measurement is achieved through the use of scales. A scale is a measurement tool that can be used to measure a question with a predetermined number of outcomes" [16]. Building off of published technology adoption research, e.g. Davis (1989) [209] and (Venkatesh et al. 2003) [199], and in recognition of the importance of using scales whenever possible that have been 
empirically tested and validated [304], [16], this study used a five-point Likert-type ordinal measurement scale.

As an ordinal, i.e. ranking scale, a Likert scale is often used for measuring attitudes or opinions, and often asks respondents to use a five-point scale like the following to assess the strength of agreement or disagreement about a statement [16]: 1. Strongly disagree; 2. Disagree; 3. Neutral; 4. Agree; 5. Strongly agree. In the survey for this study, all scales were 5-point scales, and all except one scale was a Likert scale as just described.

As with all survey types, the design of the instrument itself is important. For web-based surveys, several guidelines were taken into consideration in the design of the web-based survey [359] and in light of the capabilities of Qualtrics, the survey platform that was used. These guidelines are based on Dillman et al. (2014) [359] and include:

- Creating informative welcome and closing screens

- Optimizing the questionnaire for mobile devices

- Using a consistent page layout across screens

- Allowing respondents to navigate back in the survey

- Not including a graphical progress indicators

Preliminary Survey Instrument

A preliminary survey instrument for the target variables (those related to the technology indicators and factors) was developed based on the research 
model and survey instruments that have been used in the following published research that utilized widely accepted technology adoption models:

- Venkatesh et al. (2003) developed UTAUT and a corresponding instrument by synthesizing eight technology adoption models and then extensively testing UTAUT [199]

- Davis (1989) developed and validated scales for perceived usefulness and perceived ease of use [209]

- Pituch and Less (2006) tested college student intention to use an e-learning system by a combined model derived from TAM and TRA [261]

- Moran, Hawkes and El Gayar (2010) studied college student adoption of personal tablets based on UTAUT [247]

- Kim, Chun and Lee (2014) examined smartphone adoption by college students by combining all components of IDT, TAM, the value-based adoption model (VAM), and the social influence (SI) model [235]

- Park (2009) studied college students' behavioral intention to use e-learning based on TAM [112]

- Lee (2006) researched the factors influencing college student adoption of an e-learning system based on TAM [233]

- Saadé and Bahli (2005) studied college student acceptance of an Internet-based learning system based on TAM [262] 
Additionally, questions (items) were developed and adapted to fit the self-service software context in higher education, including adjusting the scales for each factor/latent construct as needed to fit the context of this study.

In addition to the target variables (i.e. questions/items about technology adoption), the survey included several auxiliary variables. There were several demographic questions to aid with understanding the representativeness of the respondents in relation to the target population. Additionally, respondents were asked to indicate the primary ways they access myPSU (via a browser on a laptop, smartphone mobile app, etc.), as well an item - Net Promoter Score - that helps gauge students' overall experiences with myPSU. Net Promoter Score was developed by Bain and Company, and is regarded as a simple and effective way to gauge customer satisfaction, experience and loyalty [78]. NPS is calculated by subtracting the percentage of customers who are detractors (rating of o-6, Not Likely at All) from the percentage who are promoters (rating of 9 or 10, Extremely Likely) in response to the question: "How likely is it you would recommend us to a friend?” [79]. In addition to the above demographic questions, detailed data was secured from Portland State University as it relates to each individual student, which aided with distributing the survey as well as understanding the degree to which the respondents mirrored the target population.

Validating the Survey Instrument 
Two critical components for developing an effective survey and validating it for use are validity and reliability [16], [355], [360]. Validity was addressed in the survey validation process, as summarized below and based on Andrews et al. (2003) [361] and Aldhaban (2016) [226].

Table 18: Survey Instrument Validation Actions

\begin{tabular}{|l|l|l|}
\hline Step & Description & Output \\
\hline $\begin{array}{l}\text { 1. Develop } \\
\text { instrument }\end{array}$ & $\begin{array}{l}\text { Developed the survey instrument based on } \\
\text { related research and surveys }\end{array}$ & Version 1 \\
\hline $\begin{array}{l}\text { 2. Pre-validation: } \\
\text { Read aloud }\end{array}$ & $\begin{array}{l}\text { Three students (graduate students in PSU's } \\
\text { Department of Engineering and Technology } \\
\text { Management PhD program) read the survey } \\
\text { aloud and provided feedback }\end{array}$ & Version 2 \\
\hline $\begin{array}{l}\text { 3. Expert panel } \\
\text { review (validity) }\end{array}$ & $\begin{array}{l}\text { An expert panel of eight participants } \\
\text { reviewed the instrument: Seven content } \\
\text { experts (professionals in the higher } \\
\text { education sector); and one lay expert } \\
\text { (undergraduate student) }\end{array}$ & Version 3 \\
\hline $\begin{array}{l}\text { 4. Pilot testing } \\
\text { (reliability) }\end{array}$ & $\begin{array}{l}\text { 21 undergraduate students (matching the } \\
\text { target population) took the survey in its } \\
\text { web-based form, which was distributed via } \\
\text { email, and evaluated it }\end{array}$ & Version 4 \\
\hline 5. Final review & $\begin{array}{l}\text { The researcher conducted a final review of } \\
\text { the instrument to catch any last typos or } \\
\text { errors }\end{array}$ & Version 5 - Final \\
\hline
\end{tabular}

\section{Read Aloud}

The survey instrument - which was developed based on existing research and surveys - was read aloud by three students (graduate students in PSU's Department of Engineering and Technology Management PhD program) [226], [362]. They were presented with the survey as it appeared in the Qualtrics survey platform, to secure feedback on both the content and how it was displayed. No compensation was provided to these students. The read aloud, or cognitive 
interview, is a means of soliciting feedback on the questionnaire to identify any wording, question order, visual design or navigation problems [359]. The read aloud sessions were conducted via video conference in March 2020, prior to the State of Oregon's COVID-19 stay-at-home order (which was issued on March 23, 2020) and prior to Portland State University's move to all-remote learning (which started with the Spring 2020 term, beginning on March 30, 2020). The feedback from the read aloud was used to create a new version of the survey instrument, Version 2.

Expert Panel Review

Next, an expert panel reviewed Version 2 of the instrument, with a focus on evaluating the instrument's validity. Validity, or the ability of a questionnaire to measure what it is intended to measure [304], [16], often is described as consisting of three components:

- Content validity - the extent to which the survey questions adequately cover the investigative questions

- Criterion-related validity - the degree to which the questions are able to make accurate predictions

- Construct validity - the degree to which the questions adequately measure the construct they are intended to measure [304], [16]

Hair et al. (2015) write that "Before using the scores from any concept (construct) for analysis, the researcher must ensure the variables (indicators) selected to represent and measure the concept do so in an accurate and 
consistent manner. Accuracy is associated with the term validity, while consistency is associated with the term reliability" [16].

The validity of the survey instrument was examined by consulting with a small group of experts to "pass judgement on the suitability of the items (indicators) chosen to represent the constructs" [16], including the goal of eliminating irrelevant items from the survey and where needed, provide new wording [363].

Expert judgement plays a large role in science and engineering [364]. It is commonly used in business-related research, including in technology adoption [16], [226], [365]. The size of the expert panel, at eight participants, was within the range of accepted numbers of experts - six to twelve - for survey instrument validity assessment [363], [226], [309]. The following factors were considered when creating the expert panel, based on scholarly literature:

- Experts who are available and willing to participate [226]

- A mix of content experts and lay experts with knowledge and experience related to student information technology. Content experts are professionals or those who have substantive academic experience in the field of student information technology, and lay experts are those "for whom the topic is most salient" - in this case, undergraduate students [309], [310].

- Experts who represent a diversity of backgrounds will support the inclusion of a wide base of knowledge [366]. 
- The method for soliciting expert opinions, should strive to encourage experts to state their true opinions, so as not to bias results [364]

The expert panel used in this study consisted of both content and lay experts. The content experts were recruited through contacts that the researcher has at Portland State University, in the higher education, educational technology and the technology innovation sector(s) and represented a diverse group. The lay expert (undergraduate student at PSU) was recruited at the same time as students who were recruited for participating in the individual interviews and the focus groups. The student was provided with a $\$ 10$ Amazon.com gift card for participating and the professionals were not compensated. The expert panel, which was conducted remotely using an online feedback mechanism (described below), occurred in mid-March 2020, prior to Portland State University's move to all-remote learning (which started with the Spring 2020 term, beginning on March 30, 2020) and prior to the State of Oregon's COVID-19 stay-at-home order (which was issued on March 23, 2020). However, not all experts were based in Oregon. Materials for engaging the expert panelists are provided in Appendix F. The experts represented a diversity of backgrounds in the higher education sector, with 9-28 years of experience, from institutions including Portland State University, Georgia State University, Stanford University and the Association of Public and Land Grant Universities. The panelists are summarized below. 
Table 19: Summary of Expert Panelists

\begin{tabular}{|c|c|c|}
\hline Participant & Role Description & $\begin{array}{l}\text { Years of professional } \\
\text { experience in higher } \\
\text { education, educational } \\
\text { technology and/or the } \\
\text { technology innovation } \\
\text { sector(s) }\end{array}$ \\
\hline 1 & $\begin{array}{l}\text { Expert working for an association of higher } \\
\text { education universities }\end{array}$ & 14 \\
\hline 2 & $\begin{array}{l}\text { Evaluation and research expert in higher } \\
\text { education }\end{array}$ & 28 \\
\hline 3 & Data expert in higher education & 15 \\
\hline 4 & $\begin{array}{l}\text { Human centered design expert in higher } \\
\text { education }\end{array}$ & 9 \\
\hline 5 & $\begin{array}{l}\text { Advising and student success leader in higher } \\
\text { education }\end{array}$ & 17 \\
\hline 6 & Data expert in higher education & 9.5 \\
\hline 7 & Student success expert in higher education & 9 \\
\hline 8 & $\begin{array}{l}\text { Portland State University undergraduate } \\
\text { student }\end{array}$ & - \\
\hline
\end{tabular}

While experts can be used to provide both qualitative and quantitative feedback on a survey instrument, quantitative feedback is an accepted practice for assessing content validity [363], [367]. Largely based on the work of Rubio et al. (2003) [309], but also from Hyrkäs et al. (2003) [363] and Aldhaban (2016) [226], the evaluation form, distributed electronically using the Qualtrics survey platform, consisted of the following: Rating each item/observed variable in the survey on three dimensions, each using a four-point scale, along with space for comments: 
- Relevance was used to evaluate the construct validity - the degree to which the questions adequately measure the construct they are intended to measure [304], [16]

- Representativeness was used for content validity - "Content validity at the item level expresses the extent to which each item measures the target or content domain, which it is supposed to measure" [363]

- Clarity was used to gauge how the language/wording for an item could be improved. The figure below provides an example of the evaluation tool. 
Listed below are items (questions) that are in the draft myPSU survey/questionnaire, along with a theoretical definition for each item. Students will be asked to rate each item on a 5-point scale (1. Strongly agree; 2. Disagree; 3. Neutral; 4. Agree; 5 . Strongly agree).

Each of the items in this section is hypothesized to relate to the following construct, or underlying theme: Facilitating conditions - The degree to which an individual believes that an organizational and technical infrastructure exists to support use of the system.

Please rate each item on the following three dimensions, and provide any comments about what could be improved.
\begin{tabular}{|c|c|c|}
\hline $\begin{array}{c}\text { Relevance - of item in relation to the above } \\
\text { construct }\end{array}$ & $\begin{array}{c}\text { Representativeness - of item in relation to the } \\
\text { definition }\end{array}$ & $\begin{array}{c}\text { Clarity - how clearly an item is } \\
\text { worded }\end{array}$ \\
\hline 1 - Item is not relevant & 1 - Item is not representative & 1 - Item is not clear \\
\hline 2 - Item is mildly relevant & $\begin{array}{c}2-\text { Item needs major revisions to be } \\
\text { representative }\end{array}$ & 2 - Item needs major revisions to be \\
\hline 3 - Item is relevant & $\begin{array}{c}\text { clear } \\
\text { representative }\end{array}$ & 3 - Item needs minor revisions to be \\
\hline 4 - Item is highly relevant & 4 - Item is representative & 4 - Item is clear \\
\hline
\end{tabular}

\begin{tabular}{|c|c|c|c|c|c|c|c|c|c|c|c|c|c|}
\hline & \multicolumn{4}{|c|}{ Relevance } & \multicolumn{4}{|c|}{ Representativeness } & \multicolumn{4}{|c|}{ Clarity } & \multirow{2}{*}{$\begin{array}{l}\text { Comments } \\
\text { Please provide any comments about } \\
\text { what could be improved }\end{array}$} \\
\hline & 1 & 2 & 3 & 4 & 1 & 2 & 3 & 4 & 1 & 2 & 3 & 4 & \\
\hline $\begin{array}{l}\# 1 \text { - Item: I can access other PSU software } \\
\text { platforms and online tools seamlessly through } \\
\text { myPSU } \\
\text { Definition: Degree to which a student can } \\
\text { access other university software platforms } \\
\text { and online tools seamlessly through the } \\
\text { software platform being studied (e.g. students } \\
\text { do not have to log-in multiple times when } \\
\text { accessing other platforms). }\end{array}$ & & & & & & & & & & & & & \\
\hline $\begin{array}{l}\text { \#2 - Item: A specific person or group is } \\
\text { available for assistance with myPSU } \\
\text { technical difficulties } \\
\text { Definition: Degree to which a specific person } \\
\text { (or group) is available for assistance with the } \\
\text { software platform's technical difficulties. }\end{array}$ & C & O & & & O & $\cap$ & & $\mathrm{O}$ & & & & ○ & \\
\hline $\begin{array}{l}\text { \#3 - Item: Education about myPSU's features } \\
\text { and functionality and how to use them has } \\
\text { helped me learn how to use myPSU } \\
\text { Definition: Degree to which education about } \\
\text { a software platform (such as about its } \\
\text { features and functionality, and how to use } \\
\text { them) has helped a student learn how to use } \\
\text { the platform. }\end{array}$ & & O & & & $\bigcirc$ & 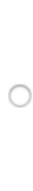 & & 0 & 0 & & & 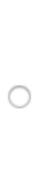 & \\
\hline
\end{tabular}

Figure 18: Example of the Expert Panel Evaluation Tool

The data from the expert panel was analyzed with respect to each dimension and based on Hyrkäs et al. 2003 [363], Aldhaban 2016 [226] and Rubio et al. 2003 [309]. The score for each dimension was determined by calculating the number of raters giving a rating of ' 3 ' or ' 4 ' divided by the total number of raters. Items were considered adequate if the score was $>79 \%$, questionable if the score was 70-79\% agreement and not acceptable if there was 
less than or equal to $69 \%$ agreement. Additionally, the comments were reviewed. The results of the expert panel were that two items were removed (one as it was redundant and one as there was $69 \%$ or less agreement) and the wording of nearly all items was improved as a result of expert feedback. These changes resulted in Version 3 of the survey instrument.

Pilot Testing

Next, evaluating the reliability of the survey instrument resulted from using Version 3 of the survey instrument in a pilot test, following the guideline that pilot testing should involve "a small sample of respondents with characteristics similar to those of the target population" [16] and in a setting similar to what will occur in the study [16]. Portland State University undergraduate students were recruited at the same time as students who were recruited for participating in the individual interviews and the focus groups. The pilot tester students were each provided with a $\$ 10$ Amazon.com gift card for participating. The instructions for the pilot testers and the consent form are provided in Appendix G. The pilot testers received the instructions for how to participate in the pilot test via email and took the pilot test in Qualtrics, which mirrored the methods used in data collection, i.e. survey administration. The pilot test occurred in late March 2020, after the State of Oregon's COVID-19 stay-at-home order (which was issued on March 23, 2020), but prior to Portland State University's move to all-remote learning (which started with the Spring 2020 term, beginning on March 30, 2020). 
Following guidelines that at least five to 20 individuals should be engaged in pilot testing for a small-scale study such as this [353], [16], 21 students participated from a range of backgrounds. The pilot testers were diverse, and included: a mix of class levels and majors; students who received financial aid and those who did not; first-generation college students and those who were not; students who lived with a disability and those who did not; and students who identified as White, Asian, or Native Hawaiian or Other Pacific Islander. Given that there were a sufficient number of student pilot testers, other researchers and experts were not needed [353].

Pilot respondents were asked to take Version 3 of the survey and were excluded from receiving the actual survey. Pilot respondents were asked to evaluate all aspects of the survey instrument using a rating scale (1-5), as represented in the table below and based on [353], [358], [368] and [359].

Table 2o: Survey Instrument Pilot Testing Tool

\begin{tabular}{|l|l|}
\hline Prompt & Response \\
\hline $\begin{array}{l}\text { How long did it take you to complete } \\
\text { the survey? }\end{array}$ & $\begin{array}{l}\text { Multiple choice (Less than 5 minutes; 6-9 } \\
\text { minutes; 10-13 minutes; 14-19 minutes; More than } \\
\text { 20 minutes) }\end{array}$ \\
\hline $\begin{array}{l}\text { Did the questions in the draft myPSU } \\
\text { survey sound right to you? Click/tap } \\
\text { here for a list of the survey questions. }\end{array}$ & $\begin{array}{l}\text { Rating (1=Strongly disagree; 2=Disagree; } \\
\text { 3=Neutral; 4=Agree; 5=Strongly agree) }\end{array}$ \\
\hline $\begin{array}{l}\text { Is there a better way to ask any of the } \\
\text { questions in the draft myPSU } \\
\text { survey? Click/tap here for a list of } \\
\text { the survey questions. }\end{array}$ & $\begin{array}{l}\text { Close-ended (Yes/No) with open-ended prompt if } \\
\text { "Yes" ("Please describe in detail") }\end{array}$ \\
\hline $\begin{array}{l}\text { Does the order of the questions in } \\
\text { the draft myPSU survey seem right } \\
\text { to you? Click/tap here for a list of the } \\
\text { survey questions. }\end{array}$ & $\begin{array}{l}\text { Close-ended (Yes/No) with open-ended prompt if } \\
\text { "No" (Please describe in detail") }\end{array}$ \\
\hline
\end{tabular}




\begin{tabular}{|l|l|}
\hline $\begin{array}{l}\text { Did you notice any spelling or } \\
\text { grammatical errors in the draft } \\
\text { myPSU survey? Click/tap here for a } \\
\text { list of the survey questions. }\end{array}$ & $\begin{array}{l}\text { Close-ended (Yes/No) with open-ended prompt if } \\
\text { "Yes" ("Please describe in detail") }\end{array}$ \\
\hline $\begin{array}{l}\text { Were there any problems with the } \\
\text { formatting, design, display, etc. of } \\
\text { the draft myPSU survey? Click/tap } \\
\text { here for a list of the survey questions. }\end{array}$ & $\begin{array}{l}\text { Close-ended (Yes/No) with open-ended prompt if } \\
\text { "Yes" ("Please describe in detail") }\end{array}$ \\
\hline $\begin{array}{l}\text { What kind of device are you using } \\
\text { now? }\end{array}$ & $\begin{array}{l}\text { Multiple choice (Laptop, desktop, tablet, } \\
\text { smartphone) }\end{array}$ \\
\hline $\begin{array}{l}\text { Any additional comments or } \\
\text { feedback are welcome! }\end{array}$ & Text box for comments \\
\hline
\end{tabular}

The survey instrument was modified according to the above pilot testing, including adjusting the language in several of the questions, adjusting the survey instructions and improving the formatting and design of the instrument. Results of the pilot test are provided below.

Table 21: Summary of Pilot Testing Results

\begin{tabular}{|l|l|l|}
\hline $\begin{array}{l}\text { Question in evaluation } \\
\text { tool }\end{array}$ & Summary of responses & $\begin{array}{l}\text { Changes to draft survey } \\
\text { instrument }\end{array}$ \\
\hline $\begin{array}{l}\text { Did the questions sound right } \\
\text { to you? }\end{array}$ & $\begin{array}{l}\text { On a scale of 1 - 5, with 1 - } \\
\text { Strongly disagree and 5 - } \\
\text { Strongly agree, average of the } \\
\text { responses was 3.9 }\end{array}$ & $\begin{array}{l}\text { Several specific changes, as } \\
\text { summarized below. }\end{array}$ \\
\hline $\begin{array}{l}\text { Is there a better way to ask } \\
\text { any of the questions in the } \\
\text { draft myPSU survey? }\end{array}$ & Yes - 19\%; 81\% - no & Changed eight survey items. \\
\hline $\begin{array}{l}\text { Does the order of the } \\
\text { questions in the draft myPSU } \\
\text { survey seem right to you? }\end{array}$ & Yes - 90\%; No - 10\% & No changes. \\
\hline $\begin{array}{l}\text { Did you notice any spelling or } \\
\text { grammatical errors in the } \\
\text { draft myPSU survey? }\end{array}$ & Yes - 5\%; No - 95\% & No changes. \\
\hline $\begin{array}{l}\text { Were there any problems with } \\
\text { the formatting, design, }\end{array}$ & Yes - 5\%; No - 95\% & Made one change. \\
\hline
\end{tabular}


display, etc. of the draft

myPSU survey?

A final copy edit was conducted by the researcher, resulting in a final survey instrument. The final survey instrument is in Appendix $\mathrm{H}$.

\subsubsection{Data Collection}

As described above, web based surveys are an appropriate methodology for this study and for higher education students. Data collection involved emailing students who were members of the target population with a link to complete the survey. When emailing a survey to college students, several considerations are important and were followed in the research:

- Keeping the description of the survey short and concise [357]

- Including incentives to help increase response rates, which has been shown to increase response rates for web-based email surveys [359], particularly with college students [357]. Lottery/prize drawings of a cash or gift card incentive have been shown to have improved response rates [357].

- Sending several reminders, including using different subject lines [357]

- Extra reminders have been found to be effective in increasing response rates but are not an aid for diversifying the sample [356]

- Up the three to four reminders can be appropriate and helpful with increasing response rates [369]

- Based on the above, this study: 
- Used a concise invitation to the survey

- Used a lottery/prize drawing of several Amazon gift cards to incent participation and help improve response rates.

○ Sent three reminders, each using different subject lines. The reminders were sent in waves of several days to a week apart, depending on response rates.

\section{Sampling}

One component that is necessary in order to draw generalizable conclusions based on the survey data is to have a representative sample, which is a sample that mirrors the characteristics of the target population [16], [303], [370], [371], [358]. Per Hair et al. (2015), representative samples are developed through the following procedure:

- Define the target population

- Choose the sampling frame

- Select the sampling method

- Determine the sample size

- Implement the sampling plan [16]

This procedure is articulated by others as well when considering multivariate statistical techniques such as SEM [372], [226]. Samples are used for several main reasons, including reducing the time, costs and effort it takes to thoroughly study large populations, and in many cases, it is not possible to study everyone in a target population [370]. 


\section{Target Population and Sampling Frame}

The target population is defined as a subset of the population that encompasses the complete group of elements relevant to the research question and objectives and allows conclusions to be drawn about the population [16], [304], which is the "full set of cases or elements from which a sample is taken" [304]. In survey research the definition of the target population is critical [353], as "a survey collects information about a well-defined population" [358] and to which the conclusions of the survey will apply [358]. An element, or case, is the basic unit selected from the population, such as "individuals" or "groups" [303], or people, households or companies [358]. There is a strong relationship between the target population and the variables used in a survey, to help ensure that the survey provides data for answering the research questions. Target variables are those that are used to directly answer research questions - in this case, about technology adoption - and auxiliary variables are those that provide background characteristics of the elements [358].

The sampling frame is a list of all of the elements (or cases) in the target population [303], [358]. A sample is a small subset of the target population [16], and in quantitative survey research, the "researcher draws the sample from the sampling frame" using a variety of sampling methods or techniques [303].

\section{Sampling Method}

Sampling methods are generally conceived of as falling into two broad categories - probability or representative sampling and non-probability sampling 
[16], [304]. Probability sampling involves the use of a random sample from the target population, which enables generalizing results to the target population [16] and is often used in survey research [304]. Probability sampling was used in this study. On the other hand, non-probability sampling is often used in qualitative research, where the researcher's judgement is used to select a sample [16], [304]. Sample Size Needed

Finally, it is important to consider the sample size requirements necessary for SEM in order to "reduce the likelihood of convergence problems and to obtain unbiased estimates or standard errors" [373]. SEM is sensitive to the sample size needed, perhaps more than other multivariate techniques, and also to addressing missing data [256]. No consensus has been reached among researchers on the ideal sample size needed, except that sample size is an important consideration [345].

Hair et al. (2013) provide guidelines to match sample size requirements with the model being evaluated including that a minimum sample size of 300 is recommended for models with seven or fewer constructs, and that models with larger number of constructs require a minimum sample size of 500 [256].

Related points of view on the sample size needed are that in SEM, "'bigger is always better' when it comes to sample size" [374], [375] and that a rough rule of thumb is that sample sizes of greater than 200 are desirable [375], [374]. Additionally, as described above, fit indices are critical in evaluating the fit of a structural model with the data and it is important to consider the influence of 
sample size on popular fit indices. Iacobucci (2010) describes the influence as sample size increases: chi-square, $\chi^{2}$, increases; standardized root mean square residual (SRMR; absolute fit index), and comparative fit index (CFI; incremental fit index) is enhanced but the effect after a sample size of 50 is "negligible" [374].

Yet another lens is to use ratios to determine the appropriate sample size. One view is that for maximum likelihood estimation, which was used in this study, a 10:1 ratio of cases to indicators is appropriate [373] and a related view is that this ratio should be the lower bound for an appropriate sample size [226].

Given that many of the perspectives on sample size requirements depend on the number of constructs and indicators in the research model, the following table, based also on the response rate discussion below, helps to articulate a few plausible scenarios of what was needed for this research.

\section{Table 22: Sample Size Requirements}

\begin{tabular}{|l|l|l|l|l|}
\hline $\begin{array}{l}\text { Number of } \\
\text { possible } \\
\text { constructs in } \\
\text { the research } \\
\text { model }\end{array}$ & $\begin{array}{l}\text { Number of } \\
\text { possible } \\
\text { indicators } \\
\text { (assumes 3 per } \\
\text { construct on } \\
\text { average) }\end{array}$ & $\begin{array}{l}\text { Analytic sample } \\
\text { (i.e. sample size } \\
\text { needed after } \\
\text { nonresponse } \\
\text { issues are } \\
\text { addressed) with a } \\
\text { lower bound of } \\
\text { 1:10 } \\
\text { (indicators:respo } \\
\text { ndents) }\end{array}$ & $\begin{array}{l}\text { Estimat } \\
\text { ed } \\
\text { minimu } \\
\text { m } \\
\text { respons } \\
\text { e rate }\end{array}$ & Sample N \\
\hline 6 & 18 & $\begin{array}{l}180 \\
210\end{array}$ & $6 \%$ & 3,000 \\
\hline 7 & 21 & 240 & $6 \%$ & 3,500 \\
\hline 8 & 24 & & 6,000 \\
\hline
\end{tabular}




\section{Data Collection Approach}

The target population that was surveyed for the research was undergraduate students at Portland State University who were pursuing a degree and who were users of myPSU. This stems from the primary research question for the study, which is "What are the critical factors that influence undergraduate students themselves in adopting software for accessing university services (one type of student information technology)?” The full population was all undergraduate students at Portland State University, which includes both students who were pursuing a degree and those who were not (e.g. post-baccalaureate students, who had already completed an undergraduate or baccalaureate degree, are considered undergraduate students even though they are not pursuing degrees [376]). The target population included only degree-seeking students as non-degree-seeking students are not as often a focal point for student success efforts [69]. Additionally, given that the research hinges on a student using myPSU, students were screened at the beginning of the survey about whether they had used myPSU. Only students who indicated they had used myPSU were able to take the survey.

The surveyed undergraduates, i.e. target population, are defined in detail as: full or part-time; students who first enrolled as first-time freshman or transfer students; degree-seeking students who were active students in the term the survey was administered (Spring 2020), as well as excluding students who had withdrawn from all classes in the term the survey was administered; excluding 
students who were also Portland State University employees (as they might have an insiders' perspective and bias the results); not including students who were enrolled as part of a high school, exchange or pre-college program; and excluding students who had not used myPSU before.

The elements of the target population were individual students and the sampling frame was a list of all students who met the aforementioned definition of the target population, with the exception of students who had not used myPSU before. The data about whether a student had used myPSU before was not known. Thus, a screening question was added to the survey instrument, and students who indicated they had not used myPSU before were excluded from taking the survey. The target population (excluding information about students who had used myPSU before) was 14,847 students. This list was secured from Portland State University's Office of Institutional Research and Planning. A written agreement exists between Dr. Daim and PSU for access to this data. Following is a table that summarizes the demographics of the target population.

Table 23: Target Population

\begin{tabular}{|l|r|r|}
\hline & \multicolumn{2}{|c|}{ Target Population } \\
\hline Variable & \multicolumn{1}{|c|}{ Count } & Percent \\
\hline Degree-seeking undergraduate students & 14,847 & \\
\hline Gender & 8,141 & $55 \%$ \\
\hline Female & 6,507 & $44 \%$ \\
\hline Male & 199 & $1 \%$ \\
\hline No response & 24.5 & - \\
\hline Average age & \multicolumn{3}{|r|}{} \\
\hline Student type & 5,793 & $39 \%$ \\
\hline Freshman & 8,992 & $61 \%$ \\
\hline Transfer & 62 & $.42 \%$ \\
\hline Not known & & \\
\hline
\end{tabular}




\begin{tabular}{|c|c|c|}
\hline \multicolumn{3}{|l|}{ Race/ethnicity } \\
\hline American Indian & 82 & $1 \%$ \\
\hline Asian & 1,191 & $8 \%$ \\
\hline Black & 502 & $3 \%$ \\
\hline Declined to Respond & 547 & $4 \%$ \\
\hline Hispanic/Latino & 2,441 & $16 \%$ \\
\hline International Student & 1,403 & $9 \%$ \\
\hline Multi Race & 1,143 & $8 \%$ \\
\hline Pacific Islander & 90 & $1 \%$ \\
\hline White & 7,448 & $50 \%$ \\
\hline \multicolumn{3}{|l|}{ Class standing } \\
\hline Freshman & 1,141 & $8 \%$ \\
\hline Sophomore & 4,146 & $28 \%$ \\
\hline Junior & 7,564 & $51 \%$ \\
\hline Senior & 1,996 & $13 \%$ \\
\hline \multicolumn{3}{|l|}{ Full/part-time status } \\
\hline Full-time & 11,785 & $79 \%$ \\
\hline Part-time & 3,062 & $21 \%$ \\
\hline \multicolumn{3}{|l|}{ First-generation status } \\
\hline Did not graduate from college & 5,232 & $35 \%$ \\
\hline Graduated from other 4-yr institution & 5,635 & $38 \%$ \\
\hline Graduated from Portland State University & 730 & $5 \%$ \\
\hline Unknown & 3,250 & $22 \%$ \\
\hline Financial aid recipient & $\begin{array}{r}10,372 / 20 \\
357 \\
\end{array}$ & $51 \%$ \\
\hline Pell grant recipient & \begin{tabular}{r|}
$8,175 / 20,3$ \\
57 \\
\end{tabular} & $40 \%$ \\
\hline
\end{tabular}

Sources: Data provided by Portland State University as part of data pull for this research; and data pulled from the National Center for Education Statistics for 2017-18 (most recent year available [377].

A sample of 8,000 PSU undergraduates was drawn from the sampling frame using probability/representative sampling so that the results could be generalizable to the target population.

Given that the primary research question for this study relates to students themselves as individual adopters of a digital services platform, and following the sample design and sampling protocols outlined above, it would not have been 
appropriate to survey different stakeholders such as faculty or information technology staff, as they are not the target population for this study's research questions. Understanding staff adoption of a technology platform, for example, would stem from different research questions. A well-defined target population that relates to the research question that will be investigated using a survey - with the goal of developing results that are generalizable to the target population - is critical [16], [303], [370], [371], [226], [304], [353]. Additionally, for the results to have external validity - or the "extent to which the results of a study can be generalized to and across populations or persons, settings and times" - a target group of individuals must be identified [303].

Furthermore, technology adoption models, including UTAUT, hinge on having a well-defined user group. While some technology adoption models have been focused at the organizational level, the application of the UTAUT technology adoption model in this case is for individual adoption, following other well-established research [194], [199], [200], [205], [206], [210].

The final procedural step was to implement the sampling plan, which occurred through the data collection processes articulated in this chapter.

\section{Data Collection}

The survey to the 8,00o Portland State University students in the sample was administered via email using the Qualtrics survey platform in several waves between April 12, 2020 and May 3, 2020. This occurred after the State of Oregon's COVID-19 stay-at-home order (which was issued on March 23, 2020) 
and after Portland State University's move to all-remote learning (which started with the Spring 2020 term, beginning on March 30, 2020). The invitation emails, one to a soft launch group of 100 students and the other to the remaining 7,900 students in the sample the next day, were followed by three reminders. All students received the remainders at the same times (i.e. the "soft launch" group received the exact same treatment as the larger group). The soft launch was used as a way to catch any errors in survey administration prior to the survey being administered to the larger group of 7,900 students. The primary change after the soft launch was that the consent form was kept the same, but its size was decreased, to make it easier to read.

The invitation email to the 7,900 students and the three reminders were all distributed prior to $7: 30 \mathrm{AM}$ on weekdays, so as to maximize response rates. The first reminder was sent on Monday, April 20, 2020, the second reminder was sent on Wednesday, April 23, 2020, and the final reminder was sent on Tuesday, April 28, 2020. Following the best practices identified above, the invitation emails and reminder emails used slightly different language, and were designed to engage possible respondents. As a way to incentivize participation, students who completed the survey were entered into a drawing for six, \$50 Amazon.com gift cards. In the invitation and reminder emails to students, it was indicated that the survey was estimated to take 5-10 minutes to complete. On average, it took respondents approximately 5 minutes to complete the survey. The invitation email, reminder emails and consent form are provided in Appendix $\mathrm{H}$. 


\subsubsection{Data Editing and Nonresponse Evaluation}

Once the survey was administered and the data was collected, the third major step in the measurement model phase was to edit the data by creating an analytic sample and then conduct an evaluation of the response rate, evaluate the representativeness of the sample, and investigate if there were any differences in the waves of respondents. Data editing "is the process of detecting errors in survey data and correcting the detected errors" [358] with a goal of deriving an analytic sample that adequately represents the target population.

Analytic Sample

2,363 respondents attempted or completed the survey, and the analytic sample was derived from this group through a detailed process. The analytic sample was defined as:

- Respondents who agreed to the consent form;

- Respondents who were not employees (a screening question was added to the survey to confirm the data pull from Portland State was accurate; student employees were not intentionally screened out);

- Respondents who had used myPSU;

- Respondents who answered all questions for the indicator variables (nonresponse check); and

- Respondents who were not unengaged (unengaged was defined as having straight-lined, or answered all of the indicator variable questions with the same response). 
The following were screened out of the analytic sample: 317 respondents who did not agree to the consent form, were a PSU employee or had not used myPSU before; and 171 respondents who started a survey but had not submitted it.

Next the data was examined to see if there were any patterns of missing data for variables [256]. Based on an analysis of the percent of missing responses for each variable involved in this study, there were not any patterns of missing data, as the percent of missing responses was consistent across all variables, at less than $1 \%$ for each of the indicator variables. A high proportion of missing data for a particular variable might indicate a problem with the survey question [256], [358]. Also, the data was examined to see if there were any patterns of missing data for variables [256], using an automated analysis in Stata 15.1, the software that was used for data analysis [378]. A high proportion of missing data for a particular variable might indicate a problem with the survey question [256], [358]. No patterns of missing data were identified.

The nonresponse check was next. Nonresponse "occurs when elements in the selected sample that are also eligible for the survey do not provide the requested information or that the provided information is not usable" [358]. This is a critical issue as it can lead to biased results and thus question the "validity of inference about the population" [358]. Per Hair et al. (2013) there are four basic remedies for addressing missing data problems, with one being the complete case, or listwise deletion approach, where any case with any missing 
data/responses is deleted. Listwise deletion is considered the most appropriate for SEM [256] and was used in this case. 11 cases had one or more missing responses on the indicator variables and were deleted.

Finally, unengaged respondents were considered. Unengaged respondents are those who may have answered each question with the same response [379]. This is referred to as non-response error, or item nonresponse. Standard deviation was used to determine if any respondents "straight-lined" (standard deviation of o) [379] on any questions in the research model (i.e. observed variables). 23 cases that straight-lined were deleted. This resulted in the analytic sample of 1,841 .

Table 24: Results for Developing the Analytic Sample

\begin{tabular}{|l|l|l|}
\hline $\begin{array}{l}\text { Response } \\
\text { type }\end{array}$ & Description & $\begin{array}{l}\text { Number of } \\
\text { responden } \\
\text { ts }\end{array}$ \\
\hline $\begin{array}{l}\text { Overall } \\
\text { response }\end{array}$ & & 2,363 \\
\hline & $\begin{array}{l}\text { Respondents who did not agree to the consent form, were a } \\
\text { PSU employee or had not used myPSU before }\end{array}$ & $(317)$ \\
\hline & Respondents who started a survey but had not submitted it. & $(171)$ \\
\hline & $\begin{array}{l}\text { Cases that had one or more missing responses on the } \\
\text { indicator variable. }\end{array}$ & $(11)$ \\
\hline $\begin{array}{l}\text { Analytic } \\
\text { sample }\end{array}$ & Unengaged respondents who "straightlined" & $(23)$ \\
\hline
\end{tabular}




\section{Response Rate and Sample Size Requirements}

Next, evaluating the response rate, or the "proportion of eligible elements in the sample for which a questionnaire has been completed," [358] was conducted. The response rate was calculated by dividing the total number of responses by the total number in the sample (excluding those who were ineligible and unreachable) [304]. Accepted response rates for web surveys include response rates below $10 \%$ and there is some agreement that "student surveys with a $10 \%$ or lower response rate can eventually be considered trustworthy if the researcher checks the response quality" [356]. Accepted ranges for $\mathrm{PhD}$ dissertation surveys range from $6.1 \%$ to $11.4 \%$ [226]. With an analytic sample of 1,841 , and a sample of 8,000 , the response rate was $23 \%$. Following these response rate guidelines and the guidelines outlined above, indicating a minimum SEM sample size ratio with a lower bound of 1:10 (indicators:respondents) [373], the analytic sample for this study is acceptable by wide margins, as this ratio would result in a sample size of at least 310 respondents (31 indicators were included in the data collection). The response rates are summarized below, as are the response rates in relation to the survey reminders.

Table 25: Survey Response Rates

\begin{tabular}{|l|l|l|l|}
\hline Response type & $\begin{array}{l}\text { Number of } \\
\text { respondents }= \\
\text { Sample size }\end{array}$ & $\begin{array}{l}\text { Sample size } \\
\text { of target } \\
\text { population }\end{array}$ & Response rate \\
\hline Overall response rate & 2,363 & 8,000 & $29.5 \%$ \\
\hline Analytic sample response rate & 1,841 & 8,000 & $23.0 \%$ \\
\hline
\end{tabular}




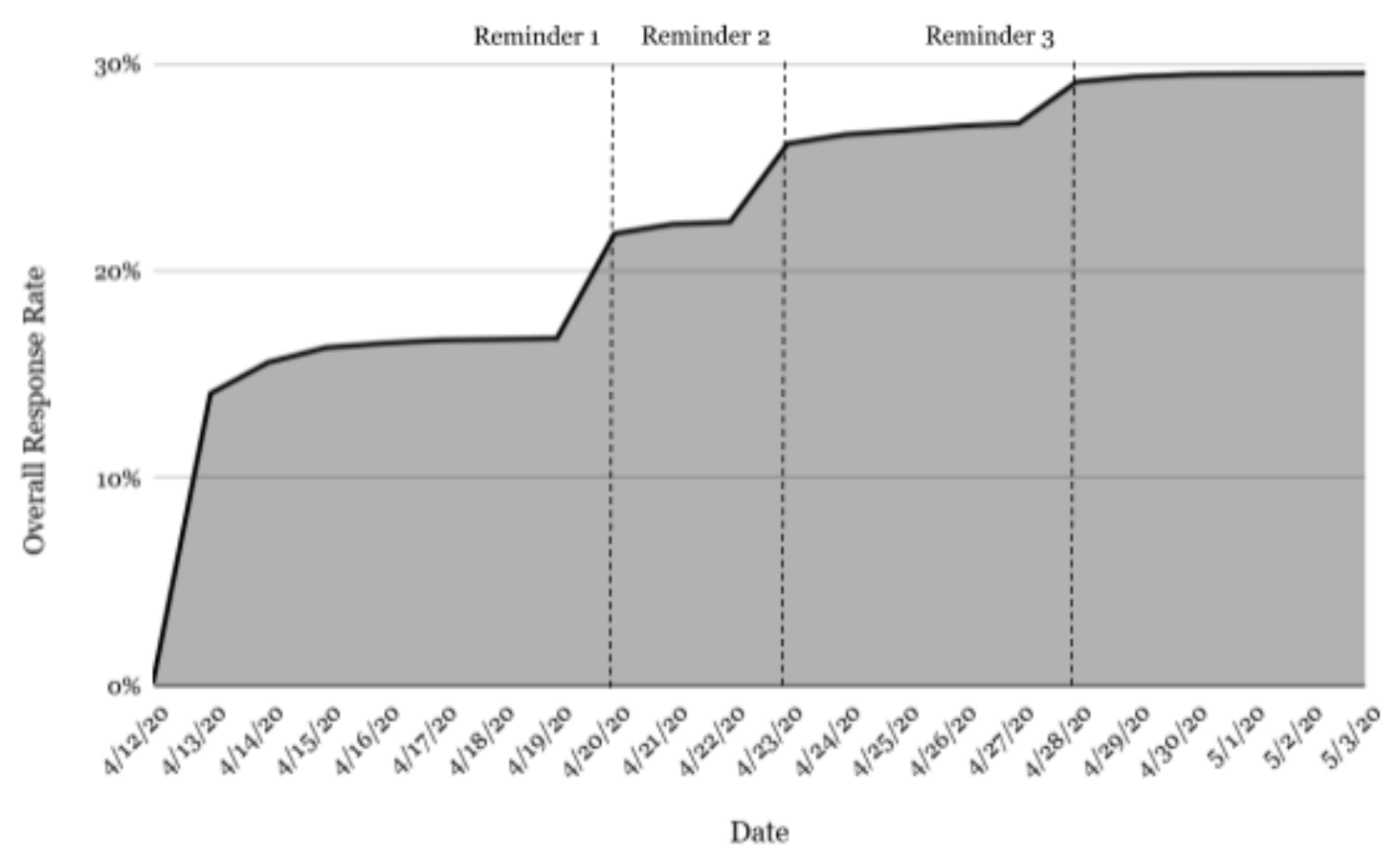

Figure 19: Visualization of the Overall Response Rate with Reminders

Representativeness Check

As an additional check to understand the validity of the inferences that can be drawn, the profile of the respondents can be compared to the target population using the auxiliary variables or background characteristics of the elements [358]. In the case of this study, respondents were compared to the target population by gender, age, student type (freshman or transfer), race/ethnicity, class standing (freshman, sophomore, etc.), full/part-time status, first-generation status, financial aid status and Pell grant status. Overall, when comparing the analytic sample respondents with the target population, the results show a generally representative sample with five of the nine variables 
(56\%) showing a five percentage point difference or less. The exceptions, where the percentage point difference is greater than five, are: Gender (11 percentage point difference), full/part-time status (5 percentage point difference), financial aid (18 percentage point difference) and Pell grant recipient status (8 percentage point difference). The representativeness comparisons are provided below in detail.

Table 26: Target Population and Demographics of Respondents (Analytic Sample)

\begin{tabular}{|c|c|c|c|c|c|}
\hline \multirow[b]{2}{*}{ Variable } & \multicolumn{2}{|c|}{ Target population } & \multicolumn{2}{|c|}{$\begin{array}{c}\text { Respondents (analytic } \\
\text { sample) }\end{array}$} & \multirow{2}{*}{$\begin{array}{l}\text { Difference } \\
\text { (percentag } \\
\text { e point, } \\
\text { except } \\
\text { age) }\end{array}$} \\
\hline & Count & Percent & Count & Percent & \\
\hline $\begin{array}{l}\text { Degree-seeking } \\
\text { undergraduate } \\
\text { students }\end{array}$ & 14,847 & 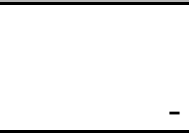 & 1,841 & - & \\
\hline \multicolumn{6}{|l|}{ Gender } \\
\hline Female & 8,141 & $55 \%$ & 1,214 & $66 \%$ & 11 \\
\hline Male & 6,507 & $44 \%$ & 612 & $33 \%$ & -11 \\
\hline No response & 199 & $1 \%$ & 15 & $1 \%$ & $\mathrm{O}$ \\
\hline Average age & 24.5 & - & 25.05 & & $\begin{array}{r}0.54 \\
\text { difference in } \\
\text { years }\end{array}$ \\
\hline \multicolumn{6}{|l|}{ Student type } \\
\hline Freshman & 5,793 & $39 \%$ & 688 & $37 \%$ & -2 \\
\hline Transfer & 8,992 & $61 \%$ & 1,147 & $62 \%$ & 1 \\
\hline Not known & 62 & $.42 \%$ & 6 & $\mathrm{O}$ & 0 \\
\hline \multicolumn{6}{|l|}{ Race/ethnicity } \\
\hline American Indian & 82 & $1 \%$ & 12 & $1 \%$ & $\mathrm{O}$ \\
\hline Asian & 1,191 & $8 \%$ & 123 & $7 \%$ & -1 \\
\hline Black & 502 & $3 \%$ & 50 & $3 \%$ & $\mathrm{O}$ \\
\hline Declined to Respond & 547 & $4 \%$ & 62 & $3 \%$ & -1 \\
\hline Hispanic/Latino & 2,441 & $16 \%$ & 293 & $16 \%$ & $\mathrm{O}$ \\
\hline International Student & 1,403 & $9 \%$ & 166 & $9 \%$ & $\mathrm{O}$ \\
\hline Multi Race & 1,143 & $8 \%$ & 125 & $7 \%$ & -1 \\
\hline Pacific Islander & 90 & $1 \%$ & 8 & $0.40 \%$ & $\mathrm{O}$ \\
\hline White & 7,448 & $50 \%$ & 1,002 & $54 \%$ & 4 \\
\hline
\end{tabular}




\begin{tabular}{|c|c|c|c|c|c|}
\hline Freshman & 1,141 & $8 \%$ & 162 & $9 \%$ & 1 \\
\hline Sophomore & 4,146 & $28 \%$ & 536 & $29 \%$ & 1 \\
\hline Junior & 7,564 & $51 \%$ & 899 & $49 \%$ & -2 \\
\hline Senior & 1,996 & $13 \%$ & 244 & $13 \%$ & $\mathrm{O}$ \\
\hline \multicolumn{6}{|l|}{ Full/part-time status } \\
\hline Full-time & 11,785 & $79 \%$ & 1,546 & $84 \%$ & 5 \\
\hline Part-time & 3,062 & $21 \%$ & 295 & $16 \%$ & -5 \\
\hline \multicolumn{6}{|l|}{ First-generation status } \\
\hline $\begin{array}{l}\text { Did not graduate from } \\
\text { college }\end{array}$ & 5,232 & $35 \%$ & 698 & $38 \%$ & 3 \\
\hline $\begin{array}{l}\text { Graduated from other 4-yr } \\
\text { institution }\end{array}$ & 5,635 & $38 \%$ & 709 & $39 \%$ & 1 \\
\hline $\begin{array}{l}\text { Graduated from Portland } \\
\text { State University }\end{array}$ & 730 & $5 \%$ & 84 & $5 \%$ & O \\
\hline Unknown & 3,250 & $22 \%$ & 350 & $19 \%$ & -3 \\
\hline Financial aid recipient & $\begin{array}{r}10,372 / 20,35 \\
7 \\
\end{array}$ & $51 \%$ & 1,268 & $69 \%$ & 18 \\
\hline Pell grant recipient & $8,175 / 20,357$ & $40 \%$ & 876 & $48 \%$ & 8 \\
\hline
\end{tabular}

Sources: Data provided by Portland State University as part of data pull for this study; and data pulled from the National Center for Education Statistics for 2017-18 (most recent year available [377]

In order to investigate if the percentage point differences that were greater than five were meaningful, and could have influenced the interpretation of the survey results, a one sample test of a proportion can be helpful for those variables that could be relevant to the interpretation of the survey. In this case, gender, financial aid status and Pell grant status could be germane to this research.

A one sample test of a proportion can be used to compare the proportion of the sample population with the reference value, i.e. the proportion of the target population (or also known as the population proportion), to see if there are meaningful differences between the two [380]. The null hypothesis is that the sample proportion is equal to the target proportion, with the alternative hypothesis that the sample proportion is not equal to the target population [381]. 
In this case using alpha $=0.05$, the null hypothesis is rejected if the test is statistically significant $(\mathrm{p}<.05)$ [381]. Thus, for each of the three variables with percentage point differences greater than five, a one sample test of a proportion was calculated. The results are that in all three cases, the results are statistically significant and thus the null hypothesis is rejected: in each case, the difference between the target population proportion and the sample proportion is not due to random sampling error (i.e. due to chance) - i.e., it is unlikely that the target population proportion and the sample proportion are the same at the alpha $=0.05$ significance level.

Table 27: One Sample Test of a Proportion Results

\begin{tabular}{|l|l|l|}
\hline Variable & p-value & Analysis \\
\hline Gender & $\mathrm{p}=0.00$ & $\begin{array}{l}\text { Results are statistically significant and reject the } \\
\text { null hypothesis: the difference between the target } \\
\text { population proportion and the sample proportion is } \\
\text { not due to random sampling error (i.e. due to } \\
\text { chance) - i.e., it is unlikely that the target } \\
\text { population proportion and the sample proportion } \\
\text { are the same at the alpha=0.05 significance level. }\end{array}$ \\
\hline Financial aid status & $\mathrm{p}=0.00$ & $\begin{array}{l}\text { Results are statistically significant and reject the } \\
\text { null hypothesis: the difference between the target } \\
\text { population proportion and the sample proportion is } \\
\text { not due to random sampling error (i.e. due to } \\
\text { chance) - i.e., it is unlikely that the target } \\
\text { population proportion and the sample proportion } \\
\text { are the same at the alpha=0.05 significance level. }\end{array}$ \\
\hline $\begin{array}{l}\text { Pell grant recipient } \\
\text { status }\end{array}$ & $\mathrm{p}=0.00$ & $\begin{array}{l}\text { Results are statistically significant and reject the } \\
\text { null hypothesis: the difference between the target } \\
\text { population proportion and the sample proportion is } \\
\text { not due to random sampling error (i.e. due to } \\
\text { chance) - i.e., it is unlikely that the target } \\
\text { population proportion and the sample proportion } \\
\text { are the same at the alpha=0.o5 significance level. }\end{array}$ \\
\hline
\end{tabular}


Based on the above results that three of the variables indicate the sample might not be as representative as would be ideal, it is important to consider in detail whether these three variables are relevant to technology adoption. In terms of gender, studies involving college students are inconclusive about its impact on technology adoption. Some studies have found there are no differences related to gender [254], [382], [383], including with respect to the use of technology itself [384], some studies are mixed in their findings (i.e. gender influenced some variables) [384], [252] and some studies found gender does influence adoption [385], [386], [387], [388].

In terms of financial need and how this might influence technology adoption, there is some evidence that college students who have higher financial need might disproportionately benefit from and rely on technology [7], [231]. Thus, it might not be surprising that proportionately more respondents when compared to the target population have greater financial need.

Also, it is important to note that the percentage point differences comparison for financial aid and Pell Grant statuses is likely only roughly accurate - which could influence whether there are any meaningful differences between the sample population and the target population - for two reasons. First, the data involved in the comparison was collected several years apart and student financial needs could have changed during this time. The most recent data for the target population that could be identified is from the 2017-18 academic year [377], while the target population data is from April 2020, approximately 
two-and-a-half years later. Second, there are important differences in the way the financial aid data was collected. The target population data with respect to financial aid and Pell grant eligibility reflects an action captured by federal authorities (whether a student received aid or not) while the sample population data is self-reported by students. These important differences could introduce accuracy errors relevant to the comparisons. Perhaps how "financial aid" was interpreted by students is different from the way that the financial aid information for the target population data is reported by the federal government, and it is possible that a student's memory might not have been accurate.

In summary, for the reasons stated above, overall it is not clear that when comparing the sample population and the target population, that the differences in the proportions of respondents related to gender, financial aid and Pell Grant status are meaningful, even though there are statistically significant differences, in light of the focus of this research on technology adoption. Thus, for the purposes of this study, the respondents, i.e. analytic sample, is considered to be appropriate for generalizing findings.

\section{Wave Analysis}

Next, the data was evaluated to gauge whether there were statistically significant differences between the respondents in each of the waves of the data collection using the analytic sample - this is the nonresponse error wave analysis. A one-way ANOVA was used on seven important variables - one for each of the constructs - comparing the mean responses for each variable across each of the 
four waves. The null hypothesis is that there are no differences between the groups. If there is statistical significance, one can reject the null hypothesis, meaning that the differences might not be due to random sampling error. However, if there is no significance, this means that the test fails to reject the null hypothesis and that the differences are likely due to random sampling error, or in other words, due to chance [380]. The results below show that for all seven variables across all of the four waves, there are no statistically significant differences at $\mathrm{p}<.05$, meaning that any differences in the means of the groups are due to random sampling error, or by chance. The ANOVA results of the seven variables are provided below.

Table 28: ANOVA Results for Performance Expectancy (Item PE1)

\begin{tabular}{|c|c|c|c|c|c|}
\hline \multirow[b]{2}{*}{ Source } & \multicolumn{3}{|c|}{ Analysis of Variance } & \multirow[b]{2}{*}{$\mathbf{F}$} & \multirow[b]{2}{*}{ Prob $>F$} \\
\hline & SS & $d f$ & MS & & \\
\hline Between groups & 4.96489692 & 3 & 1.65496564 & 2.40 & 0.0659 \\
\hline Within groups & 1265.01555 & 1837 & .688631219 & & \\
\hline Total & 1269.98045 & 1840 & .690206764 & & \\
\hline
\end{tabular}

Table 29: ANOVA Results for Effort Expectancy (Item EE1)

\begin{tabular}{|c|c|c|c|c|c|}
\hline \multirow{2}{*}{ Source } & \multicolumn{3}{|c|}{ Analysis of Variance } & \multirow[b]{2}{*}{$\mathbf{F}$} & \multirow[b]{2}{*}{ Prob $>F$} \\
\hline & SS & $d f$ & MS & & \\
\hline Between groups & .935586621 & 3 & .311862207 & 0.40 & 0.7558 \\
\hline Within groups & 1446.44084 & 1837 & .787392945 & & \\
\hline Total & 1447.37643 & 1840 & .786617623 & & \\
\hline
\end{tabular}


Table 30: ANOVA Results for Social Influence (Item SI1)

\begin{tabular}{|c|c|c|c|c|c|}
\hline \multirow[b]{2}{*}{ Source } & \multicolumn{3}{|c|}{ Analysis of Variance } & \multirow[b]{2}{*}{$\mathbf{F}$} & \multirow[b]{2}{*}{ Prob $>F$} \\
\hline & ss & $d f$ & MS & & \\
\hline Between groups & 1.10919333 & 3 & .369731109 & 0.31 & 0.8176 \\
\hline Within groups & 2185.44485 & 1837 & 1.18968147 & & \\
\hline Total & 2186.55405 & 1840 & 1.18834459 & & \\
\hline
\end{tabular}

Table 31: ANOVA Results for Facilitating Conditions (Item FC1)

\begin{tabular}{|c|c|c|c|c|c|}
\hline \multicolumn{6}{|c|}{ Analysis of Variance } \\
\hline Source & SS & $d f$ & MS & $F$ & Prob $>F$ \\
\hline Between groups & 4.9382881 & 3 & 1.64609603 & 1.99 & 0.1129 \\
\hline Within groups & 1516.64889 & 1837 & .825611809 & & \\
\hline Total & 1521.58718 & 1840 & .826949555 & & \\
\hline
\end{tabular}

Table 32: ANOVA Results for Perceived Quality (Item PQ1)

\begin{tabular}{|c|c|c|c|c|c|}
\hline \multirow[b]{2}{*}{ Source } & \multicolumn{3}{|c|}{ Analysis of Variance } & \multirow[b]{2}{*}{$\mathrm{F}$} & \multirow[b]{2}{*}{ Prob $>F$} \\
\hline & ss & $d f$ & MS & & \\
\hline Between groups & 2.44067962 & 3 & .813559872 & 1.18 & 0.3167 \\
\hline Within groups & 1268.82168 & 1837 & .690703145 & & \\
\hline Total & 1271.26236 & 1840 & .690903455 & & \\
\hline
\end{tabular}

Table 33: ANOVA Results for Self-Efficacy and Skills (Item SS1)

\begin{tabular}{|c|c|c|c|c|c|}
\hline \multicolumn{6}{|c|}{ Analysis of Variance } \\
\hline Source & ss & $d f$ & MS & $\mathrm{F}$ & Prob $>F$ \\
\hline Between groups & 1.7727075 & 3 & .590902498 & 0.73 & 0.5351 \\
\hline Within groups & 1490.67162 & 1837 & .811470668 & & \\
\hline Total & 1492.44432 & 1840 & .811111046 & & \\
\hline
\end{tabular}


Table 34: ANOVA Results for Behavior Intention (Item BI1)

\begin{tabular}{|c|c|c|c|c|c|}
\hline \multirow[b]{2}{*}{ Source } & \multicolumn{3}{|c|}{ Analysis of Variance } & \multirow[b]{2}{*}{$\mathbf{F}$} & \multirow[b]{2}{*}{ Prob $>F$} \\
\hline & SS & $d f$ & MS & & \\
\hline Between groups & 5.59372587 & 3 & 1.86457529 & 2.27 & 0.0787 \\
\hline Within groups & 1509.39269 & 1837 & .821661783 & & \\
\hline Total & 1514.98642 & 1840 & .823362185 & & \\
\hline
\end{tabular}

\subsection{Principal Components Analysis}

The fourth step in the measurement model development process is to conduct a Principal Components Analysis followed by a reliability analysis. Importantly from this step onward in SEM, the steps are often conducted iteratively, as was done in this study.

Principal Components Analysis is used to evaluate whether the latent constructs and their indicators are measuring what the theory suggests they ought to be measuring. Or, in other words, it is used to "explore how many factors (and which indicators) are appropriate" for a measurement model [257]. Thus, the output of this step is that adjustments to the indicators are made to better specify the measurement model.

Factor analysis is an "interdependence [statistical] technique whose primary purpose is to define the underlying structure among the variables in the analysis" [256]. In this technique, a factor consists of a linear combination of variables that are "highly interrelated" and as such, it enables researchers to examine a large number of variables [256]. "It is hoped, generally, that the $\mathrm{k}$ constructs will explain a good portion of the variance in the original $\mathrm{j} \times \mathrm{j}$ matrix of associations (e.g., correlation matrix) so that the constructs, or factors, can 
then be used to represent the observed variables" [389]. For example, one might be interested in studying leadership, but there could be many variables that relate to leadership. Factor analysis could be used to identify groups of interrelated variables that help to measure components of leadership.

Two primary approaches to factor analysis are exploratory factor analysis (EFA) and confirmatory factor analysis (CFA). EFA can be used to identify the factors, or latent variables, for a linear combination of variables and can be used to "generate theory" [389] when there is little knowledge about how variables could be related [343]. At times, EFA is used by a researcher "even though they have a well developed idea about the factor structure and wants to confirm it" [390]. Additionally, EFA attempts to identify the number of factors and does not specify which items/indicators load onto which factors [390]. Principal components analysis is most commonly used in EFA [258] as a means of extracting factors from a data set.

Once the factors are extracted, they are often rotated in order to redistribute the variance to achieve a simpler factor pattern [256], i.e. one where variables load "heavily on one and only one factor" [258]. Two common rotations are the orthogonal and oblique rotations. Conducting both the orthogonal and the oblique rotations, which were undertaken in this study, enables an understanding of whether the factors are correlated and "if the factors are uncorrelated, orthogonal and oblique rotation will produce nearly identical 
results" [391]. The goal is that factors are largely uncorrelated, meaning they are measuring unique constructs.

When using an orthogonal rotation, one assumes that the factors are supposed to be different theoretically [355] and uncorrelated [258]. An orthogonal varimax rotation with Kaiser on was used, which makes it easy to identify each indicator with a single factor [258]. The pattern matrix results were used, as they are what is commonly reported [256], [285]. Additionally, varimax focuses on simplifying the columns of a factor matrix to make the number of high loadings as few as possible and is the most common method [258], [256]. "A varimax solution yields results which make it as easy as possible to identify each variable with a single factor" [258]. A factor loading "represents the correlation between an original variable and its factor" [256].

An oblimin oblique rotation with Kaiser on was also used. An oblique rotation creates a simpler structure compared to an orthogonal varimax rotation, as an oblique rotation allows correlated factors instead of maintaining independence between rotated factors, as happens with a varimax rotation [256]. One risk of an oblique rotation is that allowing the factors to be correlated might create a situation, especially for small samples or a low case-to-variable ratio, where the factors are specific to the sample and not generalizable [256].

Comparing the results from the varimax and oblique rotations helps with refining the measurement model. The orthogonal varimax rotation in Stata 15.1 (the statistical analysis software used in this research) maintains only factors 
with eigenvalues of greater than 1 , which is commonly used as the criteria for significance [256]. The goal is to keep indicators with factor loadings that are greater than .50 , which is a commonly accepted threshold for practical significance [256], although loadings of .4 can be used as well [355] and ideally, loadings are at least .7 , indicating that an indicator loads heavily on a construct [258]. At .7, "this is the level at which the latent variable is explaining at least half of the variance in the indicator variable in the measurement model" [257]. Additionally, cross-loadings (where an indicator loads onto multiple factors) are examined. The criteria are that ideally any indicators that cross-load are dropped [392] or that in some cases depending on theoretical justifications, small cross-loadings can be accepted [256], [393]. It is also important to keep in mind that generating meaning from factors hinges on a researcher's perspective and as such is subjective [389]. The result of the orthogonal and oblique rotations result in a revised measurement model, i.e. a revised mapping of the indicators with their related latent constructs, or factors.

Next, a reliability analysis can be conducted to test the internal consistency for each of the latent constructs in the measurement model, that is to gauge whether taken together, the indicators are measuring the same underlying structure and if so, forming a reliable factor [394]. Cronbach's alpha is often used as it is the most common measure of internal consistency [355], or the degree to which "multiple indicators for a latent variable belong together" [257]. Cronbach's alpha ranges from o to 1 [256], [304] and values of 0.7 or above are 
often interpreted to mean that the questions/indicators for each construct have an acceptable level of internal consistency and reliability [304], [226], [16], although it may be appropriate to accept slightly lower coefficients for a compelling rationale [16]. Conducting reliability analysis in tandem with factor analysis and/or SEM is accepted in the technology evaluation and acceptance literature [394], [350]. The results of the principal components analysis and the reliability analysis are a measurement model that consists of indicators and factors that adequately represent the underlying structures, or latent constructs, in a model.

\subsection{Confirmatory Factor Analysis}

The fifth and final step in the measurement model development process is to use CFA to develop statistics to further evaluate the degree to which the latent constructs are measured by the indicator variables, also known as the confirmatory factor analysis step [257]. CFA is used to test a theory when a strong rationale for the factors and variables that define each factor are known [389], [256]. CFA is different from EFA because CFA investigates how well a hypothesized factor structure fits with the data [390] - i.e. it tests the degree to which specific indicators load onto specific factors. In CFA, "the researcher's a priori assumption is that each factor is associated with a specified subset of indicator variables" [258]. There are no structural relationships between latent variables in this stage however, only within the latent variables. The statistics that are used at this stage to evaluate the model are goodness of fit measures, the 
significance of path weights, discriminant validity and modification indices [257]. Principal factor analysis (PFA) is the primary technique in confirmatory research and also for CFA in structural equation modeling [258].

While there are no simple rules about goodness of fit measures that distinguish good from poor models, a commonly accepted guideline is to use three to four fit indices of differing types [256], [257], with at least one absolute index and one incremental index, and to report the chi-square value along with the associated degrees of freedom [256]. Chi-square is a "statistical measure of difference used to compare the observed and estimated covariance matrices" [256]. Degrees of freedom, or df, is the "number of bits of information available to estimate the sampling distribution of the data after all model parameters have been estimated" [256]. An absolute fit index is "a direct measure of how well the model specified by the researcher reproduces the observed data" and provides a basic evaluation of "how well a researcher's theory matches the sample data" [256]. An incremental fit index assesses how "well the estimated model fits relative to some alternative baseline model" [256]. It is also best practice to report chi-square $\left(\chi^{2}\right)$ and the associated degrees of freedom [256]. Of note, goodness-of-fit index (GFI) and adjusted goodness-of-fit are no longer preferred [257], and normed chi-square is not highly regarded [255].

A few notes about fit measures are important to consider: they overestimate good fit when the sample is small [257]; they are influenced by the number of indicator variables - "a model with fewer indicators per factor will 
have a higher apparent fit than a model with more indicators per factor" [257]; simpler models with smaller samples should be evaluated more strictly than more complex models with larger samples [256]; and conversely, complex models with smaller samples may need less strict criteria [256]. This study will report chi-square $\left(\chi^{2}\right)$ and the associated degrees of freedom, and use root mean square error of approximation (RMSEA; absolute fit index), standardized root mean square residual (SRMR; absolute fit index), and the comparative fit index (CFI; incremental fit index).

The chi-square $\left(\chi^{2}\right)$ statistic is the only statistically based SEM measure, and it is the "fundamental measure of differences between the observed and estimated covariance matrices" [256]. However, using it as the only evaluation measure of a model is problematic [255] [256]. In particular, chi-square is sensitive to sample size, and less meaningful as sample sizes become larger. For samples sizes of greater than 250, with 30 or more observed variables, significant p-values for chi-square are to be expected [256]. For this study, chi-square (along with significance) and the associated degrees of freedom will be reported.

Root mean square error of approximation, or RMSEA, is widely used, and attempts to correct for a large sample or a large number of observed variables, and also attempts to correct for model complexity [256]. The cut-off values in this study are as follows: good model fit if RMSEA is less than or equal to .05; adequate fit if RMSEA is less than or equal to .08; and RMSEA of .10 or greater is a poor fit [257], [339]. 
Standardized root mean residual (SRMR), another absolute fit index, is an alternative to the root mean square residual (RMR), and can be considered one of a handful of badness-of-fit measures, where a high value indicates a poor fit [256]. SRMR $=0$ indicates a perfect fit, with rules of thumb of a cut-off as high as $<.10$ to as low as .05 [257]. This study uses the rule of thumb that an SRMR greater than .10 suggests a problem with fit [256].

Finally, this study used an incremental fit index, the comparative fit index (CFI). CFI is one of the most widely reported incremental fit indexes [256] and is an improved version of the normal fit index. It is one of the measures that is the least affected by sample size [257]. CFI varies from o to 1 , where a CFI close to 1 indicates a very good fit. It is generally accepted that a CFI of $>.9$ is usually associated with a model that fits well [256] and is the standard used in this study.

It is important to mention that specific cut-off points are considered somewhat arbitrary: "Fit is relative to progress in the field. Although there are rules of thumb for acceptance of model fit (ex., that CFI should be at least .90), Bollen (1989) observes that these cut-offs are arbitrary. A more salient criterion may be simply to compare the fit of one's model to the fit of other, prior models of the same phenomenon. For example, a CFI of .85 may represent progress in a field where the best prior model had a fit of .70" [257]. Additionally and importantly, one can gain additional insight into the goodness of fit of a structural model by comparing fit statistics with the CFA, or measurement model, which provides a baseline for comparison [256]. One can conclude that 
the "structural theory lacks validity if the structural model fit is substantially worse than the CFA model fit" [256].

Table 35: Goodness of Fit Measures and Recommended Values

\begin{tabular}{|c|c|c|}
\hline $\begin{array}{l}\text { Statistic or measure } \\
\text { name }\end{array}$ & Description & $\begin{array}{l}\text { Recommended } \\
\text { value }\end{array}$ \\
\hline Chi-square, $\chi^{2}$ & $\begin{array}{l}\text { Measures differences between the } \\
\text { observed and estimated covariance } \\
\text { matrices. Reported with degrees of } \\
\text { freedom. }\end{array}$ & $\begin{array}{c}\chi^{2} \text { expected to not be } \\
\text { significant with sample } \\
\text { sizes larger than } \mathrm{n}>250 \\
\text { and the number of } \\
\text { observed variables is } \\
\text { greater than or equal to } \\
30 .\end{array}$ \\
\hline $\begin{array}{l}\text { Root mean square error } \\
\text { of approximation } \\
\text { (RMSEA) }\end{array}$ & $\begin{array}{l}\text { Attempts to correct for a large sample or a } \\
\text { large number of observed variables, and } \\
\text { also attempts to correct for model } \\
\text { complexity. }\end{array}$ & $\leq .05$ \\
\hline $\begin{array}{l}\text { Standardized root mean } \\
\text { residual (SRMR) }\end{array}$ & $\begin{array}{l}\text { An alternative to the root mean square } \\
\text { residual (RMR), and can be considered } \\
\text { one of a handful of badness-of-fit } \\
\text { measures, where a high value indicates a } \\
\text { poor fit. }\end{array}$ & $<.10$ \\
\hline $\begin{array}{l}\text { Comparative fit index } \\
\text { (CFI) }\end{array}$ & $\begin{array}{l}\text { Assesses how well the estimated model } \\
\text { fits in comparison to a baseline model, } \\
\text { usually the null model, which assumes } \\
\text { that all observed variables are } \\
\text { uncorrelated. It is one of the measures } \\
\text { that is the least affected by sample size. }\end{array}$ & $>.9$ \\
\hline
\end{tabular}

In addition to evaluating a measurement model by using goodness of fit measures, a researcher also can evaluate the significance of the indicator paths that is, the loadings that each indicator has on a construct and the significance of the loadings [257], [256], which is one means to evaluate the convergent validity [256]. Loadings (i.e. standardized loading estimates) should be at least .5 and ideally .7 or higher. Non-significant estimates suggest an item should be dropped and a significant loading does not indicate an item might be performing well 
enough [256], [257]. When the loading is .7, "this is the level at which the latent variable is explaining at least half of the variance in the indicator variable in the measurement model" [257]. Importantly, the loadings should also be examined to see if there are any overall problems. For example, standardized loadings of greater than 1.0 or below -1.0 indicate problems with a model [256].

An additional evaluation step is to look at discriminant validity, which aids in determining the distinctiveness of the latent constructs [256], [395]. In order to assess discriminant validity, one can compare the Average Variance Extracted (AVE) to the squared correlations between constructs [256]. AVE is "the mean variance extracted for the items loading on a construct and is a summary indicator of convergence" [256]. AVE of .5 or greater is an accepted rule of thumb for adequate convergence, and AVE of less than .5 indicates that "on average, more error remains in the items than the variance explained by the latent factor structure imposed on the measure" [256]. For discriminant validity, one looks for the AVE estimates to be larger than the corresponding squared correlation constructs [256], which was originally proposed by Fornell and Larcker (1981) [396].

Finally, measurement models can also be evaluated by looking at modification indices (MIs), which are estimates of "how much the chi-squared will be reduced if we estimated a particular extra parameter" [339], and are calculated for every possible relationship that is not estimated in a model [256]. MIs suggest where adding an arrow/path or co-variance might improve the 
model fit [257]. The usual approach is to overfit the model by changing only one parameter at a time - as the MIs will change at each step and the structural coefficients and their significance may change, too - and then dropping paths one at a time based on the likelihood ratio (chi-square difference) test or Wald tests of the significance of the structural coefficients [257]. Large modification indices can indicate candidates for drawing an arrow, but rules-of-thumb about the definition of "large" vary, from an MI that is $>4,>10,>30$ and $>100$ and that "the MI is simply a flag which suggests to the researcher which arrows to consider" [257]. Researchers can also add a path for the largest MI and "in a measurement model, the researcher typically looks at MI's for the error covariances connecting indicators for two different latent variables" [257]. Importantly, arrows should be added when they align with theory and such changes should improve the model fit to an acceptable level [257], [339]. When the model has grown as far as appropriate, then a researcher can start model trimming based on non-significant structural paths, such as a $\mathrm{p}$-value/significance level of $\mathrm{p}<.01$ level for a more stringent approach, rather than the customary $\mathrm{p}$-value of $\mathrm{p}<.05$ [257].

The results of the measurement model evaluation are often presented in terms of the standardized loading estimates and their significance, as well as identifying the best measurement model. 


\subsection{SEM Process - Structural Model}

\subsubsection{Specify Structural Model}

Once the measurement model has been specified and then improved to create an adequate fit, the researcher begins the second major phase of SEM developing and assessing the structural model. As a reminder, the structural model is "the set of exogenous and endogenous latent and simple variables in the model (but not indicator variables), together with the direct effects (straight arrows) connecting them, covariances connecting the exogenous variables, and the disturbance terms for endogenous variables" [257]. A structural model represents the theory of the research, often represented in a visual diagram, and the main goal at this step is to examine the relationships between the latent constructs and to test the hypothesized theoretical model [256]. To create the structural model, the researcher specifies relationships between the latent variables. The structural model shows the structural relationships between all factors, the type of relationships (whether direct or indirect) and the significance of each relationship [226], [256].

\subsubsection{Evaluate Structural Model}

Structural models are evaluated in largely the same ways as measurement models are evaluated, using goodness of fit measures, significance tests for paths and modification indices [257]. In Stata 15.1, which was used for this study, the Lagrange multiplier (LM) statistic is provided, rather than the MI statistics. LM serves the same function [257]. For the structural model evaluation, this study 
used the same goodness of fit measures and recommended values as were used in CFA. After evaluating the structural model, one might consider modifying it. Modifications can include adding paths and/or covariance (model building/growing), or removing paths and/or covariance (model trimming) [257]. Critically, any respecifications of the model must be based on strong theoretical and empirical support [256], while at the same time balancing the goals of model simplicity (parsimoniousness) with goodness of fit, which sometimes can be negatively affected by removing items from a model. The results of this evaluation and any possible modifications are the final structural model.

\subsubsection{Identify Final Structural Model}

The final step in the SEM process is to identify the final structural model (select the best fitting model from above) and analyze the research study's hypotheses in light of the results. In terms of interpreting the results of structural models, researchers look at the goodness of fit measures, and also the directionalities of the presumed causal effects, which are represented by arrows in the visual model depictions and are drawn to connect the latent constructs based on theory, time precedence and the direction of the inferred causal relationship [255]. Researchers also look at the path coefficients, which are "statistical estimates of direct effects" [255] between latent constructs or between indicators and their related latent constructs. Path coefficients, or path estimates or structural parameter estimates, are the "SEM equivalent of a regression 
coefficient that measures the linear relationship between a predictor construct and an outcome construct” [256]. When path coefficients are standardized (which is a common approach) - meaning that the variable is transformed so its mean is 0 and its standard deviation is 1 [255], which enables comparing variables that are measured in different units or scales [397] - it is possible to directly compare the magnitude of various standardized path coefficients from the same model [255].

For example, the magnitude of the standardized direct effect of a standardized path coefficient of .40 is about four times greater than standardized direct effect of a standardized path coefficient of .10 [255]. Additionally, when analyzing the path coefficients, it is critical to look at their statistical significance (i.e. an individual effect) to understand whether or not the hypothesis of a relationship between variables is supported [255]. In SEM, statistical tests can carry less weight, as "there is some sense in SEM that the view of the entire landscape (the whole model) has precedence over that of specific details (individual effects)" [255].

Additionally, when considering the relationships between latent constructs, the path coefficient represents the response of the dependent variable/construct to a one-unit change in the explanatory variable/construct, when the other variables in the model are held constant [398]. For example, a positive path coefficient means that a one-unit increase in the explanatory construct leads to a direct and positive increase in the dependent construct that is 
proportional to the path coefficient [399]. For example, if a path coefficient for the influence of $A$ on $B$ is .10 , this means that for every one-unit increase in $A, \mathrm{~B}$ will increase by .10 [399]. Also, a negative coefficient can be interpreted to mean that a one-unit increase in the explanatory construct leads to a direct and negative increase in the dependent construct that is proportional to the path coefficient. For example, if a path coefficient for the influence of A on B is -..10, this means that for every one-unit increase in A, B will decrease by .10

Finally, it might be important to consider the strength or size of a standardized path coefficient. While there is some hesitation in the literature about providing interpretive guidelines of effect size, there are rough guidelines, which are intended for when "there is little theoretical or empirical basis to differentiate between smaller versus larger effects, which is most likely to happen in new research areas" [255]. One set of guidelines are: the absolute values of standardized path coefficients that are less than .10 may indicate a "small" effect; values around .30 may indicate a "medium" effect; and values $\geq .50$ might be "large" effects [255].

The model results can also be used to determine the variances for the endogenous constructs using the $\mathrm{R}^{2}$ statistic, which is independent of the model fit statistics [255]. The same general guidelines apply for interpreting $\mathrm{R}^{2}$ in SEM as with multiple regression [256].

Additionally, it is common that when providing the responses for each of the survey items, basic statistics are provided to aid with interpretation of each 
item, such as the mean, as a measure of central tendency [16], the variance and the standard deviation [16], [226]. 


\section{Chapter Nine: Structural Equation Modeling Analysis and Results}

This chapter presents the results from the SEM analysis, which entailed developing three different modeling approaches, in an effort to identify a model in line with UTAUT and the research model that best fit the survey data. The first approach, "Approach \#1", used the full research model and the analytic sample from the data collection, but did not use PCA (principal components analysis, or factor analysis) prior to CFA (confirmatory factor analysis). The second approach, "Approach \#2", started with the full research model and used the analytic sample, but employed PCA (factor analysis) for the constructs that were hypothesized to influence Behavioral intention, prior to CFA. The third approach, "Approach \#3", started with the full research model and used the analytic sample, but employed PCA (factor analysis) for all constructs in the research model. Approach \#1 and Approach \#2 each failed to identify a structural model with an adequate fit. As a result, the researcher pivoted to consider Approach \#3, which resulted in a structural model that fit the data. Approach \#3 was then named as the revised research model and is interpreted in light of this study's research questions. The pivot towards Approach \#3 enhanced this researcher's understanding of not only SEM and PCA, but also how exploring new research topics asks for open-mindedness and a drive to fully explore theoretical models and their relationships with reality. As a reminder, the research model, which all three approaches are based on, the research hypotheses and the taxonomy are provided below. 


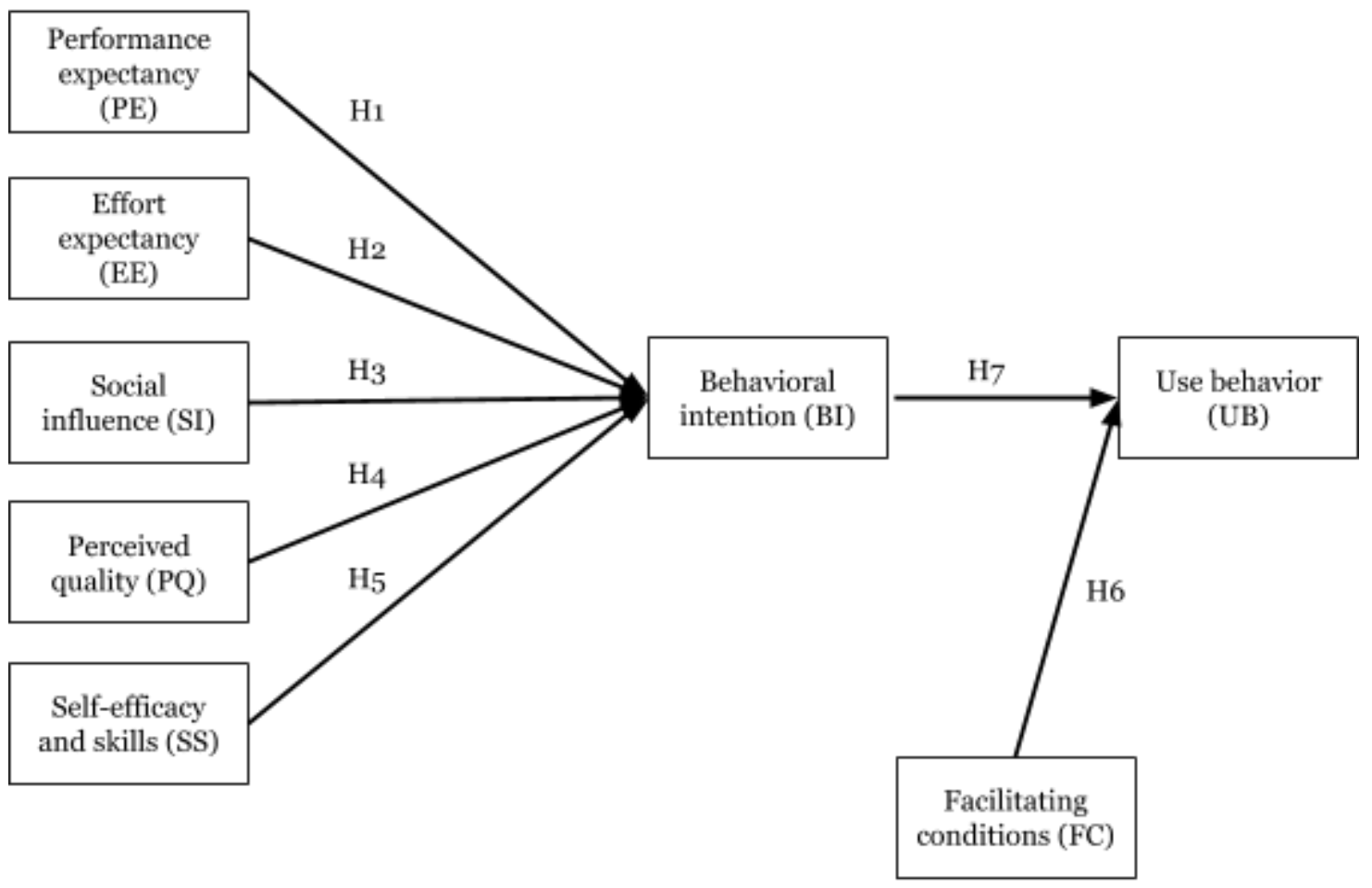

Figure 20: Visual Diagram of Research Model with Hypotheses 


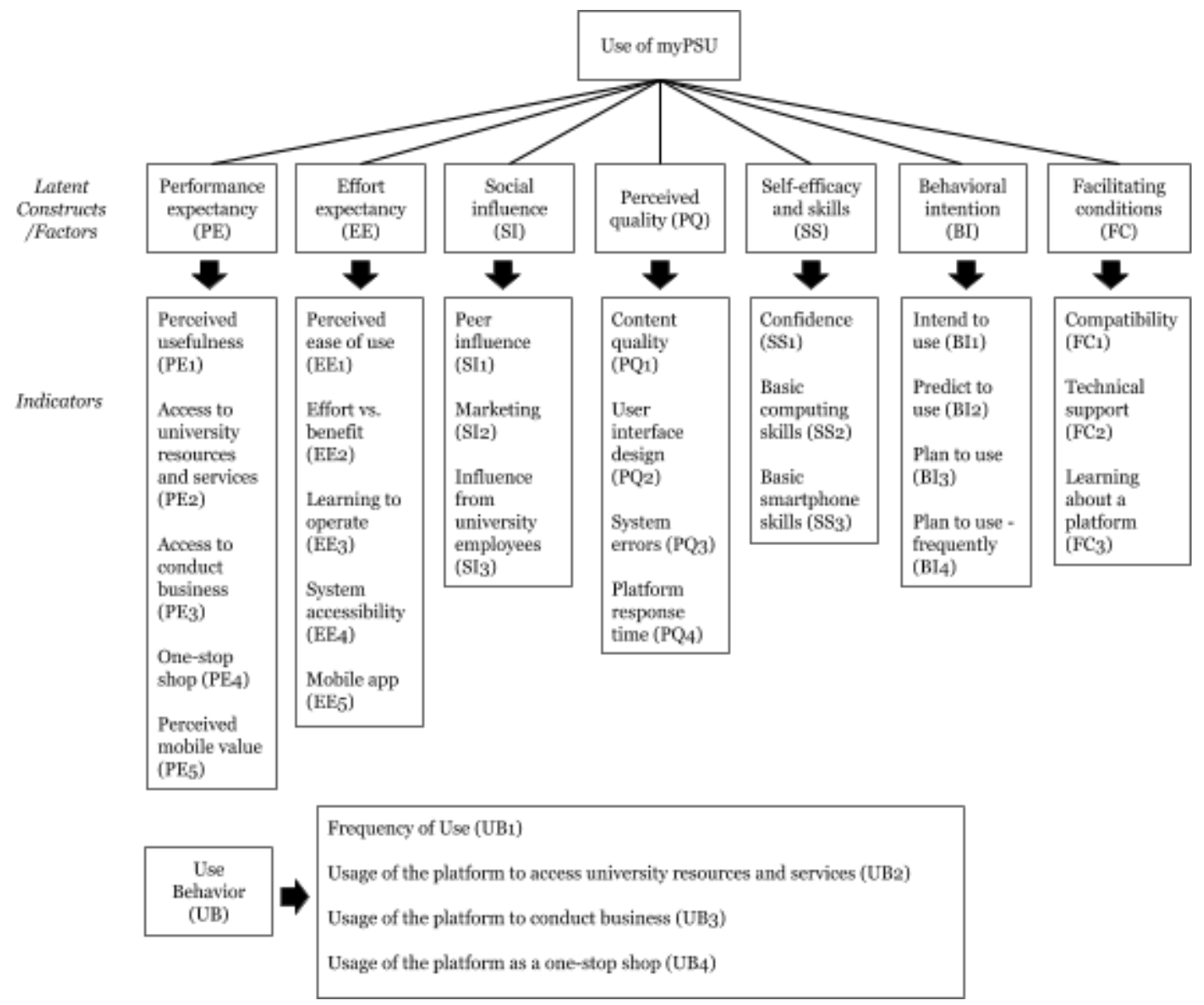

Figure 21: Research Model Factors and Indicators, Organized as a Taxonomy

\subsection{Descriptive Statistics for Each Indicator}

Before beginning the SEM analysis, it is helpful to review the means (a measure of central tendency) and the standard deviations (a measure of variability) of the responses to the indicators in the research model. All indicators used a five-point Likert scale. 30 of the variables used an agreement scale (1. Strongly disagree; 2. Disagree; 3. Neutral; 4. Agree; 5. Strongly agree) and one variable, UB1, Frequency of use, used a frequency scale (1. Rarely; 2. Several times per term; 3. Several times per month; 4. Weekly; 5 . Daily). The range of 
the means is from 2.49 (SI2, Marketing) to 4.65 (SS3, Basic smartphone skills). Nine of the 31 indicators, or $29 \%$, have a mean of 4.0 or larger (agree or strongly agree), three of the 31 indicators, or 10\%, have a mean of less than 3.0 (strongly disagree or disagree), and 19 , or $61 \%$, have a mean between 3.0 and less than 4.0 (neutral). The standard deviations range from 0.59 ( $\mathrm{SS}_{3}$, Basic smartphone skills) to 1.38 (UB1, Frequency of use). 12, or $39 \%$, of the indicators have standard deviations between 1.0 and 1.38 , and 19 , or $61 \%$, of indicators have a standard deviation of less than 1.o. The frequencies and means for each indicator are provided in Appendix I.

\subsection{SEM Approach \#1}

Approach \#1 used the full research model and the analytic sample from the data collection, but did not use PCA (principal components analysis, or factor analysis) prior to CFA (confirmatory factor analysis).

\subsubsection{Reliability Analysis- Approach \#1}

The first step for Approach \#1 was to conduct a reliability analysis using Cronbach's alpha, with ideally alpha coefficients of at least 0.7, but slightly lower amounts can be acceptable as well. Alpha coefficients of 0.7 or above are often interpreted to mean that the questions/indicators for each construct have an acceptable level of internal consistency and reliability [304], [226], [16], although it may be appropriate to accept slightly lower coefficients for a compelling rationale [16]. The reliability analysis results, provided below, show that of the original constructs, six of the eight, or $75 \%$ have alpha coefficients of at least 0.7 . 
The two constructs with alpha coefficients below 0.7 are both acceptable: Facilitating conditions has an alpha of 0.63 and Self-efficacy and skills has an alpha of 0.60 . Facilitating conditions is left intact as when looking at the item scale correlations, no changes are warranted [400]. However, for Self-efficacy and skills, when looking at the item scale correlations, dropping item SS1 increases Cronbach's alpha to 0.82. Thus, the Confirmatory Factor Analysis step will start with a baseline measurement model that includes all indicators in the original research model except for item SS1. Since SS1 (Confidence) was the only variable related to self-efficacy, the Self-efficacy and skills construct was renamed as Skills. With this change, seven of the eight constructs, or $87.5 \%$, have alpha coefficients that exceed the ideal value of 0.7 .

Table 36: Approach \# 1 Reliability Analysis

\begin{tabular}{|l|c|c|l|}
\hline Construct & $\begin{array}{l}\text { Number of } \\
\text { Indicators/Ite } \\
\text { ms }\end{array}$ & $\begin{array}{l}\text { Cronbach's } \\
\text { Alpha }\end{array}$ & Analysis \\
\hline $\begin{array}{l}\text { Performance } \\
\text { expectancy } \\
\text { factor (PE) }\end{array}$ & 5 & 0.89 & Exceeds cut-off of 0.7 - no changes \\
\hline $\begin{array}{l}\text { Effort } \\
\text { expectancy } \\
\text { factor (EE) }\end{array}$ & 5 & 0.84 & Exceeds cut-off of 0.7 - no changes \\
\hline $\begin{array}{l}\text { Social influence } \\
\text { factor (SI) }\end{array}$ & 3 & 0.71 & Exceeds cut-off of o.7 - no changes \\
\hline $\begin{array}{l}\text { Facilitating } \\
\text { conditions } \\
\text { factor (FC) }\end{array}$ & 3 & 0.63 & $\begin{array}{l}\text { Does not exceed ideal cut-off of o.7, } \\
\text { and when looking at item scale } \\
\text { correlations, no changes are } \\
\text { warranted [400] }\end{array}$ \\
\hline $\begin{array}{l}\text { Perceived } \\
\text { quality factor } \\
\text { (PQ) }\end{array}$ & 4 & 0.83 & \begin{tabular}{l} 
Exceeds cut-off of o.7 - no changes \\
\hline Self-efficacy
\end{tabular} \\
\hline
\end{tabular}




\begin{tabular}{|l|c|c|l|}
\hline $\begin{array}{l}\text { and skills factor } \\
\text { (SS) }\end{array}$ & & $\begin{array}{l}\text { and when looking at the item scale } \\
\text { correlations, dropping item SS1 } \\
\text { increases Cronbach's alpha to } 0.82 \\
\rightarrow \text { drop item SS1 }\end{array}$ \\
\hline $\begin{array}{l}\text { Behavioral } \\
\text { intention factor } \\
\text { (BI) }\end{array}$ & 4 & 0.94 & Exceeds cut-off of 0.7 - no changes \\
\hline $\begin{array}{l}\text { Use behavior } \\
\text { factor (UB) }\end{array}$ & 4 & 0.85 & Exceeds cut-off of 0.7 - no changes \\
\hline
\end{tabular}

9.2.2 Confirmatory Factor Analysis - Approach \#1

The baseline measurement model for Approach \#1 was evaluated on several fronts using CFA. Two of the three goodness of fit measures were acceptable, with the third being adequate: RMSEA was adequate at $0.07(\leq .05$ being a good model fit and $\leq .08$ being adequate), SRMR was acceptable at 0.05 (recommended value of <.10), and CFI was acceptable at 0.91 (recommended value at $>9.0$ ). It is important to point out that while cut-offs do matter, indexes are intended as "continuous measures of model-data correspondence" [255]. The loadings for the baseline measurement model were strong: the loadings for each indicator on its requisite construct were at least .5 and with many above .7; all of the loadings were significant at $\mathrm{p}=0.000$.

In an effort to improve this baseline measurement model, the modification indices were examined, and two changes were made. Several error terms showed a high covariance and were correlated with one change happening at a time (e24 and e25; and e26 and e27). Theoretically these adjustments make sense, as e24 (error for BI2) and e25 (error for BI3) are related as part of the Behavioral 
intention construct and e26 (error for BI4, about whether frequent use of myPSU is planned for the future) and e27 (error for UB1, about actual frequency of use) relate to frequency of use. 


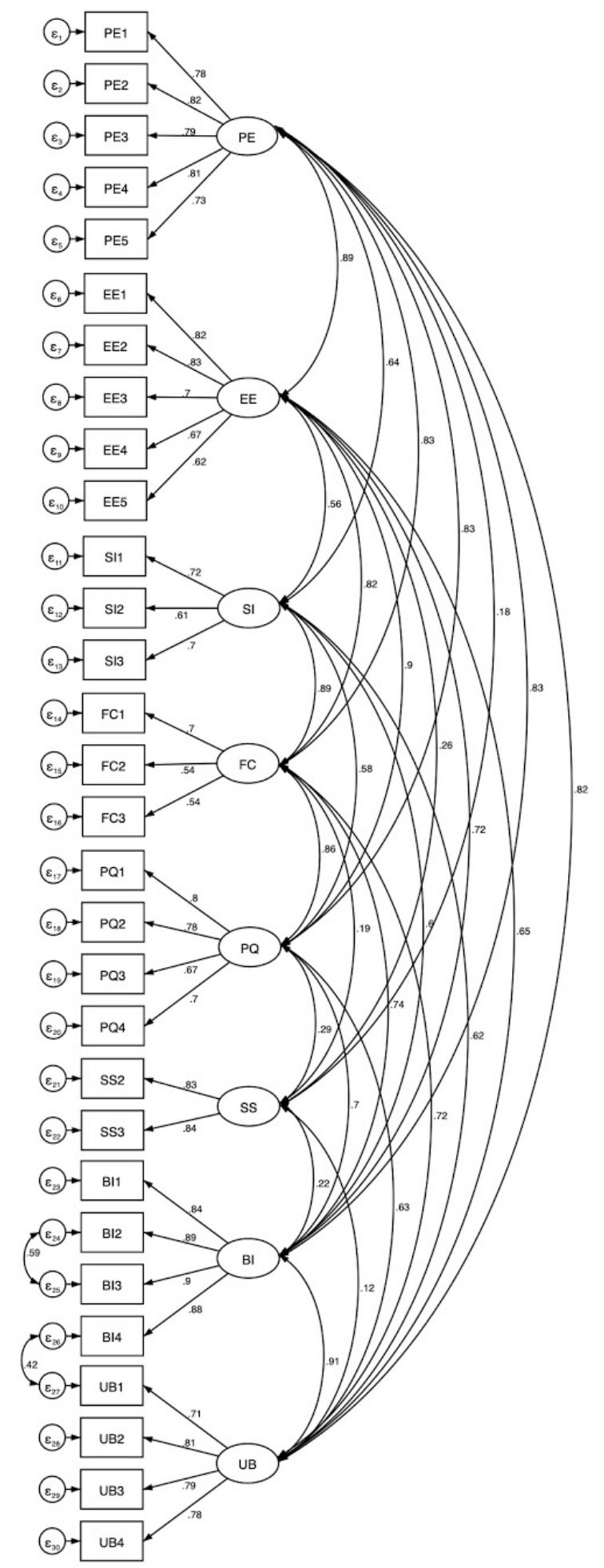

Figure 22: Approach \# 1 - Measurement Model with Standardized Loadings (Final Model) 
After these changes, the revised model performed slightly better on the goodness of fit measures - it is acceptable or adequate on all three measures. The loadings were all above .5 with many still above .7 , and all of the loadings were still significant at $\mathrm{p}=0.000$. Thus, no items were dropped. The results are provided below.

Table 37: Approach \#1 - Measurement Model - Goodness of Fit Measure Comparisons

\begin{tabular}{|c|c|c|c|c|}
\hline $\begin{array}{l}\text { Statistic or } \\
\text { measure name }\end{array}$ & $\begin{array}{l}\text { Reported or } \\
\text { recommend } \\
\text { ed value }\end{array}$ & $\begin{array}{l}\text { Baseline } \\
\text { measuremen } \\
\text { t model (first } \\
\text { model fit) }\end{array}$ & $\begin{array}{l}\text { Revised } \\
\text { measurement } \\
\text { model (final } \\
\text { model fit) }\end{array}$ & $\begin{array}{l}\text { Analysis of final } \\
\text { model }\end{array}$ \\
\hline Chi-square, $\chi^{2}$ & $\begin{array}{l}\chi^{2} \text { (along } \\
\text { with } \\
\text { significance) } \\
\text { and degrees } \\
\text { of freedom }\end{array}$ & $\begin{array}{l}\chi^{2}=3643 \\
\text { P-value }= \\
\text { o.ooo } \\
\text { df }=378\end{array}$ & $\begin{array}{l}\chi^{2}=3124 \\
P \text {-value }=0.000 \\
d f=376\end{array}$ & $\begin{array}{l}\text { Expected that } \chi^{2} \\
\text { is significant }\end{array}$ \\
\hline $\begin{array}{l}\text { Root mean } \\
\text { square error of } \\
\text { approximation } \\
\text { (RMSEA) }\end{array}$ & $\begin{array}{c}\leq .05 \text { being a } \\
\text { good model } \\
\text { fit and } \leq .08 \\
\text { being } \\
\text { adequate }\end{array}$ & 0.07 & 0.06 & $\begin{array}{l}\text { Adequate fit, with } \\
\leq .05 \text { being a good } \\
\text { model fit and } \\
\leq .08 \text { being } \\
\text { adequate - slight } \\
\text { improvement } \\
\text { from baseline to } \\
\text { revised/final } \\
\text { model }\end{array}$ \\
\hline $\begin{array}{l}\text { Standardized root } \\
\text { mean residual } \\
\text { (SRMR) }\end{array}$ & $<.10$ & 0.05 & 0.05 & $\begin{array}{l}\text { Acceptable and no } \\
\text { change from } \\
\text { baseline to } \\
\text { revised/final } \\
\text { model }\end{array}$ \\
\hline $\begin{array}{l}\text { Comparative fit } \\
\text { index (CFI) }\end{array}$ & $>.9$ & 0.91 & 0.93 & $\begin{array}{l}\text { Acceptable and } \\
\text { slight } \\
\text { improvement } \\
\text { from baseline to } \\
\text { revised/final } \\
\text { model }\end{array}$ \\
\hline
\end{tabular}




\subsubsection{Structural Model Analysis - Approach \#1}

Using the final measurement model, a structural model was identified based on the research model's paths, and an analysis of this structural model was completed. Critically, a structural model is considered acceptable only when it demonstrates acceptable fit and the path estimates representing each of the hypotheses are significant and in the predicted direction [256]. The baseline structural model was analyzed using goodness of fit measures and also using modification indices. The baseline structural model, based on the modification indices, was adjusted by adding correlations between two error terms, e5 (error for PE5) and e10 (error for EE5), and e4 (error for PE4) and e29 (error for UB4). These adjustments were made one at a time. These both make theoretical sense as PE5 (convenience of accessing myPSU) and EE5 (using the mobile app to access myPSU) are related to the ability to access myPSU and PE4 and UB4 are both related to myPSU as a one-stop shop. 


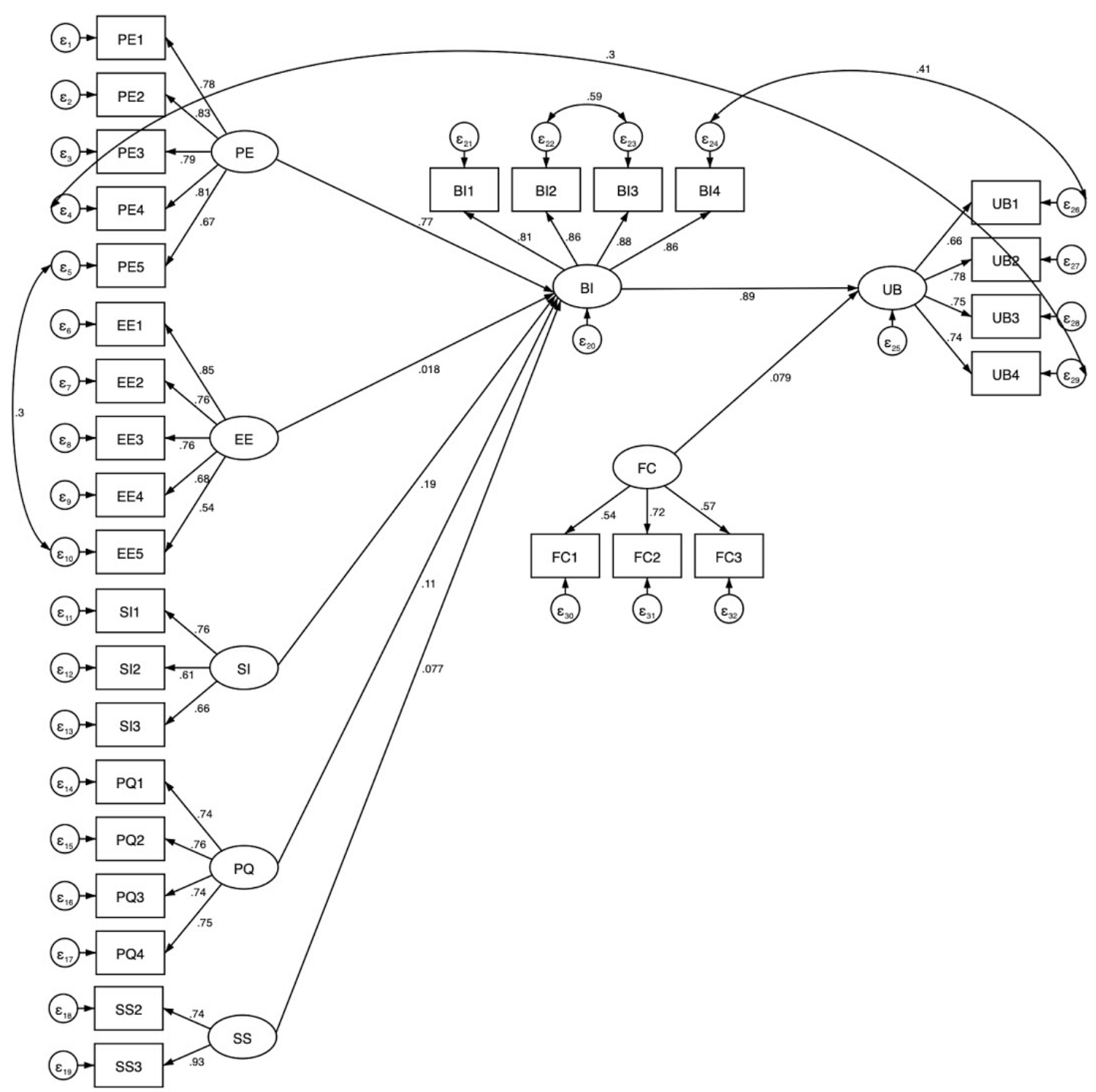

Figure 23: Approach \#1 - Structural Model with Standardized Loadings (Final Model)

The final structural model for Approach \#1 is a poor fit in terms of its ability to match the data. It is not acceptable for all three goodness of fit measures and it deteriorates compared to the measurement model. The results of the goodness of fit analysis are provided below. As a result of this poor fit, the 
analysis for Approach \#1 was not continued and the results were not interpreted.

Results are below.

Table 38: Approach \# 1 - Structural Model - Goodness of Fit Measure Comparisons

\begin{tabular}{|c|c|c|c|c|c|}
\hline $\begin{array}{l}\text { Statistic or } \\
\text { measure } \\
\text { name }\end{array}$ & $\begin{array}{l}\text { Reported } \\
\text { or } \\
\text { recomme } \\
\text { nded } \\
\text { value }\end{array}$ & $\begin{array}{l}\text { Measure } \\
\text { ment } \\
\text { model } \\
\text { (final } \\
\text { model fit) }\end{array}$ & $\begin{array}{l}\text { Baseline } \\
\text { structural } \\
\text { model } \\
\text { (first } \\
\text { model fit) }\end{array}$ & $\begin{array}{l}\text { Revised } \\
\text { structural } \\
\text { model } \\
\text { (final } \\
\text { model fit) }\end{array}$ & $\begin{array}{l}\text { Analysis of } \\
\text { final model }\end{array}$ \\
\hline $\begin{array}{l}\text { Chi-square, } \\
\chi^{2}\end{array}$ & $\begin{array}{l}\chi^{2} \text { (along } \\
\text { with } \\
\text { significance } \\
\text { ) and } \\
\text { degrees of } \\
\text { freedom }\end{array}$ & $\begin{array}{l}\chi^{2}=3,124 \\
\text { P-value }= \\
\text { o.ooo } \\
\text { df }=376\end{array}$ & $\begin{array}{l}\chi^{2}=8,817 \\
\text { P-value }= \\
\text { o.ooo } \\
\text { df }=396\end{array}$ & $\begin{array}{l}\chi^{2}=8,559 \\
\text { P-value }= \\
\text { o.ooo } \\
\text { df }=394\end{array}$ & $\begin{array}{l}\text { Expected that } \chi^{2} \\
\text { is significant }\end{array}$ \\
\hline $\begin{array}{l}\text { Root mean } \\
\text { square error } \\
\text { of } \\
\text { approximati } \\
\text { on (RMSEA) }\end{array}$ & $\begin{array}{l}\leq .05 \text { being } \\
\text { a good } \\
\text { model fit } \\
\text { and } \leq .08 \\
\text { being } \\
\text { adequate }\end{array}$ & 0.06 & 0.11 & 0.11 & $\begin{array}{l}\text { Not acceptable; } \\
\text { no change from } \\
\text { baseline to } \\
\text { revised/final } \\
\text { structural model; } \\
\text { and deterioration } \\
\text { from the } \\
\text { measurement } \\
\text { model }\end{array}$ \\
\hline $\begin{array}{l}\text { Standardize } \\
\text { d root mean } \\
\text { residual } \\
\text { (SRMR) }\end{array}$ & $<.10$ & 0.05 & 0.31 & 0.31 & $\begin{array}{l}\text { Not acceptable; } \\
\text { no change from } \\
\text { baseline to } \\
\text { revised/final } \\
\text { structural model; } \\
\text { and deterioration } \\
\text { from the } \\
\text { measurement } \\
\text { model }\end{array}$ \\
\hline $\begin{array}{l}\text { Comparative } \\
\text { fit index } \\
(\mathrm{CFI})\end{array}$ & $>.9$ & 0.93 & 0.77 & 0.78 & $\begin{array}{l}\text { Not acceptable; } \\
\text { very slight } \\
\text { improvement } \\
\text { from baseline to } \\
\text { revised/final } \\
\text { structural model; } \\
\text { and deterioration } \\
\text { from the } \\
\text { measurement } \\
\text { model }\end{array}$ \\
\hline
\end{tabular}




\subsection{SEM Approach \# 2}

Approach \#2 started with the full research model and used the analytic sample, but employed PCA (factor analysis) for the constructs that were hypothesized to influence Behavioral intention, prior to CFA.

\subsubsection{Principal Components Analysis - Approach \#2}

PCA, or factor analysis, was conducted to evaluate the degree to which the indicators fit the theorized latent constructs in the research model. The factor analysis was scoped to only the constructs and corresponding indicators that were hypothesized to influence Behavioral intention, as BI, UB and FC are important to the model and UTAUT theoretically.

Overall, the factor analysis showed somewhat consistent results between the orthogonal and oblique results. As a result of the factor analysis with a cutoff of keeping only loadings that were greater than or equal to 0.5 , the following changes were made. First and surprisingly, the Effort expectancy construct was dropped: its primary indicator, Perceived ease of use cross-loaded; a second indicator (Effort vs. benefit) loaded with the Performance expectancy indicators (which is supported theoretically as effort and benefit tradeoffs could be more related to usefulness than effort/ease of use); and its other two indicators loaded with three Perceived quality indicators (both of these loadings made sense theoretically).

Second, Perceived quality was renamed Perceived quality and effort to acknowledge the inclusion of the two Effort expectancy indicators. Third, two 
additional variables were dropped - Mobile app, as its loading was less than 0.5 and Confidence, as it did not make sense theoretically to be part of the Perceived quality indicator. Fourth, the Self-efficacy and skills construct was changed to Skills, as the self-efficacy indicator in this construct, Confidence, was dropped. The factor analysis results are below.

Table 39: Approach \#2 - Principal Components Analysis - Factor Analysis Results

\begin{tabular}{|c|c|c|c|c|c|c|c|c|c|c|c|}
\hline \multirow[b]{2}{*}{$\begin{array}{l}\text { Constru } \\
\text { ct }\end{array}$} & \multirow[b]{2}{*}{$\begin{array}{l}\text { Indicat } \\
\text { or }\end{array}$} & \multirow[b]{2}{*}{$\begin{array}{l}\text { Ite } \\
\text { m }\end{array}$} & \multirow[b]{2}{*}{$\begin{array}{l}\text { Const } \\
\text { ruct } \\
\text { mapp } \\
\text { ing }\end{array}$} & \multicolumn{2}{|c|}{ Factor 1} & \multicolumn{2}{|c|}{ Factor 2} & \multicolumn{2}{|c|}{ Factor 3} & \multicolumn{2}{|c|}{ Factor 4} \\
\hline & & & & $\begin{array}{l}\text { Ortho } \\
\text { gonal }\end{array}$ & $\begin{array}{l}\text { Obliq } \\
\text { ue }\end{array}$ & $\begin{array}{l}\text { Ortho } \\
\text { gonal }\end{array}$ & $\begin{array}{l}\text { Obliq } \\
\text { ue }\end{array}$ & $\begin{array}{l}\text { Ortho } \\
\text { gonal }\end{array}$ & $\begin{array}{l}\text { Obli } \\
\text { que }\end{array}$ & $\begin{array}{l}\text { Ortho } \\
\text { gonal }\end{array}$ & $\begin{array}{l}\text { Obli } \\
\text { que }\end{array}$ \\
\hline \begin{tabular}{|l|} 
Perfor \\
mance \\
expecta \\
ncy \\
factor \\
$($ PE $)$ \\
\end{tabular} & \begin{tabular}{|l} 
Perceive \\
d \\
usefulne \\
ss \\
\end{tabular} & PE1 & \begin{tabular}{|l|} 
PE \\
(factor \\
$1)$ \\
\end{tabular} & 0.75 & 0.82 & 0.22 & 0.44 & 0.24 & 0.36 & 0.08 & 0.17 \\
\hline & \begin{tabular}{|l} 
Access to \\
universit \\
y \\
resource \\
s and \\
services \\
\end{tabular} & PE2 & \begin{tabular}{|l|}
$\mathrm{PE}$ \\
(factor \\
1 ) \\
\end{tabular} & 0.78 & 0.84 & 0.26 & 0.49 & 0.17 & 0.31 & 0.07 & 0.17 \\
\hline & $\begin{array}{l}\text { Access to } \\
\text { conduct } \\
\text { business }\end{array}$ & $\mathrm{PE}_{3}$ & \begin{tabular}{|l|}
$\mathrm{PE}$ \\
(factor \\
1 ) \\
\end{tabular} & 0.76 & 0.82 & 0.25 & 0.46 & 0.19 & 0.32 & 0.02 & 0.11 \\
\hline & $\begin{array}{l}\text { One-stop } \\
\text { shop }\end{array}$ & $\mathrm{PE}_{4}$ & \begin{tabular}{|l|}
$\mathrm{PE}$ \\
(factor \\
1 ) \\
\end{tabular} & 0.74 & 0.82 & 0.23 & 0.46 & 0.31 & 0.44 & 0.02 & 0.11 \\
\hline & \begin{tabular}{|l|} 
Perceive \\
d mobile \\
value
\end{tabular} & $\mathrm{PE}_{5}$ & \begin{tabular}{|l|} 
PE \\
(factor \\
1 ) \\
\end{tabular} & 0.59 & 0.74 & 0.47 & 0.63 & 0.17 & 0.30 & 0.05 & 0.16 \\
\hline $\begin{array}{l}\text { Effort } \\
\text { expecta } \\
\text { ncy } \\
\text { factor } \\
\text { (EE) } \\
\end{array}$ & $\begin{array}{l}\text { Perceive } \\
\text { d ease of } \\
\text { use }\end{array}$ & EE1 & $\begin{array}{l}\text { Drop - } \\
\text { cross } \\
\text { loads }\end{array}$ & 0.56 & 0.72 & 0.62 & 0.74 & 0.02 & 0.16 & 0.03 & 0.16 \\
\hline & \begin{tabular}{|l|} 
Efforts \\
vs. \\
benefit \\
\end{tabular} & EE2 & \begin{tabular}{|l|}
$\mathrm{PE}$ \\
(factor \\
1 ) \\
\end{tabular} & 0.71 & 0.83 & 0.41 & 0.61 & 0.21 & 0.36 & 0.07 & 0.18 \\
\hline & $\begin{array}{l}\text { Learning } \\
\text { to }\end{array}$ & $\mathrm{EE}_{3}$ & \begin{tabular}{|l|}
$\mathrm{PQE}$ \\
(factor
\end{tabular} & 0.45 & 0.60 & 0.57 & 0.67 & -0.04 & 0.08 & 0.10 & 0.21 \\
\hline
\end{tabular}




\begin{tabular}{|c|c|c|c|c|c|c|c|c|c|c|c|}
\hline & operate & & 2) & & & & & & & & \\
\hline & \begin{tabular}{|l|} 
System \\
accessibi \\
lity
\end{tabular} & $\mathrm{EE}_{4}$ & \begin{tabular}{|l|}
$\mathrm{PQE}$ \\
(factor \\
2 ) \\
\end{tabular} & 0.47 & 0.61 & 0.51 & 0.62 & 0.00 & 0.12 & 0.12 & 0.23 \\
\hline & $\begin{array}{l}\text { Mobile } \\
\text { app }\end{array}$ & EE 5 & \begin{tabular}{|l|} 
Drop - \\
loadin \\
g less \\
than \\
0.50 \\
\end{tabular} & 0.42 & 0.57 & 0.47 & 0.58 & 0.17 & 0.28 & -0.01 & 0.09 \\
\hline \multirow[t]{3}{*}{\begin{tabular}{|l} 
Social \\
influen \\
ce \\
factor \\
(SI) \\
\end{tabular}} & \begin{tabular}{|l} 
Peer \\
influence
\end{tabular} & SI1 & \begin{tabular}{|l|} 
SI \\
(factor \\
3 ) \\
\end{tabular} & 0.24 & 0.40 & 0.14 & 0.29 & 0.76 & 0.80 & -0.05 & -0.01 \\
\hline & $\begin{array}{l}\text { Marketin } \\
\mathrm{g}\end{array}$ & $\mathrm{SI} 2$ & \begin{tabular}{|l|} 
SI \\
(factor \\
3 ) \\
\end{tabular} & 0.08 & 0.29 & 0.26 & 0.36 & 0.72 & 0.75 & -0.13 & $\begin{array}{c}-0.0 \\
8\end{array}$ \\
\hline & \begin{tabular}{|l|} 
Influenc \\
e from \\
universit \\
y \\
employe \\
es \\
\end{tabular} & $\mathrm{SI}_{3}$ & \begin{tabular}{|l|} 
SI \\
(factor \\
3 ) \\
\end{tabular} & 0.32 & 0.44 & 0.05 & 0.23 & 0.72 & 0.76 & 0.10 & 0.13 \\
\hline \multirow[t]{4}{*}{$\begin{array}{l}\text { Perceiv } \\
\text { ed } \\
\text { quality } \\
\text { factor } \\
\text { (PQ) } \\
\end{array}$} & $\begin{array}{l}\text { Content } \\
\text { quality }\end{array}$ & PQ1 & \begin{tabular}{|l|} 
Drop - \\
cross \\
loads \\
\end{tabular} & 0.51 & 0.69 & 0.53 & 0.68 & 0.24 & 0.36 & 0.16 & 0.27 \\
\hline & $\begin{array}{l}\text { User } \\
\text { interface } \\
\text { design } \\
\end{array}$ & $\mathrm{PQ}_{2}$ & \begin{tabular}{|l|}
$\mathrm{PQE}$ \\
(factor \\
2 ) \\
\end{tabular} & 0.39 & 0.61 & 0.69 & 0.78 & 0.15 & 0.28 & 0.00 & 0.12 \\
\hline & \begin{tabular}{|l} 
System \\
errors
\end{tabular} & PQ3 & \begin{tabular}{|l|}
$\mathrm{PQE}$ \\
(factor \\
2 ) \\
\end{tabular} & 0.18 & 0.44 & 0.77 & 0.80 & 0.12 & 0.22 & 0.05 & 0.17 \\
\hline & \begin{tabular}{|l|} 
Platform \\
response \\
time
\end{tabular} & $\mathrm{PQ}_{4}$ & \begin{tabular}{|l|}
$\mathrm{PQE}$ \\
(factor \\
2 ) \\
\end{tabular} & 0.21 & 0.47 & 0.69 & 0.76 & 0.25 & 0.34 & 0.16 & 0.27 \\
\hline \multirow[t]{3}{*}{$\begin{array}{l}\text { Self-effi } \\
\text { cacy } \\
\text { and } \\
\text { skills } \\
\text { factor } \\
\text { (SS) } \\
\end{array}$} & $\begin{array}{l}\text { Confiden } \\
\text { ce }\end{array}$ & $\mathrm{SS} 1$ & \begin{tabular}{|l|} 
Drop - \\
does \\
not \\
make \\
sense \\
theore \\
tically \\
\end{tabular} & 0.17 & 0.42 & 0.61 & 0.68 & 0.28 & 0.36 & 0.24 & 0.33 \\
\hline & \begin{tabular}{|l|} 
Basic \\
computi \\
ng skills \\
\end{tabular} & $\mathrm{SS} 2$ & \begin{tabular}{|l|} 
SS \\
(factor \\
4 ) \\
\end{tabular} & 0.06 & 0.14 & 0.14 & 0.21 & -0.03 & $\begin{array}{c}-0.0 \\
2\end{array}$ & 0.90 & 0.91 \\
\hline & \begin{tabular}{|l|} 
Basic \\
smartph \\
one skills
\end{tabular} & $\mathrm{SS}_{3}$ & \begin{tabular}{|l|} 
SS \\
(factor \\
4 ) \\
\end{tabular} & 0.07 & 0.13 & 0.11 & 0.18 & -0.04 & $\begin{array}{c}-0.0 \\
4 \\
\end{array}$ & 0.90 & 0.91 \\
\hline
\end{tabular}

Grey highlights indicate loadings $>=0.50$ 
Orthogonal - varimax rotation with Kaiser on - pattern matrix factor loadings

Oblimin oblique rotation with Kaiser on - structure matrix factor loadings

\subsubsection{Reliability Analysis - Approach \#2}

After the factor analysis was complete, a reliability analysis was conducted on all of the constructs remaining in the model, with ideally Cronbach's alpha coefficients of at least 0.7 , but slightly lower amounts can be acceptable as well. Six of the seven constructs, or $86 \%$, exceeded the 0.7 guideline. While the Facilitating conditions construct had a Cronbach's alpha coefficient of 0.63 , which was not ideal, the construct was retained for theoretical reasons as it was relatively close to the 0.7 guideline. The revised model with the Cronbach's alpha coefficients are below.

Table 40: Approach \#2 - Revised Model/Taxonomy with Reliability Analysis Results

\begin{tabular}{|c|c|c|c|c|}
\hline Construct & Indicator & Item & $\begin{array}{l}\text { Changes as a } \\
\text { result of factor } \\
\text { analysis }\end{array}$ & $\begin{array}{l}\text { Cronbach's } \\
\text { alpha }\end{array}$ \\
\hline \multicolumn{4}{|c|}{ Performance expectancy factor (PE) } & 0.91 \\
\hline & Perceived usefulness & PE1 & No change & \\
\hline & $\begin{array}{l}\text { Access to university resources and } \\
\text { services }\end{array}$ & PE2 & No change & \\
\hline & Access to conduct business & $\mathrm{PE}_{3}$ & No change & \\
\hline & One-stop shop & $\mathrm{PE}_{4}$ & No change & \\
\hline & Perceived mobile value & $\mathrm{PE}_{5}$ & No change & \\
\hline & Efforts vs. benefit & EE2 & Now in PE factor & \\
\hline \multicolumn{4}{|c|}{ Social influence factor (SI) } & 0.71 \\
\hline & Peer influence & SI1 & No change & \\
\hline & Marketing & SI2 & No change & \\
\hline & Influence from university employees & $\mathrm{SI}_{3}$ & No change & \\
\hline \multicolumn{4}{|c|}{ Perceived quality and effort factor (PQE) } & 0.83 \\
\hline & User interface design & $\mathrm{PQ} 2$ & No change & \\
\hline & System errors & PQ3 & No change & \\
\hline & Platform response time & PQ4 & No change & \\
\hline & Learning to operate & EE3 & Now in PQE factor & \\
\hline & System accessibility & EE4 & Now in PQE factor & \\
\hline
\end{tabular}




\begin{tabular}{|c|c|c|c|}
\hline \multicolumn{3}{|c|}{ Skills factor (SS) (Self-efficacy dropped from name of factor) } & \multirow[t]{3}{*}{0.82} \\
\hline Basic computing skills & $\mathrm{SS} 2$ & No change & \\
\hline Basic smartphone skills & $\mathrm{SS}_{3}$ & No change & \\
\hline \multicolumn{3}{|l|}{ Facilitating conditions factor (FC) } & 0.63 \\
\hline Compatibility & FC1 & No change & \\
\hline Technical support & $\mathrm{FC} 2$ & No change & \\
\hline Learning about a platform & FC3 & No change & \\
\hline \multicolumn{3}{|l|}{ Behavioral intention factor (BI) } & 0.94 \\
\hline Intend to use & BI1 & No change & \\
\hline Predict to use & $\mathrm{BI} 2$ & No change & \\
\hline Plan to use & $\mathrm{BI} 3$ & No change & \\
\hline Plan to use - frequently & $\mathrm{BI} 4$ & No change & \\
\hline \multicolumn{3}{|l|}{ Use behavior factor (UB) } & 0.85 \\
\hline Frequency of use & UB1 & No change & \\
\hline \begin{tabular}{|l|} 
Usage of the platform to access \\
university resources and services \\
\end{tabular} & $\mathrm{UB} 2$ & No change & \\
\hline $\begin{array}{l}\text { Usage of the platform to conduct } \\
\text { business }\end{array}$ & UB3 & No change & \\
\hline $\begin{array}{l}\text { Usage of the platform as a one-stop } \\
\text { shop }\end{array}$ & UB4 & No change & \\
\hline
\end{tabular}

This revised model, when compared with UTAUT, is similar, but there are several important differences. In UTAUT, the three constructs that are hypothesized to influence Behavioral intention are Performance expectancy, Effort expectancy and Social influence. The revised model contains Performance expectancy and Social influence, but importantly, Effort expectancy has been dropped for the reasons outlined above. Two constructs that are not in UTAUT remained: Perceived quality and effort (formerly the Perceived quality factor), and Skills (formerly the Self-efficacy and skills factor). Additionally, in both UTAUT and the revised model, both Behavioral intention and Facilitating conditions are hypothesized to influence Use behavior. 


\subsubsection{Confirmatory Factor Analysis - Approach \#2}

The baseline measurement model for Approach \#2 was analyzed using CFA. The baseline measurement model was acceptable or adequate for all three goodness of fit measures: RMSEA was adequate at 0.07 ( $\leq .05$ being a good model fit and $\leq .08$ being adequate), SRMR was acceptable at 0.05 (recommended value of <.10), and CFI was acceptable at 0.92 (recommended value at >9.0). Additionally, the baseline measurement model was strong in terms of loadings: loadings for each indicator on its requisite construct were at least .5 and with many above .7; and all of the loadings were significant at $\mathrm{p}=0.000$

In an effort to improve the model, the modification indices were examined, and two changes were made. Several error terms showed a high covariance and were correlated with one change introduced at a time (e19 and e20; and e21 and e22). Theoretically these adjustments made sense, as e19 (error for BI2) and e2o (error for $\mathrm{BI}_{3}$ ) are related as part of the Behavioral intention construct and e21 (error for $\mathrm{BI} 4$, about whether frequent use of myPSU is planned for the future) and e22 (error for UB1, about actual frequency of use) are both related to frequency of use. After these changes, the revised model performed slightly better on the goodness of fit measures - it is acceptable on all three of the measures. Also, the loadings were all above .5 with many still above .7 , and all of the loadings were still significant at $\mathrm{p}=0.000$. Thus, no items were dropped. The results are provided below. 


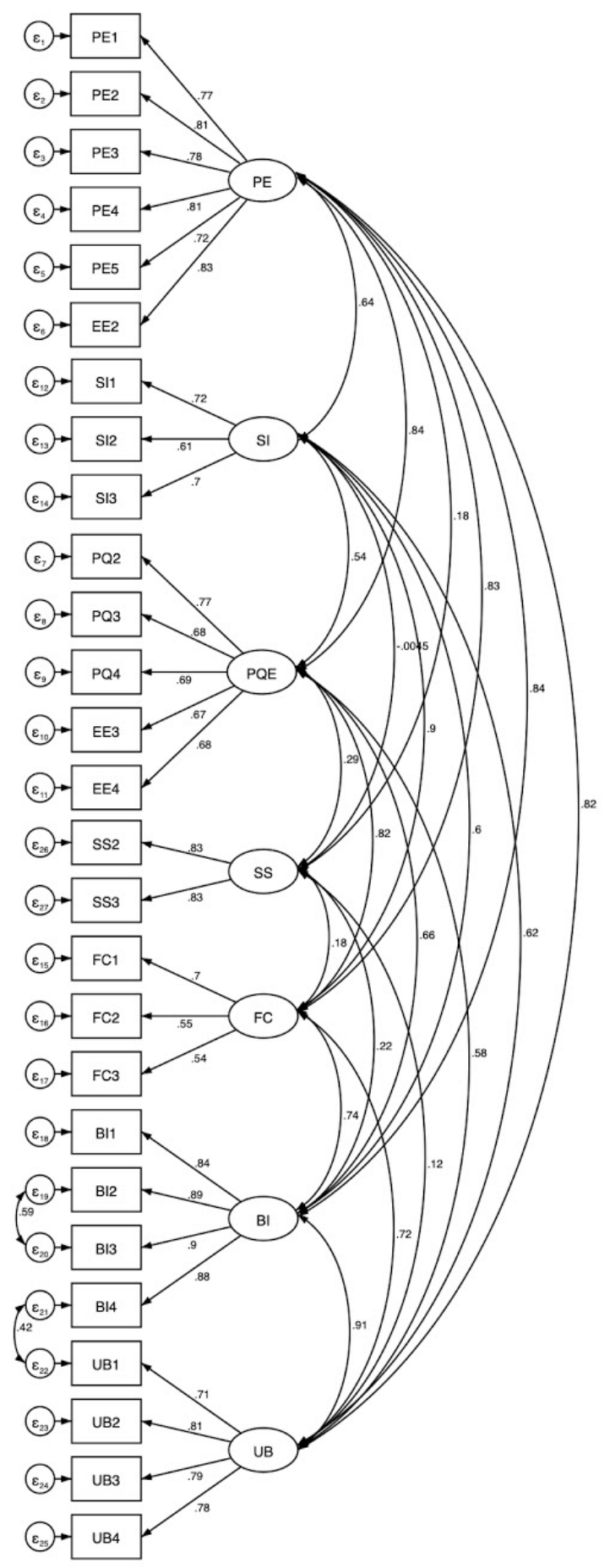

Figure 24: Approach \#2 - Measurement Model with Standardized Loadings (Final Model) 
Table 41: Approach \#2 - Measurement Model - Goodness of Fit Measure Comparisons

\begin{tabular}{|c|c|c|c|c|}
\hline $\begin{array}{l}\text { Statistic or } \\
\text { measure } \\
\text { name }\end{array}$ & $\begin{array}{l}\text { Reported or } \\
\text { recommend } \\
\text { ed value }\end{array}$ & $\begin{array}{l}\text { Baseline } \\
\text { measureme } \\
\text { nt model } \\
\text { (first model } \\
\text { fit) }\end{array}$ & $\begin{array}{l}\text { Revised } \\
\text { measurem } \\
\text { ent model } \\
\text { (final } \\
\text { model fit) }\end{array}$ & $\begin{array}{l}\text { Analysis of final } \\
\text { model }\end{array}$ \\
\hline Chi-square, $\chi^{2}$ & $\begin{array}{l}\chi^{2} \text { (along } \\
\text { with } \\
\text { significance) } \\
\text { and degrees } \\
\text { of freedom }\end{array}$ & $\begin{array}{c}\chi^{2}=2294 \\
\text { p-value }= \\
\text { o.ooo } \\
\mathrm{df}=303\end{array}$ & $\begin{array}{c}\chi^{2}=2407 \\
\text { p-value }= \\
\text { o.ooo } \\
\mathrm{df}=301\end{array}$ & $\begin{array}{l}\text { Expected that } \chi^{2} \text { is } \\
\text { significant }\end{array}$ \\
\hline $\begin{array}{l}\text { Root mean } \\
\text { square error of } \\
\text { approximation } \\
\text { (RMSEA) }\end{array}$ & $\begin{array}{c}\leq .05 \text { being a } \\
\text { good model } \\
\text { fit and } \leq .08 \\
\text { being } \\
\text { adequate }\end{array}$ & 0.07 & 0.06 & $\begin{array}{l}\text { Adequate fit, with } \\
\leq .05 \text { being a good model } \\
\text { fit and } \leq .08 \text { being } \\
\text { adequate - } \\
\text { slight improvement from } \\
\text { baseline to revised/final } \\
\text { model }\end{array}$ \\
\hline $\begin{array}{l}\text { Standardized } \\
\text { root mean } \\
\text { residual (SRMR) }\end{array}$ & $<.10$ & 0.05 & 0.05 & $\begin{array}{l}\text { Acceptable and no change } \\
\text { from baseline to } \\
\text { revised/final model }\end{array}$ \\
\hline $\begin{array}{l}\text { Comparative fit } \\
\text { index (CFI) }\end{array}$ & $>.9$ & 0.92 & 0.94 & $\begin{array}{l}\text { Acceptable and slight } \\
\text { improvement from } \\
\text { baseline to revised/final } \\
\text { model }\end{array}$ \\
\hline
\end{tabular}

\subsubsection{Structural Model - Approach \#2}

Using the final measurement model, the structural model was specified using the paths in the research model, and an analysis of the structural model was completed. The baseline structural model was analyzed and adjusted in light of the modification indices by adding correlations between the error terms for EE3 and EE4 (both are related to the Perceived quality and effort factor) to create the second structural model and between the error terms for PE3 and UB3 (both are related to conducting business through myPSU) to create the third structural 
model. Both adjustments made theoretical sense and the adjustments were made one at a time.

After analyzing the goodness of fit measures and the significance of the path weights for each of the three structural models, from the first to the third model, there were only very minor changes to the goodness of fit measures and the statistical significance of the path coefficients deteriorated. As a result, the baseline structural model was selected as the final structural model for Approach \#2. Finally, model trimming was considered on this final structural model by removing the PQE construct, as it was not significant. This change had very little material impact on the goodness of fit measures, thus no change was made to this structural model. The final structural model for Approach \#2 then is the same as the baseline structural model used in Approach \#2. 


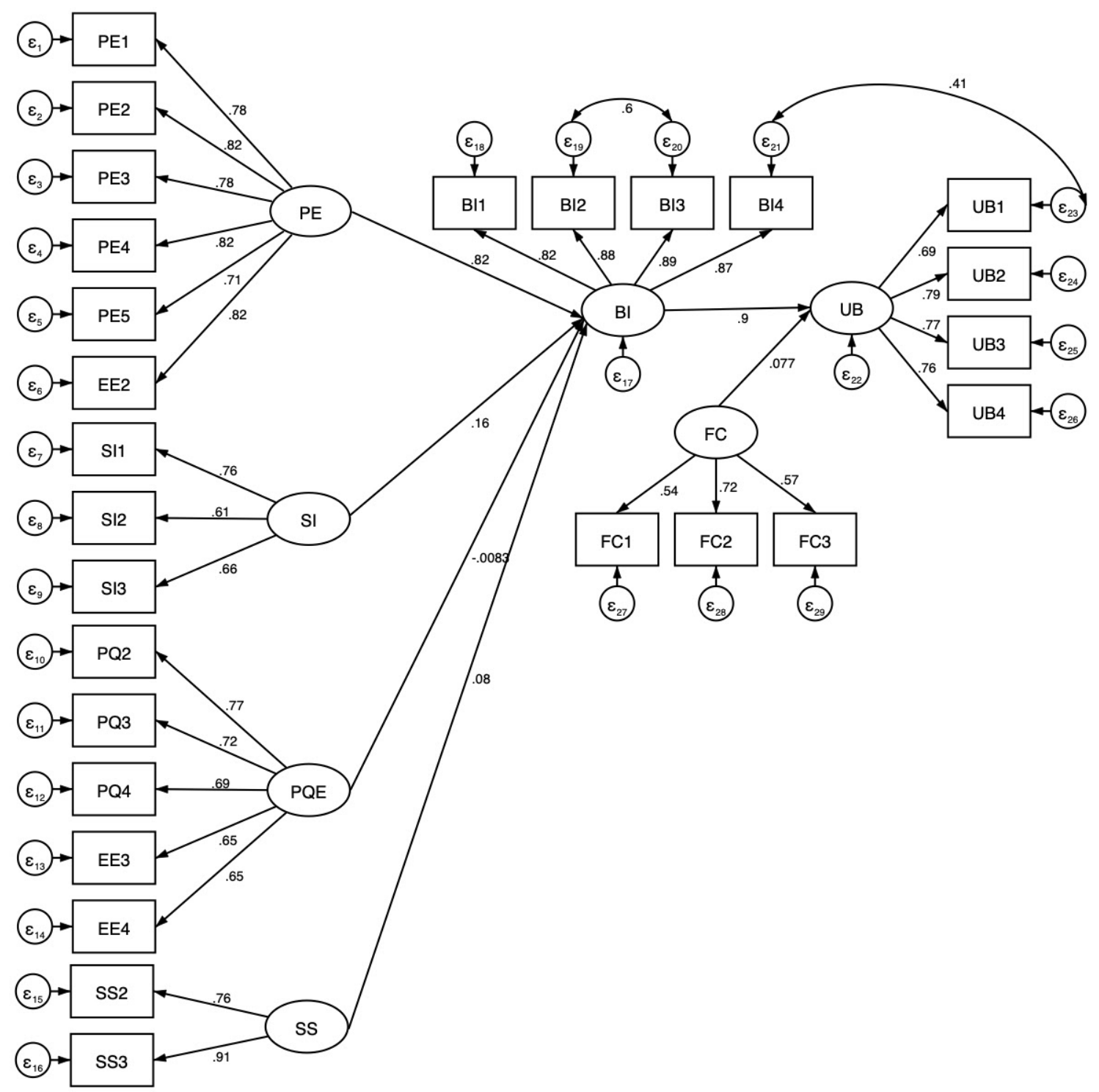

Figure 25: Approach \#2 - Structural Model with Standardized Loadings (Final Model)

Importantly, the baseline/final structural model is a poor fit with the data.

- it is not acceptable for all three goodness of fit measures. As a result of this poor fit, the analysis for Approach \#2 was not continued and the results were not interpreted. Results are below. 
Table 42: Approach \#2 - Structural Model - Goodness of Fit Measure Comparisons

\begin{tabular}{|c|c|c|c|c|c|}
\hline $\begin{array}{l}\text { Statistic } \\
\text { or } \\
\text { measure } \\
\text { name }\end{array}$ & $\begin{array}{l}\text { Reported } \\
\text { or } \\
\text { recomme } \\
\text { nded } \\
\text { value }\end{array}$ & $\begin{array}{l}\text { Measure } \\
\text { ment } \\
\text { model } \\
\text { (final } \\
\text { model fit) }\end{array}$ & $\begin{array}{l}\text { Intermediar } \\
\text { y model } \\
\text { (after } \\
\text { adding two } \\
\text { co-variances } \\
\text { ) }\end{array}$ & $\begin{array}{l}\text { Baseline/fi } \\
\text { nal } \\
\text { structural } \\
\text { model } \\
\text { (final } \\
\text { model fit) }\end{array}$ & $\begin{array}{l}\text { Analysis of final } \\
\text { model }\end{array}$ \\
\hline $\begin{array}{l}\text { Chi-square } \\
, \chi^{2}\end{array}$ & $\begin{array}{l}\chi^{2} \text { (along } \\
\text { with } \\
\text { significanc } \\
\text { e) and } \\
\text { degrees of } \\
\text { freedom }\end{array}$ & $\begin{array}{c}\chi^{2}=2,407 \\
\text { p-value }= \\
\text { o.ooo } \\
\text { df }=301\end{array}$ & $\begin{array}{c}\chi^{2}=5,664 \\
\text { p-value }= \\
\text { o.ooo } \\
d f=314\end{array}$ & $\begin{array}{c}\chi^{2}=5,976 \\
\text { p-value }= \\
\text { o.ooo } \\
\mathrm{df}=316\end{array}$ & $\begin{array}{l}\text { Expected that } \chi^{2} \text { is } \\
\text { significant }\end{array}$ \\
\hline $\begin{array}{l}\text { Root mean } \\
\text { square } \\
\text { error of } \\
\text { approxima } \\
\text { tion } \\
\text { (RMSEA) }\end{array}$ & $\begin{array}{l}\leq .05 \text { being } \\
\text { a good } \\
\text { model fit } \\
\text { and } \leq .08 \\
\text { being } \\
\text { adequate }\end{array}$ & 0.06 & 0.10 & 0.10 & $\begin{array}{l}\text { Not acceptable; } \\
\text { measure is the same } \\
\text { between both } \\
\text { structural models; } \\
\text { and deteriorates } \\
\text { compared to the } \\
\text { measurement model }\end{array}$ \\
\hline $\begin{array}{l}\text { Standardiz } \\
\text { ed root } \\
\text { mean } \\
\text { residual } \\
\text { (SRMR) }\end{array}$ & $<.10$ & 0.05 & 0.26 & 0.27 & $\begin{array}{l}\text { Not acceptable; } \\
\text { baseline/final } \\
\text { structural model } \\
\text { performs slightly } \\
\text { worse than the } \\
\text { intermediary model; } \\
\text { deteriorates } \\
\text { compared to the } \\
\text { measurement model }\end{array}$ \\
\hline $\begin{array}{l}\text { Comparati } \\
\text { ve fit index } \\
\text { (CFI) }\end{array}$ & $>.9$ & 0.94 & 0.84 & 0.83 & $\begin{array}{l}\text { Moderately } \\
\text { acceptable in terms } \\
\text { of final CFI results; } \\
\text { while baseline/final } \\
\text { structural model } \\
\text { performs slightly } \\
\text { worse than the } \\
\text { intermediary model, } \\
\text { the model } \\
\text { deteriorates } \\
\text { compared to the } \\
\text { measurement model }\end{array}$ \\
\hline
\end{tabular}




\subsection{SEM - Approach \#3}

Approach \#3 used the same starting point as Approaches \#1 and \#2, i.e. the full research model and the analytic sample of the data collected via the web survey, and also employed Principal Components Analysis (PCA) as in Approach \#2. However, given that Approaches \#1 and \#2 did not result in structural models that fit the data, Approach \#3 took a more exploratory approach by conducting PCA using all constructs in the research model, and by more liberally adding structural paths if they made sense theoretically, but were not aligned with UTAUT.

\subsubsection{Principal Components Analysis - Approach \# 3}

Overall, the factor analysis for Approach \#3 of all constructs and indicators in the research model showed consistent results between the orthogonal and oblique results. The details and what was changed are provided below. Of note, four of the five PE indicators cross-loaded and were dropped, resulting in the dropping of the PE construct; nearly all of the Perceived quality indicators loaded onto Effort expectancy; the Self-efficacy and skills factor was shortened to Skills as its remaining indicators do not relate to self-efficacy; and while the BI and UB indicators all loaded on one factor, they were kept as distinct constructs because of their importance to UTAUT. The PCA resulted in 24 indicators and five constructs, representing a simpler structure (fewer original variables spread across factors) with many of the loadings above .70 [258]. Detailed factor analysis results are below. 
Table 43: Approach \# 3 - Principal Components Analysis - Factor Analysis Results

\begin{tabular}{|c|c|c|c|c|c|c|c|c|c|c|c|}
\hline \multirow[b]{2}{*}{$\begin{array}{l}\text { Const } \\
\text { ruct }\end{array}$} & \multirow[b]{2}{*}{$\begin{array}{l}\text { Indicat } \\
\text { or }\end{array}$} & \multirow[b]{2}{*}{$\begin{array}{l}\text { Ite } \\
\text { m }\end{array}$} & \multirow[b]{2}{*}{$\begin{array}{l}\text { Const } \\
\text { ruct } \\
\text { mapp } \\
\text { ing }\end{array}$} & \multicolumn{2}{|c|}{ Factor 1} & \multicolumn{2}{|c|}{ Factor 2} & \multicolumn{2}{|c|}{ Factor 3} & \multicolumn{2}{|c|}{ Factor 4} \\
\hline & & & & $\begin{array}{l}\text { Orth } \\
\text { ogon } \\
\text { al } \\
\end{array}$ & $\begin{array}{l}\text { Obli } \\
\text { que }\end{array}$ & $\begin{array}{l}\text { Orth } \\
\text { ogon } \\
\text { al } \\
\end{array}$ & $\begin{array}{l}\text { Obliq } \\
\text { ue }\end{array}$ & $\begin{array}{l}\text { Orth } \\
\text { ogo } \\
\text { nal } \\
\end{array}$ & $\begin{array}{l}\text { Obliq } \\
\text { ue }\end{array}$ & $\begin{array}{l}\text { Orth } \\
\text { ogon } \\
\text { al } \\
\end{array}$ & $\begin{array}{l}\text { Obliqu } \\
\mathrm{e}\end{array}$ \\
\hline $\begin{array}{l}\text { Perfo } \\
\text { rman } \\
\text { ce } \\
\text { expec } \\
\text { tancy } \\
\text { factor } \\
(\text { PE) } \\
\end{array}$ & $\begin{array}{l}\text { Perceive } \\
\text { d } \\
\text { usefulne } \\
\text { ss }\end{array}$ & PE1 & $\begin{array}{l}\text { Dropp } \\
\text { ed - } \\
\text { cross } \\
\text { loads } \\
\end{array}$ & 0.52 & 0.66 & 0.54 & 0.68 & 0.16 & 0.40 & 0.00 & 0.11 \\
\hline & \begin{tabular}{|l|} 
Access \\
to \\
universi \\
ty \\
resource \\
s and \\
services \\
\end{tabular} & $\mathrm{PE} 2$ & $\begin{array}{l}\text { Dropp } \\
\text { ed - } \\
\text { cross } \\
\text { loads } \\
\end{array}$ & 0.56 & 0.70 & 0.56 & 0.70 & 0.12 & 0.37 & 0.00 & 0.11 \\
\hline & \begin{tabular}{|l|} 
Access \\
to \\
conduct \\
business \\
\end{tabular} & $\mathrm{PE}_{3}$ & \begin{tabular}{|l|} 
Dropp \\
ed - \\
cross \\
loads \\
\end{tabular} & 0.54 & 0.68 & 0.52 & 0.66 & 0.16 & 0.40 & -0.05 & 0.06 \\
\hline & $\begin{array}{l}\text { One-sto } \\
\text { p shop }\end{array}$ & $\mathrm{PE}_{4}$ & $\begin{array}{l}\text { Dropp } \\
\text { ed - } \\
\text { cross } \\
\text { loads } \\
\end{array}$ & 0.50 & 0.66 & 0.59 & 0.72 & 0.23 & 0.47 & -0.05 & 0.05 \\
\hline & $\begin{array}{l}\text { Perceive } \\
\text { d mobile } \\
\text { value }\end{array}$ & $\mathrm{PE}_{5}$ & $\begin{array}{l}\text { EE } \\
\text { (factor } \\
1 \text { ) }\end{array}$ & 0.69 & 0.76 & 0.31 & 0.50 & 0.17 & 0.39 & 0.01 & 0.14 \\
\hline $\begin{array}{l}\text { Effort } \\
\text { expec } \\
\text { tancy } \\
\text { factor } \\
\text { (EE) }\end{array}$ & $\begin{array}{l}\text { Perceive } \\
\text { d ease of } \\
\text { use }\end{array}$ & EE1 & \begin{tabular}{|l} 
EE \\
(factor \\
1 ) \\
\end{tabular} & 0.80 & 0.83 & 0.23 & 0.45 & 0.09 & 0.32 & 0.02 & 0.16 \\
\hline & $\begin{array}{l}\text { Efforts } \\
\text { vs. } \\
\text { benefit }\end{array}$ & EE2 & $\begin{array}{l}\text { Dropp } \\
\text { ed - } \\
\text { cross } \\
\text { loads }\end{array}$ & 0.64 & 0.77 & 0.51 & 0.68 & 0.18 & 0.44 & 0.02 & 0.14 \\
\hline & \begin{tabular}{|l|} 
Learnin \\
$\mathrm{g}$ to \\
operate
\end{tabular} & EE3 & $\begin{array}{l}\mathrm{EE} \\
\text { (factor } \\
1 \text { ) }\end{array}$ & \begin{tabular}{|l|}
0.73 \\
\end{tabular} & 0.74 & 0.13 & 0.32 & 0.05 & 0.25 & 0.09 & 0.21 \\
\hline & \begin{tabular}{|l|} 
System \\
accessib \\
ility
\end{tabular} & $\mathrm{EE}_{4}$ & \begin{tabular}{|l} 
EE \\
(factor \\
1 )
\end{tabular} & 0.66 & 0.70 & 0.20 & 0.38 & 0.08 & 0.27 & 0.11 & 0.23 \\
\hline & $\begin{array}{l}\text { Mobile } \\
\text { app }\end{array}$ & EE5 & \begin{tabular}{|l}
$\mathrm{EE}$ \\
(factor \\
1 ) \\
\end{tabular} & 0.61 & 0.66 & 0.19 & 0.37 & 0.19 & 0.37 & -0.03 & 0.08 \\
\hline
\end{tabular}




\begin{tabular}{|c|c|c|c|c|c|c|c|c|c|c|c|}
\hline $\begin{array}{l}\text { Social } \\
\text { influe } \\
\text { nce } \\
\text { factor } \\
\text { (SI) } \\
\end{array}$ & \begin{tabular}{|l|} 
Peer \\
influenc \\
e
\end{tabular} & SI1 & \begin{tabular}{|l} 
SI \\
(factor \\
2 )
\end{tabular} & 0.19 & 0.35 & 0.23 & 0.39 & 0.71 & 0.77 & -0.07 & -0.03 \\
\hline & $\begin{array}{l}\text { Marketi } \\
\text { ng }\end{array}$ & SI2 & $\begin{array}{l}\text { SI } \\
\text { (factor } \\
2 \text { ) }\end{array}$ & 0.23 & 0.34 & 0.10 & 0.26 & 0.68 & 0.72 & -0.12 & -0.08 \\
\hline & \begin{tabular}{|l|} 
Influenc \\
e from \\
universi \\
ty \\
employe \\
es
\end{tabular} & SI3 & $\begin{array}{l}\text { SI } \\
\text { (factor } \\
2 \text { ) }\end{array}$ & 0.11 & 0.31 & 0.39 & 0.51 & 0.63 & 0.71 & 0.07 & 0.09 \\
\hline $\begin{array}{l}\text { Facilit } \\
\text { ating } \\
\text { condit } \\
\text { ions } \\
\text { factor } \\
\text { (FC) } \\
\end{array}$ & $\begin{array}{l}\text { Compati } \\
\text { bility }\end{array}$ & $\mathrm{FC} 1$ & \begin{tabular}{|l} 
EE \\
(factor \\
1 ) \\
\end{tabular} & 0.57 & 0.68 & 0.33 & 0.52 & 0.28 & 0.47 & 0.11 & 0.21 \\
\hline & $\begin{array}{l}\text { Technic } \\
\text { al } \\
\text { support }\end{array}$ & FC2 & $\begin{array}{l}\text { Dropp } \\
\text { ed - } \\
\text { does } \\
\text { not } \\
\text { make } \\
\text { sense } \\
\text { theore } \\
\text { tically }\end{array}$ & 0.29 & 0.41 & 0.14 & 0.31 & 0.57 & 0.64 & 0.13 & 0.17 \\
\hline & \begin{tabular}{|l|} 
Learnin \\
g about \\
a \\
platform
\end{tabular} & $\mathrm{FC}_{3}$ & $\begin{array}{l}\text { SI } \\
\text { (factor } \\
2 \text { ) }\end{array}$ & 0.11 & 0.27 & 0.17 & 0.32 & 0.75 & 0.78 & -0.04 & -0.02 \\
\hline $\begin{array}{l}\text { Percei } \\
\text { ved } \\
\text { qualit } \\
\text { y } \\
\text { factor } \\
\text { (PQ) } \\
\end{array}$ & $\begin{array}{l}\text { Content } \\
\text { quality }\end{array}$ & PQ1 & \begin{tabular}{|l} 
EE \\
(factor \\
1 ) \\
\end{tabular} & 0.64 & 0.75 & 0.35 & 0.55 & 0.25 & 0.46 & 0.16 & 0.27 \\
\hline & \begin{tabular}{|l|} 
User \\
interface \\
design \\
\end{tabular} & $\mathrm{PQ} 2$ & \begin{tabular}{|l|} 
EE \\
(factor \\
1 ) \\
\end{tabular} & 0.74 & 0.79 & 0.21 & 0.43 & 0.19 & 0.40 & 0.02 & 0.15 \\
\hline & $\begin{array}{l}\text { System } \\
\text { errors }\end{array}$ & PQ3 & $\begin{array}{l}\text { EE } \\
\text { (factor } \\
1 \text { ) }\end{array}$ & 0.67 & 0.70 & 0.13 & 0.33 & 0.13 & 0.31 & 0.11 & 0.22 \\
\hline & \begin{tabular}{|l|} 
Platform \\
respons \\
e time
\end{tabular} & $\mathrm{PQ}_{4}$ & \begin{tabular}{|l|} 
EE \\
(factor \\
1 ) \\
\end{tabular} & 0.60 & 0.67 & 0.21 & 0.40 & 0.23 & 0.40 & 0.22 & 0.32 \\
\hline $\begin{array}{l}\text { Skills } \\
\text { factor } \\
\text { (SS) }\end{array}$ & $\begin{array}{l}\text { Confide } \\
\text { nce }\end{array}$ & SS1 & $\begin{array}{l}\text { Dropp } \\
\text { ed - } \\
\text { does } \\
\text { not } \\
\text { make }\end{array}$ & 0.51 & 0.60 & 0.18 & 0.37 & 0.29 & 0.44 & 0.29 & 0.38 \\
\hline
\end{tabular}




\begin{tabular}{|c|c|c|c|c|c|c|c|c|c|c|c|}
\hline & & & $\begin{array}{l}\text { sense } \\
\text { theore } \\
\text { tically }\end{array}$ & & & & & & & & \\
\hline & $\begin{array}{l}\text { Basic } \\
\text { computi } \\
\text { ng skills }\end{array}$ & $\mathrm{SS} 2$ & $\begin{array}{l}\text { SS } \\
\text { (factor } \\
3 \text { ) } \\
\end{array}$ & 0.15 & 0.21 & 0.06 & 0.11 & $\begin{array}{r}-0.0 \\
4 \\
\end{array}$ & 0.00 & 0.88 & 0.89 \\
\hline & $\begin{array}{l}\text { Basic } \\
\text { smartph } \\
\text { one } \\
\text { skills } \\
\end{array}$ & $\mathrm{SS}_{3}$ & $\begin{array}{l}\text { SS } \\
\text { (factor } \\
3 \text { ) } \\
\end{array}$ & 0.14 & 0.20 & 0.05 & 0.10 & $\begin{array}{r}-0.0 \\
5 \\
\end{array}$ & -0.01 & 0.88 & 0.89 \\
\hline \multirow[t]{4}{*}{$\begin{array}{l}\text { Behav } \\
\text { ioral } \\
\text { intent } \\
\text { ion } \\
\text { factor } \\
\text { (BI) }\end{array}$} & $\begin{array}{l}\text { Intend } \\
\text { to use }\end{array}$ & BI1 & $\begin{array}{l}\text { BI } \\
\text { (factor } \\
4 \text { ) } \\
\end{array}$ & 0.43 & 0.62 & 0.69 & 0.80 & 0.16 & 0.41 & 0.13 & 0.23 \\
\hline & $\begin{array}{l}\text { Predict } \\
\text { to use }\end{array}$ & BI2 & \begin{tabular}{|l|} 
BI \\
(factor \\
4 ) \\
\end{tabular} & 0.28 & 0.52 & 0.83 & 0.89 & 0.14 & 0.39 & 0.16 & 0.23 \\
\hline & $\begin{array}{l}\text { Plan to } \\
\text { use }\end{array}$ & $\mathrm{BI}_{3}$ & $\begin{array}{l}\text { BI } \\
\text { (factor } \\
4 \text { ) } \\
\end{array}$ & 0.27 & 0.52 & 0.84 & 0.90 & 0.15 & 0.40 & 0.13 & 0.21 \\
\hline & $\begin{array}{l}\text { Plan to } \\
\text { use - } \\
\text { frequent } \\
\text { ly }\end{array}$ & $\mathrm{BI}_{4}$ & $\begin{array}{l}\text { BI } \\
\text { (factor } \\
4 \text { ) }\end{array}$ & 0.29 & 0.53 & 0.81 & 0.89 & 0.20 & 0.45 & 0.04 & 0.12 \\
\hline \multirow[t]{4}{*}{$\begin{array}{l}\text { Use } \\
\text { behav } \\
\text { ior } \\
\text { factor } \\
\text { (UB) } \\
\end{array}$} & $\begin{array}{l}\text { Frequen } \\
\text { cy of use }\end{array}$ & UB1 & $\begin{array}{l}\text { UB } \\
\text { (factor } \\
5 \text { ) }\end{array}$ & 0.08 & 0.30 & 0.77 & 0.78 & 0.15 & 0.34 & -0.06 & -0.02 \\
\hline & $\begin{array}{l}\text { Usage of } \\
\text { the } \\
\text { platform } \\
\text { to access } \\
\text { universi } \\
\text { ty } \\
\text { resource } \\
\text { s and } \\
\text { services } \\
\end{array}$ & UB2 & $\begin{array}{l}\text { UB } \\
\text { (factor } \\
5 \text { ) }\end{array}$ & 0.19 & 0.42 & 0.78 & 0.82 & 0.14 & 0.36 & 0.06 & 0.12 \\
\hline & $\begin{array}{l}\text { Usage of } \\
\text { the } \\
\text { platform } \\
\text { to } \\
\text { conduct } \\
\text { business }\end{array}$ & UB3 & $\begin{array}{l}\text { UB } \\
\text { (factor } \\
5 \text { ) }\end{array}$ & 0.20 & 0.42 & 0.74 & 0.79 & 0.20 & 0.40 & 0.04 & 0.10 \\
\hline & $\begin{array}{l}\text { Usage of } \\
\text { the } \\
\text { platform } \\
\text { as a } \\
\text { one-stop } \\
\text { shop }\end{array}$ & UB4 & $\begin{array}{l}\text { UB } \\
\text { (factor } \\
5 \text { ) }\end{array}$ & 0.33 & 0.53 & 0.66 & 0.76 & 0.26 & 0.47 & -0.01 & 0.06 \\
\hline
\end{tabular}


Grey highlights indicate loadings $>=0.50$

Orthogonal - varimax rotation with Kaiser on - pattern matrix factor loadings

Oblimin oblique rotation with Kaiser on - structure matrix factor loadings

\subsubsection{Reliability Analysis - Approach \#3}

After the factor analysis was completed, a reliability analysis was conducted on the remaining constructs, with ideally Cronbach's alpha coefficients of at least 0.7 , but slightly lower amounts can be acceptable as well. All five of the constructs exceeded the 0.7 guideline. Given these results, this was named as the revised research model, which is provided below with the Cronbach's alpha coefficients as well as a summary of the revised research model taxonomy. Appendix J provides the revised research model detailed taxonomy.

Table 44: Approach \#3 - Revised Research Model/Taxonomy with Reliability Analysis Results

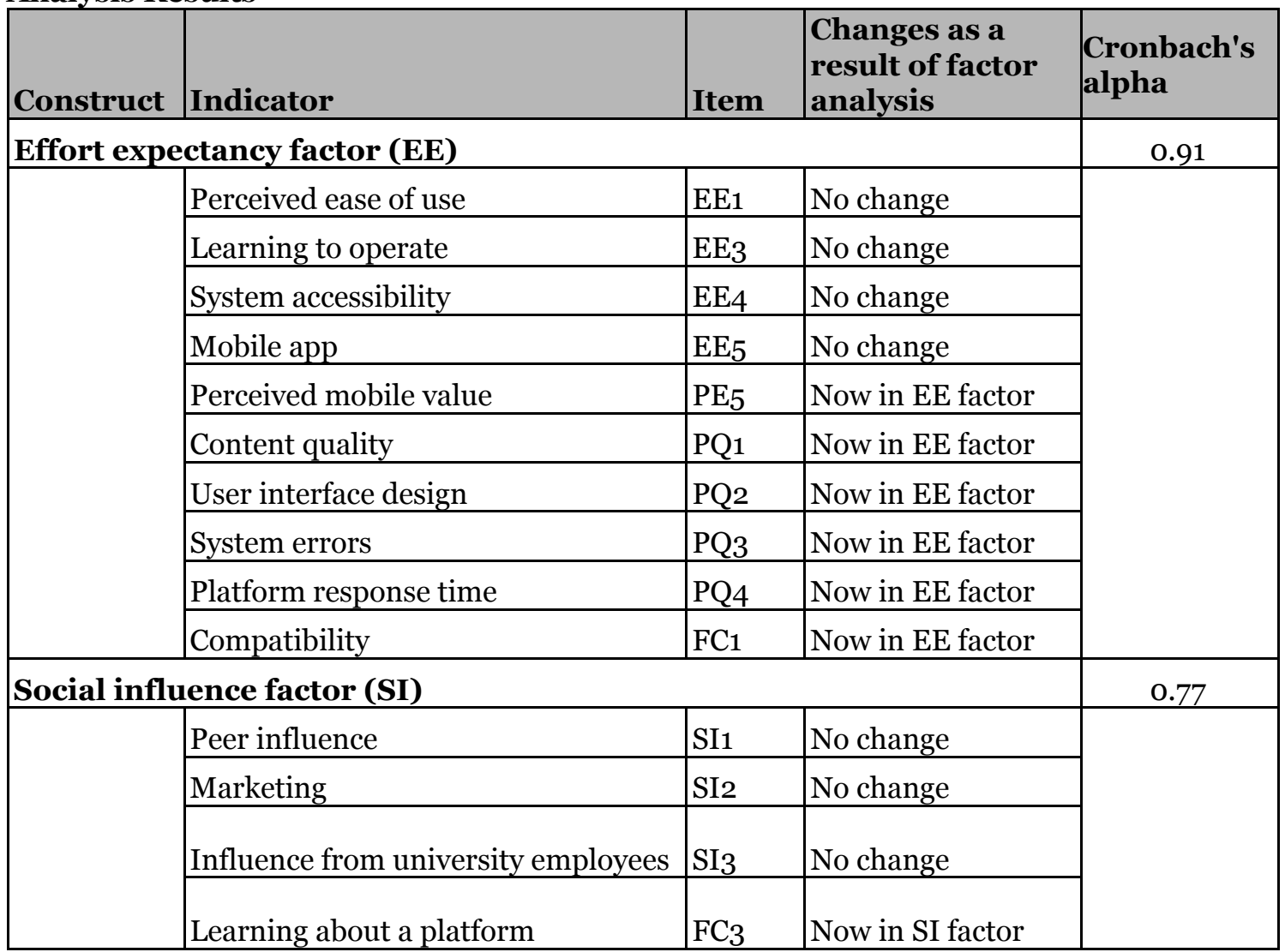




\begin{tabular}{|c|c|c|c|}
\hline \multicolumn{3}{|l|}{ Skills factor (SS) } & \multirow[t]{3}{*}{0.82} \\
\hline Basic computing skills & SS2 & No change & \\
\hline Basic smartphone skills & SS3 & No change & \\
\hline \multicolumn{3}{|l|}{ Behavioral intention factor (BI) } & 0.94 \\
\hline Intend to use & BI1 & No change & \\
\hline Predict to use & $\mathrm{BI} 2$ & No change & \\
\hline Plan to use & $\mathrm{BI} 3$ & No change & \\
\hline Plan to use - frequently & $\mathrm{BI} 4$ & No change & \\
\hline \multicolumn{3}{|l|}{ Use behavior factor (UB) } & 0.85 \\
\hline Frequency of use & UB1 & No change & \\
\hline $\begin{array}{l}\text { Usage of the platform to access } \\
\text { university resources and services }\end{array}$ & $\mathrm{UB} 2$ & No change & \\
\hline $\begin{array}{l}\text { Usage of the platform to conduct } \\
\text { business }\end{array}$ & UB3 & No change & \\
\hline $\begin{array}{l}\text { Usage of the platform as a one-stop } \\
\text { shop }\end{array}$ & UB4 & No change & \\
\hline
\end{tabular}

Table 45: Revised Research Model Taxonomy (Summary)

\begin{tabular}{|c|c|c|c|}
\hline $\begin{array}{l}\text { Factors and } \\
\text { indicators }\end{array}$ & Definition & $\begin{array}{l}\text { Reference } \\
\text { (s) for } \\
\text { definition( } \\
\text { s) }\end{array}$ & $\begin{array}{l}\text { Reference(s) } \\
\text { for studies } \\
\text { indicating an } \\
\text { influence on } \\
\text { other factors }\end{array}$ \\
\hline \multicolumn{4}{|c|}{ UTAUT Factors } \\
\hline $\begin{array}{l}\text { Effort } \\
\text { expectancy }\end{array}$ & $\begin{array}{l}\text { "Degree of ease associated with the use } \\
\text { of the system" [199]; construct } \\
\text { includes perceived ease of use }\end{array}$ & [199] & $\begin{array}{l}{[253],[265],} \\
{[266],[247],} \\
{[254],[252],} \\
{[268]}\end{array}$ \\
\hline Social influence & $\begin{array}{l}\text { "Extent to which users perceive that } \\
\text { those important to them believe they } \\
\text { should be using a technology" [263] }\end{array}$ & [263] & $\begin{array}{l}\text { Social influence - } \\
\text { [264], [253], } \\
{[265],[266],} \\
{[267],[247],} \\
{[254],[252],} \\
{[224],[268],} \\
{[269] ; \text { Subjective }} \\
\text { norm - [270], } \\
{[233],[271],} \\
{[242],[112],} \\
{[272],[273],} \\
{[274]}\end{array}$ \\
\hline $\begin{array}{l}\text { Behavioral } \\
\text { intention to use }\end{array}$ & $\begin{array}{l}\text { "The decision maker's disposition } \\
\text { toward using a system" [271] }\end{array}$ & {$[271]$} & $\begin{array}{l}{[277],[270],} \\
{[241],[271],} \\
{[244],[264],} \\
{[278],[247],} \\
{[279]}\end{array}$ \\
\hline Use behavior & Actual usage of the system. & [199] & - \\
\hline
\end{tabular}




\begin{tabular}{|l|l|l|l|}
\hline \multicolumn{1}{|l|}{ Factors added to UTAUT } \\
\hline Skills & The judgement of one's own skills in & {$[292]$} & {$[295],[290]$,} \\
& performing specific technology-related & & {$[292],[292]$,} \\
& tasks. & & {$[263],[286]_{2}$} \\
& & & {$[274]_{2}[112]$} \\
\hline
\end{tabular}

This revised research model contains five constructs, four of which are a part of UTAUT and are also in the research model for this study: Effort expectancy (EE), Social influence (SI), Behavioral intention (BI) and Use behavior (UB). The fifth construct, Skills, is not part of UTAUT, but was similar to the Self-efficacy and skills construct (one indicator difference), which was in the research model for this study.

\subsubsection{Confirmatory Factor Analysis - Approach \#3}

The baseline measurement model for Approach \#3, specified as per the above taxonomy, was analyzed using CFA. The model was acceptable or adequate for all three goodness of fit measures: RMSEA was adequate at 0.7 ( $\leq .05$ being a good model fit and $\leq .08$ being adequate), SRMR was acceptable at 0.05 (recommended value of <.10), and CFI was acceptable at 0.93 (recommended value at $>9.0$ ). Additionally, the baseline measurement model's loadings were strong: loadings for each indicator on its requisite construct were at least .6 and with many above .7; and all of the loadings were significant at $\mathrm{p}=0.000$.

In an effort to improve the model, the modification indices were examined, and seven changes were made. The error terms with a high covariance, i.e. modification index of 100 or more (large), were correlated as they each made sense theoretically: e1 (error for EE1) and e2 (error for EE3) are related as part of 
the Effort expectancy construct; e2 (error for EE3) and e3 (error for EE4) are related as part of the Effort expectancy construct; e4 (error for EE5) and e5 (error for PE5) are related as part of the Effort expectancy construct; e8 (error for PQ3) and e9 (error for PQ4) are related as part of the Effort expectancy construct; e18 (error for BI2) and e19 (error for BI3) are related as part of the Behavioral intention construct; e18 (error for BI2) and e20 (error for BI4) are related as part of the Behavioral intention construct; and e2o (error for BI4, whether frequent use of myPSU is planned for the future) and e21 (error for UB1, actual frequency of use) are related as they both pertain to frequency of use. After these changes, the loadings were all still above .6 with many still above .7 , and all of the loadings were still significant at $\mathrm{p}=0.000$. Thus, no items were dropped. Additionally, the revised model performed better on the goodness of fit measures - it is acceptable on all three of the measures with RMSEA of 0.05, SRMR of 0.04, and CFI of 0.97. The results are provided below. 


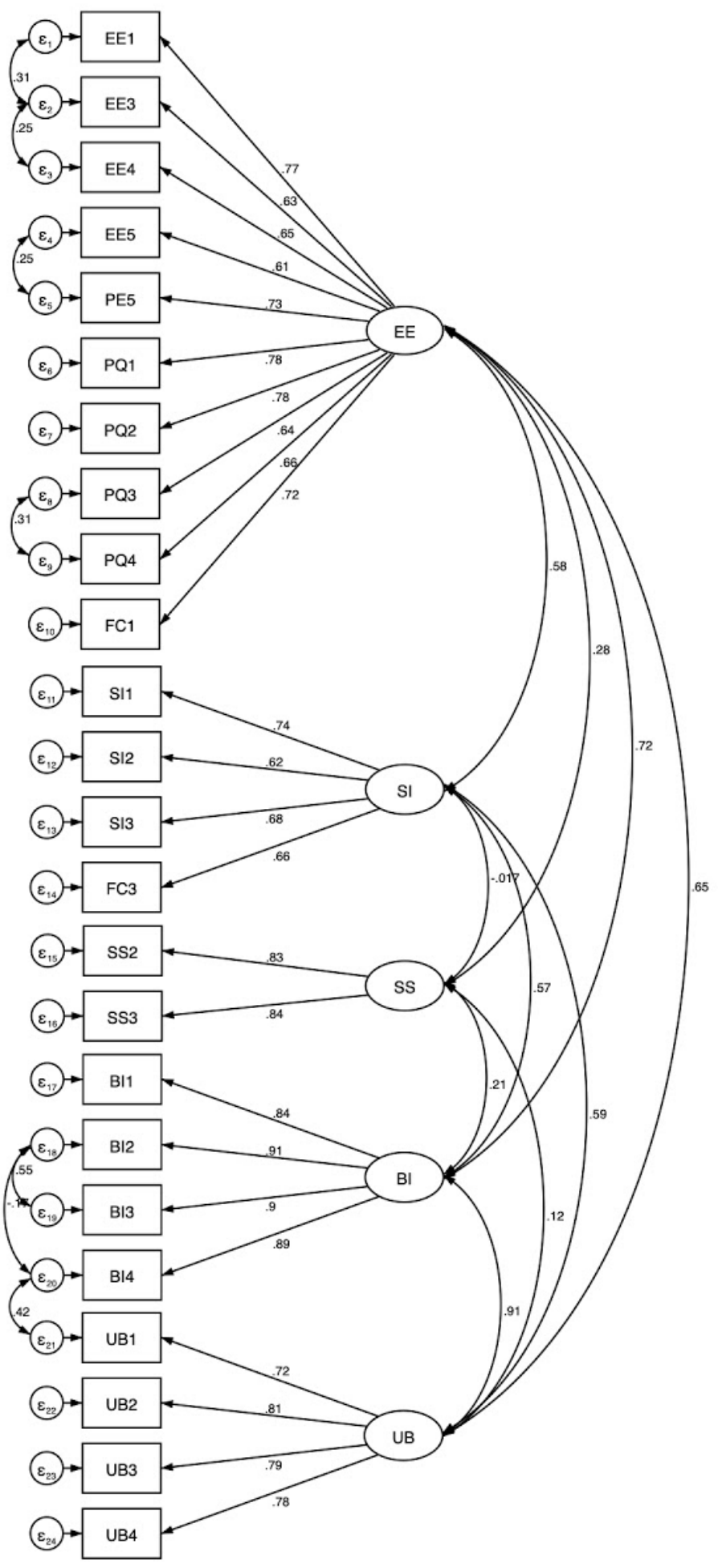

Figure 26: Approach \#3 - Measurement Model with Standardized Loadings (Final Model) 
Table 46: Approach \#3 - Measurement Model - Goodness of Fit Measure Comparisons

\begin{tabular}{|c|c|c|c|c|}
\hline $\begin{array}{l}\text { Statistic or } \\
\text { measure } \\
\text { name }\end{array}$ & $\begin{array}{l}\text { Reported or } \\
\text { recommended } \\
\text { value }\end{array}$ & $\begin{array}{l}\text { Baseline } \\
\text { measureme } \\
\text { nt model } \\
\text { (first model } \\
\text { fit) }\end{array}$ & $\begin{array}{l}\text { Revised } \\
\text { measurement } \\
\text { model (final } \\
\text { model fit) }\end{array}$ & $\begin{array}{l}\text { Analysis of final } \\
\text { model }\end{array}$ \\
\hline $\begin{array}{l}\text { Chi-square, } \\
\chi^{2}\end{array}$ & $\begin{array}{l}\chi^{2} \text { (along with } \\
\text { significance) and } \\
\text { degrees of } \\
\text { freedom }\end{array}$ & $\begin{array}{c}\chi^{2}=2321 \\
\text { p-value }= \\
\text { o.ooo } \\
\text { df }=242\end{array}$ & $\begin{array}{c}\chi^{2}=1211 \\
\text { p-value }=0.000 \\
\text { df }=235\end{array}$ & $\begin{array}{l}\text { Expected that } \chi^{2} \\
\text { is significant }\end{array}$ \\
\hline $\begin{array}{l}\text { Root mean } \\
\text { square error } \\
\text { of } \\
\text { approximatio } \\
\mathrm{n} \text { (RMSEA) }\end{array}$ & $\begin{array}{c}\leq .05 \text { being a good } \\
\text { model fit and } \\
\leq .08 \text { being } \\
\text { adequate }\end{array}$ & 0.07 & 0.05 & $\begin{array}{l}\text { Good fit and } \\
\text { slight } \\
\text { improvement from } \\
\text { baseline to } \\
\text { revised/final } \\
\text { model }\end{array}$ \\
\hline $\begin{array}{l}\text { Standardized } \\
\text { root mean } \\
\text { residual } \\
\text { (SRMR) }\end{array}$ & $<.10$ & 0.05 & 0.04 & $\begin{array}{l}\text { Acceptable and } \\
\text { slight } \\
\text { improvement from } \\
\text { baseline to } \\
\text { revised/final } \\
\text { model }\end{array}$ \\
\hline $\begin{array}{l}\text { Comparative } \\
\text { fit index } \\
(\mathrm{CFI})\end{array}$ & $>.9$ & 0.93 & 0.97 & $\begin{array}{l}\text { Acceptable and } \\
\text { improvement from } \\
\text { baseline to } \\
\text { revised/final } \\
\text { model }\end{array}$ \\
\hline
\end{tabular}

As a final check of the final measurement model, a discriminant validity analysis was completed, by analyzing the Average Variance Extracted (AVE) and the squared construct correlations for each construct. All AVE of all constructs exceeded, or almost nearly met, the recommended 0.5 threshold. For the discriminant validity check, all of the squared correlations between the constructs were less than the AVEs, except for the squared correlation for UB and BI (which was expected, as they loaded together in PCA but were kept separate for 
theoretical reasons to align with UTAUT). This indicated satisfactory distinctions between the constructs. The results are below.

Table 47: Discriminant Validity of the Measurement Model (Final Fit)

\begin{tabular}{|c|c|c|c|c|c|c|c|c|c|c|}
\hline \multirow{3}{*}{$\begin{array}{l}\text { Varia } \\
\text { bles } \\
\end{array}$} & \multicolumn{8}{|c|}{ Correlation } & \multirow{3}{*}{ AVE } & \multirow{3}{*}{ Analysis } \\
\hline & \multicolumn{2}{|c|}{$\mathbf{E E}$} & \multicolumn{2}{|c|}{ SI } & \multicolumn{2}{|c|}{ SS } & \multicolumn{2}{|r|}{ BI } & & \\
\hline & phi & $\begin{array}{l}\text { phi } \\
\text { squared }\end{array}$ & phi & $\begin{array}{l}\text { phi } \\
\text { square } \\
\text { d }\end{array}$ & phi & $\begin{array}{l}\text { phi } \\
\text { squared }\end{array}$ & phi & $\begin{array}{l}\text { phi } \\
\text { squared }\end{array}$ & & \\
\hline $\mathrm{EE}$ & \multicolumn{2}{|c|}{1.00} & & & & & & & 0.49 & - \\
\hline SI & 0.58 & 0.33 & \multicolumn{2}{|c|}{1.00} & & & & & 0.46 & Acceptable \\
\hline SS & 0.28 & 0.08 & -0.02 & 0.00 & \multicolumn{2}{|c|}{1.00} & & & 0.69 & Acceptable \\
\hline BI & 0.72 & 0.52 & 0.57 & 0.33 & 0.21 & 0.05 & \multicolumn{2}{|c|}{1.00} & 0.78 & Acceptable \\
\hline UB & 0.65 & 0.42 & 0.59 & 0.35 & 0.12 & 0.01 & 0.91 & 0.82 & 0.60 & $\begin{array}{l}\text { Acceptable, } \\
\text { except for } \\
\text { BI and UB, } \\
\text { which is } \\
\text { clear from } \\
\text { the factor } \\
\text { analysis } \\
\text { that they } \\
\text { are highly } \\
\text { correlated }\end{array}$ \\
\hline
\end{tabular}

${ }^{*}$ Grey shading is used to highlight the squared correlations between constructs

\subsubsection{Structural Model - Approach \#3}

To develop the structural model, the constructs from the final measurement model were transformed into a model showing relationships between constructs, and in light of the research model and UTAUT's hypothesized relationships. As mentioned above, this revised research model consists of five constructs, four of which are a part of UTAUT and are also in the research model for this study: Effort expectancy (EE), Social influence (SI), Behavioral intention (BI) and Use behavior (UB). The fifth construct, Skills, is not part of UTAUT, but was approximately in the research model for this study: two 
of the three indicators that were in the Self-efficacy and skills construct that were part of the research model have been retained in the Skills construct. In a departure from UTAUT, paths were added that are not in UTAUT but that make sense theoretically. The revised research model with hypotheses is below.

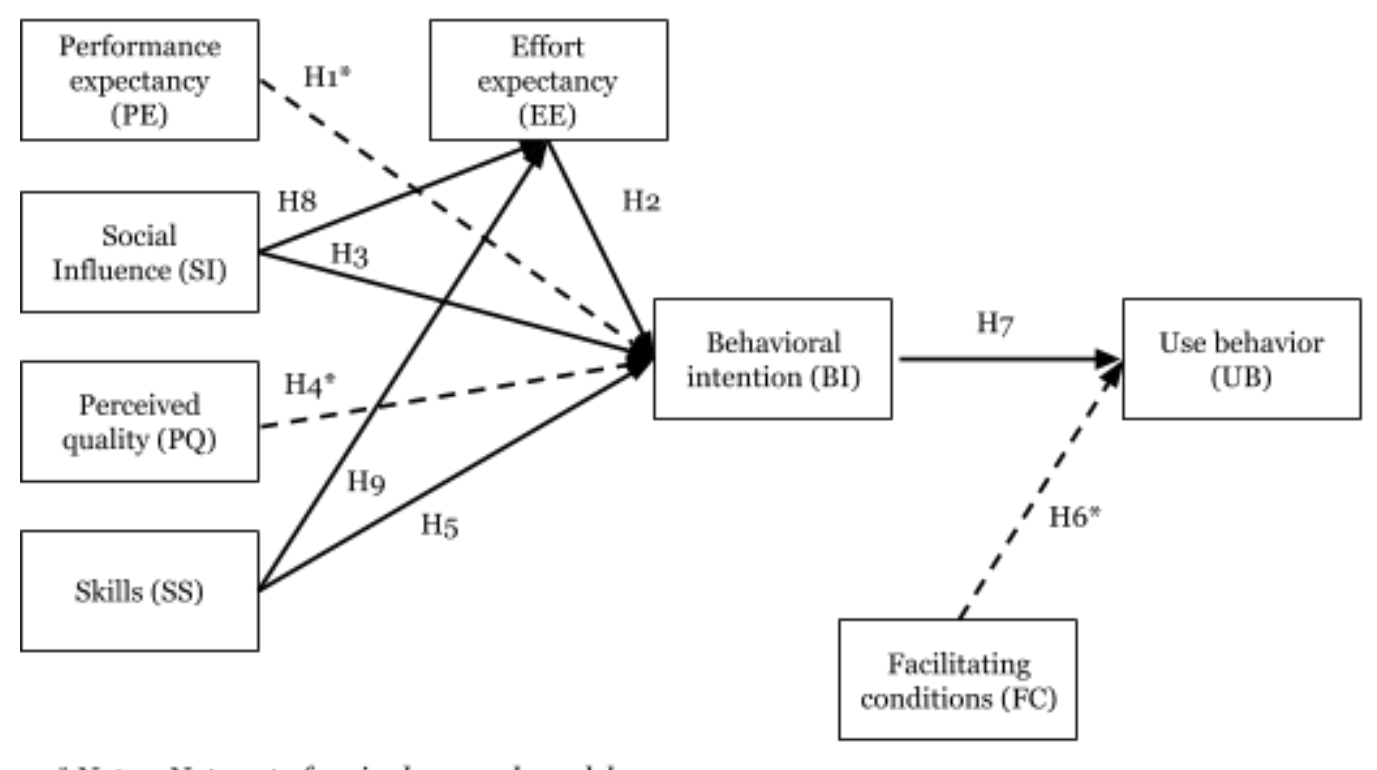

"Note - Not part of revised research model

Figure 27: Approach \# 3 - Revised Research Model with Hypotheses

The revised research model contains six hypotheses.

H2: Effort expectancy - "degree of ease associated with the use of the system" [199] - is hypothesized to positively influence Behavioral intention to use. Effort expectancy has been found in a variety of studies to have a positive influence on the adoption of technology [253], [265], [266], [247], [254], [252], [268]. 
H3 and H8: Social influence - "extent to which users perceive that those important to them believe they should be using a technology" [263] - is hypothesized to positively influence Behavioral intention to use (H3) and Effort expectancy (H8). Social influence has been found in a variety of studies to have a positive influence on adoption of technology [264], [253], [265], [266], [267], [247], [254], [252], [224], [268], [269]). Subjective norm, which is highly related to social influence, has also been found in a variety of studies to have a positive influence on adoption of technology [270], [233], [271], [242], [112], [272], [273], [274].

H5 and H9: Skills - the judgement of one's skills in performing specific technology-related tasks - is hypothesized to positively influence Behavioral intention to use ( $\mathrm{H}_{5}$ ) and Effort expectancy (H9). Skills has been found in a variety of studies to have a positive influence on adoption of technology [295], [290], [292], [292], [263],,[286], [274], [112].

H7: Behavioral intention to use - "The decision maker's disposition toward using a system" [271] - is hypothesized to positively influence Use behavior (actual use). Behavioral intention to use has been found in a variety of studies to have a positive influence on the adoption of technology [277], [270], [241] $\_$[271], [244], [264], [278], [247], [279]. Behavioral intention is widely accepted as an antecedent of actual usage [335].

Using the final measurement model, an analysis of the structural model as specified above was completed. No changes were warranted, as it was acceptable 
for all goodness of fit measures and the measures stayed consistent when compared to the final measurement model. RMSEA is acceptable at 0.05 (recommended value is $\leq .05$ ), SRMR is acceptable at 0.04 (recommended value is <.10), and CFI is acceptable at 0.96 (recommended value is >.9). Results are provided below.

Table 48: Approach \#3 - Structural Model - Goodness of Fit Measure Comparisons

\begin{tabular}{|c|c|c|c|c|}
\hline $\begin{array}{l}\text { Statistic or } \\
\text { measure } \\
\text { name }\end{array}$ & $\begin{array}{l}\text { Reported or } \\
\text { recommend } \\
\text { ed value }\end{array}$ & $\begin{array}{l}\text { Measurem } \\
\text { ent model } \\
\text { (final } \\
\text { model fit) }\end{array}$ & $\begin{array}{l}\text { Structural } \\
\text { model }\end{array}$ & $\begin{array}{l}\text { Analysis of final } \\
\text { model }\end{array}$ \\
\hline Chi-square, $\chi^{2}$ & $\begin{array}{l}\chi^{2} \text { (along with } \\
\text { significance) } \\
\text { and degrees of } \\
\text { freedom }\end{array}$ & $\begin{array}{c}\chi^{2}=1211 \\
\text { p-value }= \\
\text { o.ooo } \\
\mathrm{df}=235\end{array}$ & $\begin{array}{c}\chi^{2}=1256 \\
\text { p-value }= \\
\text { o.ooo } \\
\mathrm{df}=239\end{array}$ & $\begin{array}{l}\text { Expected that } \chi^{2} \text { is } \\
\text { significant }\end{array}$ \\
\hline $\begin{array}{l}\text { Root mean } \\
\text { square error of } \\
\text { approximation } \\
\text { (RMSEA) }\end{array}$ & $\begin{array}{c}\leq .05 \text { being a } \\
\text { good model fit } \\
\text { and } \leq .08 \\
\text { being } \\
\text { adequate }\end{array}$ & 0.05 & 0.05 & $\begin{array}{l}\text { Acceptable and } \\
\text { consistent with the } \\
\text { measurement model }\end{array}$ \\
\hline $\begin{array}{l}\text { Standardized } \\
\text { root mean } \\
\text { residual } \\
\text { (SRMR) }\end{array}$ & $<.10$ & 0.04 & 0.04 & $\begin{array}{l}\text { Acceptable and } \\
\text { consistent with the } \\
\text { measurement model }\end{array}$ \\
\hline $\begin{array}{l}\text { Comparative fit } \\
\text { index (CFI) }\end{array}$ & $>.9$ & 0.97 & 0.96 & $\begin{array}{l}\text { Acceptable and } \\
\text { consistent with the } \\
\text { measurement model }\end{array}$ \\
\hline
\end{tabular}

Turning to the path coefficients, all six of the path coefficients are significant in the structural model. Five of the paths $(\mathrm{EE} \rightarrow \mathrm{BI}, \mathrm{SI} \rightarrow \mathrm{BI}, \mathrm{BI} \rightarrow \mathrm{UB}$, $\mathrm{SI} \rightarrow \mathrm{EE}$ and $\mathrm{SS} \rightarrow \mathrm{EE})$ are significant at $\mathrm{p}<0.001$ with $\mathrm{p}=0.000$ in each case. The final path $(\mathrm{SS} \rightarrow \mathrm{BI})$ is significant at $\mathrm{p}<.05$, with $\mathrm{p}=0.016$. The standardized path 
coefficients ranged from having small (less than .10), to medium (medium is around .30) and large ( $\geq .50)$ effects [255]. The three largest effects are $\mathrm{BI} \rightarrow \mathrm{UB}$ (.91), SI $\rightarrow \mathrm{EE}(.58)$ and $\mathrm{EE} \rightarrow \mathrm{BI}(.55) . \mathrm{SS} \rightarrow \mathrm{EE}(.29)$ and $\mathrm{SI} \rightarrow \mathrm{BI}(.26)$ are medium effects, and $\mathrm{SS} \rightarrow \mathrm{BI}$ is quite small (.05). The $\mathrm{R}^{2}$ statistics are: $\mathrm{EE}$ is .42, meaning the data explains $42 \%$ of the variance for EE; BI is .56, meaning the data explains $56 \%$ of the variance for $\mathrm{BI}$; and UB is .83 , meaning the data explains $83 \%$ of the variance for UB.

In summary, the structural model is a strong fit with the data as it performs well on both goodness of fit measures and path significance, and paths are supported in the right direction [256]. Importantly, while this model is a good fit, it does not prove causation. "Rather, it shows that our assumptions are not contradicted and may be valid. We only can say 'may be valid' because other models and assumptions also may fit the data" [398]. 


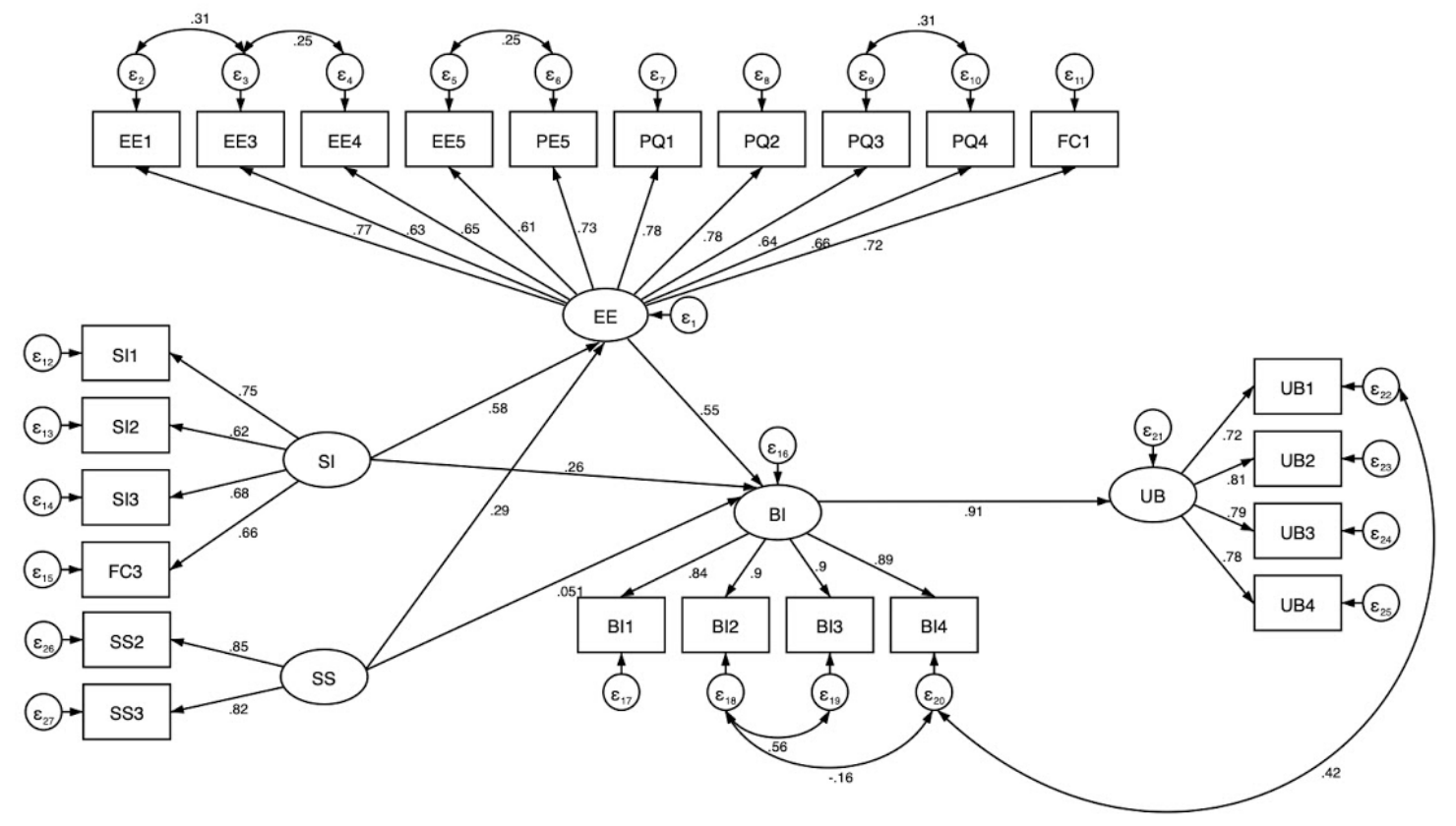

Figure 28: Approach \#3 - Structural Model (Revised Research Model) with Standardized Loadings 


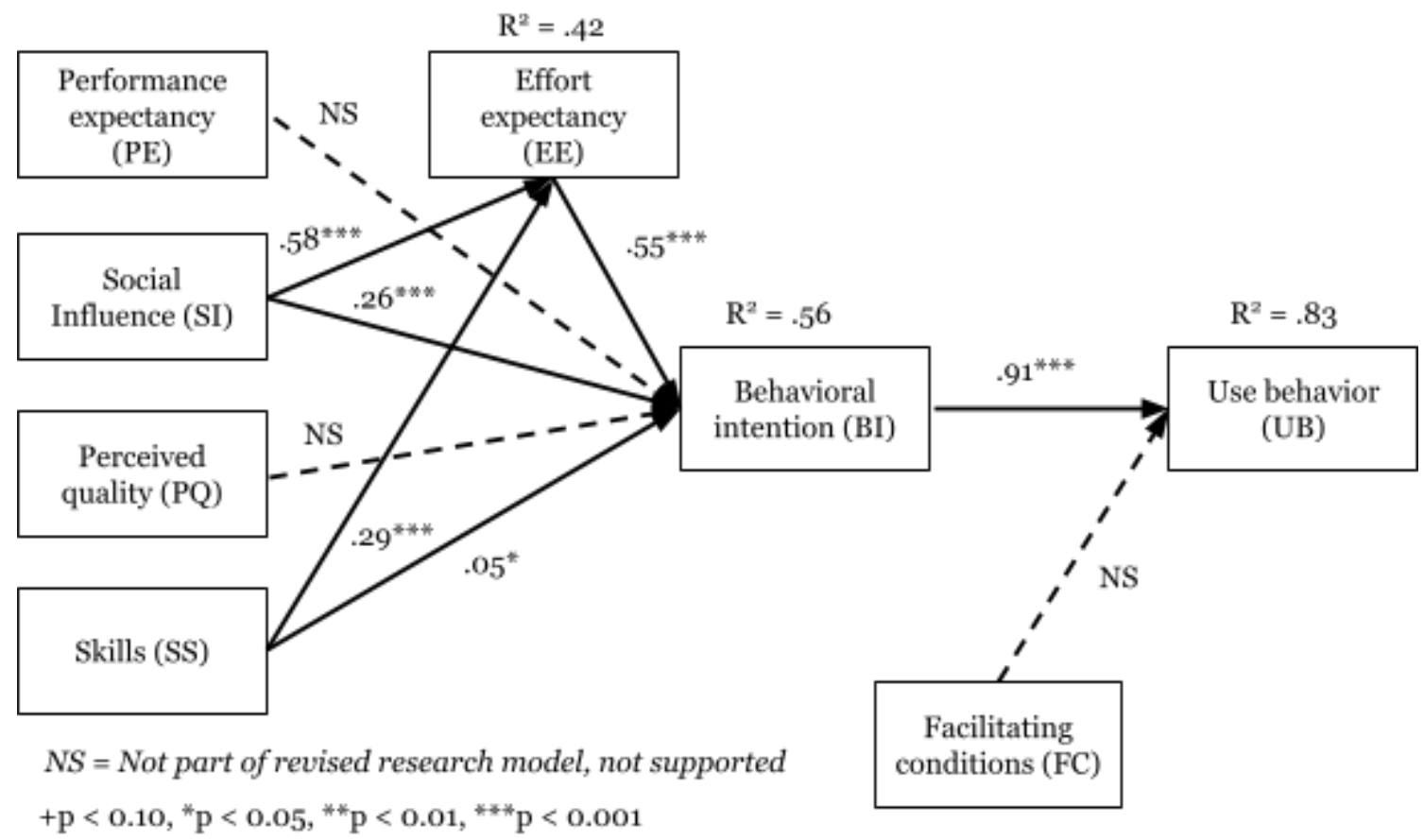

Figure 29: Approach \#3 - Visual Diagram of Structural Model (Revised Research Model) with Standardized Loadings

Table 49: Approach \#3 - Results of the Structural Model Analysis of the Revised Research Model

\begin{tabular}{|c|c|c|c|c|c|}
\hline $\begin{array}{l}\text { Relationshi } \\
\text { p }\end{array}$ & $\begin{array}{l}\text { Hypothe } \\
\text { sis }\end{array}$ & $\begin{array}{l}\text { Standardized } \\
\text { path coefficient }\end{array}$ & p-value & $\begin{array}{l}\text { Interpretati } \\
\text { on }\end{array}$ & Result \\
\hline $\begin{array}{l}\text { Behavioral } \\
\text { intention } \\
(\mathrm{BI}) \leftarrow \\
\text { Performance } \\
\text { expectancy } \\
\text { (PE) }\end{array}$ & $\mathrm{H} 1$ & $\begin{array}{c}\text { PE was dropped in } \\
\text { the Approach \#3 } \\
\text { PCA, as five of its } \\
\text { indicators } \\
\text { cross-loaded. }\end{array}$ & $\mathrm{n} / \mathrm{a}$ & $\mathrm{n} / \mathrm{a}$ & $\begin{array}{l}\text { Not } \\
\text { included in } \\
\text { revised } \\
\text { research } \\
\text { model }\end{array}$ \\
\hline $\begin{array}{l}\text { Behavioral } \\
\text { intention } \\
(\mathrm{BI}) \leftarrow \text { Effort } \\
\text { expectancy } \\
\text { (EE) }\end{array}$ & $\mathrm{H} 2$ & .55 & $0.000^{* * *}$ & $\begin{array}{l}\text { Significant at } \\
\mathrm{p}<0.001 ; \\
\text { positive }- \text { as } \\
\text { EE increases } \\
\text { by } 1, \mathrm{BI} \text { will } \\
\text { increase by } .55\end{array}$ & Supported \\
\hline $\begin{array}{l}\text { Behavioral } \\
\text { intention } \\
(\mathrm{BI}) \leftarrow \text { Social } \\
\text { influence (SI) }\end{array}$ & $\mathrm{H}_{3}$ & .26 & $0.000^{* * *}$ & $\begin{array}{l}\text { Significant at } \\
\mathrm{p}<0.001 ; \\
\text { positive - as SI } \\
\text { increases by 1, } \\
\text { BI will }\end{array}$ & Supported \\
\hline
\end{tabular}




\begin{tabular}{|c|c|c|c|c|c|}
\hline & & & & $\begin{array}{l}\text { increase by } \\
.26\end{array}$ & \\
\hline $\begin{array}{l}\text { Behavioral } \\
\text { intention } \\
(\mathrm{BI}) \leftarrow \\
\text { Perceived } \\
\text { quality (PQ) }\end{array}$ & $\mathrm{H}_{4}$ & $\begin{array}{l}\text { PQ was dropped in } \\
\text { the Approach \# } 3 \\
\text { PCA, as four of its } \\
\text { indicators loaded } \\
\text { onto EE and were } \\
\text { included in that } \\
\text { construct }\end{array}$ & $\mathrm{n} / \mathrm{a}$ & $\mathrm{n} / \mathrm{a}$ & $\begin{array}{l}\text { Not } \\
\text { included in } \\
\text { revised } \\
\text { research } \\
\text { model }\end{array}$ \\
\hline $\begin{array}{l}\text { Behavioral } \\
\text { intention } \\
(\mathrm{BI}) \leftarrow \text { Skills } \\
(\mathrm{SS})\end{array}$ & $\mathrm{H}_{5}$ & .05 & $0.016^{*}$ & $\begin{array}{l}\text { Significant at } \\
\text { p < 0.05; } \\
\text { positive - as } \\
\text { SS increases } \\
\text { by } 1, \text { BI will } \\
\text { increase by } \\
.05\end{array}$ & Supported \\
\hline $\begin{array}{l}\text { Use behavior } \\
\text { (UB) } \leftarrow \\
\text { Facilitating } \\
\text { conditions } \\
\text { (FC) }\end{array}$ & H6 & $\begin{array}{l}\text { FC was dropped in } \\
\text { the Approach \# } 3 \\
\text { PCA, as its } \\
\text { indicators loaded } \\
\text { on other constructs } \\
\text { or did not make } \\
\text { sense theoretically }\end{array}$ & $\mathrm{n} / \mathrm{a}$ & $\mathrm{n} / \mathrm{a}$ & $\begin{array}{l}\text { Not } \\
\text { included in } \\
\text { revised } \\
\text { research } \\
\text { model }\end{array}$ \\
\hline $\begin{array}{l}\text { Use behavior } \\
\text { (UB) } \leftarrow \\
\text { Behavioral } \\
\text { intention } \\
\text { (BI) }\end{array}$ & $\mathrm{H}_{7}$ & .91 & $0.000^{* * *}$ & $\begin{array}{l}\text { Significant at } \\
\mathrm{p}<0.001 ; \\
\text { positive - as } \\
\text { BI increases } \\
\text { by 1, UB will } \\
\text { increase by .91 }\end{array}$ & Supported \\
\hline $\begin{array}{l}\text { Effort } \\
\text { expectancy } \\
\text { (EE) } \leftarrow \\
\text { Social } \\
\text { influence (SI) }\end{array}$ & H8 & .58 & $0.000^{* * *}$ & $\begin{array}{l}\text { Significant at } \\
\mathrm{p}<0.001 ; \\
\text { positive - as SI } \\
\text { increases by } 1, \\
\text { EE will } \\
\text { increase by } \\
.58\end{array}$ & Supported \\
\hline $\begin{array}{l}\text { Effort } \\
\text { expectancy } \\
(\mathrm{EE}) \leftarrow \text { Skills } \\
\text { (SS) }\end{array}$ & H9 & .29 & $0.000^{* * *}$ & $\begin{array}{l}\text { Significant at } \\
\text { p }<0.001 ; \\
\text { positive - as } \\
\text { SS increases } \\
\text { by } 1 \text {, EE will } \\
\text { increase by } \\
.29\end{array}$ & Supported \\
\hline
\end{tabular}

$+\mathrm{p}<0.10,{ }^{*} \mathrm{p}<0.05,{ }^{* *} \mathrm{p}<0.01,{ }^{* * *} \mathrm{p}<0.001$ 


\subsubsection{Hypothesis Tests - Approach \#3}

When considering the final structural model results for Approach \#3, i.e. the revised research model, in light of the research hypotheses for this study, several hypotheses related to UTAUT were found to be significant, while several were not included in the model. Detailed path coefficients and statistical significance are provided in Table 49 for the revised research model, while all hypotheses for the research model and revised research model are interpreted below.

H1 is that Performance expectancy (PE), a construct that is part of UTAUT, was hypothesized to positively influence Behavioral intention to use myPSU (BI). The PE construct was dropped in the PCA for Approach \#3, as five of its indicators cross-loaded. Other studies have found PE to positively influence technology adoption [263], [264], [253], [265], [266], [267], [247], [252], [268]. PE could be a meaningful construct in other models related to the adoption of myPSU.

H2 is that Effort expectancy (EE), a construct that is part of UTAUT, was hypothesized to positively influence BI. This hypothesis was supported, with a standardized path coefficient of .55, which was the third largest path coefficient, indicating that EE can be considered to have a large effect on BI (large is $\geq .50$ ) [255]. EE in the revised research model was a combination of ease of use indicators and quality indicators. The finding that EE positively influences adoption is consistent with other studies about EE [253], [265], [266], [247], 
[254], [252], [268] and also consistent with other studies that system quality and information quality also positively influence adoption [277], [271], [291], [260]. This suggests that the effort it takes to use a platform, including traditional ease of use indicators plus quality indicators, has a positive influence on students' adoption of myPSU. The implication of this finding is that effort expectancy such as perceived ease of use, ease of use in learning to operate, the accessibility/navigation to a system, mobile app convenience, perceived mobile value, content quality, user interface design, system errors, platform response time and compatibility with other software platforms and online tools - matters significantly in students' intention to use the myPSU platform. Based on this analysis and consistent with previous findings, one can conclude that the effort expectancy of a student platform for accessing services could be an important and significant determinant of users' intention to adopt an information technology like myPSU.

H3 is that Social Influence (SI), a construct that is part of UTAUT, was hypothesized to positively influence BI. This hypothesis was supported, with a standardized path coefficient of .26 , which can be considered to be a medium effect on BI (medium is around .30) [255]. This finding is consistent with other studies [264], [253], [265], [266], [267], [247], [254], [252], [224], [268], [269]) and suggests that social influence has a positive influence on students' adoption of myPSU. The implication of this finding is that influence from others - such as peer influence, marketing, influence from university employees and learning 
about how to use a platform from others - matters significantly in students' intention to use the myPSU platform. Based on this analysis and consistent with previous findings, one can conclude that social influence from others could be an important and significant determinant of users' intention to adopt an information technology like myPSU.

H4 is that Perceived quality (PQ), a construct that was added to the UTAUT-based research model, was hypothesized to positively influence BI. The PQ construct was dropped in the PCA for Approach \#3, as four of its indicators loaded onto EE and were included in that construct. The implication of this finding is that PQ does not seem to be a relevant construct in relation to the adoption of myPSU.

H5 is that Skills (SS), a construct that was added to the UTAUT-based research model, was hypothesized to positively influence BI. This hypothesis was supported, with a standardized path coefficient of .05, which can be considered to be a small effect on BI (small is less than .10) [255]. This finding is consistent with other studies [295], [290], [292], [292], [263],_[286], [274], [112] and suggests that skills have a positive influence on students' adoption of myPSU. In the research model, self-efficacy as measured by Confidence was included in the Self-efficacy and skills construct, but this indicator was dropped in the revised research model, and the construct used for $\mathrm{H}_{5}$ became Skills. The implication of this finding related to $\mathrm{H}_{5}$ is that skills - basic computer and basic smartphone skills - matter significantly, although with a small effect, in students' intention to 
use the myPSU platform. Based on this analysis and consistent with previous findings, one can conclude that students' skills could be a minor but important and significant determinant of users' intention to adopt an information technology platform like myPSU.

H6 is that Facilitating conditions (FC), a construct that is part of UTAUT, was hypothesized to positively influence Use behavior (UB). The FC construct was dropped in the PCA for Approach \#3, as its indicators loaded on other constructs or did not make sense theoretically. Other studies have found FC to positively influence technology adoption [263], [275], [266], [267], [247], [268], [276], [269]. FC could be a meaningful construct in other models related to the adoption of myPSU

H7 is that Behavioral intention (BI), a construct that is part of UTAUT, was hypothesized to positively influence Use behavior (UB). This hypothesis was supported, with a path coefficient of .91, which was the highest standardized path coefficient in the model. This is a very large effect size (large is $\geq .50$ ) [255]. This finding is consistent with other studies [277], [270], [241] [ [271], [244], [264], [278], [247], [279]. Also, BI is widely accepted as an antecedent of actual usage [335]. That BI positively influences UB suggests that behavioral intention to use a platform has a positive influence on students' adoption of myPSU. The implication of this finding is that the behavioral intention to use myPSU consisting of an intention to use, a prediction to use, a plan to use and frequency of planned use - matters quite significantly in students' adoption of myPSU. 
Based on this analysis and consistent with previous findings, one can conclude that the behavioral intention to use a platform could be an important and significant determinant of adoption of an information technology like myPSU.

$\mathbf{H 8}$ is that Social Influence (SI), a construct that is part of UTAUT, was hypothesized to positively influence EE. This hypothesis was supported, with a standardized path coefficient of .58 , which can be considered to have a large effect on EE (large is 2.50 ) [255]. This finding is consistent with other studies in that social influence was found to positively influence adoption [264], [253], [265], [266], [267], [247], [254], [252], [224], [268], [269]) and suggests that social influence has a positive influence on the effort expectancy of myPSU. The implication of this finding related to $\mathrm{H} 8$ is that influence from others - such as peer influence, marketing, influence from university employees and learning about how to use a platform from others - matters significantly in students' effort expectancy of the myPSU platform. For example, it is possible that social influence contributes to learning about how to use a platform, thus impacting the ease of using it. Sung et al. (2014) also found in a higher education context that the SI $\rightarrow$ EE path matters significantly [401]. Based on this analysis and consistent with previous findings, one can conclude that social influence from others could be an important and significant determinant of effort expectancy in relation to an information technology like myPSU.

H9 is that Skills (SS), a construct that was added to the UTAUT-based model, was hypothesized to positively influence EE. This hypothesized 
relationship is not part of UTAUT. This hypothesis was supported, with a standardized path coefficient of .29, which can be considered to be a medium effect on EE (medium is around .30) [255]. This finding is consistent with other studies in that skills were found to positively influence adoption [295], [290], [292], [292], [263],_[286], [274], [112] and suggests that skills have a positive influence on the effort expectancy of myPSU. The implication of this finding related to $\mathrm{H} 9$ is that skills - basic computer and basic smartphone skills - matters significantly in students' effort expectancy of the myPSU platform. Based on this analysis and consistent with previous findings, one can conclude that students' skills could be an important and significant determinant of effort expectancy in relation to an information technology platform like myPSU. 


\section{Chapter Ten: Discussion, Conclusion and Research Contributions}

\subsection{Findings and Discussion}

The statistical analysis of the proposed theory about why students might adopt myPSU, as a type of student information technology, sheds light into the two primary research questions for this study.

\subsubsection{Practical Implications}

When considering the first of the two research questions for this study What are the critical factors that influence undergraduate students themselves in adopting software for accessing university services (one type of student information technology)? - this study provides several critical findings and implications.

As a whole, this research:

- Offers universities and the educational technology sector with insights about how to improve service delivery through technology-enabled services

- Provides leaders, managers and software developers in universities with ideas for concrete action to improve student information technology

- Suggests ways to enhance software in support of institutional and societal goals to improve student success 
- Found that the statistically significant and most important factors that influence behavioral intention to adopt myPSU are Effort expectancy (EE construct) and Social influence (SI construct)

- Identified that two additional critical factors - Social influence and Skills - influence Effort expectancy

- Resulted in a revised research model that accounts for $42 \%$ of the variance for Effort expectancy, 56\% for the variance in Behavioral intention to use myPSU and 83\% of the variance for Use behavior.

Turning to the detailed results from this research, there are several important practical implications. First, the practical implications related to Effort expectancy and its positive and significant impact on Behavioral intention (H2) include that when building and designing student information technology like myPSU, how easy the platform is to use and how easy the software is to access, are incredibly important. University leaders, software developers, product managers and platform vendors could consider prioritizing their energies to:

- Enhance content quality and clear navigation paths to access software (user interface design), with student diversity in mind

- Ensure that platforms are easy to access/find in complex digital ecosystems where students are faced with a multitude of platforms and tools

- Ensure that platforms are interoperable and compatible with each other. 
In higher education environments challenged by legacy student information systems, this can be incredibly challenging.

While effort expectancy is commonly found to be a determinant of technology adoption [253], [265], [266], [247], [254], [252], [268], this research suggests specific ways that effort expectancy takes shape in a university services setting. Given the lack of research about student information technology adoption related to software for accessing university services, this is an important contribution. Additionally, the importance of accessing software independent of time and location, including access through mobile devices (such as a mobile app), stands out as a critical component of effort expectancy and in many ways is a hallmark of today's college students, as smartphone ownership is prolific .

Second, the practical implications related to Social influence's positive and significant impact on Effort expectancy (H8) are interesting to consider. From an applied perspective, the influence of social items on effort expectancy could be interpreted to mean that the influence of others - such as from peers, university employees and the university itself through marketing - could help students become more familiar with a platform. This familiarity could then make the platform easier to use, as students might approach myPSU for the first time with a frame of reference and a basic understanding that derives from peer influences. For example, if Student A, a student who is an active myPSU user, tells Student B, a student who has not used myPSU, about the ability to see final grades on the platform and explains how to find this feature, this might make it easier for 
Student B to use the platform. Universities could consider using structured, yet straightforward, ways to use peers and university employees to walk students through a platform to help improve its adoption, such as at new student orientations or including an offer to walk through a platform as part of routine technical support/Help Desk interactions.

Third, the practical implications of Skills' positive and significant influence on Effort expectancy (H9) are helpful to consider. Not surprisingly, a students' basic computer skills and basic smartphone skills positively influence effort expectancy. From an applied perspective, these results suggest that if a student is more skilled in using technology they could find it easier to use a platform. Given that Portland State University and other urban-serving universities might serve higher proportions of students who are less comfortable with technology, as several interviewees expressed in the qualitative research for this study, universities could consider creating or enhancing formal support and tutorials for basic technology skills. A quick scan of the Portland State University website, as an example, turned up helpful workshops (e.g. about the Google Suite and Computer Basics) that could be promoted more to students.

Fourth, turning again to Social influence, this also had a positive and significant impact on Behavioral intention to use the myPSU platform ( $\left.\mathrm{H}_{3}\right)$. Practical implications of this finding include that influence from others manifested in several ways in this study - from influence from peers, to the importance of marketing a platform, to influence from university employees, to 
learning about how to use a platform from others. Practitioners interested in supporting the adoption of student information technology could consider amplifying efforts that leverage social influences, such as targeted marketing during students' first experiences at a university, encouraging university employees to promote a platform, such as during the first class of each course, and facilitating interactions where students could learn from each other about how to use a platform.

These practical implications sit in a context of extreme stress for higher education institutions yet one that also has opportunity. Given the tremendous budget and performance challenges many public universities face [2], exacerbated now by the operational challenges related to COVID-19 and the potential of large declines in enrollment [402], technology innovations might now be more important than ever. Innovating service delivery could enable some institutions to use technology to create operating leverage, personalize services and reduce costs [1]. Further, institutions' strategies to enhance service experiences could create a sustained competitive advantage [17], [18], [19], [20]. Perhaps more importantly, innovation can reduce bureaucratic hassles in online services, which has the promise of promoting student belonging, which in turn influences persistence [229], [230], all toward the end goal of helping more students reap the benefits of a college degree [21]. 


\subsubsection{Theoretical Implications}

When considering the second of the two research questions for this study To what degree does the Unified Theory of Acceptance and Use of Technology (UTAUT) technology adoption model predict adoption of software for accessing university services (one type of student information technology)? - this study provides several critical findings and implications.

First, and perhaps most critically, UTAUT was only partially validated. The extended UTAUT model used in this study as the research model was not a good fit with the data, meaning that in its most pure form as first modified for this study, UTAUT was not able to predict adoption of software for accessing university services. Only after exploratory analysis resulting in the addition of structural paths not present in UTAUT was a satisfactory model identified - the revised research model. Critically, though, the revised model included several key constructs from UTAUT, all of which have been supported in the literature as influencers of adoption: Effort expectancy [253], [265], [266], [247], [254], [252], [268]; Social influence [264], [253], [265], [266], [267], [247], [254], [252], [224], [268], [269]); and Behavioral intention [277], [270], [241], [271], [244], [264], [278], [247], [279].

Additionally, while UTAUT was only partially validated, it was selected because of its widespread application across industries and user types [221] and its use in organizational contexts [225], as Portland State University students are more like participants in the Portland State University organization, as opposed 
to consumers, since myPSU is the only platform of its kind for them to use. Comparing UTAUT to other models that could have been selected highlights how UTAUT was useful for this research:

- Theory of Reasoned Action (TRA) [200] and Theory of Planned Behavior (TPB) [205] do not include effort expectancy, which is a key construct of UTAUT [199] and was a critical part of the revised research model and this study's findings

- Technology Acceptance Model (TAM) [210] and Technology Acceptance Model 2 (TAM2) [215] include similar constructs to UTAUT, but UTAUT includes facilitating conditions, which, while it was not in the revised research model, was a topic that this research explored

- In comparison to UTAUT, the Task-Technology Fit Model (TTF) focuses more on specific technology tasks and the performance that derives from those tasks [218], which, in contrast to UTAUT, TTF does not include contextual factors (i.e. factors that include considerations beyond just the technology itself) that are in UTAUT and enabled critical findings in this research model, such as that Social influence and Effort expectancy are significant influencers of adoption.

In summary, while UTAUT was only partially validated, it was an appropriate and helpful model for this research.

Second, an additional theoretical consideration related to UTAUT as a whole is that Performance expectancy (PE factor), i.e. perceived usefulness, and 
Facilitating conditions, both UTAUT constructs, were not present in the revised research model, although they could be present in other models that fit this data, as PE has been found to have a positive influence on adoption [263], [264], [253], [265], [266], [267], [247], [252], [268], as has FC [263], [275], [266], [267], [247], [268], [276], [269].

Third, the findings suggest that UTAUT might be enhanced, at least as applied to information technology used by college students, by including a factor related to basic technology skills, which was validated in this research, providing new evidence to contribute to the development of UTAUT.

Fourth, this research advances the theory as the revised research model accounted for $42 \%$ of the variance for Effort expectancy, $56 \%$ for the variance in Behavioral intention to use myPSU and $83 \%$ of the variance for Use behavior.

Fifth, the PCA factor analysis approach was critical in identifying a model that fit the data. PCA clarified distinct constructs, simplified the factor structure by ensuring that indicators loaded heavily on constructs, provided insight that there were fewer factors than had been hypothesized (contributing to model parsimony), and was critical in leading to a fitted model. A comparison of the three SEM approaches used in this study illustrates the importance of PCA. As the analysis moved from more to less adherence with UTAUT, i.e. from Approach \#1 to Approach \#3, and thus became more exploratory in nature, the goodness of fit measures improved as did model parsimony. Comparisons of the three 
approaches in terms of goodness of fit measures and model parsimony are provided below.

Table 5o: Comparison of SEM Approaches using Final Structural Models for each Approach

\begin{tabular}{|c|c|c|c|c|c|}
\hline $\begin{array}{l}\text { Measure } \\
\text { name }\end{array}$ & $\begin{array}{l}\text { Recomme } \\
\text { nd value }\end{array}$ & $\begin{array}{l}\text { Approach } \\
\text { \#1 final } \\
\text { structural } \\
\text { model } \\
\text { value (no } \\
\text { factor } \\
\text { analysis) }\end{array}$ & $\begin{array}{l}\text { Approach \#2 } \\
\text { final } \\
\text { structural } \\
\text { model value } \\
\text { (limited } \\
\text { scope of } \\
\text { factor } \\
\text { analysis) }\end{array}$ & $\begin{array}{l}\text { Approach } \\
\text { \#3 final } \\
\text { structural } \\
\text { model } \\
\text { value } \\
\text { (factor } \\
\text { analysis } \\
\text { used all } \\
\text { constructs } \\
\text { ) }\end{array}$ & Analysis \\
\hline $\begin{array}{l}\text { Root mean } \\
\text { square } \\
\text { error of } \\
\text { approxima } \\
\text { tion } \\
\text { (RMSEA) }\end{array}$ & $\begin{array}{c}\leq .05 \text { being } \\
\text { a good } \\
\text { model fit } \\
\text { and } \leq .08 \\
\text { being } \\
\text { adequate }\end{array}$ & $\begin{array}{c}0.11 \text { (not } \\
\text { acceptable) }\end{array}$ & $\begin{array}{c}\text { o.10 (not } \\
\text { acceptable) }\end{array}$ & $\begin{array}{c}0.05 \\
\text { (acceptable) }\end{array}$ & \multirow[t]{3}{*}{$\begin{array}{l}\text { Approach \#3 } \\
\text { performs better } \\
\text { on all three } \\
\text { goodness of fit } \\
\text { measures, and is } \\
\text { acceptable for all } \\
\text { three }\end{array}$} \\
\hline $\begin{array}{l}\text { Standardiz } \\
\text { ed root } \\
\text { mean } \\
\text { residual } \\
\text { (SRMR }\end{array}$ & $<.10$ & $\begin{array}{c}0.31 \text { (not } \\
\text { acceptable) }\end{array}$ & $\begin{array}{c}0.27 \text { (not } \\
\text { acceptable) }\end{array}$ & $\begin{array}{c}0.04 \\
\text { (acceptable) }\end{array}$ & \\
\hline $\begin{array}{l}\text { Comparati } \\
\text { ve fit index } \\
\text { (CFI) }\end{array}$ & $>.9$ & $\begin{array}{c}0.78 \text { (not } \\
\text { acceptable) }\end{array}$ & $\begin{array}{c}0.83 \\
\text { (moderately } \\
\text { acceptable) }\end{array}$ & $\begin{array}{c}0.96 \\
\text { (acceptable) }\end{array}$ & \\
\hline $\begin{array}{l}\text { Model } \\
\text { parsimony }\end{array}$ & $\begin{array}{l}\text { Parsimonio } \\
\text { usness (i.e. } \\
\text { fewer } \\
\text { number of } \\
\text { constructs } \\
\text { is } \\
\text { preferred) }\end{array}$ & 8 constructs & 7 constructs & 5 constructs & $\begin{array}{l}\text { Approach \# } 3 \text { is } \\
\text { more } \\
\text { parsimonious }\end{array}$ \\
\hline
\end{tabular}

Notes: Approach \#1 did not include factor analysis; Approach \#2 included a factor analysis of all constructs and related indicators that were hypothesized to influence BI); and Approach \#3 included factor analysis of all constructs and related indicators.

Finally, Perceived quality (PQ) was hypothesized to be a new construct that could extend UTAUT. In the revised research model, PQ and EE loaded onto 
the same factor, indicating they were highly related and suggesting that PQ might not be a distinct construct in relation to the data collected in this study and in this context.

\subsection{Conclusion}

This paper has explored two primary research questions -1 . What are the critical factors that influence undergraduate students themselves in adopting software for accessing university services (one type of student information technology)? 2. To what degree does the Unified Theory of Acceptance and Use of Technology (UTAUT) technology adoption model predict adoption of software for accessing university services (one type of student information technology)? through a robust mixed-methods study involving:

- Qualitative approaches (e.g. in-depth literature review, interviews and focus groups)

- Data collection through a web-survey administered to undergraduate students at Portland State University (Portland, Oregon; analytic sample of 1,841 respondents)

- Quantitative analysis using Structural Equation Modeling.

Through the qualitative approaches, a preliminary research model was transformed into a research model, which was then tested using advanced statistical techniques. These techniques, namely Structural Equation Modeling involving Principal Components Analysis, Confirmatory Factor Analysis and structural model evaluation, were deployed to create a revised research model. 
This revised research model provides insights into the factors that influence undergraduates themselves in adopting software for accessing university services, as one type of student information technology, and helps further enhance UTAUT.

When considering the findings about the factors that are critical in influencing students' adoption of a technology platform such as myPSU, effort expectancy and social influence stand out as critical influences on intention to adopt a technology, and social influence and a students' basic technology skills stand out as determinants of effort expectancy. While these findings are perhaps not surprising to practitioners in the field, they validate and provide statistical evidence about the key factors that likely influence adoption of student information technology.

Additionally, the findings emphasize the importance of effort expectancy, which might not be a focal point of universities' designs and implementations of digital services. In fact, this finding points to what some argue is a large gap for many universities - that how students experience technologies, and how effortlessly they can be used, is a critical factor influencing student outcomes [230], particularly in light of students' desires that the service quality they experience at universities is on par with what they find in their personal lives outside of college [124]. Not surprisingly, skills was supported as a positive antecedent to effort expectancy, indicating that basic computer and smartphone skills could be important for effort expectancy. 
In contrast to other research, Performance expectancy and the Facilitating conditions constructs both were not present in the revised research model. Perceived quality, which was hypothesized to be a distinct construct, was found to be very similar to Effort expectancy and was not a unique construct.

Theoretically, this study builds on the development of the UTAUT technology adoption model by indicating the need, in a higher education context, of skills as an important factor, as well as supporting the idea that more complex relationships exist between latent variables than a strict application of the UTAUT model affords.

\subsection{Research Contributions}

In sum, this empirical research uniquely contributes to the research literature. It applies UTAUT to a higher education context to study the delivery of technology-enabled services and in doing so it makes contributions towards explaining the critical determinants of the adoption of software for accessing university services (one type of student information technology). Applying and empirically evaluating a technology adoption model specific to platforms that provide university services, with an overarching goal of promoting student degree attainment, is a new strain of research in the technology adoption field. Thus, the results provide insights into technology adoption and service delivery generally and specifically in the context of higher education. Second, the research makes unique contributions to the body of knowledge: the research used a novel 
application of UTAUT, the research explored how UTAUT could be applied in the university setting and the research suggests how the model could be enhanced.

Applied contributions of this research include that the factors that influence adoption could aid universities in more effectively leveraging student information technology, contributing to improvements in service delivery and more importantly, contributing to improving educational attainment rates, which benefits students, universities and greater society. Second, the findings from this study could benefit Portland State University specifically as it seeks to improve the student experience, digital services and student success. Finally, this research could aid educational technology companies with improving their products by providing insights that enable them to meet core user needs in improved ways.

\subsection{Limitations and Future Research}

Despite the meaningful findings and research contributions, this empirical research is not without limitations and the need for future research. Performance expectancy, which is widely accepted as a critical determinant of technology adoption, was not present in the revised research model and this construct was found to be quite similar to Behavioral intention and Use behavior. Future research could conduct a more in-depth investigation into this topic, including reaching out to experts in the educational technology and higher education sectors for their opinions on this and the other findings. Preliminary outreach to experts indicates that the findings regarding the supported hypotheses is in line 
with expert opinions about adoption of myPSU, based on their general expertise, observations of student behavior and/or anecdotal evidence.

While the research has made contributions by explaining variances for the endogenous constructs ( $42 \%$ of the variance for Effort expectancy, $56 \%$ of the variance for Behavioral intention to use and $83 \%$ of the variance for Use behavior), the proportions of unexplained variance for each construct indicate opportunities for further study. Also, future research in line with UTAUT's use of moderators could examine moderating variables, such as gender, age or financial aid recipient status, to determine if they might influence adoption. An additional area for further inquiry could be to understand how student perceptions of technology might have shifted as a result of COVID-19, which has required institutions like Portland State University to more effectively leverage technology not only for service delivery, but also for online learning [403].

Finally, the results from this research, as is true with many published studies, provide an important but limited contribution to the knowledge of technology adoption, given that this research was conducted at one university at a single point in time. Conducting additional research across different universities, with different platforms but in the same technology class (software for accessing university services), could inform the generalizability of any results.

\subsection{Closing}

In closing, I hope that these findings, if even in a very small way, might contribute to nationwide and university goals to improve service delivery and 
drastically improve student attainment for all students, and particularly for first generation college students, who are less likely to graduate compared to their traditional counterparts [106], [181], [182]. An undergraduate degree remains integral for societal goals of an informed and educated citizenry, for workforce needs and for goals of increasing social mobility [21].

Technology, including technology that enables service delivery like myPSU, plays a central role in supporting students. This is true particularly in light of recent societal impacts due to the COVID-19 illness and its unprecedented impact on nearly all facets of life, including at universities, where technology tools and platforms are even more critical, given the needs for physical distancing. John O'Brien, president and CEO of Educause, a nonprofit association whose mission is to advance higher education through technology innovation, wrote recently: "Their [Universities' IT staff's] tireless work reminds us that technology can no longer be seen as a utility working quietly in the background. Now more than ever, technology is a strategic asset that is vital to the success of every institution" [404].

My hope is that given the increasing centrality of technology in higher education institutions, this study might provide helpful insights - to academic leaders, information technologists, student services staff, philanthropists and the educational technology sector - so that together we can support technology-enabled service innovations that make a difference for all students, 
and particularly those for whom a college degree provides critical social mobility and a path to realizing their dreams. 


\section{References}

[1] P. Y. K. Chau, S. Y. Ho, K. K. W. Ho, and Y. Yao, "Examining the effects of malfunctioning personalized services on online users' distrust and behaviors," Decision Support Systems, vol. 56, pp. 180-191, Dec. 2013.

[2] P. Bransberger and D. K. Michelau, "Knocking at the college door: projections of high school graduates," WICHE Western Interstate Commission for Higher Education, Dec. 2016.

[3] P. Trostel, "It's not just the money: the benefits of college education to individuals and to society," Lumina Foundation, Oct. 2015.

[4] National Student Clearinghouse Research Center, "Completing college: a national view of student attainment rates - fall 2009 cohort | National Student Clearinghouse Research Center," National Student Clearinghouse Research Center, Nov. 2015. http://nscresearchcenter.org/signaturereport10/ (accessed Jun. 04, 2017).

[5] D. Leonhardt and S. Chinoy, "The college dropout crisis," The New York Times, May 23, 2019.

[6] C. Brooks and J. Pomerantz, "ECAR study of undergraduates students and information technology, 2017," EDUCAUSE Center for Analysis and Research, Oct. 2017.

[7] J. Galanek, D. C. Gierdowski, and C. Brooks, "ECAR study of undergraduates students and information technology, 2018," EDUCAUSE Center for Analysis and Research, Oct. 2018.

[8] L. M. Gambino, "Innovation in action: iPASS, student success, and transformative institutional change," Planning for Higher Education, vol. 45, no. 2, p. 65, 2017.

[9] J. Fletcher, M. Grant, M. Ramos, and M. M. Karp, "Integrated Planning and Advising for Student Success (iPASS): state of the literature. CCRC Working Paper No. 90," Community College Research Center, Oct. 2016. [Online]. Available: https://eric.ed.gov/?id=ED570697.

[10]M. M. Karp, H. S. Kalamkarian, S. Klempin, and J. Fletcher, "How colleges use Integrated Planning and Advising for Student Success (iPASS) to transform student support. CCRC Working Paper No. 89," Community College Research Center, Teachers College, Columbia University, 2016, [Online]. Available: https://eric.ed.gov/?id=ED568156.

[11] S. Klempin and M. M. Karp, "Leadership for transformative change: lessons from technology-mediated reform in broad-access colleges," The Journal of Higher Education, vol. 89, no. 1, pp. 81-105, 2018.

[12]L. A. Pasquini and G. E. Steele, "Technology in academic advising: perceptions and practices in higher education," NACADA Technology in Advising Commission Sponsored Survey, 2013. [Online]. Available: https://www.researchgate.net/profile/Laura_Pasquini/publication/2963331 77_Technology_in_Academic_Advising_Perceptions_and_Practices_in_Hi gher_Education/links/56d4a47co8aefd177bof5d54.pdf. 
[13]G. E. Steele and K. C. Thurmond, "Academic advising in a virtual university," New Directions for Higher Education, vol. 2009, no. 146, pp. 85-95, Jun. 2009.

[14]J. Natsu, "Advanced analytics: helping educators approach the ideal," eCampusNews,

2010. https://www.ecampusnews.com/special-reports/advanced-analytics-helping -educators-approach-the-ideal/ (accessed Jan. 23, 2018).

[15]A. Van Barneveld, K. E. Arnold, and J. P. Campbell, "Analytics in higher education: establishing a common language," library.educause.edu, 2012. [Online].

Available: https://library.educause.edu/ /media/files/library/2012/1/eli3026-pdf.pdf.

[16]J. F. Hair Jr, M. Wolfinbarger, A. H. Money, P. Samouel, and M. J. Page, Essentials of business research methods. Routledge, 2015.

[17]P. R. Dickson and J. L. Ginter, "Market segmentation, product differentiation, and marketing strategy," Journal of Marketing, vol. 51, no. 2, pp. $1-10,1987$.

[18]M. E. Porter, "How competitive forces shape strategy," Harvard Business Review, 1979, [Online]. Available: http://faculty.bcitbusiness.ca/KevinW/480o/porter79.pdf.

[19]A. S. Bharadwaj, "A resource-based perspective on information technology capability and firm performance: An empirical investigation," MIS Quarterly, vol. 24, no. 1, pp. 169-196, 2000.

[20] J. Barney, "Firm resources and sustained competitive advantage," Journal of Management, vol. 17, no. 1, pp. 99-120, Mar. 1991.

[21] The Hechinger Report, "Research offers hope to first-gen college grads," US News \& World Report, Feb. 26, 2018. https://www.usnews.com/news/national-news/articles/2018-02-26/new-re search-offers-hope-to-first-generation-college-grads (accessed Feb. 05, 2019).

[22] "Lumina fact sheet," Lumina Foundation, Apr. 2017. Accessed: Apr. 23, 2017.

[Online]. Available:

https://www.luminafoundation.org/resources/lumina-fact-sheet.

[23] U.S. Department of Education, "Fact sheet: a college degree: surest pathway to expand opportunity, success for American students," U.S. Department of Education, Sep. 16, 2016. https://www.ed.gov/news/press-releases/fact-sheet-college-degree-surest-p athway-expanded-opportunity-success-american-students (accessed Mar. 25, 2019).

[24] "A stronger nation: learning beyond high schools builds American talent (national report 2018)," Lumina Foundation, Feb. 2018.

[25] J. M. Braxton, W. R. Doyle, I. Harold V. Hartley, A. S. Hirschy, W. A. Jones, and M. K. McLendon, Rethinking college student retention. John Wiley \& Sons, 2013.

[26] Institute of Education Services, "Educational attainment," National 
Center for Education 2018. https://nces.ed.gov/fastfacts/display.asp?id=27 (accessed Mar. 25, 2019).

[27]Institute of Education Services, "The condition of education - international educational attainment," National Center for Education Statistics, May 2018. https://nces.ed.gov/programs/coe/indicator_cac.asp (accessed Mar. 25, 2019).

[28] C. I. Agency, "The world factbook - Central Intelligence Agency," 2017. https://www.cia.gov/library/publications/the-world-factbook/fields/2012.ht $\mathrm{ml}$ (accessed Jun. 04, 2017).

[29] A. Smith and M. Anderson, "Online shopping and e-commerce," Pew Research Center, Dec. 2016. [Online]. Available: http://www.pewinternet.org/2016/12/19/online-shopping-and-e-commerce $/$.

[30] M. J. Bitner and S. W. Brown, "The evolution and discovery of services science in business schools," Communications of the ACM, vol. 49, no. 7, pp. 73-78, Jul. 2006.

[31]M. J. Bitner and S. W. Brown, "The service imperative," Business Horizons, vol. 51, no. 1, pp. 39-46, Jan. 2008.

[32] A. P. Massey, V. Khatri, and M. M. Montoya-Weiss, "Usability of online services: the role of technology readiness and context," Decision Sciences, vol. 38, no. 2, pp. 277-308, 2007.

[33] P. J. Dirr, "Putting principles into practice: promoting effective support services for students in distance learning programs: A report on the findings of a survey," Western Cooperative for Educational Telecommunications, 1999.

[34] A. Crawley, Supporting online students: a practical guide to planning, implementing, and evaluating services. John Wiley \& Sons, 2012.

[35] M. LaPadula, "A Comprehensive Look at Online Student Support Services for Distance Learners," American Journal of Distance Education, vol. 17, no. 2, pp. 119-128, Jun. 2003.

[36] J. Morshed, "Today's student, yesterday's technology: a digital upgrade hits campus," Planning for Higher Education, vol. 44, no. 4, p. 75, 2016.

[37]M. Britto and S. Rush, "Developing and implementing comprehensive student support services for online students," Journal of Asynchronous Learning Networks, vol. 17, no. 1, pp. 29-42, 2013.

[38] T. T. Dao and C.-H. Yang, "The Effects of Service Innovation on Customer Retention: An Integration of Customer Satisfaction," in 2014 Proceedings of PICMET '14: Infrastructure and Service Integration.

[39] R. Junco, J. M. Mastrodicasa, A. V. Aguiar, E. M. Longnecker, and J. N. Rokkum, "Impact of Technology-Mediated Communication on Student Evaluations of Advising," NACADA Journal, Mar. 2017, doi: 10.12930/NACADA-16-014.

[40] A. H. Van de Ven, "Central Problems in the Management of Innovation," Management Science, vol. 32, no. 5, pp. 590-607, 1986. 
[41]National Center for Education Statistics, "National Center for Education Statistics, IPEDS Trend Generator," National Center for Education Statistics, IPEDS Trend Generator. https://nces.ed.gov/ipeds/trendgenerator/ (accessed Jun. 04, 2017).

[42] "Global report predicts edtech spend to reach $\$ 252 \mathrm{bn}$ by 2020," MarketWatch.

http://www.marketwatch.com/story/global-report-predicts-edtech-spend-to -reach-252bn-by-2020-2016-05-25-4203228 (accessed Jun. 04, 2017).

[43] J. Traxler, "Sustaining mobile learning and its institutions," International Journal of Mobile and Blended Learning (IJMBL), vol. 2, no. 4, pp. 58-65, 2010, Accessed: May 31, 2017. [Online].

[44] J. W. Creswell, Research design: qualitative, quantitative and mixed methods approaches. Thousand Oaks: SAGE Publications, 2014.

[45] B. K. Nastasi, J. H. Hitchcock, and L. M. Brown, "An inclusive framework for conceptualizing mixed methods design typologies: moving toward fully integrated synergistic research models," in SAGE handbook of mixed methods in social \& behavioral research, Thousand Oaks: SAGE, 2015, pp. 305-338.

[46] G. Biesta, "Pragmatism and the philosophical foundations of mixed methods research," in SAGE handbook of mixed methods in social \& behavioral research, A. Tashakkori and C. Teddlie, Eds. Thousand Oaks: SAGE, 2015, pp. 95-118.

[47] D. R. Cooper and P. S. Schindler, Business research methods. New York: McGraw-Hill Higher Education, 2014.

[48] T. D. Jick, "Mixing qualitative and quantitative methods: triangulation in action," Administrative Science Quarterly, vol. 24, no. 4, pp. 602-611, 1979.

[49] L. S. Hagedorn, "How to define retention: a new look at an old problem," Transfer and Retention of Urban Community College Students Project (TRUCCS) , 2006.

[50] Higher Learning Commission, "Defining student success data recommendations for changing the conversation," Higher Learning Commission, Dec. 2018.

[51]H. K. Swecker, M. Fifolt, and L. Searby, "Academic advising and first-generation college students: a quantitative study on student retention," NACADA Journal, Jul. 2013, doi: 10.12930/NACADA-13-192.

[52] T. Nazerian, "How should colleges approach student success when different definitions abound?," EdSurge, Mar. 21, 2018. https://www.edsurge.com/news/2018-03-21-how-should-colleges-approach -student-success-when-different-definitions-abound (accessed Apr. 10, 2019).

[53] R. J. Stiles and K. Wilcox, "Blending human intelligence and analytics for student success," EDUCAUSE Review, 2016. https://er.educause.edu/articles/2016/9/blending-human-intelligence-andanalytics-for-student-success (accessed Apr. 11, 2019). 
[54] J. Roberts and R. Styron, "Student satisfaction and persistence: factors vital to student retention," Research in Higher Education Journal, vol. 6, p. $1,2010$.

[55]V. Tinto, "Research and practice of student retention: what next?," Journal of College Student Retention, vol. 8, no. 1, pp. 1-19, 2006.

[56] D. R. Jones-White, P. M. Radcliffe, R. L. Huesman, and J. P. Kellogg, "Redefining student success: applying different multinomial regression techniques for the study of student graduation across institutions of higher education," Research in Higher Education, vol. 51, no. 2, pp. 154-174, Mar. 2010.

[57]Bill \& Melinda Gates Foundation, "Postsecondary success," Bill \& Melinda Gates Foundation. https://www.gatesfoundation.org/What-We-Do/US-Program/Postsecondary -Success (accessed Apr. 11, 2019).

[58] University of South Florida, "Student success annual report, 2012-13 academic year," University of South Florida, 2013.

[59] T. P. Gordon and M. Fischer, "Communicating performance: the extent and effectiveness of performance reporting by U.S. colleges and universities," Journal of Public Budgeting, Accounting \& Financial Management, vol. 20, no. 2, pp. 217-255, 2008.

[6o] V. McGowan, "Improving institutional report card indicators," International Journal of Education and Development using ICT, vol. 12, no. 1, 2016, [Online]. Available: https://www.learntechlib.org/p/173437/.

[61]F. K. Alexander, "The changing face of accountability: monitoring and assessing institutional performance in higher education," Journal of Higher Education, vol. 71, no. 4, pp. 411-431, 2000.

[62] T. Reindl and R. Reyna, "Complete to compete: from information to action-revamping higher education accountability systems," National Governors Association, 2011. [Online]. Available: https://eric.ed.gov/?id=ED522081.

[63] J. C. Shin, "Impacts of performance-based accountability on institutional performance in the U.S," Higher Education, vol. 6o, no. 1, pp. 47-68, Jul. 2010.

[64] R. Reyna, T. Reindl, K. Witham, and J. Stanley, "Complete to compete: common college completion metrics: technical guide," National Governors Association, 2010. [Online]. Available: https://eric.ed.gov/?id=ED516183.

[65] C. Whitfield, "Data-informed policy innovations in Tennessee: effective use of state data systems," State Higher Education Executive Officers Association, 2017. [Online]. Available: https://eric.ed.gov/?id=ED589740.

[66] A. Djurovich et al., "Minnesota measures 2015: a report on higher education performance," Minnesota Office of Higher Education, 2015.

[67] B. L. Killingsworth, M. A. Mansaray, and L. Rhodes, "Adapting the graduation efficiency index to provide a consistent basis for assessment of student progress towards graduation," Perspectives: Policy and Practice in 
Higher Education, vol. 22, no. 4, pp. 124-133, Oct. 2018.

[68] K. Henz, "Undergraduate retention \& graduation report, 2014-15," University of North Carolina, Aug. 2016.

[69] The Institute for Higher Education Policy, "Toward convergence: a technical guide for the postsecondary metrics framework," The Institute for Higher Education Policy, May 2016.

[70] O. Aljohani, "A comprehensive review of the major studies and theoretical models of student retention in higher education," Higher Education Studies, vol. 6, no. 2, pp. 1-18, 2016.

[71] D. Moxley, A. Najor-Durack, and C. Dumbrigue, Keeping students in higher education: successful practices and strategies for retention. Routledge, 2013.

[72]A. W. Astin, "How 'good' is your institution's retention rate?," Research in Higher Education, vol. 38, no. 6, pp. 647-658, Dec. 1997.

[73]R. Reyna, "Complete to compete: common college completion metrics," National Governors Association, Jun. 2010. [Online]. Available: https://eric.ed.gov/?id=ED516183.

[74] J. Offenstein, C. Moore, and N. Shulock, "Advancing by Degrees: a framework for increasing college completion," The Education Trust, Apr. 2010. [Online]. Available: https://market.android.com/details?id=book-etkxvwEACAAJ.

[75]J. Offenstein and N. Shulock, "Taking the next step: the promise of intermediate measures for meeting postsecondary completion goals," Achieving the Dream, 2010. [Online]. Available: https://eric.ed.gov/?id=ED520014.

[76] J. Engle, "Answering the call: institutions and states lead the way toward better measures of postsecondary performance," Bill \& Melinda Gates Foundation, 2016.

[77]K. Kristensen and J. Eskildsen, "Is the Net Promoter Score a reliable performance measure?," in 2011 IEEE International Conference on Quality and Reliability, Sep. 2011, pp. 249-253.

[78] "The history of Net Promoter - Bain \& Company: Net Promoter System." http://netpromotersystem.com/about/why-net-promoter.aspx (accessed Apr. 25, 2019).

[79] "Measuring your Net Promoter Score - Bain \& Company: Net Promoter System."

http://netpromotersystem.com/about/measuring-your-net-promoter-score. aspx (accessed Apr. 25, 2019).

[80] D. Okes, Performance metrics: the levers for process improvement. Milwaukee: ASQ Quality Press, 2013.

[81]Integrated Postsecondary Education Data System, "IPEDS - compare institutions," IPEDS - compare institutions. https://nces.ed.gov/ipeds/datacenter/InstitutionList.aspx (accessed Apr. 15, 2019). 
[82] Integrated Postsecondary Education Data System, "IPEDS - 2018-2019 glossary," IPEDS - 2018-2019 glossary. https://surveys.nces.ed.gov/ipeds/VisGlossaryAll.aspx? (accessed Apr. 15, 2019).

[83] Higher Education Coordinating Commission, "Oregon higher education university snapshot: universities," State of Oregon, Apr. 2018.

[84] "SAM - Student Achievement Measure," SAM - Student Achievement Measure, 2019. https://www.studentachievementmeasure.org/about (accessed Apr. 14, 2019).

[85] "Office of Institutional Research and Planning," Portland State University, 2019. https://www.pdx.edu/oirp/ (accessed Apr. 14, 2019).

[86] G. D. Levy and S. L. Ronco, "How benchmarking and higher education came together," New Directions for Institutional Research, vol. 2012, no. 156, pp. 5-13, Dec. 2012.

[87] C. J. Grayson, "Benchmarking in higher education," in New thinking on higher education - creating a context for change, J. W. Meyerson, Ed. Bolton: Anker Publishing Company, 1998, pp. 105-119.

[88] Committee for Oversight and Assessment of U.S. Department of Energy Project Management, Measuring performance and benchmarking project management at the Department of Energy. Washington, DC: The National Academies Press, 2005.

[89] P. Keehley, S. Medlin, S. MacBride, and L. Longmire, Benchmarking for best practices in the public sector: achieving performance breakthroughs in federal, state, and local agencies. San Francisco: Jossey-Bass Publishers, 1997.

[90] R. C. Camp, Benchmarking: the search for industry best practices that lead to superior performance. Milwaukie: ASQC Quality Press, 1989.

[91]L. J. Redlinger, J. J. Wiorkowski, and A. I. Moses, "Taming multivariate data: conceptual and methodological issues," New Directions for Institutional Research, 2012, doi: 10.1002/ir.20033.

[92] S. D. Carrigan, "Selecting peer institutions with IPEDS and other nationally available data," New Directions for Institutional Research, 2012, doi: 10.1002/ir.20031.

[93] Higher Education Coordinating Commission, "State of Oregon: research statewide higher education snapshots," Statewide higher education snapshots.

https://www.oregon.gov/highered/research/Pages/snapshots.aspx (accessed Apr. 21, 2019).

[94] IPEDS, “About IPEDS," Integrated Postsecondary Education Data System, 2019. https://eric.ed.gov/?id=ED388157 (accessed Apr. 14, 2019).

[95] Office of Institutional Research and Planning, "Research update: a comparison of three completion reports," Portland State University, Jul. 2014.

[96] "Portland State University," SAM - Student Achievement Measure, 2019. 
https://www.studentachievementmeasure.org/participants/209807 (accessed Apr. 14, 2019).

[97] Higher Education Coordinating Commission, "Oregon higher education university snapshot: Portland State University," State of Oregon, Apr. 2018.

[98] Higher Education Coordinating Commission, "Oregon higher education university snapshot: University of Oregon," State of Oregon, Apr. 2018.

[99] Higher Education Coordinating Commission, "Oregon higher education university snapshot: Oregon State University," State of Oregon, Apr. 2018.

[100] K. Ketcheson, "Institutional data on student success," presented at the 2019 Winter Symposium: What We Know About Student Success, Portland State University, Feb. 28, 2019.

[101] Portland State University, "Requirements for a baccalaureate degree," Graduation Requirements. https://www.pdx.edu/advising/requirements-for-a-baccalaureate-degree (accessed Apr. 17, 2019).

[102] H. VanDerSchaaf and R. Harris, "Office of Student Success - Work in Progress/Ahead and Metrics," presented at the Academic and Student Affairs Meeting, PSU Board of Trustees, Portland State University, Jun. 06, 2019, [Online]. Available: https://www.pdx.edu/board/academic-and-student-affairs-committee.

[103] M. H. Duggan and J. W. Pickering, "Barriers to transfer student academic success and retention," Journal of College Student Retention: Research, Theory \& Practice, vol. 9, no. 4, pp. 437-459, Feb. 2008.

[104] P. J. Collier and D. L. Morgan, “Is that paper really due today?': differences in first-generation and traditional college students' understandings of faculty expectations," Higher Education, vol. 55, no. 4, pp. 425-446, 2008.

[105] G. R. Pike and G. D. Kuh, "First- and second-generation college students: a comparison of their engagement and intellectual development," The Journal of Higher Education, vol. 76, no. 3, pp. 276-300, May 2005.

[106] E. T. Pascarella, C. T. Pierson, G. C. Wolniak, and P. T. Terenzini, "First-generation college students: additional evidence on college experiences and outcomes," The Journal of Higher Education, vol. 75, no. 3, pp. 249-284, 2004.

[107] L. Banks-Santilli, "Guilt is one of the biggest struggles first-generation college students face," The Washington Post, The Washington Post, Jun. 03, 2015.

[108] D. Wohlgemuth, D. Whalen, J. Sullivan, C. Nading, M. Shelley, and Y. (rebecca) Wang, "Financial, academic, and environmental influences on the retention and graduation of students," Journal of College Student Retention: Research, Theory \& Practice, vol. 8, no. 4, pp. 457-475, Feb. 2007.

[109] M. Kurfalı, A. Arifoğlu, G. Tokdemir, and Y. Paçin, "Adoption of e-government services in Turkey," Computers in Human Behavior, vol. 66, pp. 168-178, Jan. 2017. 
[110] A. Tiwana and B. Ramesh, "E-services: problems, opportunities, and digital platforms," in Proceedings of the 34th Annual Hawaii International Conference on System Sciences, Jan. 2001, p. 8.

[111] N. Kim-Soon, A. Rahman, and M. Ahmed, "E-eervice quality in higher education and frequency of use of the service," International Education Studies, vol. 7, no. 3, pp. 1-10, 2014.

[112] S. Y. Park, "An analysis of the Technology Acceptance Model in understanding university students' behavioral intention to use e-learning," Journal of Educational Technology \& Society, vol. 12, no. 3, pp. 150-162, 2009.

[113] F. Calisir, C. Altin Gumussoy, A. E. Bayraktaroglu, and D. Karaali, "Predicting the intention to use a web-based learning system: Perceived content quality, anxiety, perceived system quality, image, and the technology acceptance model," Human Factors and Ergonomics in Manufacturing \& Service Industries, vol. 24, no. 5, pp. 515-531, 2014.

[114] A. Abu-Al-Aish and S. Love, "Factors influencing students' acceptance of m-learning: an investigation in higher education," The International Review of Research in Open and Distributed Learning, vol. 14, no. 5, 2013, [Online]. Available: http://www.irrodl.org/index.php/irrodl/article/view/1631.

[115] D. R. Garrison and H. Kanuka, "Blended learning: uncovering its transformative potential in higher education," The Internet and Higher Education, vol. 7, no. 2, pp. 95-105, Apr. 2004.

[116] M. Masrom, "Technology acceptance model and e-learning," 12th International Conference on Education, Sultan Hassanal Bolkiah Institute of Education, vol. 21, no. 24, p. 81, 2007.

[117] N. S. Alzaza and A. R. Yaakub, "Students' awareness and requirements of mobile learning services in the higher education environment," American Journal of Economics and Business Administration, vol. 3, no. 1, pp. 95-100, 2011.

[118] A. Crawley and M. Fetzner, "Providing service innovations to students inside and outside of the online classroom: focusing on student success," Journal of Asynchronous Learning Networks, vol. 17, no. 1, pp. 7-12, 2013.

[119] L. Moneta, "Technology and student affairs: redux," New Directions for Student Services, vol. 2005, no. 112, pp. 3-14, Dec. 2005.

[120] B. Taylor and K. Holley, "Providing academic and support services to students enrolled in online degree programs," College Student Affairs Journal, vol. 28, no. 1, p. 81, 2009.

[121] T. L. Bailey and A. Brown, "Online student services: current practices and recommendations for implementation," Journal of Educational Technology Systems, vol. 44, no. 4, pp. 450-462, May 2016.

[122] E. T. Cabellon and R. Junco, "The digital age of student affairs," New Directions for Student Services, vol. 2015, no. 151, pp. 49-61, Sep. 2015.

[123] D. Hossler, "The impact of implementing new information systems on the priorities, management, and allocation of resources at colleges and 
universities," New Directions for Higher Education, vol. 2006, no. 136, pp. 69-76, Dec. 2006.

[124] P. Shea and S. Armitage, "Guidelines for creating student services online," Western Interstate Commission for Higher Education, 2002.

[125] A. Abugabah and L. Sanzogni, "Enterprise resource planning (ERP) system in higher education: A literature review and implications," International Journal of Human and Social Sciences, vol. 5, no. 6, pp. 395-399, 2010.

[126] N. Basoglu, T. Daim, and O. Kerimoglu, "Organizational adoption of enterprise resource planning systems: a conceptual framework," The Journal of High Technology Management Research, vol. 18, no. 1, pp. 73-97, Jan. 2007.

[127] W. Gorr and D. Hossler, "Why all the fuss about information systems? or information systems as golden anchors in higher education," New Directions for Higher Education, vol. 2006, no. 136, pp. 7-20, Dec. 2006.

[128] A. W. Bates, T. Bates, and A. Sangra, Managing technology in higher education: strategies for transforming teaching and learning. John Wiley \& Sons, 2011.

[129] G. Seo, "Challenges in implementing enterprise resource planning (ERP) system in large organizations : similarities and differences between corporate and university environment," Massachusetts Institute of Technology, 2013.

[130] G. Sabau, M. Munten, A.-R. Bologa, R. Bologa, and T. Surcel, "An evaluation framework for higher education ERP Systems," WSEAS Trans. Comput., vol. 8, no. 11, pp. 1790-1799, 2009.

[131] R. A. Pickett and W. B. Hamre, "Building portals for higher education," New Directions for Institutional Research, vol. 2002, no. 113, pp. 37-56, Mar. 2002.

[132] R. Newberry and C. DeLuca, "Building a foundation for success through student services for online learners," Journal of Asynchronous Learning Networks, vol. 17, no. 4, Dec. 2013, doi: 10.24059/olj.v17i4.385.

[133] J. Waycott, S. Bennett, G. Kennedy, B. Dalgarno, and K. Gray, "Digital divides? Student and staff perceptions of information and communication technologies," Computers \& Education, vol. 54, no. 4, pp. 1202-1211, May 2010.

[134] M.-I. R. M. Jaradat, "Understanding the acceptance of mobile university services: an empirical analysis," International Journal of Mobile Learning and Organisation, vol. 4, no. 4, pp. 407-427, Jan. 2010.

[135] R. Hill, S. Li, and I. Troshani, "A conceptual framework and propositions for the acceptance of mobile services," Journal of Theoretical and Applied Electronic Commerce Research, vol. 2, no. 2, pp. 61-73, 2007.

[136] S. So, "Mobile instant messaging support for teaching and learning in higher education," Internet and Higher Education, vol. 31, pp. 32-42, Oct. 2016.

[137] J. Martín-Gutiérrez, P. Fabiani, W. Benesova, M. D. Meneses, and C. E. 
Mora, "Augmented Reality to Promote Collaborative and Autonomous Learning in Higher Education," Computers in Human Behavior, vol. 51, Part B, pp. 752-761, Oct. 2015.

[138] B. Smith, M. Jacobs, S. Wilson, and G. McCarthy, "The mobile university: from the library to the campus," Ref. Serv. Rev., vol. 38, no. 2, pp. 214-232, 2010.

[139] B. Kargin, N. Basoglu, and T. Daim, "Factors affecting the adoption of mobile services," International Journal of Services Sciences, vol. 2, no. 1, pp. 29-52, 2009.

[140] E. Georgieva, A. Smrikarov, and T. Georgiev, "A general classification of mobile learning systems," in International conference on computer systems and technologies-CompSysTech, 2005, vol. 8, pp. 14-16.

[141] A. B. Nassuora, "Students acceptance of mobile learning for higher education in Saudi Arabia," American Academic \& Scholarly Research Journal, vol. 4, no. 2, p. 1, 2012.

[142] A. E. E. Sobaih, M. A. Moustafa, P. Ghandforoush, and M. Khan, "To use or not to use? Social media in higher education in developing countries," Computers in Human Behavior, vol. 58, pp. 296-305, May 2016.

[143] Roblyer, M. McDaniel, M. Webb, J. Herman, and J. V. Witty, "Findings on Facebook in higher education: a comparison of college faculty and student uses and perceptions of social networking sites," Internet and Higher Education, vol. 13, no. 3, pp. 134-140, Jun. 2010.

[144] A. Moura and A. A. Carvalho, "Mobile learning: using SMS in educational contexts," in Key Competencies in the Knowledge Society, Springer, Berlin, Heidelberg, 2010, pp. 281-291.

[145] S. Lauricella and R. Kay, "Exploring the use of text and instant messaging in higher education classrooms," Research in Learning Technology, vol. 21, no. $1, \quad 2013, \quad$ [Online]. Available: http://www.researchinlearningtechnology.net/index.php/rlt/article/view/19 061.

[146] H. Else, "How do universities use big data?," Times Higher Education (THE), Apr. $\quad 13,2017$. https://www.timeshighereducation.com/features/how-do-universities-use-b ig-data (accessed Jul. 07, 2017).

[147] E. G. Echenique, L. M. Molías, and M. Bullen, "Students in higher education: social and academic uses of digital technology," RUSC. Universities and Knowledge Society Journal, vol. 12, no. 1, pp. 25-37, Jan. 2015, Accessed: Jun. 18, 2017. [Online].

[148] P. Brett, "Students' experiences and engagement with SMS for learning in higher education," Innovations in Education and Teaching International, vol. 48, no. 2, pp. 137-147, 2011.

[149] L. Naismith, "Using text messaging to support administrative communication in higher education," Active Learning in Higher Education, vol. 8, no. 2, pp. 155-171, 2007. 
[150] A. Walsh, "Text messaging (SMS) and libraries," Library Hi Tech News, vol. 26, no. 8, pp. 9-11, 2009.

[151] R. Tomaszewski, "SMS Text Messaging and Science Students: New Opportunities for Librarian Outreach," Science \& Technology Libraries, vol. 30, no. 3, pp. 277-291, Apr. 2011.

[152] G. de Bakker, P. Sloep, and W. Jochems, "Students and instant messaging: a survey of current use and demands for higher education," ALT-J, vol. 15, no. 2, pp. 143-153, Jun. 2007.

[153] A. Samochadin, D. Raychuk, S. Nosnitsyn, and I. Khmelkov, "A comprehensive set of mobile services supporting education process," Procedia - Social and Behavioral Sciences, vol. 182, pp. 613-618, May 2015.

[154] D. Sambasivan, N. John, S. Udayakumar, and R. Gupta, "Generic framework for mobile application development," in 2011 Second Asian Himalayas International Conference on Internet (AH-ICI), Nov. 2011, pp. 1-5.

[155] N. Serrano, J. Hernantes, and G. Gallardo, "Mobile web apps," IEEE Software, vol. 30, no. 5, pp. 22-27, 2013.

[156] M. Valoris, "A mixed-methods analysis of best practices for land-grant university mobile applications from a user experience design perspective," Master of Science, Colorado State University, 2015.

[157] R. Budiu, "Mobile: Native Apps, Web Apps, and Hybrid Apps," Nielsen Norman Group, 2013. https://www.nngroup.com/articles/mobile-native-apps/ (accessed Jun. 15, 2017).

[158] A. M. Christ, "Bridging the mobile app gap," Connectivity and the User Experience, vol. 11, no. 1, p. 27, 2011.

[159] A. Singh and J. Ranjan, "A framework for mobile apps in colleges and universities: data mining perspective," Education and Information Technologies, vol. 21, no. 3, pp. 643-654, May 2016, Accessed: Jun. 15, 2017. [Online].

[160] A. A. Economides and A. Grousopoulou, "Mobiles in education: students' usage, preferences and desires," International Journal of Mobile Learning and Organisation, vol. 4, no. 3, pp. 235-252, 2010.

[161] B. Chen and A. deNoyelles, "Exploring Students' Mobile Learning Practices in Higher Education," Educause Review, Oct. 2013.

[162] C. Brooks, "ECAR study of undergraduate students and information technology, 2016," EDUCAUSE Center for Analysis and Research, Oct. 2016.

[163] E. D. Cassidy, A. Colmenares, G. Jones, T. Manolovitz, L. Shen, and S. Vieira, "Higher education and emerging technologies: shifting trends in student usage," The Journal of Academic Librarianship, vol. 40, no. 2, pp. 124-133, Mar. 2014.

[164] F. Yu and A. R. Conway, "Mobile/smartphone use in higher education," in Proceedings of the 2012 Southwest Decision Sciences Institute, 2012, pp. 831-839. 
[165] K. Bowen and M. D. Pistilli, "Student Preferences for Mobile App Usage," EDUCAUSE Center for Applied Research, 2012.

[166] L. Carter and F. Bélanger, "The utilization of e-government services: citizen trust, innovation and acceptance factors," Information Systems Journal, vol. 15, no. 1, pp. 5-25, 2005.

[167] F. Sá, Á. Rocha, and M. Pérez Cota, "From the quality of traditional services to the quality of local e-Government online services: a literature review," Government Information Quarterly, vol. 33, no. 1, pp. 149-160, 2016/1.

[168] S. F. H. Zaidi and M. K. Qteishat, "Assessing e-government service delivery (government to citizen)," International Journal of eBusiness and eGovernment Studies, vol. 4, no. 1, pp. 45-54, 2012.

[169] M. Parthasarathy and A. Bhattacherjee, "Understanding post-adoption behavior in the context of online services," Information Systems Research, vol. 9, no. 4, pp. 362-379, Dec. 1998.

[170] K. Shelton and G. Saltsman, An Administrator's guide to online education. IAP, 2005.

[171] C. Wang, J. Harris, and P. Patterson, "The roles of habit, self-efficacy, and satisfaction in driving continued use of self-service technologies: a longitudinal study," Journal of Service Research, vol. 16, no. 3, pp. 400-414, 2013.

[172] E. D. Seeman and M. O'Hara, "Customer relationship management in higher education: using information systems to improve the student-school relationship," Campus-Wide Information Systems, vol. 23, no. 1, pp. 24-34, 2006.

[173] “Today's college students infographic," Bill \& Melinda Gates Foundation Postsecondary Success, $\quad$ Dec. 2014. http://postsecondary.gatesfoundation.org/areas-of-focus/incentives/policyadvocacy/advocacy-priorities/america-10o-college-students/ (accessed Jun. 04, 2017).

[174] A. Perrin and M. Duggan, "Americans' internet access: 2000-2015," Pew Research Center: Internet, Science \& Tech, Jun. 26, 2015. http://www.pewinternet.org/2015/o6/26/americans-internet-access-20002015/ (accessed Jun. 15, 2017).

[175] Unit, " $73 \%$ of students are dissatisfied with their university's digital strategy," Unit4, May 25, 2016. http://www.unit4.com/us/about/news/2016/05/73-of-students-recommend -university-improve-digital-strategy-copy-2 (accessed Jun. 26, 2017).

[176] Fiserv, "Digital banking more essential to consumers than ever before: insights from 13th annual Consumer Trends Survey," Fiserv, Aug. 2015.

[177] C. Fornell, "ASCI commentary February 2012: customer satisfaction slowly improves as U.S. economy continues a sluggish recovery," American Customer Satisfaction Index, Feb. 2012.

[178] S. Moisey and J. Hughes, "Supporting the online learner," in The Theory 
and Practice of Online Learning, T. Anderson, Ed. Athabasca University Press, 2008, pp. 419-439.

[179] H. S. Kalamkarian and M. M. Karp, "Student attitudes toward technology-mediated advising systems," Online Learning, vol. 21, no. 2, p. n2, 2017.

[180] R. E. Sharpe, “Are you first gen? Depends on who's asking," The New York Times, Nov. 03, 2017.

[181] E. F. Cataldi, C. T. Bennett, and X. Chen, "First-generation students: college access, persistence, and postbachelor's outcomes," National Center for Education Statistics, Feb. 2018. Accessed: Feb. 12, 2018. [Online]. Available: https://nces.ed.gov/pubsearch/pubsinfo.asp?pubid=2018421.

[182] I. S. Pratt, H. B. Harwood, J. T. Cavazos, and C. P. Ditzfeld, "Should I stay or should I go? Retention in first-generation college students," Journal of College Student Retention, pp. 1-14, Feb. 2017.

[183] P. M. McDonough, "Counseling matters: knowledge, assistance, and organizational commitment in college preparation," in Preparing For College: Nine Elements of Effective Outreach, W. G. Tierney, Z. B. Corwin, and J. E. Colyar, Eds. 2004, pp. 69-87.

[184] J. R. Slate, M. Manuel, and J. B. K. H., "The 'Digital Divide': Hispanic college students' views of educational uses of the Internet," Assessment \& Evaluation in Higher Education, vol. 27, no. 1, pp. 75-93, Jan. 2002.

[185] H. Peng, C. Tsai, and Y. Wu, "University students' self-efficacy and their attitudes toward the Internet: the role of students' perceptions of the Internet," Educational Studies, vol. 32, no. 1, pp. 73-86, Mar. 2006.

[186] S. Mamonov and R. Benbunan-Fich, "Exploring factors affecting social e-commerce service adoption: The case of Facebook Gifts," International Journal of Information Management, vol. 37, no. 6, pp. 590-600, Dec. 2017.

[187] M. K. Ahuja and J. B. Thatcher, "Moving beyond intentions and toward the theory of trying: effects of work environment and gender on post-adoption information technology use," Management Information Systems Quarterly, vol. 29, no. 3, pp. 427-459, Sep. 2005.

[188] V. Venkatesh and M. G. Morris, "Why don't men ever stop to ask for directions? Gender, social influence, and their role in technology acceptance and usage behavior," MIS Quarterly, vol. 24, no. 1, pp. 115-139, 2000.

[189] S. Li, R. Glass, and H. Records, "The influence of gender on new technology adoption and sse-mobile commerce," Journal of Internet Commerce, vol. 7, no. 2, pp. 270-289, Jul. 2008.

[190] P. E. Pedersen and R. Ling, "Mobile end-user service adoption studies: a selective review," Scandinavian Journal of Information Systems, vol. 14, no. 1, pp. 3-17, 2002.

[191] S. AlAwadhi and A. Morris, "Factors influencing the adoption of e-government services," Journal of Software, vol. 4, no. 6, pp. 584-590, 2009.

[192] Y. Sun, N. Wang, X. Guo, and Z. Peng, "Understanding the acceptance of 
mobile health services: a comparison and integration of alternative models," Journal of Electronic Commerce Research, vol. 14, no. 2, pp. 183-200, 2013.

[193] E. Park and K. J. Kim, "An integrated adoption model of mobile cloud services: exploration of key determinants and extension of Technology Acceptance Model," Telematics and Informatics, vol. 31, no. 3, pp. 376-385, Aug. 2014.

[194] A. Dillon and M. G. Morris, "User acceptance of new information technology: theories and models," in Annual Review of Information Science and Technology, Medford, NJ: Information Today, 1996.

[195] E. Rogers, Diffusion of innovations. New York: The Free Press, 1983.

[196] T. B. Chiyangwa and P. M. Alexander, "Rapidly co-evolving technology adoption and diffusion models," Telematics and Informatics, vol. 33, no. 1, pp. 56-76, Feb. 2016.

[197] G. C. Moore and I. Benbasat, "Development of an instrument to measure the perceptions of adopting an information technology innovation," Information Systems Research, vol. 2, no. 3, pp. 192-222, Sep. 1991.

[198] R. Agarwal and J. Prasad, "The role of innovation characteristics and perceived voluntariness in the acceptance of information technologies," Decision Sciences, vol. 28, no. 3, pp. 557-582, Jul. 1997.

[199] V. Venkatesh, M. G. Morris, G. B. Davis, and F. D. Davis, "User acceptance of information technology: toward a unified view," MIS Quarterly, vol. 27, no. 3, pp. 425-478, 2003.

[200] M. Fishbein and I. Ajzen, Belief, attitude, intention and behavior: an introduction to theory and research. Reading, Mass.: Addison-Wesley Pub. Co., 1975 .

[201] D. Mishra, I. Akman, and A. Mishra, "Theory of Reasoned Action application for Green Information Technology acceptance," Computers in Human Behavior, vol. 36, pp. 29-40, Jul. 2014.

[202] C.-W. Chang and G. M. Chen, "College students' disclosure of location-related information on Facebook," Computers in Human Behavior, vol. 35, pp. 33-38, 2014.

[203] H. Aleassa, J. M. Pearson, and S. McClurg, "Investigating software piracy in Jordan: An extension of the Theory of Reasoned Action," Journal of Business Ethics, vol. 98, no. 4, pp. 663-676, Feb. 2011.

[204] B. H. Sheppard, J. Hartwick, and P. R. Warshaw, "The Theory of Reasoned Action: a meta-analysis of past research with recommendations for modifications and future research," The Journal of Consumer Research, vol. 15, no. 3, pp. 325-343, Dec. 1988, Accessed: Apr. 26, 2018. [Online].

[205] I. Ajzen, "The Theory of Planned Behavior," Organizational Behavior and Human Decision Processes, vol. 50, no. 2, pp. 179-211, Dec. 1991.

[206] I. Ajzen, "Perceived behavioral control, self-efficacy, locus of control, and the Theory of Planned Behavior," Journal of Applied Psychology, 2002, [Online]. Available: http://onlinelibrary.wiley.com/doi/10.1111/j.1559-1816.2002.tboo236.x/full. 
[207] I. Ajzen, Attitudes, personality, and behavior. McGraw-Hill Education (UK), 2005.

[208] J. Sauro, "Do attitudes predict behavior?," MeasuringU, Jun. 11, 2019. https://measuringu.com/attitudes-behavior/ (accessed Jun. 13, 2020).

[209] F. D. Davis, "Perceived usefulness, perceived ease of use, and user acceptance of information technology," MIS Quarterly, vol. 13, no. 3, pp. 319-340, 1989.

[210] F. D. Davis, R. P. Bagozzi, and P. R. Warshaw, "User acceptance of computer technology: a comparison of two theoretical models," Management Science, vol. 35, no. 8, pp. 982-1003, Aug. 1989.

[211] M. Y. Chuttur, "Overview of the Technology Acceptance Model: Origins, developments and future directions," Working Papers on Information Systems, vol. 9, no. 37, pp. 9-37, 2009.

[212] R. J. Holden and B.-T. Karsh, "The technology acceptance model: its past and its future in health care," Journal of Biomedical Informatics, vol. 43, no. 1, pp. 159-172, Feb. 2010.

[213] V. Venkatesh and H. Bala, "Technology Acceptance Model 3 and a research agenda on interventions," Decision Sciences, vol. 39, no. 2, pp. 273-315, May 2008.

[214] P. Legris, J. Ingham, and P. Collerette, "Why do people use information technology? A critical review of the technology acceptance model," Information \& Management, vol. 40, no. 3, pp. 191-204, Jan. 2003.

[215] V. Venkatesh and F. D. Davis, "A theoretical extension of the Technology Acceptance Model: four longitudinal field studies," Management Science, vol. 46, no. 2, pp. 186-204, Feb. 2000.

[216] D. L. Goodhue, "Understanding user evaluations of information systems," Management Science, vol. 41, no. 12, pp. 1827-1844, Dec. 1995.

[217] D. L. Goodhue and R. L. Thompson, "Task-technology fit and individual performance," MIS Quarterly, vol. 19, no. 2, pp. 213-236, 1995.

[218] M. T. Dishaw and D. M. Strong, "Extending the technology acceptance model with task-technology fit constructs," Information \& Management, vol. 36, no. 1, pp. 9-21, Jul. 1999.

[219] M. Pagani, "Determinants of adoption of High Speed Data Services in the business market: Evidence for a combined technology acceptance model with task technology fit model," Information \& Management, vol. 43, no. 7, pp. 847-860, Oct. 2006.

[220] M. Dishaw, D. Strong, and D. B. Bandy, "Extending the task-technology fit model with self-efficacy constructs," AMCIS 2002 Proceedings, p. 143, 2002.

[221] V. Venkatesh, J. Y. L. Thong, and X. Xu, "Unified Theory of Acceptance and Use of Technology: a synthesis and the road ahead," Journal of the Association for Information Systems, vol. 17, no. 5, pp. 328 - 376, May 2016.

[222] S. Attuquayefio and H. Addo, "Review of studies with UTAUT as conceptual framework," European Scientific Journal, ESJ, vol. 10, no. 8, Mar. 2014, Accessed: Mar. 14, 2017. [Online]. Available: 
http://eujournal.org/index.php/esj/article/view/3020.

[223] T. Zhou, Y. Lu, and B. Wang, "Integrating TTF and UTAUT to explain mobile banking user adoption," Computers in Human Behavior, vol. 26, no. 4, pp. 760-767, Jul. 2010.

[224] D.-H. Shin, Y.-J. Shin, H. Choo, and K. Beom, "Smartphones as smart pedagogical tools: implications for smartphones as u-learning devices," Computers in Human Behavior, vol. 27, no. 6, pp. 2207-2214, Nov. 2011.

[225] V. Venkatesh, J. Thong, and X. Xu, "Consumer acceptance and use of information technology: extending the Unified Theory of Acceptance and Use of Technology," MIS Quarterly, vol. 36, no. 1, p. 157, 2012.

[226] F. A. Aldhaban, "Exploratory study of the adoption and use of the smartphone technology in emerging regions: case of Saudi Arabia," PhD, Portland State University, 2016.

[227] Portland State University, "Redesign myPSU project charter," Portland State University, $2016 . \quad$ [Online]. Available: https://www.pdx.edu/student-success/redesign-mypsu.

[228] "Redesign myPSU," Portland State University. https://www.pdx.edu/student-success/redesign-mypsu (accessed Nov. 08, 2019).

[229] M. C. Murphy, "Social-psychological interventions to support student success," presented at the 69th Education Writers Association National Seminar, Boston, MA, May 02, 2016, [Online]. Available: https://www.ewa.org/agenda/69th-ewa-national-seminar-agenda.

[230] S. L. Reeves, "Caught up in red tape: bureaucratic hassles undermine sense of belonging in college among first generation students," Master of Arts, The University of Texas at Austin, 2015.

[231] "Georgia State University chatbot supports every student - AdmitHub," AdmitHub.

https://www.admithub.com/case-study/how-georgia-state-university-suppo rts-every-student-with-personalized-text-messaging/ (accessed May 17, 2020).

[232] B. J. L. Landry, R. Griffeth, and S. Hartman, "Measuring student perceptions of Blackboard using the Technology Acceptance Model," Decision Sciences Journal of Innovative Education, Jan. 2006, [Online]. Available:

http://onlinelibrary.wiley.com/doi/10.1111/j.1540-4609.2006.00103.x/full.

[233] Y.-C. Lee, "An empirical investigation into factors influencing the adoption of an e-learning system," Online Information Review, vol. 30, no. 5, pp. 517-541, 2006.

[234] M. I. Merhi, "Factors influencing higher education students to adopt podcast: an empirical study," Computers \& Education, vol. 83, pp. 32-43, Apr. 2015.

[235] D. Kim, H. Chun, and H. Lee, "Determining the factors that influence college students' adoption of smartphones," Information Science and 
Technology, 2014, [Online]. Available: http://onlinelibrary.wiley.com/doi/10.1002/asi.22987/full.

[236] L. Leung and R. Wei, "Who are the mobile phone have-nots?: influences and consequences," New Media \& Society, vol. 1, no. 2, pp. 209-226, Aug. 1999.

[237] A. K. Kazi, "An empirical study of factors influencing adoption of Internet banking among students of higher education: evidence from Pakistan," The Journal of Internet Banking and Commerce, 2013, [Online]. Available: http://www.icommercecentral.com/open-access/an-empirical-study-of-facto rs-influencing-adoption-of-internet-banking-among-students-of-higher-educ ation-evidence-from-pakistan-1-13.php?aid=38213.

[238] G. Grosseck, "To use or not to use web 2.0 in higher education?," Procedia-Social and Behavioral Sciences, 2009, [Online]. Available: https://www.sciencedirect.com/science/article/pii/S1877042809000895.

[239] C. Wagner, "Wiki: a technology for conversational knowledge management and group collaboration," The Communications of the Association for Information Systems, vol. 13, no. 1, p. 58, 2004.

[240] P. D. Duffy and A. Bruns, "The use of blogs, wikis and RSS in education: a conversation of possibilities," in Proceedings Online Learning and Teaching Conference 2006, Brisbane, 2006, pp. 31-38.

[241] Z. Shana and E. S. Abulibdeh, "Cloud computing issues for higher education: theory of acceptance model," International Journal of Emerging Technologies in Learning, vol. 12, no. 11, pp. 168-184, Nov. 2017.

[242] S. Y. Park, M.-W. Nam, and S.-B. Cha, "University students' behavioral intention to use mobile learning: evaluating the Technology Acceptance Model," British Journal of Educational Technology, 2012, [Online]. Available:

http://onlinelibrary.wiley.com/doi/10.1111/j.1467-8535.2011.01229.x/full.

[243] M. Thongmak, "Social network system in classroom: antecedents of Edmodo(C) adoption," Journal of e-Learning and Higher Education, 2013, [Online].

Available: https://pdfs.semanticscholar.org/o53e/20ed89ff7ofbbb2d525169a2a6b2fc4 3b9ce.pdf.

[244] N. B. Dastjerdi, "Factors affecting ICT adoption among distance education students based on the Technology Acceptance Model-a case study at a distance education university in Iran," International Education Studies, vol. 9, no. 2, pp. 73-80, Jan. 2016.

[245] W. Huanhuan and L. Xu, "Research on technology adoption and promotion strategy of MOOC," in 2015 6th IEEE International Conference on Software Engineering and Service Science, 2015, pp. 907-910.

[246] P. Garcia Molina, "An integrated model for the adoption of information technologies in US colleges and universities," Doctor of Philosophy in Liberal Studies, Georgetown University, 2013.

[247] M. Moran, M. Hawkes, and O. El Gayar, "Tablet personal computer 
integration in higher education: applying the Unified Theory of Acceptance and Use Technology Model to understand supporting factors," Journal of Educational Computing Research, vol. 42, no. 1, pp. 79-101, Jan. 2010.

[248] R. H. Shroff, C. C. Deneen, and E. M. W. Ng, "Analysis of the technology acceptance model in examining students' behavioural intention to use an e-portfolio system," Australasian Journal of Educational Technology, vol. 27, no. 4, Aug. 2011, doi: 10.14742/ajet.940.

[249] Portland State University, "Redesign myPSU, discovery and design phases report," Portland State University, Aug. 2016. Accessed: May 13, 2019. [Online]. Available: https://www.pdx.edu/student-success/redesign-mypsu.

[250] "Student Success - Status Reports," Portland State University. https://www.pdx.edu/student-success/status-reports (accessed Nov. 27, 2019).

[251] H. VanDerSchaaf and R. Harris, "Office of Student Success Update," presented at the Academic and Student Affairs Committee Meeting, PSU Board of Trustees, Portland State University, Mar. 13, 2019, [Online]. Available:

https://www.pdx.edu/board/academic-and-student-affairs-committee.

[252] Y.-S. Wang, M.-C. Wu, and H.-Y. Wang, "Investigating the determinants and age and gender differences in the acceptance of mobile learning," British Journal of Educational Technology, vol. 40, no. 1, pp. 92-118, Jan. 2009.

[253] A. Mosunmola, A. Mayowa, S. Okuboyejo, and C. Adeniji, "Adoption and use of mobile learning in higher education: the UTAUT model," in Proceedings of the 9th International Conference on E-Education, E-Business, E-Management and E-Learning, San Diego, California, 2018, pp. 20-25.

[254] J. T. Marchewka and K. Kostiwa, "An application of the UTAUT Model for understanding student perceptions using course management software," Communications of the IIMA, vol. 7, no. 2, pp. 93-104, 2007, Accessed: May 16, 2018. [Online].

[255] R. B. Kline, Principles and practice of structural equation modeling, fourth edition. Guilford Publications, 2016.

[256] J. F. Hair, W. C. Black, B. J. Babin, and R. E. Anderson, Multivariate data analysis. Pearson Education Limited, 2013.

[257] G. D. Garson, Structural equation modeling. Statistical Associates Publishing, 2015.

[258] G. D. Garson, Factor analysis. Statistical Associates Publishing, 2013.

[259] H. Baumgartner and C. Homburg, "Applications of structural equation modeling in marketing and consumer research: a review," International Journal of Research in Marketing, vol. 13, no. 2, pp. 139-161, Apr. 1996.

[260] W.-T. Wang and C.-C. Wang, "An empirical study of instructor adoption of web-based learning systems," Computers \& Education, vol. 53, no. 3, pp. 761-774, Nov. 2009.

[261] K. A. Pituch and Y.-K. Lee, "The influence of system characteristics on 
e-learning use," Computers \& Education, vol. 47, no. 2, pp. 222-244, Sep. 2006.

[262] R. Saadé and B. Bahli, "The impact of cognitive absorption on perceived usefulness and perceived ease of use in on-line learning: an extension of the technology acceptance model," Information \& Management, vol. 42, no. 2, pp. 317-327, Jan. 2005.

[263] E. Adam, C. Blewett, and J. Wassermann, "Investigating UKZN students' adoption and utilisation of personal cloud technologies," South African Journal of Higher Education, vol. 29, no. 6, pp. 13-38, Nov. 2015.

[264] C. Chen, J. Wu, and S. C. Yang, "Accelerating the use of weblogs as an alternative method to deliver case-based learning," International Journal on E-Learning, vol. 7, no. 2, pp. 331-349, Apr. 2008.

[265] A. Tarhini, R. 'ed Masa'deh, K. A. Al-Busaidi, A. B. Mohammed, and M. Maqableh, "Factors influencing students' adoption of e-learning: a structural equation modeling approach," Journal of International Education in Business, vol. 10, no. 2, pp. 164-182, Jan. 2017.

[266] J. S. Mtebe and R. Raisamo, "Investigating students' behavioural intention to adopt and use mobile learning in higher education in East Africa," International Journal of Education and Development using Information and Communication Technology, vol. 10, no. 3, pp. 4-20, 2014.

[267] T. D. Thomas, L. Singh, and K. Gaffar, "The utility of the UTAUT model in explaining mobile learning adoption in higher education in Guyana," International Journal of Education and Development using Information and Communication Technology, vol. 9, no. 3, pp. 71-85, 2013.

[268] P. Jakkaew and S. Hemrungrote, "The use of UTAUT2 model for understanding student perceptions using Google Classroom: a case study of Introduction to Information Technology course," in 2017 International Conference on Digital Arts, Media and Technology (ICDAMT), 2017, pp. $205^{-209 .}$

[269] R. Arteaga Sánchez, V. Cortijo, and U. Javed, "Students' perceptions of Facebook for academic purposes," Computers \& Education, vol. 70, pp. 138-149, Jan. 2014.

[270] R. Hartshorne and H. Ajjan, "Examining student decisions to adopt Web 2.0 technologies: theory and empirical tests," Journal of Computing in Higher Education, vol. 21, no. 3, p. 183, Dec. 2009, Accessed: May 16, 2018. [Online].

[271] S. W. S. Beasley, "The decision to adopt educational technology in technical education: a multivariate study," Northcentral University, 2016.

[272] J. Cheon, S. Lee, S. M. Crooks, and J. Song, "An investigation of mobile learning readiness in higher education based on the Theory of Planned Behavior," Computers \& Education, vol. 59, no. 3, pp. 1054-1064, Nov. 2012.

[273] E. M. van Raaij and J. J. L. Schepers, "The acceptance and use of a virtual learning environment in China," Computers \& Education, vol. 50, no. 3, pp. 838-852, Apr. 2008. 
[274] G. W.-H. Tan, K.-B. Ooi, J.-J. Sim, and K. Phusavat, "Determinants of mobile learning adoption: an empirical analysis," Journal of Computer Information Systems, vol. 52, no. 3, pp. 82-91, Mar. 2012.

[275] A. Mosunmola, A. Mayowa, S. Okuboyejo, and C. Adeniji, "Adoption and Use of Mobile Learning in Higher Education: The UTAUT Model," in Proceedings of the 9th International Conference on E-Education, E-Business, E-Management and E-Learning, San Diego, California, 2018, pp. 20-25.

[276] C. Lai, Q. Wang, and J. Lei, "What factors predict undergraduate students' use of technology for learning? A case from Hong Kong," Computers \& Education, vol. 59, no. 2, pp. 569-579, Sep. 2012.

[277] S. C. Chang and F. C. Tung, "An empirical investigation of students' behavioural intentions to use the online learning course websites," British Journal of Educational Technology, 2008, [Online]. Available: http://onlinelibrary.wiley.com/doi/10.1111/j.1467-8535.2007.00742.x/full.

[278] R. Cheung and D. Vogel, "Predicting user acceptance of collaborative technologies: an extension of the Technology Acceptance Model for e-learning," Computers \& Education, vol. 63, pp. 160-175, 2013/4.

[279] M. R. Martínez-Torres, S. L. Toral Marín, F. B. García, S. G. Vázquez, M. A. Oliva, and T. Torres, "A technological acceptance of e-learning tools used in practical and laboratory teaching, according to the European higher education area," Behaviour \& Information Technology, vol. 27, no. 6, pp. 495-505, Nov. 2008.

[280] L. L. Martins and F. W. Kellermanns, "A model of business school students' acceptance of a web-based course management system," Academy of Management Learning \& Education, 2004, [Online]. Available: http://amle.aom.org/content/3/1/7.short.

[281] J. Drennan, J. Kennedy, and A. Pisarski, "Factors affecting student attitudes toward flexible online learning in management education," The Journal of Educational Research, vol. 98, no. 6, pp. 331-338, Jul. 2005.

[282] R. A. Sánchez and A. D. Hueros, "Motivational factors that influence the acceptance of Moodle using TAM," Computers in Human Behavior, vol. 26, no. 6, pp. 1632-1640, Nov. 2010.

[283] R. Edmunds, M. Thorpe, and G. Conole, "Student attitudes towards and use of ICT in course study, work and social activity: a technology acceptance model approach," British Journal of Educational Technology, vol. 42, no. 1, pp. 71-84, 2012.

[284] H. M. Selim, "An empirical investigation of student acceptance of course websites," Computers \& Education, vol. 40, no. 4, pp. 343-36o, May 2003.

[285] E. W. T. Ngai, J. K. L. Poon, and Y. H. C. Chan, "Empirical examination of the adoption of WebCT using TAM," Computers \& Education, vol. 48, no. 2, pp. 250-267, Feb. 2007.

[286] M. M. Abbad, D. Morris, and C. de Nahlik, "Looking under the bonnet: factors affecting student adoption of e-Learning systems in Jordan," The 
International Review of Research in Open and Distributed Learning, vol. 10, no. 2, Apr. 2009, doi: 10.19173/irrodl.v10i2.596.

[287] N. O. Ndubisi, "Factors of online learning adoption: a comparative juxtaposition of the Theory of Planned Behaviour and the Technology Acceptance Model," International Journal on ELearning, vol. 5, no. 4, pp. 571-591, 2006.

[288] P.-C. Sun, R. J. Tsai, G. Finger, Y.-Y. Chen, and D. Yeh, "What drives a successful e-learning? An empirical investigation of the critical factors influencing learner satisfaction," Computers \& Education, vol. 50, no. 4, pp. 1183-1202, May 2008.

[289] T. S. Behrend, E. N. Wiebe, J. E. London, and E. C. Johnson, "Cloud computing adoption and usage in community colleges," Behaviour \& Information Technology, vol. 30, no. 2, pp. 231-240, Mar. 2011.

[290] W. Cheung and W. Huang, "Proposing a framework to assess Internet usage in university education: an empirical investigation from a student's perspective," British Journal of Educational Technology, vol. 36, no. 2, pp. 237-253, 2005.

[291] C. L. Gan and V. Balakrishnan, "An empirical study of factors affecting mobile wireless technology adoption for promoting interactive lectures in higher education," International Review of Research in Open and Distributed Learning, vol. 17, no. 1, pp. 214-239, Jan. 2016.

[292] K. Mac Callum and L. Jeffrey, "The influence of students' ICT skills and their adoption of mobile learning," Australasian Journal of Educational Technology, vol. 29, no. 3, pp. 303-314, 2013.

[293] M. Vasquez, "Do training, complexity and critical mass affect Wiki adoption?," Phd, University of Illinois at Chicago, 2010.

[294] T. Escobar-Rodriguez and P. Monge-Lozano, "The acceptance of Moodle technology by business administration students," Computers \& Education, vol. 58, no. 4, pp. 1085-1093, May 2012.

[295] E. Yadegaridehkordi, N. A. Iahad, and H. Z. Baloch, "Success factors influencing the adoption of m-learning," International Journal of Continuing Engineering Education \& Lifelong Learning, vol. 23, no. 2, pp. 167-178, Jan. 2013.

[296] W. H. DeLone and E. R. McLean, "Information systems success: the quest for the dependent variable," Information Systems Research, vol. 3, no. 1, pp. 60-95, Mar. 1992.

[297] I. T. J. Brown, "Individual and technological factors affecting perceived ease of use of web-based learning technologies in a developing country," The Electronic Journal of Information Systems in Developing Countries, vol. 9, no. 1, pp. 1-15, 2002.

[298] B. Littig and F. Pöchhacker, "Socio-translational collaboration in qualitative inquiry: the case of expert interviews," Qualitative Inquiry, vol. 20, no. 9, pp. 1085-1095, Nov. 2014.

[299] M. A. Meyer and J. M. Booker, Eliciting and analyzing expert judgment: 
a practical guide. Philadelphia: SIAM, 2001.

[300] M. Sandelowski, "The call to experts in qualitative research," Research in Nursing \& Health, vol. 21, no. 5, pp. 467-471, Oct. 1998.

[301] M. Muskat, D. A. Blackman, and B. Muskat, "Mixed methods: combining expert interviews, cross-impact analysis and scenario development," Electronic Journal of Business Research Methods, vol. 10, no. 1, 2012, Accessed: May 05, 2019. [Online]. Available: https://papers.ssrn.com/abstract=2269508.

[302] H. Kallio, A.-M. Pietilä, M. Johnson, and M. Kangasniemi, "Systematic methodological review: developing a framework for a qualitative semi-structured interview guide," Journal of Advanced Nursing, vol. 72, no. 12, pp. 2954-2965, 2016.

[303] B. Johnson and L. Christensen, Educational research: quantitative and qualitative approaches. Needham Heights: Allyn \& Bacon, 2000.

[304] M. Saunders, P. Lewis, and A. Thornhill, Research methods for business students. Pearson, 2016.

[305] A. Dickinger, M. Arami, and D. Meyer, "Reconsidering the adoption process: enjoyment and social norms - antecedents of hedonic mobile technology use," in Proceedings of the 39th Hawaii International Conference on System Sciences, Hawaii, Jan. 2006, doi: 10.1109/hicss.2006.410.

[306] V. Bhatiasevi, "An extended UTAUT model to explain the adoption of mobile banking," Information Development, vol. 32, no. 4, pp. 799-814, Sep. 2016.

[307] S. Alateyah, R. M. Crowder, and G. B. Wills, "An exploratory study of proposed factors to adopt e-government services," International Journal of Advanced Computer Science and Applications, vol. 4, no. 11, Nov. 2013, doi: ). "> Alateyah, Sulaiman, Crowder, Richard M. and Wills, Gary B. (2013) An exploratory study of proposed factors to adopt e-government services. International Journal of Advanced Computer Science and Applications, 4 (11). (doi:10.14569/IJACSA.2013.041108 <http://dx.doi.org/10.14569/IJACSA.2013.041108>). .

[308] H. Mahdizadeh, H. Biemans, and M. Mulder, "Determining factors of the use of e-learning environments by university teachers," Computers \& Education, vol. 51, no. 1, pp. 142-154, Aug. 2008.

[309] D. M. Rubio, M. Berg-Weger, S. S. Tebb, E. S. Lee, and S. Rauch, "Objectifying content validity: conducting a content validity study in social work research," Social Work Research, vol. 27, no. 2, pp. 94-104, Jun. 2003 , Accessed: Nov. 18, 2019. [Online].

[310] J. Hehn, F. Uebernickel, and M. Herterich, "Design thinking methods for service innovation - a Delphi study," in Pacific Asia Conference on Information Systems (PACIS), 2018, p. 126.

[311] A. Tashakkori and C. Teddlie, "Integrating qualitative and quantitative approaches to research," in The SAGE handbook of applied social research 
methods, L. Bickman and D. J. Rog, Eds. 2011, pp. 283-317.

[312] S. E. Hove and B. Anda, "Experiences from conducting semi-structured interviews in empirical software engineering research," in 11th IEEE International Software Metrics Symposium (METRICS'05), Sep. 2005, pp. $10-23$.

[313] M. C. Harrell and M. Bradley, "Data collection methods: semi-structured interviews and focus groups," Rand, 2009. [Online]. Available: https://play.google.com/store/books/details?id=PnMjQwAACAAJ.

[314] S. J. Tracy, Qualitative research methods: collecting evidence, crafting analysis, communicating impact. West Sussex: Blackwell Publishing Ltd, 2013.

[315] L. Ayres, "Semi-structured interview," in The SAGE encyclopedia of qualitative research methods, L. M. Given, Ed. Thousand Oaks: SAGE Publications, Inc., 2008, pp. 811-812.

[316] R. A. Singleton and B. C. Straits, "Survey interviewing," in The SAGE handbook of interview research: the complexity of the craft, 2nd ed., J. F. Gubrium, J. A. Holstein, A. B. Marvasti, and K. D. McKinney, Eds. London: SAGE Publications, Inc., 2012, pp. 77-98.

[317] J. Dadzie, G. Runeson, G. Ding, and F. K. Bondinuba, "Barriers to adoption of sustainable technologies for energy-efficient building upgrade-semi-structured interviews," Buildings, vol. 8, no. 4, p. 57, Apr. 2018, Accessed: Nov. 11, 2019. [Online].

[318] N. G. Vinson and J. Singer, "A practical guide to ethical research involving humans," in Guide to advanced empirical software engineering, F. Shull, J. Singer, and D. Sjøberg, Eds. London: Springer London, 2008, pp. 229-256.

[319] C. Davis, Focus groups: applying communication theory through design, facilitation, and analysis. New York: Taylor \& Francis, 2017.

[320] D. Stewart, P. Shamdasani, and D. Rook, Focus groups. Thousand Oaks: SAGE Publication Ltd, 2011.

[321] C. J. Oates and P. J. Alevizou, Conducting focus groups for business and management students. SAGE, 2017.

[322] M. Bloor, J. Frankland, M. Thomas, and K. Robson, Focus groups in social research. London: SAGE Publications Ltd, 2011.

[323] M. S. Sohail, M. Sadiq Sohail, and N. M. Shaikh, "Quest for excellence in business education: a study of student impressions of service quality," International Journal of Educational Management, vol. 18, no. 1. pp. 58-65, 2004, doi: 10.1108/09513540410512163.

[324] R. Barbour, Doing focus groups. London: SAGE Publications Ltd, 2011.

[325] H. Edmunds, The focus group research handbook. Chicago: NTC Business Books, 1999.

[326] D. L. Morgan, "Focus groups," Annual Review of Sociology, vol. 22, no. 1, pp. 129-152, 1996.

[327] M. Pagani, "Determinants of adoption of third generation mobile multimedia services," Journal of Interactive Marketing, vol. 18, no. 3, pp. 
46-59, Jan. 2004.

[328] Á. Herrero and H. San Martín, "Developing and testing a global model to explain the adoption of websites by users in rural tourism accommodations," International Journal of Hospitality Management, vol. 31, no. 4, pp. 1178-1186, Dec. 2012.

[329] N. Mallat, "Exploring consumer adoption of mobile payments - a qualitative study," The Journal of Strategic Information Systems, vol. 16, no. 4. pp. 413-432, 2007, doi: 10.1016/j.jsis.2007.08.001.

[330] P. Eriksson and A. Kovalainen, "Focus group research," in Qualitative methods in business research, P. Eriksson and A. Kovalainen, Eds. London: SAGE Publications Ltd, 2011, pp. 174-192.

[331] H. Finch, J. Lewis, and C. Turley, "Focus groups," in Qualitative research practice: a guide for social science students and researchers, J. Ritchie, J. Lewis, of Social Policy Jane Lewis, C. M. Nicholls, and R. Ormston, Eds. SAGE, 2013, pp. 211-242.

[332] P. Liamputtong, Focus group methodology: principle and practice. SAGE Publications, 2011.

[333] D. Morgan, Focus groups as qualitative research. Thousand Oaks: SAGE Publications Ltd, 2011.

[334] D. Stewart, P. Shamdasani, and D. Rook, "Group depth interviews: focus group research," in The SAGE handbook of applied social research methods, L. Bickman and D. J. Rog, Eds. 2011, pp. 589-616.

[335] R. C. Brusso, "Employee behavioral intention and technology use: mediating processes and individual difference moderators," $\mathrm{PhD}$, Old Dominion University, 2015.

[336] M. P. Allen, Understanding regression analysis. New York: Plenum Press, 1997.

[337] D. Gefen, D. Straub, and M.-C. Boudreau, "Structural equation modeling and regression: guidelines for research practice," Communications of the Association for Information Systems, vol. 4, no. 1, p. 7, 2000.

[338] M. C. Shelley, "Structural equation modeling," in Encyclopedia of Educational Leadership and Administration, F. English, Ed. 2455 Teller Road, Thousand Oaks California 91320 United States : SAGE Publications, Inc., 2006.

[339] A. C. Acock, Discovering structural equation modeling using Stata 13 (Revised Edition). Stata Press, 2013.

[340] A. J. Tomarken and N. G. Waller, "Structural equation modeling: strengths, limitations, and misconceptions," Annual Review of Clinical Psychology, vol. 1, pp. 31-65, 2005.

[341] J. C. Anderson and D. W. Gerbing, "Structural equation modeling in practice: a review and recommended two-step approach," Psychological Bulletin, vol. 103, no. 3, pp. 411-423, 1988.

[342] W. W. Chin, "Commentary: issues and opinion on structural equation modeling," MIS Quarterly, vol. 22, no. 1, pp. vii-xvi, 1998. 
[343] J. F. Hair Jr., G. T. M. Hult, C. Ringle, and M. Sarstedt, A primer on Partial Least Squares Structural Equation Modeling (PLS-SEM). SAGE Publications, 2016.

[344] J. F. Hair, M. Sarstedt, L. Hopkins, and V. G. Kuppelwieser, "Partial least squares structural equation modeling (PLS-SEM): an emerging tool in business research," European Business Review, vol. 26, no. 2, pp. 106-121, 2014.

[345] T. Teo, L. T. Tsai, and C.-C. Yang, "Applying Structural Equation Modeling (SEM) in Educational Research," in Application of structural equation modeling in educational research and practice, M. S. Khine, Ed. Rotterdam: SensePublishers, 2013, pp. 3-21.

[346] R. C. MacCallum and J. T. Austin, "Applications of structural equation modeling in psychological research," Annual Review of Psychology, vol. 51, pp. 201-226, 2000.

[347] T. Teo and J. Noyes, "An assessment of the influence of perceived enjoyment and attitude on the intention to use technology among pre-service teachers: A structural equation modeling approach," Computers \& Education, vol. 57, no. 2, pp. 1645-1653, Sep. 2011.

[348] J. Ram, D. Corkindale, and M.-L. Wu, "Enterprise resource planning adoption: structural equation modeling analysis of antecdants," Journal of Computer Information Systems, vol. 54, no. 1, pp. 53-65, Sep. 2013.

[349] A. A. Bakar, F. Z. A. Razak, and W. S. W. Abdullah, "Assessing the effects of UTAUT and self-determination predictor on students continuance intention to use student portal," World Applied Sciences Journal, vol. 21, no. 10, pp. 1484-1489, 2013.

[350] J.-H. Wu, S.-C. Wang, and L.-M. Lin, "Mobile computing acceptance factors in the healthcare industry: a structural equation model," International Journal of Medical Informatics, vol. 76, no. 1, pp. 66-77, Jan. 2007.

[351] A. J. Tomarken and N. G. Waller, "Potential problems with 'well fitting' models," Journal of Abnormal Psychology, vol. 112, no. 4, pp. 578-598, Nov. 2003.

[352] X. Fan, B. Thompson, and L. Wang, "Effects of sample size, estimation methods, and model specification on structural equation modeling fit indexes," Structural Equation Modeling: A Multidisciplinary Journal, vol. 6, no. 1, pp. 56-83, Jan. 1999.

[353] Y. Ekinci, Designing research questionnaires for business and management students. SAGE, 2015.

[354] P. Palvia, E. Mao, A. F. Salam, and K. S. Soliman, "Management information systems research: what's there in a methodology?," Communications of the Association for Information Systems, vol. 11, no. 1, p. 16, 2003.

[355] J. Dawson, Analysing quantitative survey data for business and management students. SAGE, 2016. 
[356] C. Van Mol, "Improving web survey efficiency: the impact of an extra reminder and reminder content on web survey response," International Journal of Social Research Methodology, vol. 20, no. 4, pp. 317-327, Jul. 2017.

[357] N. Betancourt and C. Wolff-Eisenberg, "Surveying community college students: strategies for maximizing engagement and increasing participation," Ithaka S-R, 2019. doi: 10.18665/sr.312046.

[358] J. Bethlehem, Applied survey methods: a statistical perspective. Hoboken: John Wiley \& Sons, 2009.

[359] D. A. Dillman, J. D. Smyth, and L. M. Christian, Internet, phone, mail, and mixed-mode surveys: the tailored design method. John Wiley \& Sons, 2014.

[360] R. Y. Cavana, B. L. Delahaye, and U. Sekaran, Applied business research: qualitative and quantitative methods. Milton, Queensland: John Wiley \& Sons Inc, 2001.

[361] D. Andrews, B. Nonnecke, and J. Preece, "Electronic survey methodology: a case study in reaching hard-to-involve Internet users," International Journal of Human-Computer Interaction, vol. 16, no. 2, pp. 185-210, Oct. 2003.

[362] N. A. Behkami, "Examining health information technology implementations: case of the patient-centered medical home," PhD, Portland State University, 2012.

[363] K. Hyrkäs, K. Appelqvist-Schmidlechner, and L. Oksa, "Validating an instrument for clinical supervision using an expert panel," International Journal of Nursing Studies, vol. 40, no. 6, pp. 619-625, Aug. 2003.

[364] R. M. Cooke and L. H. J. Goossens, "Procedures guide for structural expert judgement in accident consequence modeling," Radiation Protection Dosimetry, vol. 90, no. 3, pp. 303-309, Aug. 2000, Accessed: Nov. 18, 2019. [Online].

[365] S.-C. Ho, W.-Y. Sun, and Y.-M. Wang, "Investigation of factors influencing the adoption of mobile data services," in Proceedings of the 13th International Conference on Electronic Commerce, Liverpool, United Kingdom, 2012, pp. 11:1-11:8.

[366] G. Rowe, G. Wright, and F. Bolger, "Delphi: A reevaluation of research and theory," Technological Forecasting and Social Change, vol. 39, no. 3, pp. 235-251, May 1991.

[367] R. L. Worthington and T. A. Whittaker, "Scale development research: a content analysis and recommendations for best practices," The Counseling Psychologist, vol. 34, no. 6, pp. 806-838, Nov. 2006.

[368] T. R. Anderson, Research methods for technology management and other fields: tools and techniques for conducting research. Portland: Timothy Anderson, 2013.

[369] K. Rao and J. Pennington, "Should the third reminder be sent? The tole of survey response timing on web survey results," International Journal of Market Research, vol. 55, no. 5. pp. 651-674, 2013, doi: 
10.2501/ijmr-2013-056.

[370] G. D. Bouma and R. Ling, The research process. Oxford University Press, USA, 2004.

[371] G. D. Bouma and G. B. J. Atkinson, Handbook of social science research. Oxford University Press, 1995.

[372] S. G. Heeringa, B. T. West, and P. A. Berglund, Applied survey data analysis. Boca Raton: CRC Press, 2017.

[373] J. Newsom, "Minimum sample size recommendations," Portland State University, Spring $2018 . \quad$ [Online]. Available: http://web.pdx.edu/ newsomj/semclass/ho_sample\%2osize.pdf.

[374] D. Iacobucci, "Structural equations modeling: fit Indices, sample size, and advanced topics," Journal of Consumer Psychology, vol. 20, no. 1, pp. 90-98, Jan. 2010.

[375] A. Boomsma and J. J. Hoogland, "The robustness of LISREL modeling revisited," in Structural equation modeling: present and future, vol. 2, S. DuToit, R. Cudeck, and D. Sorbom, Eds. Scientific Software International, 2000, pp. 139-168.

[376] H. pdx.edu/student-financial/post-baccalaureate-tuition, "Post baccalaureate tuition," Portland State University - Student Financial Services. https://www.pdx.edu/student-financial/post-baccalaureate-tuition (accessed Nov. 27, 2019).

[377] National Center for Education Statistics, "College Navigator - Portland State University," CollegeNavigator National Center for Education Statistics - Portland State University. https://nces.ed.gov/collegenavigator/?q=Portland+State+University\&s=all\& $\mathrm{id}=209807$ \# general (accessed May 11, 2020).

[378] S. G. Heeringa, B. T. West, and P. A. Berglund, Applied survey data analysis. Boca Raton: CRC Press, 2010.

[379] T. Downes-Le Guin, R. Baker, J. Mechling, and E. Ruyle, "Myths and realities of respondent engagement in online surveys," International Journal of Market Research, vol. 54, no. 5, pp. 613-633, Sep. 2012.

[380] T. C. Urdan, Statistics in plain English. New York: Routledge, 2017.

[381] B. Illowsky and S. Dean, Introductory statistics. Houston: Rice University, 2018.

[382] C. Davison and E. Argyriou, "Gender preferences in technology adoption: an empirical investigation of technology trends in higher education," International Journal of Gender, Science and Technology, vol. 8, no. 3, pp. 405-419, Dec. 2016, Accessed: May 13, 2020. [Online].

[383] M. P. B. Govindarajan and A. R. Krishnan, "A study on moderating effect of gender, and experience on Massive Open Online Courses (MOOCs) technology adoption by extending the UTAUT model with reference to Student MOOD U=users," Journal of the Gujarat Research Society, vol. 21, no. 3, pp. 350-358, 2019.

[384] K. E. Heron, K. A. Romano, and A. L. Braitman, "Mobile technology use 
and mhealth text message preferences: an examination of gender, racial, and ethnic differences among emerging adult college students," mHealth, vol. 5, pp. 2-2, 2019.

[385] J. He and L. A. Freeman, "Are men more technology-oriented than women? The role of gender on the development of general computer self-efficacy of college students," Journal of Information Systems Education, vol. 21, no. 2, p. 7, 2019.

[386] C. Park, D.-G. Kim, S. Cho, and H.-J. Han, "Adoption of multimedia technology for learning and gender difference," Computers in Human Behavior, vol. 92, pp. 288-296, Mar. 2019.

[387] D. Liu and X. Guo, "Exploring gender differences in acceptance of mobile computing devices among college students," Information Systems and e-Business Management, vol. 15, no. 1, pp. 197-223, Feb. 2017.

[388] M. Al-Emran, Y. Alkhoudary, V. Mezhuyev, and M. Al-Emran, "Students and educators attitudes towards the use of m-learning: gender and smartphone ownership differences," International Association of Online Engineering, 2019, [Online]. Available: https://www.learntechlib.org/p/207191/.

[389] R. K. Henson and J. K. Roberts, "Use of Exploratory Factor Analysis in published research: common errors and some comment on improved practice," Educational and Psychological Measurement, vol. 66, no. 3, pp. 393-416, Jun. 2006.

[390] J. Newsom, "Exploratory and Confirmatory Factor Analysis," presented at the Class Lecture, Portland State University, 2017.

[391] J. W. Osborne and A. B. Costello, "Best practices in exploratory factor analysis," Practical Assessment Research \& Evaluation, vol. 10, no. 7, pp. 86-99, 2005.

[392] D. Straub, M.-C. Boudreau, and D. Gefen, "Validation guidelines for IS positivist research," Communications of the Association for Information Systems, vol. 13, no. 1, p. 24, 2004.

[393] T. Asparouhov and B. Muthén, "Exploratory Structural Equation Modeling," Structural Equation Modeling, vol. 16, no. 3, pp. 397-438, Jul. 2009.

[394] S. Ozkan and R. Koseler, "Multi-dimensional students' evaluation of e-learning systems in the higher education context: an empirical investigation," Computers \& Education, vol. 53, pp. 1285-1296, 2009.

[395] M. Mehmetoglu and T. G. Jakobsen, Applied statistics using Stata: a guide for the social cciences. SAGE, 2016.

[396] C. Fornell and D. F. Larcker, "Evaluating structural equation models with unobservable variables and measurement error," J. Mark. Res., vol. 18, no. 1, p. $39,1981$.

[397] J. L. Kwan and W. Chan, "Comparing standardized coefficients in structural equation modeling: a model reparameterization approach," Behavior Research Methods, vol. 43, no. 3, pp. 730-745, Sep. 2011. 
[398] K. A. Bollen, Structural equations with latent variables. New York: John Wiley \& Sons, Inc., 1989.

[399] A. R. McIntosh and F. Gonzalez-Lima, "Structural equation modeling and its application to network analysis in functional brain imaging," Human Brain Mapping, vol. 2, no. 1-2, pp. 2-22, Oct. 1994.

[400] G. Hertel, S. Naumann, U. Konradt, and B. Batinic, "Personality assessment via Internet: comparing online and paper-and-pencil questionnaires," Online Social Sciences, pp. 115-133, 2002.

[401] H.-N. Sung, D.-Y. Jeong, Y.-S. Jeong, and J.-I. Shin, "The relationship among self-efficacy, social influence, performance expectancy, effort expectancy, and behavioral intention in mobile learning service," International Journal of u-and e-Service, Science and Technology, vol. 8, no. 9, pp. 197-206, 2015.

[402] The Associated Press, "Amid pandemic, fewer students seek federal aid for college," The New York Times, Jul. 06, 2020.

[403] K. Carey, "Everybody ready for the big migration to online college? Actually, no," The New York Times, Mar. 13, 2020.

[404] J. O'Brien, "More than a lifeline," Inside Higher Ed, May 05, 2020. https://www.insidehighered.com/views/2020/05/05/covid-19-has-demonst rated-how-technology-higher-ed-major-strategic-asset-opinion (accessed Jun. 09, 2020).

[405] F. D. Davis, "User acceptance of information technology: system characteristics, user perceptions and behavioral impacts," International Journal of Man-Machine Studies, vol. 38, no. 3, pp. 475-487, Mar. 1993.

[406] A. Fini, "The technological dimension of a Massive Open Online Course: the case of the CCKo8 course tools," The International Review of Research in Open and Distributed Learning, vol. 10, no. 5, Nov. 2009, doi: 10.19173/irrodl.v10i5.643.

[407] M. I. Tariq, S. Tayyaba, H. Rasheed, and M. W. Ashraf, "Factors influencing the cloud computing adoption in higher education institutions of Punjab, Pakistan," in 2017 International Conference on Communication, Computing and Digital Systems (C-CODE), 2017, doi: 10.1109/C-CODE.2017.7918925.

[408] S. Chea and M. M. Luo, "eService customer retention: the roles of negative affectivity and perceived switching costs," in AMCIS 2005 Proceedings, 2005, pp. 214-220.

[409] D. J. Kim, D. L. Ferrin, and H. R. Rao, "A trust-based consumer decision-making model in electronic commerce: the role of trust, perceived risk, and their antecedents," Decision Support Systems, vol. 44, no. 2, pp. 544-564, Jan. 2008.

[410] V. Venkatesh and F. D. Davis, "A model of the antecedents of perceived ease of use: development and test," Decision Sciences, vol. 27, no. 3, pp. 451-481, Sep. 1996. 


\section{Appendices}

\section{Appendix A: Taxonomy of Factors Related to University Student}

Adoption of Technology

\begin{tabular}{|c|c|c|c|c|c|}
\hline Category & Factor & Definition & $\begin{array}{l}\text { Influence } \\
\text { on other } \\
\text { factors }\end{array}$ & $\begin{array}{l}\text { Referenc } \\
\text { e for } \\
\text { definitio } \\
\mathbf{n}\end{array}$ & $\begin{array}{l}\text { Reference } \\
\text { (s) for } \\
\text { influence } \\
\text { on other } \\
\text { factors } \\
\end{array}$ \\
\hline \multicolumn{6}{|c|}{ Accessibility } \\
\hline & $\begin{array}{l}\text { System } \\
\text { accessibility }\end{array}$ & $\begin{array}{l}\text { "the degree of ease with } \\
\text { which a university student } \\
\text { can access and use a } \\
\text { campus e-learning system } \\
\text { as an organizational factor." }\end{array}$ & $\begin{array}{l}\text { Not } \\
\text { significant }\end{array}$ & {$[112]$} & {$[112]$} \\
\hline & $\begin{array}{l}\text { System } \\
\text { accessibility }\end{array}$ & $\begin{array}{l}\text { "the degree of ease with } \\
\text { which a university student } \\
\text { can access and use a } \\
\text { campus e-learning system } \\
\text { as an organizational factor." }\end{array}$ & Positive & [112] & {$[112]$} \\
\hline & Accessibility & $\begin{array}{l}\text { degree to which a user can } \\
\text { easily access the tool }\end{array}$ & Positive & {$[279]$} & [279] \\
\hline & Cloud accessibility & $\begin{array}{l}\text { "investigate how users } \\
\text { access the personal cloud as } \\
\text { well as how users perceive } \\
\text { the challenges surrounding } \\
\text { Internet access, reliability } \\
\text { and associated costs" }\end{array}$ & Positive & {$[263]$} & {$[263]$} \\
\hline & Access to software & $\begin{array}{l}\text { degree of access to a } \\
\text { personal copy of the } \\
\text { software needed for a } \\
\text { course }\end{array}$ & Negative & [289] & [289] \\
\hline & Convenience & $\begin{array}{l}\text { "a class of consumer } \\
\text { products that were } \\
\text { intensively distributed and } \\
\text { required minimal....effort to } \\
\text { purchase; ...other } \\
\text { researchers...expanded the } \\
\text { concept...to incorporate } \\
\text { nonshopping activities" }\end{array}$ & Positive & {$[237]$} & {$[237]$} \\
\hline & Enablers & $\begin{array}{l}\text { access to the system, } \\
\text { availability of technical } \\
\text { support, prior experience } \\
\text { with computer and Web } \\
\text { use, self-efficacy in using } \\
\text { the Web }\end{array}$ & Positive & {$[280]$} & {$[280]$} \\
\hline \multicolumn{6}{|l|}{ Age } \\
\hline & Age & respondent's age & Positive & {$[274]$} & {$[274]$} \\
\hline \multicolumn{6}{|l|}{ Anxiety } \\
\hline & Computer anxiety & $\begin{array}{l}\text { "the level of learners' } \\
\text { anxiety when they apply } \\
\text { computers in e-Learning" }\end{array}$ & Negative & [288] & {$[273],[297]$} \\
\hline & Computer anxiety & $\begin{array}{l}\text { "the level of learners' } \\
\text { anxiety when they apply } \\
\text { computers in e-Learning" }\end{array}$ & $\begin{array}{l}\text { Not } \\
\text { significant }\end{array}$ & {$[289]$} & {$[254]$} \\
\hline & Technology anxiety & $\begin{array}{l}\text { degree to which computer } \\
\text { technology creates anxiety, } \\
\text { including interference with } \\
\text { student learning }\end{array}$ & Negative & [289] & {$[289]_{2}[247]$} \\
\hline
\end{tabular}




\begin{tabular}{|c|c|c|c|c|c|}
\hline & $\begin{array}{l}\text { Attitude toward } \\
\text { the system }\end{array}$ & $\begin{array}{l}\text { satisfaction with the system, } \\
\text { preference for the system } \\
\text { (Martins and Kellermanns } \\
\text { 2004); "degree to which a } \\
\text { user is interested in using } \\
\text { the system" (Cheung and } \\
\text { Vogel 2013) }\end{array}$ & Positive & $\begin{array}{l}{[280]_{2}} \\
{[278]}\end{array}$ & $\begin{array}{l}280]_{2} \\
{[270]_{2}[112]_{2}} \\
{[287]_{2}} \\
{[278]_{2}} \\
{[253]_{2}} \\
{[267]_{2}} \\
{[247]_{2}} \\
{[254]_{2}} \\
{[276]_{2}[295]}\end{array}$ \\
\hline & $\begin{array}{l}\text { Attitude toward } \\
\text { use }\end{array}$ & $\begin{array}{l}\text { "the degree of evaluative } \\
\text { affect that an individual } \\
\text { associates with using the } \\
\text { target system in his or her } \\
\text { job" }\end{array}$ & $\begin{array}{l}\text { Not } \\
\text { significant }\end{array}$ & {$[405]$} & $\begin{array}{l}{[282]_{2}} \\
{[244]_{2}} \\
{[248]_{2}[285]}\end{array}$ \\
\hline & Innovative attitude & $\begin{array}{l}\text { "highly innovative students } \\
\text { would accept and more } \\
\text { enthusiastically adopt the } \\
\text { changes proposed in the } \\
\text { delivery of the management } \\
\text { course" }\end{array}$ & Positive & {$[281]$} & [281] \\
\hline & $\begin{array}{l}\text { Mobile learning } \\
\text { attitude }\end{array}$ & $\begin{array}{l}\text { "Students' positive attitude } \\
\text { toward m-learning" }\end{array}$ & Positive & {$[242]$} & {$[242]_{2}[272]$} \\
\hline \multicolumn{6}{|c|}{ Behavioral intention } \\
\hline & $\begin{array}{l}\text { Behavioral } \\
\text { intention to use } \\
\text { (i.e. decision to } \\
\text { use) }\end{array}$ & $\begin{array}{l}\text { "the decision maker's } \\
\text { disposition toward using a } \\
\text { system" }\end{array}$ & Positive & {$[271]$} & $\begin{array}{l}{[277],} \\
{[270],} \\
{[241],} \\
{[271],} \\
{[244],} \\
{[264],} \\
{[278],} \\
{[247],[279]}\end{array}$ \\
\hline & $\begin{array}{l}\text { Competing } \\
\text { behavioral } \\
\text { intention }\end{array}$ & $\begin{array}{l}\text { ("determined by a positive } \\
\text { function of intention to use } \\
\text { the ELS and the } \\
\text { simultaneous negative } \\
\text { functions of intention to use } \\
\text { competing learning media" }\end{array}$ & $\begin{array}{l}\text { Not } \\
\text { significant }\end{array}$ & {$[233]$} & {$[233]$} \\
\hline \multicolumn{6}{|c|}{ Communicativeness } \\
\hline & $\begin{array}{l}\text { Communicativenes } \\
\mathrm{s}\end{array}$ & $\begin{array}{l}\text { degree to which the system } \\
\text { facilitates } \\
\text { student-to-student and } \\
\text { student-to-instructor } \\
\text { interactions }\end{array}$ & Positive & [279] & [279] \\
\hline \multicolumn{6}{|l|}{ Compatibility } \\
\hline & $\begin{array}{l}\text { Perceived } \\
\text { compatibility with } \\
\text { student tasks }\end{array}$ & $\begin{array}{l}\text { degree to which the system } \\
\text { is compatible with student } \\
\text { tasks in the course and } \\
\text { student preferences for how } \\
\text { they like to study }\end{array}$ & Positive & {$[294]$} & {$[294]$} \\
\hline & $\begin{array}{l}\text { Perceived } \\
\text { compatibility with } \\
\text { student tasks }\end{array}$ & $\begin{array}{l}\text { degree to which the system } \\
\text { is compatible with student } \\
\text { tasks in the course and } \\
\text { student preferences for how } \\
\text { they like to study }\end{array}$ & $\begin{array}{l}\text { Not } \\
\text { significant }\end{array}$ & {$[294]$} & {$[294]$} \\
\hline & Compatibility & $\begin{array}{l}\text { "the degree to which the } \\
\text { innovation is perceived to } \\
\text { be consistent with the } \\
\text { potential users' existing } \\
\text { values, previous experiences } \\
\text { and needs" }\end{array}$ & Positive & {$[277]$} & $\begin{array}{l}{[277],} \\
{[270],[278]}\end{array}$ \\
\hline & $\begin{array}{l}\text { Educational } \\
\text { compatibility }\end{array}$ & $\begin{array}{l}\text { "perceived fit between the } \\
\text { use of technology and }\end{array}$ & Positive & {$[276]$} & {$[276]$} \\
\hline
\end{tabular}




\begin{tabular}{|c|c|c|c|c|c|}
\hline & & $\begin{array}{l}\text { students' learning style and } \\
\text { needs, and students' } \\
\text { constructive beliefs about } \\
\text { learning" }\end{array}$ & & & \\
\hline \multicolumn{6}{|l|}{ Control } \\
\hline & $\begin{array}{l}\text { Perception of } \\
\text { behavior control }\end{array}$ & $\begin{array}{l}\text { "the control individuals } \\
\text { have over their behavior" }\end{array}$ & Positive & [270] & $\begin{array}{l}{[270],} \\
{[287],[272]}\end{array}$ \\
\hline & Locus of control & $\begin{array}{l}\text { Those with internal locus of } \\
\text { control, that is a stronger } \\
\text { belief in the relationship } \\
\text { between efforts and } \\
\text { rewards, "would be more } \\
\text { likely to perceive the } \\
\text { usefulness of Web-based } \\
\text { flexible learning material } \\
\text { than would those with an } \\
\text { external locus of control" }\end{array}$ & Positive & {$[281]$} & [281] \\
\hline & $\begin{array}{l}\text { Perceived learning } \\
\text { autonomy }\end{array}$ & $\begin{array}{l}\text { "the extent to which } \\
\text { students are responsible } \\
\text { and have control over the } \\
\text { process of learning with } \\
\text { mobile devices" }\end{array}$ & Positive & {$[272]$} & [272] \\
\hline & $\begin{array}{l}\text { Interactivity and } \\
\text { control }\end{array}$ & $\begin{array}{l}\text { degree of control a user has } \\
\text { when interacting with a } \\
\text { system in order to custom } \\
\text { how it is used }\end{array}$ & Positive & [279] & [279] \\
\hline \multicolumn{6}{|l|}{ Cost and value } \\
\hline & Perceived cost & perceived cost of MOOCs & $\begin{array}{l}\text { Not } \\
\text { significant }\end{array}$ & {$[406]$} & {$[245]$} \\
\hline & Reduced cost & $\begin{array}{l}\text { "Perceived benefits of } \\
\text { Reduce cost has significant } \\
\text { positive effect in the cloud } \\
\text { computing adoption" }\end{array}$ & Positive & [407] & [407] \\
\hline & Price value & $\begin{array}{l}\text { a user's tradeoff between } \\
\text { perceived benefits and the } \\
\text { monetary costs of using a } \\
\text { technology }\end{array}$ & $\begin{array}{l}\text { Not } \\
\text { significant }\end{array}$ & {$[265]$} & [265] \\
\hline & Perceived Value & $\begin{array}{l}\text { "an individual's overall } \\
\text { assessment of the utility of a } \\
\text { product/service based on } \\
\text { the perceptions of what is } \\
\text { received and what is given" }\end{array}$ & Positive & {$[235]$} & [235] \\
\hline & Perceived price & $\begin{array}{l}\text { perceived price of a } \\
\text { technology }\end{array}$ & Positive & [235] & [235] \\
\hline \multicolumn{6}{|l|}{ Ease of travel } \\
\hline & Ease of travel & $\begin{array}{l}\text { Degree to which restraints } \\
\text { on transportation } \\
\text { arrangements make it } \\
\text { difficult to commute to } \\
\text { campus. }\end{array}$ & Negative & [289] & [289] \\
\hline
\end{tabular}




\begin{tabular}{|c|c|c|c|c|c|}
\hline & Effort expectancy & $\begin{array}{l}\text { "degree of ease in relation to } \\
\text { the use of a technology" }\end{array}$ & Positive & {$[263]$} & $\begin{array}{l}{[253],} \\
{[265],} \\
{[266],} \\
{[247],} \\
{[254],} \\
{[252],[268]}\end{array}$ \\
\hline & Effort expectancy & $\begin{array}{l}\text { "degree of ease in relation to } \\
\text { the use of a technology" }\end{array}$ & Negative & {$[263]$} & $\begin{array}{l}{[263],} \\
{[264],[253]}\end{array}$ \\
\hline & Effort expectancy & $\begin{array}{l}\text { "degree of ease in relation to } \\
\text { the use of a technology" }\end{array}$ & $\begin{array}{l}\text { Not } \\
\text { significant }\end{array}$ & {$[263]$} & {$[267]$} \\
\hline \multicolumn{6}{|l|}{ Enjoyment } \\
\hline & $\begin{array}{l}\text { Perceived } \\
\text { enjoyment }\end{array}$ & $\begin{array}{l}\text { "the extent to which the } \\
\text { usage of the technology is } \\
\text { perceived to be enjoyable } \\
\text { for the users apart from any } \\
\text { consequences for using the } \\
\text { technology" }\end{array}$ & Positive & {$[234]$} & [234], [290] \\
\hline & $\begin{array}{l}\text { Hedonic } \\
\text { motivation }\end{array}$ & $\begin{array}{l}\text { "the way used to measure } \\
\text { user's perceived enjoyment } \\
\text { and perceived } \\
\text { entertainment" }\end{array}$ & Positive & {$[265]$} & [265], [268] \\
\hline & $\begin{array}{l}\text { Perceived } \\
\text { playfulness }\end{array}$ & $\begin{array}{l}\text { "a state of mind that } \\
\text { includes three dimensions: } \\
\text { the extent to which the } \\
\text { individual (1) perceives that } \\
\text { his or her attention is } \\
\text { focused on the interaction } \\
\text { with the m-learning (i.e., } \\
\text { concentration); (2) is } \\
\text { curious during the } \\
\text { interaction (ie, curiosity); } \\
\text { and (3) finds the interaction } \\
\text { intrinsically enjoyable or } \\
\text { interesting (ie, enjoyment)" }\end{array}$ & Positive & {$[252]$} & {$[252]$} \\
\hline \multicolumn{6}{|l|}{ Ethnicity } \\
\hline & Ethnicity & $\begin{array}{l}\text { ethnicity of smartphone } \\
\text { user }\end{array}$ & $\begin{array}{l}\text { Influences } \\
\text { likelihood } \\
\text { of } \\
\text { technology } \\
\text { adoption }\end{array}$ & {$[235]$} & {$[235]$} \\
\hline
\end{tabular}




\begin{tabular}{|c|c|c|c|c|c|}
\hline & $\begin{array}{l}\text { Facilitating } \\
\text { conditions }\end{array}$ & $\begin{array}{l}\text { "perceptions of the } \\
\text { resources and support } \\
\text { available to adopters when } \\
\text { utilising a technology" }\end{array}$ & Positive & {$[263]$} & $\begin{array}{l}{[263],} \\
{[275],} \\
{[266],} \\
{[267],} \\
{[247],} \\
{[268],} \\
{[276],[269]}\end{array}$ \\
\hline & $\begin{array}{l}\text { Facilitating } \\
\text { conditions }\end{array}$ & $\begin{array}{l}\text { "perceptions of the } \\
\text { resources and support } \\
\text { available to adopters when } \\
\text { utilising a technology" }\end{array}$ & $\begin{array}{l}\text { Not } \\
\text { significant }\end{array}$ & {$[263]$} & [265], [254] \\
\hline & $\begin{array}{l}\text { Facilitating } \\
\text { conditions }\end{array}$ & $\begin{array}{l}\text { "perceptions of the } \\
\text { resources and support } \\
\text { available to adopters when } \\
\text { utilising a technology" }\end{array}$ & $\begin{array}{l}\text { not } \\
\text { considered, } \\
\text { as } \\
\text { reliability } \\
\text { test } \\
\text { statistic } \\
\text { below .70 }\end{array}$ & [263] & [254] \\
\hline & $\begin{array}{l}\text { Facilitating } \\
\text { conditions - } \\
\text { technology }\end{array}$ & $\begin{array}{l}\text { technology available to } \\
\text { students }\end{array}$ & $\begin{array}{l}\text { Not } \\
\text { significant }\end{array}$ & {$[270]$} & {$[270]$} \\
\hline \multicolumn{6}{|l|}{ Features } \\
\hline & $\begin{array}{l}\text { System } \\
\text { functionality }\end{array}$ & $\begin{array}{l}\text { the functions or features of } \\
\text { a system }\end{array}$ & Positive & {$[261]$} & {$[261]$} \\
\hline & User tools & $\begin{array}{l}\text { specific tools/features of an } \\
\text { e-learning system }\end{array}$ & Positive & [279] & [279] \\
\hline & $\begin{array}{l}\text { System } \\
\text { interactivity }\end{array}$ & $\begin{array}{l}\text { students' perceptions of the } \\
\text { system's ability to provide } \\
\text { interactive communication } \\
\text { between instructor and } \\
\text { students and among } \\
\text { students }\end{array}$ & $\begin{array}{l}\text { Not } \\
\text { significant }\end{array}$ & [286] & [286] \\
\hline & $\begin{array}{l}\text { System } \\
\text { interactivity }\end{array}$ & $\begin{array}{l}\text { students' perceptions of the } \\
\text { system's ability to provide } \\
\text { interactive communication } \\
\text { between instructor and } \\
\text { students and among } \\
\text { students }\end{array}$ & Positive & {$[286]$} & {$[261]$} \\
\hline & Format & $\begin{array}{l}\text { the flexibility of course } \\
\text { material and the use of } \\
\text { different formats for display } \\
\text { of material }\end{array}$ & Positive & [279] & [279] \\
\hline & User adaptation & $\begin{array}{l}\text { the degree to which the tool } \\
\text { adjusts to the user's } \\
\text { learning goals and needs }\end{array}$ & Positive & [279] & [279] \\
\hline & $\begin{array}{l}\text { Diversity in } \\
\text { assessment }\end{array}$ & $\begin{array}{l}\text { "different assessment } \\
\text { methods as perceived by } \\
\text { learners" } \\
\text { "this study assumes that if } \\
\text { an e-Learning system } \\
\text { provides more or diversified }\end{array}$ & Positive & {$[288]$} & [288] \\
\hline
\end{tabular}




\begin{tabular}{|c|c|c|c|c|c|}
\hline & & $\begin{array}{l}\text { assessment tools and } \\
\text { methods, users' satisfaction } \\
\text { will increase because of } \\
\text { feedback from the } \\
\text { assessment" }\end{array}$ & & & \\
\hline \multicolumn{6}{|l|}{ Feedback } \\
\hline & Feedback & $\begin{array}{l}\text { degree to which feedback } \\
\text { delivered through the } \\
\text { system is helpful, timely } \\
\text { and provides information } \\
\text { about how much a learner } \\
\text { knows about a topic }\end{array}$ & Positive & [279] & [279] \\
\hline \multicolumn{6}{|l|}{ Gender } \\
\hline & Gender & respondent's gender & Positive & {$[274]$} & [274] \\
\hline & Gender & respondent's gender & $\begin{array}{l}\text { Not } \\
\text { significant }\end{array}$ & {$[274]$} & {$[274]$} \\
\hline \multicolumn{6}{|l|}{ Habits } \\
\hline & $\begin{array}{l}\text { Student past } \\
\text { behavior }\end{array}$ & $\begin{array}{l}\text { "Past habit influences } \\
\text { intention and behaviour in } \\
\text { the theory of planned } \\
\text { behavior" }\end{array}$ & $\begin{array}{l}\text { Not } \\
\text { significant }\end{array}$ & {$[243]$} & {$[243]$} \\
\hline & Habit & $\begin{array}{l}\text { "the perceptional structure } \\
\text { of doing something often } \\
\text { and regularly" }\end{array}$ & Positive & {$[265]$} & [265], [268] \\
\hline \multicolumn{6}{|c|}{ Individual characteristics } \\
\hline & $\begin{array}{l}\text { Instructor } \\
\text { characteristics }\end{array}$ & $\begin{array}{l}\text { Educators establishing clear } \\
\text { guidelines for social } \\
\text { network usage by students, } \\
\text { encourage students to } \\
\text { respond to other students, } \\
\text { and keep course materials } \\
\text { up-to-date }\end{array}$ & Positive & [243] & [243] \\
\hline & $\begin{array}{l}\text { Student } \\
\text { characteristics }\end{array}$ & $\begin{array}{l}\text { Dependent, independent or } \\
\text { collaborative }\end{array}$ & $\begin{array}{l}\text { Not } \\
\text { significant }\end{array}$ & {$[243]$} & [243] \\
\hline \multicolumn{6}{|l|}{ Miscellaneous } \\
\hline & $\begin{array}{l}\text { Cognitive } \\
\text { absorption }\end{array}$ & $\begin{array}{l}\text { "a state of deep involvement } \\
\text { with the ILS [internet } \\
\text { learning system]" }\end{array}$ & Positive & {$[262]$} & [262] \\
\hline & E-error recovery & $\begin{array}{l}\text { Ability to recover from } \\
\text { computer errors }\end{array}$ & Positive & {$[281]$} & {$[281]$} \\
\hline & Course attributes & $\begin{array}{l}\text { Fit of the e-learning system } \\
\text { with course characteristics }\end{array}$ & $\begin{array}{l}\text { Not } \\
\text { significant }\end{array}$ & {$[233]$} & {$[233]$} \\
\hline & Major relevance & $\begin{array}{l}\text { Relevance of a course for a } \\
\text { student's major }\end{array}$ & Positive & {$[242]$} & [242] \\
\hline & $\begin{array}{l}\text { Willingness to use } \\
\text { social network }\end{array}$ & $\begin{array}{l}\text { "willingness to use social } \\
\text { network of MOOC" }\end{array}$ & Positive & {$[245]$} & {$[245]$} \\
\hline & $\begin{array}{l}\text { Willingness to use } \\
\text { social network }\end{array}$ & $\begin{array}{l}\text { "willingness to use social } \\
\text { network of MOOC" }\end{array}$ & Negative & {$[245]$} & [245] \\
\hline & Relative advantage & $\begin{array}{l}\text { "the degree to which a new } \\
\text { technology is perceived as } \\
\text { better than the method or } \\
\text { technique used before the } \\
\text { introduction of the new } \\
\text { technology" }\end{array}$ & Positive & {$[234]$} & [234] \\
\hline & $\begin{array}{l}\text { e-Learning course } \\
\text { flexibility }\end{array}$ & $\begin{array}{l}\text { "learners' perception of the } \\
\text { efficiency and effects of } \\
\text { adopting e-Learning in their }\end{array}$ & Positive & {$[288]$} & [288] \\
\hline
\end{tabular}




\begin{tabular}{|c|c|c|c|c|c|}
\hline & & $\begin{array}{l}\text { working, learning, and } \\
\text { commuting hours" }\end{array}$ & & & \\
\hline & Internet usage & $\begin{array}{l}\text { frequency, intensity, using } \\
\text { various tools, using for } \\
\text { various tasks }\end{array}$ & Positive & {$[290]$} & [290] \\
\hline & $\begin{array}{l}\text { Self-management } \\
\text { of learning }\end{array}$ & $\begin{array}{l}\text { "the extent to which an } \\
\text { individual feels he or she is } \\
\text { self-disciplined and can } \\
\text { engage in autonomous } \\
\text { learning" }\end{array}$ & Positive & {$[252]$} & {$[252]$} \\
\hline & $\begin{array}{l}\text { Uncertainty } \\
\text { avoidance }\end{array}$ & $\begin{array}{l}\text { "the degree of discomfort } \\
\text { when dealing with } \\
\text { uncertainties and } \\
\text { ambiguities" }\end{array}$ & Positive & {$[291]$} & [291] \\
\hline & Methodology & $\begin{array}{l}\text { the fit between the } \\
\text { e-learning system and the } \\
\text { subject }\end{array}$ & Positive & [279] & [279] \\
\hline & $\begin{array}{l}\text { Elastic resource } \\
\text { capacity }\end{array}$ & $\begin{array}{l}\text { "Perceived benefits of } \\
\text { Elastic resource capacity } \\
\text { has significant positive } \\
\text { effect in the cloud } \\
\text { computing adoption" }\end{array}$ & Positive & [407] & [407] \\
\hline \multicolumn{6}{|l|}{ Mobility } \\
\hline & Mobility & $\begin{array}{l}\text { "the extent to which } \\
\text { students can access the } \\
\text { podcast anytime and } \\
\text { anywhere with no } \\
\text { restrictions" }\end{array}$ & Positive & {$[234]$} & {$[234]$} \\
\hline & $\begin{array}{l}\text { Perceived mobility } \\
\text { value }\end{array}$ & $\begin{array}{l}\text { "consciousness of users } \\
\text { about the mobility value of } \\
\text { M-learning" }\end{array}$ & Positive & [295] & [295] \\
\hline \multicolumn{6}{|c|}{ Perceived complexity } \\
\hline & $\begin{array}{l}\text { Perceived } \\
\text { complexity }\end{array}$ & $\begin{array}{l}\text { "assesses the extent of } \\
\text { difficulty in using the } \\
\text { Internet, which is similar to } \\
\text { the concept of Perceived } \\
\text { Ease of Use" }\end{array}$ & Negative & [290] & [290], [293] \\
\hline & $\begin{array}{l}\text { Perceived } \\
\text { complexity }\end{array}$ & $\begin{array}{l}\text { degree to which a } \\
\text { technology is perceived by } \\
\text { the user as difficult to } \\
\text { understand and use }\end{array}$ & $\begin{array}{l}\text { Not } \\
\text { significant }\end{array}$ & [293] & [293] \\
\hline
\end{tabular}




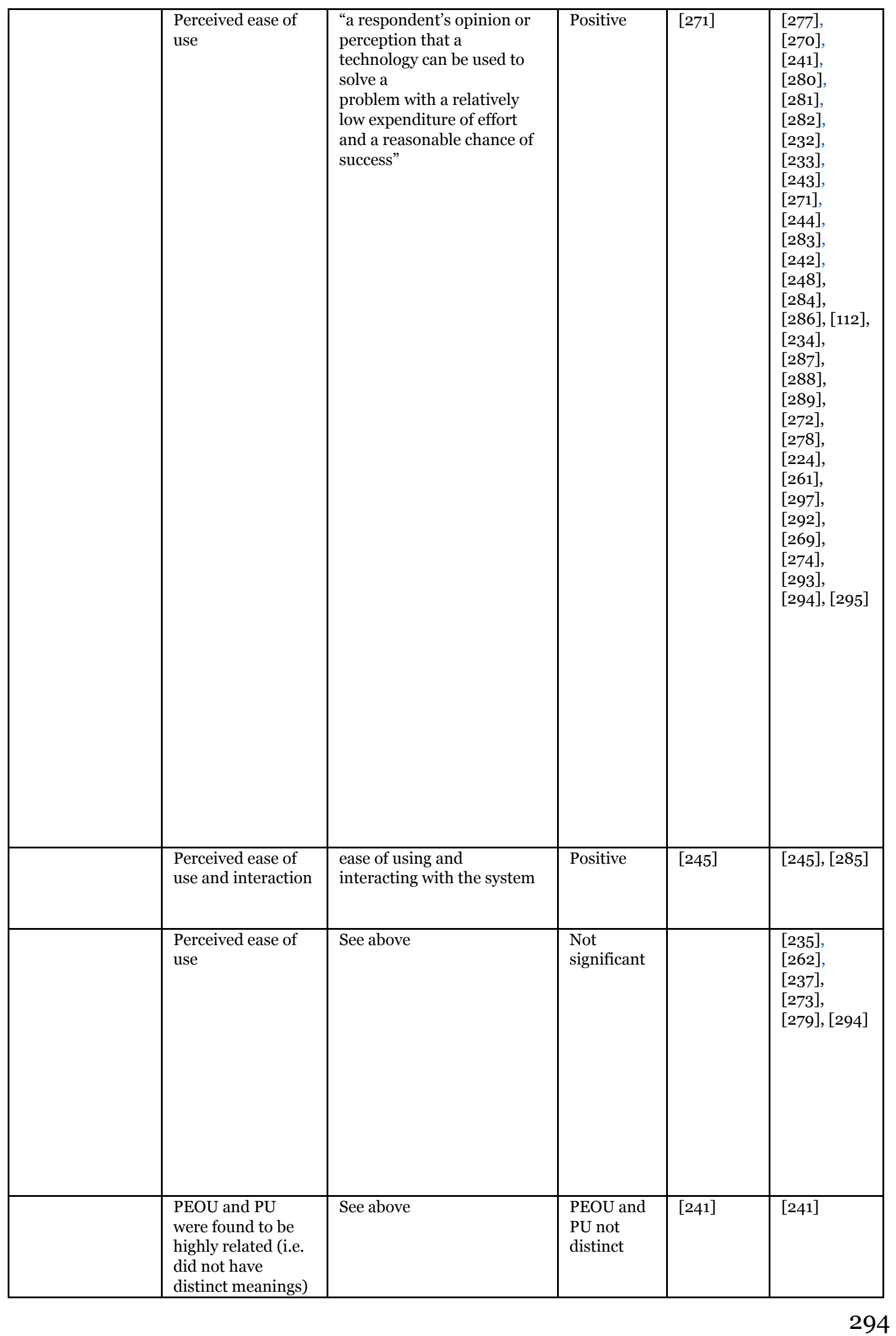




\begin{tabular}{|c|c|c|c|c|c|}
\hline & System perception & $\begin{array}{l}\text { combination of ease of use, } \\
\text { enjoyment and self-efficacy }\end{array}$ & Positive & [291] & [291] \\
\hline & Ease of finding & $\begin{array}{l}\text { "encompasses the notion } \\
\text { that a web site should be } \\
\text { easy to navigate and allow } \\
\text { easy return to previous } \\
\text { display pages" }\end{array}$ & Positive & {$[297]$} & [297] \\
\hline & $\begin{array}{l}\text { Ease of } \\
\text { understanding }\end{array}$ & $\begin{array}{l}\text { "reflects the need for a web } \\
\text { site to use understandable } \\
\text { and consistent graphics and } \\
\text { terms. It should } \\
\text { furthermore be visually } \\
\text { appealing and readable, and } \\
\text { provide links to more } \\
\text { detailed information about } \\
\text { the subject at hand" }\end{array}$ & Positive & {$[297]$} & [297] \\
\hline \multicolumn{6}{|l|}{ Perceived quality } \\
\hline & $\begin{array}{l}\text { Perceived system } \\
\text { quality }\end{array}$ & $\begin{array}{l}\text { "the user's opinion of the } \\
\text { merits and performance of a } \\
\text { technology in question with } \\
\text { respect to available } \\
\text { alternative solutions and } \\
\text { information quality } \\
\text { represents the status of } \\
\text { information produced } \\
\text { relative to that produced by } \\
\text { competing technologies" }\end{array}$ & Positive & {$[271]$} & {$[277]_{2}[271]$} \\
\hline & $\begin{array}{l}\text { Perceived quality } \\
\text { of IT }\end{array}$ & $\begin{array}{l}\text { "learners' perceived quality } \\
\text { of IT applied in e-Learning } \\
\text { (such as microphones, } \\
\text { earphones, electronic } \\
\text { blackboards, and so on)." }\end{array}$ & $\begin{array}{l}\text { Not } \\
\text { significant }\end{array}$ & {$[288]$} & [288] \\
\hline & Internet quality & $\begin{array}{l}\text { "network quality as } \\
\text { perceived by learners" }\end{array}$ & $\begin{array}{l}\text { Not } \\
\text { significant }\end{array}$ & {$[288]$} & {$[288]$} \\
\hline & $\begin{array}{l}\text { System and } \\
\text { information quality }\end{array}$ & $\begin{array}{l}\text { "Items from system quality } \\
\text { and information quality } \\
\text { loaded together, with the } \\
\text { resulting factor named SIQ } \\
\text { [system and information } \\
\text { quality], suggesting that } \\
\text { distinctions between system } \\
\text { quality and information } \\
\text { quality may no longer be } \\
\text { pivotal for mobile } \\
\text { applications." }\end{array}$ & Positive & {$[291]$} & [291] \\
\hline & $\begin{array}{l}\text { Perceived content } \\
\text { quality }\end{array}$ & $\begin{array}{l}\text { Two dimensions: content } \\
\text { richness and update } \\
\text { regularity }\end{array}$ & Positive & {$[233]$} & [233], [224] \\
\hline & $\begin{array}{l}\text { Information } \\
\text { quality }\end{array}$ & $\begin{array}{l}\text { "the quality of the output of } \\
\text { an information technology" }\end{array}$ & Positive & {$[271]$} & [271] \\
\hline & $\begin{array}{l}\text { e-Learning course } \\
\text { quality }\end{array}$ & $\begin{array}{l}\text { "Quality of e-learning } \\
\text { courses" }\end{array}$ & Positive & {$[288]$} & [288] \\
\hline
\end{tabular}




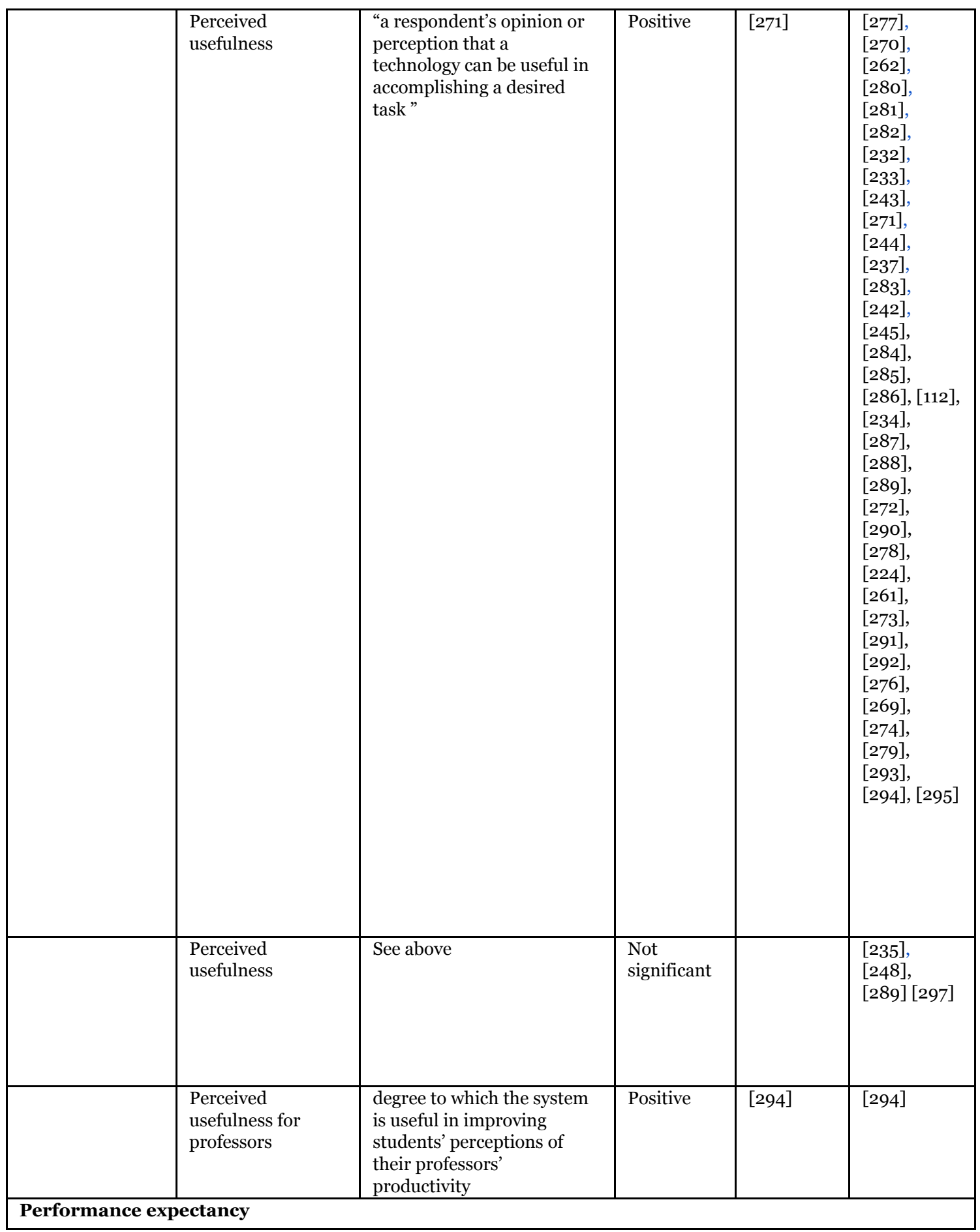




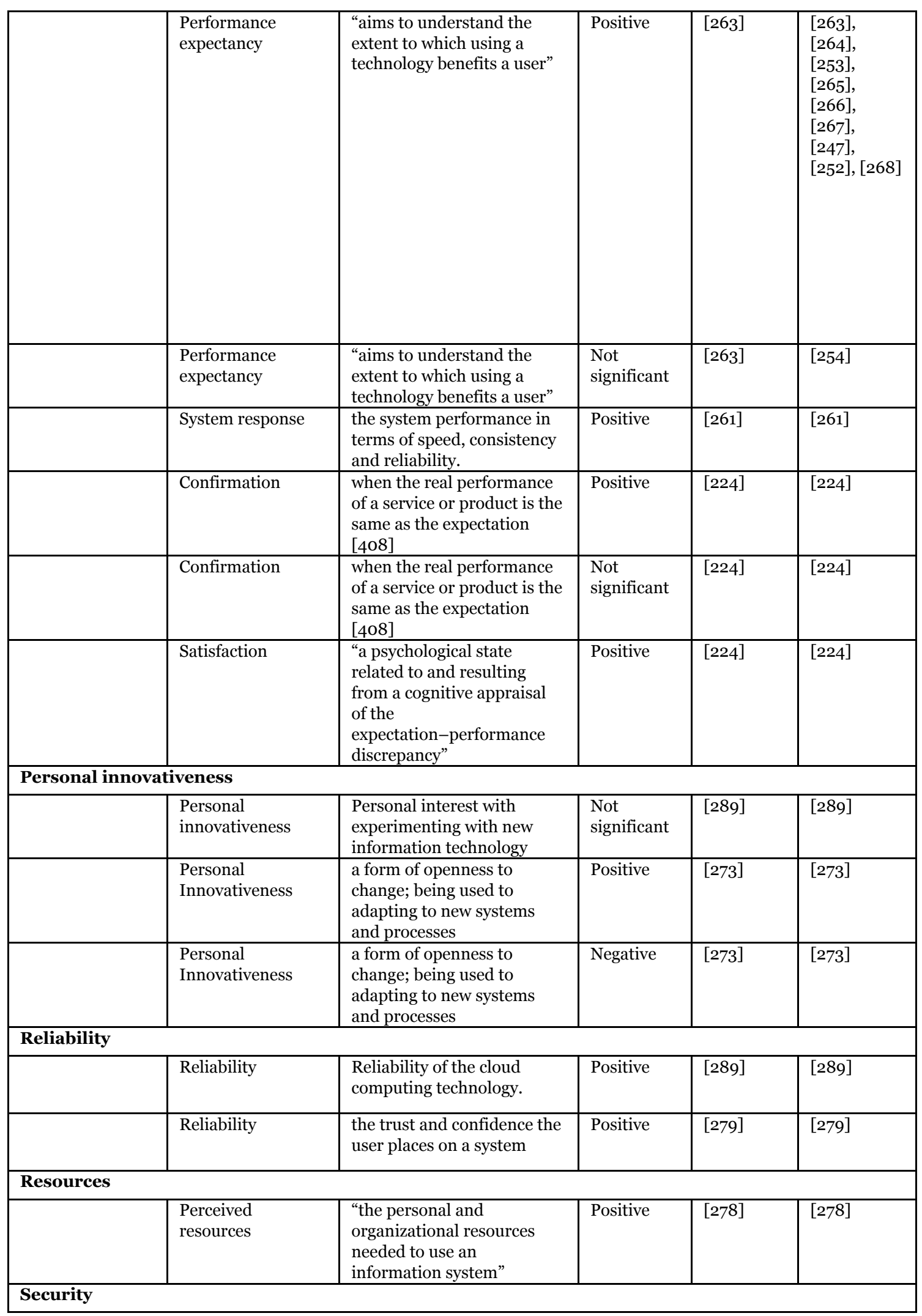




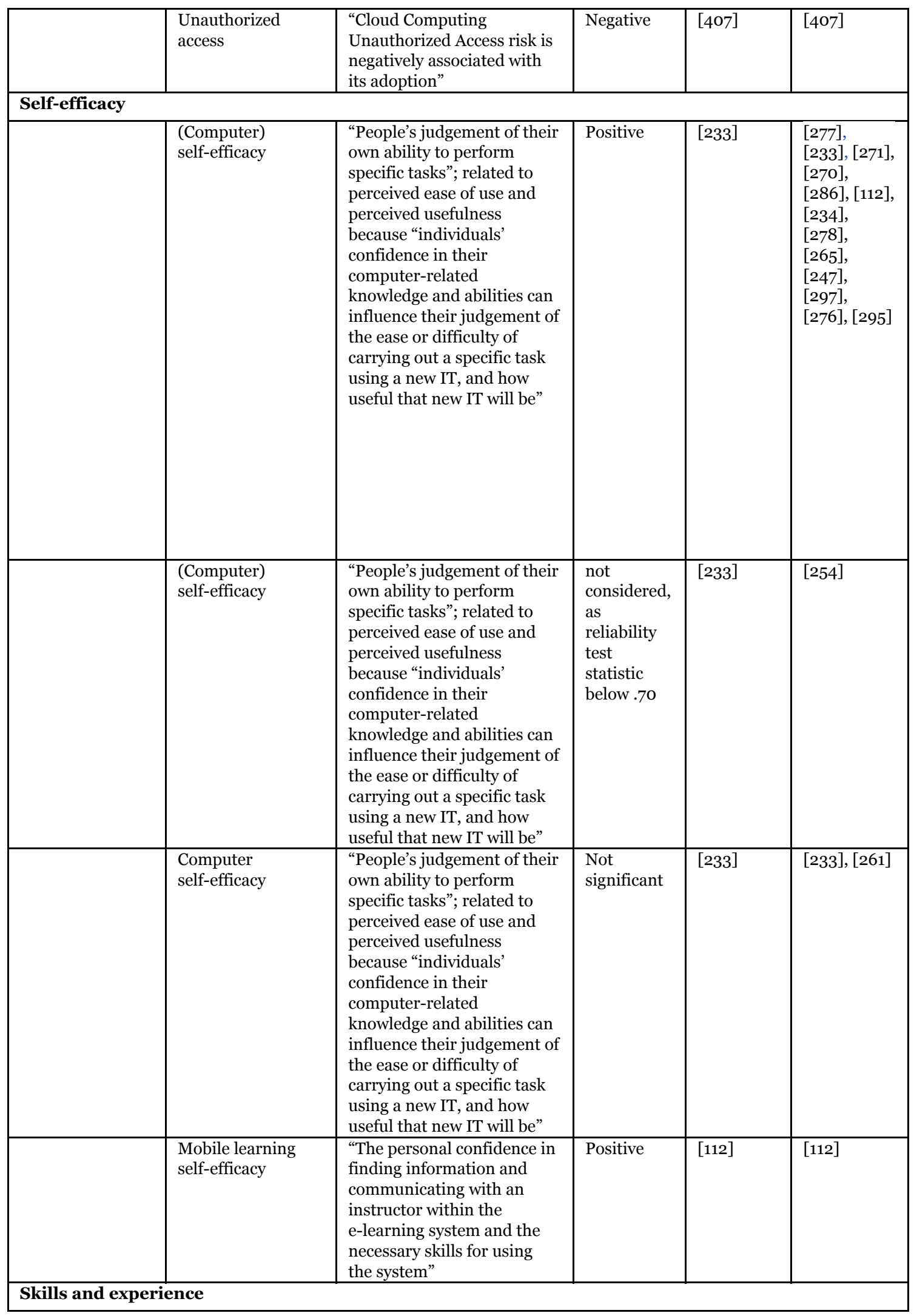




\begin{tabular}{|c|c|c|c|c|c|}
\hline & Diffusion & $\begin{array}{l}\text { past experience with the } \\
\text { system and encouragement } \\
\text { by instructors to use the } \\
\text { system }\end{array}$ & Positive & [279] & [279] \\
\hline & $\begin{array}{l}\text { Prior use of } \\
\text { electronic learning }\end{array}$ & $\begin{array}{l}\text { "experienced users of } \\
\text { electronic learning will be } \\
\text { more interested to accept } \\
\text { and use new technologies } \\
\text { such as: M-learning for } \\
\text { teaching and learning } \\
\text { processes" }\end{array}$ & Positive & [295] & [295] \\
\hline & Internet skills & $\begin{array}{l}\text { skills of a user with respect } \\
\text { to using the Internet }\end{array}$ & Positive & [290] & [290] \\
\hline & Basic ICT skills & $\begin{array}{l}\text { "everyday ICT usage"; "the } \\
\text { competency of users in } \\
\text { relation to general } \\
\text { computing tasks, such as } \\
\text { using word processing } \\
\text { software, searching and } \\
\text { emailing on the Internet } \\
\text { and doing basic mobile } \\
\text { activities, such as texting } \\
\text { and calling" }\end{array}$ & Positive & [292] & [292] \\
\hline & $\begin{array}{l}\text { Advanced ICT } \\
\text { skills }\end{array}$ & $\begin{array}{l}\text { "tasks associated with } \\
\text { expert or specialized ICT } \\
\text { usage"; "the competency of } \\
\text { users in relation to more } \\
\text { advanced computing, such } \\
\text { as modifying images and } \\
\text { sounds and using advanced } \\
\text { software (such as Skype)" }\end{array}$ & $\begin{array}{l}\text { Not } \\
\text { significant }\end{array}$ & [292] & [292] \\
\hline & $\begin{array}{l}\text { Advanced mobile } \\
\text { skills }\end{array}$ & $\begin{array}{l}\text { "tasks associated with } \\
\text { mobile usage" }\end{array}$ & Positive & [292] & [292] \\
\hline & Experience & $\begin{array}{l}\text { "perceived computer } \\
\text { literacy of adopters and } \\
\text { their experience with using } \\
\text { technology" }\end{array}$ & Positive & {$[263]$} & [263], [274] \\
\hline & Experience & $\begin{array}{l}\text { "perceived computer } \\
\text { literacy of adopters and } \\
\text { their experience with using } \\
\text { technology" }\end{array}$ & $\begin{array}{l}\text { Not } \\
\text { significant }\end{array}$ & {$[263]$} & [224], [274] \\
\hline & $\begin{array}{l}\text { Internet } \\
\text { experience }\end{array}$ & $\begin{array}{l}\text { an individual's experiences } \\
\text { with a specific technology } \\
\text { influences perceptions of } \\
\text { ease of use and usefulness } \\
\text { of that technology }\end{array}$ & Positive & [286] & [286] \\
\hline & $\begin{array}{l}\text { Internet } \\
\text { experience }\end{array}$ & $\begin{array}{l}\text { an individual's experiences } \\
\text { with a specific technology } \\
\text { influences perceptions of } \\
\text { ease of use and usefulness } \\
\text { of that technology }\end{array}$ & $\begin{array}{l}\text { Not } \\
\text { significant }\end{array}$ & {$[286]$} & [286], [261] \\
\hline
\end{tabular}




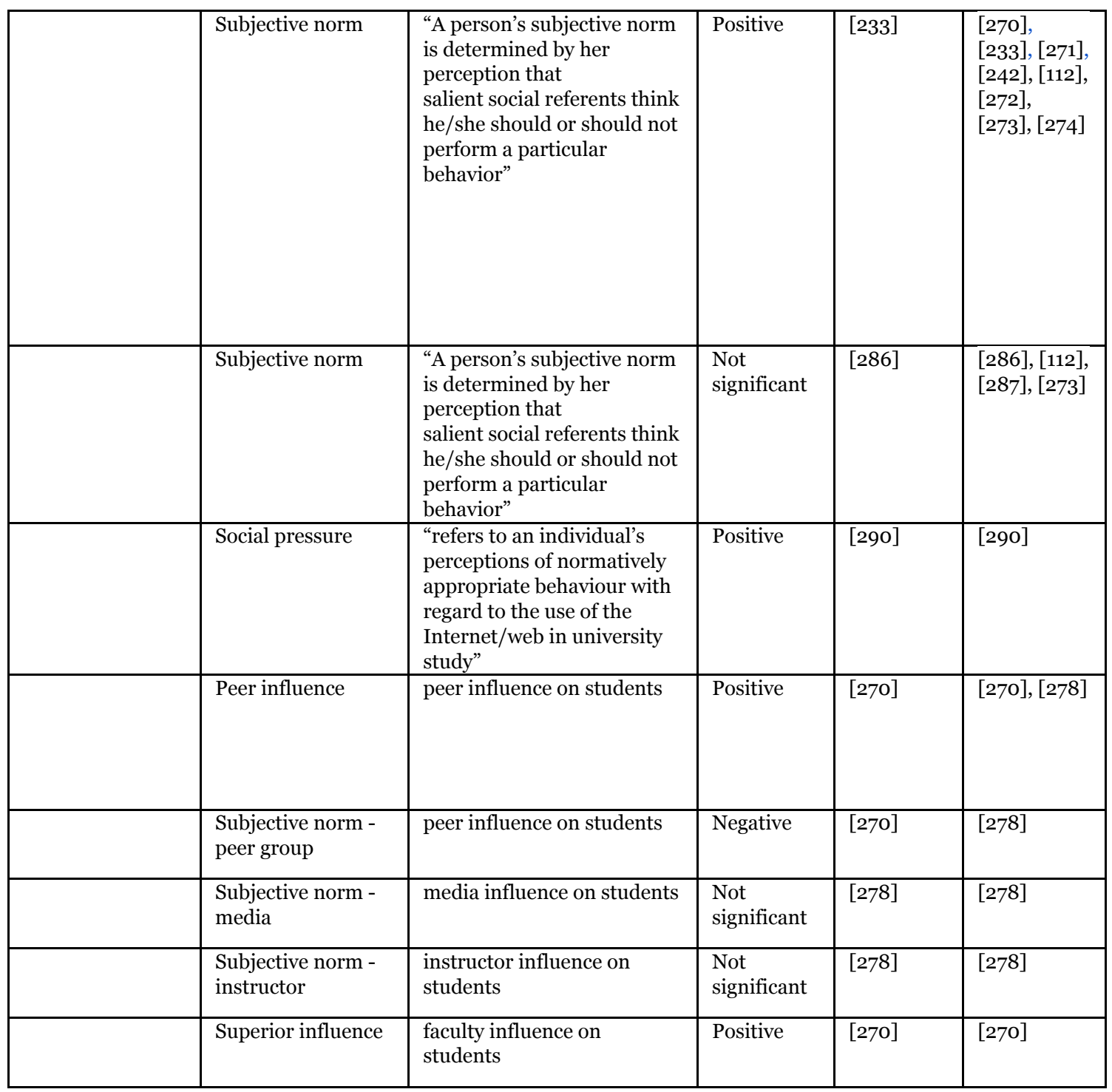




\begin{tabular}{|c|c|c|c|c|c|}
\hline & Social influence & $\begin{array}{l}\text { "extent to which users } \\
\text { perceive that those } \\
\text { important to them believe } \\
\text { they should be using a } \\
\text { technology" }\end{array}$ & Positive & {$[263]$} & $\begin{array}{l}{[264],} \\
{[253],} \\
{[265],} \\
{[266],} \\
{[267],} \\
{[247],} \\
{[254],} \\
{[252],} \\
{[224],} \\
{[268],[269]}\end{array}$ \\
\hline & Social influence & $\begin{array}{l}\text { "extent to which users } \\
\text { perceive that those } \\
\text { important to them believe } \\
\text { they should be using a } \\
\text { technology" }\end{array}$ & $\begin{array}{l}\text { Not } \\
\text { significant }\end{array}$ & {$[263]$} & {$[263]_{2}[253]$} \\
\hline & $\begin{array}{l}\text { Instructor attitude } \\
\text { toward e-Learning }\end{array}$ & $\begin{array}{l}\text { "learners' perception of } \\
\text { their instructors' attitude } \\
\text { toward e-Learning" }\end{array}$ & Positive & {$[288]$} & {$[288]$} \\
\hline & Instructor support & $\begin{array}{l}\text { Encouragement to use cloud } \\
\text { computing technology. }\end{array}$ & Positive & [289] & [289] \\
\hline & $\begin{array}{l}\text { Perceived } \\
\text { popularity }\end{array}$ & $\begin{array}{l}\text { perceived popularity of a } \\
\text { technology }\end{array}$ & Positive & [235] & [235] \\
\hline & Image & $\begin{array}{l}\text { "the extent to which } \\
\text { students would enhance } \\
\text { their image or status in } \\
\text { their social system and } \\
\text { among their peers by using } \\
\text { a podcast" }\end{array}$ & Positive & {$[234]$} & {$[234]$} \\
\hline & $\begin{array}{l}\text { Perceived critical } \\
\text { mass }\end{array}$ & $\begin{array}{l}\text { "whether an innovation has } \\
\text { attracted a critical mass of } \\
\text { users influence ensuing } \\
\text { adoption and use" }\end{array}$ & Positive & [293] & [293] \\
\hline & Affiliation & $\begin{array}{l}\text { affiliation in relation to } \\
\text { social influence }\end{array}$ & Positive & [235] & [235] \\
\hline & $\begin{array}{l}\text { Perceived network } \\
\text { externality }\end{array}$ & $\begin{array}{l}\text { "relates to an increase in the } \\
\text { value of a product or service } \\
\text { to a consumer, not because } \\
\text { of the inherent quality of } \\
\text { the product or service, but } \\
\text { because of increasing } \\
\text { numbers of others adopting } \\
\text { it" }\end{array}$ & Positive & {$[233]$} & {$[233]$} \\
\hline & $\begin{array}{l}\text { Perceived } \\
\text { reputation }\end{array}$ & $\begin{array}{l}\text { "degree of esteem in which } \\
\text { consumers hold a selling } \\
\text { party" }\end{array}$ & Positive & [409] & {$[245]$} \\
\hline & $\begin{array}{l}\text { Instructor } \\
\text { readiness }\end{array}$ & $\begin{array}{l}\text { participants 'perceptions } \\
\text { toward the extent to which } \\
\text { instructors are in favor of } \\
\text { using mobile devices in } \\
\text { their courses }\end{array}$ & Positive & [272] & [272] \\
\hline
\end{tabular}




\begin{tabular}{|c|c|c|c|c|c|}
\hline & $\begin{array}{l}\text { Peer student } \\
\text { readiness }\end{array}$ & $\begin{array}{l}\text { participants ' perceptions } \\
\text { toward the extent to which } \\
\text { students are in favor of } \\
\text { using mobile devices in } \\
\text { their courses }\end{array}$ & $\begin{array}{l}\text { Not } \\
\text { significant }\end{array}$ & {$[272]$} & {$[272]$} \\
\hline & Sharing & $\begin{array}{l}\text { perception that } \\
\text { participation enhances a } \\
\text { person's professional } \\
\text { reputation }\end{array}$ & Positive & {$[278]$} & {$[278]$} \\
\hline & Motivators & $\begin{array}{l}\text { Perceived incentive to use, } \\
\text { perceived faculty } \\
\text { engagement, peer } \\
\text { encouragement, awareness } \\
\text { of the capabilities of the } \\
\text { technology }\end{array}$ & Positive & {$[280]$} & {$[280]$} \\
\hline & $\begin{array}{l}\text { Community } \\
\text { identification }\end{array}$ & $\begin{array}{l}\text { "the individual's } \\
\text { identification with a virtual } \\
\text { community whose users } \\
\text { share the same interests" }\end{array}$ & Positive & [269] & [269] \\
\hline \multicolumn{6}{|c|}{ Support and training } \\
\hline & Internet support & $\begin{array}{l}\text { "personal Internet support } \\
\text { and training" }\end{array}$ & Positive & [290] & [290] \\
\hline & Training & $\begin{array}{l}\text { "Internal training refers to } \\
\text { intraorganizational training, } \\
\text { or training found within the } \\
\text { organization; external, to } \\
\text { training found outside the } \\
\text { organization, thus known as } \\
\text { external sources of } \\
\text { training." }\end{array}$ & Positive & {$[293]$} & [293], [294] \\
\hline & Training & $\begin{array}{l}\text { "Internal training refers to } \\
\text { intraorganizational training, } \\
\text { or training found within the } \\
\text { organization; external, to } \\
\text { training found outside the } \\
\text { organization, thus known as } \\
\text { external sources of } \\
\text { training." }\end{array}$ & $\begin{array}{l}\text { Not } \\
\text { significant }\end{array}$ & [293] & [294] \\
\hline & Technical support & $\begin{array}{l}\text { People provide support for } \\
\text { computer hardware and } \\
\text { software problems, through } \\
\text { help desks, on-line technical } \\
\text { support, the phone, etc. }\end{array}$ & Positive & {$[282]$} & $\begin{array}{l}{[282],} \\
{[285],[286]}\end{array}$ \\
\hline & Service quality & $\begin{array}{l}\text { "accounts for the perceived } \\
\text { level of support available to } \\
\text { users of a given technology" }\end{array}$ & Positive & {$[271]$} & [271], [224] \\
\hline & $\begin{array}{l}\text { Organizational } \\
\text { support }\end{array}$ & $\begin{array}{l}\text { support from the University } \\
\text { to "ensure the necessary } \\
\text { resources are allocated for } \\
\text { Internet access and use" } \\
\text { and instructor support, } \\
\text { which "can encourage more } \\
\text { active use of the Internet for } \\
\text { class assignments and } \\
\text { interaction" }\end{array}$ & Positive & {$[290]$} & [290] \\
\hline \multicolumn{6}{|l|}{ Trust } \\
\hline & Cloud trust & $\begin{array}{l}\text { personal cloud security and } \\
\text { privacy }\end{array}$ & $\begin{array}{l}\text { Various } \\
\text { experience } \\
\text { s across } \\
\text { adopters } \\
\end{array}$ & {$[263]$} & [263] \\
\hline
\end{tabular}




\begin{tabular}{|c|c|c|c|c|c|}
\hline & Trust & $\begin{array}{l}\text { "a subjective expectation } \\
\text { that someone or something } \\
\text { is reliable and willing to } \\
\text { accept vulnerability" }\end{array}$ & Positive & {$[265]$} & {$[265]$} \\
\hline & Integrity & $\begin{array}{l}\text { "Lower degree of Integrity } \\
\text { in cloud computing } \\
\text { adoption has negative } \\
\text { impact" }\end{array}$ & Negative & {$[407]$} & {$[407]$} \\
\hline & Credibility & $\begin{array}{l}\text { "The certainty and pleasant } \\
\text { consequences of using an } \\
\text { electronic application } \\
\text { service, when there is no } \\
\text { financial risk, physical risk, } \\
\text { functional risk, social risk, } \\
\text { time-loss risk, opportunity } \\
\text { cost risk, and information } \\
\text { risk" }\end{array}$ & Positive & {$[237]$} & [237] \\
\hline \multicolumn{6}{|c|}{ Voluntariness of use } \\
\hline & $\begin{array}{l}\text { Voluntariness of } \\
\text { use }\end{array}$ & $\begin{array}{l}\text { "the degree to which the use } \\
\text { of a technology is perceived } \\
\text { as being used out of a users' } \\
\text { free will" (the more } \\
\text { voluntary the use, the } \\
\text { higher the chances of } \\
\text { long-term adoption) }\end{array}$ & Negative & {$[263]$} & {$[263]$} \\
\hline \multicolumn{6}{|l|}{ Moderators } \\
\hline & Age & respondent's age & $\begin{array}{l}\text { No } \\
\text { significant } \\
\text { effect on } \\
\text { other } \\
\text { factors at } \\
\text { all }\end{array}$ & {$[254]$} & [254] \\
\hline & Age & respondent's age & $\begin{array}{l}\text { Generally } \\
\text { some } \\
\text { difference }\end{array}$ & {$[254]$} & {$[252]$} \\
\hline & Gender & respondent's gender & $\begin{array}{l}\text { No } \\
\text { significant } \\
\text { effect on } \\
\text { other } \\
\text { factors at } \\
\text { all }\end{array}$ & {$[254]$} & [254] \\
\hline & Gender & respondent's gender & $\begin{array}{l}\text { Generally } \\
\text { no } \\
\text { difference } \\
\end{array}$ & {$[254]$} & {$[252]$} \\
\hline
\end{tabular}




\section{Appendix B: Preliminary Research Model Detailed Taxonomy}

\begin{tabular}{|c|c|c|c|}
\hline $\begin{array}{l}\text { Factors and } \\
\text { indicators }\end{array}$ & Definition & $\begin{array}{l}\text { Reference(s } \\
\text { ) for } \\
\text { definition(s } \\
\text { ) }\end{array}$ & $\begin{array}{l}\text { Reference(s) for } \\
\text { studies indicating } \\
\text { a positive } \\
\text { influence on } \\
\text { other factors }\end{array}$ \\
\hline \multicolumn{4}{|l|}{ UTAUT factors } \\
\hline \multicolumn{4}{|c|}{ Performance expectancy factor } \\
\hline $\begin{array}{l}\text { Performance } \\
\text { expectancy }\end{array}$ & $\begin{array}{l}\text { The degree to which an individual believes that } \\
\text { using a technology will help them overall. } \\
\text { Based on - "The degree to which an individual } \\
\text { believes that using the system will help him or her } \\
\text { to attain gains in job performance" [199]; and } \\
\text { "Aims to understand the extent to which using a } \\
\text { technology benefits a user" [263]g system [279] }\end{array}$ & $\begin{array}{l}{[263]} \\
{[199]}\end{array}$ & $\begin{array}{l}263],[264],[253], \\
{[265],[266],[267],} \\
{[247],[252],[268]}\end{array}$ \\
\hline Overall usefulness & $\begin{array}{l}\text { Degree to which a student believes that using the } \\
\text { software platform is overall, useful. } \\
\text { Related to - } \\
\text { Relative advantage - "the degree to which a new } \\
\text { technology is perceived as better than the method } \\
\text { or technique used before the introduction of the } \\
\text { new technology" [234]; Satisfaction - "a } \\
\text { psychological state related to and resulting from a } \\
\text { cognitive appraisal of the expectation-performance } \\
\text { discrepancy" [224]; Perceived compatibility with } \\
\text { student tasks - degree to which the system is } \\
\text { compatible with student tasks in the course and } \\
\text { student preferences for how they like to study } \\
\text { [294]; Compatibility - "the degree to which the } \\
\text { innovation is perceived to be consistent with the } \\
\text { potential users' existing values, previous } \\
\text { experiences and needs" [277]; and Educational } \\
\text { compatibility - "perceived fit between the use of } \\
\text { technology and students' learning style and needs, } \\
\text { and students' constructive beliefs about learning" } \\
\text { [276] }\end{array}$ & [199], [247] & $\begin{array}{l}224],[234],[262], \\
{[294],[277],[276]}\end{array}$ \\
\hline $\begin{array}{l}\text { Increase chances of } \\
\text { graduating }\end{array}$ & $\begin{array}{l}\text { Degree to which using the software platform is } \\
\text { perceived as increasing a students' own chances of } \\
\text { graduating. }\end{array}$ & [199] & - \\
\hline $\begin{array}{l}\text { Speed of } \\
\text { conducting tasks }\end{array}$ & $\begin{array}{l}\text { Degree to which a student can conduct the } \\
\text { non-academic work of being a student more quickly } \\
\text { by using the software platform. }\end{array}$ & [199] & - \\
\hline $\begin{array}{l}\text { Platform response } \\
\text { time }\end{array}$ & $\begin{array}{l}\text { Degree to which a student experiences the software } \\
\text { platform response as fast. } \\
\text { Based on - the system performance in terms of } \\
\text { speed; when the real performance of a service or } \\
\text { product is the same as the expectation [408] }\end{array}$ & {$[261]$} & {$[261]$} \\
\hline \multicolumn{4}{|c|}{ Effort expectancy factor } \\
\hline $\begin{array}{l}\text { Effort } \\
\text { expectancy }\end{array}$ & $\begin{array}{l}\text { "Degree of ease associated with the use of the } \\
\text { system" [199]; construct includes perceived ease of } \\
\text { use }\end{array}$ & [199] & $\begin{array}{l}{[253],[265],[266],} \\
{[247],[254],[252],} \\
{[268]}\end{array}$ \\
\hline $\begin{array}{l}\text { Perceived ease of } \\
\text { use }\end{array}$ & $\begin{array}{l}\text { Degree to which the software platform is easy for a } \\
\text { student to use. } \\
\text { Based on - “A respondent's opinion or perception } \\
\text { that a technology can be used to solve a } \\
\text { problem with a relatively low expenditure of effort } \\
\text { and a reasonable chance of success" [271] and }\end{array}$ & {$[271]$} & $\begin{array}{l}277],[270],[241], \\
{[280],[281],[282],} \\
{[232],[233],[243],} \\
{[271],[244],[283]} \\
{[242],[248],[284],} \\
{[286],[112],[234],} \\
{[287],[288],[289],}\end{array}$ \\
\hline
\end{tabular}




\begin{tabular}{|c|c|c|c|}
\hline & $\begin{array}{l}\text { related to - "The degree of ease of use of a } \\
\text { technology" [263] and Perceived complexity - } \\
\text { "assesses the extent of difficulty in using the } \\
\text { Internet, which is similar to the concept of } \\
\text { Perceived Ease of Use" [290] }\end{array}$ & & $\begin{array}{l}272],[278],[224], \\
{[261],[297],[292],} \\
{[269],[274],[293],} \\
{[294],[295],[245],} \\
{[285],[290],[293]}\end{array}$ \\
\hline Effort vs. benefit & $\begin{array}{l}\text { Degree to which a student believes that the effort it } \\
\text { takes to use a software platform is worth the } \\
\text { benefits. }\end{array}$ & [235] & - \\
\hline $\begin{array}{l}\text { Learning to } \\
\text { operate }\end{array}$ & $\begin{array}{l}\text { Degree to which learning how to operate the } \\
\text { software platform is easy for a student. }\end{array}$ & [247] & [290], [293] \\
\hline Skillful at using & $\begin{array}{l}\text { Degree to which it is easy to become skillful at } \\
\text { using the software platform. }\end{array}$ & [247] & {$[247]$} \\
\hline $\begin{array}{l}\text { System } \\
\text { accessibility }\end{array}$ & $\begin{array}{l}\text { Degree to which it is easy for a student to access the } \\
\text { software platform. } \\
\text { Related to - } \\
\text { System accessibility [112]; Accessibility [279]; } \\
\text { Cloud accessibility [263]; Access to software [289]; } \\
\text { Enablers [280]; and Ease of finding [297] }\end{array}$ & {$[112]$} & $\begin{array}{l}{[279],[112]_{2}[263]} \\
{[289]_{2}[280],[297]}\end{array}$ \\
\hline \multicolumn{4}{|c|}{ Social influence factor } \\
\hline Social influence & $\begin{array}{l}\text { "Extent to which users perceive that those } \\
\text { important to them believe they should be using a } \\
\text { technology" [263] } \\
\text { Related to Subjective norm - "A person's subjective } \\
\text { norm is determined by her perception that } \\
\text { salient social referents think he/she should or } \\
\text { should not perform a particular behavior" [233]; } \\
\text { and based on - "the degree to which an individual } \\
\text { perceives that important others believe he or she } \\
\text { should use the new system" [199] }\end{array}$ & {$[263]$} & $\begin{array}{l}\text { Social influence - } \\
\text { [264], [253], [265], } \\
\text { [266], [267], [247], } \\
\text { [254], [252], [224], } \\
\text { [268], [269]; } \\
\text { Subjective positive- } \\
\text { [270], [233], [271], } \\
\text { [242], [112], [272], } \\
\text { [273], [274] }\end{array}$ \\
\hline $\begin{array}{l}\text { Organizational } \\
\text { support }\end{array}$ & $\begin{array}{l}\text { Degree to which the university has supported the } \\
\text { use of the software platform. } \\
\text { Based on - support from the University "ensures } \\
\text { the necessary resources are allocated for Internet } \\
\text { access and use" [290]; and Instructor support, } \\
\text { which "can encourage more active use of the } \\
\text { Internet for class assignments and interaction" } \\
\text { [290] }\end{array}$ & [290] & [290] \\
\hline Peer influence & $\begin{array}{l}\text { Degree to which a student's peers think they should } \\
\text { use the software platform. } \\
\text { Based on - Social pressure - "Refers to an } \\
\text { individual's perceptions of normatively appropriate } \\
\text { behaviour with regard to the use of the } \\
\text { Internet/web in university study" [290]; Perceived } \\
\text { critical mass - "whether an innovation has attracted } \\
\text { a critical mass of users influence ensuing adoption } \\
\text { and use" [293]; Perceived network externality - } \\
\text { "relates to an increase in the value of a product or } \\
\text { service to a consumer, not because of the inherent } \\
\text { quality of the product or service, but because of } \\
\text { increasing numbers of others adopting it" [233] }\end{array}$ & {$[270]$} & $\begin{array}{l}\text { [270], [278], [290], } \\
{[293],[233]}\end{array}$ \\
\hline $\begin{array}{l}\text { Perceived } \\
\text { popularity }\end{array}$ & $\begin{array}{l}\text { Perceived popularity of a technology. } \\
\text { Relates to Perceived network externality - "an } \\
\text { increase in the value of a product or service to a } \\
\text { consumer, not because of the inherent quality of } \\
\text { the product or service, but because of increasing } \\
\text { numbers of others adopting it" [233] }\end{array}$ & [235] & [235], [233] \\
\hline
\end{tabular}




\begin{tabular}{|c|c|c|c|}
\hline $\begin{array}{l}\text { Influence from } \\
\text { university } \\
\text { employees }\end{array}$ & $\begin{array}{l}\text { Degree to which university employees are very } \\
\text { supportive of student use of the software platform. } \\
\text { Based on Faculty influence on students (superior } \\
\text { influence) [270]; "learners' perception of their } \\
\text { instructors' attitude toward e-Learning" (Instructor } \\
\text { attitude toward e-learning) [288]; and } \\
\text { Encouragement to use the cloud computing } \\
\text { technology. (Instructor support) [289] }\end{array}$ & {$[247]$} & {$[270],[288],[289]$} \\
\hline \multicolumn{4}{|c|}{ Facilitating conditions factor } \\
\hline $\begin{array}{l}\text { Facilitating } \\
\text { conditions }\end{array}$ & $\begin{array}{l}\text { "The degree to which an individual believes that an } \\
\text { organizational and technical infrastructure exists to } \\
\text { support use of the system" [199] }\end{array}$ & [199] & $\begin{array}{l}263],[275],[266], \\
{[267],[247],[268],} \\
{[276],[269]}\end{array}$ \\
\hline Knowledge & $\begin{array}{l}\text { Degree to which a student has the necessary } \\
\text { knowledge to use the software platform. }\end{array}$ & [199] & - \\
\hline Compatibility & $\begin{array}{l}\text { Degree to which the software platform is } \\
\text { compatible with other software platforms or online } \\
\text { tools a student uses. }\end{array}$ & [199] & - \\
\hline Technical support & $\begin{array}{l}\text { Degree to which a specific person (or group) is } \\
\text { available for assistance with the software platform's } \\
\text { technical difficulties. } \\
\text { Based on - Technical support - People provide } \\
\text { support for computer hardware and software } \\
\text { problems, through help desks, on-line technical } \\
\text { support, the phone, etc. [282]; and Service quality - } \\
\text { "accounts for the perceived level of support } \\
\text { available to users of a given technology" [271] }\end{array}$ & {$[282],[271]$} & $\begin{array}{l}{[282],[285],[286],} \\
{[271],[224]}\end{array}$ \\
\hline \multicolumn{4}{|c|}{ Behavioral intention factor } \\
\hline $\begin{array}{l}\text { Behavioral } \\
\text { intention to use }\end{array}$ & $\begin{array}{l}\text { "The decision maker's disposition toward using a } \\
\text { system" [271] } \\
\text { Related to - Attitude toward the system, } \\
\text { satisfaction with the system, preference for the } \\
\text { system [280]; and "Degree to which a user is } \\
\text { interested in using the system" [278] }\end{array}$ & {$[271]$} & $\begin{array}{l}277],[270],[241]_{2} \\
{[271],[244],[264],} \\
{[278],[247],[279]}\end{array}$ \\
\hline $\begin{array}{l}\text { Intention to use - } \\
\text { general }\end{array}$ & $\begin{array}{l}\text { Degree to which a student intends to use the } \\
\text { software platform. }\end{array}$ & [247] & - \\
\hline $\begin{array}{l}\text { Intention to use - } \\
\text { specific }\end{array}$ & $\begin{array}{l}\text { Degree to which a student intends to use the } \\
\text { software platform in the next month. }\end{array}$ & {$[247]$} & - \\
\hline Frequency of use & $\begin{array}{l}\text { Degree to which a student intends to use the } \\
\text { software platform frequently. }\end{array}$ & [247] & - \\
\hline \multicolumn{4}{|c|}{ Use behavior factor } \\
\hline Use behavior & Actual usage of the system. & [199] & - \\
\hline $\begin{array}{l}\text { Usage of the } \\
\text { software platform - } \\
\text { general. }\end{array}$ & $\begin{array}{l}\text { Degree to which a student uses the software } \\
\text { platform to conduct the non-academic work of } \\
\text { being a student. }\end{array}$ & [247] & - \\
\hline $\begin{array}{l}\text { Usage of the } \\
\text { software platform - } \\
\text { specific }\end{array}$ & $\begin{array}{l}\text { Degree to which a student has used the software } \\
\text { platform in the past month. }\end{array}$ & [247], [199] & - \\
\hline Frequency of use & Frequency of use of the software platform. & {$[247],[225]$} & - \\
\hline $\begin{array}{l}\text { Usage of the } \\
\text { software platform } \\
\text { to access university } \\
\text { resources }\end{array}$ & $\begin{array}{l}\text { Degree to which a student uses the software } \\
\text { platform to access university resources (calendars, } \\
\text { campus map, library, university-related software, } \\
\text { etc.). }\end{array}$ & {$[247]$} & - \\
\hline $\begin{array}{l}\text { Usage of the } \\
\text { software platform }\end{array}$ & $\begin{array}{l}\text { Degree to which a student uses the software } \\
\text { platform to access university services (academic }\end{array}$ & {$[247]$} & - \\
\hline
\end{tabular}




\begin{tabular}{|c|c|c|c|}
\hline $\begin{array}{l}\text { to access university } \\
\text { services }\end{array}$ & $\begin{array}{l}\text { advising, career services, financial wellness center, } \\
\text { resource centers, tutoring, etc.). }\end{array}$ & & \\
\hline $\begin{array}{l}\text { Usage of the } \\
\text { software platform } \\
\text { to conduct the } \\
\text { business of being a } \\
\text { student }\end{array}$ & $\begin{array}{l}\text { Degree to which a student uses the software } \\
\text { platform to conduct business related to being a } \\
\text { student (viewing account balance, accessing the } \\
\text { platform to pay bills, accessing information about } \\
\text { financial aid, accessing the platform for registering } \\
\text { for courses, viewing course schedule, etc.) }\end{array}$ & {$[247]$} & - \\
\hline \multicolumn{4}{|c|}{ Factors added to UTAUT } \\
\hline \multicolumn{4}{|c|}{ Perceived usefulness factor } \\
\hline $\begin{array}{l}\text { Perceived } \\
\text { usefulness }\end{array}$ & $\begin{array}{l}\text { The degree to which a person believes that using } \\
\text { the features of a particular technology are useful in } \\
\text { accomplishing a desired task. } \\
\text { Based on - "A respondent's opinion or perception } \\
\text { that a technology can be useful in accomplishing a } \\
\text { desired task" [271]; } \\
\text { "The degree to which a person believes that using a } \\
\text { particular system would enhance his or her job } \\
\text { performance" [209]; } \\
\text { System functionality - the functions or features of a } \\
\text { system [261]; User tools - specific tools/features of } \\
\text { an e-learning system [279] }\end{array}$ & $\begin{array}{l}{[271]_{2}[209]_{2}} \\
{[261],[279]}\end{array}$ & 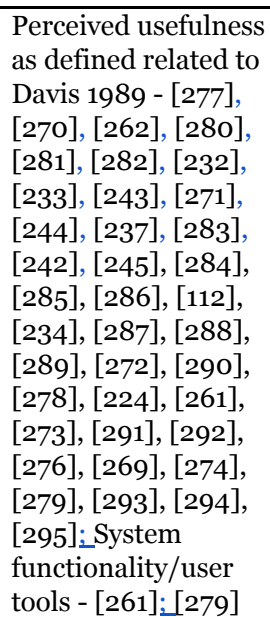 \\
\hline $\begin{array}{l}\text { Access to } \\
\text { university } \\
\text { resources }\end{array}$ & $\begin{array}{l}\text { Degree to which using the software platform } \\
\text { provides easy access to university resources } \\
\text { (calendars, campus map, library, university-related } \\
\text { software, etc.). }\end{array}$ & [262] & - \\
\hline $\begin{array}{l}\text { Access to } \\
\text { university services }\end{array}$ & $\begin{array}{l}\text { Degree to which using the software platform } \\
\text { provides easy access to university services } \\
\text { (academic advising, career services, financial } \\
\text { wellness center, resource centers, tutoring, etc.). }\end{array}$ & {$[262]$} & \\
\hline $\begin{array}{l}\text { Access to conduct } \\
\text { business }\end{array}$ & $\begin{array}{l}\text { Degree to which using the software platform } \\
\text { provides easy access to conduct the business of } \\
\text { being a student (viewing account balance, accessing } \\
\text { the platform to pay bills, accessing information } \\
\text { about financial aid, accessing the platform for } \\
\text { registering for courses, viewing course schedule, } \\
\text { etc.). }\end{array}$ & {$[262]$} & - \\
\hline Individual needs & $\begin{array}{l}\text { Degree to which the software platform meets a } \\
\text { student's individual needs. } \\
\text { Related to - } \\
\text { Interactivity and control - the degree of control a } \\
\text { user has when interacting with a system in order to } \\
\text { customize how it is used [279] }\end{array}$ & - & [279] \\
\hline $\begin{array}{l}\text { Perceived mobile } \\
\text { value }\end{array}$ & $\begin{array}{l}\text { The degree to which the software platform is } \\
\text { accessible independent of time and location. } \\
\text { Related to - } \\
\text { "Consciousness of users about the mobility value of } \\
\text { M-learning" [295]; and Mobility - "the extent to } \\
\text { which students can access the podcast anytime and } \\
\text { anywhere with no restrictions" [234] }\end{array}$ & [295] & [295], [234] \\
\hline
\end{tabular}




\begin{tabular}{|c|c|c|c|}
\hline $\begin{array}{l}\text { Perceived } \\
\text { quality }\end{array}$ & $\begin{array}{l}\text { The user's opinion of the quality of a software } \\
\text { platform. } \\
\text { Related to - "Items from system quality and } \\
\text { information quality loaded together, with the } \\
\text { resulting factor named SIQ [system and } \\
\text { information quality], suggesting that distinctions } \\
\text { between system quality and information quality } \\
\text { may no longer be pivotal for mobile applications" } \\
\text { [291]; System quality - "The user's opinion of the } \\
\text { merits and performance of a technology in question } \\
\text { with respect to available alternative solutions" } \\
\text { [271]; Information quality - "The quality of the } \\
\text { output from an IS" [26o], [296]; and Information } \\
\text { quality - "the independent variable information } \\
\text { quality reflects the quality of the results produced } \\
\text { by a technology" [271] }\end{array}$ & $\begin{array}{l}\text { [271], [260], } \\
{[296],[271]}\end{array}$ & $\begin{array}{l}\text { System quality - } \\
{[277]_{2}[271],[291] ;} \\
\text { Information quality - } \\
{[271],[260],[291]}\end{array}$ \\
\hline Content quality & $\begin{array}{l}\text { The quality of the content in the software platform. } \\
\text { Related to - Information quality - "The quality of } \\
\text { the output from an IS" [260], [296]; Information } \\
\text { quality - "the independent variable information } \\
\text { quality reflects the quality of the results produced } \\
\text { by a technology" [271]; Two dimensions of } \\
\text { perceived content quality - content richness and } \\
\text { update regularity [233]; Trust - "a subjective } \\
\text { expectation that someone or something is reliable } \\
\text { and willing to accept vulnerability" [265]; } \\
\text { Credibility - "The certainty and pleasant } \\
\text { consequences of using an electronic application } \\
\text { service, when there is no financial risk, physical } \\
\text { risk, functional risk, social risk, time-loss risk, } \\
\text { opportunity cost risk, and information risk" [237]; } \\
\text { Accuracy of information [26o]; Reliability - the } \\
\text { trust and confidence the user places on a system } \\
\text { [279]; and Sufficiency of information [26o] }\end{array}$ & $\begin{array}{l}\text { [260], [296], } \\
{[271]}\end{array}$ & $\begin{array}{l}{[271],[260],[291],} \\
{[233],[265],[237],} \\
{[279]}\end{array}$ \\
\hline $\begin{array}{l}\text { User interface } \\
\text { design }\end{array}$ & $\begin{array}{l}\text { Degree to which a student believes the software } \\
\text { platform has well-designed user interfaces (pages, } \\
\text { graphics, visuals, content, navigation, etc.). } \\
\text { Related to - Ease of understanding - "Reflects the } \\
\text { need for a web site to use understandable and } \\
\text { consistent graphics and terms. It should } \\
\text { furthermore be visually appealing and readable, } \\
\text { and provide links to more detailed information } \\
\text { about the subject at hand" [297] }\end{array}$ & {$[260]$} & {$[297]$} \\
\hline System errors & $\begin{array}{l}\text { Degree to which a student encounters system errors } \\
\text { when using the software platform. }\end{array}$ & {$[291]$} & - \\
\hline \multicolumn{4}{|c|}{ Self-efficacy and skills factor } \\
\hline $\begin{array}{l}\text { Self-efficacy and } \\
\text { skills }\end{array}$ & $\begin{array}{l}\text { The judgement of one's own ability to perform } \\
\text { specific technology-related tasks and the skills to } \\
\text { do so. } \\
\text { Related to - (Computer) self-efficacy - "People's } \\
\text { judgement of their own ability to perform specific } \\
\text { tasks" [233]; Perceived ease of use and perceived } \\
\text { usefulness because "individuals' confidence in their } \\
\text { computer-related knowledge and abilities can } \\
\text { influence their judgement of the ease or difficulty of } \\
\text { carrying out a specific task using a new IT, and how } \\
\text { useful that new IT will be" [233]; and Basic ICT }\end{array}$ & $\begin{array}{l}233], \\
{[292]}\end{array}$ & $\begin{array}{l}\text { Self-efficacy - [277], } \\
{[233],[271],[270],} \\
{[286],[112],[234],} \\
{[278],[265],[247],} \\
{[297],[276],[295] ;} \\
\text { Skills - }[295],[290], \\
{[292],[292],[263],} \\
{[286],[274],[112]}\end{array}$ \\
\hline
\end{tabular}




\begin{tabular}{|c|c|c|c|}
\hline & $\begin{array}{l}\text { skills - The competency of users related to basic } \\
\text { computing and mobile activities [292] }\end{array}$ & & \\
\hline Confidence & $\begin{array}{l}\text { Degree to which a student feels confident they can } \\
\text { overcome any obstacles when using a software } \\
\text { platform. }\end{array}$ & [233] & $\begin{array}{l}{[277],[233],[271],} \\
{[270],[286],[112],} \\
{[234],[278],[265],} \\
{[247],[297],[276],} \\
{[295]}\end{array}$ \\
\hline Internet skills & $\begin{array}{l}\text { Degree to which a student rates their } \\
\text { Internet/online skills to be high. } \\
\text { Related to - } \\
\text { Experience - "perceived computer literacy of } \\
\text { adopters and their experience with using } \\
\text { technology" [263]; Internet skills - skills of a user } \\
\text { with respect to using the Internet [290]; and } \\
\text { Internet experience - an individual's experiences } \\
\text { with a specific technology influences perceptions of } \\
\text { ease of use and usefulness of that technology [286] }\end{array}$ & {$[286]$} & $\begin{array}{l}{[263],[290]_{2}[286]_{2}} \\
{[274]}\end{array}$ \\
\hline $\begin{array}{l}\text { Basic computing } \\
\text { skills }\end{array}$ & $\begin{array}{l}\text { The competency of users related to basic computing } \\
\text { activities (using writing/word processing software, } \\
\text { using the Internet, emailing, etc.). } \\
\text { Based on - Basic ICT skills - "everyday ICT usage"; } \\
\text { "the competency of users in relation to general } \\
\text { computing tasks, such as using word processing } \\
\text { software, searching and emailing on the Internet } \\
\text { and doing basic mobile activities, such as texting } \\
\text { and calling" [292] }\end{array}$ & [292] & {$[292]_{2}[112]$} \\
\hline $\begin{array}{l}\text { Basic smartphone } \\
\text { skills }\end{array}$ & $\begin{array}{l}\text { The competency of users related to basic } \\
\text { mobile/smartphone activities (using apps, texting } \\
\text { and calling, etc.). } \\
\text { Based on - Basic ICT skills - "everyday ICT usage"; } \\
\text { "the competency of users in relation to general } \\
\text { computing tasks, such as using word processing } \\
\text { software, searching and emailing on the Internet } \\
\text { and doing basic mobile activities, such as texting } \\
\text { and calling" [292] } \\
\text { Related to Advance mobile tasks - "tasks associated } \\
\text { with mobile usage" [292]; and Mobile learning } \\
\text { self-efficacy - "The personal confidence in finding } \\
\text { information and communicating with an instructor } \\
\text { within the e-learning system and the necessary } \\
\text { skills for using the system" [112] }\end{array}$ & [292] & {$[292]_{2}[112]$} \\
\hline
\end{tabular}




\section{Appendix C: Individual Interviews Appendices C.1 Qualitative Methods Invitation - Students}

Subject: Share your voice (and get paid for research) about myPSU

Greetings fellow students -

Are you interested in participating in research related to the reasons why you use myPSU?

A select group of students will help create a survey for PSU undergraduates, to help understand why students use myPSU and to benefit PSU and other universities. There are a variety of ways to participate, including interviews, in a focus group, and through an online form.

Students who participate will be compensated with Amazon gift cards, ranging from \$10-\$40.

\section{If you're interested, follow this link to the interest form.}

This research is endorsed by PSU, as it will contribute to efforts to improve student experiences. Verification of the approval to conduct this research is here.

Sincerely,

Hans VanDerSchaaf

\section{C.2 Interview Interest Form - Students}

(Was in the form of a Qualtrics survey)

Thanks for your interest in participating in research about myPSU! Answers to the following questions will help the research participants be representative of the diversity of the PSU undergraduate population.

Participating is voluntary and your responses are confidential.

This research is endorsed by PSU, as it will contribute to efforts to improve student experiences.

(All questions are required)

- Are you a current PSU undergraduate student?

- Are you enrolled in a degree-seeking academic program?

- Are you a PSU staff or faculty member? (If you're a student employee, select "No").

- Yes

- No

- Do you plan to be a degree-seeking undergraduate student in Spring 2020?

- Yes

- No 
- Unsure

- Are you interested in participating in any of the following research opportunities? Please select all that you're interested in.

- $1: 1$ interview - 60 minutes - in-person on the PSU campus - \$25 Amazon gift card - February 2020

- If yes, for the 1:1 interview (\$25 Amazon gift card), please indicate which times are convenient for you

- $\quad$ Monday, February 10, 8:30-9:30

- $\quad$ Monday, February 10, 9:30-10:30

- Tuesday, February 11, 1:30-2:30

- $\quad$ Tuesday, February 11, 2:30-3:30

- $\quad$ Tuesday, February 11, 3-4

- Wednesday, February 12, 10:45-11:45

- Friday, February 14, 1-2

- $\quad$ Friday, February 14, 4-5

- Tuesday, February 18, 1-2

- Tuesday, February 18, 2-3

- $\quad$ Tuesday, February 18, 3-4

- $\quad$ Tuesday, February 18, 4-5

- Wednesday, February 19, 1-2

- Wednesday, February 19, 2-3

- Wednesday, February 19, 3-4

- Interested, but the times are not convenient

- $\quad$ Focus group of 6-8 students - 90 minutes - in-person on the PSU campus - \$40 Amazon gift card - February 2020

- If yes, please indicate which times are convenient for you

- $\quad$ Friday, February 21, 2-3:30

- $\quad$ Friday, February 21, 3-4:30

- $\quad$ Monday, February 24, 9-10:30

- Monday, February 24, 3-4:30pm

- Wednesday, February 26, 9-10:30

- $\quad$ Friday, February 28, 9-10:30am

- Interested, but the times are not convenient

- Evaluate a draft survey - about 20 minutes - remote/on-line participation - $\$ 10$ Amazon gift card - March 2020

- Take a draft survey and provide feedback - about 10-15 minutes - remote/on-line participation - \$10 Amazon gift card - March/April 2020

- I'm not interested in participating

- What is your preferred first name?

- What is your preferred last name?

- What is your preferred email?

- What is your gender?

- Female

- Male

- Non-binary/third gender

- Prefer to self-describe

- Prefer not to say

- What is your class level?

- Freshman

- Sophomore

- Junior

- Senior 
- What is your major?

- Text field

- Do you receive financial aid? (if yes, participants will see the following question; if no, skip)

- Yes

- No

- Don't know

- Prefer not to answer

- Is part of your financial aid a Pell Grant?

- Yes

- No

- Don't know

- Prefer not to answer

- Are you a first-generation college student? "First generation student" means your parents or legal guardians have not completed a bachelor's degree yet.

- Yes

- No

- Don't know

- Prefer not to answer

- Are you currently living with a disability? (if yes, participants will see the following question; if no, skip)

- Yes

- No

- Don't know

- Prefer not to answer

- Do you find that online environments are not accessible to you because of your disability and/or accessibility-related barriers?

- Yes

- No

- Which of the following best describes your race or ethnicity? Please select all that apply.

- American Indian or Alaska Native

- Asian

- Black or African American

- Hispanic or Latino

- Middle Eastern or North African

- Native Hawaiian or Other Pacific Islander

- White

- Other, please specify

- $\quad$ Prefer not to answer

- Participation in this research requires participants to sign or agree to this consent form ( link to a Google document that contains the consent form). If selected for this research, will you be comfortable signing or agreeing to this form?

- Yes

- No

Thank you for your interest! I'll be in touch if you've been selected to participate.

Hans VanDerSchaaf

\section{C.3 Interview Confirmation - Students}

Subject: Interview confirmation - myPSU research - DAY/DATE/TIME 
Hello

Thank you for your interest in participating in a 60-minute interview about myPSU!

I'm writing to confirm your interview for DAY/DATE/TIME. I'll send a calendar invite shortly - please accept this invite to indicate you plan to attend the interview.

Let's meet in the lobby of Fariborz Maseeh Hall (FMH), near the Park Blocks entrance, and find a public place to sit and conduct the interview. I'm 6' tall, with glasses and light brown hair. My cell is below if you need to be in touch.

During the interview, we'll review information about why students might adopt myPSU. Attached are a preliminary research model, as well as an evaluation sheet, that we'll use in our interview. Also, I'll email the \$25 Amazon gift card immediately after our interview.

Thanks again for your willingness to participate (I really appreciate it!), and please let me know if there are any questions.

Best,

Hans

\section{C.4 Interview Invitation - Experts}

Subject: Adoption of software for student success and university services

Greetings

I hope this email finds you well. My name is Hans VanDerSchaaf, and I'm a PhD candidate in the Department of Engineering and Technology Management at PSU.

I'm working on my dissertation and I'm writing to inquire if you might be available to participate in a 60 minute interview related to the adoption of university services software that supports student success? Your expertise related to student success and student success technology will be incredibly helpful for this research! Additionally, your contributions will help move the field forward, in terms of enabling us to develop more insights about student technology use.

I'm hoping to conduct my interviews in the next 2-3 weeks if at all possible, and additional details about the interview are below.

Thanks so much for considering!

Hans 
My research topic is - What are the critical factors that influence undergraduate students themselves in adopting software for accessing university services (one type of student success technology)? The technology that I'm analyzing is myPSU, which is a web-based digital services platform that aids undergraduate and graduate students in accessing services and resources critical to maintaining their enrollment. myPSU is available to Portland State University students as both a native mobile application and as a website, with content between the two being very similar.

As part of my research, interviews with experts (hopefully like you!) will be used to provide input on the factors related to undergraduate student adoption of myPSU. I've identified initial factors through a literature review and in relation to a research model that has been used in other settings to help predict adoption of technology (it's called the Unified Theory of Acceptance and use of Technology, or UTAUT). In the interview, we'll review and discuss what I've found to date, with goals of identifying new factors that influence adoption and selecting the most important factors that could be included in the research model.

The findings from the interviews and focus groups I'll be conducting will be synthesized to create a research model that will be empirically evaluated, hopefully contributing to the development of student success technology at Portland State University and other institutions across the country.

The interviews can either be in person or over Zoom. Your expertise and insights would be incredibly helpful!

If you're able to participate, I'll send more details about the interview.

Thanks for considering this invitation

Hans

\section{C.5 Interview Details Provided to Participants - Experts}

Subject: Additional details for the technology adoption interview

Hello

Thank you for accepting my invitation to participate in an interview for my $\mathrm{PhD}$ dissertation, happening on date/time/location.

In advance of our interview I wanted to share additional details. Attached is information about the preliminary research model that I've developed in light of considering myPSU adoption by students. This preliminary model is based on the Unified Theory of Acceptance and Use of Technology (UTAUT) technology adoption model and also reflects factors and indicators (and their definitions) that I identified in a literature review of why higher education students adopt technology. If you're not aware, factors are concepts that cannot be directly measured and must be approximately measured by multiple indicators (Hair et al. 2013), or variables, that could be items in a survey (Garson 2015). Also attached is a summary of myPSU.

In the interview, participants will be asked to review the factors and indicators, identify any new factors or indicators, and evaluate and select only the factors and indicators that may be most 
important. The evaluation sheet we'll use is also attached. The results of the individual interview, plus focus groups, will be used to adjust the preliminary research model and create a final research model. I will then evaluate this final model by surveying Portland State University students.

\section{Prior to the interview, would you please:}

- Return a signed copy of the attached consent form to me via email as a PDF?

- Let me know the number of years of professional experience you have related to higher education, educational technology and/or the technology innovation sector(s)? I will use this summary information in my dissertation, but without names or identifying information.

- Join a test meeting in Zoom (link to https://zoom.us/test) and test your computer/phone setup, including the camera.

Thanks again for your willingness to participate (I really appreciate it!), and please let me know if there are any questions. My cell is should you desire to be in touch (also in the calendar

invite).

Best,

Hans

\section{C.6 Interview Consent Form - Students and Experts}

\section{Consent to Participate in Research}

Project Title:

Population:

Researcher:
Determinants of Student Information Technology Adoption

Undergraduate students at Portland State University

Tugrul U. Daim, principal investigator; Hans VanDerSchaaf, student investigator; Engineering and Technology Management, Portland State University

Researcher Contact: hansv@pdx.edu / phone

You are being asked to take part in a research study. The box below highlights the main information about this research for you to consider when making a decision whether or not to join in the study. Please carefully look over the information given to you on this form. Please ask questions about any of the information you do not understand before you decide to agree to take part.

\section{Key Information for You to Consider}

- Voluntary Consent. You are being asked to volunteer for a research study. It is up to you whether you choose to take part or not. There is no penalty if you choose not to join in or decide to stop your involvement. 
- Why is the study being done? The reason for this research is to understand the key factors that may influence undergraduate students' adoption and use of software for accessing university services, in support of improving undergraduate retention and graduation rates at universities. The research will analyze adoption of myPSU, which is available for Portland State University students. The findings will support PSU and other universities in improving student technology tools. This research is being conducted in partial fulfillment of the requirements for Hans VanDerSchaaf's doctoral degree in Technology Management. You are being asked to participate because you are an undergraduate student at PSU or you are an expert. About 50-60 people will participate in this phase of the research, which is for developing a web survey for undergraduate students.

- How long will it take? The length of time depends on how you participate (only one activity per participant): 1:1 interview, 60 minutes; or Focus group, 90 minutes; or Survey read aloud, 60 minutes; or Evaluate a draft survey, approximately 20 minutes; or Take a draft survey and provide feedback, approximately 20 minutes.

- What will I be expected to do? You will be asked to provide feedback, either:

o Verbally and/or via written communications - about the adoption factors and corresponding variables which may relate to undergraduate student adoption of myPSU, which is software for accessing university services and is available to PSU students - through 1:1 interviews and focus group research activities, held on or near the PSU campus or via a video or phone call; or

o Provide feedback on a draft survey instrument about the reasons why students adopt myPSU through a survey read aloud; or by evaluating a draft survey; or by taking a draft survey and providing feedback - all of these activities except the survey read aloud happen on-line/remotely.

o You will participate in only one part of this research.

- Risks. Some of the possible risks or discomforts of taking part in this study include that in the individual interviews and focus groups, participants may be asked to explain the reasons why they use myPSU. Also, as with any situation where sensitive information is disclosed, such as names and email addresses, there is the remote possibility of a data breach. Robust protections are in place to ensure that a data breach does not occur, including that only the investigators have access to collected data. Risks are minimal for participating in this research study.

- Benefits. Some of the benefits that may be expected include incentives for participating for students (see below) and that the researchers hope to gain helpful information to assist PSU and other universities with improving technology to help students.

- Options. Participation is voluntary and the only alternative is to not participate.

\section{What happens to the information collected?}

Information collected for this research will be used to help PSU, other universities and educational technology companies improve student information technology software and services. Any published or disseminated information will be reported in aggregate format only and no identifiable information will be included - reporting will only combine results and will never report individual results.

\section{How will my privacy and data be protected?}

We will take measures to protect your privacy including that data that contains identifiers linked to participants will be kept confidential at all times and will be accessible to only the principal 
investigator and the co-principal investigator. All data obtained from participants will be kept confidential and will only be reported in the aggregate format (reporting only combined results and never reporting individual results). Before any presentation, sharing data outside of the research team or publication, the names and identifiers linked to the participants will be removed to insure anonymity. Despite taking steps to protect your privacy, we can never fully guarantee that your privacy will be protected.

To protect all of your personal information, we will keep all collected data in password-protected and secure locations. Despite these precautions, we can never fully guarantee that all your study information will not be revealed.

Individuals and organizations that conduct or monitor this research may be permitted access to inspect research records. This may include private information. These individuals and organizations include the Institutional Review Board that reviewed this research.

\section{What if I want to stop my part in this research?}

Your part in this study is voluntary. You do not have to take part in this study, but if you do, you may stop at any time. You have the right to choose not to take part in any study activity or completely stop at any point without penalty or loss of benefits to which you are otherwise entitled. Your decision whether or not to join in will not affect your relationship with the researchers or Portland State University.

\section{Will I be paid for being in this research?}

Students will be provided with the following incentives:

- 1:1 interview, 60 minutes - \$25 Amazon gift card

- Focus group, 90 minutes - \$40 Amazon gift card

- Evaluate a draft survey, approximately 20 minutes - \$10 Amazon gift card

- Take a draft survey and provide feedback, approximately 20 minutes - \$10 Amazon gift card

\section{Who can answer my questions about this research?}

If you have questions, concerns, or have experienced a research related injury, contact the research team at:

Hans VanDerSchaaf

phone

hansv@pdx.edu

\section{Who can I speak to about my rights as a part of research?}

The Portland State University Institutional Review Board ("IRB") is overseeing this research. The IRB is a group of people who independently review research studies to ensure the rights and welfare of participants are protected. The Office of Research Integrity is the office at Portland State University that supports the IRB. If you have questions about your rights, or wish to speak with someone other than the research team, you may contact:

Office of Research Integrity

PO Box 751

Portland, OR 97207-0751

Phone: (503) 725-5484

Toll Free: 1 (877) 480-4400

Email: psuirb@pdx.edu

\section{Consent Statement}


I have had the opportunity to read and consider the information in this form. I have asked any questions necessary to make a decision about my taking part in the study. I understand that I can ask more questions at any time.

By signing below, I understand that I am volunteering to take part in this research. I understand that I am not waiving any legal rights. I have been provided with a copy of this consent form. I understand that if my ability to consent for myself changes, either I or my legal representative may be asked to provide consent before I continue in the study.

I consent to join this study.

\section{Name of Adult Participant}

\section{Signature of Adult Participant}

\section{Date}

Researcher Signature (to be completed at time of informed consent)

I have explained the research to the participant and answered all of their questions. I believe that they understand the information described in this consent form and freely consents to participate.

\section{Name of Research Team Member}

$\overline{\text { Signature of Research Team Member }}$

Date

C.7 Interview Facilitation Guide - Students and Experts

\section{PREPARATIONS}

- If interview is in person, print consent form, preliminary research model (visual, taxonomy and definitions) and evaluation tool

\section{INTRODUCTION}




\section{Consent form review and signed/verbal approval - 5 minutes}

Welcome, research summary, agenda - 5 minutes

- Introductions

- Share that audio (and video for remote interviews) will be recorded

- Start Zoom and Quicktime - hit record and test microphone

- Introduce research topic

- Summarize the preliminary research model overview

- Discuss overall research design and how interview or focus group fits in

- Review summary of myPSU (if not familiar with it)

\section{IN-DEPTH DISCUSSION}

\section{Model review and discussion - 45 minutes}

- Summarize the model and walk quickly through it

- Q1 - What are your initial impressions of the model?

- Walk through the model in detail

- Q2 - To what degree do the factors and/or indicators relate to adoption of myPSU by undergraduate students?

- What factors and/or indicators related to myPSU adoption? why?

- What factors and/or indicators should be removed? Why?

- What factors and/or indicators are most important? Why?

- What factors and/or indicators should be added? Why?

- Using evaluation sheet, factor by factor, please let me know:

- Is the factor related to myPSU adoption for undergraduate students? Why?

- Are the indicators related to myPSU adoption for undergraduate students? Why?

- Should any of the indicators be removed? Why?

- Which of the indicators are the most important for myPSU adoption for undergraduate students? Why?

- Are there any factors and/or indicators that you suggest adding to the model? Why?

- Provide any notes or comments

\section{CLOSURE}

Closing - 5 minutes

- Any closing thoughts and final reactions to the overall model?

- Thank you!

- Close Zoom; save Quicktime

\section{C.8 Preliminary Research Model for Interviews - Students and Experts}




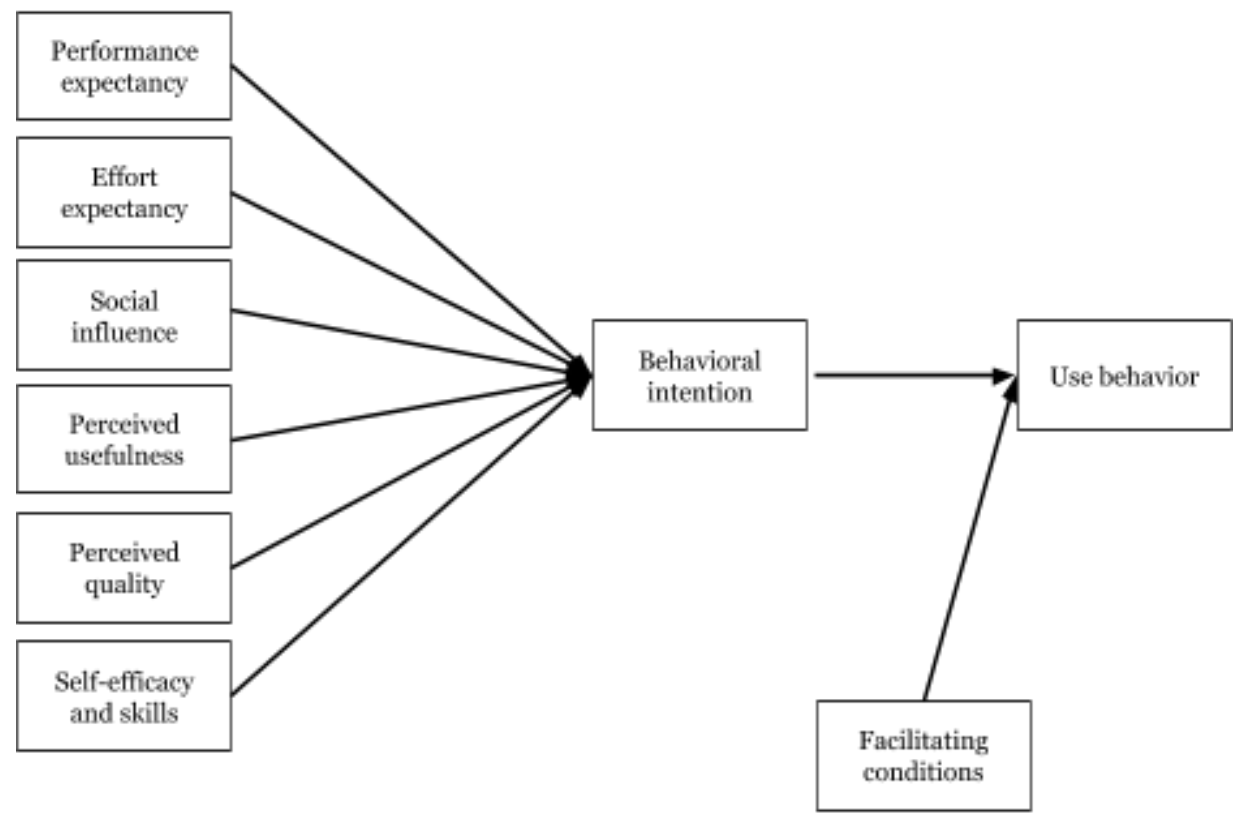

Figure 1: Visual Diagram of Preliminary Research Model

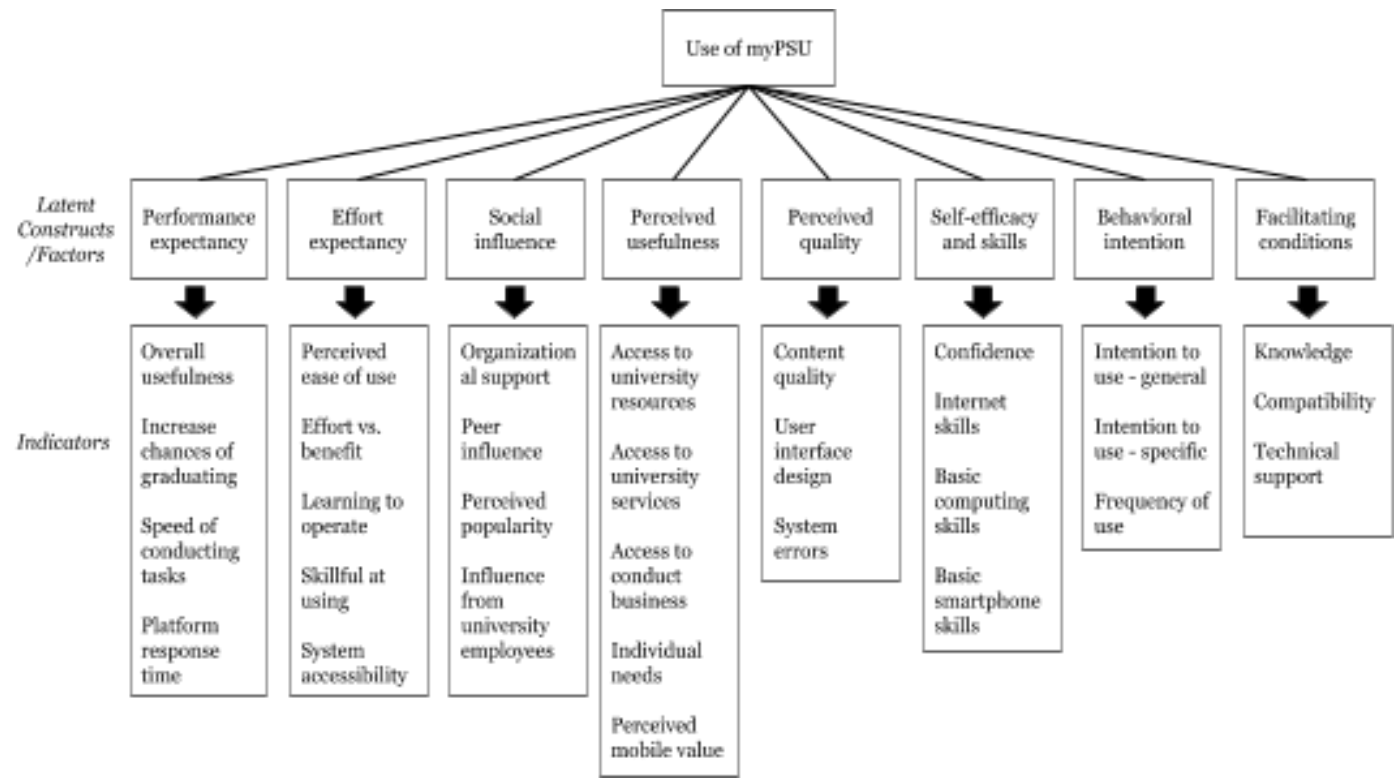

Figure 2: Factors and Indicators for Preliminary Research Model Organized as a Taxonomy - Based on the Unified Theory of Acceptance and Use of Technology (UTAUT) and on a Literature Review

* A factor, or latent construct (or latent variable), is a concept that cannot be directly measured and must be approximately measured by multiple indicators (Hair et al. 2013), or variables, that could be items in a survey (Garson 2015). 
Table 1: Definitions of Factors and Indicators in the Preliminary Research Model

\begin{tabular}{|c|c|}
\hline Factors and indicators & Definition \\
\hline \multicolumn{2}{|c|}{ Performance expectancy factor } \\
\hline Performance expectancy & $\begin{array}{l}\text { The degree to which an individual believes that using a } \\
\text { technology will help them overall. }\end{array}$ \\
\hline Overall usefulness & $\begin{array}{l}\text { Degree to which a student believes that using the } \\
\text { software platform is overall, useful. }\end{array}$ \\
\hline Increase chances of graduating & $\begin{array}{l}\text { Degree to which using the software platform is perceived } \\
\text { as increasing a students' own chances of graduating. }\end{array}$ \\
\hline Speed of conducting tasks & $\begin{array}{l}\text { Degree to which a student can conduct the non-academic } \\
\text { work of being a student more quickly by using the } \\
\text { software platform. }\end{array}$ \\
\hline Platform response time & $\begin{array}{l}\text { Degree to which a student experiences the software } \\
\text { platform response as fast. }\end{array}$ \\
\hline \multicolumn{2}{|l|}{ Effort expectancy factor } \\
\hline Effort expectancy & "Degree of ease associated with the use of the system" \\
\hline Perceived ease of use & $\begin{array}{l}\text { Degree to which the software platform is easy for a } \\
\text { student to use. }\end{array}$ \\
\hline Effort vs. benefit & $\begin{array}{l}\text { Degree to which a student believes that the effort it takes } \\
\text { to use a software platform is worth the benefits. }\end{array}$ \\
\hline Learning to operate & $\begin{array}{l}\text { Degree to which learning how to operate the software } \\
\text { platform is easy for a student. }\end{array}$ \\
\hline Skillful at using & $\begin{array}{l}\text { Degree to which it is easy to become skillful at using the } \\
\text { software platform. }\end{array}$ \\
\hline System accessibility & $\begin{array}{l}\text { Degree to which it is easy for a student to access the } \\
\text { software platform. }\end{array}$ \\
\hline \multicolumn{2}{|l|}{ Social influence factor } \\
\hline Social influence & $\begin{array}{l}\text { "Extent to which users perceive that those important to } \\
\text { them believe they should be using a technology" }\end{array}$ \\
\hline Organizational support & $\begin{array}{l}\text { Degree to which the university has supported the use of } \\
\text { the software platform. }\end{array}$ \\
\hline Peer influence & $\begin{array}{l}\text { Degree to which a student's peers think they should use } \\
\text { the software platform. }\end{array}$ \\
\hline Perceived popularity & Perceived popularity of a technology. \\
\hline $\begin{array}{l}\text { Influence from university } \\
\text { employees }\end{array}$ & $\begin{array}{l}\text { Degree to which university employees are very supportive } \\
\text { of student use of the software platform. }\end{array}$ \\
\hline \multicolumn{2}{|l|}{ Perceived usefulness factor } \\
\hline Perceived usefulness & $\begin{array}{l}\text { The degree to which a person believes that using the } \\
\text { features of a particular technology are useful in } \\
\text { accomplishing a desired task. }\end{array}$ \\
\hline Access to university resources & $\begin{array}{l}\text { Degree to which using the software platform provides } \\
\text { easy access to university resources (calendars, campus } \\
\text { map, library, university-related software, etc.). }\end{array}$ \\
\hline Access to university services & $\begin{array}{l}\text { Degree to which using the software platform provides } \\
\text { easy access to university services (academic advising, } \\
\text { career services, financial wellness center, resource } \\
\text { centers, tutoring, etc.). }\end{array}$ \\
\hline
\end{tabular}




\begin{tabular}{|c|c|}
\hline Access to conduct business & $\begin{array}{l}\text { Degree to which using the software platform provides } \\
\text { easy access to conduct the business of being a student } \\
\text { (viewing account balance, accessing the platform to pay } \\
\text { bills, accessing information about financial aid, accessing } \\
\text { the platform for registering for courses, viewing course } \\
\text { schedule, etc.). }\end{array}$ \\
\hline Individual needs & $\begin{array}{l}\text { Degree to which the software platform meets a student's } \\
\text { individual needs. }\end{array}$ \\
\hline Perceived mobile value & $\begin{array}{l}\text { The degree to which the software platform is accessible } \\
\text { independent of time and location. }\end{array}$ \\
\hline \multicolumn{2}{|l|}{ Perceived quality factor } \\
\hline Perceived quality & The user's opinion of the quality of a software platform. \\
\hline Content quality & The quality of the content in the software platform. \\
\hline User interface design & $\begin{array}{l}\text { Degree to which a student believes the software platform } \\
\text { has well-designed user interfaces (pages, graphics, } \\
\text { visuals, content, navigation, etc.). }\end{array}$ \\
\hline System errors & $\begin{array}{l}\text { Degree to which a student encounters system errors } \\
\text { when using the software platform. }\end{array}$ \\
\hline \multicolumn{2}{|c|}{ Self-efficacy and skills factor } \\
\hline Self-efficacy and skills & $\begin{array}{l}\text { The judgement of one's own ability to perform specific } \\
\text { technology-related tasks and the skills to do so. }\end{array}$ \\
\hline Confidence & $\begin{array}{l}\text { Degree to which a student feels confident they can } \\
\text { overcome any obstacles when using a software platform. }\end{array}$ \\
\hline Internet skills & $\begin{array}{l}\text { Degree to which a student rates their Internet/online } \\
\text { skills to be high. }\end{array}$ \\
\hline Basic computing skills & $\begin{array}{l}\text { The competency of users related to basic computing } \\
\text { activities (using writing/word processing software, using } \\
\text { the Internet, emailing, etc.). }\end{array}$ \\
\hline \multirow[t]{2}{*}{ Basic smartphone skills } & $\begin{array}{l}\text { The competency of users related to basic } \\
\text { mobile/smartphone activities (using apps, texting and } \\
\text { calling, etc.). }\end{array}$ \\
\hline & $\begin{array}{l}\text { Based on - Basic ICT skills - "everyday ICT usage"; "the } \\
\text { competency of users in relation to general computing } \\
\text { tasks, such as using word processing software, searching } \\
\text { and emailing on the Internet and doing basic mobile } \\
\text { activities, such as texting and calling" }\end{array}$ \\
\hline \multicolumn{2}{|l|}{ Behavioral intention factor } \\
\hline Behavioral intention to use & "The decision maker's disposition toward using a system" \\
\hline Intention to use - general & $\begin{array}{l}\text { Degree to which a student intends to use the software } \\
\text { platform. }\end{array}$ \\
\hline Intention to use - specific & $\begin{array}{l}\text { Degree to which a student intends to use the software } \\
\text { platform in the next month. }\end{array}$ \\
\hline Frequency of use & $\begin{array}{l}\text { Degree to which a student intends to use the software } \\
\text { platform frequently. }\end{array}$ \\
\hline
\end{tabular}




\begin{tabular}{|c|c|}
\hline Facilitating conditions & $\begin{array}{l}\text { "The degree to which an individual believes that an } \\
\text { organizational and technical infrastructure exists to } \\
\text { support use of the system" }\end{array}$ \\
\hline Knowledge & $\begin{array}{l}\text { Degree to which a student has the necessary knowledge } \\
\text { to use the software platform. }\end{array}$ \\
\hline Compatibility & $\begin{array}{l}\text { Degree to which the software platform is compatible with } \\
\text { other software platforms or online tools a student uses. }\end{array}$ \\
\hline Technical support & $\begin{array}{l}\text { Degree to which a specific person (or group) is available } \\
\text { for assistance with the software platform's technical } \\
\text { difficulties. }\end{array}$ \\
\hline \multicolumn{2}{|l|}{ Use behavior factor } \\
\hline Use behavior & Actual usage of the system. \\
\hline $\begin{array}{l}\text { Usage of the software platform - } \\
\text { general. }\end{array}$ & $\begin{array}{l}\text { Degree to which a student uses the software platform to } \\
\text { conduct the non-academic work of being a student. }\end{array}$ \\
\hline $\begin{array}{l}\text { Usage of the software platform - } \\
\text { specific }\end{array}$ & $\begin{array}{l}\text { Degree to which a student has used the software platform } \\
\text { in the past month. }\end{array}$ \\
\hline Frequency of use & Frequency of use of the software platform. \\
\hline $\begin{array}{l}\text { Usage of the software platform } \\
\text { to access university resources }\end{array}$ & $\begin{array}{l}\text { Degree to which a student uses the software platform to } \\
\text { access university resources (calendars, campus map, } \\
\text { library, university-related software, etc.). }\end{array}$ \\
\hline $\begin{array}{l}\text { Usage of the software platform } \\
\text { to access university services }\end{array}$ & $\begin{array}{l}\text { Degree to which a student uses the software platform to } \\
\text { access university services (academic advising, career } \\
\text { services, financial wellness center, resource centers, } \\
\text { tutoring, etc.). }\end{array}$ \\
\hline $\begin{array}{l}\text { Usage of the software platform } \\
\text { to conduct the business of being } \\
\text { a student }\end{array}$ & $\begin{array}{l}\text { Degree to which a student uses the software platform to } \\
\text { conduct business related to being a student (viewing } \\
\text { account balance, accessing the platform to pay bills, } \\
\text { accessing information about financial aid, accessing the } \\
\text { platform for registering for courses, viewing course } \\
\text { schedule, etc.) }\end{array}$ \\
\hline
\end{tabular}

\section{C.9 Interview Evaluation Sheet - Students and Experts}

\begin{tabular}{|l|l|l|l|}
\hline Factors and indicators & $\begin{array}{l}\text { Related to } \\
\text { myPSU? } \\
\text { (Yes/No) }\end{array}$ & $\begin{array}{l}\text { Which are } \\
\text { the most } \\
\text { important } \\
\text { for myPS } \\
\text { adoption? } \\
\text { (X) }\end{array}$ & Notes/comments \\
\hline Performance expectancy factor & & & \\
\hline Performance expectancy & & & \\
\hline Overall usefulness & & & \\
\hline Increase chances of graduating & & & \\
\hline Speed of conducting tasks & & & \\
\hline
\end{tabular}




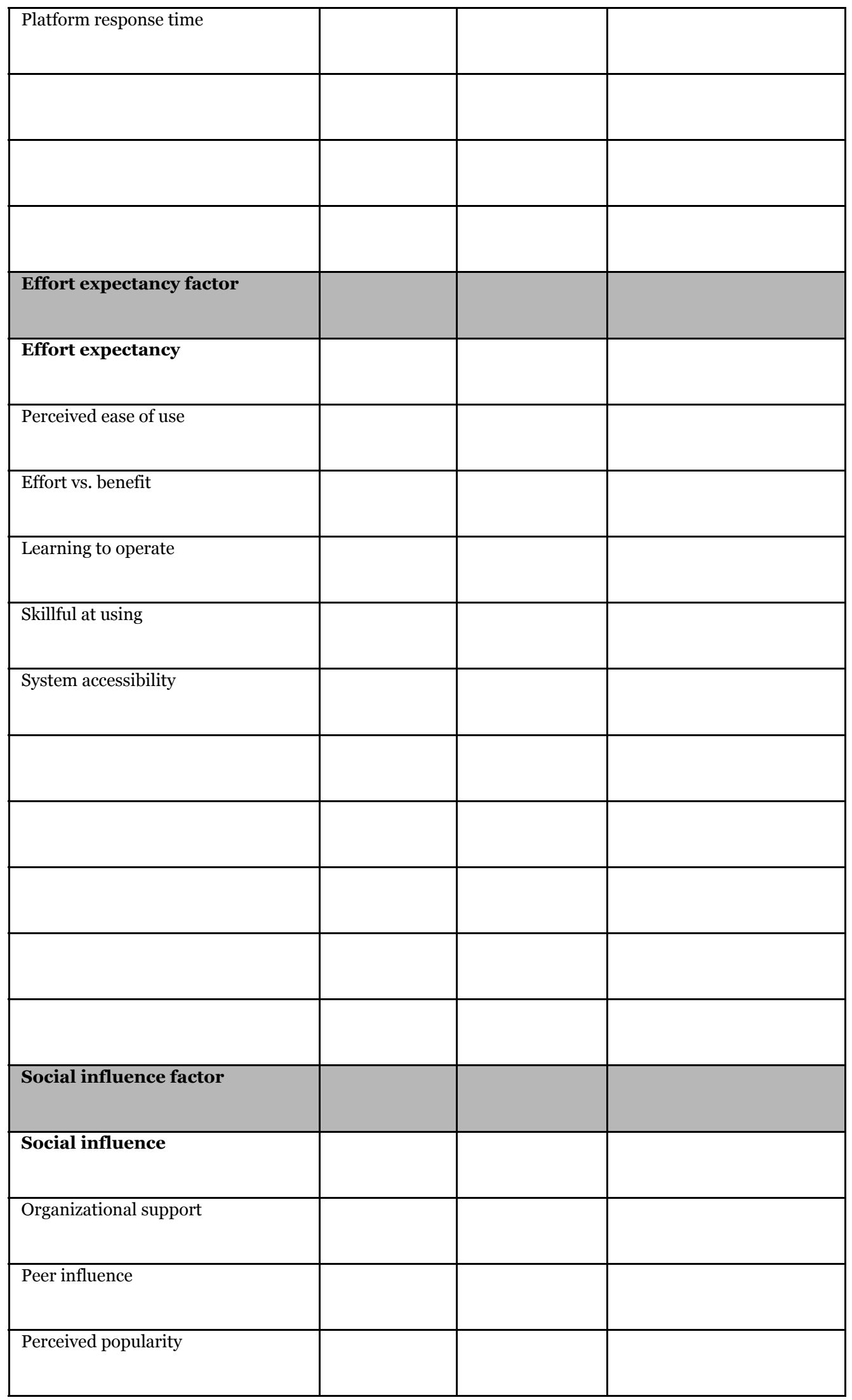




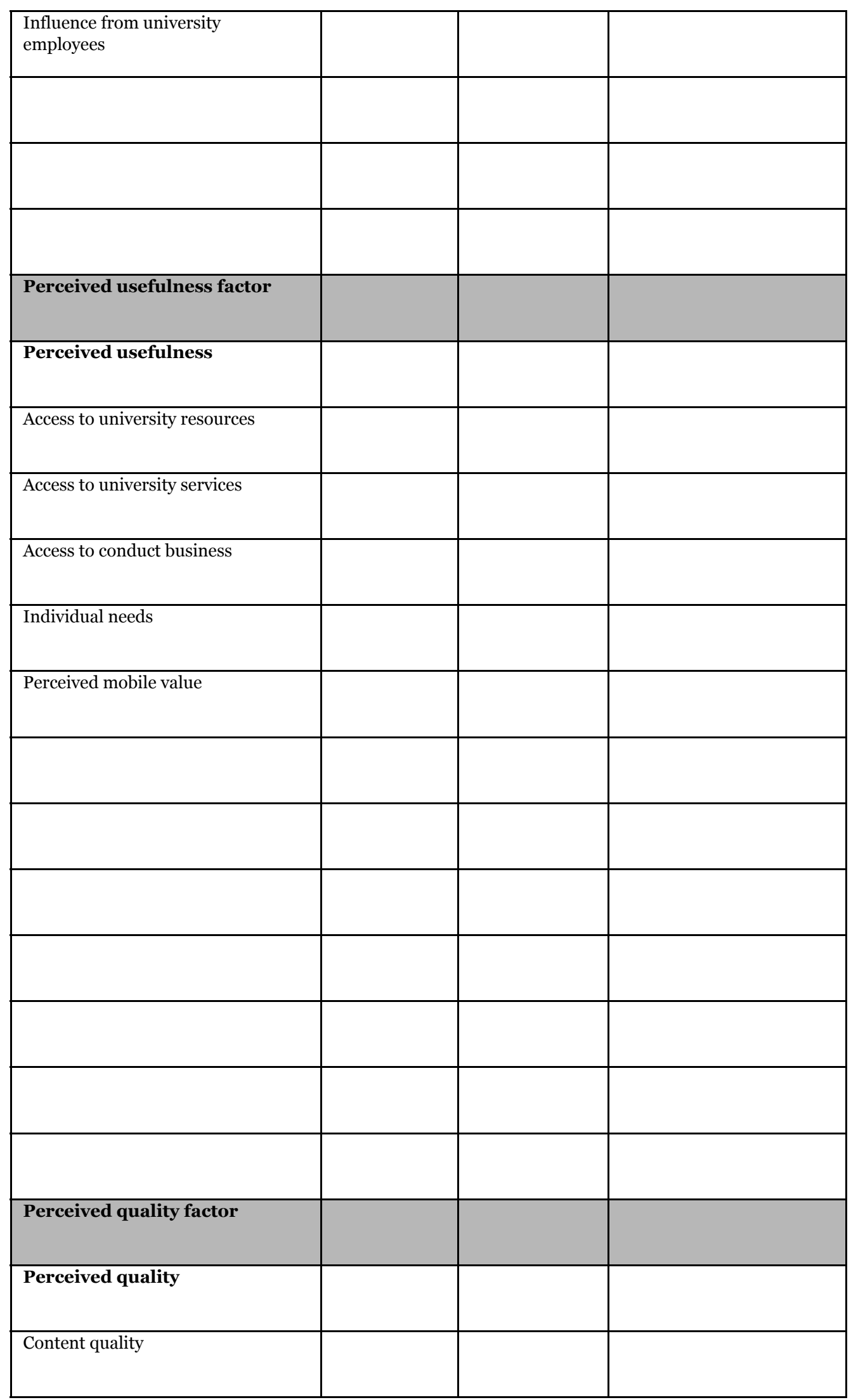




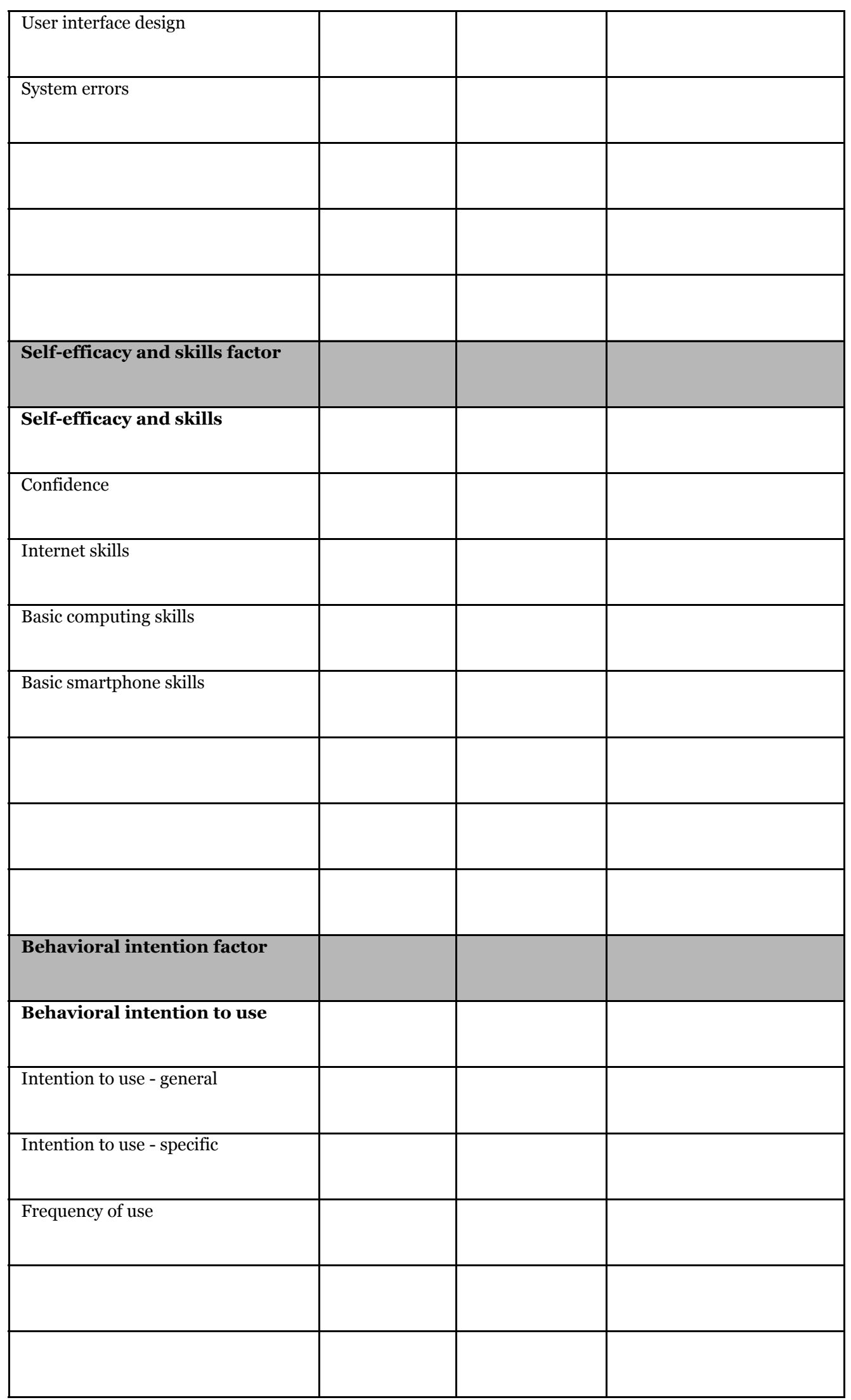




\begin{tabular}{|l|l|l|l|}
\hline & & & \\
\hline Facilitating conditions factor & & & \\
\hline Facilitating conditions & & & \\
\hline Knowledge & & & \\
\hline Compatibility & & & \\
\hline Technical support & & & \\
\hline & & & \\
\hline & & & \\
\hline Use behavior factor & & & \\
\hline Use behavior & & & \\
\hline $\begin{array}{l}\text { Usage of the software platform - } \\
\text { general. }\end{array}$ & & & \\
\hline $\begin{array}{l}\text { Usage of the software platform - } \\
\text { specific }\end{array}$ & & & \\
\hline Frequency of use & & & \\
\hline $\begin{array}{l}\text { Usage of the software platform to } \\
\text { access university resources }\end{array}$ & & & \\
\hline $\begin{array}{l}\text { Usage of the software platform to } \\
\text { access university services }\end{array}$ & & & \\
\hline $\begin{array}{l}\text { Usage of the software platform to } \\
\text { conduct the business of being a } \\
\text { student }\end{array}$ & & & \\
\hline & & & \\
\hline & & & \\
\hline & & & \\
\hline
\end{tabular}




\section{Appendix D: Focus Group Appendices \\ D.1 Qualitative Methods Invitation - Students}

Subject: Share your voice (and get paid for research) about myPSU

Greetings fellow students -

Are you interested in participating in research related to the reasons why you use myPSU?

A select group of students will help create a survey for PSU undergraduates, to help understand why students use myPSU and to benefit PSU and other universities. There are a variety of ways to participate, including interviews, in a focus group, and through an online form.

Students who participate will be compensated with Amazon gift cards, ranging from \$10-\$40.

\section{If you're interested, follow this link to the interest form.}

This research is endorsed by PSU, as it will contribute to efforts to improve student experiences. Verification of the approval to conduct this research is here.

Sincerely,

Hans VanDerSchaaf

\section{D.2 Interest Form - Students}

(Was in the form of a Qualtrics survey)

Thanks for your interest in participating in research about myPSU! Answers to the following questions will help the research participants be representative of the diversity of the PSU undergraduate population.

Participating is voluntary and your responses are confidential.

This research is endorsed by PSU, as it will contribute to efforts to improve student experiences.

(All questions are required)

- Are you a current PSU undergraduate student?

- Are you enrolled in a degree-seeking academic program?

- Are you a PSU staff or faculty member? (If you're a student employee, select "No").

- Yes

- No

- Do you plan to be a degree-seeking undergraduate student in Spring 2020?

- Yes

- No 
- Unsure

- Are you interested in participating in any of the following research opportunities? Please select all that you're interested in.

- $1: 1$ interview - 60 minutes - in-person on the PSU campus - \$25 Amazon gift card - February 2020

- If yes, for the 1:1 interview (\$25 Amazon gift card), please indicate which times are convenient for you

- $\quad$ Monday, February 10, 8:30-9:30

- $\quad$ Monday, February 10, 9:30-10:30

- Tuesday, February 11, 1:30-2:30

- $\quad$ Tuesday, February 11, 2:30-3:30

- $\quad$ Tuesday, February 11, 3-4

- Wednesday, February 12, 10:45-11:45

- Friday, February 14, 1-2

- $\quad$ Friday, February 14, 4-5

- Tuesday, February 18, 1-2

- Tuesday, February 18, 2-3

- $\quad$ Tuesday, February 18, 3-4

- $\quad$ Tuesday, February 18, 4-5

- Wednesday, February 19, 1-2

- Wednesday, February 19, 2-3

- Wednesday, February 19, 3-4

- Interested, but the times are not convenient

- $\quad$ Focus group of 6-8 students - 90 minutes - in-person on the PSU campus - \$40 Amazon gift card - February 2020

- If yes, please indicate which times are convenient for you

- $\quad$ Friday, February 21, 2-3:30

- $\quad$ Friday, February 21, 3-4:30

- $\quad$ Monday, February 24, 9-10:30

- Monday, February 24, 3-4:30pm

- Wednesday, February 26, 9-10:30

- $\quad$ Friday, February 28, 9-10:30am

- Interested, but the times are not convenient

- Evaluate a draft survey - about 20 minutes - remote/on-line participation - $\$ 10$ Amazon gift card - March 2020

- Take a draft survey and provide feedback - about 10-15 minutes - remote/on-line participation - \$10 Amazon gift card - March/April 2020

- I'm not interested in participating

- What is your preferred first name?

- What is your preferred last name?

- What is your preferred email?

- What is your gender?

- Female

- Male

- Non-binary/third gender

- Prefer to self-describe

- Prefer not to say

- What is your class level?

- Freshman

- Sophomore

- Junior

- Senior 
- What is your major?

- Text field

- Do you receive financial aid? (if yes, participants will see the following question; if no, skip)

- Yes

- No

- Don't know

- Prefer not to answer

- Is part of your financial aid a Pell Grant?

- Yes

- No

- Don't know

- Prefer not to answer

- Are you a first-generation college student? "First generation student" means your parents or legal guardians have not completed a bachelor's degree yet.

- Yes

- No

- Don't know

- Prefer not to answer

- Are you currently living with a disability? (if yes, participants will see the following question; if no, skip)

- Yes

- No

- Don't know

- Prefer not to answer

- Do you find that online environments are not accessible to you because of your disability and/or accessibility-related barriers?

- Yes

- No

- Which of the following best describes your race or ethnicity? Please select all that apply.

- American Indian or Alaska Native

- Asian

- Black or African American

- Hispanic or Latino

- Middle Eastern or North African

- Native Hawaiian or Other Pacific Islander

- White

- Other, please specify

- $\quad$ Prefer not to answer

- Participation in this research requires participants to sign or agree to this consent form ( link to a Google document that contains the consent form). If selected for this research, will you be comfortable signing or agreeing to this form?

- Yes

- No

Thank you for your interest! I'll be in touch if you've been selected to participate.

Hans VanDerSchaaf

D.3 Focus Group Details Provided to Participants - Students

Subject: You've been selected - focus group on myPSU - Friday, Feb 21, 2-3:30pm 
Hello

Thank you for your interest in participating in a 90-minute focus group about myPSU!

I'm writing to confirm the focus group for Friday, Feb 21, 2-3:30pm. I'll send a calendar invite shortly - please accept this invite to indicate you plan to attend the

focus group. And, in the coming few days I'll update the calendar invitation with a location.

During the focus group, we'll review information about why students might adopt myPSU.

Attached are a preliminary research model, as well as an evaluation sheet, that we'll use in the focus group. Also, I'll email the $\mathbf{\$ 4 0}$ Amazon gift card immediately after the focus group.

Thanks again for your willingness to participate (I really appreciate it!), and please let me know if there are any questions.

Best,

Hans

hansv@pdx.edu

\section{D.4 Focus Group Invitation - Experts}

Subject: myPSU focus group

Greetings

I hope this finds you well! I wanted to be in touch to see about your interest and availability in lending your expertise to support the research I'm doing for my PhD - it's about the factors that influence student adoption of information technology, with myPSU as the unit of analysis.

If so, a formal invitation will follow once I've received IRB approval, but I wanted to check now about your interest and availability. The findings from this research will hopefully aid PSU and other universities in their efforts to improve student experiences and student success.

Essentially, I plan to have a focus of experts (hopefully including you!) participate in a 9o-minute focus group on the PSU campus.

Perhaps you would be interested? If so, would you please indicate your availability through this Doodle poll? I'll find a time that hopefully works for all who are interested. (Apologies in advance for the number of options, but I wanted to find as many as times as possible, so that the maximum number can participate).

Thanks for considering!

Hans 


\section{D.5 Focus Group Details Provided to Participants - Experts}

Emailed as an update to the calendar invitation

"Greetings - A preliminary research model is attached, which will be the basis for the focus group. It's intended to capture the variables that are hypothesized to influence whether students adopt myPSU. The variables were identified through a literature review. It would be great if you have a few minutes prior to the focus group to review this attachment. Thanks so much and see you on Monday morning! Hans"

\section{D.6 Focus Group Consent Form - Students and Experts}

\section{Consent to Participate in Research}

Project Title:

Population:

Researcher:
Determinants of Student Information Technology Adoption

Undergraduate students at Portland State University

Tugrul U. Daim, principal investigator; Hans VanDerSchaaf, student investigator; Engineering and Technology Management, Portland State University

Researcher Contact: hansv@pdx.edu / phone

You are being asked to take part in a research study. The box below highlights the main information about this research for you to consider when making a decision whether or not to join in the study. Please carefully look over the information given to you on this form. Please ask questions about any of the information you do not understand before you decide to agree to take part.

\section{Key Information for You to Consider}

- Voluntary Consent. You are being asked to volunteer for a research study. It is up to you whether you choose to take part or not. There is no penalty if you choose not to join in or decide to stop your involvement.

- Why is the study being done? The reason for this research is to understand the key factors that may influence undergraduate students' adoption and use of software for accessing university services, in support of improving undergraduate retention and graduation rates at universities. The research will analyze adoption of myPSU, which is available for Portland State University students. The findings will support PSU and other universities in improving student technology tools. This research is being conducted in partial fulfillment of the requirements for Hans VanDerSchaaf's doctoral degree in Technology Management. You are being asked to participate because you are an undergraduate student at PSU or you are an expert. About 50-60 people will participate in this phase of the research, which is for developing a web survey for undergraduate students. 
- How long will it take? The length of time depends on how you participate (only one activity per participant): 1:1 interview, 60 minutes; or Focus group, 90 minutes; or Survey read aloud, 60 minutes; or Evaluate a draft survey, approximately 20 minutes; or Take a draft survey and provide feedback, approximately 20 minutes.

- What will I be expected to do? You will be asked to provide feedback, either:

o Verbally and/or via written communications - about the adoption factors and corresponding variables which may relate to undergraduate student adoption of myPSU, which is software for accessing university services and is available to PSU students - through 1:1 interviews and focus group research activities, held on or near the PSU campus or via a video or phone call; or

o Provide feedback on a draft survey instrument about the reasons why students adopt myPSU through a survey read aloud; or by evaluating a draft survey; or by taking a draft survey and providing feedback - all of these activities except the survey read aloud happen on-line/remotely.

o You will participate in only one part of this research.

- Risks. Some of the possible risks or discomforts of taking part in this study include that in the individual interviews and focus groups, participants may be asked to explain the reasons why they use myPSU. Also, as with any situation where sensitive information is disclosed, such as names and email addresses, there is the remote possibility of a data breach. Robust protections are in place to ensure that a data breach does not occur, including that only the investigators have access to collected data. Risks are minimal for participating in this research study.

- Benefits. Some of the benefits that may be expected include incentives for participating for students (see below) and that the researchers hope to gain helpful information to assist PSU and other universities with improving technology to help students.

- Options. Participation is voluntary and the only alternative is to not participate.

\section{What happens to the information collected?}

Information collected for this research will be used to help PSU, other universities and educational technology companies improve student information technology software and services. Any published or disseminated information will be reported in aggregate format only and no identifiable information will be included - reporting will only combine results and will never report individual results.

\section{How will my privacy and data be protected?}

We will take measures to protect your privacy including that data that contains identifiers linked to participants will be kept confidential at all times and will be accessible to only the principal investigator and the co-principal investigator. All data obtained from participants will be kept confidential and will only be reported in the aggregate format (reporting only combined results and never reporting individual results). Before any presentation, sharing data outside of the research team or publication, the names and identifiers linked to the participants will be removed to insure anonymity. Despite taking steps to protect your privacy, we can never fully guarantee that your privacy will be protected.

To protect all of your personal information, we will keep all collected data in password-protected and secure locations. Despite these precautions, we can never fully guarantee that all your study information will not be revealed. 
Individuals and organizations that conduct or monitor this research may be permitted access to inspect research records. This may include private information. These individuals and organizations include the Institutional Review Board that reviewed this research.

\section{What if I want to stop my part in this research?}

Your part in this study is voluntary. You do not have to take part in this study, but if you do, you may stop at any time. You have the right to choose not to take part in any study activity or completely stop at any point without penalty or loss of benefits to which you are otherwise entitled. Your decision whether or not to join in will not affect your relationship with the researchers or Portland State University.

\section{Will I be paid for being in this research?}

Students will be provided with the following incentives:

- 1:1 interview, 60 minutes - \$25 Amazon gift card

- Focus group, 90 minutes - $\$ 40$ Amazon gift card

- Evaluate a draft survey, approximately 20 minutes - \$10 Amazon gift card

- Take a draft survey and provide feedback, approximately 20 minutes - \$10 Amazon gift card

\section{Who can answer my questions about this research?}

If you have questions, concerns, or have experienced a research related injury, contact the research team at:

Hans VanDerSchaaf

phone

hansv@pdx.edu

\section{Who can I speak to about my rights as a part of research?}

The Portland State University Institutional Review Board ("IRB") is overseeing this research. The IRB is a group of people who independently review research studies to ensure the rights and welfare of participants are protected. The Office of Research Integrity is the office at Portland State University that supports the IRB. If you have questions about your rights, or wish to speak with someone other than the research team, you may contact:

Office of Research Integrity

PO Box 751

Portland, OR 97207-0751

Phone: (503) 725-5484

Toll Free: 1 (877) 480-4400

Email: psuirb@pdx.edu

\section{Consent Statement}

I have had the opportunity to read and consider the information in this form. I have asked any questions necessary to make a decision about my taking part in the study. I understand that I can ask more questions at any time.

By signing below, I understand that I am volunteering to take part in this research. I understand that I am not waiving any legal rights. I have been provided with a copy of this consent form. I understand that if my ability to consent for myself changes, either I or my legal representative may be asked to provide consent before I continue in the study.

I consent to join this study. 


\title{
Name of Adult Participant
}

\author{
Signature of Adult Participant
}

\section{Date}

Researcher Signature (to be completed at time of informed consent)

I have explained the research to the participant and answered all of their questions. I believe that they understand the information described in this consent form and freely consents to participate.

Name of Research Team Member

$\overline{\text { Signature of Research Team Member }}$

Date

D.7 Focus Group Facilitation Guide - Students and Experts

\section{ROOM SETUP}

- $\quad$ Taxonomy posted

- Pens and stickers out on tables

- Consent forms out

- Packet with research model (visual, taxonomy and definitions) and evaluation tool

- Presentation deck loaded

- Puck microphone connected to laptop

- Laptop plugged into outlet

- Laptop connected to projector

- $\quad$ Notes document loaded for typing

\section{INTRODUCTION}

Seating and consent form signing and review - 10 minutes

Welcome, research summary, agenda - 10 minutes

- Introductions

- Start Zoom and Quicktime recordings 
- Presentation

- Agenda overview, with focus group questions

- Introduce research topic

- Summarize the preliminary research model overview

- Show overall research design and how focus group fits in

- Instructions for the focus group

\section{IN-DEPTH DISCUSSION}

Model review - 30 minutes

- Individual work - model evaluation - 30 minutes

- First names on evaluation sheets and please write legibly

- I'll read through the definitions of each indicator, to help us all have a common understanding of the variable

- Using the evaluation sheet, for each factor and indicator, indicate whether:

- It is related to myPSU adoption

- If it's one of the most important for myPSU adoption

- Provide any notes or comments

- Add new factors and/or indicators to sheet - under an existing indicator or at the bottom for new factors

- Each person adds information from evaluation sheets to the papers on the wall (which are representations of the taxonomy):

- Add red stickers if indicator or factor does not relate to myPSU adoption

- Add new indicators and factors to a piece of paper (one on each piece of paper) and place on wall

- Add green stickers if indicator or factor are the most important to myPSU adoption

- Group discussion - 40 minutes

Q1. In reference to the preliminary research model information:

- What are your impressions of the model?

- What factors and/or indicators do you believe should be removed? Why? Are there any differing opinions about whether any proposed indicators and/or factors should be removed?

- What new factors and/or indicators do you believe should be added? Why? Are there any differing opinions about whether any proposed indicators and/or factors should be added?

Q2. What factors and/or indicators are most important to undergraduate students' adoption of myPSU? Why? Are there any differing opinions about which factors and/or indicators are the most important?

\section{CLOSURE}

Closing - 5 minutes

- Any closing thoughts?

- Next steps - gift cards emailed (to students)

- Thank you!

- Turn off recordings

- Save Quicktime 


\section{D.8 Preliminary Research Model for Focus Groups - Students and Experts}

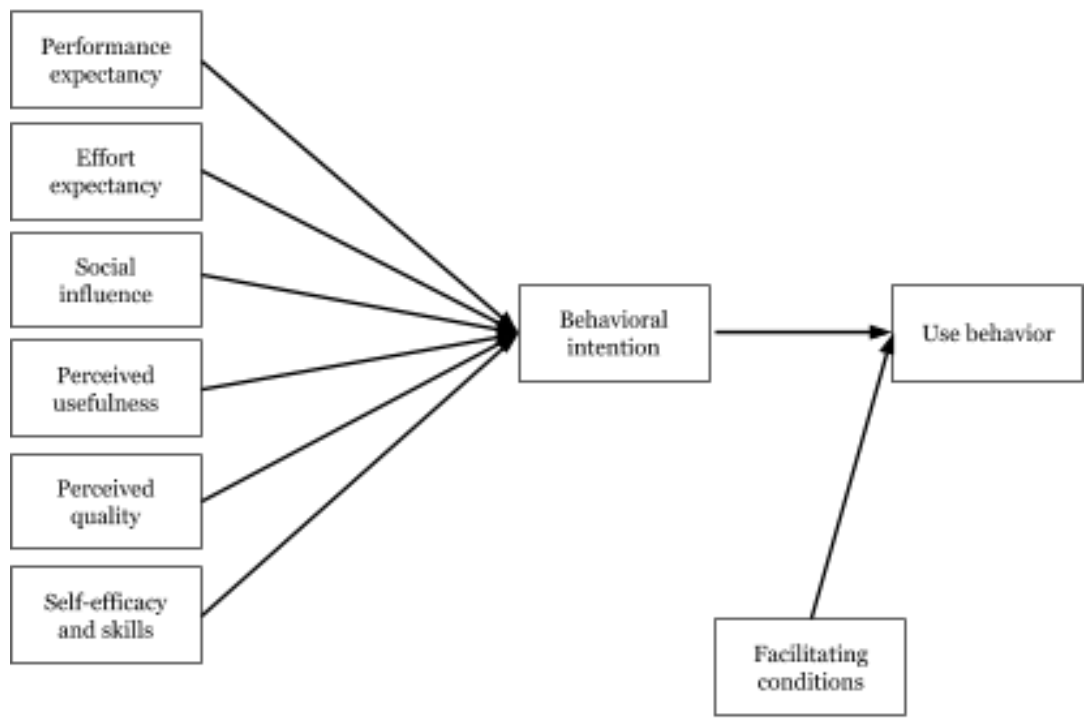

Figure 1: Visual Diagram of Preliminary Research Model

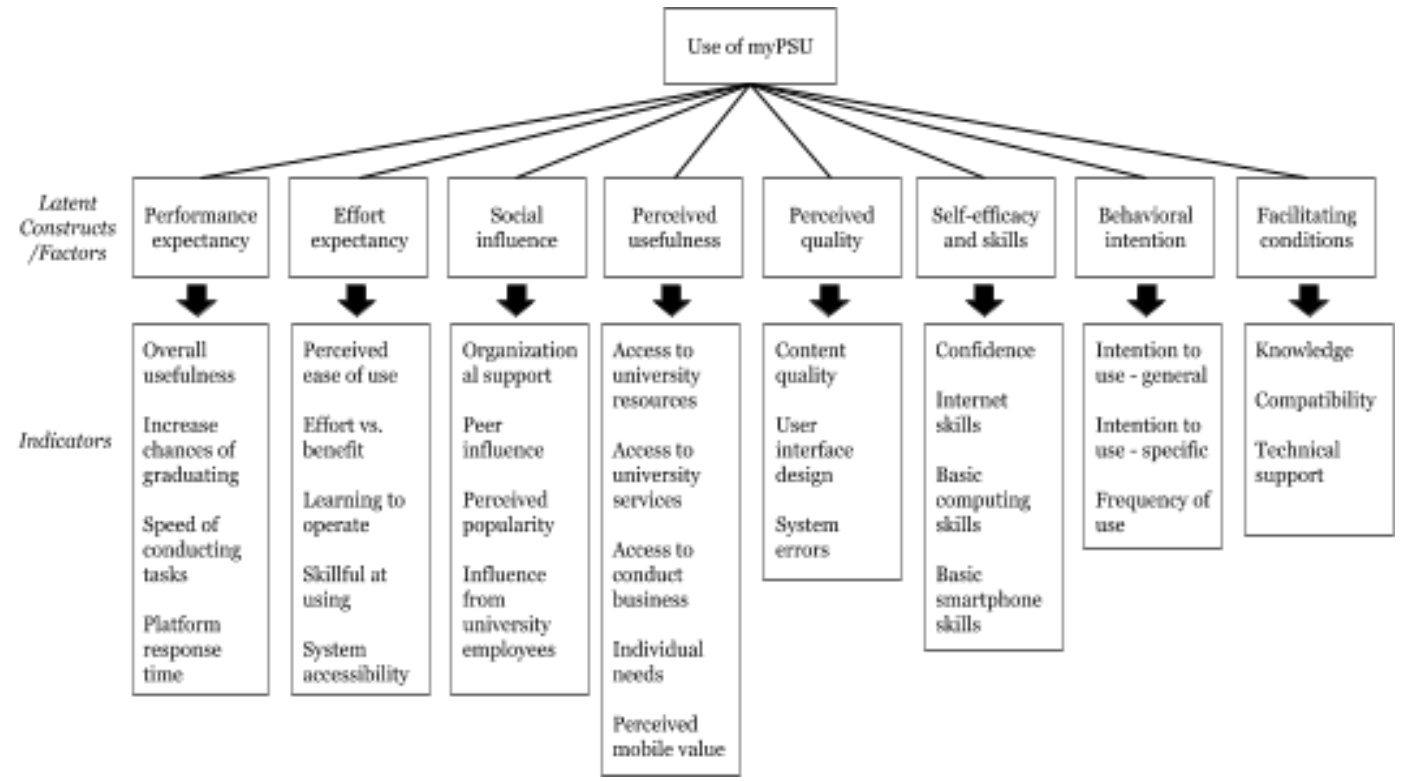


Figure 2: Factors and Indicators for Preliminary Research Model Organized as a Taxonomy - Based on the Unified Theory of Acceptance and Use of Technology (UTAUT) and on a Literature Review

* A factor, or latent construct (or latent variable), is a concept that cannot be directly measured and must be approximately measured by multiple indicators (Hair et al. 2013), or variables, that could be items in a survey (Garson 2015).

Table 1: Definitions of Factors and Indicators in the Preliminary Research Model

\begin{tabular}{|c|c|}
\hline Factors and indicators & Definition \\
\hline \multicolumn{2}{|c|}{ Performance expectancy factor } \\
\hline Performance expectancy & $\begin{array}{l}\text { The degree to which an individual believes that using a } \\
\text { technology will help them overall. }\end{array}$ \\
\hline Overall usefulness & $\begin{array}{l}\text { Degree to which a student believes that using the } \\
\text { software platform is overall, useful. }\end{array}$ \\
\hline Increase chances of graduating & $\begin{array}{l}\text { Degree to which using the software platform is perceived } \\
\text { as increasing a students' own chances of graduating. }\end{array}$ \\
\hline Speed of conducting tasks & $\begin{array}{l}\text { Degree to which a student can conduct the non-academic } \\
\text { work of being a student more quickly by using the } \\
\text { software platform. }\end{array}$ \\
\hline Platform response time & $\begin{array}{l}\text { Degree to which a student experiences the software } \\
\text { platform response as fast. }\end{array}$ \\
\hline \multicolumn{2}{|l|}{ Effort expectancy factor } \\
\hline Effort expectancy & "Degree of ease associated with the use of the system" \\
\hline Perceived ease of use & $\begin{array}{l}\text { Degree to which the software platform is easy for a } \\
\text { student to use. }\end{array}$ \\
\hline Effort vs. benefit & $\begin{array}{l}\text { Degree to which a student believes that the effort it takes } \\
\text { to use a software platform is worth the benefits. }\end{array}$ \\
\hline Learning to operate & $\begin{array}{l}\text { Degree to which learning how to operate the software } \\
\text { platform is easy for a student. }\end{array}$ \\
\hline Skillful at using & $\begin{array}{l}\text { Degree to which it is easy to become skillful at using the } \\
\text { software platform. }\end{array}$ \\
\hline System accessibility & $\begin{array}{l}\text { Degree to which it is easy for a student to access the } \\
\text { software platform. }\end{array}$ \\
\hline \multicolumn{2}{|l|}{ Social influence factor } \\
\hline Social influence & $\begin{array}{l}\text { "Extent to which users perceive that those important to } \\
\text { them believe they should be using a technology" }\end{array}$ \\
\hline Organizational support & $\begin{array}{l}\text { Degree to which the university has supported the use of } \\
\text { the software platform. }\end{array}$ \\
\hline Peer influence & $\begin{array}{l}\text { Degree to which a student's peers think they should use } \\
\text { the software platform. }\end{array}$ \\
\hline Perceived popularity & Perceived popularity of a technology. \\
\hline $\begin{array}{l}\text { Influence from university } \\
\text { employees }\end{array}$ & $\begin{array}{l}\text { Degree to which university employees are very supportive } \\
\text { of student use of the software platform. }\end{array}$ \\
\hline \multicolumn{2}{|l|}{ Perceived usefulness factor } \\
\hline Perceived usefulness & $\begin{array}{l}\text { The degree to which a person believes that using the } \\
\text { features of a particular technology are useful in } \\
\text { accomplishing a desired task. }\end{array}$ \\
\hline
\end{tabular}




\begin{tabular}{|c|c|}
\hline Access to university resources & $\begin{array}{l}\text { Degree to which using the software platform provides } \\
\text { easy access to university resources (calendars, campus } \\
\text { map, library, university-related software, etc.). }\end{array}$ \\
\hline Access to university services & $\begin{array}{l}\text { Degree to which using the software platform provides } \\
\text { easy access to university services (academic advising, } \\
\text { career services, financial wellness center, resource } \\
\text { centers, tutoring, etc.). }\end{array}$ \\
\hline Access to conduct business & $\begin{array}{l}\text { Degree to which using the software platform provides } \\
\text { easy access to conduct the business of being a student } \\
\text { (viewing account balance, accessing the platform to pay } \\
\text { bills, accessing information about financial aid, accessing } \\
\text { the platform for registering for courses, viewing course } \\
\text { schedule, etc.). }\end{array}$ \\
\hline Individual needs & $\begin{array}{l}\text { Degree to which the software platform meets a student's } \\
\text { individual needs. }\end{array}$ \\
\hline Perceived mobile value & $\begin{array}{l}\text { The degree to which the software platform is accessible } \\
\text { independent of time and location. }\end{array}$ \\
\hline \multicolumn{2}{|l|}{ Perceived quality factor } \\
\hline Perceived quality & The user's opinion of the quality of a software platform. \\
\hline Content quality & The quality of the content in the software platform. \\
\hline User interface design & $\begin{array}{l}\text { Degree to which a student believes the software platform } \\
\text { has well-designed user interfaces (pages, graphics, } \\
\text { visuals, content, navigation, etc.). }\end{array}$ \\
\hline System errors & $\begin{array}{l}\text { Degree to which a student encounters system errors } \\
\text { when using the software platform. }\end{array}$ \\
\hline \multicolumn{2}{|l|}{ Self-efficacy and skills factor } \\
\hline Self-efficacy and skills & $\begin{array}{l}\text { The judgement of one's own ability to perform specific } \\
\text { technology-related tasks and the skills to do so. }\end{array}$ \\
\hline Confidence & $\begin{array}{l}\text { Degree to which a student feels confident they can } \\
\text { overcome any obstacles when using a software platform. }\end{array}$ \\
\hline Internet skills & $\begin{array}{l}\text { Degree to which a student rates their Internet/online } \\
\text { skills to be high. }\end{array}$ \\
\hline Basic computing skills & $\begin{array}{l}\text { The competency of users related to basic computing } \\
\text { activities (using writing/word processing software, using } \\
\text { the Internet, emailing, etc.). }\end{array}$ \\
\hline \multirow[t]{2}{*}{ Basic smartphone skills } & $\begin{array}{l}\text { The competency of users related to basic } \\
\text { mobile/smartphone activities (using apps, texting and } \\
\text { calling, etc.). }\end{array}$ \\
\hline & $\begin{array}{l}\text { Based on - Basic ICT skills - "everyday ICT usage"; "the } \\
\text { competency of users in relation to general computing } \\
\text { tasks, such as using word processing software, searching } \\
\text { and emailing on the Internet and doing basic mobile } \\
\text { activities, such as texting and calling" }\end{array}$ \\
\hline \multicolumn{2}{|l|}{ Behavioral intention factor } \\
\hline Behavioral intention to use & "The decision maker's disposition toward using a system" \\
\hline Intention to use - general & $\begin{array}{l}\text { Degree to which a student intends to use the software } \\
\text { platform. }\end{array}$ \\
\hline
\end{tabular}




\begin{tabular}{|c|c|}
\hline Intention to use - specific & $\begin{array}{l}\text { Degree to which a student intends to use the software } \\
\text { platform in the next month. }\end{array}$ \\
\hline Frequency of use & $\begin{array}{l}\text { Degree to which a student intends to use the software } \\
\text { platform frequently. }\end{array}$ \\
\hline \multicolumn{2}{|l|}{ Facilitating conditions factor } \\
\hline Facilitating conditions & $\begin{array}{l}\text { "The degree to which an individual believes that an } \\
\text { organizational and technical infrastructure exists to } \\
\text { support use of the system" }\end{array}$ \\
\hline Knowledge & $\begin{array}{l}\text { Degree to which a student has the necessary knowledge } \\
\text { to use the software platform. }\end{array}$ \\
\hline Compatibility & $\begin{array}{l}\text { Degree to which the software platform is compatible with } \\
\text { other software platforms or online tools a student uses. }\end{array}$ \\
\hline Technical support & $\begin{array}{l}\text { Degree to which a specific person (or group) is available } \\
\text { for assistance with the software platform's technical } \\
\text { difficulties. }\end{array}$ \\
\hline \multicolumn{2}{|l|}{ Use behavior factor } \\
\hline Use behavior & Actual usage of the system. \\
\hline $\begin{array}{l}\text { Usage of the software platform - } \\
\text { general. }\end{array}$ & $\begin{array}{l}\text { Degree to which a student uses the software platform to } \\
\text { conduct the non-academic work of being a student. }\end{array}$ \\
\hline $\begin{array}{l}\text { Usage of the software platform - } \\
\text { specific }\end{array}$ & $\begin{array}{l}\text { Degree to which a student has used the software platform } \\
\text { in the past month. }\end{array}$ \\
\hline Frequency of use & Frequency of use of the software platform. \\
\hline $\begin{array}{l}\text { Usage of the software platform } \\
\text { to access university resources }\end{array}$ & $\begin{array}{l}\text { Degree to which a student uses the software platform to } \\
\text { access university resources (calendars, campus map, } \\
\text { library, university-related software, etc.). }\end{array}$ \\
\hline $\begin{array}{l}\text { Usage of the software platform } \\
\text { to access university services }\end{array}$ & $\begin{array}{l}\text { Degree to which a student uses the software platform to } \\
\text { access university services (academic advising, career } \\
\text { services, financial wellness center, resource centers, } \\
\text { tutoring, etc.). }\end{array}$ \\
\hline $\begin{array}{l}\text { Usage of the software platform } \\
\text { to conduct the business of being } \\
\text { a student }\end{array}$ & $\begin{array}{l}\text { Degree to which a student uses the software platform to } \\
\text { conduct business related to being a student (viewing } \\
\text { account balance, accessing the platform to pay bills, } \\
\text { accessing information about financial aid, accessing the } \\
\text { platform for registering for courses, viewing course } \\
\text { schedule, etc.) }\end{array}$ \\
\hline
\end{tabular}




\section{Agenda overview}

Welcome and thank you!

Q1. In reference to the preliminary research model information:

- What are your impressions of the model?

- What factors and/or indicators do you believe should be removed?

- What factors and/or indicators do you believe should be added?

Q2. What factors and/or indicators are most important to undergraduate students' adoption of myPSU?

(Mix of individual and group discussion)

\section{Research topic}

What are the critical factors that influence undergraduate students themselves in adopting software for accessing university services (one type of student information technology)? 


\section{Research methodology overview}

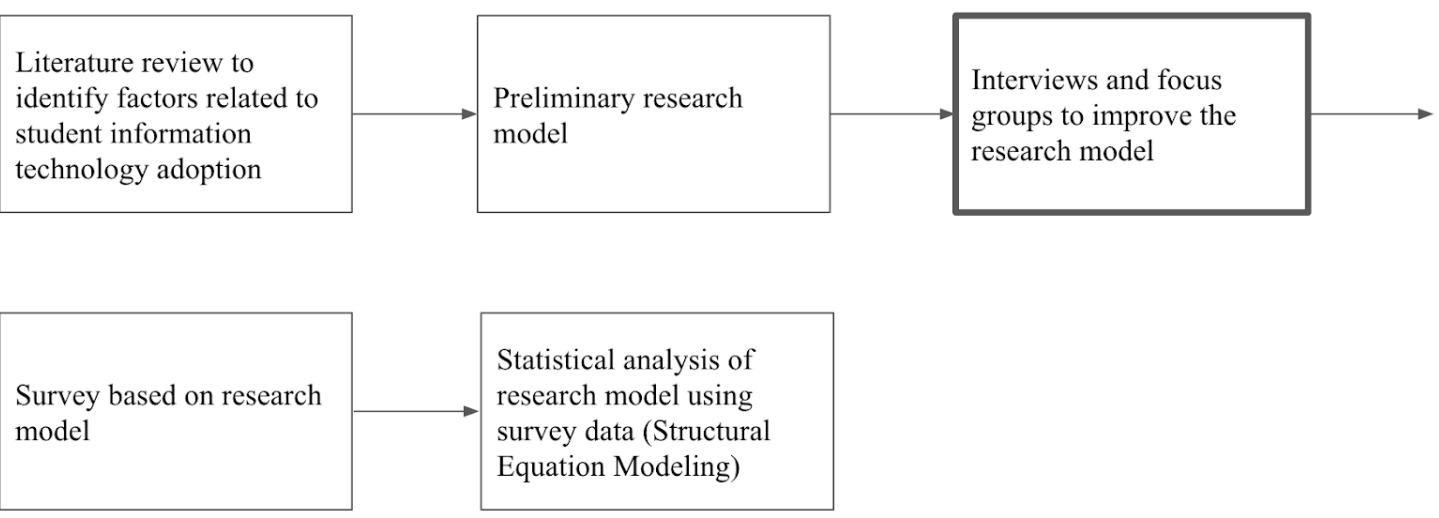

D.1o Focus Group Evaluation Sheet - Students and Experts

\begin{tabular}{|l|l|l|l|}
\hline Factors and indicators & $\begin{array}{l}\text { Related to } \\
\text { myPSU? } \\
\text { (Yes/No) }\end{array}$ & $\begin{array}{l}\text { Which are } \\
\text { the most } \\
\text { important } \\
\text { for myPSU } \\
\text { adoption? } \\
\text { (X) }\end{array}$ & Notes/comments \\
\hline Performance expectancy factor & & & \\
\hline Performance expectancy & & & \\
\hline Overall usefulness & & & \\
\hline Increase chances of graduating & & & \\
\hline Speed of conducting tasks & & & \\
\hline Platform response time & & & \\
\hline & & & \\
\hline & & & \\
\hline Effort expectancy factor & & & \\
\hline
\end{tabular}




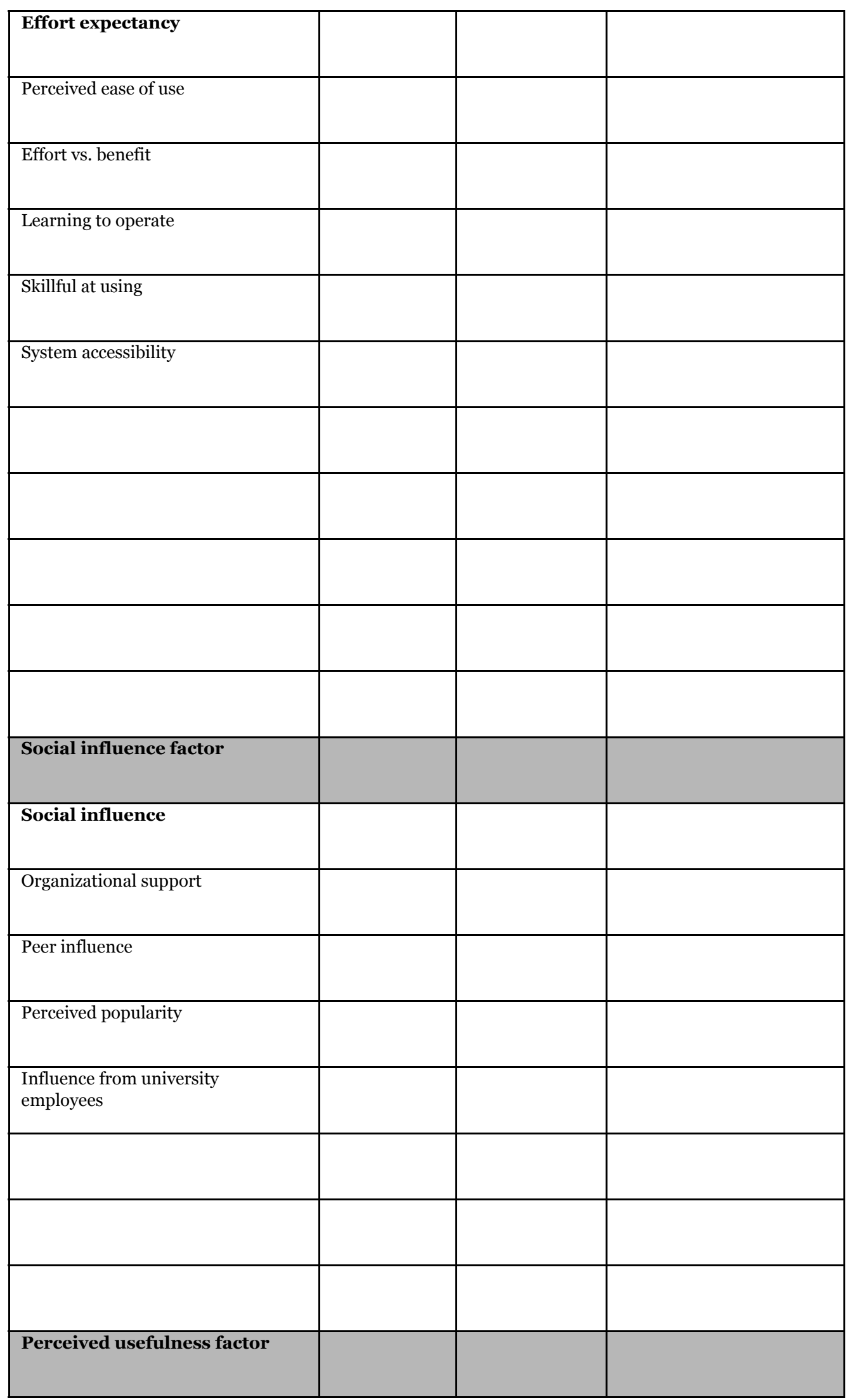




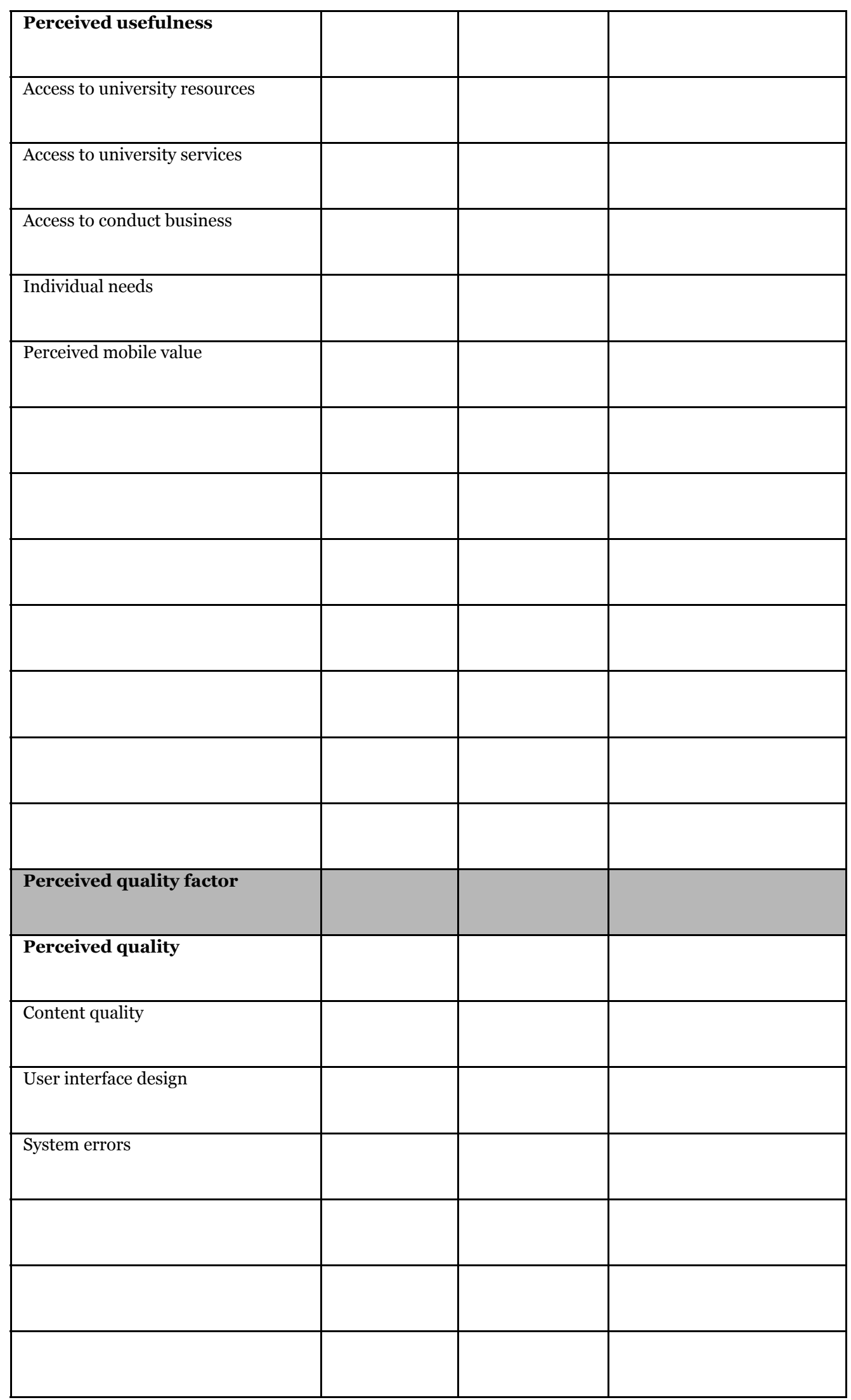




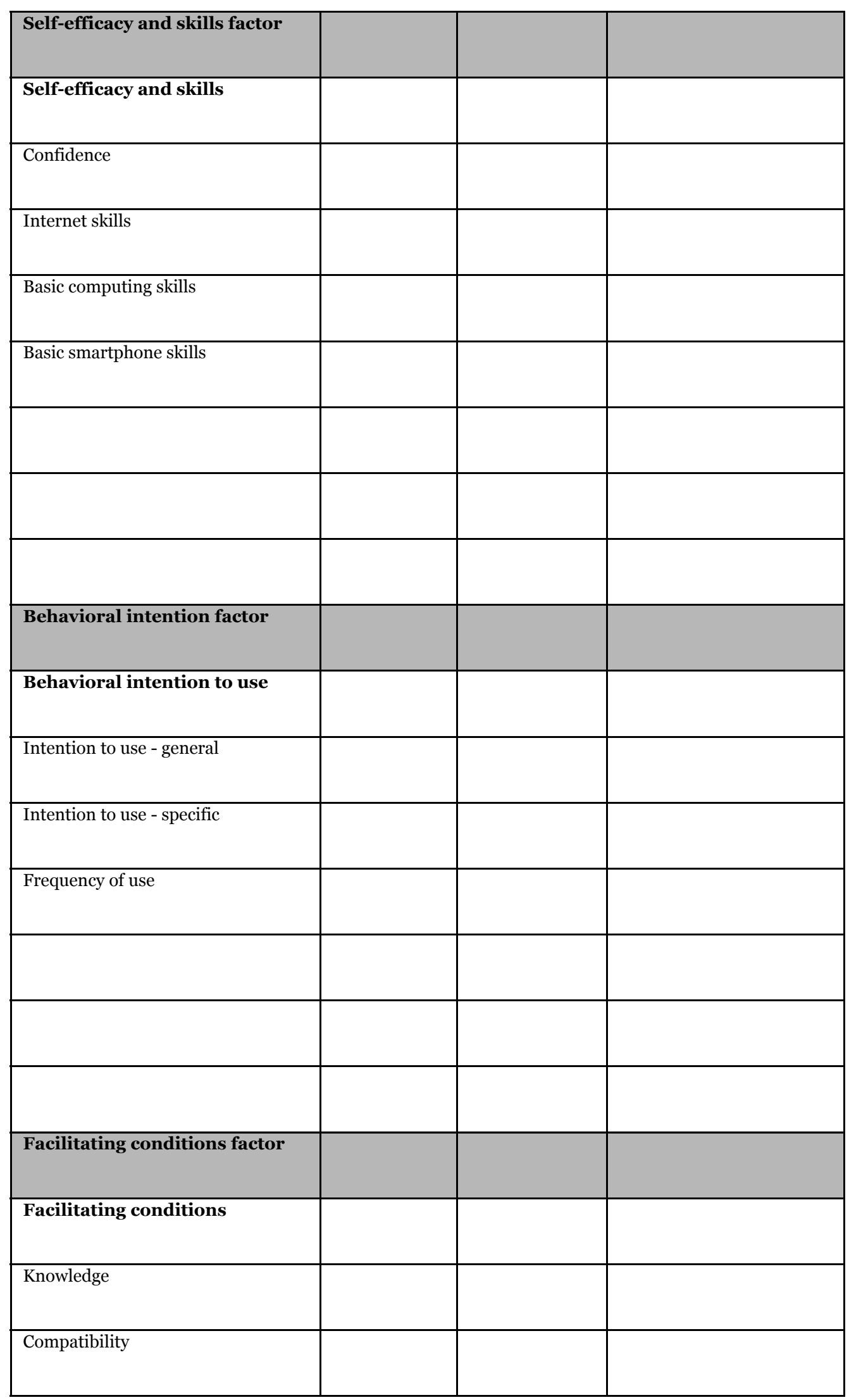




\begin{tabular}{|l|l|l|l|}
\hline Technical support & & & \\
\hline & & & \\
\hline & & & \\
\hline Use behavior factor & & & \\
\hline Use behavior & & & \\
\hline $\begin{array}{l}\text { Usage of the software platform - } \\
\text { general. }\end{array}$ & & & \\
\hline $\begin{array}{l}\text { Usage of the software platform - } \\
\text { specific }\end{array}$ & & & \\
\hline $\begin{array}{l}\text { Frequency of use } \\
\text { Usage of the software platform to } \\
\text { access university resources }\end{array}$ & & & \\
\hline $\begin{array}{l}\text { Usage of the software platform to } \\
\text { access university services }\end{array}$ & & & \\
\hline $\begin{array}{l}\text { Usage of the software platform to } \\
\text { conduct the business of being a } \\
\text { student }\end{array}$ & & & \\
\hline & & & \\
\hline & & & \\
\hline & & & \\
\hline & & & \\
\hline & & & \\
\hline
\end{tabular}

\begin{tabular}{|l|l|l|l|}
\hline Factors and indicators & $\begin{array}{l}\text { Related to } \\
\text { myPSU? } \\
\text { (Yes/No) }\end{array}$ & $\begin{array}{l}\text { Which are the } \\
\text { most important } \\
\text { for myPSU } \\
\text { adoption? (X) }\end{array}$ & $\begin{array}{l}\text { Notes/commen } \\
\text { ts }\end{array}$ \\
\hline Performance expectancy factor & & & \\
\hline Performance expectancy & & & \\
\hline Usefulness in being a student & & & \\
\hline Speed of building degree plan & & & \\
\hline Increase chances of graduating & & \\
\hline
\end{tabular}




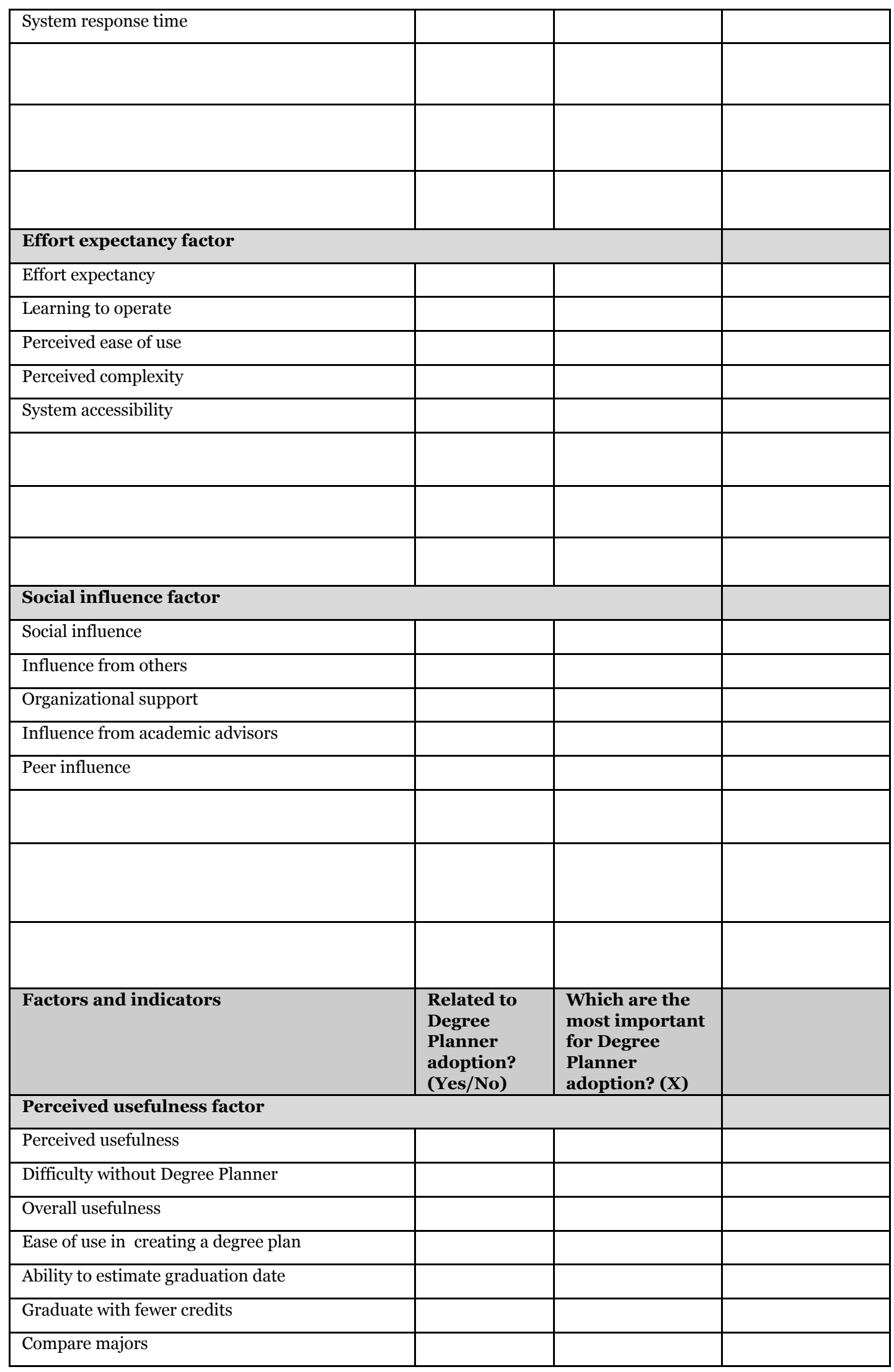




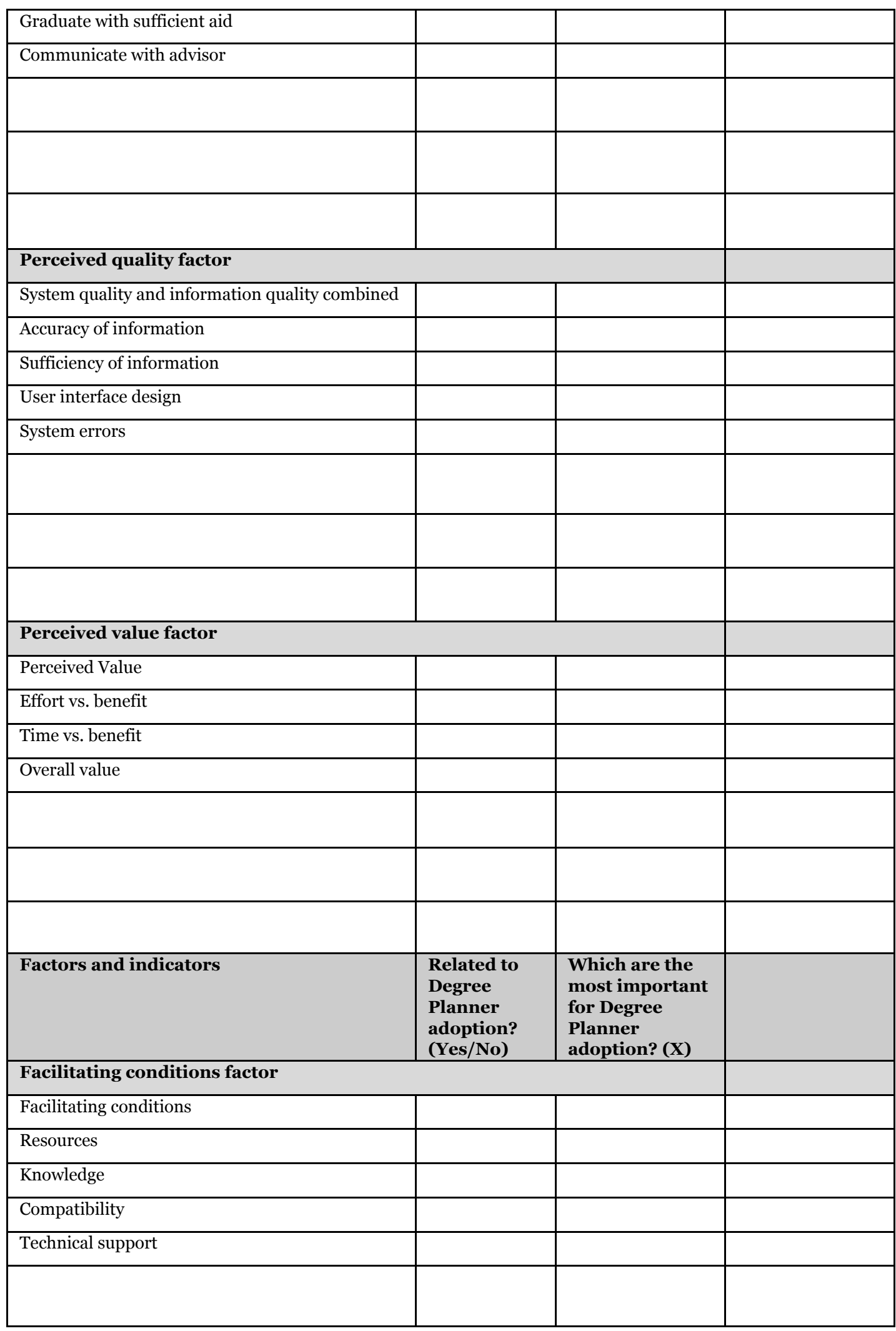




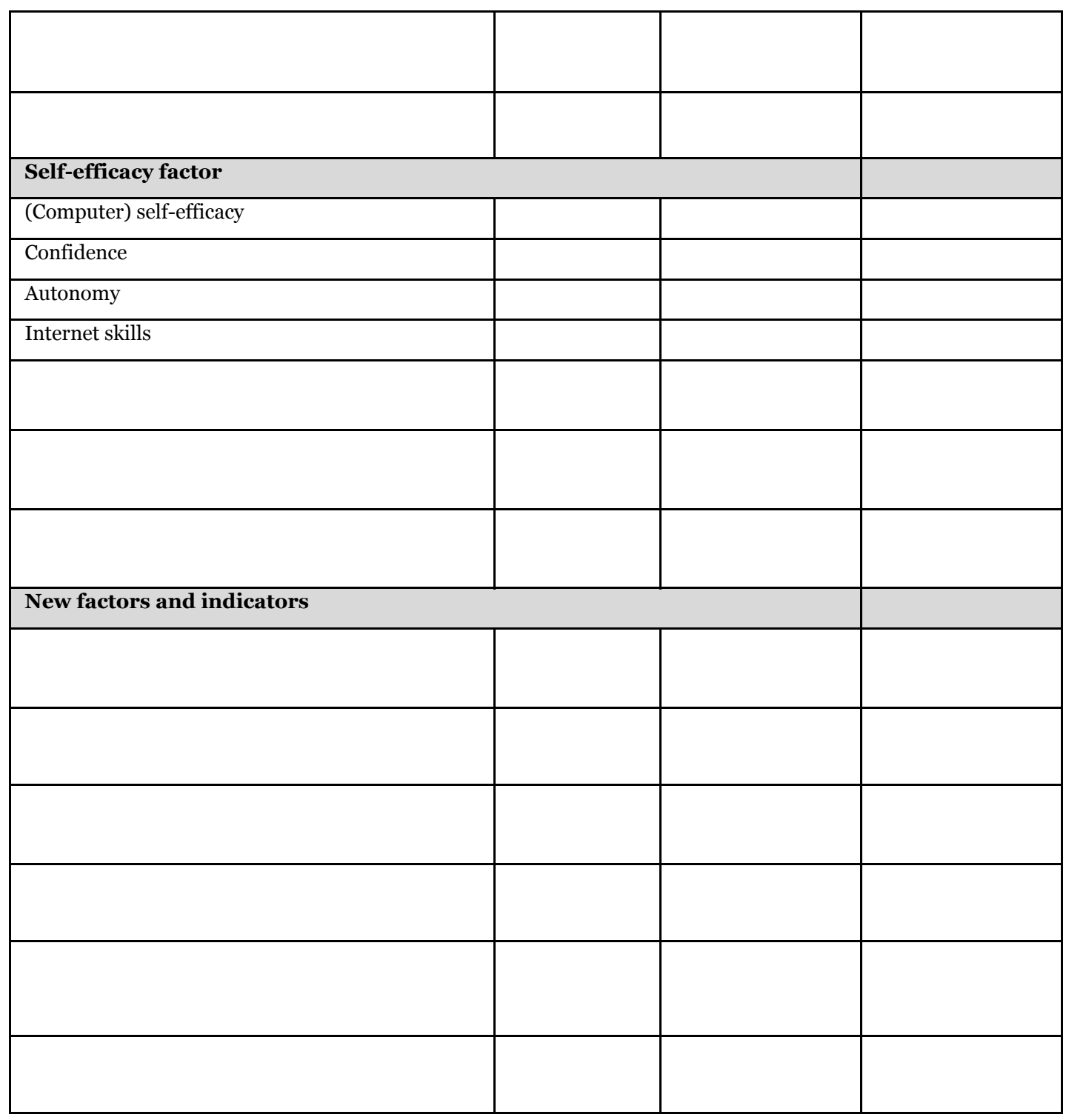




\section{Appendix E: Research Model Detailed Taxonomy}

\begin{tabular}{|c|c|c|c|}
\hline $\begin{array}{l}\text { Factors and } \\
\text { indicators }\end{array}$ & Definition & $\begin{array}{l}\text { Reference(s } \\
\text { ) for } \\
\text { definition(s } \\
\text { ) }\end{array}$ & $\begin{array}{l}\text { Reference(s) for } \\
\text { studies indicating } \\
\text { a positive } \\
\text { influence on } \\
\text { other factors }\end{array}$ \\
\hline \multicolumn{4}{|l|}{ UTAUT factors } \\
\hline \multicolumn{4}{|c|}{ Performance expectancy factor } \\
\hline $\begin{array}{l}\text { Performance } \\
\text { expectancy }\end{array}$ & $\begin{array}{l}\text { The degree to which an individual believes that } \\
\text { using a technology will help them overall. } \\
\text { Based on - "The degree to which an individual } \\
\text { believes that using the system will help him or her } \\
\text { to attain gains in job performance" [199]; and } \\
\text { "Aims to understand the extent to which using a } \\
\text { technology benefits a user" [263]g system [279] }\end{array}$ & $\begin{array}{l}{[263],} \\
{[199]}\end{array}$ & $\begin{array}{l}{[263],[264],[253]} \\
{[265],[266],[267]} \\
{[247],[252],[268]}\end{array}$ \\
\hline $\begin{array}{l}\text { Perceived } \\
\text { usefulness }\end{array}$ & $\begin{array}{l}\text { The degree to which a student believes that using } \\
\text { the software platform is useful. } \\
\text { Based on - "A respondent's opinion or perception } \\
\text { that a technology can be useful in accomplishing a } \\
\text { desired task" [271]; } \\
\text { "The degree to which a person believes that using a } \\
\text { particular system would enhance his or her job } \\
\text { performance" [209]; } \\
\text { System functionality - the functions or features of a } \\
\text { system [261]; User tools - specific tools/features of } \\
\text { an e-learning system [279]; Related to - Relative } \\
\text { advantage - "the degree to which a new technology } \\
\text { is perceived as better than the method or technique } \\
\text { used before the introduction of the new technology" } \\
\text { [234]; Satisfaction - "a psychological state related } \\
\text { to and resulting from a cognitive appraisal of the } \\
\text { expectation-performance discrepancy" [224]; } \\
\text { Perceived compatibility with student tasks - degree } \\
\text { to which the system is compatible with student } \\
\text { tasks in the course and student preferences for how } \\
\text { they like to study [294]; Compatibility - "the degree } \\
\text { to which the innovation is perceived to be } \\
\text { consistent with the potential users' existing values, } \\
\text { previous experiences and needs" [277]; and } \\
\text { Educational compatibility - "perceived fit between } \\
\text { the use of technology and students' constructive } \\
\text { beliefs about learning" [276] }\end{array}$ & $\begin{array}{l}{[209]_{2}[271]_{2}} \\
{[261],[279]_{2}} \\
{[199],[247]}\end{array}$ & $\begin{array}{l}\text { Perceived usefulness } \\
\text { as defined related to } \\
\text { Davis 1989- [277], } \\
{[270],[262],[280],} \\
{[281],[282],[232],} \\
{[233],[243],[271],} \\
{[244],[237],[283],} \\
{[242],[245],[284],} \\
{[285],[286],[112],} \\
{[234],[287],[288],} \\
{[289],[272],[290],} \\
{[278],[224],[261],} \\
{[273],[291],[292],} \\
{[276],[269],[274],} \\
{[279],[293],[294],} \\
{[295] ; \text { System }} \\
\text { functionality/user } \\
\text { tools - [261]; [279] }\end{array}$ \\
\hline $\begin{array}{l}\text { Access to } \\
\text { university } \\
\text { resources and } \\
\text { services }\end{array}$ & $\begin{array}{l}\text { Degree to which using the software platform } \\
\text { enables a student to quickly access university } \\
\text { resources (calendars, campus map, library, } \\
\text { university-related software, etc.) and services } \\
\text { (academic advising, career services, financial } \\
\text { wellness center, resource centers, tutoring, etc.). }\end{array}$ & {$[262],[199]$} & {$[261]$} \\
\hline $\begin{array}{l}\text { Access to conduct } \\
\text { business }\end{array}$ & $\begin{array}{l}\text { Degree to which using the software platform } \\
\text { enables a student to conduct business quickly (e.g. } \\
\text { viewing account balance, accessing the platform to } \\
\text { pay bills, accessing information about financial aid, } \\
\text { accessing the platform for registering for courses, } \\
\text { etc.). }\end{array}$ & {$[262],[199]$} & {$[261]$} \\
\hline One-stop shop & $\begin{array}{l}\text { Degree to which a students' productivity increases } \\
\text { by using the software platform as a one-stop shop } \\
\text { for navigating the university (e.g. accessing }\end{array}$ & {$[261] ;[199]$} & {$[261]$} \\
\hline
\end{tabular}




\begin{tabular}{|c|c|c|c|}
\hline & $\begin{array}{l}\text { services, resources and university-related software, } \\
\text { and conducting student business, all in one place). } \\
\text { Related to System functionality - } \\
\text { "The functions or features of a system" [261] }\end{array}$ & & \\
\hline $\begin{array}{l}\text { Perceived mobile } \\
\text { value }\end{array}$ & $\begin{array}{l}\text { The degree to which the software platform is } \\
\text { convenient to access anytime and anywhere with no } \\
\text { restrictions. } \\
\text { Related to - } \\
\text { "Consciousness of users about the mobility value of } \\
\text { M-learning" [295]; and Mobility - "the extent to } \\
\text { which students can access the podcast anytime and } \\
\text { anywhere with no restrictions" [234] }\end{array}$ & {$[295]_{2}[234]$} & [295], [234] \\
\hline \multicolumn{4}{|c|}{ Effort expectancy factor } \\
\hline $\begin{array}{l}\text { Effort } \\
\text { expectancy }\end{array}$ & $\begin{array}{l}\text { "Degree of ease associated with the use of the } \\
\text { system" [199] }\end{array}$ & [199] & $\begin{array}{l}253],[265],[266], \\
{[247],[254],[252],} \\
{[268]}\end{array}$ \\
\hline $\begin{array}{l}\text { Perceived ease of } \\
\text { use }\end{array}$ & $\begin{array}{l}\text { Degree to which the software platform is easy for a } \\
\text { student to use. } \\
\text { Based on - "A respondent's opinion or perception } \\
\text { that a technology can be used to solve a } \\
\text { problem with a relatively low expenditure of effort } \\
\text { and a reasonable chance of success" [271] and } \\
\text { related to - "The degree of ease of use of a } \\
\text { technology" [263] and Perceived complexity - } \\
\text { "assesses the extent of difficulty in using the } \\
\text { Internet, which is similar to the concept of } \\
\text { Perceived Ease of Use" [290] }\end{array}$ & {$[271]$} & $\begin{array}{l}{[277],[270],[241],} \\
{[280],[281],[282],} \\
{[232],[233],[243],} \\
{[271],[244],[283],} \\
{[242],[248],[284],} \\
{[286],[112],[234],} \\
{[287],[288],[289],} \\
{[272],[278],[224],} \\
{[261],[297],[292],} \\
{[269],[274],[293],} \\
{[294],[295],[245],} \\
{[285],[290],[293]}\end{array}$ \\
\hline Effort vs. benefit & $\begin{array}{l}\text { Degree to which a student believes that the effort it } \\
\text { takes to use a software platform is worth the } \\
\text { benefits. }\end{array}$ & [235] & - \\
\hline $\begin{array}{l}\text { Learning to } \\
\text { operate }\end{array}$ & $\begin{array}{l}\text { Degree to which learning how to operate the } \\
\text { software platform was easy for a student. }\end{array}$ & {$[247]$} & {$[290],[293]$} \\
\hline $\begin{array}{l}\text { System } \\
\text { accessibility }\end{array}$ & $\begin{array}{l}\text { Degree to which a student can easily navigate to the } \\
\text { software platform on the Internet. } \\
\text { Related to - } \\
\text { System accessibility [112]; Accessibility [279]; } \\
\text { Cloud accessibility [263]; Access to software [289]; } \\
\text { Enablers [280]; and Ease of finding [297] }\end{array}$ & [112] & $\begin{array}{l}279],[112]_{2}[263] \\
{[289]_{2}[280],[297]}\end{array}$ \\
\hline Mobile app & $\begin{array}{l}\text { Degree to which using the smartphone/mobile app } \\
\text { makes it convenient to access the platform. } \\
\text { Based on Perceived mobility value - "Consciousness } \\
\text { of users about the mobility value of M-learning" } \\
\text { [295] }\end{array}$ & {$[295]$} & {$[295]$} \\
\hline \multicolumn{4}{|c|}{ Social influence factor } \\
\hline Social influence & $\begin{array}{l}\text { "Extent to which users perceive that those } \\
\text { important to them believe they should be using a } \\
\text { technology" [263] } \\
\text { Related to Subjective norm - "A person's subjective } \\
\text { norm is determined by her perception that } \\
\text { salient social referents think he/she should or } \\
\text { should not perform a particular behavior" [233]; } \\
\text { and based on - "the degree to which an individual } \\
\text { perceives that important others believe he or she } \\
\text { should use the new system" [199] }\end{array}$ & {$[263]$} & $\begin{array}{l}\text { Social influence - } \\
\text { [264], [253], [265], } \\
\text { [266], [267], [247], } \\
\text { [254], [252], [224], } \\
\text { [268], [269]; } \\
\text { Subjective positive- } \\
\text { [270], [233], [271], } \\
\text { [242], [112], [272], } \\
\text { [273], [274] }\end{array}$ \\
\hline Peer influence & $\begin{array}{l}\text { Degree to which a student's peers have } \\
\text { recommended use of the software platform. }\end{array}$ & {$[270]$} & $\begin{array}{l}\text { [270], [278], [290], } \\
\text { [293], [233] }\end{array}$ \\
\hline
\end{tabular}




\begin{tabular}{|c|c|c|c|}
\hline & $\begin{array}{l}\text { Based on - Social pressure - "Refers to an } \\
\text { individual's perceptions of normatively appropriate } \\
\text { behaviour with regard to the use of the } \\
\text { Internet/web in university study" [290]; Perceived } \\
\text { critical mass - "whether an innovation has attracted } \\
\text { a critical mass of users influence ensuing adoption } \\
\text { and use" [293]; Perceived network externality - } \\
\text { "relates to an increase in the value of a product or } \\
\text { service to a consumer, not because of the inherent } \\
\text { quality of the product or service, but because of } \\
\text { increasing numbers of others adopting it" [233] }\end{array}$ & & \\
\hline Marketing & $\begin{array}{l}\text { Degree to which receiving marketing messages } \\
\text { about the software platform, such as posters, social } \\
\text { media, emails, flyers and other } \\
\text { promotional/marketing materials or outreach, has } \\
\text { encouraged a student to use it. }\end{array}$ & $\begin{array}{l}\text { Generated } \\
\text { through } \\
\text { qualitative } \\
\text { research } \\
\text { methods }\end{array}$ & $\begin{array}{l}\text { Generated through } \\
\text { qualitative research } \\
\text { methods }\end{array}$ \\
\hline $\begin{array}{l}\text { Influence from } \\
\text { university } \\
\text { employees }\end{array}$ & $\begin{array}{l}\text { Degree to which university employees (e.g. faculty, } \\
\text { staff, advisors, etc.) think a student should use the } \\
\text { software platform. } \\
\text { Based on Faculty influence on students (superior } \\
\text { influence) [270]; "learners' perception of their } \\
\text { instructors' attitude toward e-Learning" (Instructor } \\
\text { attitude toward e-learning) [288]; and } \\
\text { Encouragement to use the cloud computing } \\
\text { technology (Instructor support) [289]; } \\
\text { Organizational support - support from the } \\
\text { University "ensures the necessary resources are } \\
\text { allocated for Internet access and use" [290]; and } \\
\text { Instructor support, which "can encourage more } \\
\text { active use of the Internet for class assignments and } \\
\text { interaction" [290] }\end{array}$ & {$[199]_{2}[247]$} & $\begin{array}{l}\text { [270], [288], [289], } \\
{[290]}\end{array}$ \\
\hline \multicolumn{4}{|c|}{ Facilitating conditions factor } \\
\hline $\begin{array}{l}\text { Facilitating } \\
\text { conditions }\end{array}$ & $\begin{array}{l}\text { "The degree to which an individual believes that an } \\
\text { organizational and technical infrastructure exists to } \\
\text { support use of the system" [199] }\end{array}$ & [199] & $\begin{array}{l}\text { [263], [275], [266], } \\
{[267],[247],[268],} \\
{[276],[269]}\end{array}$ \\
\hline Compatibility & $\begin{array}{l}\text { Degree to which a student can easily/seamlessly } \\
\text { access other university software platforms and } \\
\text { online tools through the software platform being } \\
\text { studied (e.g. students do not have to log-in multiple } \\
\text { times when accessing other platforms, degree to } \\
\text { which other platforms are easy to find in the } \\
\text { software platform being studied, etc.). } \\
\text { Related to Perceived behavioral control - "The } \\
\text { system is not compatible with other systems I use" } \\
\text { [199] and Perceived compatibility with student } \\
\text { tasks - "Degree to which the system is compatible } \\
\text { with student tasks in the course and student } \\
\text { preferences for how they like to study" [294] }\end{array}$ & [199] & [294] \\
\hline Technical support & $\begin{array}{l}\text { Degree to which a specific person (or group) is } \\
\text { available for assistance with the software platform's } \\
\text { technical difficulties. } \\
\text { Based on - Technical support - People provide } \\
\text { support for computer hardware and software } \\
\text { problems, through help desks, on-line technical } \\
\text { support, the phone, etc. [282]; and Service quality - } \\
\text { "accounts for the perceived level of support } \\
\text { available to users of a given technology" [271] }\end{array}$ & {$[282],[271]$} & $\begin{array}{l}{[282],[285],[286],} \\
{[271],[224]}\end{array}$ \\
\hline
\end{tabular}




\begin{tabular}{|c|c|c|c|}
\hline $\begin{array}{l}\text { Learning about a } \\
\text { platform }\end{array}$ & $\begin{array}{l}\text { Degree to which learning about a software platform } \\
\text { (e.g. about how to use its features and } \\
\text { functionality) has helped a student learn how to use } \\
\text { it. } \\
\text { Based on - "Internal training refers to } \\
\text { intraorganizational training, or training found } \\
\text { within the organization" [293] }\end{array}$ & {$[293]$} & {$[293],[294]$} \\
\hline \multicolumn{4}{|c|}{ Behavioral intention factor } \\
\hline $\begin{array}{l}\text { Behavioral } \\
\text { intention to use }\end{array}$ & $\begin{array}{l}\text { "The decision maker's disposition toward using a } \\
\text { system" [271] } \\
\text { Related to - Attitude toward the system, } \\
\text { satisfaction with the system, preference for the } \\
\text { system [280]; and "Degree to which a user is } \\
\text { interested in using the system" [278] }\end{array}$ & {$[271]$} & $\begin{array}{l}{[277],[270],[241]_{2}} \\
{[271],[244],[264],} \\
{[278],[247],[279]}\end{array}$ \\
\hline Intend to use & $\begin{array}{l}\text { Degree to which a student intends to use the } \\
\text { software platform in the future. }\end{array}$ & {$[225]$} & - \\
\hline Predict to use & $\begin{array}{l}\text { Degree to which a student predicts they will use the } \\
\text { software platform during an academic term. }\end{array}$ & [199] & - \\
\hline Plan to use & $\begin{array}{l}\text { Degree to which a student plans to use the software } \\
\text { platform during an academic term. }\end{array}$ & [199] & - \\
\hline $\begin{array}{l}\text { Plan to use - } \\
\text { frequently }\end{array}$ & $\begin{array}{l}\text { Degree to which a student plans to use the software } \\
\text { platform frequently. }\end{array}$ & {$[225]$} & - \\
\hline \multicolumn{4}{|c|}{ Use behavior factor } \\
\hline Use behavior & Actual usage of the system. & [199] & - \\
\hline Frequency of use & Frequency of use of the software platform. & {$[247],[225]$} & - \\
\hline $\begin{array}{l}\text { Usage of the } \\
\text { platform to access } \\
\text { university } \\
\text { resources and } \\
\text { services }\end{array}$ & $\begin{array}{l}\text { Degree to which a student uses the software } \\
\text { platform to access university resources (calendars, } \\
\text { campus map, library, university-related software, } \\
\text { etc.) and services (academic advising, career } \\
\text { services, financial wellness center, resource centers, } \\
\text { tutoring, etc.). }\end{array}$ & [247] & - \\
\hline $\begin{array}{l}\text { Usage of the } \\
\text { platform to } \\
\text { conduct business }\end{array}$ & $\begin{array}{l}\text { Degree to which a student uses the software } \\
\text { platform to conduct business (e.g. viewing account } \\
\text { balance, accessing the platform to pay bills, } \\
\text { accessing information about financial aid, accessing } \\
\text { the platform for registering for courses, etc.) }\end{array}$ & [247] & - \\
\hline $\begin{array}{l}\text { Usage of the } \\
\text { platform as a } \\
\text { one-stop shop }\end{array}$ & $\begin{array}{l}\text { Degree to which a student uses the software } \\
\text { platform as a one-stop shop for navigating the } \\
\text { university (e.g. accessing services, resources and } \\
\text { university-related software, and conducting student } \\
\text { business, all in one place). }\end{array}$ & {$[261]$} & - \\
\hline \multicolumn{4}{|c|}{ Factors added to UTAUT } \\
\hline \multicolumn{4}{|c|}{ Perceived quality factor } \\
\hline $\begin{array}{l}\text { Perceived } \\
\text { quality }\end{array}$ & $\begin{array}{l}\text { The user's opinion of the quality of a software } \\
\text { platform. } \\
\text { Related to - "Items from system quality and } \\
\text { information quality loaded together, with the } \\
\text { resulting factor named SIQ [system and } \\
\text { information quality], suggesting that distinctions } \\
\text { between system quality and information quality } \\
\text { may no longer be pivotal for mobile applications" } \\
\text { [291]; System quality - "The user's opinion of the } \\
\text { merits and performance of a technology in question } \\
\text { with respect to available alternative solutions" } \\
\text { [271]; Information quality - "The quality of the } \\
\text { output from an IS" [26o], [296]; and Information }\end{array}$ & $\begin{array}{l}271],[260], \\
{[296],[271]}\end{array}$ & $\begin{array}{l}\text { System quality - } \\
{[277]_{2}[271],[291] ;} \\
\text { Information quality } \\
-[271],[260],[291]\end{array}$ \\
\hline
\end{tabular}




\begin{tabular}{|c|c|c|c|}
\hline & $\begin{array}{l}\text { quality - "the independent variable information } \\
\text { quality reflects the quality of the results produced } \\
\text { by a technology" [271] }\end{array}$ & & \\
\hline Content quality & $\begin{array}{l}\text { Degree to which the quality of the content in the } \\
\text { software platform is sufficient in meeting a } \\
\text { student's needs. } \\
\text { Related to - Information quality - "The quality of } \\
\text { the output from an IS" [26o], [296]; Information } \\
\text { quality - "the independent variable information } \\
\text { quality reflects the quality of the results produced } \\
\text { by a technology" [271]; Two dimensions of } \\
\text { perceived content quality - content richness and } \\
\text { update regularity [233]; Trust - "a subjective } \\
\text { expectation that someone or something is reliable } \\
\text { and willing to accept vulnerability" [265]; } \\
\text { Credibility - "The certainty and pleasant } \\
\text { consequences of using an electronic application } \\
\text { service, when there is no financial risk, physical } \\
\text { risk, functional risk, social risk, time-loss risk, } \\
\text { opportunity cost risk, and information risk" [237]; } \\
\text { Accuracy of information [26o]; Reliability - the } \\
\text { trust and confidence the user places on a system } \\
\text { [279]; and Sufficiency of information [26o] }\end{array}$ & $\begin{array}{l}{[260],[296],} \\
{[271]}\end{array}$ & $\begin{array}{l}{[271],[260],[291],} \\
{[233],[265],[237],} \\
{[279]}\end{array}$ \\
\hline $\begin{array}{l}\text { User interface } \\
\text { design }\end{array}$ & $\begin{array}{l}\text { Degree to which a student believes the software } \\
\text { platform has well-designed user interfaces (pages, } \\
\text { graphics, visuals, content, navigation, etc.). } \\
\text { Related to - Ease of understanding - "Reflects the } \\
\text { need for a web site to use understandable and } \\
\text { consistent graphics and terms. It should } \\
\text { furthermore be visually appealing and readable, } \\
\text { and provide links to more detailed information } \\
\text { about the subject at hand" [297] }\end{array}$ & [260] & [297] \\
\hline System errors & $\begin{array}{l}\text { Degree to which a student encounters system errors } \\
\text { when using the software platform. }\end{array}$ & [291] & - \\
\hline $\begin{array}{l}\text { Platform response } \\
\text { time }\end{array}$ & $\begin{array}{l}\text { Degree to which a student experiences the software } \\
\text { platform response as fast. } \\
\text { Based on - the system performance in terms of } \\
\text { speed; when the real performance of a service or } \\
\text { product is the same as the expectation [408] }\end{array}$ & [261] & {$[261]$} \\
\hline \multicolumn{4}{|c|}{ Self-efficacy and skills factor } \\
\hline $\begin{array}{l}\text { Self-efficacy and } \\
\text { skills }\end{array}$ & $\begin{array}{l}\text { The judgement of one's own ability to perform } \\
\text { specific technology-related tasks and the skills to } \\
\text { do so. } \\
\text { Related to - (Computer) self-efficacy - "People's } \\
\text { judgement of their own ability to perform specific } \\
\text { tasks" [233]; Perceived ease of use and perceived } \\
\text { usefulness because "individuals' confidence in their } \\
\text { computer-related knowledge and abilities can } \\
\text { influence their judgement of the ease or difficulty of } \\
\text { carrying out a specific task using a new IT, and how } \\
\text { useful that new IT will be" [233]; and Basic ICT } \\
\text { skills - The competency of users related to basic } \\
\text { computing and mobile activities [292] }\end{array}$ & $\begin{array}{l}233], \\
{[292]}\end{array}$ & $\begin{array}{l}\text { Self-efficacy - [277], } \\
{[233],[271],[270],} \\
{[286],[112],[234],} \\
{[278],[265],[247],} \\
{[297],[276],[295] ;} \\
\text { Skills - }[295],[290], \\
{[292],[292],[263],} \\
{[286],[274],[112]}\end{array}$ \\
\hline Confidence & $\begin{array}{l}\text { Degree to which a student feels confident they can } \\
\text { overcome any technology-related obstacles when } \\
\text { using a software platform. }\end{array}$ & {$[233]$} & $\begin{array}{l}\text { [277], [233], [271], } \\
{[270],[286],[112],} \\
{[234],[278],[265]}\end{array}$ \\
\hline
\end{tabular}




\begin{tabular}{|c|c|c|c|}
\hline & & & $\begin{array}{l}\text { [247], [297], [276], } \\
\text { [295] }\end{array}$ \\
\hline $\begin{array}{l}\text { Basic computing } \\
\text { skills }\end{array}$ & $\begin{array}{l}\text { The proficiency of users related to conducting basic } \\
\text { computing activities (using writing/word } \\
\text { processing software, using the Internet, emailing, } \\
\text { etc.). } \\
\text { Based on - Basic ICT skills - "everyday ICT usage"; } \\
\text { "the competency of users in relation to general } \\
\text { computing tasks, such as using word processing } \\
\text { software, searching and emailing on the Internet } \\
\text { and doing basic mobile activities, such as texting } \\
\text { and calling" [292]; Experience - "perceived } \\
\text { computer literacy of adopters and their experience } \\
\text { with using technology" [263]; Internet skills - skills } \\
\text { of a user with respect to using the Internet [29o]; } \\
\text { and Internet experience - an individual's } \\
\text { experiences with a specific technology influences } \\
\text { perceptions of ease of use and usefulness of that } \\
\text { technology [286] }\end{array}$ & [292] & $\begin{array}{l}{[292]_{2}[112]_{2}[263],} \\
{[290]_{2}[286]_{2}[274]}\end{array}$ \\
\hline $\begin{array}{l}\text { Basic smartphone } \\
\text { skills }\end{array}$ & $\begin{array}{l}\text { The proficiency of users related to basic } \\
\text { smartphone activities (using apps, texting and } \\
\text { calling, etc.). } \\
\text { Based on - Basic ICT skills - "everyday ICT usage"; } \\
\text { "the competency of users in relation to general } \\
\text { computing tasks, such as using word processing } \\
\text { software, searching and emailing on the Internet } \\
\text { and doing basic mobile activities, such as texting } \\
\text { and calling" [292] } \\
\text { Related to Advance mobile tasks - "tasks associated } \\
\text { with mobile usage" [292]; and Mobile learning } \\
\text { self-efficacy - "The personal confidence in finding } \\
\text { information and communicating with an instructor } \\
\text { within the e-learning system and the necessary } \\
\text { skills for using the system" [112] }\end{array}$ & [292] & {$[292]_{2}[112]$} \\
\hline
\end{tabular}




\section{Appendix F: Expert Panel Materials}

F.1 Instructions - Lay Experts (Students)

Subject: Evaluate myPSU draft survey (\$10 Amazon gift card) - response by Monday, 3/16 at 9pm

Dear

Thank you for accepting my invitation to evaluate the draft myPSU survey for my PhD dissertation research! Participating is estimated to take approximately 20 minutes.

As a reminder, after you complete the evaluation and it's clear that you've been thoughtful and thorough in your responses, I'll email you a \$10 Amazon gift card.

Would you please evaluate the survey by Monday, March 16, at 9pm? Here's the link: https://portlandstate.qualtrics.com/jfe/form/SV_6PSjiN6WTY2zZUp

You're the expert, and I'm really relying on your feedback, as only a few select students were selected to participate - thank you!

Additional details that might be helpful are below.

Thanks again for your willingness to participate (I really appreciate it!), and please let me know if there are any questions.

Best,

Hans

Here are additional details for evaluating the draft survey:

- Attached is information about the research model that I've developed in light of considering myPSU adoption by students.

- This model is based on the Unified Theory of Acceptance and Use of Technology (UTAUT) technology adoption model and also reflects factors and indicators (and their definitions) that: I identified in a literature review of why higher education students adopt technology; and have been evaluated and improved in the past few weeks through focus groups and interviews. If you're not aware, factors, or constructs, are concepts that cannot be directly measured and must be approximately measured by multiple indicators (Hair et al. 2013), or variables, that could be items in a survey (Garson 2015).

\section{F.2 Invitation to Participate - Content Experts (Professionals)}

Subject: Expert panel invitation re: adoption of software for student success and university services

Greetings

I hope this email finds you well. My name is Hans VanDerSchaaf, and I'm a PhD candidate in the Department of Engineering and Technology Management at PSU. 
I'm working on my dissertation and I'm writing to inquire if you might be available to participate as an expert panelist - approximately 15-30 minutes of your time - to review a draft survey instrument (via an online form) related to the adoption of university services software that supports student success? Your expertise will be incredibly helpful for this research! Additionally, your contributions will help move the field forward, in terms of enabling us to develop more insights about student technology use in support of improving student success.

I anticipate sharing the draft survey instrument around the first or second week of March, with a request that the panelists provide their feedback within a few days of my outreach. Additional details about the research and the role of the expert panelists is below.

Thanks so much for considering!

Hans

\section{Research Summary}

My research topic is - What are the critical factors that influence undergraduate students themselves in adopting software for accessing university services (one type of student success technology)? The technology that I'm analyzing is myPSU, which is a web-based digital services platform that aids undergraduate and graduate students in accessing services and resources critical to maintaining their enrollment. myPSU is available to Portland State University students as both a native mobile application and as a website, with content between the two being very similar. Information about myPSU is attached.

I've identified initial factors that might influence myPSU adoption through a literature review and in relation to a research model that has been used in other settings to help predict adoption of technology (it's called the Unified Theory of Acceptance and use of Technology, or UTAUT). The preliminary research model is attached - this will be modified based on interviews and focus group feedback in the coming few weeks. I'll then create a revised model with a corresponding survey instrument, which will be distributed to Portland State undergraduates. The survey responses will be empirically evaluated, with the findings hopefully contributing to the development of student success technology at Portland State University and other institutions across the country.

\section{Expert Panelists}

- Expert panelists will be asked to review a draft survey instrument to help gauge the validity of the instrument, including whether the survey items are relevant to adoption of myPSU and the ease of answering each question.

- A survey instrument (43 questions) based off of the preliminary research model is attached, along with an example of what the evaluation form will look like - to help provide a sense of what panelists will be asked to review and how to do so.

\section{If you're able to participate, would you please:}

- Share the number of years of professional experience you have related to higher education, educational technology and/or the technology innovation sector(s)?) This information will help me summarize, without names or identifying information, the expert panelist participants.

- Sign a copy of the attached consent form and email to me. 
Thanks for considering this invitation

Hans

F.3 Instructions - Content Experts (Professionals)

Subject: Evaluation of draft survey instrument for dissertation research - response by Fri, 3/20?

Dear

Thank you for accepting my invitation to review the draft myPSU survey instrument for my PhD dissertation research! Participating is estimated to take 30-45 minutes.

Would you please evaluate the survey instrument by Friday, March 2o, at 5pm? Here's the link: link

Additional details that might be helpful are below.

Thanks again for your willingness to participate (I really appreciate it!). Your expertise will be incredibly helpful.

Please let me know if there are any questions.

Best,

Hans

Here are additional details for evaluating the draft survey instrument:

- Attached is information about the research model that I've developed in light of considering myPSU adoption by students. This model is based on the Unified Theory of Acceptance and Use of Technology (UTAUT) technology adoption model and also reflects factors and indicators (and their definitions) that: I identified in a literature review of why higher education students adopt technology; and have been evaluated and improved in the past few weeks through focus groups and interviews. If you're not aware, factors, or constructs, are concepts that cannot be directly measured and must be approximately measured by multiple indicators (Hair et al. 2013), or variables, that could be items in a survey (Garson 2015).

- Also attached is a summary of myPSU, which is the software that will be analyzed in my study.

F.4 Consent Form for Expert Panel

Consent to Participate in Research

Project Title: Determinants of Student Information Technology

Adoption

Population:

Undergraduate students at Portland State University 
Researcher:

\section{Researcher Contact: $\quad$ hansv@pdx.edu / phone}

You are being asked to take part in a research study. The box below highlights the main information about this research for you to consider when making a decision whether or not to join in the study. Please carefully look over the information given to you on this form. Please ask questions about any of the information you do not understand before you decide to agree to take part.

\section{Key Information for You to Consider}

- Voluntary Consent. You are being asked to volunteer for a research study. It is up to you whether you choose to take part or not. There is no penalty if you choose not to join in or decide to stop your involvement.

- Why is the study being done? The reason for this research is to understand the key factors that may influence undergraduate students' adoption and use of software for accessing university services, in support of improving undergraduate retention and graduation rates at universities. The research will analyze adoption of myPSU, which is available for Portland State University students. The findings will support PSU and other universities in improving student technology tools. This research is being conducted in partial fulfillment of the requirements for Hans VanDerSchaaf's doctoral degree in Technology Management. You are being asked to participate because you are an undergraduate student at PSU or you are an expert. About 50-60 people will participate in this phase of the research, which is for developing a web survey for undergraduate students.

- How long will it take? The length of time depends on how you participate (only one activity per participant): 1:1 interview, 60 minutes; or Focus group, 90 minutes; or Survey read aloud, 6o minutes; or Evaluate a draft survey, approximately 20 minutes; or Take a draft survey and provide feedback, approximately 20 minutes.

- What will I be expected to do? You will be asked to provide feedback, either:

o Verbally and/or via written communications - about the adoption factors and corresponding variables which may relate to undergraduate student adoption of myPSU, which is software for accessing university services and is available to PSU students - through 1:1 interviews and focus group research activities, held on or near the PSU campus or via a video or phone call; or

o Provide feedback on a draft survey instrument about the reasons why students adopt myPSU through a survey read aloud; or by evaluating a 
draft survey; or by taking a draft survey and providing feedback - all of these activities except the survey read aloud happen on-line/remotely.

o You will participate in only one part of this research.

- Risks. Some of the possible risks or discomforts of taking part in this study include that in the individual interviews and focus groups, participants may be asked to explain the reasons why they use myPSU. Also, as with any situation where sensitive information is disclosed, such as names and email addresses, there is the remote possibility of a data breach. Robust protections are in place to ensure that a data breach does not occur, including that only the investigators have access to collected data. Risks are minimal for participating in this research study.

- Benefits. Some of the benefits that may be expected include incentives for participating for students (see below) and that the researchers hope to gain helpful information to assist PSU and other universities with improving technology to help students.

- Options. Participation is voluntary and the only alternative is to not participate.

\section{What happens to the information collected?}

Information collected for this research will be used to help PSU, other universities and educational technology companies improve student information technology software and services. Any published or disseminated information will be reported in aggregate format only and no identifiable information will be included - reporting will only combine results and will never report individual results.

\section{How will my privacy and data be protected?}

We will take measures to protect your privacy including that data that contains identifiers linked to participants will be kept confidential at all times and will be accessible to only the principal investigator and the co-principal investigator. All data obtained from participants will be kept confidential and will only be reported in the aggregate format (reporting only combined results and never reporting individual results). Before any presentation, sharing data outside of the research team or publication, the names and identifiers linked to the participants will be removed to insure anonymity. Despite taking steps to protect your privacy, we can never fully guarantee that your privacy will be protected.

To protect all of your personal information, we will keep all collected data in password-protected and secure locations. Despite these precautions, we can never fully guarantee that all your study information will not be revealed.

Individuals and organizations that conduct or monitor this research may be permitted access to inspect research records. This may include private information. These individuals and organizations include the Institutional Review Board that reviewed this research. 


\section{What if I want to stop my part in this research?}

Your part in this study is voluntary. You do not have to take part in this study, but if you do, you may stop at any time. You have the right to choose not to take part in any study activity or completely stop at any point without penalty or loss of benefits to which you are otherwise entitled. Your decision whether or not to join in will not affect your relationship with the researchers or Portland State University.

\section{Will I be paid for being in this research?}

Students will be provided with the following incentives:

- 1:1 interview, 60 minutes - \$25 Amazon gift card

- Focus group, 90 minutes - \$40 Amazon gift card

- Evaluate a draft survey, approximately 20 minutes - \$10 Amazon gift card

- Take a draft survey and provide feedback, approximately 20 minutes - \$10 Amazon gift card

\section{Who can answer my questions about this research?}

If you have questions, concerns, or have experienced a research related injury, contact the research team at:

Hans VanDerSchaaf

phone

hansv@pdx.edu

\section{Who can I speak to about my rights as a part of research?}

The Portland State University Institutional Review Board ("IRB") is overseeing this research. The IRB is a group of people who independently review research studies to ensure the rights and welfare of participants are protected. The Office of Research Integrity is the office at Portland State University that supports the IRB. If you have questions about your rights, or wish to speak with someone other than the research team, you may contact:

Office of Research Integrity

PO Box 751

Portland, OR 97207-0751

Phone: (503) 725-5484

Toll Free: 1 (877) 480-4400

Email: psuirb@pdx.edu

\section{Consent Statement}

I have had the opportunity to read and consider the information in this form. I have asked any questions necessary to make a decision about my taking part in the study. I understand that I can ask more questions at any time.

By agreeing to this statement by checking the box below, I understand that I am volunteering to take part in this research. I understand that I am not waiving any legal rights. I have been provided with a copy of this consent form. I understand that if my ability to consent for myself changes, either I or my legal representative may be asked to provide consent before I continue in the study. 
Please print this screen to secure a copy of this consent form (Mac laptop/desktop instructions; Windows laptop/desktop instructions; Android mobile device instructions; iPhone instructions).

I consent to join this study.

Please type your first and last name:

Please indicate whether or not you agree to participate in this study:

_ I agree to participate in this study

_ I do not agree to participate in this study.

Please provide today's date: 


\section{Appendix G: Pilot Tester Materials \\ G.1 Pilot Tester Invitation Email}

Subject: Evaluate draft myPSU survey - \$10 Amazon gift card

Hello NAME,

My name is Hans (PhD student at PSU) and a few weeks ago, you let me know you would evaluate a draft myPSU survey, to help out with my dissertation research and to benefit other students! You're one of a small group of students who have been selected to participate. As a reminder, this is voluntary and confidential.

If you're eligible (you're not a PSU faculty or staff member, and you've used myPSU before) and you complete the evaluation, you'll receive a \$10 Amazon.com gift card for about 10-15 minutes of your time.

Here's how to participate by Thursday, April 2, at $7 \mathrm{pm}$ and receive your $\$ 10$ Amazon gift card: $\$\{1: / /$ SurveyLink?d=Take the Survey $\}$

Or copy and paste the URL below into your internet browser:

$\$\{1: / /$ SurveyURL $\}$

Life happens, so if you're not able to participate now, no worries. But, please let me know so I can invite another student.

Thanks again!

Hans VanDerSchaaf

hansv@pdx.edu

PhD Student

Engineering and Technology Management

Portland State University

Follow the link to opt out of future emails:

$\$\{1: / / O p t O u t L i n k ? d=C l i c k$ here to unsubscribe $\}$

G.2 Consent Form for Pilot Testers

Consent to Participate in Research

Project Title: $\quad$ Determinants of Student Information Technology Adoption

Population: $\quad$ Undergraduate students at Portland State University 


\section{Researcher:}

Tugrul U. Daim, principal investigator; Hans VanDerSchaaf, student investigator; Engineering and Technology Management, Portland State University

\section{Researcher Contact: hansv@pdx.edu}

You are being asked to take part in a research study. The box below highlights the main information about this research for you to consider when making a decision whether or not to join in the study. Please carefully look over the information given to you on this form. Please ask questions about any of the information you do not understand before you decide to agree to take part.

\section{Key Information for You to Consider}

- Voluntary Consent. You are being asked to volunteer for a research study. It is up to you whether you choose to take part or not. There is no penalty if you choose not to join in or decide to stop your involvement.

- Why is the study being done? The reason for this research is to understand the key factors that may influence undergraduate students' adoption and use of software for accessing university services, in support of improving undergraduate retention and graduation rates at universities. The research will analyze adoption of myPSU, which is available for Portland State University students. The findings will support PSU and other universities in improving student technology tools. This research is being conducted in partial fulfillment of the requirements for Hans VanDerSchaaf's doctoral degree in Technology Management. You are being asked to participate because you are an undergraduate student at PSU or you are an expert. About 50-60 people will participate in this phase of the research, which is for developing a web survey for undergraduate students.

- How long will it take? Your participation should last 10-15 minutes.

- What will I be expected to do? You will be asked to provide feedback, either:

o Verbally and/or via written communications - about the adoption factors and corresponding variables which may relate to undergraduate student adoption of myPSU, which is software for accessing university services and is available to PSU students - through 1:1 interviews and focus group research activities, held on or near the PSU campus or via a video or phone call; or

o Provide feedback on a draft survey instrument about the reasons why students adopt myPSU through a survey read aloud; or by evaluating a draft survey; or by taking a draft survey and providing feedback - all of these activities except the survey read aloud happen on-line/remotely.

o You will participate in only one part of this research.

- Risks. Some of the possible risks or discomforts of taking part in this study include that in the individual interviews and focus groups, participants may be asked to explain the reasons why they use myPSU. Also, as with any situation where sensitive information is disclosed, such as names and email addresses, there is the remote possibility of a data breach. Robust protections are in place to ensure that a data breach does not occur, including that only the investigators have access to collected data. Risks are minimal for participating in this research study.

- Benefits. Some of the benefits that may be expected include incentives for participating for students (see below) and that the researchers hope to gain helpful 
information to assist PSU and other universities with improving technology to help students.

- Options. Participation is voluntary and the only alternative is to not participate.

\section{What happens to the information collected?}

Information collected for this research will be used to help PSU, other universities and educational technology companies improve student information technology software and services. Any published or disseminated information will be reported in aggregate format only and no identifiable information will be included - reporting will only combine results and will never report individual results.

\section{How will my privacy and data be protected?}

We will take measures to protect your privacy including that data that contains identifiers linked to participants will be kept confidential at all times and will be accessible to only the principal investigator and the co-principal investigator. All data obtained from participants will be kept confidential and will only be reported in the aggregate format (reporting only combined results and never reporting individual results). Before any presentation, sharing data outside of the research team or publication, the names and identifiers linked to the participants will be removed to insure anonymity. Despite taking steps to protect your privacy, we can never fully guarantee that your privacy will be protected.

To protect all of your personal information, we will keep all collected data in password-protected and secure locations. Despite these precautions, we can never fully guarantee that all your study information will not be revealed.

Individuals and organizations that conduct or monitor this research may be permitted access to inspect research records. This may include private information. These individuals and organizations include the Institutional Review Board that reviewed this research.

\section{What if I want to stop my part in this research?}

Your part in this study is voluntary. You do not have to take part in this study, but if you do, you may stop at any time. You have the right to choose not to take part in any study activity or completely stop at any point without penalty or loss of benefits to which you are otherwise entitled. Your decision whether or not to join in will not affect your relationship with the researchers or Portland State University.

\section{Will I be paid for being in this research?}

Students will be provided with the following incentives:

- 1:1 interview, 60 minutes - \$25 Amazon gift card

- Focus group, 90 minutes - \$40 Amazon gift card

- Evaluate a draft survey, approximately 20 minutes - $\$ 10$ Amazon gift card

- Take a draft survey and provide feedback, approximately 20 minutes - \$10 Amazon gift card

\section{Who can answer my questions about this research?}

If you have questions, concerns, or have experienced a research related injury, contact the research team at:

Hans VanDerSchaaf

hansv@pdx.edu

\section{Who can I speak to about my rights as a part of research?}


The Portland State University Institutional Review Board ("IRB") is overseeing this research. The IRB is a group of people who independently review research studies to ensure the rights and welfare of participants are protected. The Office of Research Integrity is the office at Portland State University that supports the IRB. If you have questions about your rights, or wish to speak with someone other than the research team, you may contact:

Office of Research Integrity

PO Box 751

Portland, OR 97207-0751

Phone: (503) 725-5484

Toll Free: 1 (877) 480-4400

Email: psuirb@pdx.edu

\section{Consent Statement}

I have had the opportunity to read and consider the information in this form. I have asked any questions necessary to make a decision about my taking part in the study. I understand that I can ask more questions at any time.

By agreeing to this statement by checking the box below, I understand that I am volunteering to take part in this research. I understand that I am not waiving any legal rights. I have been provided with a copy of this consent form. I understand that if my ability to consent for myself changes, either I or my legal representative may be asked to provide consent before I continue in the study.

Please print this screen to secure a copy of this consent form (Mac laptop/desktop instructions; Windows laptop/desktop instructions; Android mobile device instructions; iPhone instructions).

Please indicate whether or not you agree to participate in this study:

_ I agree to participate in this study

_ I do not agree to participate in this study. 


\section{Appendix H: Data Collection Materials}

\section{H.1 Invitation to Participate in Survey}

Subject: Share your myPSU expertise

Greetings $\$\{\mathrm{~m}: / /$ FirstName $\}$,

You've been selected to share your expertise about myPSU by taking a 5-10 minute survey. This opportunity is only available for a limited number of PSU students. Your feedback will help PSU and other universities improve software for students.

For participating, you can enter into a drawing for one of $\underline{\text { six }}, \$ 50$ Amazon.com gift cards!

Start the survey by answering this question, or following the link below.

On a scale from $0-10$, how likely are you to recommend myPSU to a friend or colleague?

Not at all likely

Extremely likely

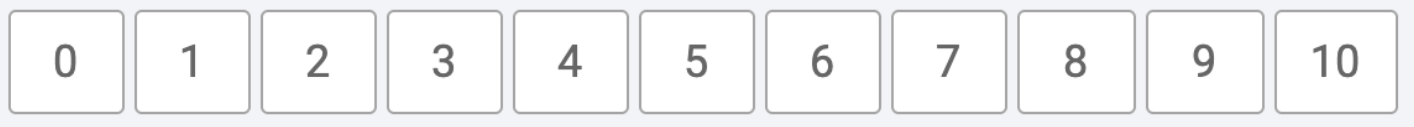

\section{$\$\{1: / /$ SurveyLink?d=Take the Survey $\}$}

Or copy and paste the URL below into your internet browser:

$\$\{1: / /$ SurveyURL $\}$

Thanks in advance for taking the survey!

Sincerely,

Hans VanDerSchaaf

hansv@pdx.edu

PhD Student

Engineering and Technology Management

Portland State University

Follow the link to opt out of future emails:

$\$\{1: / / O p t O u t L i n k ? d=C l i c k$ here to unsubscribe $\}$

\section{H.2 Reminder Emails}

\section{First reminder}

Subject: Would you recommend myPSU to a friend? 
Greetings $\$\{\mathrm{~m}: / /$ FirstName $\}$,

A few days ago I emailed about a 5-10 minute survey about your experiences with myPSU, to help PSU and other universities improve software for students.

You've been especially selected for this survey. Maybe you would participate and share your expertise? For participating, you can enter into a drawing for one of six, \$50 Amazon.com gift cards!

Start the survey by answering this question, or following the link below.

On a scale from $0-10$, how likely are you to recommend myPSU to a friend or colleague?

Not at all likely

Extremely likely

\begin{tabular}{|c|c|c|c|c|c|c|c|c|c|}
\hline 0 & 1 & 2 & 3 & & 4 & 5 & & & - \\
\hline
\end{tabular}

$\$\{1: / /$ SurveyLink?d=Take the Survey $\}$

Or copy and paste the URL below into your internet browser:

$\$\{1: / /$ SurveyURL $\}$

Thanks in advance for taking the survey!

Sincerely,

Hans VanDerSchaaf

hansv@pdx.edu

PhD Student

Engineering and Technology Management

Portland State University

Follow the link to opt out of future emails:

$\$\{1: / / O p t O u t L i n k ? d=$ Click here to unsubscribe $\}$

\section{Second reminder}

Subject: You're a myPSU expert. What do you think?

Dear $\$\{\mathrm{~m}: / /$ FirstName $\}$,

I hope your spring term is going okay! I emailed recently to ask if you might take a 5-10 minute survey about myPSU, to help PSU and other universities improve software for students. We could really use your input, as only a limited number of students have been invited!

For participating, you can enter into a drawing for one of $\underline{\text { six }}$, \$50 Amazon.com gift cards! 
Start the survey by answering this question, or following the link below.

On a scale from 0-10, how likely are you to recommend myPSU to a friend or colleague?

Not at all likely

Extremely likely

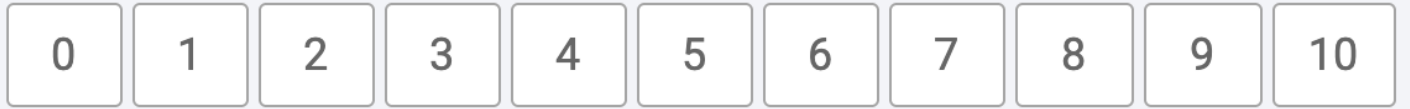

\section{$\$\{1: / /$ SurveyLink?d=Take the Survey $\}$}

Or copy and paste the URL below into your internet browser:

$\$\{1: / /$ SurveyURL $\}$

I know you're busy, so thanks in advance for taking this survey.

Sincerely,

Hans VanDerSchaaf

hansv@pdx.edu

PhD Student

Engineering and Technology Management

Portland State University

Follow the link to opt out of future emails:

$\$\{1: / / O p t O u t L i n k ? d=C l i c k$ here to unsubscribe $\}$

\section{Final reminder}

Subject: Last chance - You're a myPSU expert. What do you think?

Dear $\$\{\mathrm{~m}: / /$ FirstName $\}$,

I wanted to follow-up and share that this is the last chance to take a 5-10 minute survey about your experiences with myPSU, before Sunday at 7:00 pm when the survey closes.

The findings will assist PSU and other universities improve software for students. It would be great if you could share your expertise as only a limited number of students have been invited!

For participating, you can enter into a drawing for one of $\underline{\text { six }}$, \$50 Amazon.com gift cards!

Start the survey by answering this question, or following the link below. 
On a scale from $0-10$, how likely are you to recommend myPSU to a friend or colleague?

Not at all likely

Extremely likely

\begin{tabular}{|l|l|l|l|l|l|l|l|l|l|}
\hline 0 & 1 & 2 & 3 & 4 & 5 & 6 & 7 & 8 & 9 \\
\hline
\end{tabular}

$\$\{1: / /$ SurveyLink?d=Take the Survey $\}$

Or copy and paste the URL below into your internet browser:

$\$\{1: / /$ SurveyURL $\}$

Thanks in advance for taking this survey!

Sincerely,

Hans VanDerSchaaf

hansv@pdx.edu

PhD Student

Engineering and Technology Management

Portland State University

Follow the link to opt out of future emails:

$\$\{1: / / O p t O u t L i n k ? d=$ Click here to unsubscribe $\}$

H.3 Consent Form for Survey

Consent to Participate in Research

Project Title: $\quad$ Determinants of Student Information Technology Adoption

Population: $\quad$ Undergraduate students at Portland State University

Researcher: $\quad$ Tugrul U. Daim, principal investigator; Hans VanDerSchaaf, student investigator; Engineering and Technology Management, Portland State University

Researcher Contact: hansv@pdx.edu

You are being asked to take part in a research study. The box below highlights the main information about this research for you to consider when making a decision whether or not to join in the study. Please carefully look over the information given to you on this form. Please ask questions about any of the information you do not understand before you decide to agree to take part. 


\section{Key Information for You to Consider}

- Voluntary Consent. You are being asked to volunteer for a research study. It is up to you whether you choose to take part or not. There is no penalty if you choose not to join in or decide to stop your involvement.

- Why is the study being done? The reason for this research is to understand the key factors that may influence undergraduate students' adoption and use of software for accessing university services, in support of improving undergraduate retention and graduation rates at universities. The research will analyze adoption of myPSU, which is available for Portland State University students. This research is being conducted in partial fulfillment of the requirements for Hans VanDerSchaaf's doctoral degree in Technology Management. You are being asked to participate because you are an undergraduate student at PSU. At the minimum, several hundred students will participate in this research.

- How long will it take? Your participation should take 5-10 minutes.

- What will I be expected to do? You will be asked to complete a web-based survey about myPSU.

- Risks. Some of the possible risks or discomforts of taking part in this study include that, as with any situation where sensitive information is disclosed, such as an email address, there is the remote possibility of a data breach. Robust protections are in place to ensure that a data breach does not occur, including that only the investigators have access to collected data. Risks are minimal for participating in this research study.

- Benefits. Some of the benefits that may be expected include possible incentives for participating (see below) and that the researchers hope to gain helpful information to assist PSU and other universities with improving technology to help students.

- Options. Participation is voluntary and the only alternative is to not participate.

\section{What happens to the information collected?}

Information collected for this research will be used to help PSU, other universities and educational technology companies improve student information technology software and services. Any published or disseminated information will be reported in aggregate format only and no identifiable information will be included - reporting will only combine results and will never report individual results.

\section{How will my privacy and data be protected?}

We will take measures to protect your privacy including that data that contains identifiers linked to the participants will be kept confidential at all times and will be accessible to only the principal investigator and the co-principal investigator. All data obtained from participants will be kept confidential and will only be reported in the aggregate format (reporting only combined results and never reporting individual results). Before any presentation, sharing data outside of the research team or publication, the names and identifiers linked to the participants will be removed to ensure anonymity. Despite taking steps to protect your privacy, we can never fully guarantee that your privacy will be protected.

To protect all of your personal information, we will keep all collected data in password-protected and secure locations. Despite these precautions, we can never fully guarantee that all your study information will not be revealed. 
Individuals and organizations that conduct or monitor this research may be permitted access to inspect research records. This may include private information. These individuals and organizations include the Institutional Review Board that reviewed this research.

\section{What if I want to stop my part in this research?}

Your part in this study is voluntary. You do not have to take part in this study, but if you do, you may stop at any time. You have the right to choose not to take part in any study activity or completely stop at any point without penalty or loss of benefits to which you are otherwise entitled. Your decision whether or not to join in will not affect your relationship with the researchers or Portland State University.

\section{Will I be paid for being in this research?}

Maybe. Up to 6 students who respond will each receive a \$50 Amazon.com gift card through a drawing.

\section{Who can answer my questions about this research?}

If you have questions, concerns, or have experienced a research related injury, contact the research team at:

Hans VanDerSchaaf

hansv@pdx.edu

\section{Who can I speak to about my rights as a part of research?}

The Portland State University Institutional Review Board ("IRB") is overseeing this research. The IRB is a group of people who independently review research studies to ensure the rights and welfare of participants are protected. The Office of Research Integrity is the office at Portland State University that supports the IRB. If you have questions about your rights, or wish to speak with someone other than the research team, you may contact:

Office of Research Integrity

PO Box 751

Portland, OR 97207-0751

Phone: (503) 725-5484

Toll Free: 1 (877) 480-4400

Email: psuirb@pdx.edu

\section{Consent Statement}

I have had the opportunity to read and consider this information.

By agreeing to this statement by checking the box below, I understand that I am volunteering to take part in this research. I understand that I am not waiving any legal rights. Please print this screen to secure a copy of this consent form. I understand that if my ability to consent for myself changes, either I or my legal representative may be asked to provide consent before I continue in the study.

Please indicate whether or not you agree to participate in this study:

_ I agree to participate in this study

_ I do not agree to participate in this study. 


\begin{tabular}{|c|c|c|c|}
\hline $\begin{array}{l}\text { Item } \\
\text { code }\end{array}$ & Indicator & Survey text (item) & $\begin{array}{l}\text { Reference for } \\
\text { question text }\end{array}$ \\
\hline \multicolumn{4}{|c|}{ Performance expectancy factor (PE) } \\
\hline PE1 & $\begin{array}{l}\text { Perceived } \\
\text { usefulness }\end{array}$ & I find myPSU useful. & [199], [247] \\
\hline PE2 & $\begin{array}{l}\text { Access to university } \\
\text { resources and } \\
\text { services }\end{array}$ & $\begin{array}{l}\text { Using myPSU helps me quickly access university resources } \\
\text { (e.g. PSU software - D2L, Banweb, etc.) and services (e.g. } \\
\text { academic advising). }\end{array}$ & $\begin{array}{l}{[209],[199],} \\
{[262]}\end{array}$ \\
\hline PE3 & $\begin{array}{l}\text { Access to conduct } \\
\text { business }\end{array}$ & $\begin{array}{l}\text { Using myPSU helps me quickly conduct student business (e.g. } \\
\text { viewing account balance, accessing financial aid information, } \\
\text { etc.). }\end{array}$ & $\begin{array}{l}{[209],[199],} \\
{[262]}\end{array}$ \\
\hline PE4 & One-stop shop & $\begin{array}{l}\text { My productivity increases by using myPSU as a one-stop shop } \\
\text { for navigating the university (e.g. accessing services, resources } \\
\text { and PSU software, and conducting student business, all in one } \\
\text { place). }\end{array}$ & $\begin{array}{l}{[209],[199],} \\
{[262]}\end{array}$ \\
\hline PE5 & $\begin{array}{l}\text { Perceived mobile } \\
\text { value }\end{array}$ & myPSU is convenient to access anytime and anywhere. & [295], [234] \\
\hline \multicolumn{4}{|c|}{ Effort expectancy factor (EE) } \\
\hline EE1 & $\begin{array}{l}\text { Perceived ease of } \\
\text { use }\end{array}$ & I find myPSU easy to use. & [247], [199] \\
\hline EE2 & Efforts vs. benefit & $\begin{array}{l}\text { The effort it takes to use myPSU is worth the benefits I get } \\
\text { from it. }\end{array}$ & [235] \\
\hline EE3 & Learning to operate & Learning to use myPSU was easy for me. & [199] \\
\hline EE4 & System accessibility & $\begin{array}{l}\text { It is easy for me to navigate to myPSU (my.pdx.edu) on the } \\
\text { Internet. }\end{array}$ & [112] \\
\hline EE5 & Mobile app & $\begin{array}{l}\text { Using the smartphone/mobile app makes it convenient to } \\
\text { access myPSU. }\end{array}$ & {$[295]$} \\
\hline \multicolumn{4}{|c|}{ Social influence factor (SI) } \\
\hline SI1 & Peer influence & Other students have recommended I use myPSU. & {$[199]_{2}[247]$} \\
\hline SI2 & Marketing & $\begin{array}{l}\text { Receiving marketing messages (e.g. via email or a poster) has } \\
\text { encouraged me to use myPSU. }\end{array}$ & {$[199]_{2}[247]$} \\
\hline SI3 & $\begin{array}{l}\text { Influence from } \\
\text { university } \\
\text { employees }\end{array}$ & $\begin{array}{l}\text { University employees (e.g. faculty, staff, advisors, etc.) think I } \\
\text { should use myPSU. }\end{array}$ & {$[199]_{2}[247]$} \\
\hline \multicolumn{4}{|c|}{ Facilitating conditions factor (FC) } \\
\hline FC1 & Compatibility & $\begin{array}{l}\text { I can easily access other PSU software platforms and online } \\
\text { tools through myPSU. }\end{array}$ & [199], [247] \\
\hline FC2 & Technical support & $\begin{array}{l}\text { A specific person or group is available to provide assistance } \\
\text { with myPSU technical difficulties. }\end{array}$ & [199] \\
\hline $\mathrm{FC} 3$ & $\begin{array}{l}\text { Learning about a } \\
\text { platform }\end{array}$ & $\begin{array}{l}\text { Learning from others about how to use myPSU's functionality } \\
\text { has helped me learn how to use it. }\end{array}$ & [293], [410] \\
\hline \multicolumn{4}{|c|}{ Perceived quality factor (PQ) } \\
\hline PQ1 & Content quality & $\begin{array}{l}\text { The quality of the information in myPSU meets my needs as a } \\
\text { student. }\end{array}$ & {$[260]$} \\
\hline PQ2 & $\begin{array}{l}\text { User interface } \\
\text { design }\end{array}$ & $\begin{array}{l}\text { myPSU has well-designed user interfaces (pages, graphics, } \\
\text { visuals, content, navigation, etc.). }\end{array}$ & [260] \\
\hline PQ3 & System errors & I rarely encounter errors when I use myPSU. & [291] \\
\hline PQ4 & $\begin{array}{l}\text { Platform response } \\
\text { time }\end{array}$ & The response time of the myPSU software platform is fast. & {$[261]$} \\
\hline \multicolumn{4}{|c|}{ Self-efficacy and skills factor (SS) } \\
\hline SS1 & Confidence & $\begin{array}{l}\text { I am confident I can overcome any technology-related } \\
\text { obstacles when using myPSU. }\end{array}$ & {$[233]$} \\
\hline SS2 & $\begin{array}{l}\text { Basic computing } \\
\text { skills }\end{array}$ & I am proficient at conducting basic activities on a computer. & {$[292]_{2}[112]$} \\
\hline SS3 & $\begin{array}{l}\text { Basic smartphone } \\
\text { skills }\end{array}$ & I am proficient at using a smartphone. & {$[292][$ [112] } \\
\hline
\end{tabular}




\begin{tabular}{|c|c|c|c|}
\hline \multicolumn{4}{|c|}{ Behavioral intention factor (BI) } \\
\hline BI1 & Intend to use & $\begin{array}{l}\text { I intend to continue using myPSU in the future. } \\
\text { Graduating students, please respond as if you were planning } \\
\text { to be a student beyond this term. }\end{array}$ & [247], [199] \\
\hline BI2 & Predict to use & I predict I will use myPSU during this academic term. & [199] \\
\hline $\mathrm{BI} 3$ & Plan to use & I plan to use myPSU during this academic term. & [247], [199] \\
\hline $\mathrm{BI} 4$ & $\begin{array}{l}\text { Plan to use - } \\
\text { frequently }\end{array}$ & $\begin{array}{l}\text { I plan to use myPSU frequently. } \\
\text { Graduating students, please respond as if you were planning } \\
\text { to be a student beyond this term. }\end{array}$ & [247], [225] \\
\hline \multicolumn{4}{|c|}{ Use behavior factor (UB) } \\
\hline UB1 & Frequency of use & $\begin{array}{l}\text { On average, how often do you use myPSU? [1. Rarely; } 2 . \\
\text { Several times per term; } 3 \text {. Several times per month; } 4 \text {. Weekly; } \\
\text { 5. Daily]. }\end{array}$ & [247], [225] \\
\hline UB2 & $\begin{array}{l}\text { Usage of the } \\
\text { platform to access } \\
\text { university resources } \\
\text { and services }\end{array}$ & $\begin{array}{l}\text { I use myPSU to access university resources (e.g. PSU software } \\
\text { - D2L, Banweb, etc.) and services (e.g. academic advising). }\end{array}$ & {$[247]$} \\
\hline UB3 & $\begin{array}{l}\text { Usage of the } \\
\text { platform to conduct } \\
\text { business }\end{array}$ & $\begin{array}{l}\text { I use myPSU to conduct student business (e.g. viewing account } \\
\text { balance, accessing financial aid information, etc.). }\end{array}$ & {$[247]$} \\
\hline UB4 & $\begin{array}{l}\text { Usage of the } \\
\text { platform as a } \\
\text { one-stop shop }\end{array}$ & $\begin{array}{l}\text { I use myPSU as a one-stop shop for navigating the university } \\
\text { (e.g. accessing services, resources and PSU software, and } \\
\text { conducting student business, all in one place). }\end{array}$ & {$[247]$} \\
\hline \multicolumn{4}{|c|}{$\begin{array}{l}\text { The measurement scale for the above target variables is a 5-point Likert scale- } \\
\text { 1. Strongly disagree; 2. Disagree; 3. Neutral; 4. Agree; 5. Strongly agree - with the exception of the Frequency of } \\
\text { use indicator, which uses a 5-point Likert scale, modeled after what was used in Venkatesh } 2012 \text { [225], with these } \\
\text { text cues: } 1 \text {. Rarely; } 2 \text {. Several times per term; } 3 \text {. Several times per month; } 4 \text {. Weekly; } 5 \text {. Daily. Students were asked, } \\
\text { if they access myPSU on multiple devices, to please respond to the relevant questions with respect to their overall } \\
\text { experience across all of their devices. }\end{array}$} \\
\hline \multicolumn{4}{|c|}{ Introductory text } \\
\hline \multirow{2}{*}{\multicolumn{4}{|c|}{$\begin{array}{l}\text { As a reminder, the survey is voluntary and confidential. You can choose to exit the survey at any point. It should take } \\
\text { about 5-10 minutes to complete. } \\
\text { If you're eligible to take the survey (you're not a PSU faculty or staff member, and you've used myPSU before) and } \\
\text { you complete the survey, you'll have the option to be entered into the drawing for one of six } \mathbf{\$ 5 0} \text { Amazon.com } \\
\text { gift cards. }\end{array}$}} \\
\hline & & & \\
\hline \multicolumn{4}{|c|}{ Introductory questions (I) } \\
\hline I1 & Consent & $\begin{array}{l}\text { Please indicate whether or not you agree to participate in this } \\
\text { study. } \\
\text { - I agree to participate in this study } \\
\text { - I do not agree to participate in this study }\end{array}$ & \\
\hline I2 & Staff/Faculty & $\begin{array}{l}\text { Are you a PSU staff or faculty member? Student employees } \\
\text { please select "No." (if yes, survey ends) } \\
\text { - Yes } \\
\text { - No }\end{array}$ & \\
\hline 13 & myPSU affirmation & $\begin{array}{l}\text { Please answer the survey questions with respect to myPSU } \\
\text { only (not Banweb, D2L, myNextSteps, or other PSU software } \\
\text { platforms). } \\
\text { myPSU is available at my.pdx.edu or as a mobile app from } \\
\text { Google Play or the App Store. } \\
\text { - I'm aware that this survey is about the myPSU software } \\
\text { platform only }\end{array}$ & \\
\hline
\end{tabular}




\begin{tabular}{|c|c|c|c|}
\hline 14 & Use of myPSU & $\begin{array}{l}\text { Have you used myPSU before? (if no or don't know, survey } \\
\text { ends) } \\
\text { - Yes } \\
\text { - No } \\
\text { - Don't know }\end{array}$ & \\
\hline \multicolumn{4}{|c|}{ Demographics and other auxiliary variables (D) } \\
\hline D1 & myPSU & $\begin{array}{l}\text { In which way(s) do you most often access myPSU? Please } \\
\text { select all that apply. } \\
\text { - Laptop or desktop computer browser } \\
\text { - Smartphone - browser } \\
\text { - Smartphone - myPSU app } \\
\text { - Tablet - browser } \\
\text { - Tablet - myPSU app }\end{array}$ & \\
\hline D2 & Net Promoter Score & $\begin{array}{l}\text { On a scale from o-10, how likely are you to recommend } \\
\text { myPSU to a friend or colleague? } \\
\text { o-10 scale following Net Promoter Score methodology (NPS; } \\
\text { o=Not at all likely; 10=Extremely } \\
\text { likely) }\end{array}$ & \\
\hline D3 & Financial aid & $\begin{array}{l}\text { Do you receive financial aid? (if yes, see the following question; } \\
\text { if no, skip) } \\
\text { - Yes } \\
\text { - No } \\
\text { - Don't know } \\
\text { - Prefer not to say }\end{array}$ & - \\
\hline D4 & Pell grant & $\begin{array}{l}\text { Is part of your financial aid a Pell Grant? } \\
\text { - Yes } \\
\text { - No } \\
\text { - Don't know } \\
\text { - Prefer not to say }\end{array}$ & - \\
\hline D5 & $\begin{array}{l}\text { First generation } \\
\text { status }\end{array}$ & $\begin{array}{l}\text { Are you a first-generation college student? "First generation } \\
\text { student" means your parents or legal guardians have not } \\
\text { completed a bachelor's degree yet. } \\
\text { - Yes } \\
\text { - No } \\
\text { - Don't know } \\
\text { - Prefer not to say }\end{array}$ & - \\
\hline D7 & Gender & $\begin{array}{l}\text { What is your preferred gender? [Note: Question should have } \\
\text { read "What is your gender?"] } \\
\text { - Male } \\
\text { - Female } \\
\text { - Non-binary/third gender } \\
\text { - Prefer to self-describe } \\
\text { - Prefer not to say }\end{array}$ & \\
\hline D8 & Race/ethnicity & $\begin{array}{l}\text { Which of the following best describes your race or ethnicity? } \\
\text { Please select all that apply. } \\
\text { - American Indian or Alaska Native } \\
\text { - Asian } \\
\text { - Black or African American } \\
\text { - Hispanic or Latino } \\
\text { - Middle Eastern or North African } \\
\text { - Native Hawaiian or Other Pacific Islander } \\
\text { - White } \\
\text { - Other, please specify } \\
\text { - Prefer not to say }\end{array}$ & - \\
\hline
\end{tabular}




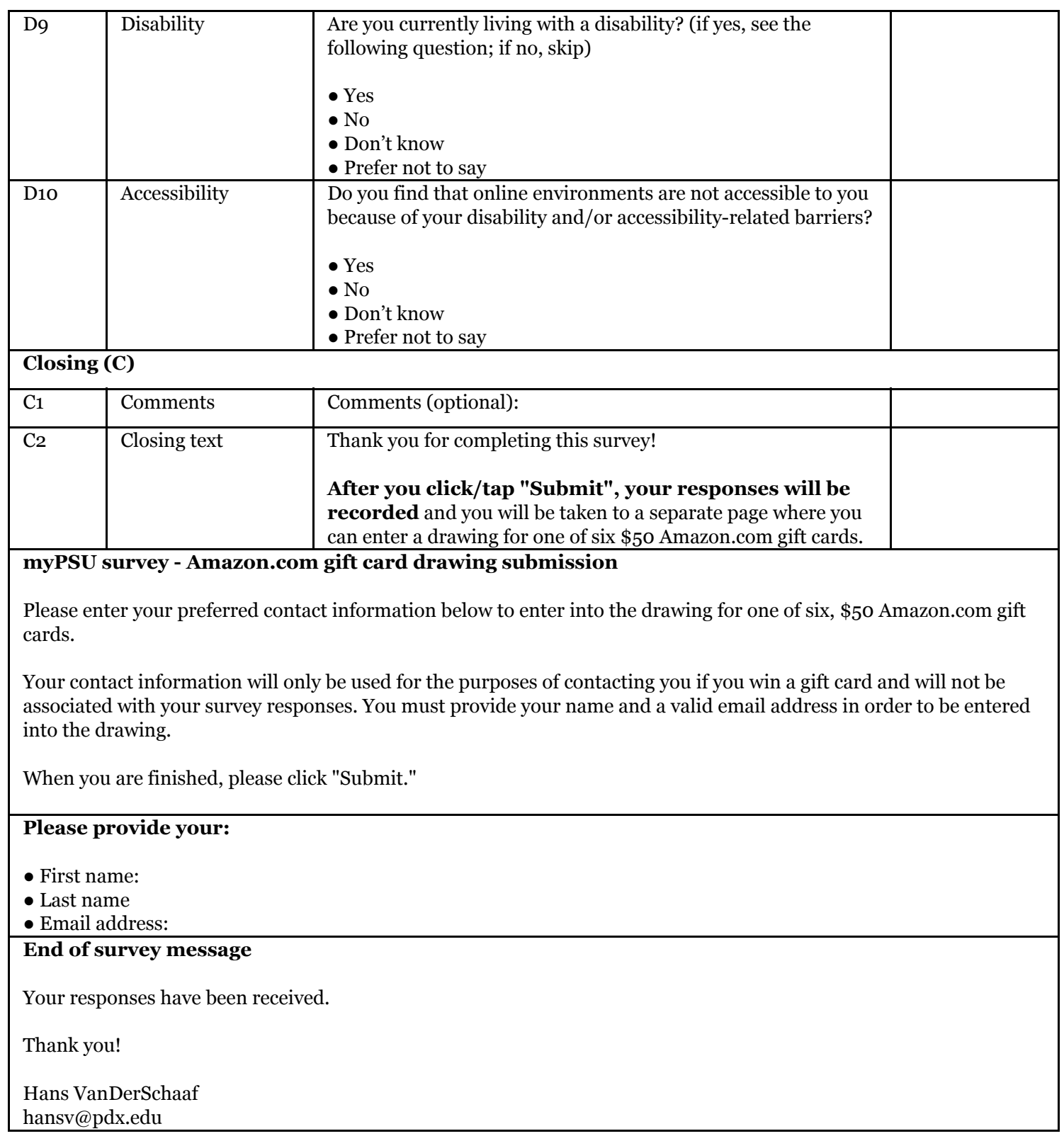




\section{Appendix I: Frequencies and Means for Indicator Variables}

\section{PE1 - Perceived usefulness}

Table 1: Frequencies for Item PE1 (Perceived Usefulness)

\begin{tabular}{|l|r|r|}
\hline & Frequency & Percent \\
\hline 1 - Strongly Disagree & 25 & $1 \%$ \\
\hline 2 - Disagree & 72 & $4 \%$ \\
\hline 3 - Neutral & 266 & $14 \%$ \\
\hline 4 - Agree & 987 & $54 \%$ \\
\hline 5 - Strongly Agree & 491 & $27 \%$ \\
\hline Total & 1,841 & $100 \%$ \\
\hline
\end{tabular}

Table 2: Statistics for Item PE1 (Perceived Usefulness)

\begin{tabular}{|r|r|l|l|l|}
\hline $\begin{array}{l}\text { Total } \\
\text { Responses }\end{array}$ & Mean & $\begin{array}{l}\text { Standard } \\
\text { Deviation }\end{array}$ & Minimum & Maximum \\
\hline 1,841 & 4.00 & 0.83 & 1 & 5 \\
\hline
\end{tabular}

\section{PE2 - Access to university resources and services}

Table 3: Frequencies for Item PE2 (Access to university resources and services)

\begin{tabular}{|l|r|r|}
\hline & \multicolumn{1}{|l|}{ Frequency } & Percent \\
\hline 1 - Strongly Disagree & 34 & $2 \%$ \\
\hline 2 - Disagree & 124 & $7 \%$ \\
\hline 3 - Neutral & 233 & $13 \%$ \\
\hline 4 - Agree & 812 & $44 \%$ \\
\hline 5 - Strongly Agree & 638 & $35 \%$ \\
\hline Total & 1,841 & $100 \%$ \\
\hline
\end{tabular}

Table 4: Statistics for Item PE2 (Access to university resources and services)

\begin{tabular}{|r|rr|l|l|l|}
\hline $\begin{array}{l}\text { Total } \\
\text { Responses }\end{array}$ & Mean & $\begin{array}{l}\text { Standard } \\
\text { Deviation }\end{array}$ & Minimum & \multicolumn{2}{|l|}{ Maximum } \\
\hline 1,841 & 4.03 & & 0.95 & 1 & 5 \\
\hline
\end{tabular}




\section{PE3 - Access to conduct business}

Table 5: Frequencies for Item PE3 (Access to conduct business)

\begin{tabular}{|l|r|r|}
\hline & Frequency & Percent \\
\hline 1 - Strongly Disagree & 34 & $2 \%$ \\
\hline 2 - Disagree & 165 & $9 \%$ \\
\hline 3 - Neutral & 317 & $17 \%$ \\
\hline 4 - Agree & 820 & $45 \%$ \\
\hline 5 - Strongly Agree & 505 & $27 \%$ \\
\hline Total & 1,841 & $100 \%$ \\
\hline
\end{tabular}

Table 6: Statistics for Item PE3 (Access to conduct business)

\begin{tabular}{|r|r|l|l|l|}
\hline $\begin{array}{l}\text { Total } \\
\text { Responses }\end{array}$ & Mean & $\begin{array}{l}\text { Standard } \\
\text { Deviation }\end{array}$ & Minimum & Maximum \\
\hline 1,841 & 3.87 & 0.98 & 1 & 5 \\
\hline
\end{tabular}

\section{PE4 - One-stop shop}

Table 7: Frequencies for Item PE4 (One-stop shop)

\begin{tabular}{|l|r|r|}
\hline & \multicolumn{1}{|l|}{ Frequency } & Percent \\
\hline 1 - Strongly Disagree & 62 & $3 \%$ \\
\hline 2 - Disagree & 210 & $11 \%$ \\
\hline 3 - Neutral & 497 & $27 \%$ \\
\hline 4 - Agree & 684 & $37 \%$ \\
\hline 5 - Strongly Agree & 388 & $21 \%$ \\
\hline Total & 1,841 & $100 \%$ \\
\hline
\end{tabular}

Table 8: Statistics for Item PE4 (One-stop shop)

\begin{tabular}{|r|rr|l|l|l|}
\hline $\begin{array}{l}\text { Total } \\
\text { Responses }\end{array}$ & Mean & $\begin{array}{l}\text { Standard } \\
\text { Deviation }\end{array}$ & Minimum & Maximum \\
\hline 1,841 & 3.61 & 1.04 & 1 & 5 \\
\hline
\end{tabular}




\section{PE5 - Perceived mobile value}

Table 9: Frequencies for Item PE5 (Perceived mobile value)

\begin{tabular}{|l|r|r|}
\hline & Frequency & Percent \\
\hline 1 - Strongly Disagree & 36 & $2 \%$ \\
\hline 2 - Disagree & 132 & $7 \%$ \\
\hline 3 - Neutral & 301 & $16 \%$ \\
\hline 4 - Agree & 791 & $43 \%$ \\
\hline 5 - Strongly Agree & 581 & $32 \%$ \\
\hline Total & 1,841 & $100 \%$ \\
\hline
\end{tabular}

Table 10: Statistics for Item PE5 (Perceived mobile value)

\begin{tabular}{|l|l|l|l|l|}
\hline $\begin{array}{l}\text { Total } \\
\text { Responses }\end{array}$ & Mean & $\begin{array}{l}\text { Standard } \\
\text { Deviation }\end{array}$ & Minimum & Maximum \\
\hline 1,841 & 3.95 & 0.97 & 1 & 5 \\
\hline
\end{tabular}

\section{EE1 - Perceived ease of use}

Table 11: Frequencies for Item EE1 (Perceived ease of use)

\begin{tabular}{|l|r|r|}
\hline & \multicolumn{1}{|l|}{ Frequency } & Percent \\
\hline 1 - Strongly Disagree & 27 & $1 \%$ \\
\hline 2 - Disagree & 116 & $6 \%$ \\
\hline 3 - Neutral & 281 & $15 \%$ \\
\hline 4 - Agree & 949 & $52 \%$ \\
\hline 5 - Strongly Agree & 468 & $25 \%$ \\
\hline Total & 1,841 & $100 \%$ \\
\hline
\end{tabular}

Table 12: Statistics for Item EE1 (Perceived ease of use)=

\begin{tabular}{|l|lr|l|l|l|}
\hline $\begin{array}{l}\text { Total } \\
\text { Responses }\end{array}$ & Mean & $\begin{array}{l}\text { Standard } \\
\text { Deviation }\end{array}$ & Minimum & Maximum \\
\hline 1,841 & 3.93 & 0.89 & 1 & 5 \\
\hline
\end{tabular}




\section{EE2 - Effort vs. benefit}

Table 13: Frequencies for Item EE2 (Effort vs. benefit)

\begin{tabular}{|l|r|r|}
\hline & \multicolumn{1}{|l|}{ Frequency } & Percent \\
\hline 1 - Strongly Disagree & 37 & $2 \%$ \\
\hline 2 - Disagree & 120 & $7 \%$ \\
\hline 3 - Neutral & 358 & $19 \%$ \\
\hline 4 - Agree & 836 & $45 \%$ \\
\hline 5 - Strongly Agree & 490 & $27 \%$ \\
\hline Total & 1,841 & $100 \%$ \\
\hline
\end{tabular}

Table 14: Statistics for Item EE2 (Effort vs. benefit)

\begin{tabular}{|c|c|c|c|c|}
\hline $\begin{array}{l}\text { Total } \\
\text { Responses }\end{array}$ & Mean & $\begin{array}{l}\text { Standard } \\
\text { Deviation }\end{array}$ & Minimum & Maximum \\
\hline 1,841 & 3.88 & 0.94 & 1 & 5 \\
\hline
\end{tabular}

\section{EE3 - Learning to operate}

Table 15: Frequencies for Item EE3 (Learning to operate)

\begin{tabular}{|l|r|r|}
\hline & \multicolumn{1}{|l|}{ Frequency } & Percent \\
\hline 1 - Strongly Disagree & 29 & $2 \%$ \\
\hline 2 - Disagree & 125 & $7 \%$ \\
\hline 3 - Neutral & 282 & $15 \%$ \\
\hline 4 - Agree & 843 & $46 \%$ \\
\hline 5 - Strongly Agree & 562 & $31 \%$ \\
\hline Total & 1,841 & $100 \%$ \\
\hline
\end{tabular}

Table 16: Statistics for Item EE3 (Learning to operate)

\begin{tabular}{|r|r|l|l|l|}
\hline $\begin{array}{l}\text { Total } \\
\text { Responses }\end{array}$ & Mean & $\begin{array}{l}\text { Standard } \\
\text { Deviation }\end{array}$ & Minimum & Maximum \\
\hline 1,841 & 3.97 & 0.93 & 1 & 5 \\
\hline
\end{tabular}




\section{EE4 - System accessibility}

Table 17: Frequencies for Item EE4 (System accessibility)

\begin{tabular}{|l|r|r|}
\hline & Frequency & Percent \\
\hline 1 - Strongly Disagree & 19 & $1 \%$ \\
\hline 2 - Disagree & 81 & $4 \%$ \\
\hline 3 - Neutral & 246 & $13 \%$ \\
\hline 4 - Agree & 889 & $48 \%$ \\
\hline 5 - Strongly Agree & 606 & $33 \%$ \\
\hline Total & 1,841 & $100 \%$ \\
\hline
\end{tabular}

Table 18: Statistics for Item EE4 (System accessibility)

\begin{tabular}{|r|r|l|l|l|}
\hline $\begin{array}{l}\text { Total } \\
\text { Responses }\end{array}$ & Mean & $\begin{array}{l}\text { Standard } \\
\text { Deviation }\end{array}$ & Minimum & Maximum \\
\hline 1,841 & 4.08 & 0.85 & 1 & 5 \\
\hline
\end{tabular}

\section{EE5 - Mobile app}

Table 19: Frequencies for Item EE5 (Mobile app)

\begin{tabular}{|l|r|r|}
\hline & Frequency & Percent \\
\hline 1 - Strongly Disagree & 71 & $4 \%$ \\
\hline 2 - Disagree & 157 & $9 \%$ \\
\hline 3 - Neutral & 471 & $26 \%$ \\
\hline 4 - Agree & 602 & $33 \%$ \\
\hline 5 - Strongly Agree & 540 & $29 \%$ \\
\hline Total & 1,841 & $100 \%$ \\
\hline
\end{tabular}

Table 20: Statistics for Item EE5 (Mobile app)

\begin{tabular}{|l|lr|l|l|l|}
\hline $\begin{array}{l}\text { Total } \\
\text { Responses }\end{array}$ & Mean & & $\begin{array}{l}\text { Standard } \\
\text { Deviation }\end{array}$ & Minimum & \multicolumn{2}{|l|}{ Maximum } \\
\hline 1,841 & 3.75 & 1.08 & & 1 & 5 \\
\hline
\end{tabular}




\section{SI1 - Peer influence}

Table 21: Frequencies for Item SI1 (Peer influence)

\begin{tabular}{|l|r|r|}
\hline & Frequency & Percent \\
\hline 1 - Strongly Disagree & 285 & $15 \%$ \\
\hline 2 - Disagree & 532 & $29 \%$ \\
\hline 3 - Neutral & 648 & $35 \%$ \\
\hline 4 - Agree & 262 & $14 \%$ \\
\hline 5 - Strongly Agree & 114 & $6 \%$ \\
\hline Total & 1,841 & $100 \%$ \\
\hline
\end{tabular}

Table 22: Statistics for Item SI1 (Peer influence)

\begin{tabular}{|c|c|c|c|c|}
\hline \begin{tabular}{|l} 
Total \\
Responses
\end{tabular} & Mean & $\begin{array}{l}\text { Standard } \\
\text { Deviation }\end{array}$ & Minimum & Maximum \\
\hline 1,841 & 2.67 & 1.09 & 1 & 5 \\
\hline
\end{tabular}

\section{SI2 - Marketing}

Table 23: Frequencies for Item SI2 (Marketing)

\begin{tabular}{|l|r|r|}
\hline & Frequency & Percent \\
\hline 1 - Strongly Disagree & 326 & $18 \%$ \\
\hline 2 - Disagree & 689 & $37 \%$ \\
\hline 3 - Neutral & 499 & $27 \%$ \\
\hline 4 - Agree & 248 & $13 \%$ \\
\hline 5 - Strongly Agree & 79 & $4 \%$ \\
\hline Total & 1,841 & $100 \%$ \\
\hline
\end{tabular}

Table 24: Statistics for Item SI2 (Marketing)

\begin{tabular}{|r|r|l|l|l|}
\hline $\begin{array}{l}\text { Total } \\
\text { Responses }\end{array}$ & Mean & $\begin{array}{l}\text { Standard } \\
\text { Deviation }\end{array}$ & Minimum & Maximum \\
\hline 1,841 & 2.49 & 1.06 & 1 & 5 \\
\hline
\end{tabular}




\section{SI3 - Influence from university employees}

Table 25: Frequencies for Item SI3 (Influence from university employees)

\begin{tabular}{|l|r|r|}
\hline & \multicolumn{1}{|l|}{ Frequency } & Percent \\
\hline 1 - Strongly Disagree & 115 & $6 \%$ \\
\hline 2 - Disagree & 246 & $13 \%$ \\
\hline 3 - Neutral & 748 & $41 \%$ \\
\hline 4 - Agree & 490 & $27 \%$ \\
\hline 5 - Strongly Agree & 242 & $13 \%$ \\
\hline Total & 1,841 & $100 \%$ \\
\hline
\end{tabular}

Table 26: Statistics for Item SI3 (Influence from university employees)

\begin{tabular}{|r|r|l|l|l|l|}
\hline $\begin{array}{l}\text { Total } \\
\text { Responses }\end{array}$ & Mean & $\begin{array}{l}\text { Standard } \\
\text { Deviation }\end{array}$ & Minimum & Maximum \\
\hline 1,841 & 3.27 & 1.05 & 1 & 5 \\
\hline
\end{tabular}

\section{FC1 - Compatibility}

Table 27: Frequencies for Item FC1 (Compatibility)

\begin{tabular}{|l|r|r|}
\hline & \multicolumn{1}{|l|}{ Frequency } & Percent \\
\hline 1 - Strongly Disagree & 38 & $2 \%$ \\
\hline 2 - Disagree & 104 & $6 \%$ \\
\hline 3 - Neutral & 339 & $18 \%$ \\
\hline 4 - Agree & 911 & $49 \%$ \\
\hline 5 - Strongly Agree & 449 & $24 \%$ \\
\hline Total & 1,841 & $100 \%$ \\
\hline
\end{tabular}

Table 28: Statistics for Item FC1 (Compatibility)

\begin{tabular}{|r|r|l|l|l|l|}
\hline $\begin{array}{l}\text { Total } \\
\text { Responses }\end{array}$ & Mean & $\begin{array}{l}\text { Standard } \\
\text { Deviation }\end{array}$ & Minimum & Maximum \\
\hline 1,841 & 3.88 & & 0.91 & & 5 \\
\hline
\end{tabular}




\section{FC2 - Technical support}

Table 29: Frequencies for Item FC2 (Technical support)

\begin{tabular}{|l|r|r|}
\hline & Frequency & Percent \\
\hline 1 - Strongly Disagree & 51 & $3 \%$ \\
\hline 2 - Disagree & 187 & $10 \%$ \\
\hline 3 - Neutral & 878 & $48 \%$ \\
\hline 4 - Agree & 538 & $29 \%$ \\
\hline 5 - Strongly Agree & 187 & $10 \%$ \\
\hline Total & 1,841 & $100 \%$ \\
\hline
\end{tabular}

Table 30: Statistics for Item FC2 (Technical support)

\begin{tabular}{|l|l|l|l|l|}
\hline $\begin{array}{l}\text { Total } \\
\text { Responses }\end{array}$ & Mean & $\begin{array}{l}\text { Standard } \\
\text { Deviation }\end{array}$ & Minimum & Maximum \\
\hline 1,841 & 3.34 & 0.89 & 1 & 5 \\
\hline
\end{tabular}

\section{FC3 - Learning about a platform}

Table 31: Frequencies for Item FC3 (Learning about a platform)

\begin{tabular}{|l|r|r|}
\hline & \multicolumn{1}{|l|}{ Frequency } & Percent \\
\hline 1 - Strongly Disagree & 174 & $9 \%$ \\
\hline 2 - Disagree & 444 & $24 \%$ \\
\hline 3 - Neutral & 632 & $34 \%$ \\
\hline 4 - Agree & 414 & $22 \%$ \\
\hline 5 - Strongly Agree & 177 & $10 \%$ \\
\hline Total & 1,841 & $100 \%$ \\
\hline
\end{tabular}

Table 32: Statistics for Item FC3 (Learning about a platform)

\begin{tabular}{|r|r|l|l|l|l|}
\hline $\begin{array}{l}\text { Total } \\
\text { Responses }\end{array}$ & Mean & $\begin{array}{l}\text { Standard } \\
\text { Deviation }\end{array}$ & Minimum & Maximum \\
\hline 1,841 & 2.99 & 1.11 & 1 & 5 \\
\hline
\end{tabular}




\section{PQ1 - Content quality}

Table 33: Frequencies for Item PQ1 (Content quality)

\begin{tabular}{|l|r|r|}
\hline & \multicolumn{1}{|l|}{ Frequency } & Percent \\
\hline 1 - Strongly Disagree & 19 & $1 \%$ \\
\hline 2 - Disagree & 95 & $5 \%$ \\
\hline 3 - Neutral & 316 & $17 \%$ \\
\hline 4 - Agree & 995 & $54 \%$ \\
\hline 5 - Strongly Agree & 416 & $23 \%$ \\
\hline Total & 1,841 & $100 \%$ \\
\hline
\end{tabular}

Table 34: Statistics for Item PQ1 (Content quality)

\begin{tabular}{|l|l|l|l|l|l|}
\hline $\begin{array}{l}\text { Total } \\
\text { Responses }\end{array}$ & Mean & & $\begin{array}{l}\text { Standard } \\
\text { Deviation }\end{array}$ & Minimum & Maximum \\
\hline 1,841 & 3.92 & 0.83 & 1 & 5 \\
\hline
\end{tabular}

\section{PQ2 - User interface design}

Table 35: Frequencies for Item PQ2 (User interface design)

\begin{tabular}{|l|r|r|}
\hline & \multicolumn{1}{|l|}{ Frequency } & Percent \\
\hline 1 - Strongly Disagree & 52 & $3 \%$ \\
\hline 2 - Disagree & 184 & $10 \%$ \\
\hline 3 - Neutral & 351 & $19 \%$ \\
\hline 4 - Agree & 864 & $47 \%$ \\
\hline 5 - Strongly Agree & 390 & $21 \%$ \\
\hline Total & 1,841 & $100 \%$ \\
\hline
\end{tabular}

Table 36: Statistics for Item PQ1 (User interface design)

\begin{tabular}{|r|r|l|l|l|l|}
\hline $\begin{array}{l}\text { Total } \\
\text { Responses }\end{array}$ & Mean & $\begin{array}{l}\text { Standard } \\
\text { Deviation }\end{array}$ & Minimum & Maximum \\
\hline 1,841 & 3.74 & 0.99 & 1 & 5 \\
\hline
\end{tabular}




\section{PQ3 - System errors}

Table 37: Frequencies for Item PQ3 (System errors)

\begin{tabular}{|l|r|r|}
\hline & Frequency & Percent \\
\hline 1 - Strongly Disagree & 44 & $2 \%$ \\
\hline 2 - Disagree & 193 & $10 \%$ \\
\hline 3 - Neutral & 347 & $19 \%$ \\
\hline 4 - Agree & 873 & $47 \%$ \\
\hline 5 - Strongly Agree & 384 & $21 \%$ \\
\hline Total & 1,841 & $100 \%$ \\
\hline
\end{tabular}

Table 38: Statistics for Item PQ3 (System errors)

\begin{tabular}{|l|l|l|l|l|l|}
\hline $\begin{array}{l}\text { Total } \\
\text { Responses }\end{array}$ & Mean & $\begin{array}{l}\text { Standard } \\
\text { Deviation }\end{array}$ & Minimum & Maximum \\
\hline 1,841 & 3.74 & 0.98 & 1 & 5 \\
\hline
\end{tabular}

\section{PQ4 - Platform response time}

Table 39: Frequencies for Item PQ4 (Platform response time)

\begin{tabular}{|l|r|r|}
\hline & \multicolumn{1}{|l|}{ Frequency } & Percent \\
\hline 1 - Strongly Disagree & 37 & $2 \%$ \\
\hline 2 - Disagree & 124 & $7 \%$ \\
\hline 3 - Neutral & 404 & $22 \%$ \\
\hline 4 - Agree & 903 & $49 \%$ \\
\hline 5 - Strongly Agree & 373 & $20 \%$ \\
\hline Total & 1,841 & $100 \%$ \\
\hline
\end{tabular}

Table 40: Statistics for Item PQ4 (Platform response time)

\begin{tabular}{|l|lr|l|l|l|}
\hline $\begin{array}{l}\text { Total } \\
\text { Responses }\end{array}$ & Mean & & $\begin{array}{l}\text { Standard } \\
\text { Deviation }\end{array}$ & Minimum & \multicolumn{2}{|l|}{ Maximum } \\
\hline 1,841 & 3.79 & & 0.91 & 1 & 5 \\
\hline
\end{tabular}




\section{SS1 - Confidence}

Table 41: Frequencies for Item SS1 (Confidence)

\begin{tabular}{|l|r|r|}
\hline & \multicolumn{1}{|l|}{ Frequency } & Percent \\
\hline 1 - Strongly Disagree & 31 & $2 \%$ \\
\hline 2 - Disagree & 132 & $7 \%$ \\
\hline 3 - Neutral & 463 & $25 \%$ \\
\hline 4 - Agree & 870 & $47 \%$ \\
\hline 5 - Strongly Agree & 345 & $19 \%$ \\
\hline Total & 1,841 & $100 \%$ \\
\hline
\end{tabular}

Table 42: Statistics for Item SS1 (Confidence)

\begin{tabular}{|l|l|l|l|l|}
\hline $\begin{array}{l}\text { Total } \\
\text { Responses }\end{array}$ & Mean & $\begin{array}{l}\text { Standard } \\
\text { Deviation }\end{array}$ & Minimum & Maximum \\
\hline 1,841 & 3.74 & 0.90 & 1 & 5 \\
\hline
\end{tabular}

\section{SS2 - Basic computing skills}

Table 43: Frequencies for Item SS2 (Basic computing skills)

\begin{tabular}{|l|r|r|}
\hline & Frequency & Percent \\
\hline 1 - Strongly Disagree & 3 & 0\% \\
\hline 2 - Disagree & 15 & $1 \%$ \\
\hline 3 - Neutral & 66 & $4 \%$ \\
\hline 4 - Agree & 595 & $32 \%$ \\
\hline 5 - Strongly Agree & 1,162 & $63 \%$ \\
\hline Total & 1,841 & $100 \%$ \\
\hline
\end{tabular}

Table 44: Statistics for Item SS2 (Basic computing skills)

\begin{tabular}{|l|r|l|l|l|l|}
\hline $\begin{array}{l}\text { Total } \\
\text { Responses }\end{array}$ & Mean & $\begin{array}{l}\text { Standard } \\
\text { Deviation }\end{array}$ & Minimum & Maximum \\
\hline 1,841 & 4.57 & & 0.62 & 1 & 5 \\
\hline
\end{tabular}




\section{SS3 - Basic smartphone skills}

Table 45: Frequencies for Item SS3 (Basic smartphone skills)

\begin{tabular}{|l|r|r|}
\hline & Frequency & Percent \\
\hline 1 - Strongly Disagree & 4 & $0 \%$ \\
\hline 2 - Disagree & 9 & $0 \%$ \\
\hline 3 - Neutral & 61 & $3 \%$ \\
\hline 4 - Agree & 480 & $26 \%$ \\
\hline 5 - Strongly Agree & 1,287 & $70 \%$ \\
\hline Total & 1,841 & $100 \%$ \\
\hline
\end{tabular}

Table 46: Statistics for Item SS3 (Basic smartphone skills)

\begin{tabular}{|l|l|l|l|l|}
\hline $\begin{array}{l}\text { Total } \\
\text { Responses }\end{array}$ & Mean & $\begin{array}{l}\text { Standard } \\
\text { Deviation }\end{array}$ & Minimum & Maximum \\
\hline 1,841 & 4.65 & 0.59 & 1 & 5 \\
\hline
\end{tabular}

\section{BI1 - Intend to use}

Table 47: Frequencies for Item BI1 (Intend to use)

\begin{tabular}{|l|r|r|}
\hline & \multicolumn{1}{|l|}{ Frequency } & Percent \\
\hline 1 - Strongly Disagree & 36 & $2 \%$ \\
\hline 2 - Disagree & 80 & $4 \%$ \\
\hline 3 - Neutral & 187 & $10 \%$ \\
\hline 4 - Agree & 815 & $44 \%$ \\
\hline 5 - Strongly Agree & 723 & $39 \%$ \\
\hline Total & 1,841 & $100 \%$ \\
\hline
\end{tabular}

Table 48: Statistics for Item BI1 (Intend to use)

\begin{tabular}{|r|r|l|l|l|l|}
\hline $\begin{array}{l}\text { Total } \\
\text { Responses }\end{array}$ & Mean & $\begin{array}{l}\text { Standard } \\
\text { Deviation }\end{array}$ & Minimum & \multicolumn{2}{|l|}{ Maximum } \\
\hline 1,841 & 4.15 & & 0.91 & 1 & 5 \\
\hline
\end{tabular}




\section{BI2 - Predict to use}

Table 49: Frequencies for Item BI2 (Predict to use)

\begin{tabular}{|l|r|r|}
\hline & \multicolumn{1}{|l|}{ Frequency } & Percent \\
\hline 1 - Strongly Disagree & 48 & $3 \%$ \\
\hline 2 - Disagree & 90 & $5 \%$ \\
\hline 3 - Neutral & 117 & $6 \%$ \\
\hline 4 - Agree & 702 & $38 \%$ \\
\hline 5 - Strongly Agree & 884 & $48 \%$ \\
\hline Total & 1,841 & $100 \%$ \\
\hline
\end{tabular}

Table 50: Statistics for Item BI2 (Predict to use)

\begin{tabular}{|l|l|l|l|l|}
\hline $\begin{array}{l}\text { Total } \\
\text { Responses }\end{array}$ & Mean & $\begin{array}{l}\text { Standard } \\
\text { Deviation }\end{array}$ & Minimum & Maximum \\
\hline 1,841 & 4.24 & 0.96 & 1 & 5 \\
\hline
\end{tabular}

\section{BI3 - Plan to use}

Table 51: Frequencies for Item BI3 (Plan to use)

\begin{tabular}{|l|r|r|}
\hline & Frequency & Percent \\
\hline 1 - Strongly Disagree & 53 & $3 \%$ \\
\hline 2 - Disagree & 109 & $6 \%$ \\
\hline 3 - Neutral & 152 & $8 \%$ \\
\hline 4 - Agree & 640 & $35 \%$ \\
\hline 5 - Strongly Agree & 887 & $48 \%$ \\
\hline Total & 1,841 & $100 \%$ \\
\hline
\end{tabular}

Table 52: Statistics for Item BI3 (Plan to use)

\begin{tabular}{|r|r|l|l|l|}
\hline $\begin{array}{l}\text { Total } \\
\text { Responses }\end{array}$ & Mean & $\begin{array}{l}\text { Standard } \\
\text { Deviation }\end{array}$ & Minimum & Maximum \\
\hline 1,841 & 4.19 & 1.01 & 1 & 5 \\
\hline
\end{tabular}




\section{BI4 - Plan to use - frequently}

Table 53: Frequencies for Item BI4 (Plan to use - frequently)

\begin{tabular}{|l|r|r|}
\hline & \multicolumn{1}{|l|}{ Frequency } & Percent \\
\hline 1 - Strongly Disagree & 69 & $4 \%$ \\
\hline 2 - Disagree & 180 & $10 \%$ \\
\hline 3 - Neutral & 347 & $19 \%$ \\
\hline 4 - Agree & 565 & $31 \%$ \\
\hline 5 - Strongly Agree & 680 & $37 \%$ \\
\hline Total & 1,841 & $100 \%$ \\
\hline
\end{tabular}

Table 54: Statistics for Item BI4 (Plan to use - frequently)

\begin{tabular}{|l|l|l|l|l|}
\hline $\begin{array}{l}\text { Total } \\
\text { Responses }\end{array}$ & Mean & $\begin{array}{l}\text { Standard } \\
\text { Deviation }\end{array}$ & Minimum & Maximum \\
\hline 1,841 & 3.87 & 1.13 & 1 & 5 \\
\hline
\end{tabular}

\section{UB1 - Frequency of use}

Table 55: Frequencies for Item UB1 (Frequency of use)

\begin{tabular}{|c|c|c|}
\hline & Frequency & Percent \\
\hline 1 - Rarely & 207 & $11 \%$ \\
\hline $\begin{array}{l}2 \text { - Several times per } \\
\text { term }\end{array}$ & 360 & $20 \%$ \\
\hline $\begin{array}{l}3 \text { - Several times per } \\
\text { month }\end{array}$ & 255 & $14 \%$ \\
\hline 4-Weekly & 478 & $26 \%$ \\
\hline 5 - Daily & 541 & $29 \%$ \\
\hline Total & 1,841 & $100 \%$ \\
\hline
\end{tabular}

Table 56: Statistics for Item UB1 (Frequency of use)

\begin{tabular}{|l|r|l|l|l|}
\hline $\begin{array}{l}\text { Total } \\
\text { Responses }\end{array}$ & Mean & $\begin{array}{l}\text { Standard } \\
\text { Deviation }\end{array}$ & Minimum & Maximum \\
\hline 1,841 & 3.43 & 1.38 & 1 & 5 \\
\hline
\end{tabular}


UB2 - Usage of the platform to access university resources and services

Table 57: Frequencies for Item UB2 (Usage of the platform to access university resources and services)

\begin{tabular}{|l|r|r|}
\hline & \multicolumn{1}{|l|}{ Frequency } & Percent \\
\hline 1 - Strongly Disagree & 77 & $4 \%$ \\
\hline 2 - Disagree & 146 & $8 \%$ \\
\hline 3 - Neutral & 132 & $7 \%$ \\
\hline 4 - Agree & 677 & $37 \%$ \\
\hline 5 - Strongly Agree & 809 & $44 \%$ \\
\hline Total & 1,841 & $100 \%$ \\
\hline
\end{tabular}

Table 58: Statistics for Item UB2 (Usage of the platform to access university resources and services)

\begin{tabular}{|r|r|l|l|l|}
\hline $\begin{array}{l}\text { Total } \\
\text { Responses }\end{array}$ & Mean & $\begin{array}{l}\text { Standard } \\
\text { Deviation }\end{array}$ & Minimum & \multicolumn{2}{|l|}{ Maximum } \\
\hline 1,841 & 4.08 & 1.09 & 1 & 5 \\
\hline
\end{tabular}

\section{UB3 - Usage of the platform to conduct business}

Table 59: Frequencies for Item UB3 (Usage of the platform to conduct business)

\begin{tabular}{|l|r|r|}
\hline & \multicolumn{1}{|l|}{ Frequency } & Percent \\
\hline 1 - Strongly Disagree & 86 & $5 \%$ \\
\hline 2 - Disagree & 181 & $10 \%$ \\
\hline 3 - Neutral & 197 & $11 \%$ \\
\hline 4 - Agree & 730 & $40 \%$ \\
\hline 5 - Strongly Agree & 647 & $35 \%$ \\
\hline Total & 1,841 & $100 \%$ \\
\hline
\end{tabular}

Table 6o: Statistics for Item UB3 (Usage of the platform to conduct business)

\begin{tabular}{|r|r|l|l|l|l|}
\hline $\begin{array}{l}\text { Total } \\
\text { Responses }\end{array}$ & Mean & $\begin{array}{l}\text { Standard } \\
\text { Deviation }\end{array}$ & Minimum & Maximum \\
\hline 1,841 & 3.91 & 1.12 & 1 & 5 \\
\hline
\end{tabular}




\section{UB4 - Usage of the platform as a one-stop shop}

Table 61: Frequencies for Item UB4 (Usage of the platform as a one-stop shop)

\begin{tabular}{|l|r|r|}
\hline & Frequency & Percent \\
\hline 1 - Strongly Disagree & 103 & $6 \%$ \\
\hline 2 - Disagree & 232 & $13 \%$ \\
\hline 3 - Neutral & 352 & $19 \%$ \\
\hline 4 - Agree & 681 & $37 \%$ \\
\hline 5 - Strongly Agree & 473 & $26 \%$ \\
\hline Total & 1,841 & $100 \%$ \\
\hline
\end{tabular}

Table 62: Statistics for Item UB4 (Usage of the platform as a one-stop shop)

\begin{tabular}{|l|lr|l|l|l|}
\hline $\begin{array}{l}\text { Total } \\
\text { Responses }\end{array}$ & Mean & $\begin{array}{l}\text { Standard } \\
\text { Deviation }\end{array}$ & Minimum & Maximum \\
\hline 1,841 & 3.65 & 1.15 & 1 & 5 \\
\hline
\end{tabular}




\section{Appendix J: Revised Research Model Detailed Taxonomy}

\begin{tabular}{|c|c|c|c|}
\hline $\begin{array}{l}\text { Factors and } \\
\text { indicators }\end{array}$ & Definition & $\begin{array}{l}\text { Reference(s } \\
\text { ) for } \\
\text { definition(s } \\
\text { ) }\end{array}$ & $\begin{array}{l}\text { Reference(s) for } \\
\text { studies } \\
\text { indicating a } \\
\text { positive } \\
\text { influence on } \\
\text { other factors }\end{array}$ \\
\hline \multicolumn{4}{|l|}{ UTAUT factors } \\
\hline \multicolumn{4}{|c|}{ Effort expectancy factor } \\
\hline $\begin{array}{l}\text { Effort } \\
\text { expectancy }\end{array}$ & $\begin{array}{l}\text { "Degree of ease associated with the use of the } \\
\text { system" [199] }\end{array}$ & {$[199]$} & $\begin{array}{l}\text { [253], [265], [266], } \\
{[247],[254],[252],} \\
{[268]}\end{array}$ \\
\hline $\begin{array}{l}\text { Perceived ease of } \\
\text { use }\end{array}$ & $\begin{array}{l}\text { Degree to which the software platform is easy for a } \\
\text { student to use. } \\
\text { Based on - "A respondent's opinion or perception } \\
\text { that a technology can be used to solve a } \\
\text { problem with a relatively low expenditure of effort } \\
\text { and a reasonable chance of success" [271] and } \\
\text { related to - "The degree of ease of use of a } \\
\text { technology" [263] and Perceived complexity - } \\
\text { "assesses the extent of difficulty in using the } \\
\text { Internet, which is similar to the concept of } \\
\text { Perceived Ease of Use" [290] }\end{array}$ & {$[271]$} & $\begin{array}{l}{[277],[270],[241],} \\
{[280],[281],[282],} \\
{[232],[233],[243],} \\
{[271],[244],[283],} \\
{[242],[248],[284],} \\
{[286],[112],[234],} \\
{[287],[288],[289],} \\
{[272],[278],[224],} \\
{[261],[297],[292],} \\
{[269],[274],[293],} \\
{[294],[295],[245],} \\
{[285],[290],[293]}\end{array}$ \\
\hline $\begin{array}{l}\text { Learning to } \\
\text { operate }\end{array}$ & $\begin{array}{l}\text { Degree to which learning how to operate the } \\
\text { software platform was easy for a student. }\end{array}$ & {$[247]$} & {$[290],[293]$} \\
\hline $\begin{array}{l}\text { System } \\
\text { accessibility }\end{array}$ & $\begin{array}{l}\text { Degree to which a student can easily navigate to the } \\
\text { software platform on the Internet. } \\
\text { Related to - } \\
\text { System accessibility [112]; Accessibility [279]; } \\
\text { Cloud accessibility [263]; Access to software [289]; } \\
\text { Enablers [280]; and Ease of finding [297] }\end{array}$ & {$[112]$} & $\begin{array}{l}{[279],[112],[263]} \\
{[289],[280],[297]}\end{array}$ \\
\hline Mobile app & $\begin{array}{l}\text { Degree to which using the smartphone/mobile app } \\
\text { makes it convenient to access the platform. } \\
\text { Based on Perceived mobility value - "Consciousness } \\
\text { of users about the mobility value of M-learning" } \\
\text { [295] }\end{array}$ & {$[295]$} & {$[295]$} \\
\hline $\begin{array}{l}\text { Perceived mobile } \\
\text { value }\end{array}$ & $\begin{array}{l}\text { The degree to which the software platform is } \\
\text { convenient to access anytime and anywhere with no } \\
\text { restrictions. } \\
\text { Related to - } \\
\text { "Consciousness of users about the mobility value of } \\
\text { M-learning" [295]; and Mobility - "the extent to } \\
\text { which students can access the podcast anytime and } \\
\text { anywhere with no restrictions" [234] }\end{array}$ & {$[295]_{2}[234]$} & {$[295],[234]$} \\
\hline Content quality & $\begin{array}{l}\text { Degree to which the quality of the content in the } \\
\text { software platform is sufficient in meeting a } \\
\text { student's needs. } \\
\text { Related to - Information quality - "The quality of } \\
\text { the output from an IS" [260], [296]; Information } \\
\text { quality - "the independent variable information } \\
\text { quality reflects the quality of the results produced } \\
\text { by a technology" [271]; Two dimensions of } \\
\text { perceived content quality - content richness and } \\
\text { update regularity [233]; Trust - "a subjective } \\
\text { expectation that someone or something is reliable } \\
\text { and willing to accept vulnerability" [265]; }\end{array}$ & $\begin{array}{l}{[260],[296],} \\
{[271]}\end{array}$ & $\begin{array}{l}{[271],[260],[291],} \\
{[233],[265],[237],} \\
{[279]}\end{array}$ \\
\hline
\end{tabular}




\begin{tabular}{|c|c|c|c|}
\hline & $\begin{array}{l}\text { Credibility - "The certainty and pleasant } \\
\text { consequences of using an electronic application } \\
\text { service, when there is no financial risk, physical } \\
\text { risk, functional risk, social risk, time-loss risk, } \\
\text { opportunity cost risk, and information risk" [237]; } \\
\text { Accuracy of information [26o]; Reliability - the } \\
\text { trust and confidence the user places on a system } \\
\text { [279]; and Sufficiency of information [26o] }\end{array}$ & & \\
\hline $\begin{array}{l}\text { User interface } \\
\text { design }\end{array}$ & $\begin{array}{l}\text { Degree to which a student believes the software } \\
\text { platform has well-designed user interfaces (pages, } \\
\text { graphics, visuals, content, navigation, etc.). } \\
\text { Related to - Ease of understanding - "Reflects the } \\
\text { need for a web site to use understandable and } \\
\text { consistent graphics and terms. It should } \\
\text { furthermore be visually appealing and readable, } \\
\text { and provide links to more detailed information } \\
\text { about the subject at hand" [297] }\end{array}$ & {$[260]$} & {$[297]$} \\
\hline System errors & $\begin{array}{l}\text { Degree to which a student encounters system errors } \\
\text { when using the software platform. }\end{array}$ & {$[291]$} & - \\
\hline $\begin{array}{l}\text { Platform response } \\
\text { time }\end{array}$ & $\begin{array}{l}\text { Degree to which a student experiences the software } \\
\text { platform response as fast. } \\
\text { Based on - the system performance in terms of } \\
\text { speed; when the real performance of a service or } \\
\text { product is the same as the expectation [408] }\end{array}$ & {$[261]$} & [261] \\
\hline Compatibility & $\begin{array}{l}\text { Degree to which a student can easily/seamlessly } \\
\text { access other university software platforms and } \\
\text { online tools through the software platform being } \\
\text { studied (e.g. students do not have to log-in multiple } \\
\text { times when accessing other platforms, degree to } \\
\text { which other platforms are easy to find in the } \\
\text { software platform being studied, etc.). } \\
\\
\text { Related to Perceived behavioral control - "The } \\
\text { system is not compatible with other systems I use" } \\
\text { [199] and Perceived compatibility with student } \\
\text { tasks - "Degree to which the system is compatible } \\
\text { with student tasks in the course and student } \\
\text { preferences for how they like to study" [294] }\end{array}$ & [199] & {$[294]$} \\
\hline \multicolumn{4}{|c|}{ Social influence factor } \\
\hline Social influence & $\begin{array}{l}\text { "Extent to which users perceive that those } \\
\text { important to them believe they should be using a } \\
\text { technology" [263] } \\
\text { Related to Subjective norm - "A person's subjective } \\
\text { norm is determined by her perception that } \\
\text { salient social referents think he/she should or } \\
\text { should not perform a particular behavior" [233]; } \\
\text { and based on - "the degree to which an individual } \\
\text { perceives that important others believe he or she } \\
\text { should use the new system" [199] }\end{array}$ & {$[263]$} & $\begin{array}{l}\text { Social influence - } \\
\text { [264], [253], [265], } \\
\text { [266], [267], [247], } \\
\text { [254], [252], [224], } \\
\text { [268], [269]; } \\
\text { Subjective positive- } \\
\text { [270], [233], [271], } \\
\text { [242], [112], [272], } \\
\text { [273], [274] }\end{array}$ \\
\hline Peer influence & $\begin{array}{l}\text { Degree to which a student's peers have } \\
\text { recommended use of the software platform. } \\
\text { Based on - Social pressure - "Refers to an } \\
\text { individual's perceptions of normatively appropriate } \\
\text { behaviour with regard to the use of the } \\
\text { Internet/web in university study" [290]; Perceived } \\
\text { critical mass - "whether an innovation has attracted } \\
\text { a critical mass of users influence ensuing adoption } \\
\text { and use" [293]; Perceived network externality - }\end{array}$ & {$[270]$} & $\begin{array}{l}\text { [270], [278], [290], } \\
\text { [293], [233] }\end{array}$ \\
\hline
\end{tabular}




\begin{tabular}{|c|c|c|c|}
\hline & $\begin{array}{l}\text { "relates to an increase in the value of a product or } \\
\text { service to a consumer, not because of the inherent } \\
\text { quality of the product or service, but because of } \\
\text { increasing numbers of others adopting it" [233] }\end{array}$ & & \\
\hline Marketing & $\begin{array}{l}\text { Degree to which receiving marketing messages } \\
\text { about the software platform, such as posters, social } \\
\text { media, emails, flyers and other } \\
\text { promotional/marketing materials or outreach, has } \\
\text { encouraged a student to use it. }\end{array}$ & $\begin{array}{l}\text { Generated } \\
\text { through } \\
\text { qualitative } \\
\text { research } \\
\text { methods }\end{array}$ & $\begin{array}{l}\text { Generated through } \\
\text { qualitative research } \\
\text { methods }\end{array}$ \\
\hline $\begin{array}{l}\text { Influence from } \\
\text { university } \\
\text { employees }\end{array}$ & $\begin{array}{l}\text { Degree to which university employees (e.g. faculty, } \\
\text { staff, advisors, etc.) think a student should use the } \\
\text { software platform. } \\
\text { Based on Faculty influence on students (superior } \\
\text { influence) [270]; "learners' perception of their } \\
\text { instructors' attitude toward e-Learning" (Instructor } \\
\text { attitude toward e-learning) [288]; and } \\
\text { Encouragement to use the cloud computing } \\
\text { technology (Instructor support) [289]; } \\
\text { Organizational support - support from the } \\
\text { University "ensures the necessary resources are } \\
\text { allocated for Internet access and use" [29o]; and } \\
\text { Instructor support, which "can encourage more } \\
\text { active use of the Internet for class assignments and } \\
\text { interaction" [290] }\end{array}$ & {$[199]_{2}[247]$} & $\begin{array}{l}\text { [270], [288], [289], } \\
{[290]}\end{array}$ \\
\hline $\begin{array}{l}\text { Learning about a } \\
\text { platform }\end{array}$ & $\begin{array}{l}\text { Degree to which learning about a software platform } \\
\text { (e.g. about how to use its features and } \\
\text { functionality) has helped a student learn how to use } \\
\text { it. } \\
\text { Based on - "Internal training refers to } \\
\text { intraorganizational training, or training found } \\
\text { within the organization" [293] }\end{array}$ & [293] & [293], [294] \\
\hline \multicolumn{4}{|c|}{ Behavioral intention factor } \\
\hline $\begin{array}{l}\text { Behavioral } \\
\text { intention to use }\end{array}$ & $\begin{array}{l}\text { "The decision maker's disposition toward using a } \\
\text { system" [271] } \\
\text { Related to - Attitude toward the system, } \\
\text { satisfaction with the system, preference for the } \\
\text { system [280]; and "Degree to which a user is } \\
\text { interested in using the system" [278] }\end{array}$ & {$[271]$} & $\begin{array}{l}277],[270],[241]_{2} \\
{[271],[244],[264],} \\
{[278],[247],[279]}\end{array}$ \\
\hline Intend to use & $\begin{array}{l}\text { Degree to which a student intends to use the } \\
\text { software platform in the future. }\end{array}$ & {$[225]$} & - \\
\hline Predict to use & $\begin{array}{l}\text { Degree to which a student predicts they will use the } \\
\text { software platform during an academic term. }\end{array}$ & [199] & - \\
\hline Plan to use & $\begin{array}{l}\text { Degree to which a student plans to use the software } \\
\text { platform during an academic term. }\end{array}$ & [199] & - \\
\hline $\begin{array}{l}\text { Plan to use - } \\
\text { frequently }\end{array}$ & $\begin{array}{l}\text { Degree to which a student plans to use the software } \\
\text { platform frequently. }\end{array}$ & {$[225]$} & - \\
\hline \multicolumn{4}{|c|}{ Use behavior factor } \\
\hline Use behavior & Actual usage of the system. & [199] & - \\
\hline Frequency of use & Frequency of use of the software platform. & [247], [225] & - \\
\hline $\begin{array}{l}\text { Usage of the } \\
\text { platform to access } \\
\text { university } \\
\text { resources and } \\
\text { services }\end{array}$ & $\begin{array}{l}\text { Degree to which a student uses the software } \\
\text { platform to access university resources (calendars, } \\
\text { campus map, library, university-related software, } \\
\text { etc.) and services (academic advising, career } \\
\text { services, financial wellness center, resource centers, } \\
\text { tutoring, etc.). }\end{array}$ & [247] & - \\
\hline
\end{tabular}




\begin{tabular}{|c|c|c|c|}
\hline $\begin{array}{l}\text { Usage of the } \\
\text { platform to } \\
\text { conduct business }\end{array}$ & $\begin{array}{l}\text { Degree to which a student uses the software } \\
\text { platform to conduct business (e.g. viewing account } \\
\text { balance, accessing the platform to pay bills, } \\
\text { accessing information about financial aid, accessing } \\
\text { the platform for registering for courses, etc.) }\end{array}$ & {$[247]$} & - \\
\hline $\begin{array}{l}\text { Usage of the } \\
\text { platform as a } \\
\text { one-stop shop }\end{array}$ & $\begin{array}{l}\text { Degree to which a student uses the software } \\
\text { platform as a one-stop shop for navigating the } \\
\text { university (e.g. accessing services, resources and } \\
\text { university-related software, and conducting student } \\
\text { business, all in one place). }\end{array}$ & {$[261]$} & - \\
\hline \multicolumn{4}{|c|}{ Factors added to UTAUT } \\
\hline \multicolumn{4}{|l|}{ Skills factor } \\
\hline Skills & $\begin{array}{l}\text { The judgement of one's own skills in performing } \\
\text { specific technology-related tasks. }\end{array}$ & {$[292]$} & $\begin{array}{l}{[295],[290],[292],} \\
{[292],[263],[286]_{2}} \\
{[274]_{2}[112]}\end{array}$ \\
\hline $\begin{array}{l}\text { Basic computing } \\
\text { skills }\end{array}$ & $\begin{array}{l}\text { The proficiency of users related to conducting basic } \\
\text { computing activities (using writing/word } \\
\text { processing software, using the Internet, emailing, } \\
\text { etc.). } \\
\text { Based on - Basic ICT skills - "everyday ICT usage"; } \\
\text { "the competency of users in relation to general } \\
\text { computing tasks, such as using word processing } \\
\text { software, searching and emailing on the Internet } \\
\text { and doing basic mobile activities, such as texting } \\
\text { and calling" [292]; Experience - "perceived } \\
\text { computer literacy of adopters and their experience } \\
\text { with using technology" [263]; Internet skills - skills } \\
\text { of a user with respect to using the Internet [29o]; } \\
\text { and Internet experience - an individual's } \\
\text { experiences with a specific technology influences } \\
\text { perceptions of ease of use and usefulness of that } \\
\text { technology [286] }\end{array}$ & {$[292]$} & $\begin{array}{l}{[292]_{2}[112]_{2}[263]} \\
{[290]_{2}[286]_{2}[274]}\end{array}$ \\
\hline $\begin{array}{l}\text { Basic smartphone } \\
\text { skills }\end{array}$ & $\begin{array}{l}\text { The proficiency of users related to basic } \\
\text { smartphone activities (using apps, texting and } \\
\text { calling, etc.). } \\
\text { Based on - Basic ICT skills - "everyday ICT usage"; } \\
\text { "the competency of users in relation to general } \\
\text { computing tasks, such as using word processing } \\
\text { software, searching and emailing on the Internet } \\
\text { and doing basic mobile activities, such as texting } \\
\text { and calling" [292] } \\
\text { Related to Advance mobile tasks - "tasks associated } \\
\text { with mobile usage" [292]; and Mobile learning } \\
\text { self-efficacy - "The personal confidence in finding } \\
\text { information and communicating with an instructor } \\
\text { within the e-learning system and the necessary } \\
\text { skills for using the system" [112] }\end{array}$ & {$[292]$} & {$[292]_{2}[112]$} \\
\hline
\end{tabular}

